\title{
Preliminary Assessment of the Ecological Risks to Wide-ranging Wildlife Species on the Oak Ridge Reservation
}

\section{Update}

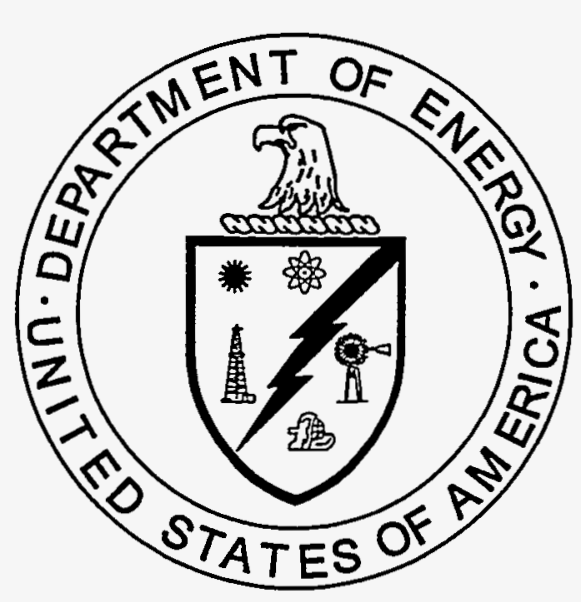

RECEIVED

SEP 231996

$08 T 1$

This document has been approved by the

$\mathrm{K}-25$ Site Technical Information Office

for release to the public. Date: $9 / 11 / 96$

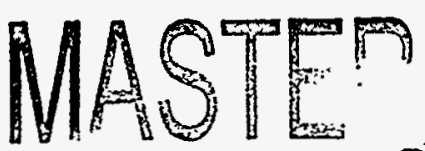


This report has been reproduced directly from the best available copy.

Available to DOE and DOE contractors from the Office of Scientific and Technical Information, P.O. Box 62, Oak Ridge, TN 37831; prices available from 423-576-8401 (fax 423-576-2865).

Available to the public from the National Technical Information Service, U.S. Department of Commerce, 5285 Port Royal Rd., Springfield, VA 22161. 


\section{DISCLAIMER}

Portions of this document may be illegible in electronic image products. Images are produced from the best available original document. 



\title{
Preliminary Assessment of the Ecological Risks to Wide-ranging Wildlife Species on the Oak Ridge Reservation
}

\section{Update}

\author{
B. E. Sample \\ R. L. Hinzman \\ B. L. Jackson \\ L. Baron \\ Environmental Restoration Division \\ P.O. Box 2003 \\ Oak Ridge, Tennessee 37831-7298
}

Date Issued-Spetember 1996

\author{
Prepared by \\ Environmental Sciences Division \\ Oak Ridge National Laboratory \\ Oak Ridge, Tennessee \\ Prepared for the \\ U.S. Department of Energy \\ Office of Environmental Management \\ under budget and reporting code EW 2010301 \\ LOCKHEED MARTIN ENERGY SYSTEMS, INC. \\ managing the \\ Environmental Management Activities at the \\ Oak Ridge K-25 Site Paducah Gaseous Diffusion Plant \\ Oak Ridge Y-12 Plant Portsmouth Gaseous Diffusion Plant \\ Oak Ridge National Laboratory \\ under contract DE-AC05-84OR21400 \\ for the \\ U.S. DEPARTMENT OF ENERGY
}




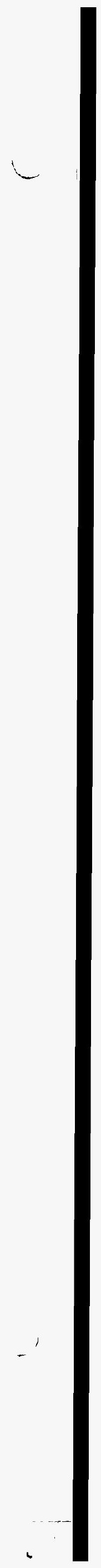




\section{PREFACE}

This report, Preliminary Assessment of the Ecological Risks to Wide-ranging Wildlife Species on the Oak Ridge Reservation: 1996 Update, DOE/OR/01-1407\&D2, was prepared as a technical report documenting work performed under the Oak Ridge Reservation Ecological Assessment Program. This work was performed under work breakdown structure 1.4.12.2.3.4 (activity data sheet 8304, "Technical Integration"). Publication of this document meets an activity data sheet milestone of September 13, 1996. This document provides the Environmental Restoration Program with a preliminary evaluation of the ecological risks that contaminants on the Oak Ridge Reservation present to selected wide-ranging species. These results will aid in the understanding of the magnitude of ecological risks to populations at larger spatial scales and will assist in the prioritization of source operable units for investigation and remediation. 


\section{CONTENTS}

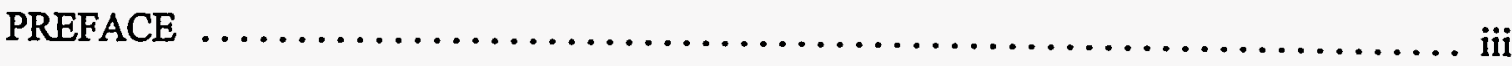

FIGURES $\ldots \ldots \ldots \ldots \ldots \ldots \ldots \ldots \ldots \ldots \ldots \ldots \ldots \ldots \ldots \ldots \ldots \ldots \ldots \ldots \ldots \ldots \ldots \ldots$

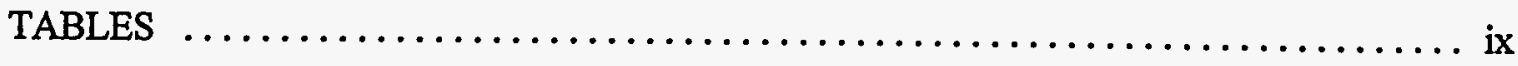

ACRONYMS $\ldots \ldots \ldots \ldots \ldots \ldots \ldots \ldots \ldots \ldots \ldots \ldots \ldots \ldots \ldots \ldots \ldots \ldots \ldots \ldots \ldots \ldots \ldots \ldots \ldots$

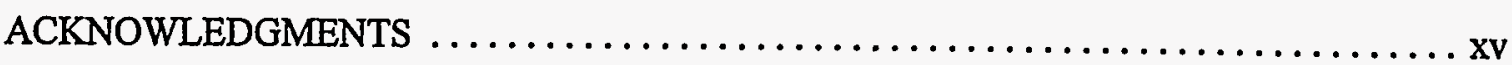

EXECUTIVE SUMMARY $\ldots \ldots \ldots \ldots \ldots \ldots \ldots \ldots \ldots \ldots \ldots \ldots \ldots \ldots \ldots \ldots \ldots \ldots \ldots$

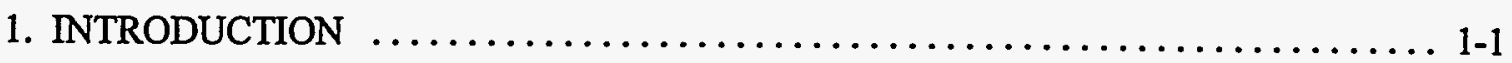

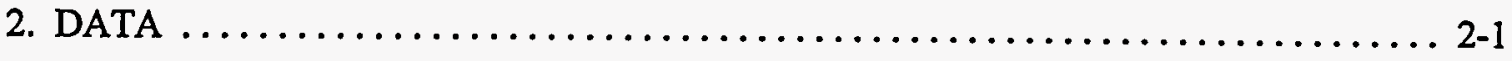

3. EVALUATION OF POTENTIAL USE OF OPERABLE UNITS

ON THE OAK RIDGE RESERVATION BY WILDLIFE $\ldots \ldots \ldots \ldots \ldots \ldots \ldots \ldots . . \ldots .1$

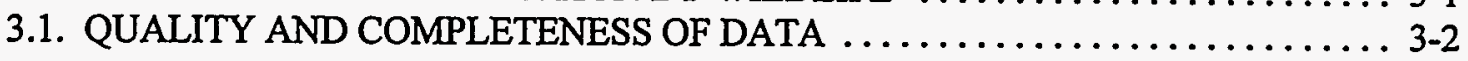

4. ASSESSMENT OF RISKS TO PISCIVORES

ON THE OAK RIDGE RESERVATION $\ldots \ldots \ldots \ldots \ldots \ldots \ldots \ldots \ldots \ldots \ldots \ldots \ldots . \ldots \ldots \ldots \ldots$

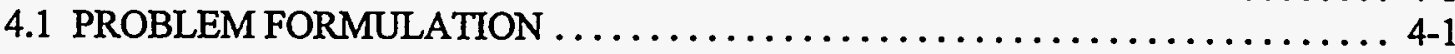

4.1.1 Ecological Assessment Endpoints $\ldots \ldots \ldots \ldots \ldots \ldots \ldots \ldots \ldots \ldots \ldots \ldots$ 4-1

4.1.2 Ecological Conceptual Model $\ldots \ldots \ldots \ldots \ldots \ldots \ldots \ldots \ldots \ldots \ldots \ldots \ldots . \ldots . \ldots \ldots$

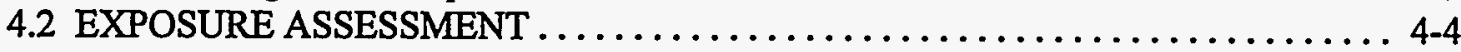

4.2.1 Exposure Through Oral Ingestion of Fish $\ldots \ldots \ldots \ldots \ldots \ldots \ldots \ldots . . \ldots .4$

4.2.2 Internal Exposure of Great Blue Herons to Contaminants . . . . . . . . . . 4-9

4.3 EFFECTS ASSESSMENT FOR PISCIVOROUS WILDLIFE . . . . . . . . . . . . 4-9

4.3.1 Single Chemical Toxicity Data .......................... 4-9

4.3.2 Effects of Contaminants on the Reproductive Performance of Mink ...... . 4-11

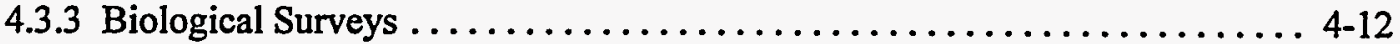

4.4 RISK CHARACTERIZATION FOR PISCIVOROUS WILDLIFE $\ldots \ldots \ldots \ldots \ldots .4$ 4-14

4.4.1 Single Chemical Toxicity Data $\ldots \ldots \ldots \ldots \ldots \ldots \ldots \ldots \ldots \ldots . \ldots \ldots$ 4-15

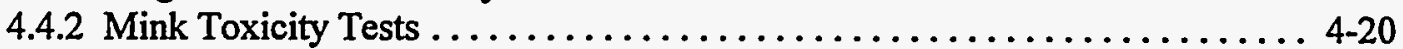

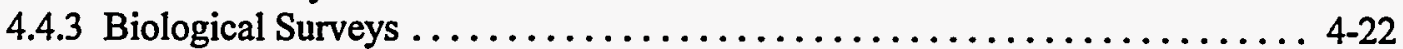

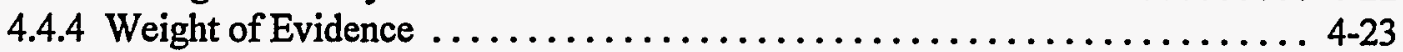

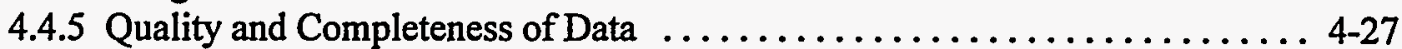

4.4.6 Uncertainties Concerning Risks to Piscivorous Wildlife $\ldots \ldots \ldots \ldots \ldots .4$ 4-28

5. ASSESSMENT OF RISKS TO VERMIVORES, HERBIVORES, AND PREDATORS

ON THE OAK RIDGE RESERVATION $\ldots \ldots \ldots \ldots \ldots \ldots \ldots \ldots \ldots \ldots \ldots \ldots \ldots \ldots, \ldots \ldots \ldots$

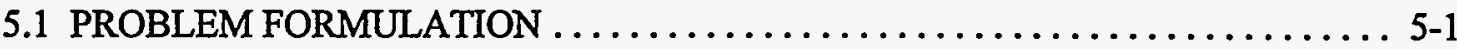

5.1 .1 Ecological Assessment Endpoints $\ldots \ldots \ldots \ldots \ldots \ldots \ldots \ldots \ldots \ldots \ldots$ 5-2

5.1.2 Ecological Conceptual Model $\ldots \ldots \ldots \ldots \ldots \ldots \ldots \ldots \ldots \ldots \ldots \ldots .4$ 
5.2 EXPOSURE ASSESSMENT FOR HERBIVOROUS, VERMIVOROUS, AND PREDATORY WILDLIFE $\ldots \ldots \ldots \ldots \ldots \ldots \ldots \ldots \ldots \ldots \ldots, 5-4$

5.2.1 Exposure Through Oral Ingestion of Food and Soil $\ldots \ldots \ldots \ldots \ldots \ldots \ldots .4-4$

5.3 EFFECTS ASSESSMENT FOR HERBIVOROUS, VERMIVOROUS, AND PREDATORY WLDLIFE $\ldots \ldots \ldots \ldots \ldots \ldots \ldots \ldots \ldots \ldots \ldots \ldots, 5-7$

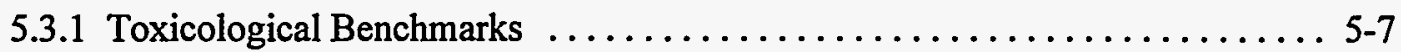

5.3.2 Ecotoxilogical Profiles for Herbivorous and Vermivorous Wildlife......... 5-8

5.4 RISK CHARACTERIZATION FOR HERBIVOROUS, VERMIVOROUS,

AND PREDATORY WILDLIFE $\ldots \ldots \ldots \ldots \ldots \ldots \ldots \ldots \ldots \ldots \ldots \ldots \ldots \ldots \ldots \ldots \ldots, 8$

5.4.1 Contaminant Screening of Soil to Background Levels .............. 5-9

5.4.2 Single Chemical Toxicity Data for Herbivorous, Vermivorous, and

Predatory Wildlife (Individuals) $\ldots \ldots \ldots \ldots \ldots \ldots \ldots \ldots \ldots \ldots \ldots \ldots \ldots \ldots$ 5 9

5.4.3 Effects of Retained Contaminants for Herbivorous, Vermivorous, and

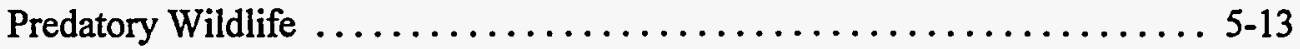

5.4.4 Population Level Risks on the Oak Ridge Reservation ............ 5-20

5.4.5 Quality and Completeness of Data ...................... 5-34

5.4.6 Uncertainties Concerning Risks to Herbivorous, Vermivorous, and Predatory Wildlife $\ldots \ldots \ldots \ldots \ldots \ldots \ldots \ldots \ldots \ldots \ldots \ldots \ldots, 5-34$

6. CONCLUSIONS $\ldots \ldots \ldots \ldots \ldots \ldots \ldots \ldots \ldots \ldots \ldots \ldots \ldots \ldots \ldots \ldots, 6,1$

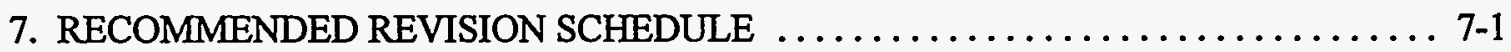

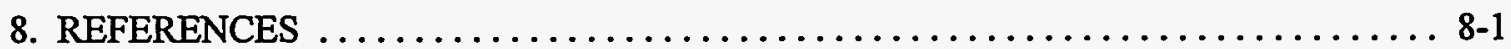

Appendix A. DATA SURVEY FOR THE OAK RIDGE RESERVATION ECOLOGICAL MONITORING AND ASSESSMENT PROGRAM TERRESTRIAL WILDLIFE RISK ASSESSMENT

Appendix B. TABLES FOR CHAPTER 3: EVALUATION OF THE POTENTIAL USE OF OPERABLE UNITS ON THE OAK RIDGE RESERVATION BY WILDLIFE

Appendix C. TABLES AND FIGURES FOR CHAPTER 4: ASSESSMENT OF RISK TO PISCIVORES ON THE OAK RIDGE RESERVATION

Appendix D. TOXICOLOGICAL PROFILES

Appendix E. REPRODUCTIVE PERFORMANCE OF MINK

Appendix F. CONTAMINANT ACCUMULATION AND EFFECTS IN GREAT BLUE HERON

Appendix G. TABLES AND FIGURES FOR CHAPTER 5: ASSESSMENT OF RISK TO VERMIVORES AND HERBIVORES ON THE OAK RIDGE RESERVATION 


\section{FIGURES}

1.1 Conceptual model of the transfer of contaminants through a source OU

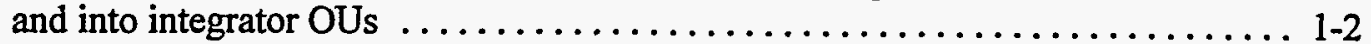

4.1 Conceptual model for the exposure of piscivorous wildlife to contaminants ..... 4-5

5.1 Conceptual model for the exposure of vermivorous, herbivorous, and predatory

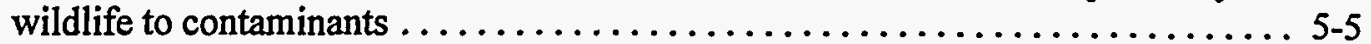

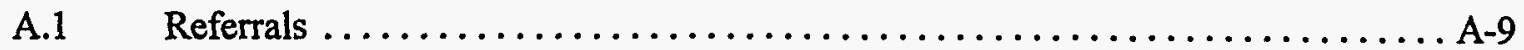

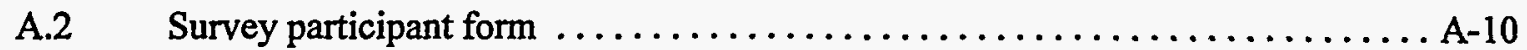

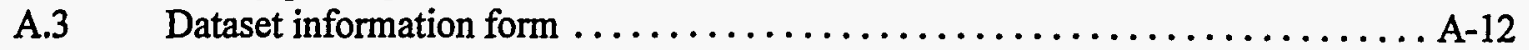

C.1 The Bear Creek fish sampling locations used in the ORR-wide ecological

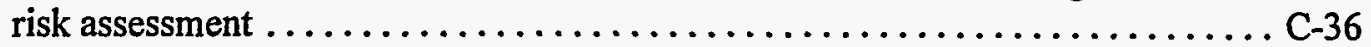

C.2 The East Fork Poplar Creek fish and ecological sampling locations (from EFPC RI) used in the ORR-wide ecological risk assessment ........ C-37

C.3 The Poplar Creek sampling locations and ponds used to evaluate risks in the K-25 vicinity for the ORR-wide ecological risk assessment .........C-38

C.4 The White Oak Creek fish sampling locations used in the ORR-wide ecological risk assessment $\ldots \ldots \ldots \ldots \ldots \ldots \ldots \ldots \ldots \ldots \ldots \ldots \ldots$ C-39

C.5 Sum of LOAEL-based toxic units for evaluation of risks to piscivores

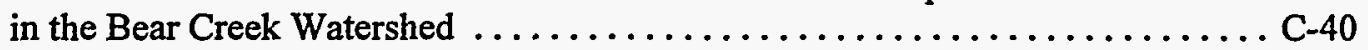

C.6 Sum of LOAEL-based toxic units for evaluation of risks to piscivores in the East Fork Poplar Creek Watershed $. . \ldots \ldots \ldots \ldots \ldots \ldots \ldots \ldots . . \ldots$ C-41

C.7 Sum of LOAEL-based toxic units for evaluation of risks to piscivores

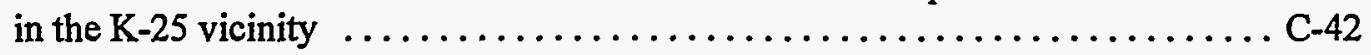

C.8 Sum of LOAEL-based toxic units for evaluation of risks to piscivores in the White Oak Creek Watershed ......................... C-44

C.9 Cumulative binomial probability of mink experiencing exposure to mercury in East Fork Poplar Creek in excess of the LOAEL ............... C-46

C.10 Cumulative binomial probability of river otter experiencing exposure to mercury in Bear Creek in excess of the LOAEL . .................... C-47

C.11 Cumulative binomial probability of river otter experiencing exposure to mercury in White Oak Creek in excess of the LOAEL ................... C-48

C.12 Cumulative binomial probability of belted kingfisher experiencing exposure to mercury in Bear Creek in excess of the LOAEL ................. C-49

C.13 Cumulative binomial probability of river otter experiencing exposure to PCBs in East Fork Poplar Creek in excess of the LOAEL ............... C-50

C.14 Cumulative binomial probability of river otter experiencing exposure to PCBs in White Oak Creek in excess of the LOAEL ................... C-51

G.1 Location of OUs evaluated as part of the ORR-wide assessment of risk to vermivores and herbivores. . . . . . . . . . . . . . . . . . G-77 
1 


\section{TABLES}

2.1 The land use/landcover classes used in habitat classification $\ldots \ldots \ldots \ldots \ldots \ldots 2-2$

4.1 Summary of risk characterization for piscivores on the ORR ........... 4-25

5.1 Location (operable units) of contaminants of potential concern

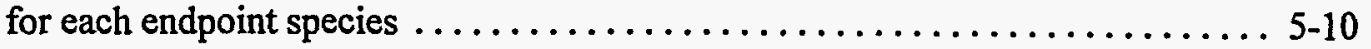

5.2 The number of potentially exposed white-tailed deer

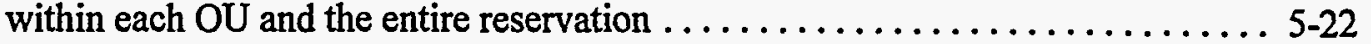

5.3 The number of potentially exposed wild turkey within each OU

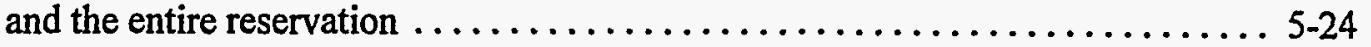

5.4 The number of potentially exposed short-tailed shrews

within each $\mathrm{OU}$ and the entire reservation $\ldots \ldots \ldots \ldots \ldots \ldots \ldots \ldots \ldots . \ldots \ldots$ 5-26

5.5 The number of potentially exposed American woodcock

within each OU and the entire reservation $\ldots \ldots \ldots \ldots \ldots \ldots \ldots \ldots \ldots \ldots$ 5-28

5.6 The number of potentially exposed red-tailed hawk

within each $\mathrm{OU}$ and the entire reservation $\ldots \ldots \ldots \ldots \ldots \ldots \ldots \ldots \ldots \ldots .6 \ldots$

5.7 The number of potentially exposed red fox

within each $\mathrm{OU}$ and the entire reservation $\ldots \ldots \ldots \ldots \ldots \ldots \ldots \ldots \ldots \ldots .32$

A.1 Contacts for data survey for ORR-EMAP terrestrial wildlife assessment . . . . . A-6

B.1 Habitat requirements for assessment and measurement

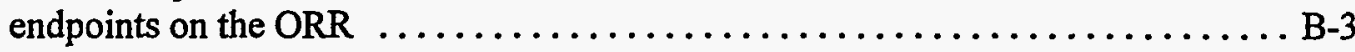

B.2 Summary of landcover types identified on the ORR and expected

use by assessment and measurement endpoints $\ldots \ldots \ldots \ldots \ldots \ldots \ldots \ldots \ldots$ B-8

B.3 Summary of landcover types identified on OUs on the ORR $\ldots \ldots \ldots \ldots \ldots . .12$

B.4 Summary of habitat availability for assessment and measurement

endpoints at $\mathrm{K}-25$ OUs. . . . . . . . . . . . .

B.5 Summary of habitat availability for assessment and measurement

endpoints at $\mathrm{X}-10$ OUs . ................................ 18

B.6 Summary of habitat availability for assessment and measurement

endpoints at Y-12 OUs, Freel's Bend, and the South Campus Facility ......... B-21

B.7 Ranking of endpoint species by the number of OUs that provide at least

one favored habitat type ............................... 24

B.8 Ranking of OUs on the ORR by the number of species for which they

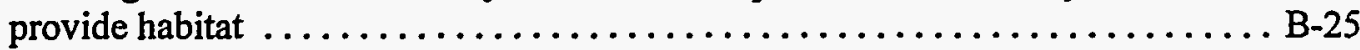

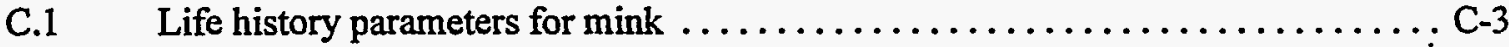

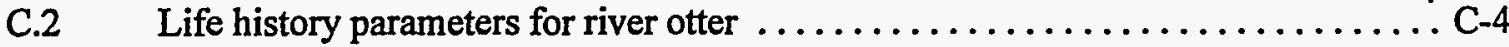

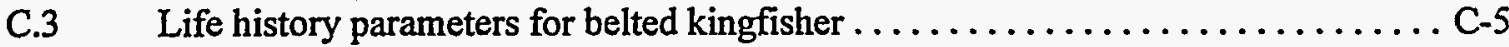

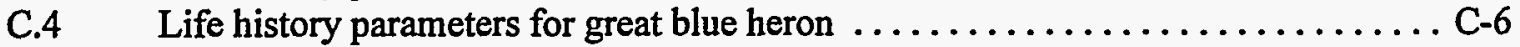

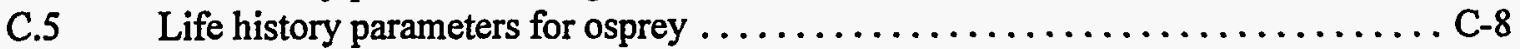

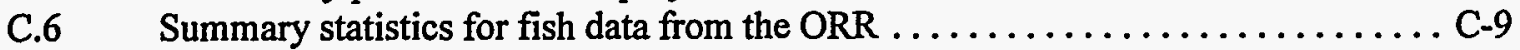

C.7 Estimated exposure of mink on the ORR to mercury and PCBs ...........

C.8 Estimated exposure of river otter on the ORR to mercury and PCBs ......... C-15

C.9 Estimated exposure of belted kingfisher on the ORR to mercury and PCBs .... C-17

C.10 Estimated exposure of great blue heron on the ORR to mercury and PCBs ..... C-19

C.11 Estimated exposure of osprey on the ORR to mercury and PCBs . . . . . . . C-21

C.12 Biomass of fish observed at fish sampling locations in Bear Creek in 1993 . . . . C C-22

C.13 Density of fish observed at fish sampling locations in East Fork Poplar Creek ... C-23 
C.14 Total biomass of fish observed at fish sampling locations in White Oak Creek Watershed . ......................... C-24

C.15 Results of Monte Carlo simulation of exposure for piscivores on the ORR .... C-25

C.16 Estimated NOAELs and LOAELs for mink and river otter ............ C-27

C.17 Estimated NOAELs and LOAELs for belted kingfisher,

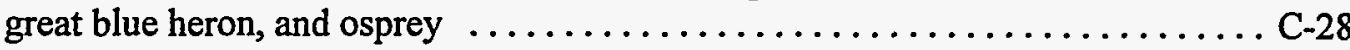

C.18 Contaminant concentrations ( $\mathrm{mg} / \mathrm{kg}$ ) found in Kingfisher egg shells and feathers found on the ORR . ..........................

C.19 Contaminant concentrations in tissues of three kingfishers found on the ORR .. C-30

C.20 Summary of number of locations where $\mathrm{HQs}>1$ were observed $\ldots \ldots \ldots \ldots$. C-31

C.21 Summary of number of individuals of piscivore endpoint species estimated to be experiencing adverse effects by watershed and for the ORR ........C-33

C.22 Simulation of exposure of mink to mercury and PCBs in toxicity test diets ..... C-35

E.1 Percent by weight of the most common fish species collected from the ORR and Clinch River above Melton Hill Dam . . . . . . . . . . . . . . E-9

E.2 Mean mercury concentrations (ppm, wet $w t)$ in homogenized fish ${ }^{1}$ collected on the $O R^{2}$, Clinch River above the $O R^{3}$, and from the ocean ${ }^{4}$ and diets

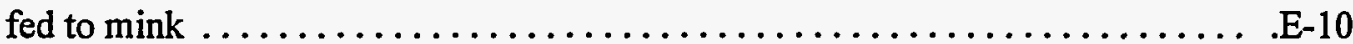

E.3 Mercury concentration (ppm, wet wt) in tissues from female mink fed ( $\mathrm{n}=8 / \mathrm{diet}$ ) various diets ${ }^{1}$ and their 6-week old kits

E.4 Mean ${ }^{1} \pm$ SE lipid adjusted Aroclor 1260 and PCB congener concentrations (ppm, wet wt) in homogenized fish ${ }^{2}$ collected on the ORR ${ }^{3}$, Clinch River

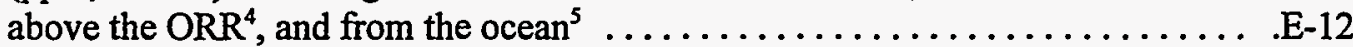

E.5 Mean \pm SE lipid adjusted Aroclor 1260 and $\mathrm{PCB}$ congener concentrations (ppm, wet wt) in mink diets ${ }^{1}(n=10 /$ diet $) . \ldots \ldots \ldots \ldots \ldots \ldots \ldots \ldots$ E-13

E.6 Mean \pm SE lipid adjusted Aroclor 1260 and PCB congener concentrations ( $\mathrm{ppm}$, wet $w$ ) in liver tissue from female mink $\left(n=8 /\right.$ diet) fed various diets ${ }^{1} . \ldots$ E-14

E.7 Mean \pm SE Aroclor 1260 and PCB congener concentrations (ppm, wet wt) in fat tissue from female mink $(n=8 /$ diet $)$ fed various diets ${ }^{1} \ldots \ldots \ldots \ldots \ldots$ E-15

E.8 Mean $^{1} \pm$ SE Aroclor 1260 and PCB congener concentrations (ppm, wet wt) in liver tissue from 6-week-old mink kits from dams fed diets of fish collected from various sources ${ }^{2} \ldots \ldots \ldots \ldots \ldots \ldots \ldots \ldots \ldots \ldots \ldots \ldots$ E-16

E.9 Mean ${ }^{1} \pm \mathrm{SE}$ Aroclor 1260 and PCB congener concentrations (ppm, wet wt) in carcass ${ }^{2}$ of 6-week-old mink kits from dams fed diets of fish collected from various sources $\ldots \ldots \ldots \ldots \ldots \ldots \ldots \ldots \ldots \ldots \ldots \ldots \ldots \ldots \ldots \ldots \ldots$

E.10 Reproductive performance of female mink fed diets of $75 \%$ fish

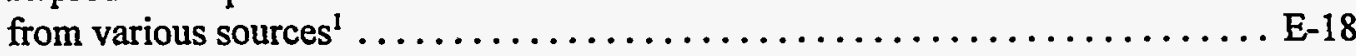

F.1 Mean $\pm \mathrm{SE}(\mathrm{N})$ concentrations (ppm, wet wt) of elements and Aroclor $1260^{1}$ from homogenized fish ${ }^{2}$ collected from great blue heron colonies located $o^{3}$ and off the ORR ........................... F

F.2 Metal ${ }^{1}$ concentrations (ppm, wet wt) detected in great blue heron eggs from colonies located on ${ }^{2}$ and off the ORR during 1992-1994. . . . . . . . . . F-10

F.3 Metal concentrations (Mean \pm SE) detected in tissues collected from great blue heron chicks from colonies located on ${ }^{1}(\mathrm{~N}=38)$ and off ${ }^{2}(\mathrm{~N}=35)$ the ORR during 1992-1994. 
F.4 Mean $\pm \mathrm{SE}(\mathrm{N})$ Aroclor 1260 and congener concentrations ${ }^{1}$ (ppm, wet wt) in great blue heron eggs collected from colonies located on ${ }^{2}$ and off the ORR. ................................... F-12

F.5 Mean $\pm \mathrm{SE}(\mathrm{N})$ Aroclor 1260 and congener concentrations (ppm, wet wt) in abdominal fat from great blue heron chicks collected from colonies located on ${ }^{1}$ and off ${ }^{2}$ the ORR

F.6 Mean $\pm \mathrm{SE}(\mathrm{N})$ Aroclor 1260 and congener concentrations ${ }^{1}$ (ppm, wet wt) in liver tissue from great blue heron chicks collected from colonies located on $^{2}$ and off the ORR

F.7 Mean $\pm \mathrm{SE}(\mathrm{N})$ Aroclor 1260 and congener concentrations ${ }^{1}$ (ppm, wet wt) in muscle tissue from great blue heron chicks collected from colonies located on $^{2}$ and off the ORR

F.8 Reproductive, physiological, and biomarker measurements $[\mathrm{Mean} \pm \mathrm{SE}(\mathrm{N})]$ in great blue heron from colonies located on ${ }^{1}$ and off ${ }^{2}$ the ORR

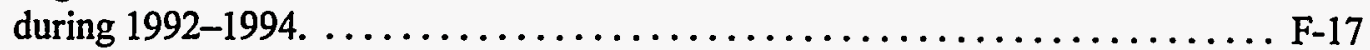

G.1 Life history parameters for the white-tailed deer (Odocoileus virginianus) ...... G-3

G.2 Life history parameters for the wild turkey (Meleagris gallopavo) $\ldots \ldots \ldots \ldots \ldots$ G-5

G.3 Life history parameters for the short-tailed shrew (Blarina brevicauda) . . . . . . . G-6

G.4 Life history parameters for the American woodcock (Scolopax minor) ........ G-8

G.5 Life history parameters for red fox (Vulpes fulva) ................. G-10

G.6 Life history parameters for red-tailed hawks (Buteo jamaicensis) . .......... G-11

G.7 Contaminant concentrations in soil on the Oak Ridge Reservation ...........

G.8 Contaminant concentrations in soil ( $\mathrm{mg} / \mathrm{kg}$ ) on the ORR compared with background soil levels .............................. G-24

G.9 Soil-plant organic contaminant uptake factors using octanol water partition coefficients . .................................. 33

G.10 Estimated exposure of white-tailed deer to contaminants on the ORR . . . . . . . G-34

G.11 Estimated exposure of wild turkey to contaminants on the ORR .......... G-41

G.12 Estimated exposure of short-tailed shrews to contaminants on the ORR ......G-45

G.13 Estimated exposure of American woodcock to contaminants on the ORR ...... G-52

G.14 Estimated exposure of red fox to contaminants on the ORR ............

G.15 Estimated exposure of red-tailed hawk to contaminants on the ORR ......... G-63

G.16 Experimental information for derivation of mammalian NOAELs and LOAELs . G-66

G.17 Estimated NOAELs and LOAELs for mammalian endpoints . . . . . . . . . . G-72

G.18 Estimated NOAELs and LOAELs for avian endpoints $\ldots \ldots \ldots \ldots \ldots \ldots \ldots$ G-74 



\section{ACRONYMS}

\begin{tabular}{|c|c|}
\hline BEIDMS & Bechtel Environmental Information Data Management System \\
\hline $\mathrm{BCK}$ & Bear Creek kilometer \\
\hline $\mathrm{BC}$ & Bear Creek \\
\hline $\mathrm{BCV}$ & Bear Creek Valley \\
\hline BMAP & Biological Monitoring and Abatement Program \\
\hline CERCLA & Comprehensive Environmental Response, Compensation, and Liability Act \\
\hline COPECs & Chemicals of Potential Ecological Concern \\
\hline CR & Chestnut Ridge \\
\hline DOE & U.S. Department of Energy \\
\hline EFPC & East Fork Poplar Creek \\
\hline EFK & East Fork kilometer \\
\hline EMAP & Ecological Monitoring and Assessment Program \\
\hline EPA & U.S. Environmental Protection Agency \\
\hline ESD & Environmental Sciences Division \\
\hline ER & Environmental Restoration \\
\hline EROD & ethoxyresorufin-0-deethylase \\
\hline FCAP & Filled Coal Ash Pond \\
\hline FFA & Federal Facilities Agreement \\
\hline GIS & geographic information system \\
\hline HQ & hazard quotient \\
\hline MEK & Melton Branch Kilometer \\
\hline MIK & Mitchell Branch Kilometer \\
\hline NOAEL & no observed adverse effects level \\
\hline NTK & Northwest Tributary Kilometer \\
\hline LEFPC & Lower East Fork Poplar Creek \\
\hline LOAEL & Lowest Observed Adverse Effects Level \\
\hline OREIS & Oak Ridge Environmental Information System \\
\hline ORNL & Oak Ridge National Laboratory \\
\hline ORR & Oak Ridge Reservation \\
\hline OU & operable unit \\
\hline PLE & product limit estimator \\
\hline RI & remedial investigation \\
\hline SAIC & Science Applications International Corporation \\
\hline $\mathrm{SCF}$ & South Campus Facility \\
\hline STD & Standard Deviation \\
\hline$T \& E$ & Threatened or Endangered \\
\hline TWRA & Tennessee Wildlife Resources Agency \\
\hline UEFPC & Upper East Fork Poplar Creek \\
\hline UCL & upper confidence limit \\
\hline WAG & Waste Area Grouping \\
\hline WCK & White Oak Creek kilometer \\
\hline WOC & White Oak Creek \\
\hline WOL & White Oak Lake \\
\hline
\end{tabular}




\section{ACKNOWLEDGMENTS}

This report is the result of the efforts, contributions, and support of many persons. We are grateful to Sigurd Christensen, Craig Brandt, Michelle Bell, and John Fackenthal for their work in identifying, locating, and acquiring data for use in this assessment. We also thank all of the ER personnel who responded to requests for data and provided input and support. We thank the following for providing us with their data and aiding in it's interpretation: George Southworth, Mark Peterson, Walter Hill, Rich Stevens, Chuck Hadden, Pat Ryon, Christy Anderson, Robert Brewer, Dick Halbrook, Chris Welsh, and Jim Evans. Brent Ziegler, John Paul Van Stone, Andrew Scholl, and Michael Aplin provided technical support. All maps were produced by Robert Washington-Allen. Finally, this report has benefitted from the reviews of Glenn Suter and Tom Ashwood. 
I 


\section{EXECUTIVE SUMMARY}

Historically, ecological risk assessment at Comprehensive Environmental Response, Compensation, and Liability Act (CERCLA) sites [such as the Oak Ridge Reservation (ORR)] has focused on species that may be definitively associated with a contaminated area or source operable unit. This is necessary to identify areas where risk is sufficiently high to warrant remediation. Consequently the species that are generally considered are those with home ranges small enough such that multiple individuals or a distinct population can be expected to reside within the boundaries of the contaminated site. This approach is adequate for sites with single, discrete areas of contamination that only provide habitat for species with limited spatial (i.e., small home range) requirements. This approach is not adequate however for large sites with multiple, spatially separated contaminated areas that provide habitat for wide-ranging wildlife species. Because wide-ranging wildlife species may travel between and use multiple contaminated sites, they may be exposed to and be at risk from contaminants from multiple locations. Use (and therefore exposure and risk) of a particular contaminated site by wide-ranging species will be dependant upon the amount of suitable habitat available at that site. Therefore to adequately evaluate risks to wide-ranging species at the ORR-wide scale, the use of multiple contaminated sites must be weighted by the amount of suitable habitat on operable units (OUs). Highly contaminated OUs that provide little habitat are unlikely to be significant contributors to ORR-scale contaminant-associated risk. Conversely, moderately contaminated sites that contain considerable habitat may significantly contribute to ORR-scale contaminant-associated risk.

In spring of 1994, a series of meetings were held among the Federal Facilities Agreement parties to develop an approach and plan for assessing risks to wide-ranging species that could not be adequately addressed at the source OU level. The results of these discussions are presented in the ORR ecological risk assessment strategy document (Suter et al. 1994a). This report is based on this document and presents the preliminary assessment of ecological risks to wide-ranging species from contaminants on the ORR.

The reservation-wide ecological risk assessment is intended to serve several purposes, including identifying (1) which endpoints are significantly at risk, (2) which contaminants are responsible for this risk, and (3) which OUs significantly contribute to risk. To address these issues, this report contains the following information:

- an evaluation of the potential use of OUs by 57 endpoint species identified in Suter et al. (1994a),

- a preliminary ranking of OUs according to those that may present the greatest ecological risk,

- a preliminary assessment of risks to selected piscivorous wildlife (i.e., mink, river otter, belted kingfisher, great blue heron, osprey),

- a preliminary assessment of risks to selected vermivorous, herbivorous, and predatory wildlife (i.e., American woodcock, short-tailed shrew, white-tailed deer, wild turkey, red fox, red-tailed hawk), and

- a proposed revision schedule. 
Data used in this preliminary assessment included a reservation-wide land use/land cover classification (Washington-Allen et al. 1995), reservation-wide fish bioaccumulation data from the Biological Monitoring Programs, and soil contamination data for 12 of 37 OUs. These data were derived from ORR computer databases (the Oak Ridge Environmental Information System and the Bechtel Environmental Information Data Management System).

Potential use of OUs by the endpoint species listed in Suter et al. (1994a) was estimated by comparing habitat requirements for the endpoint species (obtained from the literature) to the nine landcover types identified in Washington-Allen et al. (1995). An OU was considered to provide habitat for an endpoint species if at least one of the habitat types required by the species was present on the OU. OUs were ranked by the number of species for which they could potentially provide habitat, and endpoint species were ranked by the number of OUs on which suitable habitat was available. Conclusions of this evaluation include the following: (1) The largest OUs on the ORR generally have the most diverse habitat and consequently can support the greatest number of potential endpoint species; and (2) Species that can use urban habitats or that have broad habitat requirements have the highest potential to experience exposure as a result of the large numbers of OUs that provide suitable habitat.

Risks to piscivorous wildlife were assessed by using contaminant concentrations in fish from four watersheds on the ORR [i.e., Bear Creek, East Fork Poplar Creek, the K-25 vicinity, White Oak Creek (including White Oak Lake)]. Additional data used in this assessment included toxicity tests performed on mink and field surveys of mink, great blue heron, belted kingfisher, and osprey. Monte Carlo simulations of contaminant exposure estimates were calculated for each species by watershed. The resulting exposure distributions were then combined with literature-derived population density data for each endpoint species to estimate the number of individuals of each species likely to experience adverse effects within each watershed. These numbers were then summed for the reservation as a whole to estimate the proportion of the ORR population potentially at risk. By combining the multiple lines of evidence available to assess risks to piscivores, the following conclusions may be made:

- Mercury presents a hazard to mink in East Fork Poplar Creek and consequently to a significant portion (30\%) of the ORR-wide mink population. Risks to mink from PCBs are not significant (Chap. 4).

- Evaluation of the potential risks to a future ORR-wide population of otter indicates that mercury presents a risk in all watersheds on the ORR. Because the river otter is a state threatened species, effects to any individual are significant. Therefore the weight of evidence suggests that mercury is a significant risk to individual river otter that may occupy the ORR in the future (Chap. 4)

- Comparison of exposure estimates to lowest observed adverse effects level (LOAELs) indicates a significant risk from mercury in all watersheds except White Oak Creek. This translates into a risk to $81.5 \%$ of the ORR-wide kingfisher population. The limited biomonitoring data indicate that kingfisher on the ORR (particularly in the White Oak Creek area) are accumulating mercury to potentially nephrotoxicty levels. The weight of evidence suggests mercury in all watersheds presents a significant risk to the ORR-wide belted kingfisher population. Risks from PCBs are not significant (Chap. 4). 
- Although mercury in fish is estimated to represent a significant risk to great blue heron within the East Fork Poplar Creek watershed and, consequently, to an estimated $37 \%$ of the heron population on the ORR, studies on two of five colonies adjacent to the ORR (i.e., $<10 \mathrm{~km}$ from the ORR) indicate that reproduction at these locations is not impaired. Contaminant bioaccumulation and reproductive success are unknown at the three additional colonies adjacent to the ORR. Additionally, the primary foraging locations for herons at the two studied colonies are unknown. Because herons can travel long distances in search of food $(>15 \mathrm{~km})$, they are likely to forage at off-site as well as on-site locations, reducing both the exposure they receive and the risk they experience. If birds from the unstudied colonies forage more extensively on the ORR, they may experience greater risk. Because of the high risk estimated for mercury exposure on the ORR, the lack of data for three of five heron colonies adjacent to the ORR, and uncertainty as to where birds from the five ORR colonies forage, a conclusion concerning whether or not great blue heron on the ORR are at risk cannot be made.

- Comparison of exposure estimates to LOAELs for osprey indicates no significant risk from mercury or PCBs in any area on the ORR that provides suitable habitat (i.e., White Oak Lake and embayment, the K-25 area). Biomonitoring data indicates that the reproductive success at osprey nests adjacent to the ORR, along Melton Hill Lake and in Poplar Creek, is greater than the average observed in the United States. The weight of evidence suggests that mercury and PCB do not present significant risks to osprey on or near the ORR.

On the ORR, although most wide-ranging wildlife species reside primarily in the uncontaminated terrestrial habitats outside of source OUs, they may also use those source OUs on which suitable habitat is present. The degree to which a source OU is used (and therefore the risk that it may present) is dependant upon the availability of suitable habitat on the OU. OUs with little or no habitat will experience little use (and will present minimal risk), whereas those with considerable habitat are likely to experience considerable use (and depending upon the degree of contamination, may present significant risks). Although individuals may experience adverse effects through exposures received at source OUs, the primary concern for ecological risk assessment is for effects at the population-level To evaluate effects to the ORR-wide wildlife populations, habitat suitability and population density on the ORR and within OUs must be considered. A general, six-step, habitat-based approach was developed that is applicable to all wildlife species on the ORR. The approach is outlined below:

1. Individual-based contaminant exposure estimates are generated for each OU by using the generalized exposure model outlined in Sample and Suter (1994).

2. Contaminant exposure estimates are compared to no observed adverse affects levels or LOAELs to determine the magnitude and nature of effects that may result from exposure at the OU. If the exposure estimate is greater than LOAEL, then individuals at the OU may experience adverse effects.

3. Availability and distribution of habitat on the ORR and within each OU is determined by using the ORR landcover map presented in Washington-Allen et al. (1995).

4. Habitat requirements for the endpoint species of interest are compared with the ORR habitat map to determine the area of suitable habitat on the ORR and within OUs. 
5. The area of suitable habitat on the ORR and within OUs is multiplied by population density values (ORR-specific or obtained from the literature) for the selected endpoints to generate estimates of the ORR-wide population and the numbers of individuals expected to reside within each OU.

6. The number of individuals for a given endpoint species expected to be receiving exposures is greater than LOAELs for each measured contaminant is totaled. This is performed by using the OU-specific population estimate from step 5 and the results from step 2 . This number is then compared with the ORR-wide population to determine the proportion of the ORR-wide population that is receiving hazardous exposures. By using the $20 \%$ criterion outlined in Suter et al. (1994a), if the proportion of the ORR-wide population receiving hazardous exposures is $220 \%$, then an adverse population-level effect is assumed to be present.

Because contaminant concentrations in soil were the most readily available type of data and contaminant concentrations in plants and earthworms can be easily estimated with soil-plant or soil-worm uptake factors, vermivores and herbivores were selected as endpoint categories to demonstrate the applicability of the habitat-based approach. Conclusions of this assessment were that while there are significant risks to individuals of selected herbivore, vermivore, and predator endpoint species resident on OUs, the reservation-wide populations of these endpoints are unlikely to be significantly affected ( $<20 \%$ of the ORR population is affected). This conclusion must be viewed with caution, however, because data were evaluated for only 13 of 37 OUs. Inclusion of additional OUs is likely to increase the proportion of the ORR populations exposed and at risk.

Finally, this preliminary assessment of risk to wide-ranging wildlife species on the ORR is based on only a small portion of the data available for the reservation. To accurately evaluate the nature and magnitude of risks on the ORR, all available data should be incorporated and considered. It is recommended that this report be revised and updated annually until all existing data have been incorporated. Following this, revisions should be produced on a 5-year schedule to incorporate new data that become available. 


\section{INTRODUCTION}

More than approximately 50 years of operations, storage, and disposal of wastes generated by the three facilities on the Oak Ridge Reservation (ORR) (the Oak Ridge K-25 Site, Oak Ridge National Laboratory, and the Oak Ridge Y-12 Plant) has resulted in a mosaic of uncontaminated property and lands that are contaminated to varying degrees. This contaminated property includes source areas [source operable units (OUs) that are the industrial facilities themselves and the waste disposal or waste storage areas] and the terrestrial and aquatic habitats down gradient from these source areas (integrator OUs; Fig. 1.1). Although the integrator OUs generally contain considerable habitat for biota, the source OUs provide little or no suitable habitat.

Historically, ecological risk assessment at Comprehensive Environmental Response, Compensation, and Liability Act (CERCLA) sites has focused on species that may be definitively associated with a contaminated area or source OU. This is necessary to identify areas where risk is sufficiently high to warrant remediation. Figure 1.1 outlines a conceptual model for contaminant transfer both within and through a source OU. Endpoints considered in source OUs include plants, soil/litter invertebrates and processes, aquatic biota found in on-OU sediments and surface waters, and small herbivorous, omnivorous, and vermivorous (i.e., feeding on ground, litter, or soil invertebrates) wildlife. All of these endpoints have limited spatial distributions or home ranges such that numerous individuals or a distinct population can be expected to reside within the boundaries of the source OU. Contaminants move from the source to either surface soil, groundwater or surface water, or sediments (Fig. 1.1). Aquatic biota may be exposed to contaminants through direct contact with water and sediment; small herbivores, omnivores, and vermivores may be exposed through ingestion of contaminated surface water. Contaminants in soil may be taken up by plants and soil/litter invertebrates; consequently small herbivores, omnivores, and vermivores that feed on these food types may be exposed. These small terrestrial wildlife species may also be exposed to contaminants through incidental or purposeful ingestion of soil.

Assessment of the endpoints outlined above is adequate for source OUs and for sites with single, discrete areas of contamination that only provide habitat for species with limited spatial (i.e., small home range) requirements. It is not adequate however for large sites with multiple, spatially separated contaminated areas the ORR that provide habitat for wide-ranging wildlife species. Because wideranging wildlife species may travel between and use multiple contaminated sites, they may be exposed to and be at risk from contaminants from multiple locations. Use (and therefore exposure and risk) of a particular contaminated site by wide-ranging species will be dependant upon the amount of suitable habitat available at that site. Therefore to adequately evaluate risks to wide-ranging species at the reservation-wide scale, the use of multiple contaminated sites must be weighted by the amount of suitable habitat on OUs. Highly contaminated OUs that provide little habitat are unlikely to be significant contributors to ORR-scale contaminant-associated risk. Conversely, moderately contaminated sites that contain considerable habitat may significantly contribute to ORR-scale contaminant-associated risk.

In spring of 1994, a series of data quality objectives meetings were held among the Federal Facilities Agreement (FFA) parties [i.e., U.S. Department of Energy (DOE), U.S. Environmental Protection Agency (EPA), Tennessee Department of Environment and Conservation] to develop an approach and plan for assessing risks to wide-ranging species that could not be adequately addressed 


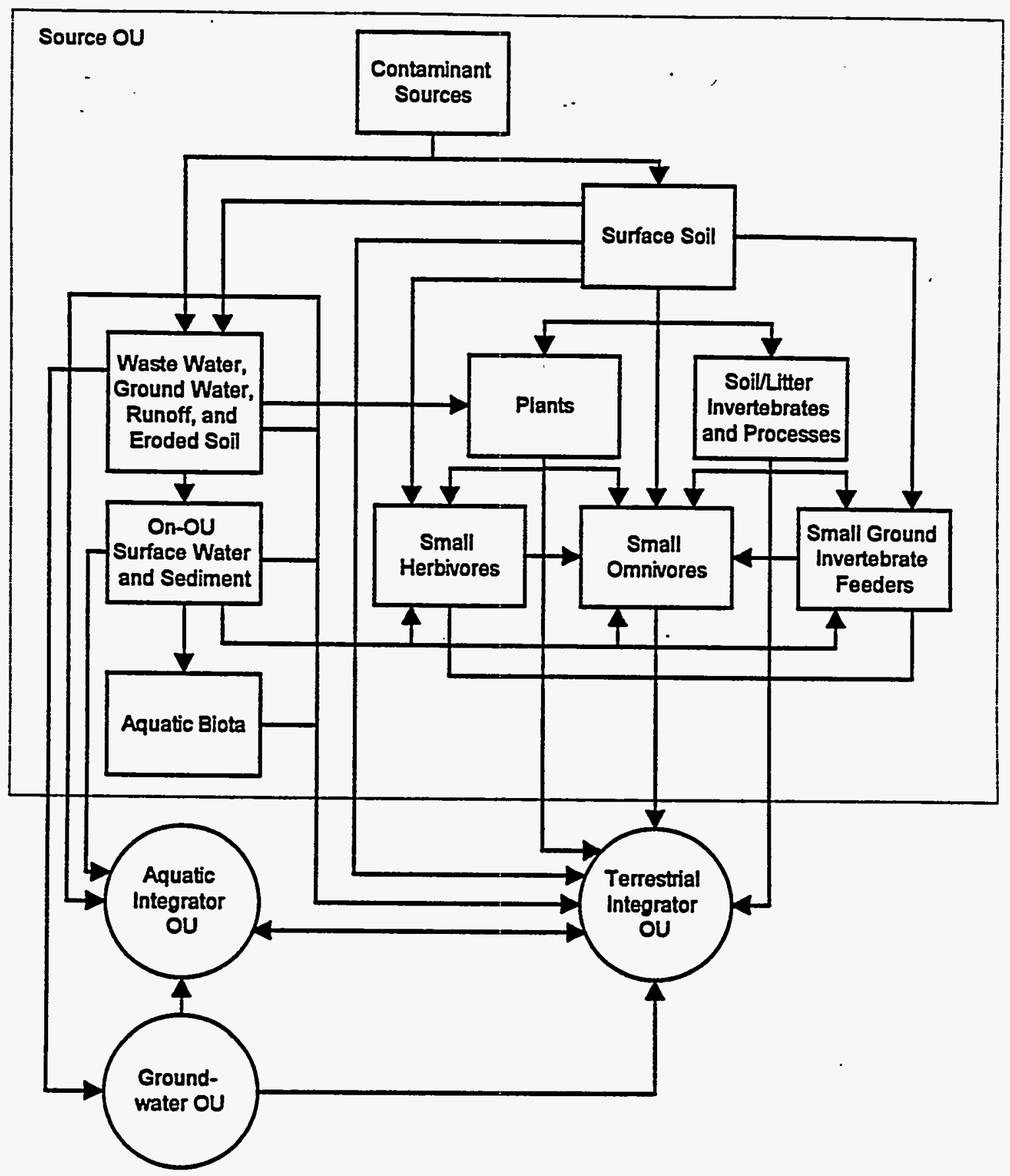

Fig. 1.1. Conceptual model of the transfer of contaminants through a source $\mathrm{OU}$ and into integrator OUs. 
at the source OU level. The results of these discussions are presented in the ORR ecological risk assessment strategy document (Suter et al. 1994). This report is based on that document and presents the preliminary assessment of ecological risks to wide-ranging species from contaminants on the ORR.

The reservation-wide ecological risk assessment is intended to serve several purposes, including identifying (1) which endpoints are significantly at risk, (2) which contaminants are responsible for this risk, and (3) which OUs significantly contribute to risk. To address these issues, this report contains the following information:

- An evaluation of the potential use of OUs by 57 endpoint species identified in Suter et al. (1994a) - This is to identify endpoint species that may require additional attention in future assessments and is based on a comparison of species-specific habitat requirements and the amount of suitable habitat within OUs.

- A preliminary ranking of OUs according to those that may present the greatest ecological risk-This is to aid in the prioritization of OUs for potential remediation and is also based on habitat in OUs and the number of species for which this habitat is suitable.

- A preliminary assessment of risks to piscivorous wildlife-Because contaminants accumulate in aquatic systems, if reservation-scale risks are likely, they should be most evident among piscivores.

- A preliminary assessment of risks to carnivorous, vermivorous, and herbivorous wildlife - This is to demonstrate the applicability of habitat-based assessment methodology.

- A proposed revision schedule-Because this assessment is based on only a portion of the data available for the ORR and because remedial investigations (RIs) are currently in progress for two potential significant OUs [Waste Area Grouping (WAG) 2 and Bear Creek], periodic updates should be performed until all available data have been assembled, incorporated, and evaluated.

Detailed assessments of risk were not performed for all 57 endpoint species for which habitat availability on OUs was evaluated. Risks were evaluated only for selected piscivores, carnivores, vermivores, and herbivores. Selection of these trophic groups was determined by availability of data (i.e., fish body burdens, soil contaminant concentrations, soil-plant or soil-earthworm uptake factors). Risks to selected species from other trophic groups identified in Suter et al. (1994a) (i.e., aquatic herbivores, aquatic invertebrate feeders, flying insectivores, arboreal insectivores, large omnivores, scavengers) will be assessed in future revisions of this report.

The species for which detailed risk assessments were performed include mink, river otter, belted kingfisher, great blue heron, osprey, red fox, red-tailed hawk, wild turkey, white-tailed deer, American woodcock, and short-tailed shrew. These species were selected because they are known or expected to be sensitive to contaminants that are present on the ORR (i.e., mink, otter), are representative of groups that are likely to be highly exposed [i.e., piscivores (mink, otter, kingfisher, and heron) and vermivores (woodcock and shrew)], are threatened or endangered (T\&E) species (i.e., osprey, otter) or a surrogates for related T\&E species (i.e., red-tailed hawk, short-tailed shrew), or are well characterized on the ORR (site-specific data exists for mink, great blue heron, white-tailed deer, and wild turkey). 
It should be emphasized that the results presented in this report are preliminary (i.e, based on only a subset of all data that exists on the ORR). The most relevant and accessible data have been selected for use at this time. As additional data are collected, made available, and incorporated, conclusions concerning the presence or magnitude of risks to wide-ranging species on the ORR may change. The quality and completeness of data used will be discussed in each chapter as it relates to the uncertainty of the risk assessment.

Assessment of ecological risks from radionuclides are not considered at this time. In human health risk assessment, the primary concern from exposure to radionuclides is increased incidence of cancer at the individual level. In ecological risk assessment, the concern is for population-level effects (except for T\&E species, however). Because there is little evidence that cancer plays any significant role in wildlife populations, radionuclides were not considered at this time. Because of the importance and prevalence of radionuclide contamination on the ORR, risks associated with radionuclide exposure will be evaluated in future revisions of this report. 


\section{DATA}

To identify data that would be useful for this project, a data search was initiated in which OU project managers were contacted and queried concerning the existence, status, nature, and availability of data concerning their $\mathrm{OU}$. The search emphasized data concerning concentrations of contaminants in soil, water, sediment, and biota. The results of this survey are summarized in Appendix A. Briefly, although considerable data have been collected at OUs on the ORR, aside from data that currently reside in the Oak Ridge Environmental Information System (OREIS) or in the Bechtel Environmental Information Data Management System (BEIDMS)', much data were not readily available. The lack of availability was primarily a result of data being stored and maintained in multiple forms (electronic vs hard copy; various database programs, etc.). Compilation and standardization of the voluminous data for the ORR was beyond the current scope of this project. The data availability issue is currently being addressed through the Environmental Information Management Program as part of the ORR environmental restoration program.

Three general categories of data were identified, acquired, and used for this assessment. These include an reservation-wide land use/land cover classification (Washington-Allen et al. 1995), fish bioaccumulation data from the Biological Monitoring Programs, and soil contamination data derived from ORR computer databases (OREIS and BEIDMS).

The reservation-wide land use/land cover classification is presented in Washington-Allen et al. (1995). Availability and distribution of nine land use/land cover types (Table 2.1) on the ORR was determined through the use of satellite imagery and ground-truthing. These data were incorporated into a geographic information system (GIS) to produce a map of the available cover types on the ORR. OU boundaries were then overlaid on the reservation-wide cover map to produce OU-specific cover maps. Finally the area (ha) of each cover type on the ORR as a whole and within each OU was calculated.

Fish bioaccumulation data consisted of contaminant concentrations in fish and were derived from five sources. Descriptions of these data sets are presented here.

- Name: Bear Creek OU4

- Spatial coverage: three locations in Bear Creek (BCK 12.4, BCK 9.4, and BCK 3.3) and one off-site location (Hinds Creek)

- Analytes: metals and PCBs

- Species: stone rollers

- Principal investigator: George Southworth.

- Name: Biological Monitoring and Abatement Program (BMAP) Bioaccumulation Task

- Spatial coverage: reservation-wide; 8 locations in vicinity of K-25, 2 locations in Bear Creek, 8 locations in White Oak Creek basin, and 7 locations in East Fork Poplar Creek

- Analytes: primarily mercury and PCBs

- Species: sunfish, largemouth bass, and carp

- Principal investigators: George Southworth and Mark Peterson.

\footnotetext{
${ }^{1}$ Reference herein to any specific commercial product, process, or service by trade name, trademark, manufacturer, or otherwise, does not necessarily constitute or imply its endorsement, recommendation, or favoring by the United States Government or any agency thereof.
} 
Table 2.1. The land use/landcover classes used in habitat classification

\begin{tabular}{|c|c|}
\hline Land use/landcover & Description \\
\hline Urban land & $\begin{array}{l}\text { Mixture of administrative buildings, laboratories, } \\
\text { heavy commercial and industrial buildings, lawns, } \\
\text { and clumped shade trees }\end{array}$ \\
\hline Deciduous forest land & Areas of hardwood forest types \\
\hline Mixed Forest Land & Areas of a mixture of hardwoods and pine trees \\
\hline Evergreen forest land & $\begin{array}{l}\text { Areas dominated by mature pine forest type with } \\
\text { trees generally older than } 35 \text { years (in 1994) and } \\
\text { having an uneven canopy }\end{array}$ \\
\hline Evergreen plantation & $\begin{array}{l}\text { Areas of pine trees which are row planted, are of } \\
\text { uniform age, and are generally younger than } 35 \\
\text { years (in 1994) }\end{array}$ \\
\hline Pasture land & $\begin{array}{l}\text { Fields of pasture grasses, grassland, row crops, } \\
\text { and/or shrub land cover }\end{array}$ \\
\hline Transitional areas & $\begin{array}{l}\text { Secondary early successional sites, usually } \\
\text { grassland to grassland shrub mix; generally mowed } \\
\text { along power line corridors }\end{array}$ \\
\hline Barren land & $\begin{array}{l}\text { Cropped fields, plowed or bare ground areas, or } \\
\text { areas where vegetation has been removed, such as } \\
\text { construction sites or quarries }\end{array}$ \\
\hline
\end{tabular}

- Name: Clinch River RI Program

| Spatial coverage: Multiple locations in the Clinch and Tennessee rivers, and Poplar Creek. Data from one location in the Clinch River, near K-25, and 7 locations in Poplar Creek were used in this assessment.

Analytes: metals, PCBs, pesticides, and other organics

Species: sunfish, largemouth bass, catfish, carp, and shad

- Name: K-901 Holding Pond

Spatial coverage: 1 location (K-901 pond)

Analytes: metals, radionuclides, PCBs, pesticides, and other organics

Species: shad, largemouth bass, and carp

Principal investigator: Science Applications International Corporation

These data were combined into one large data set. While all small fish (stonerollers, shiners, and shad) were analyzed whole, all large fish (sunfish, largemouth bass, catfish, and carp) were analyzed as 
fillets only. Whole-body contaminant concentrations in large fish were estimated by using fillet-towhole equations developed by Bevelheimer et al. (1996)

The last data set used in this report consists of contaminant concentrations in soil from OUs. These data were extracted from the OREIS and BEIDMS databases. The data were restricted to include only the top $2 \mathrm{ft}$ of soil. This was assumed to include the soil horizons that wildlife species were most likely to be exposed to. Data were obtained for the following OUs: Bear Creek OU 2, Lower East Fork Poplar Creek, Upper East Fork Poplar Creek OU 2, WAG 1, WAG 6, South Campus Facility, K-1407, K-1414, and K-1420. In addition, soil data from risk assessments completed at four OUs (Chestnut Ridge OU 2, Bear Creek Valley OU, WAG 2, and WAG 5) were evaluated.

Again it should be noted that these data do not represent all available data. They simply represent a subset of the total that could be assembled, collated, and prepared at this time. Additional data will be acquired and incorporated in future revisions of this report. 


\section{EVALUATION OF POTENTIAL USE OF OPERABLE UNITS ON THE OAK RIDGE RESERVATION BY WILDLIFE}

One of the primary factors determining the presence or absence of wildlife species in any area is the availability of suitable habitat. If suitable habitat is available (and the wildlife species of interest are present in the area), use of a site by wildlife is likely. Conversely, if no suitable habitat is available, use of the site is unlikely. In terms of risk to wildlife on the ORR, if an OU contains habitat for wildlife, it is likely to be used, and therefore wildlife that use the site may be exposed to contaminants and potentially be at risk. By comparing the habitat requirements of wildlife endpoints with the habitats available on OUs on the ORR, OUs that may present risk and endpoints that may be at risk can be identified.

Uncertainty associated with identifying OUs or endpoints as presenting or being at risk must be emphasized because contaminant data are not used in this evaluation; it is simply based on a co-occurrence of factors that increase the potential for an OU to present a risk or for an endpoint to be at risk. Although this evaluation can identify those species that are not at risk and OUs that do not present on-OU risk (if an OU contains no suitable habitat, use and exposure are unlikely, therefore risks are unlikely; it should be noted, however that OUs that do not contain any suitable habitat may act as sources of contamination to down gradient areas; therefore, although there may be no on-OU risks, they may contribute significantly to off-OU risks), without incorporating OU-specific contaminant data and estimating exposure, the actual nature and magnitude of risk at an OU cannot be determined.

Information concerning the habitat requirements for the 57 endpoint species identified in Suter et al. (1994) was obtained from the literature (Table B.1). These data were then compared to the nine landcover types identified on the ORR in Washington-Allen et al. (1995) to identify landcover types on the ORR that an endpoint is likely to use (Table B.2). Habitat requirements information for endpoint species was generally far more detailed than the landcover types identified on the ORR. Consequently some assumptions and professional judgments were applied in matching habitat requirements with available habitat types. For example, many species are listed as requiring floodplain, bottom land, or riparian forest (Table B.1). This habitat type is not specifically delineated in Washington-Allen et al. (1995). Because the dominant forest habitat types at the three OUs that are located in floodplains [WAG 2, Bear Creek, and Lower East Fork Poplar Creek (LEFPC)] are deciduous and mixed forest (Table B.3), if a species was identified as requiring floodplain forest, it was assigned to these habitats. This approach is conservative, because deciduous and mixed forests are not restricted to floodplain locations. A similar approach was used for other landcover types not specifically identified in Washington-Allen et al. (1995).

The amount of habitat (in ha) in each of the nine categories observed at each OU is summarized in Table B.3. The presence or absence of habitat for the 57 endpoint species at OUs at the K-25 Site, Oak Ridge National Laboratory (ORNL), and the Y-12 Plant are summarized in Tables B.4, B.5, and B.6, respectively. Tables B.7 and B.8 present the total number of OUs that provide habitat for each species and the total number of species with habitat on each OU, respectively. An OU was considered to have habitat for a species if any one of the landcover categories from Tables B.2 and B. 3 coincided. Professional judgement was employed in determining if the habitat at an OU was suitable for an endpoint. For example, if the species required large bodies of water, and while water was present on an OU but consisted of a small stream, the habitat was considered unsuitable. Habitat was considered only on a presence/absence basis-the amount of habitat was not incorporated into the evaluation of whether or not an species would use an OU. It is recognized that this approach is overly simplistic and 
conservative. Use of an OU by a species will depend on the amount of habitat available (not just suitability), the connectivity of the on-OU habitat to similar habitat off the OU (isolated patches will receive less use than contiguous patches), and the amount of human activity in the vicinity (use by many species is inversely related to human activity). This evaluation was performed to determine simply if an endpoint could use an OU. A more detailed evaluation of the quality and quantity of habitat at an OU will be performed in a manner similar to that discussed in Chap. 5 as part of a future revision of this report.

As would be expected, OUs with high diversity of landcover types (i.e., many landcover types present on the $\mathrm{OU}$ ) were determined to be able to support the greatest number of endpoint species (Table B.8). These OUs were also the largest on the ORR (Table B.3). Small OUs located within the plant sites [i.e., Upper East Fork Poplar Creel (UEFPC) OU 2 and OU 3] were estimated to support the lowest number of endpoint species. If potential on-OU risk is determined simply by the number of species that might use an OU, WAG 2, K-901, LEFPC, Bear Creek, and WAGs 4, 5, 6, and 7 present the greatest risk (Table B.8). OUs that present the least risk (based solely on number of endpoints) include K-1413, K-1004, K-1401, K-1420, UEFPC OU 2 and UEFPC OU 3.

Endpoint species estimated to be present at all 37 OUs are either habitat generalists (i.e., starlings, raccoons), tolerant of human activities (e.g., groundhog, American robins, Canada geese), or make use of structures (e.g., barn owl, Rafinesque's big-eared bat) (Table B.7). The next most common group of endpoint species (expected to be found at 31 OUs), consists of species with broad habitat preferences. These species use both forested and open (i.e., pasture and transitional) habitats. Species that require aquatic habitat (e.g., ponds, streams) are expected at 16 OUs, and only 3 OUs (K$901, \mathrm{~K}-1007$, and WAG 2) are suitable for those species that need large bodies of water (bald eagle, osprey, double-crested cormorant, and gray bat) (Table B.7). Only three endpoint species are not expected to be present on any OUs on the ORR: golden eagles and cougars (the ORR as a whole probably does not provide sufficient suitable habitat for these species) and the Tennessee cave salamander (no caves are currently known to exist on any OU, therefore there is no habitat for this aquatic troglodytic salamander). The last endpoint, the green salamander, requires moist rock outcroppings. Locations and possible distributions of this habitat feature within OUs is unknown at this time.

\subsection{QUALITY AND COMPLETENESS OF DATA}

The completeness of data for this portion of the assessment is adequate; however, the quality of data needs improvement. Although a highly significant first step, the level of detail in the ORR landcover map is far less than what is needed to accurately estimate the actual presence of suitable habitat on each OU. Incorporation of aspect and elevation data in the ORR landcover map would be useful to differentiate dry upland sites from moist bottom lands. It would also allow floodplain habitats to be delineated. Additional, more detailed data on habitat requirements (and their relative value) for each endpoint species would also increase the precision in the habitat use predictions for each OU. By combining the relative habitat preferences for each endpoint species with the amounts of each habitat type present on each OU, a better estimate of the likelihood of use (and therefore the potential for exposure and risk) may be obtained. 


\section{ASSESSMENT OF RISKS TO PISCIVORES ON THE OAK RIDGE RESERVATION}

Numerous, significant changes have been made throughout this section. To facilitate the flow of the document, they are summarized below but are not specifically identified in the text. The major changes in this section include the following:

- Use of BMAP bioaccumulation data only from 1994 and 1995;

- Exclusion of LEFPC RI fish data

- Inclusion of Clinch River RI fish data

- Focus on only two contaminants: mercury and FCBs. All others not considered because of a lack of ORR-wide data

- Estimated whole fish contaminant concentrations using models developed by Bevelheimer et al. (1996) instead of simple fillet-whole fish ratios.

- Use of updated benchmarks that reflect regulator comments concerning scaling factors.

- Inclusion in assessment of osprey for areas where appropriate habitats were available.

- Weighted piscivore exposures by the relative density or biomass of fish in sampling areas as per regulator comments.

\subsection{PROBLEM FORMULATION}

This section discusses the attributes and selection of appropriate ecological endpoints, describes the ecological setting, provides information on the sources and hazards to which organisms may be exposed, and integrates this information into a conceptual model that portrays the interaction among sources and endpoints at the sites. The information provided here sets the stage for the exposure assessment section that follows.

\subsubsection{Ecological Assessment Endpoints}

The hazard identification phase of an ecological risk assessment must identify both the assessment endpoints, which are explicit statements of the characteristics of the environment that are to be protected, and the measurement endpoints, which are quantitative summaries of a measurement or series of measurements that are related to effects on an assessment endpoint.

\subsubsection{Assessment endpoints}

The following assessment endpoints were selected for the assessment of risks to piscivorous wildlife: toxicity to mink (Mustela vison), river otter (Lutra canadensis), belted kingfisher (Ceryle alcyon), great blue heron (Ardea herodias), and osprey (Pandion haliaetus) resulting in a reduction in population abundance or production. These assessment endpoints are those that have been agreed to be appropriate for the ORR by the FFA parties (Suter et al. 1995). The criteria for selection of the entities are those recommended by EPA (1992), plus considerations of scale and practical considerations.

Both osprey and river otter are listed as a threatened species by the Tennessee Wildlife Resources Agency (TWRA). Osprey are found along the Clinch River and Poplar Creek adjacent to the ORR and use larger bodies of water on the ORR. Although otter are not known to occur on the ORR at the present time, they have been included in this assessment because the ORR contains suitable habitat, 
a reintroduction program is underway in East Tennessee, and they may become established on the ORR in the future. To determine if the ORR could support this threatened species, the nature and magnitude of risk that contaminants on the ORR may present to otter must be evaluated.

The appropriate properties of the entities selected by these criteria depend on the level of organization of the entity and the criteria that led to their selection. Organism level-In general, protection of individual organisms is appropriate only for threatened and endangered species. Two of the selected species, osprey and river otter, are T\&E species; therefore, organism-level properties were used for these assessment endpoints. Population level-The appropriate endpoint properties for populations of endpoint species are abundance and production.

Finally, the level of effects on these properties of the endpoint entities that is considered to be potentially significant is $20 \%$ as agreed by the FFA parties (Suter et al. 1995). This level is consistent with current regulatory practice.

Assessment of piscivores is a logical first step to evaluate reservation-wide risks. Contaminants present on the ORR are known to accumulate readily in aquatic foodwebs (i.e., mercury and PCBs). Some piscivores (mink in particular) are known to be sensitive to mercury and PCBs. The diet of piscivores frequently consists exclusively of fish or other aquatic prey, therefore members of this group are likely to be highly exposed. Finally, most piscivores are highly mobile, they therefore may be exposed to contaminants from multiple locations.

The ORR was partitioned into four watersheds: Bear Creek, East Fork Poplar Creek, the K-25 area (consisting of the K-25 ponds, Mitchell Branch, and Poplar Creek and the Clinch River adjacent to the K-25 plant ), and White Oak Creek (including White Oak Lake and the White Oak Lake

embayment). Risks were evaluated within each watershed, and these results were used to determine risks to piscivores across the ORR as a whole.

\subsubsection{Measurement endpoints}

Three basic types of effects data are potentially available to serve as measurement endpoints: results of biological surveys, toxicity tests performed using fish from the ORR, and literature-derived toxicity test results for chemicals found on the ORR. The following are measurement endpoints for each assessment endpoint:

- Mink

- Biological survey data-Limited data concerning presence/absence, movements, and bioaccumulation of contaminants are available for mink on the ORR.

- Media toxicity data-Results of reproductive toxicity tests are available for ranch mink fed fish obtained from the Poplar Creek embayment.

- Single chemical toxicity data-These data consist of chronic toxicity thresholds for contaminants of concern in mammals with greater weight given to data from long-term feeding studies with wildlife species. Preference was also given to tests that included reproductive endpoints. These test endpoints are assumed to correspond to the assessment endpoint after allometric scaling.

\section{- River otter}

- Biological survey data-None.

- Media toxicity data-Results of reproductive toxicity tests are available for ranch mink fed fish obtained from the Poplar Creek embayment. Because both mink and otter are mustelids, 
the test endpoints for mink are assumed to correspond to the assessment endpoint (otter) after allometric scaling.

- Single chemical toxicity data-These data consist of chronic toxicity thresholds for contaminants of concern in mammals with greater weight given to data from long-term feeding studies with wildlife species. Preference was also given to tests that included reproductive endpoints. These test endpoints are assumed to correspond to the assessment endpoint after allometric scaling.

- Belted kingfisher

- Biological survey data-Limited data concerning bioaccumulation of contaminants are available for belted kingfisher on the ORR.

- Media toxicity data-None.

- Single chemical toxicity data-These data consist of chronic toxicity thresholds for contaminants of concern in birds with greater weight given to data from long-term feeding studies with wildlife species. Preference was also given to tests that included reproductive endpoints. These test endpoints are assumed to correspond to the assessment endpoint after allometric scaling.

- Great blue heron

- Biological survey data-Field data concerning contaminant bioaccumulation and reproductive success were available for 4 heron rookeries near the ORR ( 2 rookeries $<10$ $\mathrm{km}$ and 2 rookeries $>10 \mathrm{~km}$ from ORR; an additional 3 rookeries are located $<10 \mathrm{~km}$ from the ORR. No data are available from these locations).

- Media toxicity data-None.

- Single chemical toxicity data-These data consist of chronic toxicity thresholds for contaminants of concern in birds with greater weight given to data from long-term feeding studies with wildlife species. Preference was also given to tests that included reproductive endpoints. These test endpoints are assumed to correspond to the assessment endpoint after allometric scaling.

- Osprey

- Biological survey data-Field data concerning reproductive success was available for three osprey nests adjacent to the ORR (2 located on Melton Hill Reservoir, and one in Poplar Creek, near K-25).

- Media toxicity data-None.

- Single chemical toxicity data-These data consist of chronic toxicity thresholds for contaminants of concern in birds with greater weight given to data from long-term feeding studies with wildlife species. Preference was also given to tests that included reproductive endpoints. These test endpoints are assumed to correspond to the assessment endpoint after allometric scaling.

\subsubsection{Ecological Conceptual Model}

The ecological conceptual model graphically represents the relationships between the contaminant sources and the endpoint receptors. It integrates the information in the other subsections of the hazard identification and presents them graphically. It is not intended to show all of the possible sources, routes of transport, modes of exposure, or effects. Rather, it includes the only identified CERCLA source, the receptors that are designated as assessment endpoint species or communities, and the major routes that result in exposure to contaminants from the ORR. 
The conceptual model for exposure of piscivores to contaminants is presented in Fig. 4.1. Components of this model include aquatic biota (aquatic plants, invertebrates, fish, and amphibians) that reside in ponds and streams on the ORR and the piscivorous wildlife that feeds on aquatic biota. The aquatic biota are exposed to contaminants from surface water and sediments. Contaminants are bioaccumulated in lower trophic levels (i.e., plants or invertebrates) and transferred to higher trophic levels (i.e., invertebrates, fish, or amphibians). Piscivorous wildlife consume fish, amphibians, and invertebrates and are therefore exposed to accumulated contaminants (Fig. 4.1).

\subsection{EXPOSURE ASSESSMENT}

Piscivorous wildlife may be exposed to contaminants through ingestion of contaminated media (fish, other aquatic prey, and water) and through contaminants accumulated in the tissues of the piscivore itself. In this assessment, ingestion of food was the only pathway considered. Exposure through ingestion of water will be included in a future revision. Contaminant exposure through ingestion was estimated for mink, otter, belted kingfisher, great blue heron, and osprey. This assessment focused only on the two contaminants, mercury and PCBs, for which there is ORR-scale data. Data on mercury and PCB concentrations in fish were available from the four watersheds on the ORR. Exposure estimates were calculated for 37 locations on the ORR: 5 locations in Bear Creek, 7 locations in East Fork Poplar Creek, 17 locations in the vicinity of the K-25 Site, and 8 locations in the White Oak Creek basin. Exposure through contaminants accumulated in tissues was measured for nestling great blue herons and among adult kingfishers. Locations of sampling locations within Bear Creek, East Fork Poplar Creek, the K-25 Site, and White Oak Creek are presented in Figs. C. 1 through C.4.

\subsubsection{Exposure Through Oral Ingestion of Fish}

For exposure estimates to be useful in the assessment of risk to wildlife, they must be expressed in terms of a body weight-normalized daily dose or milligram contaminant per kilogram body weight per day (mg/kg/d). Exposure estimates expressed in this manner may then be compared with toxicological benchmarks for wildlife, such as those derived by Sample et al. (1996a), or to doses reported in the toxicological literature. Estimation of the daily contaminant dose an individual may receive from a particular medium for a particular contaminant may be calculated by using the following equation:

$$
E_{j}=\sum_{i=1}^{m}\left(\frac{I R_{i} \times C_{i j}}{B W}\right)
$$

where:

$E_{j}=$ total exposure to contaminant $(j)(\mathrm{mg} / \mathrm{kg} / \mathrm{d})$

$\mathrm{m}=$ total number of ingested media (e.g., food, water, soil)

$\mathrm{IR}_{\mathbf{i}}=$ consumption rate for medium $(\mathrm{I})(\mathrm{kg} / \mathrm{d}$ or $\mathrm{L} / \mathrm{d})$

$\mathrm{C}_{\mathrm{ij}}=$ concentration of contaminant $(\mathrm{j})$ in medium $(\mathrm{I})(\mathrm{mg} / \mathrm{kg}$ or $\mathrm{mg} / \mathrm{L})$

$\mathrm{BW}=$ body weight of endpoint species $(\mathrm{kg})$.

Exposure estimates were calculated for all contaminants detected at all ORR sampling locations. Because wildlife are mobile, their exposure is best represented by the mean contaminant concentration 


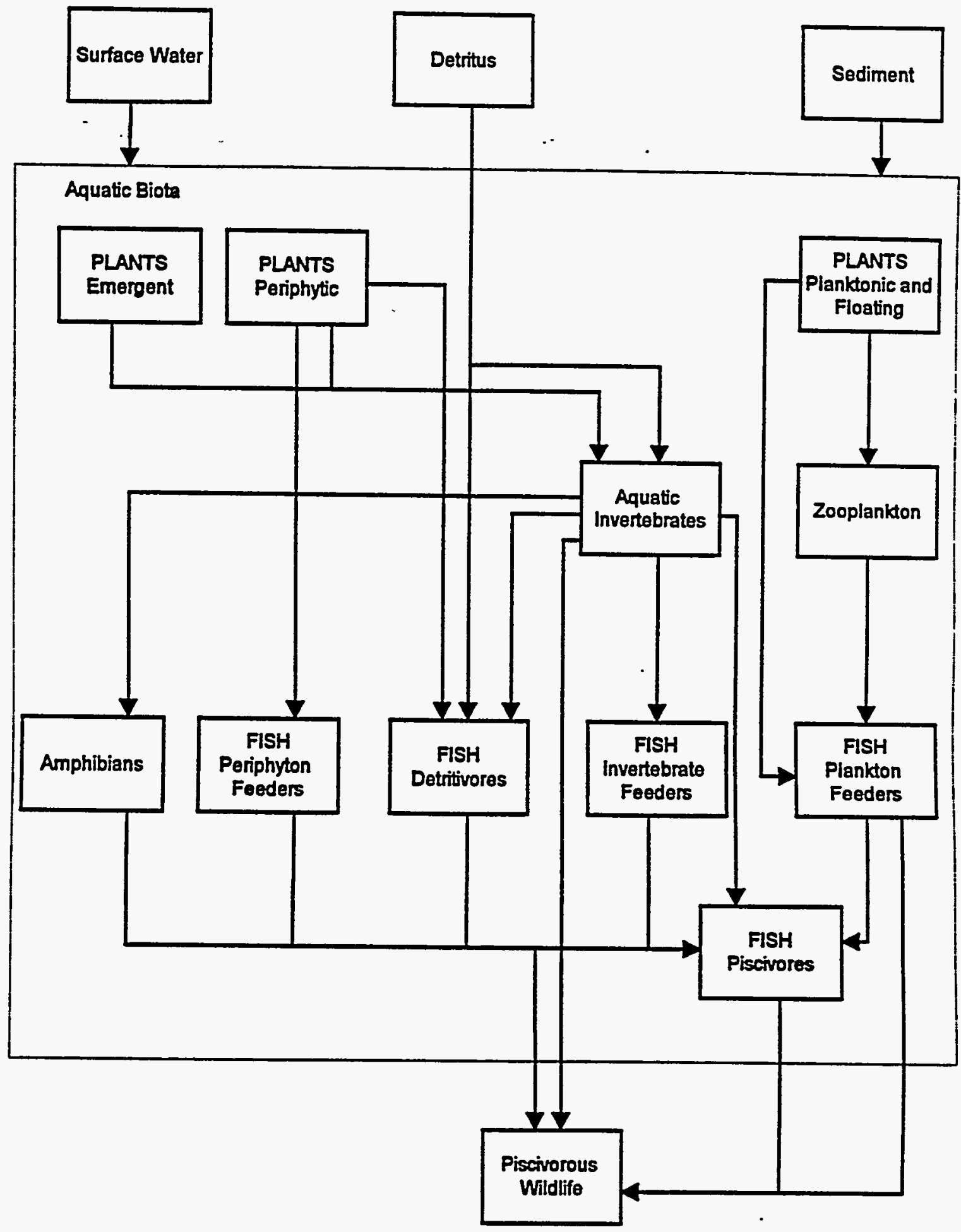

Fig. 4.1. Conceptual model for the exposure of piscivorous wildlife to contaminants. 
in media. To be conservative, the $95 \%$ upper confidence limit (UCL) is used in exposure estimates. To prevent bias that may result from calculating $95 \%$ UCLs using data that contains values below the detection limit, product limit estimator (PLE) was used to calculate the 95\% UCLs for contaminants observed in fish and water These data were used in the initial exposure estimates. Exposure estimates for contaminants that may potentially present a risk to piscivorous wildlife [based upon comparisons to no observed adverse effects levels (NOAELs) and LOAELs] were recalculated using Monte Carlo simulations. [Note: Because the purpose of the initial exposure estimate is to be conservative and to identify contaminants of potential ecological concern (COPECs), the 95\% UCL was used regardless of whether or not the value exceeded the maximum observed value. Overestimates of exposure that may occur at the screening level are addressed through the use of Monte Carlo simulation.]

\subsubsection{Estimation of whole fish contaminant concentrations from fillet data}

Fish data from the ORR consisted of analyses of both whole body concentrations (generally in stonerollers, shiners, and shad) and concentrations in fillets (in sunfish, largemouth bass, and carp). Because piscivores consume whole fish (not fillets) and fillet concentrations do not accurately represent whole body concentrations, it was necessary to estimate concentrations in whole fish for those sample for which only fillet analyses were performed. Whole-fish concentrations were estimated by using the following equations:

for mercury:

$$
C_{W B}=e^{\left[-0.8+0.76 * \ln \left(C_{F}\right)\right]}
$$

for PCBs in catfish:

$$
C_{W B}=e^{\left[0.16+0.54 * \ln \left(C_{F}\right)\right]}
$$

for PCBs in bass or other fish:

$$
C_{W B}=e^{\left[0.81+0.95 * \ln \left(C_{F}\right)\right]}
$$

where:

$\mathrm{C}_{\mathrm{WB}}=$ whole body contaminant concentration

$\mathrm{C}_{\mathrm{F}}=$ fillet contaminant concentration

A detailed discussion of the development of these equations is presented in Bevelheimer et al. (1996).

\subsubsection{Contaminant concentrations in fish}

Contaminant concentrations in fish are needed to estimate exposure. The 95\% UCLs (calculated by using the PLE) for contaminants detected in fish from the ORR are presented in Table C.6. Note that data were aggregated into two size classes: $<30 \mathrm{~cm}$ and $>30 \mathrm{~cm}$ in length. This is because piscivore species forage on different size fish and contaminant body burdens are related to size (larger, older fish generally have higher contaminant concentrations). Although mink, belted kingfisher, and great blue heron generally consume fish $<30 \mathrm{~cm}$ in size, osprey and otter forage equally on small and 
large fish (see Tables C.1 to C.5). To more accurately reflect exposure, data were segregated according to size and exposure was estimated by using data from the size of fish most likely to be consumed by that endpoint species. Because it was assumed that piscivores would select fish according to size and not by species, all species were pooled within each size class.

Although data concerning fish size were included in the BMAP, Bear Creek OU4, and Clinch River RI, fish sizes were not included in the K-901 data set. On the basis of the size data in the first three data sets, all sunfish, stonerollers and shad were assumed to be $<30 \mathrm{~cm}$ in size and largemouth bass and carp were assumed to be $>30 \mathrm{~cm}$ for the K-901 data sets.

\subsubsection{Exposure modeling using point-estimates}

Initial estimates of exposure of piscivorous wildlife to contaminants were performed for each sampling point using point estimates of parameters in the exposure model (Equation 1). Species-specific parameters necessary to estimate exposure using Equation 1 are listed in Tables C.1-C.5.

To estimate contaminant exposure experienced by mink, the following assumptions were made:

- $\quad$ Body weight $=1 \mathrm{~kg}$.

- Food consumption $=0.137 \mathrm{~kg} / \mathrm{d}$ (fresh weight).

- Diet consists $54.6 \%$ of fish or other aquatic prey.

- Contaminant concentration in fish is representative of that in other aquatic prey.

- Fish sizes consumed $=100 \%<30 \mathrm{~cm}$.

To estimate contaminant exposure experienced by otter, the following assumptions were made:

- Body weight $=8 \mathrm{~kg}$.

- Food consumption $=0.9 \mathrm{~kg} / \mathrm{d}$ (fresh weight).

- Diet consists $100 \%$ of fish or other aquatic prey.

- Contaminant concentration in fish is representative of that in other aquatic prey.

- Fish sizes consumed $=50 \%<30 \mathrm{~cm}$ and $50 \%>30 \mathrm{~cm}$.

To estimate contaminant exposure experienced by kingfisher, the following assumptions were made:

- $\quad$ Body weight $=0.148 \mathrm{~kg}$.

- Food consumption $=0.075 \mathrm{~kg} / \mathrm{d}$ (fresh weight).

- Diet consists $100 \%$ of fish.

- Fish sizes consumed $=100 \%<30 \mathrm{~cm}$.

To estimate contaminant exposure experienced by great blue heron, the following assumptions were made:

- $\quad$ Body weight $=2.39 \mathrm{~kg}$.

- Food consumption $=0.42 \mathrm{~kg} / \mathrm{d}$ (fresh weight).

- Diet consists $100 \%$ of fish or other aquatic prey.

- Contaminant concentration in fish is representative of that in other aquatic prey.

- Fish sizes consumed $=100 \%<30 \mathrm{~cm}$. 
To estimate contaminant exposure experienced by osprey, the following assumptions were made:

- $\quad$ Body weight $=1.5 \mathrm{~kg}$.

- Food consumption $=0.3 \mathrm{~kg} / \mathrm{d}$ (fresh weight).

- Diet consists $100 \%$ of fish or other aquatic prey.

- Contaminant concentration in fish is representative of that in other aquatic prey.

- Fish sizes consumed $=92.1 \%<30 \mathrm{~cm}$ and $7.9 \%>30 \mathrm{~cm}$.

Using Equation 1 and the assumptions and data described above, exposure to contaminants was estimated for mink (Table C.7), otter (Table C.8), kingfisher (Table C.9), and great blue heron (Table C.10) for each location on the ORR. Because osprey use only large bodies of water, exposure estimates were generated for only for those areas where suitable habitat was availabale (the K-25 Site and White Oak Lake and embayment; Table C.11).

\subsubsection{Exposure modeling using Monte Carlo simulations}

Employing point estimates for the input parameters in the exposure model does not take into account the variation and uncertainty associated with the parameters and therefore may over or under estimate the contaminant exposure that endpoints may receive in any given reach. In addition, calculating the model using point estimates produces a point estimate of exposure. This estimate provides no information concerning the distribution of exposures or the likelihood that individuals within a watershed will actually experience potentially hazardous exposures. To incorporate the variation in exposure parameters and to provide a better estimate of the potential exposure experienced by piscivores on the ORR, the exposure model was recalculated with the Monte Carlo simulations.

Monte Carlo simulation is a resampling technique frequently used in uncertainty analysis in risk assessment (Hammonds et al. 1994). In practice, distributions are assigned to input parameters in a model, and the model is recalculated many times to produce a distribution of output parameters (e.g., estimates of contaminant exposure). Each time the model is recalculated, a value is selected from within the distribution assigned for each input parameter. As a result, a distribution of exposure estimates is produced that reflects the variability of the input parameters. To determine which input parameters most strongly influence the final exposure estimate, a sensitivity analysis is performed (Hammonds et al. 1994). Detailed discussions of sensitivity and uncertainty analysis, and the use of Monte Carlo simulations in risk assessment are provided by Hammonds et al. (1994).

Monte Carlo simulations were performed to estimate watershed-wide exposures. It was assumed that wildlife were more likely to forage in areas where food is most abundant. Density or biomass of fish at or near locations where fish bioaccumulation data were collected were assumed to represent measures of food abundance. (Biomass data were prefered but were unavailable for all watersheds. Where unavailable, density data were used.) The relative proportion that each location contributed to overall watershed density or biomass data was used to weight the contribution to the watershedlevel exposure. The watershed level exposure was estimated to be weighted average of the exposure at each location sampled within the watershed. In this way, locations with high fish densities or greater fish biomass contribute more to exposure than do locations with lower density or biomass. Fish density or biomass data used to weight exposure for the Bear Creek, East Fork Poplar Creek, and White Oak Creek watersheds are presented in Tables C. 12 through C.14, respectively. 
No data were available with which to weight exposures in the K-25 area. Therefore watershedlevel exposures for this watershed represent the average exposure at each sampled location. Each location contributes equally to the total, with no preferential weighting applied.

The percentiles of the resulting exposure distributions represent the likelihood that an individual piscivore within a watershed will experience a given exposure level. Watershed-wide simulations were performed for mercury and PCBs because these contaminants are among the most important on the ORR and data for these contaminants were available at all sampling locations.

Distributions were used for the contaminant concentrations in fish and for the proportion of fish in the diet of mink. All contaminant distributions were assumed to be lognormal. Lognormal means and standard deviations for contaminants in fish are presented in Table C.6.

The proportion of aquatic prey in the diets of otter, kingfisher, and herons were assumed to be $100 \%$. No data suggest that nonaquatic prey constitute a significant portion of their diet (see endpoint discussion, above). In contrast, mink have a very variable diet. Aquatic prey (fish, amphibians, crayfish, etc.) may make up from $16 \%$ to $92 \%$. Nine observations from five studies indicate the proportion of aquatic prey to be $0.546 \pm 0.21$ (mean \pm standard deviation; Table C.1). The proportion of aquatic prey in the diet of mink was assumed to be normally distributed.

Monte Carlo simulations were performed using the @Risk software. Samples from each distribution were selected with Latin hypercube sampling. The number of iterations, or recalculations, of each exposure simulation was determined by the convergence criteria set in the software. Under these criteria, iterations are performed until the between-iteration percent change in the percentiles, mean, and standard deviation are below $1.5 \%$ (i.e., the percentile, mean, and standard deviation for the latest iteration is $<1.5 \%$ different than the those from the previous iteration). Using this convergence criteria, from 600 to 1000 model iterations were performed for each exposure estimate. Monte Carlo estimates of contaminant exposures are presented in Table C.16.

\subsubsection{Internal Exposure of Great Blue Herons to Contaminants}

To determine if contaminants from the ORR are being bioaccumulated by piscivorous wildlife, great blue heron eggs and chicks were collected from two colonies located within $3 \mathrm{~km}$ of the ORR and two colonies located $>10 \mathrm{~km}$ from the site (Halbrook, unpubl. data; see Appendix F). Analyses were performed to determine the concentrations of arsenic, chromium, mercury, and PCBs in eggs, and feathers, liver, fat, and muscle of chicks. Elevated levels of $\mathrm{Cr}, \mathrm{Hg}$, and PCBs were observed in eggs from the ORR colonies (Tables F.2 and F.4). Mercury concentrations in feathers and liver (Table D.3, Appendix D) and PCB concentrations in fat (Table F.5), liver (Table F.6), and muscle (Table F.7) were significantly elevated in samples from the ORR as compared to data from the off-site locations. A detailed discussion of these data is presented in Appendix F.

\subsection{EFFECTS ASSESSMENT FOR PISCIVOROUS WIDLLFE}

\subsubsection{Single Chemical Toxicity Data}

Single-chemical toxicity data consist of NOAELs and LOAELs of toxicity studies reported in the literature. 
In cases where an NOAEL for a specific chemical was not available, but a LOAEL had been determined experimentally or where the NOAEL was from a subchronic study, the chronic NOAEL was estimated. EPA (1993c) suggests the use of uncertainty factors of 1 to 10 for subchronic to chronic NOAEL and LOAEL to NOAEL estimation. Because no data were available to suggest the use of lower values, uncertainty factors of 10 were used in all instances in which they were required.

Smaller animals have higher metabolic rates and are usually more resistant to toxic chemicals because of more rapid rates of detoxification. In mammals, it has been shown that metabolism is best expressed in terms of body weight (bw) raised to the 3/4 power (bw/4) (EPA 1995). If the dose (d) itself has been calculated in terms of unit body weight (i.e., $\mathrm{mg} / \mathrm{kg}$ ), then the metabolic ratebased dose (D) equates to

$$
D=\frac{d x b w}{b w^{3 / 4}}=d x b w^{1 / 4}
$$

Mineau (1996) reports that the mean allometric scaling factor for chemical toxicity to birds is 1.15 and may range as high as 1.55 . Because the allometric scaling factors for the majority of the chemicals evaluated were not significantly different from 1,1 was used as the best estimate of the allometric scaling factor for birds. If the dose (d) itself has been calculated in terms of unit body weight (i.e., $\mathrm{mg} / \mathrm{kg}$ ), then the dose per unit body surface area (D) equates to

$$
D=\frac{d x b w}{b w^{1}}=d x b w^{0}
$$

The assumption is that the effective dose per body surface area for species " $a$ " and " $b$ " would be equivalent. Therefore, knowing the body weights of two species and the dose $\left(d_{b}\right)$ producing a given effect in species " $b$," the dose $\left(d_{2}\right)$ producing the same effect in species " $a$ " can be determined. Using this approach, if a NOAEL was available for a mammalian test species (NOAEL), the equivalent NOAEL for a mammalian wildlife species (NOAEL ${ }_{w}$ ) was calculated by using the adjustment factor for differences in body size:

$$
N O A E L_{w}=N O A E L_{t}\left(\frac{b w_{t}}{b w_{w}}\right)^{1 / 4} \text {. }
$$

For birds, if a NOAEL was available for an avian test species (NOAEL), the equivalent NOAEL for an avian wildlife species $\left(\mathrm{NOAEL}_{\mathrm{w}}\right.$ ) would be calculated by using the adjustment factor for differences in body size:

$$
N O A E L_{w}=N O A E L_{t}\left(\frac{b w_{t}}{b w_{w}}\right)^{0}=N O A E L_{t}(1)=N O A E L_{t} \text {. }
$$

This methodology for toxicity extrapolation is equivalent to that EPA uses in their carcinogenicity assessments and Reportable Quantity documents for adjusting from animal data to an equivalent human dose. 
NOAELs and LOAELs were derived for mink, river otter, belted kingfisher, great blue heron, and osprey. Mammalian and avian NOAELs and experimental information used to estimate wildlife NOAELs and LOAELs (e.g., test species, test endpoints, citation) are listed in Tables C.16 and C.17. Ecotoxicological profiles of the effects of mercury and PCBs to wildlife are presented in Appendix D.

\subsubsection{Effects of Contaminants on the Reproductive Performance of Mink}

At the Michigan State University Experimental Fur Farm, Halbrook (unpubl. data; see Appendix E) evaluated bioaccumulation of contaminants and reproductive effects in mink fed fish collected from Poplar Creek, the Clinch River (upstream of Melton Hill Dam), and the ocean. Mink were fed five diets consisting of $75 \%$ fish and $25 \%$ commercial mink diet. The diet composition and contaminant concentrations for each diet are described in the following table:

\begin{tabular}{llcc}
\hline & & \multicolumn{2}{c}{ Contaminant concentration (mg/kg) } \\
\cline { 3 - 4 } Diet & Fish composition & Mercury & PCB 1260 \\
\hline A & $75 \%$ ocean & $0.02 \pm 0.00$ & $0.169 \pm 0.002$ \\
B & $75 \%$ Clinch River & $0.05 \pm 0.00$ & $11.44 \pm 0.327$ \\
C & $25 \%$ Poplar Creek & $0.09 \pm 0.00$ & $4.69 \pm 0.174$ \\
& $50 \%$ ocean & & \\
D & $50 \%$ Poplar Creek & $0.15 \pm 0.01$ & $10.41 \pm 0.250$ \\
& $25 \%$ ocean & & \\
E & $75 \%$ Poplar Creek & $0.22 \pm 0.01$ & $20.67 \pm 0.458$ \\
\hline
\end{tabular}

Twenty-three PCB congeners were also present in varying amounts. Concentrations of most congeners increased progressively from diets A through $\mathrm{E}$ (Table E.5).

Ten mink (eight females and two males) were fed each diet for $\sim 7$ months ( 3 months before breeding - 6 weeks postpartum). Reproductive indices measured included number of females mated; number of females whelping; length of gestation; number of kits whelped (alive, dead); kit sex ratio; average kit body weight at birth, 3, and 6 weeks of age; and kit survival to 3 to 6 weeks of age. At 6 weeks of age, 3 kits from dietary groups A, B, C, and E were euthanized, organs (liver, spleen, and kidneys) were weighed, and tissue samples (liver, kidney, and remaining carcass) were analyzed for contaminant accumulation. (Note: kits from diet $D$ were not sampled). At the termination of the study, all adult mink were necropsied. Organs (brain, liver, kidneys, heart, lungs, gonads, and adrenal glands) were weighed and examined for histopathologies. Adipose tissue, liver, kidney, and hair were analyzed for contaminant accumulation. Liver tissue also was analyzed for ethoxyresorufin-odeethylase (EROD) activity.

The bioaccumulation of mercury in liver, kidney, and hair (Table E.3) and of Aroclor 1260 (and other PCB congeners) in liver and fat (Tables E.6 and E.7) substantially increased in adult female mink from groups fed diet $\mathrm{A}$ up to diet $\mathrm{E}$. Mink offspring also bioaccumulated mercury in kidney tissue and carcasses and many other PCB congeners in the liver and carcasses (Tables E.8 and E.9), increasing progressively from mink fed diets A through $\mathrm{E}$. The lowest levels were observed for mink fed diet $A$ and increased to a maximum observed among mink fed diet $E$. 
Significant effects were observed only among mink fed diet $E$; no adverse effects were observed for any other diet. Adverse effects from diet $\mathrm{E}$ included weight reduction in adult mink and their offspring, reduction in litter size, and increase in liver EROD activity in adult females. Weight reduction was observed at the end of the experimental period, increasing magnitude from diet groups $A$ to $E$. At the end of the experiment, the mean whole body weights of female mink in diet group $E$ were significantly less $(p=0.03)$ than mean weights of females in $\operatorname{diet}$ group $A$ (percent reduction = $20 \%$ ). Mean female relative organ weights (organ weights/body weight) were not significantly different among diet groups. At 6 weeks of age, mean whole body weights were also significantly lower $(p=0.004)$ in male kits from diet group E compared with those from diet group A (percent reduction $=17 \%$ ). Similar trends were observed for female kits, although differences were not statistically significant. No histological lesions were attributed to any diet. Mean litter size was significantly reduced $(\mathrm{p}=0.01)$ in diet group $\mathrm{E}$ compared with $\operatorname{diet}$ groups $\mathrm{A}, \mathrm{B}$, and $\mathrm{C}$ (percent reduction relative to diet $A=38 \%$ ) but not with diet group $D$. Liver EROD activity was significantly increased in adult female mink from diet groups $\mathrm{D}$ and $\mathrm{E}$ compared with those from diet group $\mathrm{A}$.

\subsubsection{Biological Surveys}

\subsubsection{Great blue heron reproduction survey}

To determine if contaminants from the ORR are adversely affecting great blue heron, Halbrook (unpubl. data; see Appendix F) monitored the reproductive success at two heron colonies located adjacent to the ORR and two colonies located $>10 \mathrm{~km}$ from the reservation. Data were collected from each nest colony between 1992 and 1994. The mean number of eggs/nest, number of chicks/nest, egg weight, and eggshell thickness did not differ between colonies within $3 \mathrm{~km}$ of the ORR and those $>10 \mathrm{~km}$ away (Table F.8). A detailed discussion of these data are presented in Appendix F.

\subsubsection{Mink survey}

Stevens (1995) investigated bioaccumulation of mercury in mink on the ORR in 1993 through 1995. The methods used in the mink survey, although indicating that mink are present on the reservation, cannot be used to estimate abundance or density on mink on the ORR. A total of 4 male mink were live-trapped over the course of 6073 trapnights (trapnight $=1$ trap set for $24 \mathrm{~h}$ ). One juvenile was captured along East Fork Poplar Creek, two adults were captured along Bear Creek, and one adult was captured along White Oak Creek. Captured mink were fitted with an intraperitoneal radio transmitter (to monitor movements and home range) and released. Before release samples of hair were collected and metals analysis were run. An additional eight roadkill mink (five male and three female) were collected from the ORR and surrounding areas of Roane and Anderson counties. One roadkill sample (a male) was collected on a bridge over Bear Creek and was assumed to be a resident of Bear Creek; all others were collected off the ORR and were used as references. The results of metals analysis are presented in the following table:

Metal concentrations in hair of mink from the ORR and from off-site reference samples (mean \pm standard deviation $\mathrm{mg} / \mathrm{kg}$ dry weight)

\begin{tabular}{lcccccc}
\hline Site & N & Hg & Se & As & Cd & Pb \\
\hline East Fork Poplar Creek & 1 & 104 & 0.69 & not detected & not detected & 0.33 \\
Bear Creek & 3 & $10.97 \pm 3.42$ & $1.88 \pm .1 .41$ & $0.15 \pm 0.09$ & $0.04 \pm .0 .02$ & $0.97 \pm 1.28$ \\
White Oak Creek & 1 & 8.8 & 1 & not detected & not detected & 0.37 \\
Off site & 7 & $5.15 \pm 3.43$ & $1.11 \pm 0.25$ & $0.22 \pm 0.31$ & $0.04 \pm 0.02$ & $0.7 \pm 0.31$ \\
\hline
\end{tabular}


Radiotelemetry data on home ranges and movements were obtained for 3 mink-one each from the East Fork Poplar Creek, Bear Creek, and White Oak Creek watersheds. Mean ( \pm standard deviation) home range for these three individuals was found to be $7.5 \pm 3 \mathrm{~km}$ of stream. The entire home range of the East Fork Poplar Creek mink was in a highly urbanized area; it included all of upper East Fork inside the Y-12 Plant and all areas of East Fork upstream of the Oak Ridge Tumpike-Illinois Avenue intersection. The home range of the White Oak Creek mink included all of White Oak Creek from the headwater tributaries to the Clinch River, including ORNL. This individual was observed to use dens within ORNL and moved through the facility on several occasions.

\subsubsection{Belted kingfisher survey}

A field monitoring effort (Baron et al. 1996) was initiated in 1994 to evaluate population parameters and contaminant bioaccumulation by belted kingfisher on the ORR. Areas surveyed included White Oak Creek (WOC), White Oak Lake (WOL), White Oak Lake embayment, Melton Branch, Poplar Creek, portions of East Fork Poplar Creek (EFPC) (within Y-12 Plant to downstream of Lake Reality and approximately 1 mile east of the confluence of Poplar Creek), and portions of Bear Creek.

Methods. Nest burrows were monitored for nesting activity. If activity was observed, samples of feathers and eggshells were collected. In addition to specimens collected from the burrows, three carcasses of adult kingfisher were found on the ORR (two from East Fork Poplar Creek and one from White Oak Creek). These carcasses were necropsied; organs were extracted and analyzed for metals and radionuclides. Additional detail concerning methods are reported in Baron et al. (1996).

Results. During April-July of 1994, a total of 27 potential kingfisher burrows were identified on the ORR, 11 of which contained swallow nests. Twenty-five of these burrows were found on the Clinch River. One kingfisher burrow, containing a single unhatched kingfisher egg, was found on White Oak Creek [downstream of White Oak Creek Kilometer (WCK) 3.5].

One active burrow, containing a clutch of 6-7 eggs, was found on the Clinch River. This burrow was later abandoned with no sign of the eggs or the parents. Another burrow, containing 6 nestlings was located on the Clinch River approximately 12 miles upstream of all DOE contaminant outfalls. It was, therefore, considered uncontaminated. Three weeks following the initial observation of this burrow, three nestlings had fledged and three had died. Feathers were collected and analyzed.

Results of residue analysis for eggshells and feathers from nestlings are presented in Table C.18; results for adult carcasses are presented in Table C.19.

Nestling feathers collected from the burrow on the Clinch River, upstream of ORR outfalls (Table C.18), contained relatively low levels of metal and radioactive contaminants. Feathers from the carcasses of three fledglings accumulated similar concentrations of $\mathrm{As}, \mathrm{Cd}, \mathrm{Pb}, \mathrm{Se}$, and $\mathrm{Hg}$. Mercury concentrations in feathers were approximately $1 \mathrm{mg} / \mathrm{kg}$. Mercury concentrations found in fish downstream of the nesting site are approximately $0.04 \pm 0.01 \mathrm{mg} / \mathrm{kg}$ (Peterson et al. 1994). Thus, biomagnification is occurring in kingfishers foraging in up gradient areas of the ORR. However, these feather concentrations are much lower than those found in adult kingfishers on the ORR. Although selenium concentrations in nestling feathers appear high, they are similar to selenium levels in adult kingfishers (Table C.19) and mink and raccoons collected at reference locations (Ashwood et al. 1994). The fourth feather sample presented in Table C. 18 represents a mixture of feathers retrieved from the three nestlings. This sample was analyzed to provide additional information on the variability of chemical concentrations within the feathers. 
A burrow on the Clinch River contained fragments of egg shells and fish vertebrae from regurgitant. Analysis of the egg shells indicated that minimal metal contamination was present (Clinch River downstream, Table C.18). Another burrow on White Oak Creek contained an unhatched kingfisher egg (WOC, Table C.18). Metal concentrations in this egg were similar to that for the Clinch River egg, except for ${ }^{137} \mathrm{Cs}$. The presence of this radionuclide in the egg indicates that the parent kingfisher bioaccumulated ${ }^{137} \mathrm{Cs}$ from foraging within White Oak Creek or a nearby surface impoundment ( ${ }^{137} \mathrm{Cs}$ is a typical contaminant of this stream and the impoundments).

Cesium-137, $\mathrm{Cd}, \mathrm{Pb}, \mathrm{Se}$, and $\mathrm{Hg}$ were each detected in at least one kingfisher from the ORR (Table C.19). Arsenic was analyzed for but was not detected. Feathers of adult kingfishers contained elevated levles of mercury (Table C.19) relative to feathers from the nestlings (Table C.19). The greatest burdens of $\mathrm{Hg}, \mathrm{Se}, \mathrm{Pb}$, and ${ }^{137} \mathrm{Cs}$ were observed in the bird from the White Oak Creek watershed (Bird 3; Table C.19). In contrast, cadmium levels were higher in the birds from East Fork Poplar Creek (Birds 1 and 2) than in the White Oak Creek bird (Table C.19).

\subsubsection{Osprey reproduction}

Although osprey monitoring studies are not performed by ORNL, an óngoing osprey reintroduction program is being conducted by TWRA in the Clinch/Tennessee River system. Osprey are currently nesting at three locations adjacent to the ORR: Gallaher and Solway bends (both located in subreach 1) and in Poplar Creek kilometer 1.6 (Fig. C.3). Mean reproductive success at these three osprey nests was 3 young/nest (B. Anderson, pers. comm). For comparison, mean reproductive success of osprey in North America ranges from 1.7 to 2.14 young/nest (EPA 1993b).

\subsection{RISK CHARACTERUZATION FOR PISCIVOROUS WILDLIFE}

Risk characterization integrates the results of the exposure assessment (Sect. 4.2) and effects assessment (Sect. 4.3) to estimate risks (the likelihood of effects given the exposure) based on each line of evidence and then applies a weight of evidence inference logic to determine the best estimate of risk to each assessment endpoint. In an ideal risk assessment there are three lines of evidence: literature-derived single chemical toxicity data (which indicate the toxic effects of the concentrations measured in site media), biological surveys of the affected system (these indicate the actual state of the receiving environment), and toxicity tests with ambient media (these indicate the toxic effects of the concentrations measured in site media). Although three lines of evidence are available to assess risks to piscivorous wildlife, all are not available for each endpoint or for all watersheds on the ORR. Single chemical toxicity data are available for all four endpoints within all four watersheds. Toxicity tests and a field survey/bioaccumulation study were performed for mink along Poplar Creek and in the Bear Creek, East Fork Poplar Creek, and White Oak Creek watersheds, respectively. Lastly, a field survey/bioaccumulation data were available for great blue heron and osprey along Poplar Creek and Melton Hill Lake and for kingfisher in the East Fork Poplar Creek and White Oak Creek watersheds.

Procedurally, the risk characterization is performed for each assessment endpoint by (1) screening all measured contaminants against toxicological benchmarks and background concentrations (if available), (2) estimating the effects of the contaminants retained by the screening analysis, (3) estimating the toxicity of the ambient media based on the media toxicity test results, (4) estimating 
the effects of exposure on the endpoint biota based on the results of the biological survey data, (5) logically integrating the lines of evidence to characterize risks to the endpoint, and (6) listing and discussing the uncertainties in the assessment. A detailed discussion of methods and the approach to risk characterization on the ORR is presented in Suter et al. (1995).

\subsubsection{Single Chemical Toxicity Data}

Exposure estimates generated by the exposure model (see Sect. 4.2.1.) produced by both point estimates of parameter values and Monte Carlo simulation represent exposure at the individual level. The exposure estimates using point estimates of parameter values at each individual sampling point are used to identify COPECs and locations that contribute significantly to risk. In contrast, the watershed-level exposure distributions generated by Monte Carlo simulation represent the likelihood that an individual within the area for which exposure is modeled will experience a particular exposure.

Two types of single chemical toxicity data are available with which to evaluate piscivore contaminant exposure: NOAELs and LOAELs. NOAELs are used to screen exposure estimates generated from point-estimates of exposure parameters; if the estimate is greater than the NOAEL, adverse effects are possible and additional evaluation is necessary (i.e., exposure modeling using Monte Carlo simulation). LOAELs are compared with the exposure distribution generated by the Monte Carlo simulation. If the LOAEL is lower than the 80th percentile of the exposure distribution, there is a $>20 \%$ likelihood that individuals within the modeled location are experiencing contaminant exposures that are likely to produce adverse effects. By combining literature-derived population density data with the likelihood or probability of exceeding the LOAEL, population-level impacts may be estimated.

\subsubsection{Screening point estimates of exposure}

To determine if the contaminant exposures experienced by mink, river otter, belted kingfisher, great blue heron, and osprey on the ORR are potentially hazardous, the dietary contaminant exposure estimates (generated by using point estimates of parameter values; Tables C.7 through C.11) were compared with estimated NOAELs and LOAELs for these species (Tables C.16 and C.17). To quantify the magnitude of hazard, a hazard quotient (HQ) was calculated where $\mathrm{HQ}=$ exposure/NOAEL or LOAEL. Hazard quotients $>1$ indicate that individuals may be experiencing exposures that are in excess of NOAELs or LOAELs. Exceeding the NOAEL suggests that adverse effects are possible; exceeding the LOAEL suggests that adverse effects are likely. Hazard quotients for mink, river otter, belted kingfisher, and great blue heron on the ORR are presented along with the point estimates of exposure in Tables C.7 through C.11. It should be noted that because few data are available for specific PCB (Aroclor) mixtures, all PCBs were summed and the total was compared with Aroclor-1254 toxicity data.

A summary of the number of locations within each watershed where HQs $>1$ were observed is presented in Table C.20. NOAELs for mercury and PCBs were exceeded at at least one location for all endpoints in all watersheds. LOAELs for mercury and PCBs were exceeded at at least one location within each watershed for both otter and belted kingfisher (Table C.20). LOAELs for both contaminants were exceeded for all endpoints in East Fork Poplar Creek. LOAELs for osprey were exceeded only in the K-25 Site area.

The spatial distribution of contamination and potential risks to piscivores in Bear Creek, East Fork Poplar Creek, the K-25 Site, and White Oak Creek are illustrated in Figs. C.5, C.6, C.7, and C.8, respectively. These figures display the sum of the LOAEL-based HQs (e.g., sum of toxic units) for 
total PCBs and mercury. Sampling locations were arranged upstream to downstream (right to left); side tributaries or ponds are included in the order in which they enter the main stream.

In Bear Creek, no clear spatial pattern of risk is evident. Cumulative risk is greatest at Bear Creek kilometer (BCK) 4.5 and 0.6, respectively (Figs. C.5a-d). This lack of a distinct pattern is likely a result of differences in data from each location and not related to a source. Although data from BCK $12.4,9.4$, and 3.3 consisted of bodyburdens in stonerollers (a grazing species), data from BCK 4.5 and 0.6 consisted of bodyburdens in rock bass and red-breast sunfish (both invertebrate feeders). Mercury bodyburdens were substantially higher at BCK 4.5 and 0.6 (rock bass and red-breast sunfish) than at BCK 12.4, 9.4, and 3.3 (stonerollers; see Table C.6). The differences in bodyburdens are likely related to food habits of the fish and species-specific mercury uptake kinetics and not to a particular contaminant source.

In East Fork Poplar Creek, the pattern of cumulative risk is similar for all endpoint species; hazard declines with increasing distance from the Y-12 Plant (Fig. C.6a-d). As would be expected, mercury accounts for the majority of risk, with PCBs contributing 1/3 or less to the total. Risk is greatest near the Y-12 Plant East Fork kilometer (EFK) 24.5, plateaus from EFK 24.0 through EFK 6.3, with an additional decline observed at EFK 2.1 (Fig C.6)

At K-25, in Poplar Creek, mercury accounted for most risk (highest in the vicinity of the K-25 Site), and PCBs were the primary risk agent in Mitchell Branch at Mitchell Branck kilometer (MIK) 0.2 and at the K-901 and K-1007 ponds (Fig C.7). The pattern of cumulative risk was similar for mink (Fig. C.7a), kingfisher (Fig. C.7c), and herons (Fig. C.7d), with osprey (Fig. C.7e) and otter (Fig. C.7b) differing from the other three. The difference between the pattern of cumulative risk for osprey and otter and that for other piscivores can be attributed to dietary differences and variation in contaminant concentration according to fish size. Osprey and otter were assumed to consume both large $(>30 \mathrm{~cm})$ and small $(<30 \mathrm{~cm})$ fish; all other piscivores were assumed to consume only fish $<30 \mathrm{~cm}$ in size. The generally greater contaminant concentrations in the larger fish acount for the inter-species differences in estimated exposures.

Similar to the K-25 Site, the pattern of cumulative risk in the White Oak Creek watershed was similar for mink (Fig. C.8a), kingfisher (Fig. C.8c), and herons (C.8d) but different for otters (C.8b). The pattern for osprey differed from all other species because only suitable habitat (large bodies of water; White Oak Lake and the embayment) were considered. In general, cumulative risk was greater in White Oak Creek than in its tributaries (the Northwest Tributary and Melton Branch). Mercury was the primary risk agent throughout the watershed, except at WCK 0.3 where PCBs dominated. A peak for risk to otters from PCBs was observed at White Oak Lake (WCK 1.5). This peak can be attributed to the presence of data for large fish $(>30 \mathrm{~cm})$; PCBs in large fish were 3 to 5 times higher than that in small fish (Table C.6).

\subsubsection{Screening Monte Carlo simulation estimates of exposure}

To incorporate the variation present in the parameters employed in the exposure model, Monte Carlo simulations were performed for exposure of each species to mercury and PCBs in each watershed. Simulations were performed on the average exposure within each watershed, weighted by the density or biomass of fish observed at each sampling location (see Sect. 4.2.1.4). The mean, standard deviation, and 80th percentile of the simulated exposures are presented in Table C.15. By superimposing NOAEL and LOAEL values on these distributions, the likelihood of an individual experiencing potentially hazardous exposures can be estimated and the magnitude of risk may be 
determined. Interpretation of the comparison of exposure distributions to NOAELs and LOAELs is described in the following table:

\begin{tabular}{lll}
\hline \multicolumn{1}{c}{ Comparison } & \multicolumn{1}{c}{ Meaning } & \multicolumn{1}{c}{ Risk-based interpretation } \\
\hline $\begin{array}{l}\text { NOAEL }>80 \text { th percentile of } \\
\text { exposure distribution }\end{array}$ & $\begin{array}{l}\text { Less than } 20 \% \text { of } \\
\text { exposures are greater than } \\
\text { NOAEL }\end{array}$ & $\begin{array}{l}\text { Individual- and population-level } \\
\text { adverse effects are highly unlikely }\end{array}$ \\
$\begin{array}{l}\text { NOAEL<80th } \\
\text { percentile<LOAEL }\end{array}$ & $\begin{array}{l}\text { More than } 20 \% \text { of } \\
\text { exposures are greater than } \\
\text { NOAEL, but less than } \\
\text { 20\% of exposures are } \\
\text { greater than LOAEL }\end{array}$ & $\begin{array}{l}\text { Individuals experiencing exposures at } \\
\text { the high end of the distribution may } \\
\text { experience adverse effects, but those } \\
\text { effects are unlikely to significantly } \\
\text { contribute to effects on the ORR } \\
\text { population }\end{array}$ \\
$\begin{array}{l}\text { LOAEL<80th percentile of } \\
\text { exposure distribution }\end{array}$ & $\begin{array}{l}\text { More than 20\% of } \\
\text { exposures are greater } \\
\text { than LOAEL }\end{array}$ & $\begin{array}{l}\text { Effects on some individuals are likely } \\
\text { and they may contribute significantly } \\
\text { to effects on the ORR population }\end{array}$ \\
\hline
\end{tabular}

To evaluate the likelihood and magnitude of population-level effects on piscivores, literature-derived population density data (expressed as number of individuals $/ \mathrm{km}$ of stream or pond shoreline) were combined with lengths of streams or pond shorelines for which risks were assessed to estimate the number of individuals of each endpoint species expected to be present in each watershed. Literature-derived population densities used for each endpoint species were mink: $0.6 / \mathrm{km}$; river otter: $0.37 / \mathrm{km}$; belted kingfisher: $0.4 / \mathrm{km}$; and great blue heron: $2.3 / \mathrm{km}$. It should be noted that density values for all endpoint species except the great blue heron represent the maximum values obtained from the literature (see Tables C.1, C.2, and C.3). The values for herons (see Table C.4) appear inflated and are not believed to accurately represent densities on the ORR. For this reason, the minimum value was used. Population estimates based on these densities are listed in the following table.

\begin{tabular}{|c|c|c|c|c|c|c|c|}
\hline \multirow[b]{2}{*}{ Watershed } & \multicolumn{3}{|c|}{ Watershed length (km) } & \multicolumn{4}{|c|}{ Estimated number of individuals by watershed } \\
\hline & $\begin{array}{l}\text { Stream } \\
\text { length }\end{array}$ & $\begin{array}{l}\text { Pond } \\
\text { shoreline } \\
\text { length }\end{array}$ & $\begin{array}{l}\text { Total } \\
\text { length }\end{array}$ & Mink & $\begin{array}{l}\text { River } \\
\text { otter }\end{array}$ & $\begin{array}{c}\text { Belted } \\
\text { kingfisher }\end{array}$ & $\begin{array}{l}\text { Great blue } \\
\text { heron }\end{array}$ \\
\hline Bear Creek & 12.4 & 0 & 12.4 & 7 & 5 & 5 & 29 \\
\hline $\begin{array}{l}\text { East Fork } \\
\text { Poplar Creek }\end{array}$ & 24.8 & 0 & 24.8 & 15 & 9 & 10 & 57 \\
\hline K-25 Site & 18.4 & 5.2 & 23.6 & 14 & 9 & 9 & 54 \\
\hline $\begin{array}{l}\text { White Oak } \\
\text { Creek }\end{array}$ & 3.9 & 2.5 & 6.4 & 4 & 2 & 3 & 15 \\
\hline ORR total & & & & 40 & 25 & 27 & 155 \\
\hline
\end{tabular}


Population risk estimates were not performed for osprey because as a T\&E species, adverse effects to any individual are significant and because suitable density data were not available. Population risk estimates however were performed for otter, another T\&E species. Although otter are not currently known to reside on the ORR, population estimates indicate the numbers that could reside on the ORR given available habitat and the risks that contaminant exposure could present.

The number of individuals within a given watershed likely to experience exposures greater than LOAELs can be estimated by using cumulative binomial probability functions (Dowdy and Wearden 1983). Binomial probability functions are estimated with the following equation:

$$
b(y ; n ; p)=\left(\begin{array}{l}
n \\
y
\end{array}\right) p^{y}(1-p)^{n-y}
$$

where:

$y=$ the number of individuals experiencing exposures greater than LOAEL

$\mathrm{n}=$ total number of individuals within the watershed

$p=$ probability of experiencing an exposure in excess of the LOAEL

$b(y ; n ; p)=$ probability of $y$ individuals out of a total of $n$, experiencing an exposure greater than LOAEL, given the probability of exceeding the LOAEL $=p$.

By solving Equation 4 for $y=0$ to $y=n$, a cumulative binomial probability distribution may be generated that can be used to estimate the number of individuals within a watershed that are likely to experience adverse effects. Summing the number within each watershed across all watersheds and dividing by the total estimated ORR-wide population, the proportion of the total ORR population potentially at risk may be estimated.

Binomial probability distributions were generated only for contaminant-endpoint-watershed combinations where the percent of the exposure distribution exceeding the LOAEL was $20 \%$ to $80 \%$ (these values are reported in Table C.15). If the percent of the exposure distribution exceeding the LOAEL was $<20 \%$, it was assumed that no individuals within the area of interest were experiencing adverse effects. Conversely, if the percent of the exposure distribution exceeding the LOAEL was $>80 \%$, it was assumed that all individuals within the area of interest were experiencing adverse effects. Exposure estimates for 6 contaminant-endpoint-watershed combinations met the $20 \%$ to $80 \%$ exceedance criterion: mercury exposure to mink in East Fork Poplar Creek, mercury exposure to otter and kingfisher in Bear Creek, mercury exposure to otter in White Oak Creek, PCB exposure to otter in East Fork Poplar Creek and White Oak Creek. Figures C.9-C.14 graphically display the cumulative binomial probability distributions for each contaminant-endpoint-watershed combination. The total numbers of individuals for each endpoint species estimated to be experiencing adverse effects within each watershed and with the ORR as a whole are summarized in Table C.21.

On the basis of the Monte Carlo and binomial distribution analyses (Table C.21), the following conclusions may be made:

- Because $>20 \%$ of the ORR mink population is estimated to be experiencing exposures greater than LOAEL, mercury presents a significant risk to mink. The ORR-scale risk is attributable solely to mercury risk in the East Fork Poplar Creek watershed. 
- Because $>1$ individual is estimated to be experiencing exposures greater than LOAEL, mercury presents a significant risk to otter in the East Fork Poplar Creek, Bear Creek, and K-25 watersheds.

- Because $>20 \%$ of the ORR kingfisher population is estimated to be experiencing exposures greater than LOAEL, mercury presents a significant risk to kingfisher. The ORR-scale risk is attributable to mercury exposure in all watersheds considered, except the White Oak Creek watershed.

- Because $>20 \%$ of the ORR heron population is estimated to be experiencing exposures greater than LOAEL, mercury presents a significant risk to heron. The ORR-scale risk is attributable solely to mercury risk in the East Fork Poplar Creek watershed.

- Because $<$ lindividual is estimated to be experiencing exposures greater than LOAEL, neither mercury nor PCBs presents a significant risk to osprey in the White Oak Creek or K-25 watersheds.

- Because $<20 \%$ of the ORR populations of mink, kingfisher, or herons are estimated to be experiencing exposures greater than LOAEL, PCBs do not present a significant risk to these populations.

- Because 1 individual is estimated to be experiencing exposures greater than LOAEL, PCBs present a significant risk to otter in the East Fork Poplar Creek and White Oak Creek watersheds.

\subsubsection{Effects of retained contaminants}

Mercury. For the purposes of this assessment, it is assumed that $100 \%$ of the mercury to which wildlife are exposed consists of methyl mercury.

Both the avian NOAEL and LOAEL are based upon a study of mallard ducks fed methyl mercury for three generations (Heinz 1979). The study was considered to represent a chronic exposure, and a subchronic-chronic correction factor was not employed. The only dose level administered, $0.064 \mathrm{mg} / \mathrm{kg} / \mathrm{d}$, caused hens to lay fewer eggs, lay more eggs outside of the nest box, and produce fewer ducklings. This dose level was considered to be an LOAEL. Because an experimental NOAEL was not established, the NOAEL was estimated by using LOAEL-NOAEL correction factor of 0.1. On the basis of the results of Heinz (1979), kingfisher experiencing exposure greater than or equal to LOAEL are likely to display impaired reproduction.

The mink and otter NOAELs and LOAELs for mercury were derived from a study of mink fed methyl mercury for $93 \mathrm{~d}$ (Wobeser et al. 1976). Although consumption of $0.247 \mathrm{mg} / \mathrm{kg} / \mathrm{d}$ methyl mercury resulted in significant mortality, weight loss, and behavioral impairment, no effects were observed at the $0.15 \mathrm{mg} / \mathrm{kg} / \mathrm{d}$ exposure level. The $0.15 \mathrm{mg} / \mathrm{kg} / \mathrm{d}$ exposure was considered to be an NOAEL, and the $0.247 \mathrm{mg} / \mathrm{kg} / \mathrm{d}$ exposure was considered to be an LOAEL. Because the study was subchronic in duration ( $<1$ year), a subchronic-chronic correction factor was applied (NOAEL $=0.015$, LOAEL $=0.025$ ). Based on the results of Wobeser et al. (1976), shrews, mice, and fox experiencing exposure greater than or equal to LOAEL are likely to display increased mortality, weight loss, and behavioral impairment. 
PCBs. The otter NOAEL and LOAEL for PCBs was derived from a study of mink fed Aroclor 1254 for 4.5 months (Aulerich and Ringer 1977). Although consumption of $0.69 \mathrm{mg} / \mathrm{kg} / \mathrm{d}$ Aroclor 1254 reduced kit survivorship, no effects were observed at the $0.14 \mathrm{mg} / \mathrm{kg} / \mathrm{d}$ exposure level. The $0.14 \mathrm{mg} / \mathrm{kg} / \mathrm{d}$ exposure was considered to be a chronic NOAEL; the $0.69 \mathrm{mg} / \mathrm{kg} / \mathrm{d}$ exposure was considered to be a chronic LOAEL Based on the results of Aulerich and Ringer (1977), mink experiencing exposure greater than or equal to LOAEL are likely to display reduced kit survivorship.

\subsubsection{Mink Toxicity Tests}

To evaluate the nature and magnitude of toxicity of contaminants in fish from the Clinch River to mink, fish were collected from the Poplar Creek embayment, formulated into mink diets, and fed to mink. Mink were fed five different diets. Ten mink ( 2 males, 8 females) were fed each diet for 7 months; starting approximately 3 months before breeding, extending to 6 weeks postpartum. Bioaccumulation, growth, histopathology, and reproduction were recorded. Significant effects were observed only among mink fed diet $\mathrm{E}$. These effects included statistically significant reductions in body weights of adult females and male kits and in litter size. Percent reductions were $20 \%$ and $17 \%$ for adult female and male kit weights, respectively, and 37.7\% for litter size. A detailed discussion of the methods and results of the mink toxicity test is presented in Appendix E.

To evaluate how the exposures experienced by mink in the toxicity test compare with those modeled for mink on the ORR, Monte Carlo simulations of mink exposure were performed using the concentrations of mercury and PCB 1260 measured in the five diets (Tables F.1 and F.5). Parameter values in the exposure model were as follows: body weight $=0.974 \pm 0.202 \mathrm{~kg}$; food ingestion rate $=0.137 \mathrm{~kg} / \mathrm{d}$. Results of the exposure simulation are presented in Table C.22. Estimated exposures to mercury and PCB 1260 in diet A were below both the NOAEL and LOAEL. For diets C, D, and $E$, mercury exposures exceeded the NOAEL (i.e., $>20 \%$ of distribution exceeded the NOAEL). Diets $\mathrm{D}$ and $\mathrm{E}$ also exceeded the LOAEL for mercury, with diet $\mathrm{D}$ marginally exceeding and diet $\mathrm{E}$ significantly exceeding the LOAEL (Table C.22). Exposures to PCB 1260 in diets B, C, D, and E were greater than both the NOAEL and LOAEL (Table C.22). These data suggest that toxicity in diet $E$ was a result of the combined effects of PCBs and mercury and that impaired reproduction should have been evident in diets $\mathrm{B}, \mathrm{C}, \mathrm{D}$, and $\mathrm{E}$, not just diet $\mathrm{E}$.

The mean mercury exposure in diet $\mathrm{D}(0.022 \mathrm{mg} / \mathrm{kg} / \mathrm{d}$; the highest exposure at which no adverse effects were observed) was less than the LOAEL; the mean exposure in diet E was $0.033 \mathrm{mg} / \mathrm{kg} / \mathrm{d}$ (the lowest exposure at which adverse effects were observed). This suggests that the estimated mercury LOAEL for mink $(0.025 \mathrm{mg} / \mathrm{kg} / \mathrm{d})$ is appropriate and representative of toxicity of mercury to mink on the ORR.

Estimating that toxicity should be observed in four diets but actually observing it only in the highest concentration suggests that the LOAEL for PCBs used in this assessment is too low and is not representative of the toxicity of the PCBs present on the ORR. ORR-specific NOAEL and LOAEL for PCBs (represented by PCB 1260) of $1.7 \mathrm{mg} / \mathrm{kg} / \mathrm{d}$ and $3 \mathrm{mg} / \mathrm{kg} / \mathrm{d}$ can be derived from the toxicity test exposure estimate for diets B and E (Table C.22). The ORR-specific NOAEL and LOAEL for mercury would be $0.022 \mathrm{mg} / \mathrm{kg} / \mathrm{d}$ (diet D) and $0.033 \mathrm{mg} / \mathrm{kg} / \mathrm{d}$ (diet E), respectively.

The mercury exposure estimate for mink in the watershed where the highest exposure estimate was obtained (East Fork Poplar Creek; mean $=0.031 \pm 0.006 \mathrm{mg} / \mathrm{kg} / \mathrm{d}$ ) is approximately equivolent to that observed in diet $E$ (Table C.22), the diet where significant reproductive effects were observed. The estimated total PCB exposure in East Fork Poplar Creek (mean $=0.17 \pm 0.10 \mathrm{mg} / \mathrm{kg} / \mathrm{d}$ ) is less than that in all test diets except the control diet (diet A; Table C.22). 
Several conclusions may be drawn from these toxicity test data.

- Comparisons of exposure estimates to NOAELS and LOAELs suggest that effects observed in diet $\mathrm{E}$ are attributable to PCBs and mercury.

- Because the estimated LOAEL used in this assessment is comparable to the exposure level that resulted in adverse effects, estimated mercury LOAEL for mink is appropriate and representative of toxicity of mercury to mink on the ORR.

- Given the difference between predicted and observed toxicity from the test diets, the PCB LOAEL used in this assessment is too low and does not reflect toxicity observed among mink exposed to Poplar Creek fish.

- Consumption of a diet consisting of $75 \%$ fish from the Poplar Creek produces reproductive impairment in mink.

- An LOAEL for mink on the ORR fish of $3 \mathrm{mg} / \mathrm{kg} / \mathrm{d}$ can be derived. Using the ORR-specific value rather than the literature value, $\mathrm{PCBs}$ would not be expected to cause toxic effects on survival, growth, or reproduction of mink in any ORR watershed.

Differences between the results of the toxicity tests and modeled exposures for mink on the ORR may result for several reasons.

- Differences in fish size. Exposure estimates for mink on the ORR were based solely on contaminant concentrations in fish most likely to be consumed by mink (i.e., $\leq 30 \mathrm{~cm}$ in length). Because of the large volume of fish needed to formulate the test diets and to feed mink for 7 months, the majority of fish used in the toxicity test were large (mean $=39 \mathrm{~cm}$, standard deviation $=17 \mathrm{~cm}$ ). Because body burdens of bioaccumulative contaminants like mercury and PCBs are generally greater in older, larger individuals, concentrations in the toxicity test diets were higher than that in fish expected to be consumed by mink on the ORR.

- Differences in fish species. More than $50 \%$ of the fish used in the test diets were sucker, carp, or buffalo (Table E.1). None of these species were included in the data used to estimate mink exposure on the ORR. Because fish species accumulate contaminants differently (as seen in stonerollers and sunfish in Bear Creek), variation in species included in test diets and modeled diets may have contributed to the differences in results.

- Differences in the PCB congener composition on the ORR vs. that used in the literature toxicity test. PCBs measured in environmental samples are not Aroclors. Aroclors are specific mixtures of PCB congeners as manufactured. The environmental measurements of PCBs used in the Poplar Creek toxicity test are called PCB 1254 or PCB 1260 because they have $54 \%$ or $60 \%$ chlorine. The congener makeup of PCB 1254 or 1260 from the Poplar Creek fish is likely to be very different from the congener makeup of Aroclor 1254 or 1260 . More importantly, PCB toxicity is generally correlated with individual congeners, not with Aroclors. 


\subsubsection{Biological Surveys}

\subsubsection{Great blue heron reproduction study}

To determine if contaminants from the ORR are adversely affecting great blue heron, bioaccumulation of contaminants and reproductive success of herons at two colonies located adjacent to the ORR and two colonies located $>10 \mathrm{~km}$ from the site was monitored. Data were collected from each nest colony between 1992 and 1994. A detailed discussion of these data are presented in Appendix F.

Analyses indicated statistically significantly elevated levels of $\mathrm{Cr}, \mathrm{Hg}$, and $\mathrm{PCBs}$ in eggs (Tables F.2 and F. 4), Hg in feathers and liver of chicks (Table F.3), and PCBs in fat (Table F.5), liver (Table F.6), and muscle (Table F.7) of chicks from samples from the ORR as compared with data from the off-site locations. King et al. (1991) report that 0.5 to $1.5 \mathrm{mg} / \mathrm{kg}$ mercury concentrations in bird eggs may are associated with reproductive failure; Harris et al. (1993) report a NOAEL for hatching success of Forster's Tern eggs to be $7 \mathrm{mg} / \mathrm{kg}$. Mean concentrations of mercury $(0.17 \mathrm{mg} / \mathrm{kg})$ and PCBs $(1.68 \mathrm{mg} / \mathrm{kg})$ in great blue heron eggs from within $3 \mathrm{~km}$ of the ORR are substantially below both levels, suggesting that reproductive effects from mercury or PCBs in eggs are unlikely.

Despite elevated contaminant burdens, the mean number of eggs/nest, number of chicks/nest, egg weight, and eggshell thickness did not differ between colonies within $3 \mathrm{~km}$ of the ORR and those $>10 \mathrm{~km}$ away (Table F.8). In addition, the number of eggs/nest observed at the colonies within $3 \mathrm{~km}$ of the ORR (3.5 eggs/nest) and at the colonies $>10 \mathrm{~km}$ away (3.2 eggs/nest) are comparable to those reported in EPA (1993b) (3.16 to 4.37 eggs/nest).

The results of the great blue heron reproduction survey indicate that herons are experiencing higher contaminant exposures at the colonies adjacent to the ORR. However, this exposure is not sufficiently high to result in adverse effects to the populations at the studied colonies. [Note:five great blue heron colonies currently exist around the margins of the ORR ( $R$. Brewer, pers. comm.). Bioaccumulation and reproductive success have only been evaluated for two of these five colonies.]

\subsubsection{Mink survey}

Results of the mink survey (see Sect. 4.3.3) indicate that mink are present on the ORR, have large home ranges, and do not avoid the industrial facilities on the ORR. The methods employed in the study do not allow numbers or density of mink to be determined. Although mercury levels in hair of mink were statistically significantly greater on the ORR than in reference samples, no statistically significant differences were observed for $\mathrm{As}, \mathrm{Cd}, \mathrm{Pb}$, or $\mathrm{Se}$.

\subsubsection{Kingfisher survey}

Results of the kingfisher survey indicate that contaminants are being accumulated by both juveniles and adult birds. Although contaminants in eggshells and nestling feathers indicate exposure, there is insufficient information to evaluate the toxicological significance of this contamination.

The toxicological significance of the tissue concentrations in adult kingfisher was evaluated by comparison of burdens and effects levels reported in other bird species. This comparison suggests that it is unlikely that cadmium or lead in kingfisher from the ORR contribute significantly to risk. Leach et al. (1979) observed a 50\% reduction in egg production among chickens consuming a diet containing $48 \mathrm{mg} / \mathrm{kg}$ cadmium. Cadmium concentrations in the livers and kidneys of these birds were $100 \mathrm{mg} / \mathrm{kg}$ 
and $40 \mathrm{mg} / \mathrm{kg}$, respectively. Cadmium concentrations in healthy birds from unpolluted areas ranged from 0.1 to $32 \mathrm{mg} / \mathrm{kg}$ in liver and 0.3 to $137 \mathrm{mg} / \mathrm{kg}$ in kidney (Furness 1996). In comparison, maximum cadmium concentrations in the kidney $(4.04 \mathrm{mg} / \mathrm{kg})$ and liver $(0.95 \mathrm{mg} / \mathrm{kg})$ of kingfisher collected from the ORR watershed were significantly less than concentrations associated with reproductive impairment and at the low end of the ranges observed among healthy birds from unpolluted areas. Maximum lead concentrations in the kidney $(0.42 \mathrm{mg} / \mathrm{kg})$ and liver $(0.4 \mathrm{mg} / \mathrm{kg})$ of ORR kingfisher were approximately one order of magnitude lower than the minimal level at which overt toxicity is observed in birds ( 3 to $6 \mathrm{mg} / \mathrm{kg}$; Franson 1996), suggesting that lead accumulation is unlikely to be contributing to risks to kingfishers on the ORR.

In contrast to $\mathrm{Cd}$ and $\mathrm{Pb}$, Se and $\mathrm{Hg}$ burdens may present a hazard to kingfishers on the ORR. The maximum concentration of selenium observed in the liver of kingfisher from the ORR ( $7.5 \mathrm{mg} / \mathrm{kg}$ ) is less than the $10 \mathrm{mg} / \mathrm{kg}$ toxicity threshold recommend by Heinz (1996) but greater than the $3 \mathrm{mg} / \mathrm{kg}$ reproductive impairment threshold, suggesting the potential for adverse effects on reproduction. Mercury concentrations of 49 to $125 \mathrm{mg} / \mathrm{kg}$ in kidney and 4.6 to $91 \mathrm{mg} / \mathrm{kg}$ in liver have been reported for free-living birds found dead or dying (Thompson 1996). Nephrotoxicity and kidney lesions occur in birds at mercury concentrations in kidney of 5 to $13 \mathrm{mg} / \mathrm{kg}$ (Nicholson and Osborn 1983). Although the maximum observed mercury concentrations in the kidney $(26.8 \mathrm{mg} / \mathrm{kg})$ and liver $(17.6 \mathrm{mg} / \mathrm{kg}$ ) of ORR kingfisher were generally lower than concentrations associated with mortality, the kidney concentration exceed nephrotoxic levels, suggesting that mercury accumulation may be causing kidney damage to kingfishers on the ORR.

\subsubsection{Osprey survey}

Mean reproductive success at the three osprey nests adjacent to the ORR was 3 young/nest (B. Anderson, pers. comm). For comparison, mean reproductive success of osprey in North America ranges from 1.7 to 2.14 young/nest (EPA 1993b). These data suggest that osprey near the ORR are not being adversely affected by contaminants.

\subsubsection{Weight of Evidence}

\subsubsection{Mink}

Three lines of evidence-literature toxicity data, toxicity test data, and field surveys-were available to evaluate risk to mink. Comparison of exposure estimates with LOAELs indicates a significant risk from mercury in East Fork Poplar Creek and consequently to the ORR mink population (Table C.21). PCBs are not estimated to contribute to risks to mink

Toxicity test results indicate that consumption of a diet consisting primarily of fish from the Poplar Creek embayment adversely affects mink reproduction. Mercury exposure experienced by mink at the highest dose level was comparable with that estimated for mink in East Fork Poplar Creek. This dose level was associated with impaired reproduction. PCB exposures experienced by mink on the ORR were all less than exposures experienced by mink in the toxicity test.

Limited data from field surveys indicate that although mink are present on the reservation, the health and abundance of the population is unknown (the trapping methods that were employed, although suitable for capturing animals for radiotelemetry purposes, were not adequate to estimate population abundance and density). Mink on the ORR have large home ranges, make use of the creeks within the industrial facilities, and have higher mercury concentrations in hair than do mink from off- 
site locations. Cadmium concentrations in hair were not different between mink on the ORR and those from off-site locations.

The weight of evidence suggests that mercury presents a hazard to mink in East Fork Poplar Creek and consequently to a significant portion (30\%) of the ORR-wide mink population. Risks to mink from PCBs are not significant (Table 4.1).

\subsubsection{River otter}

Two lines of evidence-literature toxicity data and the PCB and mercury NOAEL and LOAEL derived from the Poplar Creek mink toxicity test-were available to evaluate potential risk to river otter. As a T\&E species, potential adverse effects to any individual are significant. Comparison of exposure estimates with literature-derived LOAELs indicates a significant risk from mercury in Bear Creek, East Fork Poplar Creek, and the K-25 Site area and from PCBs in the East Fork Poplar Creek, and White Oak Creek watersheds.

Using Equation 3 and the ORR-specific NOAELs and LOAELs for PCBs and mercury for mink (see Sect. 4.4.2), ORR-specific values for otter were estimated to be as follows:

\begin{tabular}{lccc}
\hline & Analyte & $\begin{array}{c}\text { Estimated NOAEL } \\
(\mathrm{mg} / \mathrm{kg} / \mathrm{d})\end{array}$ & $\begin{array}{c}\text { Estimated LOAEL } \\
(\mathrm{mg} / \mathrm{kg} / \mathrm{d})\end{array}$ \\
\hline PCBs & 0.92 & 1.8 \\
Mercury & 0.013 & 0.02 \\
\hline
\end{tabular}

Comparison of the ORR-specific PCB LOAEL to the exposure distributions presented in Table C. 15 indicate that there is a $<1 \%$ likelihood of individuals in any watershed experiencing PCB exposure greater than ORR-specific LOAEL. Therefore, based upon the results of the Poplar Creek mink toxicity test, PCBs are unlikely to present a significant risk to the ORR-wide otter population.

The ORR-specific mercury LOAEL is somewhat higher but still comparable to the literaturederived LOAEL $(0.015 \mathrm{mg} / \mathrm{kg} / \mathrm{d}$; Table C.16). Therefore, the results of the Poplar Creek mink toxicity test do not significantly alter the conclusions derived from evaluation of the literature-based toxicity data.

Evaluation of the potential risks to a future ORR-wide population of otter indicates that mercury presents a risk in all watersheds on the ORR (Table C.21). Because the river otter is a state threatened species, effects to any individual is significant. Therefore the weight of evidence suggests that mercury is significant risk to individual river otter that may occupy the ORR in the future (Table 4.1).

\subsubsection{Belted kingfisher}

Two lines of evidence, literature toxicity data and biomonitoring data, were available to evaluate potential risk to belted kingfisher. Comparison of exposure estimates to LOAELs indicates a significant risk from mercury in all watersheds except White Oak Creek (Table C.15). This translates into a risk to $81.5 \%$ of the ORR-wide kingfisher population (Table C.21). The limited biomonitoring data indicate that kingfisher on the ORR (particularly in the White Oak Creek area) are accumulating mercury to potentially nephrotoxicty levels. The weight of evidence suggests mercury in all 
Table 4.1. Summary of risk characterization for piscivores on the ORR

\begin{tabular}{|c|c|c|c|}
\hline Species & Evidence & Result & Explanation \\
\hline \multirow[t]{2}{*}{ Mink } & Literature toxicity data & + & $\begin{array}{l}\text { Comparison of exposure estimates to LOAELs indicates a significant risk from mercury in East Fork Poplar Creek } \\
\text { and consequently to the ORR mink population. PCBs are not estimated to contribute to risks to mink }\end{array}$ \\
\hline & Biological surveys & \pm & $\begin{array}{l}\text { Mink are present on the ORR, but abundance and density are unclear but clearly not high. While } \mathrm{Hg} \text { in hair from } \\
\text { mink from ORR is elevated relative to references, } \mathrm{As}, \mathrm{Cd}, \mathrm{Pb} \text {, and Se are not.. }\end{array}$ \\
\hline \multirow[t]{2}{*}{ 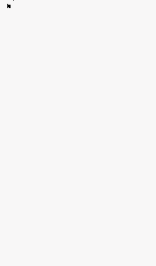 } & Medium toxicity tests & + & $\begin{array}{l}\text { Toxicity test results indicate that consumption of a diet consisting primarily of fish from the Poplar Creek embayment } \\
\text { adversely affects mink reproduction. Mercury exposure experienced by mink at the highest dose level was comparable } \\
\text { to that estimated for mink in East Fork Poplar Creek. This dose level was associated with impaired reproduction. } \\
\text { PCB exposures experienced by mink on the ORR were all less than exposures experienced by mink in the toxicity test. }\end{array}$ \\
\hline & Weight of evidence & + & $\begin{array}{l}\text { The weight of evidence suggests that mercury presents a hazard to mink in East Fork Poplar Creek and consequently to } \\
\text { the ORR-wide mink population. Risks from PCBs are not significant. }\end{array}$ \\
\hline \multirow[t]{4}{*}{ River otter } & Literature toxicity data & + & $\begin{array}{l}\text { Comparison of exposure estimates to literature-derived LOAELs indicates that individuals may be at risk from mercury } \\
\text { in Bear Creek, East fork Poplar Creek, and the K-25 area and from PCBs in the East Fork Poplar Creek, and White } \\
\text { Oak Creek watersheds. }\end{array}$ \\
\hline & Biological surveys & NA & \\
\hline & Medium toxicity tests & + & $\begin{array}{l}\text { Use of the ORR-specific PCB LOAEL generated from the mink toxicity test indicates that PCBs on the ORR are } \\
\text { unlikely to adversely affect otter. The ORR-specific mercury LOAEL was comparable to the literature-based } \\
\text { LOAEL. Conclusions concerning risk to otter from mercury are therefore unaffected by the results of the mink } \\
\text { toxicity test. }\end{array}$ \\
\hline & Weight of evidence & + & $\begin{array}{l}\text { Because the river otter is a state threatened species, effects to any individual are significant. Consequently, mercury } \\
\text { presents a significant risk to a individuals and potential ORR-wide otter population. }\end{array}$ \\
\hline \multirow[t]{4}{*}{$\begin{array}{l}\text { Belted } \\
\text { kingfisher }\end{array}$} & Literature toxicity data & + & $\begin{array}{l}\text { Comparison of exposure estimates to LOAELs indicates a significant risk from mercury in all watersheds except White } \\
\text { Oak Creek. This translates into a risk to } 81.5 \% \text { of the ORR-wide kingfisher population }\end{array}$ \\
\hline & Biological surveys & + & $\begin{array}{l}\text { The limited biomonitoring data indicate that kingfisher on the ORR (particularly in the White Oak Creek area), are } \\
\text { accumulating mercury to potentially nephrotoxicty levels. }\end{array}$ \\
\hline & Medium toxicity tests & NA & \\
\hline & Weight of evidence & + & $\begin{array}{l}\text { The weight of evidence suggests mercury in all watersheds presents a significant risk to the ORR-wide belted } \\
\text { kingfisher population. Risks from PCBs are not significant }\end{array}$ \\
\hline
\end{tabular}


Table 4.1 (continued)

\begin{tabular}{|c|c|c|c|}
\hline Species & Evidence & Result & Explanation \\
\hline \multirow[t]{4}{*}{$\begin{array}{l}\text { Great blue } \\
\text { heron }\end{array}$} & Literature toxicity data & + & $\begin{array}{l}\text { Comparison of exposure estimates to LOAELs indicates a significant risk from mercury in East Fork Poplar Creek. } \\
\text { This translates into a risk to } 36.8 \% \text { of the ORR-wide heron population. }\end{array}$ \\
\hline & Biological surveys & - & $\begin{array}{l}\text { Biomonitoring data at } 2 \text { of } 5 \text { colonies around the ORR indicate that while PCBs and mercury are being accumulated } \\
\text { in heron eggs and chicks, the levels in eggs are lower than levels reported in the literature to produce adverse } \\
\text { effects. Observations of the two of the five colonies adjacent to the ORR indicate that reproduction is not reduced } \\
\text { relative to colonies }>10 \mathrm{~km} \text { from the ORR. }\end{array}$ \\
\hline & Medium toxicity tests & NA & \\
\hline & Weight of evidence & \pm & $\begin{array}{l}\text { Contaminant bioaccumulation and reproductive success are unknown at the three additional colonies adjacent to the } \\
\text { ORR; the primary foraging locations for herons at the two studied colonies is unknown. Because herons can travel } \\
\text { long distances in search of food, they are likely to forage at offsite as well as on-site locations, reducing both the } \\
\text { exposure they receive and the risk they experience. If birds from the unstudied colonies forage more extensively on } \\
\text { the ORR, they may experience greater risk. Due to the high risk estimated for mercury exposure on the ORR, the } \\
\text { lack of data for three of five heron colonies adjacent to the ORR, and uncertainty as to where birds from the five } \\
\text { ORR colonies forage, a conclusion concerning whether or not great blue heron on the ORR are at risk cannot be } \\
\text { made }\end{array}$ \\
\hline \multirow[t]{4}{*}{ Osprey } & Literature toxicity data & - & $\begin{array}{l}\text { Comparison of exposure estimates to LOAELs indicates a no significant risk from mercury or PCBs in any area on the } \\
\text { ORR that provides suitable habitat (i.e., White Oak Lake and embayment and the K-25 area) }\end{array}$ \\
\hline & Biological surveys & - & $\begin{array}{l}\text { Biomonitoring data indicates that the reproductive success at osprey nests adjacent to the ORR (along Melton Hill } \\
\text { Lake and in Poplar Creek) is greater than the average observed in the U.S). }\end{array}$ \\
\hline & Medium toxicity tests & NA & \\
\hline & Weight of evidence & - & The weight of evidence suggests mercury and PCB do not present a significant risks to osprey on or near the ORR \\
\hline
\end{tabular}

+ indicates that the evidence is consistent with the occurrence of the endpoint effect.

- indicates that the evidence is inconsistent with the occurrence of the endpoint effect.

\pm indicates that the evidence is too ambiguous to interpret.

NA indicates that the information is not available. 
watersheds presents a significant risk to the ORR-wide belted kingfisher population. Risks from PCBs are not significant (Table 4.1).

\subsubsection{Great blue heron}

Two lines of evidence--literature toxicity data and biomonitoring data-were available to evaluate ecological risk to great blue heron. Comparison of exposure estimates with LOAELs indicates a significant risk from mercury in East Fork Poplar Creek (Table C.15). This translates into a risk to $36.8 \%$ of the ORR-wide heron population (Table C.21). Biomonitoring data at 2 of 5 colonies around the ORR indicate that although PCBs and mercury are being accumulated in heron eggs and chicks, the levels in eggs are lower than levels reported in the literature to produce adverse effects. Observations of the 2 of the 5 colonies adjacent to the ORR indicate that reproduction is not reduced relative to colonies $>10 \mathrm{~km}$ from the ORR. Contaminant bioaccumulation and reproductive success are unknown at the three additional colonies adjacent to the ORR. Additionally, the primary foraging locations for herons at the two studied colonies is unknown. Because herons can travel long distances in search of food $(>15 \mathrm{~km})$, they are likely to forage at off-site as well as on-site locations, reducing both the exposure they receive and the risk they experience. If birds from the unstudied colonies forage more extensively on the ORR, they may experience greater risk. Because of the high risk estimated for mercury exposure on the ORR, the lack of data for three of five heron colonies adjacent to the ORR, and uncertainty as to where birds from the five ORR colonies forage, a conclusion concerning whether or not great blue heron on the ORR are at risk cannot be made (Table 4.1).

\subsubsection{Osprey}

Two lines of evidence-literature toxicity data and biomonitoring data-were available to evaluate ecological risk to osprey. As a T\&E species, any adverse impact to individual osprey is significant. Comparison of exposure estimates with LOAELs indicates no significant risk from mercury or PCBs in any area on the ORR that provides suitable habitat (i.e., White Oak Lake and embayment and the $\mathrm{K}-25$ Site area; Table C.15). Biomonitoring data indicates that the reproductive success at osprey nests adjacent to the ORR (along Melton Hill Lake and in Poplar Creek) is greater than the average observed in the United States. The weight of evidence suggests mercury and PCB do not present a significant risks to osprey on or near the ORR (Table 4.1).

\subsubsection{Quality and Completeness of Data}

The fish bioaccumulation data used in the piscivore assessment was considered to be of high quality. All data were obtained directly from the principal investigators, who collected the data. Because these persons were available to answer questions concerning interpretation of their data, few assumptions concerning sampling methods, measurements, sampling locations, and so forth were necessary.

The most severe limitation of the data used in this assessment relates to contaminants analyzed for in fish tissue. Although data for PCBs and mercury were available at all locations, data for other contaminants were not. Consequently, reservation-wide scale risks that these contaminants may present cannot be evaluated. 


\subsubsection{Uncertainties Concerning Risks to Piscivorous Wildlife}

\subsubsection{Bioavailability of contaminants}

Bioavailability of contaminants was assumed to be comparable between fish collected from the ORR and the diets used in the literature toxicity tests. Because bioavailability may not be comparable, exposure estimates based on the contaminant concentrations in ORR fish may either under- or overestimate the actual contaminant exposure experienced.

\subsubsection{Extrapolation from published toxicity data}

Although published toxicity studies are available for mink, no published data exists for otter, kingfisher, or great blue heron. To estimate toxicity of contaminants at the site, it was necessary to extrapolate from studies performed on test species (i.e., mallard ducks, ring-necked pheasant, rats). Although it was assumed that toxicity could be estimated as a function of body size, the accuracy of the estimate is not known. For example, osprey or herons may be more or less sensitive to contaminants than ducks or pheasants as a result of factors other than metabolic rate.

Additional extrapolation uncertainty exists for those contaminants for which data consisted of only LOAELs or tests were subchronic in duration. For either case, an uncertainty factor of 10 was employed to estimate NOAELs or chronic data. The uncertainty factor of 10 may either over- or underestimate the actual LOAEL-NOAEL or subchronic-chronic relationship.

Toxicity of PCBs to piscivorous wildlife was evaluated by using toxicity data from studies on Aroclor 1254. Because toxicity of PCB congeners can vary dramatically, the applicability of data for Aroclor 1254 is unknown. Comparison of the results of the mink toxicity test results and the estimated LOAELs for mink suggests the Aroclor 1254 data do not accurately reflect (i.e., overestimate) the toxicity of the PCB mixture present in Clinch River fish.

\subsubsection{Variable food consumption}

Although food consumption by piscivorous wildlife was assumed to be similar to that reported for the same or related species in other locations, the validity of this assumption cannot be determined. Food consumption by wildlife on the ORR may be greater or less than that reported in the literature, resulting in either an increase or decrease in contaminant exposure.

\subsubsection{Single contaminant tests vs exposure to multiple contaminants in the field}

Although piscivores on the ORR are exposed to multiple contaminants concurrently, published toxicological values only consider effects experienced by exposures to single contaminants. Because some contaminants to which wildlife are exposed can interact antagonistically, single contaminant studies may overestimate their toxic potential. Similarly, for those contaminants that interact additively or synergistically, single contaminant studies may underestimate their toxic potential.

\subsubsection{Inorganic forms or species present in the environment}

Toxicity of metal species varies dramatically depending upon the valence state or form (organic or inorganic) of the metal. For example, arsenic (III) and methyl mercury are more toxic than arsenic (V) and inorganic mercury, respectively. The available data on the contaminant concentrations in media do not report which species or form of contaminant was observed. Because benchmarks used 
for comparison represented the more toxic species/forms of the metals (particularly for arsenic and mercury), if the less toxic species/form of the metal was actually present in fish from the Clinch River or Poplar Creek, potential toxicity at the sites may be overestimated.

\subsubsection{Contaminant concentrations in aquatic prey}

Although fish are the primary prey of piscivores, other aquatic prey are also consumed. It was assumed that the contaminant concentration in fish was representative of that in other aquatic prey. Because of the different life histories of other aquatic prey (i.e., amphibians, crayfish, benthic invertebrates), their contaminant burdens are likely to differ from that in fish. Therefore, assuming comparability to fish may either over- or underestimate exposure.

\subsubsection{Fish size selection}

Data concerning the sizes of fish consumed by piscivores were obtained from the literature. Because fish sizes consumed by piscivores on the ORR may differ from that reported in the literature, exposure may be overestimated or underestimated.

\subsubsection{Monte Carlo simulation}

To perform Monte Carlo simulations, distributions must be assigned to parameters. Because wildlife are mobile, the mean of the contaminant concentration is likely to best represent their exposure. For this report, the contaminant concentrations in fish were assumed to be normally distributed. In future revisions of this report, goodness-of-fit analyses will be performed to determine which distribution best fists the data.

The literature values used for body weights of each endpoint are nationwide values, which may overestimate or underestimate the body weight of species found at the site. Similarly the proportion of fish and aquatic prey in mink diet were derived from data from northern locations (e.g., Michigan, Canada). The applicability of these data to the percentage of fish and aquatic prey consumed by mink in Tennessee is unknown.

\subsubsection{Estimated whole fish concentrations}

Contaminant concentrations in whole fish were estimated by using contaminant-specific fillet-towhole fish ratios. Data to generate ratios were available only for PCBs in largemouth bass and channel catfish from the Clinch River. Ratios for metals were obtained from spotted bass samples from near the Portsmouth Gaseous Diffusion Plant in Ohio. Applicability of these ratios to species other than those from which they were developed is unknown. Similarly, applicability of metal ratios from Ohio spotted bass to fish on the ORR is unknown. 



\section{ASSESSMENT OF RISKS TO VERMIVORES, HERBIVORES, AND PREDATORS ON THE OAK RIDGE RESERVATION}

Numerous, significant changes have been made throughout this section. To facilitate the flow of the document, they are summarized below but are not specifically identified in the text. The major changes in this section include the following:

- use of ORR-specific soil-plant, soil-earthworm, and soil-small mammal uptake factors,

- inclusion in assessment of predators red fox and red-tailed hawks, and

- use of updated benchmarks that reflect regulator comments concerning scaling factors.

\subsection{PROBLEM FORMULATION}

On the ORR, although most wide-ranging wildlife species reside primarily in the uncontaminated terrestrial habitats outside of source OUs (the terrestrial integrator OU; Suter et al.1995), they may also use those source OUs on which suitable habitat is present. As discussed in Chap. 3, the degree to which a source OU is used (and therefore the risk that it may present) is dependant upon the availability of suitable habitat on the OU. OUs with little or no habitat will experience little use (and will present minimal risk); those with considerable habitat are likely to experience considerable use (and depending upon the degree of contamination, may present significant risks).

Although individuals may experience adverse effects through exposures received at source OUs, the primary concern for ecological risk assessment is for effects at the population-level (except for T\&E species, for which effects to individuals are a critical concern). To evaluate effects to the reservation-wide wildlife populations, habitat suitability and population density on the ORR and within OUs must be considered. A general, six-step, habitat-based approach was developed that is applicable to all wildlife species on the ORR. The approach is outlined here.

1. Individual-based contaminant exposure estimates are generated for each OU by using the generalized exposure model outlined in Sample and Suter (1994). Data used for the exposure estimate may consist of modeled data or actual measured concentrations in food, water, or soil from the OU.

2. Contaminant exposure estimates are compared with NOAELs or LOAELs to determine the magnitude and nature of effects that may result from exposure at the OU. If the exposure estimate is greater than LOAEL, then individuals at the OU may experience adverse effects.

3. Availability and distribution of habitat on the ORR and within each OU is determined by using the ORR habitat map presented in Washington-Allen et al. (1995; see Table B.2).

4. Habitat requirements for the endpoint species of interest (from Table B.1) are compared with the ORR habitat map to determine the area of suitable habitat on the ORR and within OUs (Tables B.4, B.5, and B.6).

5. The area of suitable habitat on the ORR and within OUs is multiplied by population density values for the selected endpoints to generate estimates of the reservation-wide population and the numbers of individuals expected to reside within each OU. Population density values may be derived from the literature or may consist of site-specific data. 
6. The number of individuals for a given endpoint species expected to be receiving exposures greater than LOAELs for each measured contaminant is totaled. This is performed by using the OU-specific population estimate from step 5 and the results from step 2 . This number is then compared with the reservation-wide population to determine the proportion of the reservation-wide population that is receiving hazardous exposures. By using the $20 \%$ criterion outlined in Suter et al. (1995), if the proportion of the reservation-wide population receiving hazardous exposures $220 \%$, then an adverse population-level effect is assumed to be present.

In this assessment, exposure estimates were calculated and risks considered for 9 OUs on the ORR: the Bear Creek OU 2, Lower and Upper East Fork Poplar Creek, 3 OUs at K-25 (K-1407, K-1420, K-1414), WAGs 1 and 6, and the South Campus Facility (SCF). In addition, results from completed risk assessments on the Bear Creek Valley OU, Chestnut Ridge OU 2, and WAGs 2 and 5 were included. Locations of these QUs on the ORR are presented in Fig. G.1 (Appendix G).

\subsubsection{Ecological Assessment Endpoints}

\subsubsection{Assessment endpoints}

The following assessment endpoints were selected for the assessment of risks to herbivorous, vermivorous (e.g., worm-consuming), and predatory wildlife: toxicity to white-tailed deer (Odocoileus virginianus) or wild turkey (Meleagris gallopavo) (as representative herbivores), American woodcock (Scolopax minor) or short-tailed shrew (Blarina brevicauda) (as representative vermivores), red fox (Vulpes fulva) or red-tailed hawk (Buteo jamaicensis) resulting in a reduction in population abundance or production. Deer, turkey, woodcock, red fox, and red-tailed hawk are assessment endpoints agreed to be appropriate for the ORR by the FFA parties (Suter et al. 1995). The shrew is identified as a measurement endpoint in Suter et al. (1995). It is selected here as a surrogate for the several T\&E shrew species listed in Suter et al. (1995). The criteria for selection of the entities are those recommended by the EPA (Risk Assessment Forum 1992), plus considerations of scale and practical considerations.

The appropriate properties of the entities selected by these criteria depend on the level of organization of the entity and the criteria that led to their selection. Although the primary concern for wildlife is effects at the population level, due to limited population sizes, effects to individuals are critical for T\&E species. Because none of the selected endpoint species is a T\&E species, the appropriate endpoint properties for populations of endpoint species are abundance and production.

Finally, the level of effects on these properties of the endpoint entities that is considered to be potentially significant is $20 \%$ as agreed by the FFA parties (Suter et al. 1995). This level is consistent with current regulatory practice.

\subsubsection{Measurement endpoints}

Three basic types of effects data are potentially available to serve as measurement endpoints: results of biological surveys, toxicity tests performed with fish from the ORR, and literature-derived toxicity test results for chemicals found on the ORR. Measurement endpoints for each assessment endpoint are presented here.

- White-tailed deer

- Biological Survey Data-None.

- Media Toxicity Data-None. 
- Single Chemical Toxicity Data-These data consist of chronic toxicity thresholds for contaminants of concern in mammals with greater weight given to data from long-term feeding studies with wildlife species. Preference was also given to tests that included reproductive endpoints. These test endpoints are assumed to correspond to the assessment endpoint after allometric scaling.

- Wild turkey

- Biological survey data-None.

- Media toxicity data-None.

- Single chemical toxicity data-These data consist of chronic toxicity thresholds for contaminants of concern in birds with greater weight given to data from long-term feeding studies with wildlife species. Preference was also given to tests that included reproductive endpoints. These test endpoints are assumed to correspond to the assessment endpoint after allometric scaling.

- American woodcock

- Biological survey data-None.

- Media toxicity data-None.

- Single chemical toxicity data-These data consist of chronic toxicity thresholds for contaminants of concern in birds with greater weight given to data from long-term feeding studies with wildlife species. Preference was also given to tests that included reproductive endpoints. These test endpoints are assumed to correspond to the assessment endpoint after allometric scaling.

- Short-tailed shrew

- Biological survey data-None.

- Media toxicity data-None.

- Single chemical toxicity data-These data consist of chronic toxicity thresholds for contaminants of concern in mammals with greater weight given to data from long-term feeding studies with wildlife species. Preference was also given to tests that included reproductive endpoints. These test endpoints are assumed to correspond to the assessment endpoint after allometric scaling.

- $\quad$ Red fox

- Biological survey data-None.

- Media toxicity data-None.

- Single chemical toxicity data-These data consist of chronic toxicity thresholds for contaminants of concern in mammals with greater weight given to data from long-term feeding studies with wildlife species. Preference was also given to tests that included reproductive endpoints. These test endpoints are assumed to correspond to the assessment endpoint after allometric scaling.

- $\quad$ Red-tailed hawk

- Biological survey data-None.

- Media toxicity data-None.

- Single chemical toxicity data-These data consist of chronic toxicity thresholds for contaminants of concern in mammals with greater weight given to data from long-term feeding studies with wildlife species. Preference was also given to tests that included reproductive endpoints. These test endpoints are assumed to correspond to the assessment endpoint after allometric scaling. 


\subsubsection{Ecological Conceptual Model}

The ecological conceptual model graphically represents the relationships between the contaminant sources and the endpoint receptors. It integrates the information in the other subsections of the hazard identification and presents them graphically. It is not intended to show all of the possible sources, routes of transport, modes of exposure, or effects. Rather, it includes the only identified CERCLA source, the receptors that are designated as assessment endpoint species or communities, and the major routes that result in exposure to contaminants from the ORR.

The conceptual model for exposure of herbivores, vermivores, and predators to contaminants is presented in Fig. 5.1. Components of this model include plants and soil/litter invertebrates that reside on OUs on the ORR, the herbivorous and vermivorous wildlife that feed on them, and the predators that feed on the herbivores and vermivores. Plants and soil/litter invertebrates are exposed to contaminants from surface soil. Contaminants are bioaccumulated in lower trophic levels (i.e., plants or invertebrates) and transferred to higher trophic levels (i.e., herbivores, vermivores, predators). Herbivorous and vermivorous wildlife are exposed to contaminants through consumption of plants and soil/litter invertebrates, respectively. Predators are exposed to contaminants through consumption of herbivores and vermivores. All three wildlife endpoint groups are also exposed to contaminants through incidental ingestion of contaminated soil.

\subsection{EXPOSURE ASSESSMENT FOR HERBIVOROUS, VERMIVOROUS, AND PREDATORY WILDLIFE}

Potential routes of exposure for wildlife inhabiting the ORR include ingestion of food (either plant or animal) and surface water. In addition, some species may ingest soil incidentally while foraging or purposefully to meet nutrient needs. The total exposure experienced by terrestrial wildlife is represented by the sum of the exposure from each individual source (e.g., vegetation, earthworms, small mammals, soil, water).

The primary pathway of contaminant exposure is through oral ingestion of food and soil. Consumption of surface water, in most cases, contributes minimal contaminant exposure. Exposure from ingestion of surface water within the OU will not be included in the total exposure estimation. The surface water contaminant concentrations available in the ORR database will be compared with the water consumption benchmarks for each endpoint in the future revision of this document. Contaminant exposures were estimated for white-tailed deer, wild turkey, short-tailed shrew, American woodcock, red fox, and red-tailed hawk.

\subsubsection{Exposure Through Oral Ingestion of Food and Soil}

Exposure estimates were calculated for all contaminants detected at all ORR sampling locations within an OU by using Equation 1 from Sect. 4.2.1. The 95\% UCL is used in exposure estimates.

\subsubsection{Life history parameters for endpoint species}

Species-specific parameters for herbivorous and vermivorous endpoints necessary to estimate exposure through the use of the above equation are listed in Tables G.1 to G.6. Habitat requirements and densities for each endpoint will be used to determine the percentage of the population which is experiencing unacceptable levels of contaminant exposure. 


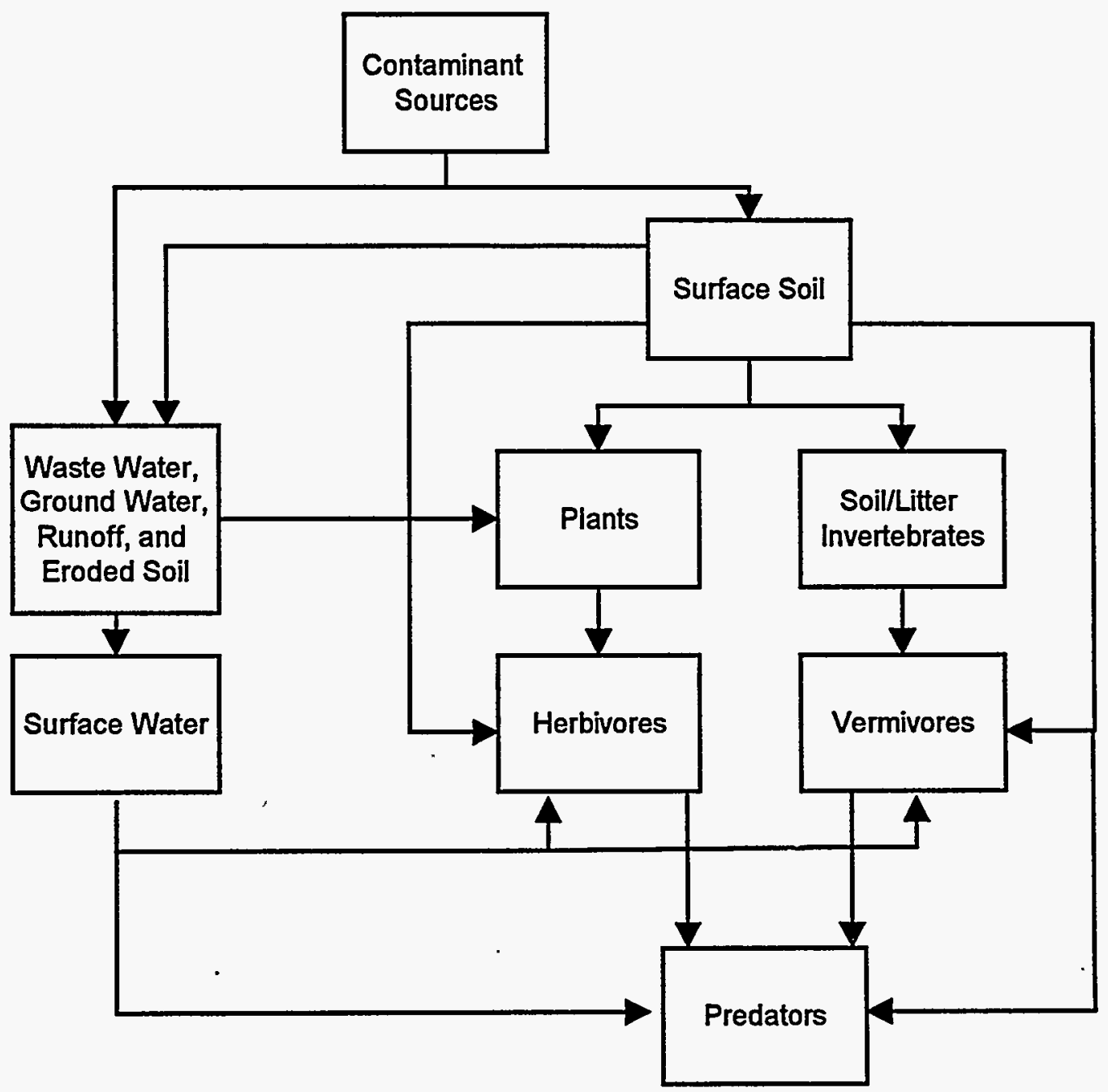

Fig. 5.1. Conceptual model for the exposure of vermivorous, herbivorous, and predatory wildlife to contaminants. 


\subsubsection{Contaminant concentrations in biotic and abiotic media}

Contaminant concentrations in soil, vegetation, soil invertebrates, and small mammals are needed to estimate exposure. The surface soil 95\% UCL (Table G.7) was used to calculate incidental ingestion of soil for each endpoint species. However, if the contaminant was only detected in a single sample, the single concentration was used to calculate exposure. The surface soil samples used in the calculations were collected at a depth ranging from 0 to $2 \mathrm{ft}$. Contaminants that were not detected or do not have an associated wildlife ecotoxicological benchmark were not evaluated. The $95 \%$ UCL soil concentrations were compared with background concentrations identified from the ORR Background Soils Characterization Project (Environmental Sciences Divison 1993; Table G.8). Concentrations of inorganic contaminants in vegetation were estimated by using the 90th percentile of the ORR-specific soil-plant uptake factors presented in Efroymson et al. (1996). Soil-plant uptake factors for organic contaminants were derived from the $\log$ octanol-water partition coefficient $\left(\log \mathrm{K}_{\mathrm{ow}}\right)$ by using the following equation (Travis and Arms 1988; Table G.9):

Log soil-plant uptake factor $=1.588-0.578\left(\log \mathrm{K}_{\text {ow }}\right)$

Concentrations of inorganic contaminants and PCBs in earthworms and small mammals were estimated using the 90 th percentile of the ORR-specific soil-earthworm and soil-small mammal uptake factors presented in Sample et al. (1996b).

\subsubsection{Exposure modeling using point-estimates}

To estimate contaminant exposure experienced by white-tailed deer feeding within each OU, the following assumptions were made:

- $\quad$ Body weight $=56.5 \mathrm{~kg}$.

- $\quad$ Food consumption $=1.74 \mathrm{~kg} / \mathrm{d}$.

- Soil consumption $=0.0348 \mathrm{~kg} / \mathrm{d}$.

- Diet consists $100 \%$ of vegetation.

To estimate contaminant exposure experienced by wild turkey feeding within each OU, the following assumptions were made:

- $\quad$ Body weight $=5.8 \mathrm{~kg}$.

- Food consumption $=0.174 \mathrm{~kg} / \mathrm{d}$.

- Soil consumption $=0.0162 \mathrm{~kg} / \mathrm{d}$.

- Diet consists $100 \%$ of vegetation, seeds, and fruits.

- Contaminant concentrations in seeds and fruits are similar to vegetation.

To estimate contaminant exposure experienced by short-tailed shrew feeding within each OU, the following assumptions were made:

- $\quad$ Body weight $=0.015 \mathrm{~kg}$.

- Food consumption $=0.009 \mathrm{~kg} / \mathrm{d}$.

- Soil consumption $=0.00117 \mathrm{~kg} / \mathrm{d}$.

- Diet consists $100 \%$ of earthworms. 
To estimate contaminant exposure experienced by American woodcock feeding within each OU, the following assumptions were made:

- Body weight $=0.198 \mathrm{~kg}$.

- Food consumption $=0.15 \mathrm{~kg} / \mathrm{d}$.

- Soil consumption $=0.0156 \mathrm{~kg} / \mathrm{d}$.

- Diet consists $100 \%$ of earthworms.

To estimate contaminant exposure experienced by red fox feeding within each $\mathrm{OU}$, the following assumptions were made:

- $\quad$ Body weight $=4.5 \mathrm{~kg}$.

- Food consumption $=0.45 \mathrm{~kg} / \mathrm{d}$.

- Soil consumption $=0.0126 \mathrm{~kg} / \mathrm{d}$.

- Diet consists $80.8 \%$ of small mammals, $10.4 \%$ plants, and $8.8 \%$ of earthworms..

To estimate contaminant exposure experienced by red-tailed hawk feeding within each OU, the following assumptions were made:

- $\quad$ Body weight $=1.126 \mathrm{~kg}$.

- Food consumption $=0.109 \mathrm{~kg} / \mathrm{d}$.

- Soil consumption $=0 \mathrm{~kg} / \mathrm{d}$.

- Diet consists $100 \%$ of small mammals

By using the Equation 1 from Sect. 4.2.1 and the assumptions and data described above, the total exposure to contaminants was estimated for the white-tailed deer (Table G.10) wild turkey (Table G.11), short-tailed shrew (Table G12), American woodcock (Table G.13), red fox (Table G.14), and red-tailed hawk (Table G.15) foraging within each OU.

\subsection{EFFECTS ASSESSMENT FOR HERBIVOROUS, VERMIVOROUS, AND PREDATORY WILDLIFE}

\subsubsection{Toxicological Benchmarks}

To determine if the contaminant exposures experienced by terrestrial wildlife foraging on individual OUs could produce adverse effects, exposure estimates are compared with NOAELs and LOAELs derived according to the methods outlined by Sample et al. (1996). NOAELs represent the highest exposure at which no adverse effects were observed among the animals tested. LOAELs represent the lowest exposure at which significant adverse effects are observed.

Toxicological studies of the effects of contaminants observed in the soil were obtained from the open literature. Only studies of long-term, chronic oral exposures were used to estimate the NOAEL or LOAEL. To make the NOAELs and LOAELs relevant to possible population effects, preference was given to studies that evaluated effects on reproductive parameters. In the absence of a reproduction endpoint, studies that considered effects on growth, survival, and longevity were used. Experimental data used for the development of NOAELs and LOAELs for mammalian endpoints are presented in Table G.16; estimated NOAELs and LOAELs for mammalian endpoints are listed in Table G. 17. Experimental data used for the development of NOAELs and LOAELs for avian 
endpoints and estimated wildlife NOAELs and LOAELs are presented in Table G.18. Specific details on development of the NOAELs and LOAELs for all wildlife endpoints are discussed in Sect. 4.3.1.

\subsubsection{Ecotoxicological Profiles for Herbivorous and Vermivorous Wildlife}

The ecotoxicological profiles for COPECs for herbivorous and vermivorous wildlife on the ORR may be found in Appendix D.

\subsection{RISK CHARACTERIZATION FOR HERBIVOROUS, VERMIVOROUS, AND PREDATORY WILDLIFE}

Risk characterization integrates the results of the exposure assessment (Sect. 5.2) and effects assessment (Sect. 5.3) to estimate risks (the likelihood of effects given the exposure) based on each line of evidence. A weight of evidence approach, as outlined in Suter et al. (1995), is applied to determine the best estimate of risk to each assessment endpoint. This risk assessment is based on only one line of evidence: literature-derived single chemical toxicity data that indicates the toxic effects of media concentrations measured within each $O U$.

Procedurally, the risk characterization in this assessment is performed for each assessment endpoint by

- screening all measured contaminants within each OU against background soil levels and toxicological benchmarks;

- estimating the effects of the contaminants retained by the screening analysis for individuals of each endpoint species;

- estimating the number of individuals within the ORR population;

- estimating the number of individuals within an OU that are potentially exposed based on habitat availability and population density;

- calculating the total number of individuals on the ORR that may be at risk (addition of number of animals exposed within all OUs for which data exist);

- calculating the percentage of the ORR population that may experience adverse effects from contaminant exposure;

- using the $20 \%$ exposure criteria outlined in Suter et al. (1995), determine if reservation-wide endpoint populations are significantly at risk from contaminants present within OUs for which data is available;

- prioritizing the OUs based on the contribution of risk to the entire ORR population; and

- discussing the uncertainties in the assessment.

Data for this assessment was limited to single chemical toxicity data and habitat availability for herbivores, vermivores, and predators inhabiting the ORR. 


\subsubsection{Contaminant Screening of Soil to Background Levels}

The initial screening for COPECs in soil begins with a comparison of the 95\% UCL or single detected concentration found in surface soil in each OU with appropriate ORR background soils identified in the ORR Background Soils Characterization Project (Environmental Sciences Division 1993). Table G.8 identifies the background levels (95\% UCL) found for each formation indicative of each OU. In some cases, an OU may be located on multiple formations. Therefore, a range of the minimum and maximum 95\% UCL background values for multiple formations were used for comparison. Data were not available for certain formations indicative of an OU; thus, the range of 95\% UCLs of all formations was used.

Chemicals were rejected from further consideration if the 95\% UCL concentrations in OU soil were $<95 \%$ UCL background concentration for the specific formation. Aluminum was eliminated from the analysis for WAG 1 and WAG 6. Arsenic was eliminated from K-1420 OU, LEFPC, and UEFPC OU 2. Chromium, mercury, and zinc were eliminated from WAG 6. Vanadium was eliminated from K-1407, the South Campus Facility, and UEFPC OU.

\subsubsection{Single Chemical Toxicity Data for Herbivorous, Vermivorous, and Predatory Wildlife (Individuals)}

Exposure of endpoint species to chemicals found in concentrations greater than background was calculated. The total contaminant exposure estimates for herbivores, vermivores, and predators foraging on vegetation, earthworms, and/or small mammals within an OU were compared with estimated LOAELs. If the LOAEL was lower than the exposure, portions of the endpoint population may experience contaminant exposures that are likely to produce adverse effects. Consequently, the individuals living within the $\mathrm{OU}$ are at risk because of hazardous exposures.

\subsubsection{Screening point estimates of exposure}

To determine if the contaminant exposures experienced by herbivores, vermivores, and predators feeding on each OU are potentially hazardous, the total exposure estimates were compared with estimated LOAELs. HQs were calculated to quantify the magnitude of the hazard where

$$
\begin{aligned}
& \text { NOAEL HQ = estimated contaminant exposure }(\mathrm{mg} / \mathrm{kg} / \mathrm{d}) / \mathrm{NOAEL} \\
& \text { LOAEL HQ = estimated contaminant exposure }(\mathrm{mg} / \mathrm{kg} / \mathrm{d}) / \mathrm{LOAEL} \text {. }
\end{aligned}
$$

HQs $>1$ indicate that individuals may be experiencing exposures that are in excess of LOAELs and suggest that adverse effects may be occurring. HQs for all endpoints are presented along with exposure estimates in Tables G.10 to G.15. Contaminants that may most likely adversely impact the individual endpoints foraging within OUs are discussed below. The location (operable unit) of COPECs for each endpoint species are further detailed in Table 5.1. This discussion is limited to those contaminants for which the $95 \%$ UCL was greater than background concentrations and for which the LOAEL HQ was $>1$.

Exposure of herbivores, vermivores, and predators to aluminum exceeded both NOAELs and LOAELs at many locations, including the background. However, it is highly unlikely that the aluminum exposures estimated within the OUs are toxic and present a hazard to wildlife. This is for several reasons. Aluminum is a common and abundant structural element in soil whose most common 
Table 5.1. Location (operable units") of contaminants of potential concern for each endpoint species

\begin{tabular}{|c|c|c|c|c|c|c|}
\hline Contaminant & White-tailed deer & Wild Turkey & Short-tailed shrew & $\begin{array}{l}\text { American } \\
\text { Woodcock }\end{array}$ & Red Fox & Red-tailed Hawk \\
\hline Acetone & SCF & & SCF & & SCF & \\
\hline Antimony & & & $\begin{array}{l}\text { BC OU } 1 \\
\text { BCV OU }\end{array}$ & & & \\
\hline Arsenic & & & $\mathrm{BC}$ OU 2 & & & \\
\hline & FCAP & & $\begin{array}{c}\text { FCAP } \\
\text { K-1407 OU } \\
\text { SCF } \\
\text { WAG } 1\end{array}$ & $\begin{array}{c}\text { BC OU } 2 \\
\mathrm{~K}-1407 \text { OU } \\
\text { SCF }\end{array}$ & $\begin{array}{c}\text { BC OU } 2 \\
\text { FCAP }\end{array}$ & . \\
\hline Barium & & & FCAP & & & \\
\hline & FCAP & & $\begin{array}{c}\text { UEFPC OU } 2 \\
\text { WAG } 5\end{array}$ & UEFPC OU 2 & & \\
\hline Boron & & & & WAG 1 & & \\
\hline Cadmium & & & $\begin{array}{c}\text { SCF } \\
\text { WAG } 2\end{array}$ & $\begin{array}{l}\text { LEFPC } \\
\text { SCF }\end{array}$ & & \\
\hline Chromium & & & $\begin{array}{l}\text { BC OU } 2 \\
\text { K-1407 OU } \\
\text { K-1420 OU } \\
\text { LEFPC } \\
\text { SCF } \\
\text { UEFPC OU } 2 \\
\text { WAG 1 }\end{array}$ & $\begin{array}{c}\text { BC OU } 2 \\
\text { K-1407 OU } \\
\text { K-1420 OU } \\
\text { UEFPC OU } 2 \\
\text { WAG } 1 \\
\text { WAG } 5\end{array}$ & $\begin{array}{c}\text { UEFPC OU } 2 \\
\text { FCAP }\end{array}$ & \\
\hline Copper & & & $\begin{array}{c}\text { BCV OU } \\
\text { LEFPC }\end{array}$ & LEFPC & & \\
\hline DDT and metabolites & & LEFPC & LEFPC & LEFPC & & \\
\hline Lead & & & & $\begin{array}{c}\text { BC OU } 2 \\
\text { K-1420 OU } \\
\text { LEFPC } \\
\text { UEFPC OU } 2\end{array}$ & & \\
\hline Lithium & & & $\mathrm{K}-1420$ OU & & & \\
\hline
\end{tabular}


Table 5.1 (continued)

\begin{tabular}{|c|c|c|c|c|c|c|}
\hline Contaminant & White-tailed deer & Wild Turkey & Short-tailed shrew & $\begin{array}{l}\text { American } \\
\text { Woodcock }\end{array}$ & Red Fox & Red-tailed Hawk \\
\hline Mercury & $\begin{array}{l}\text { BC OU } 2 \\
\text { LEFPC }\end{array}$ & $\begin{array}{c}\text { BC OU } 2 \\
\text { K-1407 OU } \\
\text { LEFPC } \\
\text { WAG } 2\end{array}$ & $\begin{array}{c}\text { BC OU } 1 \\
\text { BC OU } 2 \\
\text { BCV OU } \\
\text { K-1407 OU } \\
\text { K-1420 OU } \\
\text { LEFPC } \\
\text { SCF } \\
\text { WAG } 1 \\
\text { WAG } 2 \\
\text { WAG } 5\end{array}$ & $\begin{array}{c}\text { BC OU } 2 \\
\text { K-1407 OU } \\
\text { K-1420 OU } \\
\text { LEFPC } \\
\text { SCF } \\
\text { WAG 1 } \\
\text { WAG } 5\end{array}$ & $\begin{array}{c}\text { BC OU } 2 \\
\text { FCAP } \\
\text { K-1407 OU } \\
\text { K-1420 OU } \\
\text { LEFPC } \\
\text { SCF } \\
\text { WAG 1 } \\
\text { WAG 2 }\end{array}$ & $\begin{array}{c}\text { BC OU } 2 \\
\text { FCAP } \\
\text { K-1407 OU } \\
\text { LEFPC } \\
\text { WAG 1 }\end{array}$ \\
\hline Methylene chloride & SCF & & & & & \\
\hline Nickel & & & $\begin{array}{l}\mathrm{K}-1407 \text { OU } \\
\text { UEFPC OU } 2\end{array}$ & $\begin{array}{c}\text { BC OU } 2 \\
\text { K-1407 OU } \\
\text { K-1420 OU } \\
\text { LEFPC } \\
\text { UEFPC OU } 2 \\
\text { WAG } 6\end{array}$ & & \\
\hline Selenium & FCAP & & $\begin{array}{c}\text { BC OU } 2 \\
\text { FCAP } \\
\text { K-1407 OU } \\
\text { LEFPC } \\
\text { SCF } \\
\text { WAG 1 } \\
\text { WAG 2 }\end{array}$ & $\begin{array}{c}\text { BC OU } 2 \\
\text { K-1407 OU } \\
\text { LEFPC } \\
\text { SCF } \\
\text { WAG } 1\end{array}$ & $\begin{array}{c}\text { FCAP } \\
\text { K-1407 OU } \\
\text { LEFPC } \\
\text { WAG 1 }\end{array}$ & FCAP \\
\hline Thallium & FCAP & & $\begin{array}{l}\text { FCAP } \\
\text { WAG } 1\end{array}$ & & $\begin{array}{l}\text { FCAP } \\
\text { WAG } 1\end{array}$ & \\
\hline
\end{tabular}


Table 5.1 (continued)

\begin{tabular}{|c|c|c|c|c|c|c|}
\hline Contaminant & White-tailed deer & Wild Turkey & Short-tailed shrew & $\begin{array}{l}\text { American } \\
\text { Woodcock }\end{array}$ & Red Fox & Red-tailed Hawk \\
\hline Total PCBs & $\begin{array}{l}\text { BC OU } 2 \\
\text { K-1420 OU } \\
\text { LEFPC } \\
\text { WAG I }\end{array}$ & & $\begin{array}{c}\text { BC OU } 1 \\
\text { BC OU } 2 \\
\text { BCV OU } \\
\text { K-1420 OU } \\
\text { LEFPC } \\
\text { SCF } \\
\text { WAG 1 } \\
\text { WAG 2 }\end{array}$ & $\begin{array}{c}\text { BC OU } 2 \\
\text { K-1420 OU } \\
\text { LEFPC } \\
\text { WAG } 1\end{array}$ & $\begin{array}{l}\mathrm{K}-1420 \text { OU } \\
\text { LEFPC }\end{array}$ & \\
\hline Uranium & & & $\begin{array}{l}\mathrm{K}-1407 \text { OU } \\
\mathrm{K}-1420 \text { OU }\end{array}$ & & & \\
\hline Vanadium & FCAP & & $\begin{array}{l}\text { BC OU } 1 \\
\text { BC OU } 2 \\
\text { FCAP } \\
\text { SCF }\end{array}$ & & & \\
\hline Zinc & & & UEFPC OU 2 & $\begin{array}{c}\text { BC OU } 2 \\
\text { K-1407 OU } \\
\text { K-1420 OU } \\
\text { LEFPC } \\
\text { SCF } \\
\text { UEFPC OU } 2 \\
\text { WAG 1 } \\
\text { WAG } 5\end{array}$ & & \\
\hline
\end{tabular}

a Data from Bear Creek (BC) OU 1, Bear Creek Valley (BCV) OU, Filled Coal Ash Pond (FCAP), WAG 2, and WAG 5 were taken from the following sources:

Environmental Sciences Division. 1996. Report on the Remedial Investigation of Bear Creek Valley at the Oak Ridge Y-12 Plant, Oak Ridge, Tennessee. Volume 6. Appendix G-Baseline Ecological Risk Assessment Report. DOE/OR/01-1455/V6\&D0. Oak Ridge National Laboratory. Oak Ridge, TN.

CDM Federal. 1995. Remedial Investigation Report on Chestnut Ridge Operable Unit 2 (Filled Coal Ash Pond/Upper McCoy Branch) at the Oak Ridge Y-12 Plant, Oak Ridge, Tennessee. Volume 1. Main Text. DOE/OR/11-1268/V1\&D2. Y/ER-172/V1\&D2. OakRidge, TN.

Efroymson, R. A., B. L. Jackson, D. S. Jones, B. E. Sample, G. W. Suter II, and C. J. E. Welsh. 1996. Waste Area Grouping 2 Phase I Task Data Report: Ecological Risk Assessment and White Oak Creek Watershed Screening Ecological Risk Assessment. ORNL/ER-366. Oak Ridge National Laboratory, Oak Ridge, TN.

Bechtel National, Inc./ CH2M Hill/ Ogden/PEER. 1995. Remedial Investigation Report on Waste Area Grouping 5 at Oak Ridge National Laboratory, Oak Ridge, Tennessee. Volume 4. Appendix C: Risk Assessment. DOE/OR/01-1326\&D2/V4. ORNL/ER-284\&D2/V4. ORNL/ER/Sub/87-99053/76/V4. Oak Ridge, TN. 
forms are unlikely to be bioavailable and therefore toxic; toxicity data for aluminum are derived from soluble salts (e.g., $\mathrm{AlCl}_{3}$ ) that do not accurately reflect the toxicity of the forms generally found in soil (e.g., oxides). Therefore, aluminum was eliminated as a COPEC from all subsequent analyses.

White-tailed deer. Deer foraging on the Filled Coal Ash Pond (FCAP) are potentially at greatest risk with five COPECs (Table 5.1). Deer foraging on SCF, Bear Creek (BC) OU 2, and LEFPC are also at risk; each OU had three COPECs with HQs $>1$. K-1420 OU, K-1407 OU, UEFPC OU 2, and WAG 1 had two, one, one, and one COPECs with HQs $>1$, respectively. COPECs for deer were PCBs (five locations), mercury (two locations), acetone (one location), and methylene chloride (one location).

Wild turkey. Mercury is the only major contaminant that poses a risk to wild turkey on $\mathrm{BC}$ OU 2, K-1407 OU, and LEFPC. DDT (and metabolites) is 24 times the benchmark for turkey on LEFPC. No other COPECs were identified for wild turkey on any of the other OUs.

Short-tailed shrews. Short-tailed shrews may be at significant risk foraging at all OUs except WAG 6 (Table 5.1). Each OU had from two to eight COPECs. Mercury, Cr, Se, total PCBs, and As contributed to the majority of the risk. Mercury at BC OU 2 and LEFPC were 560 and 306 times the benchmark, respectively.

American woodcock. American woodcock may be at significant risk foraging at most OUs except for BC OU 1, Bear Creek Valley (BCV) OU, FCAP, WAG 2, and WAG 6 (Table 5.1). Risk is primarily due to exposure to mercury, DDT and metabolites, and chromium. Foraging at LEFPC poses the most significant risk, with possible exposure to 10 COPECs. The remaining OUs with HQs $>1$ had from three to eight COPECs except for WAG 6, which had only one COPEC, nickel, at only 1.73 times the benchmark. Zinc was identified as a COPEC at eight locations. Other significant COPECs for woodcock were $\mathrm{Hg}$ at seven locations, $\mathrm{Ni}$ and $\mathrm{Cr}$ at six locations, $\mathrm{Se}$ (five), $\mathrm{Pb}$ and total PCBs (four), and As (three). Barium, B, Cu, DDT, and metabolites were above benchmark values at one location, and $\mathrm{Cd}$ was found at two locations.

Red fox. Mercury poses the most significant risk to red fox foraging on 8 of the 13 OUs. Mercury concentrations at BC OU 2 and LEFPC are 462 and 253 times the benchmark, respectively. With the exception of WAG 6, each of the OUs has between two to four COPECs found at concentrations large enough to exceed benchmark values. Other COPECs for red fox were $\mathrm{Se}(4$ locations), total PCBs (2), and $\mathrm{As}, \mathrm{Cr}$, and $\mathrm{Tl}(2)$.

Red-tailed hawk. Mercury and selenium were the only contaminants that pose a risk to red-tailed hawks on the ORR. Mercury was identified as a COPEC at five locations. BC OU 2 and LEFPC were the primary contributors to risk from mercury, with levels that exceeded benchmarks by 86 and 47 times, respectively. Selenium was identified as a COPEC at FCAP.

\subsubsection{Effects of Retained Contaminants for Herbivorous, Vermivorous, and Predatory Wildlife}

\subsubsection{Acetone}

Both the NOAEL and LOAEL for mammalian endpoints are based on a study in which liver and kidney damage was observed in rats fed acetone for 90 days (EPA 1986). Three dose levels were administered $(100,500$, and $2500 \mathrm{mg} / \mathrm{kg} / \mathrm{d})$. Significant tubular degeneration of the kidneys and increases in kidney weights were observed at the $500 \mathrm{mg} / \mathrm{kg} / \mathrm{d}$ dose level. No adverse effects were observed at the $100 \mathrm{mg} / \mathrm{kg} / \mathrm{d}$ level. These doses are considered subchronic values and therefore were 
multiplied by the subchronic-chronic uncertainty factor of 0.1 . On the basis of the results of EPA (1986), white-tailed deer foraging at SCF experiencing exposure greater than or equal to LOAEL may display tubular degeneration of the kidneys.

Although acetone is highly volatile, the exposure experienced by white-tailed deer is 24.98 times the LOAEL, and the exposure to short-tailed shrews is 3.5 times the LOAEL at SCF. The presence of acetone may be a concern if it is a continuous source.

\subsubsection{Antimony}

Both the NOAEL and LOAEL for mammalian endpoints are based on a study in which lifespan and longevity was observed in mice fed antimony potassium tartrate for the lifetime of the organism (Schroeder et al. 1968b). One dose level was administered. Because median lifespan was reduced among female mice exposed to the $5 \mathrm{ppm}$ dose level and because the study considered exposure throughout the entire lifespan, this dose was considered to be a chronic LOAEL. A chronic NOAEL was estimated by multiplying the chronic LOAEL by a LOAEL-NOAEL uncertainty factor of 0.1 . On the basis of the results of Schroeder et al. (1968b), short-tailed shrews foraging on BCV OU and $\mathrm{BC}$ OU 1 may have reduced lifespans.

\subsubsection{Arsenic}

Both the NOAEL and LOAEL for mammalian endpoints are based on a study in which reproductive success and offspring survival was observed among mice fed arsenite for three generations (Schroeder and Mitchener 1971). One dose level administered $(1.261 \mathrm{mg} / \mathrm{kg} / \mathrm{d}$ ), designated as the chronic LOAEL, resulted in declining litter size with each successive generation. A chronic NOAEL was estimated by multiplying the chronic LOAEL by a LOAEL-NOAEL correction factor of 0.1. Based on the results of Schroeder and Mitchener (1971), short-tailed shrews foraging within most of the OUs and red fox foraging on BC OU 2 experiencing exposures greater than or equal to LOAEL are likely to display a decline in litter size.

The NOAEL and LOAEL for American woodcock are based upon a study in which mortality was observed in mallard ducks fed sodium arsenite for 128 days (U.S. Fish and Wildlife Service 1964). Four dose levels were administered. Mallards in the 1000,500 , and $250 \mathrm{ppm}$ groups experienced $92 \%, 60 \%$, and $12 \%$ mortality, respectively. Because those in the $100 \mathrm{ppm}$ group experienced $0 \%$ mortality, and the study considered exposure over 128 days, the $100 \mathrm{ppm}$ Sodium Arsenite $\left(51.35 \mathrm{mg} / \mathrm{kg} \mathrm{As}^{+3}\right)$ dose was considered to be a chronic NOAEL. The $250 \mathrm{ppm}$ Sodium Arsenite $\left(128.375 \mathrm{mg} / \mathrm{kg} \mathrm{As}^{+3}\right)$ dose was considered to be a chronic LOAEL. On the basis of the results of the U.S. Fish and Wildlife Service (1964), American woodcock foraging on BC OU 2, K-1407 OU, and SCF experiencing exposures greater than or equal to LOAEL may display increased mortality.

\subsubsection{Barium}

The NOAELs for mammals are based on a study in which growth, food and water consumption, and hypertension was observed among rats fed barium chloride for 16 months (Perry et al. 1983). Three dose levels were administered. The maximum dose $(5.1 \mathrm{mg} / \mathrm{kg} / \mathrm{d})$ did not affect growth or food or water consumption and was therefore considered to be a chronic NOAEL. The LOAEL was based on a study which observed mortality in rats fed barium for 10 days (Borzelleca et al. 1988). Four doses were administered and exposure of rats to the highest dose $(300 \mathrm{mg} / \mathrm{kg} / \mathrm{d})$ resulted in $30 \%$ mortality to female rats. The $300 \mathrm{mg} / \mathrm{kg} / \mathrm{d}$ dose is considered to be a subchronic LOAEL; therefore a chronic LOAEL was estimated by multiplying the subchronic LOAEL by a subchronic to chronic uncertainty 
factor of 0.1. On the basis of the results of Borzelleca et al. (1988), short-tailed shrews foraging on UEFPC OU 2 and WAG 5 experiencing exposures greater than or equal to LOAEL may display increased mortality.

Both the NOAELs and LOAELs for woodcock are based on a study that observed mortality to 1-day-old chicks fed 8 doses of barium hydroxide for 4 weeks (Johnson et al. 1960). The NOAEL dosage (208.3 mg/kg/d) produced no mortality; the LOAEL dosage $(416.5 \mathrm{mg} / \mathrm{kg}$ ) and highest dosage $(40.3 \mathrm{mg} / \mathrm{kg} / \mathrm{d})$ resulted in $5 \%$ to $100 \%$ mortality. The NOAEL and LOAEL were considered subchronic and was multiplied by the subchronic to chronic uncertainty factor of 0.1 . On the basis of the results of Johnson et al. (1960), American woodcock foraging at UEFPC OU 2 experiencing exposures greater than or equal to LOAEL may display increased mortality.

\subsubsection{Boron}

Both the NOAELs and LOAELs for mammals are based on a study in which reproductive success was observed among rats fed boric acid for three generations (Weir and Fisher 1972). Three does levels were administered. Although consumption of $1170 \mathrm{ppm}$ boron as either boric acid or borax resulted in sterility, no adverse reproductive effects were observed among rats consuming 117 or $350 \mathrm{ppm}$ boron. Because the study considered exposure throughout 3 generations including critical lifestages (reproduction), the $350 \mathrm{ppm}$ dose was considered to be a chronic NOAEL and the $1170 \mathrm{ppm}$ dose was considered a chronic LOAEL. There are no mammalian species at risk from boron at any of the OUs.

Both NOAEL and LOAEL for avian endpoints are based on a study in which reproductive success and mortality was monitored for mallard ducks fed boric acid 3 weeks before, during, and 3 weeks after reproduction (Smith and Anders 1989). Four dose levels were administered. Although consumption of $1000 \mathrm{ppm}$ boron resulted in reduced egg fertility and duckling growth and increased embryo and duckling mortality, no adverse reproductive effects were observed among the other dose levels. Because the study considered exposure throughout reproduction, the $288 \mathrm{ppm}$ dose was considered to be a chronic NOAEL and the $1000 \mathrm{ppm}$ dose was considered a chronic LOAEL. On the basis of the results of Smith and Anders (1989), American woodcock foraging on WAG 1 experiencing exposures greater than or equal to LOAEL may display decreased reproduction.

\subsubsection{Cadmium}

Both the NOAEL and LOAEL for mammalian endpoints are based upon a study in which reproductive success was observed among rats fed cadmium chloride for 6 weeks through mating and gestation (Sutou et al. 1980). Four dose levels were administered. Although no adverse effects were observed at the $1 \mathrm{mg} / \mathrm{kg} / \mathrm{d}$ dose level, fetal implantations were reduced by $28 \%$, fetal survivorship was reduced by $50 \%$, and fetal resorptions increased by $400 \%$ among the $10 \mathrm{mg} / \mathrm{kg} / \mathrm{d}$ group. Because the study considered oral exposure during reproduction, the 1 and $10 \mathrm{mg} / \mathrm{kg} / \mathrm{d}$ doses were considered to be chronic NOAELs and LOAELs, respectively. On the basis of the results of Sutou et al. (1980b), short-tailed shrews foraging on SCF experiencing exposures greater than or equal to LOAEL may display decreased reproduction.

Both the NOAEL and LOAEL for avian endpoints are based on a study in which reproductive success was observed among mallard ducks fed cadmium chloride for 90 days (White and Finley 1978). Three dose levels were administered. The highest dosage $(20.03 \mathrm{mg} / \mathrm{kg} / \mathrm{d})$, designated as the chronic LOAEL, produced significantly fewer eggs. A dosage of $1.45 \mathrm{mg} / \mathrm{kg} / \mathrm{d}$ produced no adverse effects and was designated as the chronic NOAEL. On the basis of the results of White and Finley 
(1978), American woodcock experiencing exposures greater than or equal to LOAEL at BC OU 1 may display impaired reproduction. Also on the basis of the results of White and Finely (1978), American woodcock foraging on LEFPC and SCF experiencing exposures greater than or equal to LOAEL may display decreased reproductive success.

\subsubsection{Chromium}

The LOAEL for mammalian endpoints is based upon a study in which mortality was observed in rats fed chromium $\left(\mathrm{Cr}^{+6}\right)$ for three months [Steven et al. 1976 (cited in Eisler 1986a)]. Two doses were administered. Because the $1000 \mathrm{ppm}$ dose was identified as the toxicity threshold, this dose was considered to be a subchronic LOAEL. A chronic LOAEL was estimated by multiplying the subchronic LOAEL by a subchronic-chronic uncertainty factor of 0.1 . On the basis of the studies of Steven et al. (1976), short-tailed shrews foraging on most OUs and red fox foraging on UEFPC OU 2 experiencing exposures greater than or equal to LOAEL may display increased mortality.

Both the NOAEL and LOAEL for avian endpoints are based upon a study in which reproduction in black ducks was observed fed chromium $\left[\mathrm{Cr}^{+3}\right.$ as $\left.\mathrm{CrK}\left(\mathrm{SO}_{4}\right)_{2}\right]$ for ten months (Haseltine et al., unpubl. data). Two doses were administered. Although duckling survival was reduced at the $50 \mathrm{ppm}$ dose level, no significant differences were observed at the $10 \mathrm{ppm} \mathrm{Cr}^{+3}$ dose level. Because the study considered exposure throughout a critical lifestage (reproduction), the dose $50 \mathrm{ppm}$ dose was considered to be a chronic LOAEL and the dose $10 \mathrm{ppm}$ dose was considered to be a chronic NOAEL. On the basis of the results of Haseltine et al., American woodcock foraging on most OUs experiencing exposures greater than or equal to LOAEL may display decreased reproductive success.

\subsubsection{Copper}

Both the NOAEL and LOAEL for mammalian endpoints are based on a study in which mink were fed copper sulfate for 357 days (including a critical life stage) (Aulerich et al. 1982). Although consumption of $15.14 \mathrm{mg} / \mathrm{kg} / \mathrm{d}$ copper increased the percentage of mortality in mink kits, no adverse effects were observed at a $11.71 \mathrm{mg} / \mathrm{kg} / \mathrm{d}$ exposure level. On the basis of the results of Aulerich et al. (1982), short-tailed shrews experiencing exposures greater than or equal to LOAEL within LEFPC display a reduction in offspring survival.

Both the NOAEL and LOAEL for avian endpoints are based on a study in which 1-day-old chicks were fed copper oxide for 10 weeks (Mehring et al. 1960). Eleven dose levels were administered in the study. No adverse effects were observed on the growth of chicks up to dose levels of $47 \mathrm{mg} / \mathrm{kg} / \mathrm{d}$. Consumption of $61.7 \mathrm{mg} / \mathrm{kg} / \mathrm{d}$ copper in the diet, designated as the LOAEL, resulted in reduced growth by over $30 \%$ and produced $15 \%$ mortality. On the basis of the results of Mehring et al. (1960), American woodcock experiencing exposures greater than or equal to LOAEL at LEFPC may display a reduction in growth and survivorship.

\subsubsection{DDT and metabolites}

Both the NOAEL and LOAEL for mammalian endpoints are based upon a study in which reproduction was observed in rats fed DDT for 2 years (Fitzhugh 1948). Four dose levels were administered. Although consumption of $50 \mathrm{ppm}$ or more DDT in the diet reduced the number of young produced, no adverse effects were observed at the $10 \mathrm{ppm}$ DDT dose level. Because the study considered exposure throughout 2 years and reproduction, the 10 and $50 \mathrm{ppm}$ DDT doses were considered to be chronic NOAELs and LOAELs, respectively. On the basis of the results of Fitzhugh 
(1948), short-tailed shrews experiencing exposures greater than or equal to LOAEL may display decreased reproductive success.

Both the NOAEL and LOAEL for avian endpoints are based on a study in which reproduction was observed in brown pelican for 5 years (Anderson et al. 1975). One dose level was administered. Anderson et al. (1975) studied the reproductive success of pelicans from 1969 through 1974. During this time, DDT residues in anchovies, their primary food, declined from $4.27 \mathrm{ppm}$ (wet weight) to 0.15 ppm (wet weight). Although reproductive success improved from 1969 to 1974, in 1974 the fledgling rate was still $30 \%$ below that needed to maintain a stable population. Because this study was longterm and considered reproductive effects in a wildlife species, EPA (1993) judged this study to be the most appropriate to evaluate DDT effects to avian wildlife. Therefore the $0.15 \mathrm{ppm}$ DDT value was considered to be a chronic LOAEL. To estimate the chronic NOAEL, the chronic NOAEL was multiplied by a LOAEL-NOAEL uncertainty factor of 0.1. On the basis of the results of Anderson et al. (1975), wild turkey and American woodcock experiencing exposures greater than or equal to LOAEL may experience long-term reproductive effects.

\subsubsection{Lead}

Both the NOAEL and LOAEL for mammalian endpoints are based on a study in which reproduction was observed in rats fed lead (lead acetate) for three generations (Azar et al. 1973). Five dose levels were administered. Although none of the lead exposure levels studied affected the number of pregnancies, the number of live births, or other reproductive indices, lead exposure of 1000 and $2000 \mathrm{ppm}$ resulted in reduced offspring weights and produced kidney damage in the young. Therefore the $100 \mathrm{ppm}$ lead dose was considered to be a chronic NOAEL and the $1000 \mathrm{ppm}$ lead dose was considered to be a chronic LOAEL.

The NOAEL and LOAEL for avian species are based on a study in which the reproductive success of Japanese quail fed lead (acetate) was observed for 12 weeks (Edens et al. 1976). Four dose levels were administered. Although egg hatching success was reduced among birds consuming the $100 \mathrm{ppm}$ lead dose, reproduction was not impaired by the $10 \mathrm{ppm}$ lead dose. Because the study considered exposure over 12 weeks and throughout a critical lifestage (reproduction), these values were considered to be chronic LOAELs and NOAELs. Final NOAEL: $1.13 \mathrm{mg} / \mathrm{kg} / \mathrm{d}$; final LOAEL: $11.3 \mathrm{mg} / \mathrm{kg} / \mathrm{d}$. On the basis of the results of Edens et al. (1976), American woodcock foraging on BC OU 2, K-1420 OU, LEFPC, and UEFPC OU 2 experiencing exposures greater than or equal to LOAEL may display decreased reproductive success.

\subsubsection{Mercury}

Both the NOAEL and LOAEL for mammalian endpoints are based on a study in which reproductive success and offspring survival was observed among rats fed methyl mercury for three generations (Verschuuren et al. 1976c). The highest dose administered $(0.16 \mathrm{mg} / \mathrm{kg} / \mathrm{d})$, designated as the LOAEL, resulted in reduction in offspring viability. This exposure also resulted in reduction in growth, increased kidney weight, and altered kidney histochemistry (Verschuuren et al. 1976b). No effects were observed at a dose of $0.032 \mathrm{mg} / \mathrm{kg} / \mathrm{d}$. The study was considered to represent chronic exposure; therefore, a subchronic-chronic correction factor was not employed. On the basis of the results of Verschuuren et al. $(1976 a-c)$, white-tailed deer, short-tailed shrews, and red fox experiencing exposure greater than or equal to LOAELs are likely to display impaired reproduction.

Both the wild turkey and American woodcock NOAELs and LOAELs are based on a study in which reproductive success was observed among mallard ducks that were fed methyl mercury for three 
generations (Heinz 1979). The study was considered to represent a chronic exposure. The only dose level administered, $0.064 \mathrm{mg} / \mathrm{kg} / \mathrm{d}$, caused hens to lay fewer eggs, lay more eggs outside the nest box, and produce fewer ducklings. This dose level was considered the chronic LOAEL. Because an experimental NOAEL was not established, the chronic NOAEL was estimated by multiplying the chronic LOAEL by a LOAEL-NOAEL uncertainty factor of 0.1 . On the basis of the results of Heinz (1979), wild turkeys, American woodcock, and red-tailed hawk experiencing exposures greater than or equal to LOAELs may display impaired reproduction.

\subsubsection{Methylene chloride}

The NOAEL and LOAEL for the mammalian endpoints was based on a study in which rats were fed methylene chloride for 2 years (National Coffee Association 1982). Rats fed a $5.85 \mathrm{mg} / \mathrm{kg} / \mathrm{d}$ dose level did not experience adverse effects and is considered the chronic NOAEL. Rats consuming 50 $\mathrm{mg} / \mathrm{kg} / \mathrm{d}$ or greater produced histological changes in the liver. This dose level was designated as the chronic LOAEL. On the basis of the results of the National Coffee Association (1982), white-tailed deer experiencing exposures greater than or equal to LOAELs at SCF may display changes in liver histology.

\subsubsection{Nickel}

Both the NOAEL and LOAEL for mammalian endpoints are based on a study in which reproduction was observed in rats fed nickel (nickel sulfate hexahydrate) for three generations (Ambrose et al. 1976). Three dose levels were administered. Although $1000 \mathrm{ppm} \mathrm{Ni}$ in the diet reduced offspring body weights, no adverse effects were observed in the other dose levels. Because this study considers exposures over multiple generations, the $500 \mathrm{ppm}$ dose was considered to be a chronic NOAEL and the $1000 \mathrm{ppm}$ dose was considered to be a chronic LOAEL. On the basis of the results of Ambrose et al. (1976), short-tailed shrew foraging on K-1407 OU and UEFPC OU 2 experiencing exposures greater than or equal to LOAEL may display reduced offspring body weight.

Both the NOAEL and LOAEL for avian species are based on a study in which mortality, growth, and behavior were observed in mallard ducklings fed nickel (nickel sulfate) for 90 days (Cain and Pafford 1981). Three doses were administered. Although consumption of up to $774 \mathrm{ppm}$ nickel in diet did not increase mortality or reduce growth, the $1069 \mathrm{ppm}$ nickel diet reduced growth and resulted in $70 \%$ mortality. Because the study considered exposure over 90 days, the $774 \mathrm{ppm}$ dose was considered to be a chronic NOAEL and the $1069 \mathrm{ppm}$ dose was considered to be a chronic LOAEL. To estimate daily nickel intake throughout the 90 -day study period, food consumption of 45 -day-old ducklings was calculated. Although this value will over- and underestimate food consumption by younger and older ducklings, it was assumed to approximate food consumption throughout the entire 90-day study. On the basis of the results of Cain and Pafford (1981), American woodcock foraging on most OUs experiencing exposures greater than or equal to LOAEL may have impaired growth.

\subsubsection{PCBs}

The mammalian endpoint NOAEL and LOAEL are based on a study in which old field mice were fed Aroclor 1254 for 12 months (McCoy et al. 1995). A dose level of $0.68 \mathrm{mg} / \mathrm{kg} / \mathrm{d}$, designated as the chronic LOAEL, caused a reduction in the number of litters, offspring weights, and offspring survival. Because an experimental NOAEL was not established, the chronic NOAEL was estimated by multiplying the chronic LOAEL by a LOAEL-NOAEL uncertainty factor of 0.1 . On the basis of the results of McCoy et al. (1995), short-tailed shrews and wild turkeys at most OUs, as well as red 
fox at K-1420 OU and LEFPC, experiencing exposures greater than or equal to the LOAEL may display impaired reproduction and offspring viability.

The American woodcock NOAEL and LOAEL are based on a study in which ring-necked pheasants were fed Aroclor 1254 for 17 weeks (Dahlgren et al. 1972). A dose level of $1.8 \mathrm{mg} / \mathrm{kg} / \mathrm{d}$, designated as the chronic LOAEL, caused a significant reduction in egg hatchability. Because an experimental NOAEL was not established, the chronic NOAEL was estimated by multiplying the chronic LOAEL by a LOAEL-NOAEL uncertainty factor of 0.1 . On the basis of the results of Dahlgren et al. (1972), American woodcock experiencing exposures greater than or equal to the LOAEL may display a reduction in egg hatchability.

\subsubsection{Selenium}

Both the NOAEL and LOAEL for mammalian endpoints are based on a study in which reproduction was observed in rats fed selenium $\left(\mathrm{SeO}_{4}\right)$ for 1 year (Rosenfeld and Beath 1954). Three dose levels were administered. Although no adverse effects on reproduction were observed among rats exposed to $1.5 \mathrm{mg} \mathrm{Se} / \mathrm{L}$ in drinking water, the number of second-generation young was reduced by $50 \%$ among females in the $2.5 \mathrm{mg} / \mathrm{L}$ group. In the $7.5 \mathrm{mg} / \mathrm{L}$ group, fertility, juvenile growth and survival were all reduced. Because study considered exposure over multiple generations, the 1.5 and $2.5 \mathrm{mg} / \mathrm{L}$ doses were considered to be chronic NOAEL and LOAEL, respectively. On the basis of the results of Rosenfield and Beath (1954), short-tailed shrews at most OUs, and red fox at K-1407 OU, LEFPC, and WAG 1 experiencing exposures greater than or equal to LOAEL may display long-term reductions in reproductive viability.

The NOAEL and LOAEL for avian endpoints are based on a study in which reproductive success was observed in mallard ducks fed selenium (sodium selenite) for 78 days (Heinz et al. 1987). Five dose levels were administered. Although consumption of 1,5 , or $10 \mathrm{ppm}$ selenium on the diet as Sodium Selenite had no effect on weight or survival of adults, $100 \mathrm{ppm}$ selenium reduced adult survival and $25 \mathrm{ppm}$ selenium reduced duckling survival. Consumption of 10 or $25 \mathrm{ppm}$ selenium in the diet resulted in a significantly larger frequency of lethally deformed embryos as compared with the 1 or 5 ppm selenium exposures. Because $5 \mathrm{ppm}$ selenium in the diet was the highest dose level that produced no adverse effects and the study considered exposure through reproduction, this dose was considered to be a chronic NOAEL. The lowest dose at which adverse effects were observed, $10 \mathrm{ppm}$, was considered to be a chronic LOAEL. On the basis of the results of Heinz et al. (1987), American woodcock foraging at most OUs experiencing exposures greater than or equal to LOAEL may display an increased frequency of deformed embryos.

\subsubsection{Thallium}

The mammalian endpoint NOAEL and LOAEL are based on a study in which rats were fed thallium sulfate for 60 days (Formigli et al. 1986). This study represents subchronic exposures because the duration of the study did not include a critical life stage. Rats exposed to a single dose, $0.074 \mathrm{mg} / \mathrm{kg} / \mathrm{d}$, displayed reduced sperm motility. Because this is a subchronic exposure, a subchronic-chronic uncertainty factor of 0.1 was applied to obtain a chronic LOAEL. To estimate the chronic NOAEL, the chronic LOAEL was multiplied by a LOAEL-NOAEL uncertainty factor of 0.1 . On the basis of the results of Formigli et al. (1986), short-tailed shrews and red fox foraging on WAG 1 experiencing exposures greater than or equal to the LOAEL may display impaired reproduction from a reduction of sperm motility. 


\subsubsection{Uranium}

The short-tailed shrew NOAEL and LOAEL are based on a study in which mice were fed uranyl acetate for 60 days prior to gestation, through gestation, delivery, and lactation (Paternain et al. 1989). This study represents chronic exposures because it took place during the critical life stage of the mouse. Significant effects on reproduction including increased number dead young/litter and reduction in size and weight of offspring were observed at $6.13 \mathrm{mg} / \mathrm{kg} / \mathrm{d}$. The lowest dose administered, $3.07 \mathrm{mg} / \mathrm{kg} / \mathrm{d}$, resulted in no significant differences in measured reproductive parameters. Therefore, these doses were considered the chronic LOAEL and NOAEL, respectively. On the basis of the results of Paternain et al. (1989), short-tailed shrews foraging on K-1407 or K-1420 OUs experiencing exposures greater than or equal to the LOAEL may display a reduction in reproductive success.

\subsubsection{Vanadium}

The short-tailed shrew NOAEL and LOAEL are based on a study in which rats were fed sodium metavanadate for 60 days prior to gestation, through gestation, delivery, and lactation (Domingo et al. 1986). This study represents chronic exposures because it took place during the rat's critical life stage. Significant effects on reproduction including increased number dead young/litter and reduction in size and weight of offspring were observed at the lowest dose administered, $5 \mathrm{mg} / \mathrm{kg} / \mathrm{d}$. Therefore, this dose was considered the chronic LOAEL. To estimate the chronic NOAEL, the chronic LOAEL was multiplied by a LOAEL-NOAEL uncertainty factor of 0.1 . On the basis of the results of Domingo et al. (1986), short-tailed shrews foraging at BC OU 2 or SCF experiencing exposures greaterm than or equal to the LOAEL may display a reduction in reproductive success.

\subsubsection{Zinc}

Both the NOAEL and LOAEL for mammalian endpoints are based on a study in which reproductive success was observed in rats fed zinc oxide for days 1-16 of gestation (Schlicker and Cox 1968). Two dose levels were administered. Rats exposed to $4000 \mathrm{ppm}$ zinc in the diet displayed increased rates of fetal resorption and reduced fetal growth rates. Because no effects were observed at the $2000 \mathrm{ppm}$ zinc dose rate and because the exposure occurred during gestation (a critical lifestage), this dose was considered a chronic NOAEL. The $4000 \mathrm{ppm}$ zinc dose was considered to be a chronic LOAEL. On the basis of the results of Schlicker and Cox (1968), short-tailed shrews foraging on UEFPC OU 2 experiencing exposures greater than or equal to LOAEL may display increased rates of fetal resorption and reduced fetal growth rates.

Both the NOAEL and LOAEL for avian endpoints are based upon a study in which reproductive success was observed for white leghorn hens fed zinc sulfate for 44 weeks (Stahl et al. 1990). Three dose levels were administered. Although no adverse effects were observed among hens consuming 48 and 228 ppm zinc, egg hatchability was $<20 \%$ of controls among hens consuming 2028 ppm zinc. Because the study was greater than 10 weeks in duration and considered exposure during reproduction, the $228 \mathrm{ppm}$ dose was considered a chronic NOAEL, and the $2028 \mathrm{ppm}$ dose was considered a chronic LOAEL. On the basis of the studies of Stahl et al. (1990), American woodcock foraging at most OUs experiencing exposures greater than or equal to the LOAEL may display reduced egg hatchability.

\subsubsection{Population Level Risks on the Oak Ridge Reservation}

The COPECs within each OU, as designated by the screening process (Sect. 5.4.1), may cause adverse effects (Sect. 5.4.2) to individuals foraging within each OU. To consider adverse effects on 
the reservation-wide population, steps 3 through 6 within the problem formulation (Sect. 5.1) must be completed. By comparing an endpoint species habitat requirements (Table B.1), the amount of suitable habitat within each OU (Table B.3), and population densities for each endpoint (see following), the number of individuals exposed on an OU can be estimated. The densities used for each endpoint species are presented in the following table.

\begin{tabular}{|c|c|c|c|c|c|c|}
\hline & $\begin{array}{c}\text { White-tailed } \\
\text { deer }\end{array}$ & Wild turkey & $\begin{array}{l}\text { Short- } \\
\text { tailed } \\
\text { shrew }\end{array}$ & $\begin{array}{l}\text { American } \\
\text { woodcock }\end{array}$ & Red fox & $\begin{array}{l}\text { Red- } \\
\text { tailed } \\
\text { hawk }\end{array}$ \\
\hline Density & $0.1704^{a}$ & $0.0426^{\mathrm{a}}$ & $\begin{array}{l}23 / \mathrm{ha} \\
\text { (median of } \\
2.5 \text { to } 45 / \mathrm{ha} \\
\text { range) }\end{array}$ & $\begin{array}{l}.28 / \text { ha } \\
\text { (based on } 5.6 \\
\text { males } / 100 \text { ha; } \\
\text { assuming } 1: 1 \\
\text { sex ratio) }\end{array}$ & $0.77 / \mathrm{ha}$ & $\begin{array}{l}0.03 \\
\text { pairs/ha }\end{array}$ \\
\hline $\begin{array}{l}\text { No. on the } \\
\text { ORR } \\
\text { (if known) }\end{array}$ & 2000 & $>500$ & & & & \\
\hline Source & $\begin{array}{l}\text { Personal } \\
\text { communication, } \\
\text { Jim Evans }\end{array}$ & $\begin{array}{l}\text { Personal } \\
\text { communication, } \\
\text { Jim Evans }\end{array}$ & Getz 1989 & $\begin{array}{l}\text { Stewart and } \\
\text { Robbins } 1958\end{array}$ & $\begin{array}{l}\text { EPA } \\
1993 b\end{array}$ & $\begin{array}{l}\text { EPA } \\
1993 b\end{array}$ \\
\hline
\end{tabular}

"Density calculated based on total deer and turkey habitat on ORR (11,734.8 ha) and total number of deer and turkey estimated on ORR (2000 deer and 500 turkey).

Because contaminants found on all OUs, except for $\mathrm{K}-1414$, present a risk to all assessment endpoints, the number of animals present in the $O U$ is equivalent to the number of individuals exposed at unacceptable levels. The estimated number of individuals of endpoint species exposed within each OU and the proportion of the reservation-wide population that are at risk are summarized in Tables 5.2 through 5.7 .

Although specific OUs pose unacceptable risks to the individuals, the total number of exposed individuals within the entire ORR population is minimal. Approximately $8.77 \%$ and $8.8 .1 \%$ of the reservation-wide populations of turkey and deer are at risk. Only $8.6 \%$ and $8.95 \%$ of short-tailed shrews and woodcock on the ORR are at risk. Approximately $8.82 \%$ of the red-tailed hawk and $8.71 \%$ of the red fox are at risk on the ORR. Therefore, using the $20 \%$ criterion outlined by Suter et al. (1995), the occurrence of population-level effects on the reservation are highly unlikely. However, because the short-tailed shrew is a measurement endpoint for four species of T\&E shrews, $8.6 \%$ of the impacted population may represent a significant risk to T\&E shrews on the ORR.

BCV OU and LEFPC OU contributed, by far, the highest number of deer, shrews, foxes, woodcock, and turkeys at risk on the ORR (Tables 5.2-5.7). The population of short-tailed shrews in Bear Creek Valley is estimated to be experiencing exposures greater than LOAEL from $\mathrm{Sb}, \mathrm{Cu}, \mathrm{Hg}$, $\mathrm{PCBs}$, and $\mathrm{V}$; foxes are at risk from $\mathrm{Cu}$ and $\mathrm{Hg}$ (Table 5.1). Contaminants contributing to the majority of the risk at LEFPC include $\mathrm{Hg}$, total PCBs, DDT and metabolites, Se, and Al. Other contaminants of concern include $\mathrm{Cd}, \mathrm{Cr}, \mathrm{Cu}, \mathrm{Ni}$, and $\mathrm{Zn}$. WAG 2 is the third highest contributor to risk on the ORR. The short-tailed shrew population in WAG 2 is estimated to be experiencing exposures greater 
Table 5.2. The number of potentially exposed white-tailed deer within each $O U$ and the entire reservation

\begin{tabular}{|c|c|c|c|c|}
\hline OU & Available habitat (ha) & $\begin{array}{c}\text { Total suitable } \\
\text { area (ha) }\end{array}$ & $\begin{array}{c}\text { No. of } \\
\text { animals } \\
\text { present }^{\mathrm{ab}}\end{array}$ & $\begin{array}{l}\% \text { of the } \\
\text { ORR } \\
\text { population } \\
\text { exposed }^{c}\end{array}$ \\
\hline$\overline{B C V}$ OU & $\begin{array}{l}\text { Evergreen plantation(20.94) } \\
\text { Evergreen forest (37.37) } \\
\text { Deciduous forest (192.81) } \\
\text { Mixed forest }(140.56) \\
\text { Pasture (14.62) } \\
\text { Transitional }(246.06)\end{array}$ & 652.36 & 111 & 5.55 \\
\hline LEFPC & $\begin{array}{l}\text { Evergreen plantation (2.62) } \\
\text { Evergreen forest (7.37) } \\
\text { Deciduous forest (41.06) } \\
\text { Mixed forest (50.87) } \\
\text { Pasture (8.5) } \\
\text { Transitional (133.87) }\end{array}$ & 244.29 & 42 & 2.1 \\
\hline WAG 2 & $\begin{array}{l}\text { Evergreen forest (1) } \\
\text { Deciduous forest (15.75) } \\
\text { Mixed forest (29) } \\
\text { Pasture }(0.06) \\
\text { Transitional (14.81) }\end{array}$ & 60.62 & 10 & 0.5 \\
\hline WAG 5 & $\begin{array}{l}\text { Deciduous forest (3.56) } \\
\text { Mixed forest (6.44) } \\
\text { Pasture (7.69) } \\
\text { Transitional (9.06) }\end{array}$ & 26.75 & 5 & 0.25 \\
\hline $\begin{array}{l}\text { South Campus } \\
\text { Facility }\end{array}$ & $\begin{array}{l}\text { Pasture (13.25) } \\
\text { Transitional (4.5) }\end{array}$ & 17.75 & 3 & 0.15 \\
\hline WAG 6 & $\begin{array}{l}\text { Deciduous forest (5.06) } \\
\text { Mixed forest (2.06) } \\
\text { Pasture (0.5) } \\
\text { Transitional (2.94) }\end{array}$ & 10.56 & 2 & 0.10 \\
\hline $\begin{array}{l}\text { Chestnut Ridge } \\
\text { OU2 }\end{array}$ & $\begin{array}{l}\text { Deciduous forest (3.81) } \\
\text { Mixed forest ( } 0.38) \\
\text { Transitional }(2.62)\end{array}$ & 6.81 & 1 & 0.05 \\
\hline WAG 1 & $\begin{array}{l}\text { Evergreen forest }(0.81) \\
\text { Deciduous forest }(1.25) \\
\text { Mixed forest }(0.81) \\
\text { Pasture }(0.94)\end{array}$ & 3.81 & 0.7 & 0.04 \\
\hline $\mathrm{K}-1407$ OU & Transitional (4.19) & 4.19 & 0.7 & 0.04 \\
\hline BC OU2 & Transitional (0.62) & 0.62 & 0.1 & 0.005 \\
\hline UEFPC OU2 & 0 & 0 & 0 & 0.00 \\
\hline $\begin{array}{l}\mathrm{K}-1420 \text { OU } \\
\mathrm{K}-1414 \mathrm{Ou}^{d}\end{array}$ & 0 & 0 & 0 & 0.00 \\
\hline
\end{tabular}


Table 5.2 (continued)

\begin{tabular}{|c|c|c|c|c|}
\hline OU & Available habitat (ha) & $\begin{array}{l}\text { Total suitable } \\
\text { area (ha) }\end{array}$ & $\begin{array}{l}\text { No. of } \\
\text { animals } \\
\text { present } t^{2 b}\end{array}$ & $\begin{array}{l}\% \text { of the ORR } \\
\text { population } \\
\text { exposed }\end{array}$ \\
\hline $\begin{array}{l}\text { Total no. } \\
\text { exposed within } \\
13 \text { OUs }\end{array}$ & & & $62^{b}$ & \\
\hline $\begin{array}{l}\text { Total } \\
\text { reservation }\end{array}$ & $\begin{array}{l}\text { Evergreen plantations } \\
(323.5) \\
\text { Evergreen forest }(704.87) \\
\text { Deciduous forest }(4,028.62) \\
\text { Mixed forest }(3,469) \\
\text { Pasture }(312.44) \\
\text { Transitional }(2,896.19)\end{array}$ & $11,734.8$ & $2000^{e}$ & \\
\hline $\begin{array}{l}\text { Percentage of } \\
\text { the ORR } \\
\text { population at } \\
\text { risk }\end{array}$ & & & & $8.8 \%$ \\
\hline
\end{tabular}

The number of animals present within OU was calculated by multiplying the total area of suitable habitat (ha) by $0.1704 \mathrm{deer} / \mathrm{ha}$ (calculated from 2,000 deer on reservation).

bAll white-tailed deer present on OUs are exposed at contaminant levels > LOAELs, with the exception of animals at WAG 5 and $\mathrm{K}-1414$.

The percentage of the ORR population exposed = (estimated no. of animals present on the OU/the total no. of animals on the reservation) $\times 100$.

${ }^{d}$ Habitat maps are not available for the K-1414 OU.

The approximately 2,000 deer present on the ORR were estimated from deer hunts (personal communication, Jim Evans 1995). 
Table 5.3. The number of potentially exposed wild turkey within each $\mathrm{OU}$ and the entire reservation

\begin{tabular}{|c|c|c|c|c|}
\hline OU & Available habitat (ha) & $\begin{array}{c}\text { Total suitable } \\
\text { area (ha) }\end{array}$ & $\begin{array}{c}\begin{array}{c}\text { No. of } \\
\text { animals } \\
\text { present }^{\mathbf{b}}\end{array} \\
\end{array}$ & $\begin{array}{c}\% \text { of ORR } \\
\text { population }^{\text {exposed }} \\
\end{array}$ \\
\hline BCV OU & $\begin{array}{l}\text { Evergreen plantation (20.9) } \\
\text { Evergreen forest (37.37) } \\
\text { Deciduous forest (192.81) } \\
\text { Mixed forest (140.56) } \\
\text { Pasture (14.62) } \\
\text { Transitional }(246.06)\end{array}$ & 652.32 & 28 & 5.6 \\
\hline LEFPC & $\begin{array}{l}\text { Evergreen plantation (2.62) } \\
\text { Evergreen forest (7.37) } \\
\text { Deciduous forest (41.06) } \\
\text { Mixed forest }(50.87) \\
\text { Pasture (8.5) } \\
\text { Transitional (133.87) }\end{array}$ & 244.29 & 10 & 2.0 \\
\hline WAG 2 & $\begin{array}{l}\text { Evergreen forest (1) } \\
\text { Deciduous forest (15.75) } \\
\text { Mixed forest (29) } \\
\text { Pasture }(0.06) \\
\text { Transitional (14.81) }\end{array}$ & 60.62 & 3 & 0.6 \\
\hline WAG 5 & $\begin{array}{l}\text { Deciduous forest (3.56) } \\
\text { Mixed forest (6.44) } \\
\text { Pasture (7.69) } \\
\text { Transitional }(9.06)\end{array}$ & 26.75 & 1 & 0.2 \\
\hline $\begin{array}{l}\text { South Campus } \\
\text { Facility }\end{array}$ & $\begin{array}{l}\text { Pasture (13.25) } \\
\text { Transitional (4.5) }\end{array}$ & 17.75 & 0.8 & 0.16 \\
\hline WAG 6 & $\begin{array}{l}\text { Deciduous forest (5.06) } \\
\text { Mixed forest }(2.06) \\
\text { Pasture }(0.5) \\
\text { Transitional }(2.94)\end{array}$ & 10.56 & 0.5 & 0.10 \\
\hline $\begin{array}{l}\text { Chestnut Ridge } \\
\text { OU2 }\end{array}$ & $\begin{array}{l}\text { Deciduous forest (3.81) } \\
\text { Mixed forest ( } 0.38) \\
\text { Transitional }(2.62)\end{array}$ & 6.81 & 0.3 & 0.06 \\
\hline $\mathrm{K}-1407 \mathrm{OU}$ & Transitional (4.19) & 4.19 & 0.2 & 0.04 \\
\hline BC OU2 & Transitional (0.62) & 0.62 & 0.03 & 0.006 \\
\hline WAG 1 & $\begin{array}{l}\text { Evergreen forest }(0.81) \\
\text { Deciduous forest }(1.25) \\
\text { Mixed forest }(0.81) \\
\text { Pasture }(0.94)\end{array}$ & 3.81 & 0.2 & 0.00 \\
\hline UEFPC OU2 & 0 & 0 & 0 & 0.00 \\
\hline $\mathrm{K}-1420$ OU & 0 & 0 & 0 & 0.00 \\
\hline
\end{tabular}


Table 5.3 (continued)

\begin{tabular}{|c|c|c|c|c|}
\hline OU & Available habitat (ha) & $\begin{array}{c}\text { Total suitable } \\
\text { area (ha) }\end{array}$ & $\begin{array}{c}\text { No. of } \\
\text { animals } \\
\text { present }^{\text {ab }}\end{array}$ & $\begin{array}{c}\% \text { of ORR } \\
\text { population } \\
\text { exposed }^{\mathrm{C}}\end{array}$ \\
\hline $\begin{array}{l}\text { Total no. exposed } \\
\text { within } 13 \text { OUs }\end{array}$ & & & $15^{b}$ & \\
\hline Total reservation & $\begin{array}{l}\text { Evergreen plantations }(323.5) \\
\text { Evergreen forest }(704.87) \\
\text { Deciduous forest }(4,028.62) \\
\text { Mixed forest }(3,469) \\
\text { Pasture }(312.44) \\
\text { Transitional }(2,896.19)\end{array}$ & $11,734.8$ & $500^{\circ}$ & \\
\hline $\begin{array}{l}\text { Percentage of ORR } \\
\text { population at risk }\end{array}$ & & & & $8.77 \%$ \\
\hline
\end{tabular}

'The number of animals present within the $\mathrm{OU}$ was calculated by multiplying the total area of suitable habitat (ha) by 0.0426 wild turkey/ha (calculated from 500 turkey observed on the reservation).

${ }^{b}$ All wild turkey present on OUs are exposed at contaminant levels $>$ LOAELs, with the exception of animals at WAG 1 , WAG 5, and K-1414.

The percentage of the ORR population exposed $=$ (estimated no. of animals present on the OU/total no. of animals on the reservation) $\times 100$.

${ }^{d}$ Habitat maps are not available for the $\mathrm{K}-1414$ OU.

'Approximately 500 wild turkey are present on the ORR (personal communication, Jim Evans 1995). 
Table 5.4. The number of potentially exposed short-tailed shrews within each OU and the entire reservation

\begin{tabular}{|c|c|c|c|c|}
\hline $\mathbf{O U}$ & Available habitat (ha) & $\begin{array}{c}\text { Total suitable } \\
\text { area (ha) }\end{array}$ & $\begin{array}{c}\text { No. of animals } \\
\text { present }\end{array}$ & $\begin{array}{c}\% \text { of the ORR } \\
\text { population } \\
\text { exposed }\end{array}$ \\
\hline BCV OU & $\begin{array}{l}\text { Evergreen plantation (20.9) } \\
\text { Evergreen forest (37.37) } \\
\text { Deciduous forest (192.81) } \\
\text { Mixed forest (140.56) } \\
\text { Transitional (246.06) }\end{array}$ & 637.7 & 14,667 & 5.58 \\
\hline LEFPC & $\begin{array}{l}\text { Evergreen plantation (2.62) } \\
\text { Evergreen forest (7.37) } \\
\text { Deciduous forest (41.06) } \\
\text { Mixed forest }(50.87) \\
\text { Transitional (133.87) }\end{array}$ & 235.79 & 5,423 & 2.06 \\
\hline WAG 2 & $\begin{array}{l}\text { Evergreen forest (1) } \\
\text { Deciduous forest (15.75) } \\
\text { Mixed forest (29) } \\
\text { Transitional }(14.81)\end{array}$ & 59.85 & 1377 & 0.52 \\
\hline WAG 5 & $\begin{array}{l}\text { Deciduous forest (3.56) } \\
\text { Mixed forest (6.44) } \\
\text { Transitional (9.06) }\end{array}$ & 19.06 & 438 & 0.17 \\
\hline WAG 6 & $\begin{array}{l}\text { Deciduous forest (5.06) } \\
\text { Mixed forest (2.06) } \\
\text { Transitional (2.94) }\end{array}$ & 10.06 & 231 & 0.09 \\
\hline $\begin{array}{l}\text { Chestnut Ridge } \\
\text { OU2 }\end{array}$ & $\begin{array}{l}\text { Deciduous forest (3.81) } \\
\text { Mixed forest (0.38) } \\
\text { Transitional (2.62) }\end{array}$ & 6.81 & 157 & 0.06 \\
\hline $\mathrm{K}-1407$ OU & Transitional (4.19) & 4.19 & 96 & 0.04 \\
\hline $\begin{array}{l}\text { South Campus } \\
\text { Facility }\end{array}$ & Transitional (4.5) & 4.5 & 104 & 0.04 \\
\hline WAG 1 & $\begin{array}{l}\text { Evergreen forest }(0.81) \\
\text { Deciduous forest }(1.25) \\
\text { Mixed forest }(0.81)\end{array}$ & 2.87 & 66 & 0.03 \\
\hline $\mathrm{BC}$ OU2 & Transitional (0.62) & 0.62 & 14 & 0.005 \\
\hline UEFPC OU2 & 0 & 0 & 0 & 0.00 \\
\hline $\mathrm{K}-1420$ OU & 0 & 0 & 0 & 0.00 \\
\hline $\mathrm{K}-1414 \mathrm{OU}^{\mathrm{d}}$ & & & & \\
\hline
\end{tabular}


Table 5.4 (continued)

\begin{tabular}{|c|c|c|c|c|}
\hline $\mathbf{O U}$ & Available habitat (ha) & $\begin{array}{c}\text { Total suitable } \\
\text { area (ha) }\end{array}$ & $\begin{array}{l}\text { No. of animals } \\
\text { present }{ }^{ \pm b}\end{array}$ & $\begin{array}{c}\% \text { of the ORR } \\
\text { population }^{\text {exposed }}\end{array}$ \\
\hline $\begin{array}{l}\text { Total no. } \\
\text { exposed within } \\
13 \text { OUs }\end{array}$ & & & $7,274^{b}$ & \\
\hline $\begin{array}{l}\text { Total } \\
\text { reservation }\end{array}$ & $\begin{array}{l}\text { Evergreen plantations (323.5) } \\
\text { Evergreen forest }(704.87) \\
\text { Deciduous forest }(4,028.62) \\
\text { Mixed forest }(3,469) \\
\text { Transitional }(2,896.19)\end{array}$ & $11,422.36$ & 262,714 & \\
\hline $\begin{array}{l}\text { Percentage of } \\
\text { ORR } \\
\text { population at } \\
\text { Risk }\end{array}$ & & & & $8.6 \%$ \\
\hline
\end{tabular}

'The number of animals present within the $\mathrm{OU}$ was calculated by multiplying the total area of suitable habitat (ha) by 23 short-tailed shrews/ha (Getz 1989, as cited in EPA 1987). K-1414.

${ }^{b}$ All animals present within OUs are exposed at levels exceeding LOAELs, with the exception of animals at

'The percentage of the ORR population exposed = (estimated no. of animals present on the OU/total no. of animals on the reservation) $\times 100$.

${ }^{d} \mathrm{Habitat}$ maps are not available for the $\mathrm{K}-1414$ OU. 
Table 5.5. The number of potentially exposed American woodcock within each OU and the entire reservation

\begin{tabular}{|c|c|c|c|c|}
\hline OU & Available habitat (ha) & $\begin{array}{c}\text { Total } \\
\text { suitable } \\
\text { area (ha) } \\
\end{array}$ & $\begin{array}{c}\text { No. of } \\
\text { animals } \\
\text { present }^{\mathbf{b}}\end{array}$ & $\begin{array}{l}\% \text { of the } \\
\text { ORR } \\
\text { population } \\
\text { exposed }^{c}\end{array}$ \\
\hline BCV OU & $\begin{array}{l}\text { Deciduous forest (192.81) } \\
\text { Mixed forest (140.56) } \\
\text { Pasture (14.62) } \\
\text { Transitional }(246.06)\end{array}$ & 594.05 & 166 & 5.5 \\
\hline LEFPC & $\begin{array}{l}\text { Deciduous forest (41.06) } \\
\text { Mixed forest }(50.87) \\
\text { Pasture (8.5) } \\
\text { Transitional (133.87) }\end{array}$ & 234.3 & 66 & 2.2 \\
\hline WAG 2 & $\begin{array}{l}\text { Deciduous forest (15.75) } \\
\text { Mixed forest (29) } \\
\text { Pasture }(0.06) \\
\text { Transitional }(14.81)\end{array}$ & 59.62 & 17 & 0.57 \\
\hline WAG 5 & $\begin{array}{l}\text { Deciduous forest (3.56) } \\
\text { Mixed forest (6.44) } \\
\text { Pasture (7.69) } \\
\text { Transitional (9.06) }\end{array}$ & 26.75 & 8 & 0.27 \\
\hline $\begin{array}{l}\text { South Campus } \\
\text { Facility }\end{array}$ & $\begin{array}{l}\text { Pasture (13.25) } \\
\text { Transitional (4.5) }\end{array}$ & 17.75 & 5 & 0.17 \\
\hline WAG 6 & $\begin{array}{l}\text { Deciduous forest (5.06) } \\
\text { Mixed forest (2.06) } \\
\text { Pasture (0.5) } \\
\text { Transitional (2.94) }\end{array}$ & 10.56 & 3 & 0.10 \\
\hline $\begin{array}{l}\text { Chestnut Ridge } \\
\text { OU2 }\end{array}$ & $\begin{array}{l}\text { Deciduous forest (3.81) } \\
\text { Mixed forest (0.38) } \\
\text { Transitional (2.62) }\end{array}$ & 6.81 & 2 & 0.07 \\
\hline WAG 1 & $\begin{array}{l}\text { Deciduous forest (1.25) } \\
\text { Mixed forest (0.81) } \\
\text { Pasture (0.94) }\end{array}$ & 3 & 0.8 & 0.03 \\
\hline $\mathrm{K}-1407$ OU & Transitional (4.19) & 4.19 & 1 & 0.03 \\
\hline BC OU2 & Transitional $(0.62)$ & 0.62 & 0.2 & 0.007 \\
\hline UEFPC OU2 & 0 & 0 & 0 & 0.00 \\
\hline $\mathrm{K}-1420$ OU & 0 & 0 & 0 & 0.00 \\
\hline $\mathrm{K}-1414 \mathrm{OU}^{\mathrm{d}}$ & & & & \\
\hline
\end{tabular}


Table 5.5 (continued)

\begin{tabular}{|c|c|c|c|c|}
\hline OU & Available habitat (ha) & $\begin{array}{c}\text { Total } \\
\text { suitable } \\
\text { area (ha) }\end{array}$ & $\begin{array}{c}\begin{array}{c}\text { No. of } \\
\text { animals } \\
\text { present }^{\mathbf{b}}\end{array} \\
\end{array}$ & $\begin{array}{l}\% \text { of the } \\
\text { ORR } \\
\text { population } \\
\text { exposed }\end{array}$ \\
\hline $\begin{array}{l}\text { Total no. } \\
\text { exposed within } \\
13 \text { OUs }\end{array}$ & . & & 98 & \\
\hline $\begin{array}{l}\text { Total } \\
\text { reservation }\end{array}$ & $\begin{array}{l}\text { Deciduous Forest }(4,028.62) \\
\text { Mixed Forest }(3,469) \\
\text { Pasture }(312.44) \\
\text { Transitional }(2,896.19)\end{array}$ & $10,706.25$ & 2,998 & \\
\hline $\begin{array}{l}\text { Percentage of } \\
\text { the ORR } \\
\text { population at } \\
\text { risk }\end{array}$ & & & & $8.95 \%$ \\
\hline
\end{tabular}

The number of animals present within the $\mathrm{OU}$ was calculated by multiplying the total area of suitable habitat (ha) by 0.28 American woodcock/ha (derived from Stewart and Robbins 1958). $\mathrm{K}-1414$

'All woodcock present within OUs are exposed at levels exceeding the LOAEL, with the exception of animals at

The percentage of the ORR population exposed = (estimated no. of animals present on the OU/total no. of animals on the reservation) $\times 100$.

${ }^{d}$ Habitat maps are not available for the K-1414 OU. 
Table 5.6 The number of potentially exposed red-tailed hawk within each oU and the entire reservation

\begin{tabular}{|c|c|c|c|c|}
\hline $\mathbf{O U}$ & Available habitat (ha) & $\begin{array}{c}\text { Total suitable } \\
\text { area (ha) }\end{array}$ & $\begin{array}{c}\text { No. of } \\
\text { animals } \\
\text { present" }\end{array}$ & $\begin{array}{c}\% \text { of the } \\
\text { ORR } \\
\text { population } \\
\text { exposed }^{b}\end{array}$ \\
\hline BCV OU & $\begin{array}{l}\text { Evergreen plantation (20.9) } \\
\text { Evergreen forest (37.37) } \\
\text { Deciduous forest (192.81) } \\
\text { Mixed forest }(140.56) \\
\text { Pasture (14.62) } \\
\text { Transitional }(246.06)\end{array}$ & 652.32 & 39 & 5.5 \\
\hline LEFPC & $\begin{array}{l}\text { Evergreen plantation (2.62) } \\
\text { Evergreen forest (7.37) } \\
\text { Deciduous forest (41.06) } \\
\text { Mixed forest }(50.87) \\
\text { Pasture (8.5) } \\
\text { Transitional (133.87) }\end{array}$ & 244.29 & 15 & 2.1 \\
\hline WAG 2 & $\begin{array}{l}\text { Evergreen forest (1) } \\
\text { Deciduous forest (15.75) } \\
\text { Mixed forest (29) } \\
\text { Pasture (0.06) } \\
\text { Transitional (14.81) }\end{array}$ & 606.2 & 4 & 0.57 \\
\hline WAG 5 & $\begin{array}{l}\text { Deciduous forest (3.56) } \\
\text { Mixed forest (6.44) } \\
\text { Pasture (7.69) } \\
\text { Transitional }(9.06)\end{array}$ & 26.75 & 2 & 0.28 \\
\hline $\begin{array}{l}\text { South Campus } \\
\text { Facility }\end{array}$ & $\begin{array}{l}\text { Pasture (13.25) } \\
\text { Transitional (4.5) }\end{array}$ & 17.75 & 1 & 0.14 \\
\hline WAG 6 & $\begin{array}{l}\text { Deciduous forest (5.06) } \\
\text { Mixed forest (2.06) } \\
\text { Pasture }(0.5) \\
\text { Transitional (2.94) }\end{array}$ & 10.56 & 0.63 & 0.09 \\
\hline $\begin{array}{l}\text { Chestnut Ridge } \\
\text { OU2 }\end{array}$ & $\begin{array}{l}\text { Deciduous forest (3.81) } \\
\text { Mixed forest (0.38) } \\
\text { Transitional (2.62) }\end{array}$ & 6.81 & 0.41 & 0.06 \\
\hline $\mathrm{K}-1407$ OU & Transitional (4.19) & 4.19 & 0.25 & 0.04 \\
\hline WAG 1 & $\begin{array}{l}\text { Evergreen forest }(0.81) \\
\text { Deciduous forest }(1.25) \\
\text { Mixed forest }(0.81) \\
\text { Pasture }(0.94)\end{array}$ & 3.81 & 0.23 & 0.03 \\
\hline BC OU2 & Transitional (0.62) & 0.62 & 0.04 & 0.006 \\
\hline UEFPC OU2 & 0 & 0 & 0 & 0.00 \\
\hline $\mathrm{K}-1420 \mathrm{OU}$ & 0 & 0 & 0 & 0.00 \\
\hline
\end{tabular}




\section{5-31}

Table 5.6 (continued)

\begin{tabular}{|c|c|c|c|c|}
\hline OU & Available habitat (ha) & $\begin{array}{l}\text { Total suitable } \\
\text { area (ha) }\end{array}$ & $\begin{array}{l}\text { No. of } \\
\text { animals } \\
\text { present }\end{array}$ & $\begin{array}{l}\text { \% of the } \\
\text { ORR } \\
\text { population } \\
\text { exposed }\end{array}$ \\
\hline \multicolumn{5}{|l|}{$\mathrm{K}-1414 \mathrm{OU}^{\mathrm{c}}$} \\
\hline $\begin{array}{l}\text { Total no. } \\
\text { exposed within } \\
13 \text { OUs }\end{array}$ & & & 8 & \\
\hline $\begin{array}{l}\text { Total } \\
\text { reservation }\end{array}$ & $\begin{array}{l}\text { Evergreen plantations } \\
(323.5) \\
\text { Evergreen forest }(704.87) \\
\text { Deciduous forest }(4,028.62) \\
\text { Mixed forest }(3,469) \\
\text { Pasture }(312.44) \\
\text { Transitional }(2,896.19)\end{array}$ & $11,734.8$ & 704 & * \\
\hline $\begin{array}{l}\text { Percentage of } \\
\text { the ORR } \\
\text { population at } \\
\text { risk }\end{array}$ & & & & $8.82 \%$ \\
\hline
\end{tabular}

The number of animals present within OU was calculated by multiplying the total area of suitable habitat (ha) by $0.06 \mathrm{red}$ tailed hawks/ha (calculated from 0.03 pairs/ha, EPA 1993).

The percentage of the ORR population exposed = (estimated no. of animals present on the OU/the total no. of animals on the reservation) $\times 100$.

'Habitat maps are not available for the K-1414 OU. 
Table 5.7. The number of potentially exposed red fox within each oU and the entire reservation

\begin{tabular}{|c|c|c|c|c|}
\hline OU & Available habitat (ha) & $\begin{array}{c}\text { Total suitable } \\
\text { area (ha) }\end{array}$ & $\begin{array}{c}\text { No. of } \\
\text { animals } \\
\text { present }\end{array}$ & $\begin{array}{l}\% \text { of the ORR } \\
\text { population } \\
\text { exposed }^{c}\end{array}$ \\
\hline BCV OU & $\begin{array}{l}\text { Evergreen plantation (20.9) } \\
\text { Evergreen forest (37.37) } \\
\text { Deciduous forest }(192.81) \\
\text { Mixed forest }(140.56) \\
\text { Pasture }(14.62) \\
\text { Transitional }(246.06)\end{array}$ & 652.32 & 50 & 5.5 \\
\hline LEFPC & $\begin{array}{l}\text { Evergreen plantation (2.62) } \\
\text { Evergreen forest (7.37) } \\
\text { Deciduous forest (41.06) } \\
\text { Mixed forest }(50.87) \\
\text { Pasture (8.5) } \\
\text { Transitional (133.87) }\end{array}$ & 244.29 & 19 & 2.1 \\
\hline WAG 2 & $\begin{array}{l}\text { Evergreen forest }(1) \\
\text { Deciduous forest (15.75) } \\
\text { Mixed forest (29) } \\
\text { Pasture }(0.06) \\
\text { Transitional (14.81) }\end{array}$ & 60.62 & 5 & 0.55 \\
\hline WAG 5 & $\begin{array}{l}\text { Deciduous forest (3.56) } \\
\text { Mixed forest (6.44) } \\
\text { Pasture (7.69) } \\
\text { Transitional (9.06) }\end{array}$ & 26.75 & 2 & 0.22 \\
\hline $\begin{array}{l}\text { South Campus } \\
\text { Facility }\end{array}$ & $\begin{array}{l}\text { Pasture (13.25) } \\
\text { Transitional (4.5) }\end{array}$ & 17.75 & 1 & 0.11 \\
\hline WAG 6 & $\begin{array}{l}\text { Deciduous forest (5.06) } \\
\text { Mixed forest (2.06) } \\
\text { Pasture (0.5) } \\
\text { Transitional (2.94) }\end{array}$ & 10.56 & 0.81 & 0.09 \\
\hline $\begin{array}{l}\text { Chestnut Ridge } \\
\text { OU2 }\end{array}$ & $\begin{array}{l}\text { Deciduous forest (3.81) } \\
\text { Mixed forest (0.38) } \\
\text { Transitional (2.62) }\end{array}$ & 6.81 & 0.52 & 0.05 \\
\hline $\mathrm{K}-1407$ OU & Transitional (4.19) & 4.19 & 0.32 & 0.04 \\
\hline WAG 1 & $\begin{array}{l}\text { Evergreen forest }(0.81) \\
\text { Deciduous forest }(1.25) \\
\text { Mixed forest }(0.81) \\
\text { Pasture }(0.94)\end{array}$ & 3.81 & 0.29 & 0.03 \\
\hline $\mathrm{BC}$ OU2 & Transitional (0.62) & 0.62 & 0.05 & 0.006 \\
\hline UEFPC OU2 & 0 & 0 & 0 & 0.00 \\
\hline $\mathrm{K}-1420$ OU & 0 & 0 & 0 & 0.00 \\
\hline
\end{tabular}


Table 5.7 (continued)

\begin{tabular}{|c|c|c|c|c|}
\hline OU & Available habitat (ha) & $\begin{array}{l}\text { Total suitable } \\
\text { area (ha) }\end{array}$ & $\begin{array}{l}\text { No. of } \\
\text { animals } \\
\text { present }^{\text {tb }}\end{array}$ & $\begin{array}{l}\% \text { of the } O R R \\
\text { population } \\
\text { exposed }\end{array}$ \\
\hline \multicolumn{5}{|l|}{$\mathrm{K}-1414 \mathrm{OU}^{\mathrm{d}}$} \\
\hline $\begin{array}{l}\text { Total no. } \\
\text { exposed within } \\
13 \text { OUs }\end{array}$ & & & $79^{b}$ & \\
\hline $\begin{array}{l}\text { Total } \\
\text { reservation }\end{array}$ & $\begin{array}{l}\text { Evergreen plantations } \\
(323.5) \\
\text { Evergreen forest }(704.87) \\
\text { Deciduous forest }(4,028.62) \\
\text { Mixed forest }(3,469) \\
\text { Pasture }(312.44) \\
\text { Transitional }(2,896.19)\end{array}$ & $11,734.8$ & 904 & \\
\hline $\begin{array}{l}\text { Percentage of } \\
\text { the ORR } \\
\text { population at } \\
\text { risk }\end{array}$ & & & & $8.71 \%$ \\
\hline
\end{tabular}

The number of animals present within OU was calculated by multiplying the total area of suitable habitat (ha) by 0.077 foxes/ha (EPA 1993).

'All red fox present on OUs are exposed at contaminant levels > LOAELs, with the exception of animals at WAG 5 and $\mathrm{K}-1414$.

The percentage of theORR population exposed = (estimated no. of animals present on the OU/the total no. of animals on the reservation) $\times 100$.

${ }^{\mathrm{d}}$ Habitat maps are not available for the K-1414 OU. 
than LOAEL from Aroclor 1260, Cd, Cr, Hg, and Se (Efroymson et al. 1996). WAG 5, the fourth ranked contributor, only poses a risk to the short-tailed shrew and woodcock populations from $\mathrm{Cr}, \mathrm{Hg}$, and $\mathrm{Zn}$ exposure.

\subsubsection{Quality and Completeness of Data}

Although the data used in this portion of the assessment were generally considered to be of high quality, spatial coverage of the ORR was incomplete. Soil data were available for only 12 of 37 OUs on the ORR. Consequently, the magnitude of risk to reservation-wide populations is underestimated. The actual magnitude cannot be determined without incorporating data from additional OUs.

Another limitation, discussed in Chap. 4, concerns the level of detail in the ORR habitat map. There is a need for the habitat maps to identify specific characteristics of the habitat categories. For example, identification of floodplain forests, dense forests, etc. is necessary to better determine suitable habitat for many endpoint species. Furthermore, a better estimate of the number of individuals of each endpoint species within each OU may be predicted.

Additionally, the lack of site specific vegetation and earthworm concentrations on many OUs result in the use of average calculated soil-plant or soil-earthworm uptake factors. The uptake factors have a high degree of uncertainty associated with them and may over or underestimate the risk to herbivorous or vermivorous wildlife.

\subsubsection{Uncertainties Concerning Risks to Herbivorous, Vermivorous, and Predatory Wildlife}

\subsubsection{Limitations of habitat maps}

The level of precision differs between the habitat maps and the habitat requirements data. For example, habitat type such as open forest, dense forest, or floodplain forest cannot be identified. More detailed information is necessary because the actual habitat that is used may be only portions of the habitat categories (e.g., woodcock prefer moist floodplain soils in forested areas). This may overestimate or underestimate the number of individuals present within an OU.

\subsubsection{Soil to vegetation and earthworm uptake factors}

There is a large degree of uncertainty when using soil to vegetation and earthworm uptake factors to model contaminant concentrations found in vegetation and earthworms. Uptake factors of inorganics will vary by soil condition (e.g., $\mathrm{pH}$, water availability, organic matter content, texture, aeration, elemental concentrations) and plant/earthworm conditions (species and age) (Sommers et al. 1987; Chaney et al. 1984). The use of plant uptake factors assumes that all species and all soil conditions will result in the same uptake rate. Also, the use of uptake factors assumes that the uptake rate is best estimated by taking the average of all observed values. These site specific factors within the OUs are not taken into consideration for the uptake factors that were used. Therefore, the predicted contaminant concentrations in vegetation and earthworms may be overestimated or underestimated; thus overestimating or underestimating contaminant exposure for each endpoint species. 


\subsubsection{Relative quality of habitats}

It was assumed that the quality of habitat found within each land cover type was equivalent. Although specific landcover types were designated as providing suitable habitat, the usability of the areas will vary and certain habitat types may be used preferentially. This will either overestimate or underestimate the number of animals found within each OU based on the lower or higher quality of certain habitat types.

\subsubsection{Distribution of contamination within habitats on operable units}

It was assumed that contamination was equally distributed throughout the OU. Therefore, all available habitat that is used by the specific endpoint was assumed to be equally contaminated throughout the entire OU. Because most contamination is likely to be in less suitable habitats (urban areas, lawns, etc.), on-OU contaminant exposure is likely to be overestimated.

\subsubsection{Literature density values}

The use of literature density values of endpoint species, with the exception of deer and turkey, obtained from other areas of the United States, are considered representative of the ORR. This may overestimate or underestimate the number of exposed individuals.

\subsubsection{Bioavailability of contaminants}

It was assumed that $100 \%$ of the contaminant concentrations reported in soil and modeled vegetation and earthworms were bioavailable. The double acid extraction method used to determine soil concentrations reflect the total potential pool of contaminants. The future bioavailability of these contaminants, which is dependent upon the chemical (e.g., pH, organic carbon) and physical (e.g., clay, moisture content) nature of the soil, cannot be addressed for this assessment. Therefore, exposure estimates based on the contaminant concentrations in media are highly conservative and are likely to overestimate the actual contaminant exposure experienced.

\subsubsection{Extrapolation from published toxicity data}

To estimate toxicity of contaminants at the site, it was necessary to extrapolate from NOAELs observed for test species (i.e., rats, mice). Although it was assumed that toxicity could be estimated as a function of body size, the accuracy of the estimate is not known. For example, white-tailed deer may be more or less sensitive than rats or mice.

Additional extrapolation uncertainty exists for those contaminants for which data consisted of either LOAELs or was subchronic in duration. For either case, an uncertainty factor of 10 was employed to estimate NOAELs or chronic data. The uncertainty factor of 10 may either over- or underestimate the actual LOAEL-NOAEL or subchronic-chronic relationship.

\subsubsection{Variable food and water consumption}

Although food consumption by wildlife was assumed to be similar to that reported for the same species in other locations, the validity of this assumption cannot be determined. Food consumption at the Clinch River and Poplar Creek may be greater or less than that reported in the literature, resulting in either an increase or decrease in contaminant exposure. Similarly, water consumption was 


\section{$5-36$}

estimated according to the allometric equations of Calder and Braun (1983). The accuracy with which the estimated water consumption represents actual water consumption is unknown.

\subsubsection{Single contaminant tests vs exposure to multiple contaminants in the field}

Although plants and mammals are exposed to multiple contaminants concurrently, published toxicological values only consider effects experienced by exposures to single contaminants. Because some contaminants can interact antagonistically, single contaminant studies may overestimate their toxic potential. Similarly, for those contaminants that interact additively or synergistically, single contaminant studies may underestimate their toxic potential.

\subsubsection{Inorganic constituents or species present in the environment}

Toxicity of metal species varies dramatically depending upon the valence state or form (organic or inorganic) of the metal. For example, arsenic (III) and methyl mercury are more toxic than arsenic (V) and inorganic mercury, respectively. The available data on the contaminant concentrations in media do not report which species or form of contaminant was observed. Because benchmarks used for comparison represented the more toxic species/forms of the metals (particularly for arsenic and mercury), if the less toxic species/form of the metal was actually present in modeled vegetation or sediment from the Clinch River or Poplar Creek, potential toxicity at the sites may be overestimated. 


\section{CONCLUSIONS}

Based upon a preliminary evaluation of the currently available data, the following conclusions may be made concerning risks to selected wide-ranging wildlife species on the ORR:

- The largest OUs on the ORR generally have the most diverse habitat and consequently can support the greatest number of potential endpoint species (Chap. 3).

- Species that can use urban habitats or that have broad habitat requirements have the highest potential to experience exposure because of the large numbers of OUs that provide suitable habitat (Chap. 3).

- Mercury presents a hazard to mink in East Fork Poplar Creek and consequently to a significant portion (30\%) of the ORR-wide mink population. Risks to mink from PCBs are not significant (Chap. 4).

- Evaluation of the potential risks to a future ORR-wide population of otter indicates that mercury presents a risk in all watersheds on the ORR. Because the river otter is a state threatened species, effects to any individual is significant. Therefore, the weight of evidence suggests that mercury is significant risk to individual river otter that may occupy the ORR in the future (Chap. 4)

- Comparison of exposure estimates to LOAELs indicates a significant risk from mercury in all watersheds except White Oak Creek. This translates into a risk to $81.5 \%$ of the ORR-wide kingfisher population. The limited biomonitoring data indicate that kingfisher on the ORR (particularly in the White Oak Creek area) are accumulating mercury to potentially nephrotoxicty levels. The weight of evidence suggests mercury in all watersheds presents a significant risk to the ORR-wide belted kingfisher population. Risks from PCBs are not significant (Chap. 4).

- Although mercury in fish is estimated to represent a significant risk to great blue heron within the EFPC watershed and, consequently, to an estimated $37 \%$ of the heron population on the ORR, studies on two of five colonies adjacent to the ORR indicate that reproduction at these locations is not impaired. Contaminant bioaccumulation and reproductive success are unknown at the three additional colonies adjacent to the ORR. Additionally, the primary foraging locations for herons at the two studied colonies is unknown. Because herons can travel long distances in search of food $(>15 \mathrm{~km})$, they are likely to forage at off-site as well as on-site locations, reducing both the exposure they receive and the risk they experience. If birds from the unstudied colonies forage more extensively on the ORR, they may experience greater risk. Because of the high risk estimated for mercury exposure on the ORR, the lack of data for three of five heron colonies adjacent to the ORR, and uncertainty as to where birds from the five ORR colonies forage, a conclusion concerning whether or not great blue heron on the ORR are at risk cannot be made (Chap. 4).

- Comparison of exposure estimates to LOAELs for osprey indicates no significant risk from mercury or PCBs in any area on the ORR that provides suitable habitat (i.e., White Oak Lake and embayment and the K-25 Site area). Biomonitoring data indicates that the reproductive success at osprey nests adjacent to the ORR, along Melton Hill Lake and in Poplar Creek, is greater than the average observed in the United States. The weight of evidence suggests mercury and PCB do not present significant risks to osprey on or near the ORR (Chap. 4). 
- On the basis of a habitat-based evaluation of risk, although significant risks exist to individuals of selected herbivore, vermivore, and predator endpoint species resident on OUs, the reservationwide populations of these endpoints are unlikely to be significantly affected ( $<20 \%$ of the ORR population is affected). This conclusion must be viewed with caution, however, because data were evaluated for only 13 of 37 OUs. Inclusion of additional OUs is likely to increase the proportion of the ORR populations exposed and at risk. (Chap. 5). 


\section{RECOMMENDED REVISION SCHEDULE}

This assessment is based on only a small portion of the data available on the ORR. To accurately evaluate the nature and magnitude of risks on the ORR, all available data should be incorporated and considered. This report should be revised and updated annually until all existing data have been incorporated. Following this, revisions should be produced on a 5-year schedule to incorporate new data that become available. 


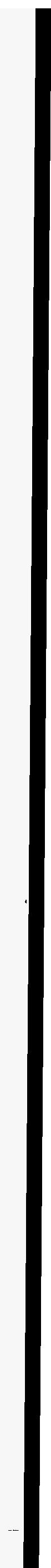




\section{REFERENCES}

Abiola, F. A. 1992. "Ecotoxicity of Organochloride Insecticides: Effects of Endosulfan on Birds" Reproduction and Evaluation of Its Induction Effects in Partridge, Perdix perdix L." Rev. Vet. Med. 143, pp. 443-450.

Ables, E.D. 1969. Home range studies of red foxes (Vulpes vulpes). J. Mamm. 50: 108-120.

ACGIH (American Conference of Governmental Industrial Hygienists). 1986. "Copper," in Documentation of the Threshold Limit Values and Biological Exposure Indices, 5th Ed. ACGIH, Cincinnati, Ohio, p. 146.

Alexander, G. R. 1977. "Food of Vertebrate Predators on Trout Waters in North Central Lower Michigan." Mich. Acad. 10, pp. 181-195.

Allen, J. G., et al. 1983. "Zinc Toxicity in Ruminants." J. Comp. Pathol. 93, pp. 363-377 (as cited in ATSDR 1989, Eisler 1993).

Alumot, E. (Olomucki), E. Nachtomi, E. Mandel, and P. Holstein. 1976a. "Tolerance and acceptable daily intake of chlorinated fumigants in the rat diet." Fd. Cosmet. Toxicol. 14: 105-110.

Alumot, E., M. Meidler, and P. Holstein. 1976. "Tolerance and Acceptable Daily Intake of Ethylene Dichloride in the Chicken Diet." Fd. Cosmet. Toxicol. 14, pp. 111-114.

Ambrose, A.M., P.S. Larson, J.R. Borzelleca and G.R. Hennigar, Jr. 1976. Long term toxicologic assessment of nickel in rats and dogs. J. Food. Sci. Technol. 13: 181-187.

Amur, M., J. McCarthy, M. Gill. 1982. "Respiratory Response of Guinea Pigs to Zinc Oxide Fume." Am. Ind. Hyg. Assoc. J. 43, pp. 887-889.

Anders, E. D., et al. 1982. "Morphological, Phamacokinetic, and Hematological Studies of Lead Exposed Pigeons.” Environ. Res. 28, pp. 344-363.

Andersen, D.E. and O.J. Rongstad. 1989. Home-range estimates of Red-tailed hawks based on random and systematic relocations. J. Wildl. Manage. 53: 802-807.

Anderson, D. W., et al. 1975. "Brown Pelicans: Improved Reproduction off the Southern California Coast." Science 190, pp. 806-808.

Anderson, D.W., R.W. Risebrough, L.A. Woods, Jr., L.R. DeWeese, and W.G. Edgecomb. 1975. "Brown pelicans: improved reproduction off the southern California coast." Science 190: 806-808.

Arnold, T. W., and E. K. Fritzell. 1987. "Food Habits of Prairie Mink During the Waterfowl Breeding Season." Can. J. Zool. 65, pp. 2322-2234.

Arthur, E., I. Motzok, and H. D. Branion. 1958. "Interaction of Dietary Copper and Molybdenum in Rations Fed to Poultry." Poult. Sci. 37, pp. 1181. 
Ashwood,T.L. et al. 1994. Eighth annual report on the ORNL Biological Monitoring and Abatement Program. Oak Ridge National Laboratory, Oak Ridge, TN. ORNL/TM-12767.

Ashwood, T. L. , C. R. Olsen, L. L Larsen, and D.D. Lowry, 1986. Sediment contamination in streams surrounding the Oak Ridge Gaseous Diffusion Plant. Environmental Sciences Division Pub. 2597, ORNL/TM-9791.

ATSDR (Agency for Toxic Substances and Disease Registry). 1988. Toxicological Profile for Nickel. ATSDR/U.S. Public Health Service, ATSDR/TP-88/19.

ATSDR (Agency for Toxic Substances and Disease Registry). 1989a. Toxicological Profile for Selected PCBs (Aroclor-1260, -1254, -1248, -1242, -1232, -1221, and -1016). ATSDR/TP-88/21, Syracuse Research Corporation for ATSDR, U.S. Public Health Service.

ATSDR (Agency for Toxic Substances and Disease Registry). 1989b. Toxicological Profile for Zinc. ATSDR/TP-89-25, Agency for Toxic Substances and Disease Registry, U.S. Public Health Service, Atlanta, Georgia.

ATSDR (Agency for Toxic Substances and Disease Registry). 1990. Toxicological Profile for Copper. ATSDR/TP-90-08, prepared by Syracuse Research Corporation for ATSDR, U.S. Public Health Service under Contract 88-0608-2.

ATSDR (Agency for Toxic Substances and Disease Registry). 1993. "Toxicological profile for 4,4'DDT, 4,4'-DDE, and 4,4'-DDD)." ATSDR/TP-92/53.

Aughey, E., L. Grant, B. L. Furman, and W. F. Dryden. 1977. "The Effects of Oral Zinc Supplementation in the Mouse." J. Comp. Pathol. 87, pp. 1-14.

Aulerich, R. J., and R. K. Ringer. 1977. "Current Status of PCB Toxicity to Mink, and Effect on Their Reproduction." Arch. Environ. Contam. Toxicol. 6, pp. 279-292.

Aulerich, R. J. and R. K. Ringer, 1979. Toxic effects of dietary polybrominated biphenyls on mink. Arch. Environ. Contam. Toxicol. 8:487-498.

Aulerich, R. J., R. K. Ringer, H. L. Seagran, and W. G. Youatt, 1971. Effects of feeding Coho salmon and other Great Lakes fish on mink reproduction. Canad. J. Zool. 49:611-616.

Aulerich, R. J., R. K. Ringer, and S. Iwamoto, 1973. Reproduetive failure and mortality in mink fed on Great Lakes fish. J. Reprod, Fertil. Suppl. 19:365-376.

Aulerich, R. J., R. K. Ringer, and S. Iwamoto, 1974. Effects of dietary mercury on mink. Arch. Environ. Contam. Toxicol. 2:43-51.

Aulerich, R. J., R. K. Ringer, M. R. Bleavins, and A. Napolitano. 1982. "Effects of Supplemental Dietary Copper on Growth, Reproductive Performance and Kit Survival of Standard Dark Mink and the Acute Toxicity of Copper to Mink." J. Animal Sci. 55, pp. 337-343 (as ciited in ATSDR 1990).

Aulerich, R.J., A.C. Napolitano, S.J. Bursian, B.A. Olson, and J.R. Hochstein. 1987. "Chronic toxicity of dietary fluorine in mink." J. Anim. Sci. 65: 1759-1767. 
Azar, A., H. J. Trochimowicz, and M. E. Maxwell. 1973. "Review of Lead Studies in Animals Carried out at Haskell Laboratory: Two-year Feeding Study and Response to Hemorrhage Study," in Environmental Health Aspects of Lead: Proceedings, International Symposium, D. Barth et al., eds. Commission of European Communities, pp. 199-210.

Baron, L. A., T. L. Ashwood, B.E. Sample, and C. Welsh. 1996. Monitoring bioaccumulation of contaminants in the belted kingfisher (Ceryle alcyon). Environmental Monitoring and Assessment. In Review.

Bean, J. R., and R. H. Hudson. 1976. "Acute Oral Toxicity and Tissue Residues of Thallium Sulfate in Golden Eagles, Aquila chrysaetos." Bull. Environ. Contam. Toxicol. 15, pp. 118-121.

Bent, A. C. 1940. Life Histories of North American Cuckoos, Goat Suckers, Hummingbirds, and Their Allies. U.S. Government Printing Office, Washington, D.C. Smithsonian Inst. U.S. Nat. Mus., Bull. 176.

Berlin, M. 1979. "Mercury" in Handbook on the Toxicology of Metals, L. Fribourg, ed. Elsevier Press, New York, pp. 503-530.

Bevelheimer, M.S., B.E. Sample, G.R. Southworth, J.J. Beauchamp, and M.J. Peterson. 1996. Estimation of whole-fish contaminant concentrations from fish fillet data. ES/ER/TM-???. Oak Ridge National Laboratory, Oak Ridge, TN

Beyer, W.N., E. Conner, and S. Gerould. 1994. "Survey of soil ingestion by wildlife." J. Wildl. Mgmt. 58: 375-382.

Blamberg, D. L., U. B. Blackwood, W. C. Supplee, and G. F. Combs. 1960. "Effect of Zinc Deficiency in Hens on Hatchability and Embryonic Development" in Proc. Soc. Exp. Biol. Med. 104, pp. 217-220.

Bleavins, M. R., R. J. Aulerich, and R. K. Ringer. 1980. "Polychlorinated Biphenyls (Aroclors 1016 and 1242): Effects on Survival and Reproduction in Mink and Ferrets." Arch. Environ. Contam. Toxicol. 9(5), pp. 627-635.

Bleavins, M. R., and R. J. Aulerich. 1981. "Feed Consumption and Food Passage Time in Mink (Mustela vison) and European Ferrets (Mustela putorius furo)." Lab. Anim. Sci. 31, pp. 268-269.

Bleavins, M. R., R. J. Aulerich, and R. K. Ringer. 1984. "Effects of Chronic Dietary Hexachlorobenzene Exposure on the Reproductive Performance and Survivability of Mink and European Ferrets." Arch. Environ. Contam. Toxicol. 13, pp. 357-365.

Borzelleca, J. F., L. W. Condie, Jr., and J. L. Egle, Jr. 1988. "Short-term Toxicity (One-and Ten-day Gavage) of Barium Chloride in Male and Female Rats." J. American College of Toxicology 7, pp. 675-685.

Boyden, R., V. R. Potter, and C. A. Elvehjem. 1938. "Effect of Feeding High Levels of Copper to Albino Rats." J. Nutr. 15(4), pp. 397-402.

Branica, M., and Z. Konrad, eds. 1980. Lead in the Marine Environment. Pergamon Press, Oxford, England. 
Braune, B.M., and R.J. Norstrom. 1989. "Dynamics of organochlorine compounds in herring gulls: III Tissue distribution and bioaccumulation in Lake Ontario gulls." Environ. Toxicol. Chem. 8: 957-968.

Brink, M. F., D. E. Becker, S. W. Terril., and A. H. Jensen. 1959. "Zinc Toxicity in the Weanling Pig." J. Anim. Sci. 18, pp. 836-842.

Brooks, R. P, and W. J. Davis. 1987. "Habitat Selection by Breeding Belted Kingfishers (Ceryle alcyon)." Am. Midl. Nat. 117, pp. 63-70.

Brown, L. and D. Amadon. 1968. Eagles, hawks, and falcons of the world: v. 1. New York, NY: McGraw-Hill.

Buben, J.A. and E.J. O'Flaherty. 1985. "Delineation of the role of metabolism in the hepatotoxicity of trichloroethylene and perchloroethylene: a dose-effect study." Toxicol. Appl. Pharmacol. 78: 105-122.

Burgess, S. A., and J. R. Bider. 1980. "Effects of Stream Habitat Improvements on Invertebrates, Trout Populations, and Mink Activity." J. Wildl. Manage. 44, pp. 871-880.

Burkart, W. 1991. Uranium, thorium, and decay products. In: Merian, E., Ed. Metals and their compounds in the environment: Occurrence, analysis, and biological relevance. VCH, Weinheim, Germany. pp. 1275-1287.

Burt, W.H. and R.P. Grossenheider. 1976. A field guide to the mammals of America north of Mexico. Third Edition. Houghton Mifflin Co., Boston

Cain, B.W., and E.A. Pafford. 1981. Effects of dietary nickel on survival and growth of mallard ducklings. Arch. Environ. Contam. Toxicol. 10:737-745.

Cain, B.W., L. Sileo, J. C. Franson, and J. Moore. 1983. "Effects of Dietary Cadmium on Mallard Ducklings." Environ. Res. 32, pp. 286-297.

Calabrese, E. J., R J Aulerich, and G. A. Padgett. 1992. Mink as a predictive model in toxicology. Drug Metab. Rev.

Calder, W. A. and E. J. Braun. 1983. "Scaling of osmotic regulation in mammals and birds." Am. J. Physiol. 224, pp. R601-R606.

Callazo, J. A. 1985. "Food Habits of Nesting Great Blue Herons at Heyburn State Park, Idaho." Northwest Science 59, pp. 144-146.

Campbell, P.G.C., and P.M. Stokes. 1985. “Acidification and Toxicity of Metals to Aquatic Biota." Can. J. Fish. Aquatic Sci. 42, pp. 2034-2049.

Carriere, D., K. Fischer, D. Peakall, and P. Angehrn. 1986. "Effects of Dietary Aluminum in Combination with Reduced Calcium and Phosphorus on the Ring Dove (Streptopelia risoria)." Water, Air, and Soil Poll. 30, pp. 757-764. 
Chakravarty, S., and P. Lahiri. 1986. "Effect of Lindane on Eggshell Characteristics and Calcium Level in the Domestic Duck." Toxicology 42, pp. 245-258.

Chaney, L. R, S. B. Sterret, and H. W. Mielke. 1984. "The Potential for Heavy Metal Exposure from Urban Gardens and Soils," in Proceedings of the Symposium on Heavy Metals in Urban Gardens. University of the District of Columbia Extension Service, Washington, D.C.

Chen, P.S., R. Terepka, and H.C. Hodge. 1961. The pharmacology and toxicology of the bone seekers. Annu. Rev. Pharmacol. 1:369-393.

Clark, D. R. 1979. "Lead Concentrations: Bats Vs. Terrestrial Mammals Collected Near a Major Highway." Environ. Sci. Technol. 3, pp. 338-341.

Clark, D. R., Jr., P. A. Ogasawara, G. J. Smith, and H. M. Ohlendorf. 1989. "Selenium Accumulation by Raccoons Exposed to Irrigation Drain Water at Kesterson National Wildlife Refuge, California, 1986." Arch. Environ. Contam. Toxicol. 18, pp. 787-794.

Conant, R. 1986. A Field Guide to the Reptiles and Amphibians of Eastern and Central North America. Houghton Mifflin Co., Boston.

Craighead, J.J., and F.C. Craighead. 1969, "Hawks, owls, and wildlife". Dover Publ. Co. New York. $443 \mathrm{pp}$.

Crum, J. A., et al. 1993. "The Reproductive Effects of Dietary Heptachlor in Mink (Mustela Vison)." Arch. Environ. Contam. Toxicol. 24, pp. 156-164.

Custer, T. W., and G. H. Heinz. 1980. "Reproductive Success and Nest Attentiveness of Mallard Ducks Fed Aroclor 1254." Environmental Pollution (Series A) 21, pp. 313-318.

Dahlgren, R. B., R. L. Linder, and C. W. Carlson. 1972. "Polychlorinated Biphenyls: Their Effects on Penned Pheasants." Environmental Health Perspectives 1, pp. 89-101.

Davis, W. J. 1982. "Territory Size in Megaceryle alcyon Along a Stream Habitat." The Auk. 99, pp. 353-362.

Davis, A., R. Barale, G. Brun, et al. 1987. "Evaluation of the genetic and embryotoxic effects of bis(tri-n-butyltin)oxide (TBTO), a broad-spectrum pesticide, in multiple in vivo and in vitro short-term tests." Muta. Res. 188: 65-95.

DeGraaf, R.M., G.M. Witman, J.W. Lanier, B.J. Hill, and J.M. Keniston. 1981. Forest habitat for birds of the northeast. U.S.D.A. Forest Service. Northeast Forest Experiment Station and Eastern Region. 598 pp.

DeGraaf, R. M., and D. D. Rudis. 1986. New England Wildlife: Habitat, Natural History, and Distribution. General Technical Report NE-108, U.S.D.A. Forest Service, Northeastern Forest Experiment Station.

Dikshith, T. S. S., R. B. Raizada, M. K. Srivastava, and B. S. Kaphalia. 1984. "Response of Rats to Repeated Oral Administration of Endosulfan.” Ind. Health 22, pp. 295-304. 
Domingo, J.L., J.M. Llobet and J. Corbella. 1985. Protection of mice against the lethaleffects of sodium metavanadate: a quantitative comparison of a number of chelating agents. Toxicol. Lett. 26: 95-99.

Domingo, J. L., J. L. Paternain, J. M. Llobet, and J. Corbella. 1986. "Effects of Vanadium on Reproduction, Gestation, Parturition and Lactation in Rats upon Oral Administration." Life Sci. 39, pp. 819-824.

Domingo, J. L., J. L. Paternain, J. M. Llobet, and J. Corbella. 1987. "The Effects of Aluminum Ingestion on Reproduction and Survival in Rats." Life Sci. 41, pp. 1127-1131.

Dounce, A. L. 1951. The mechanism of action of Uranium compounds in the animal body. Pages 951-991 in C. Voegtlin and H. C. Hodge, eds. The Pharmacology and Toxicology of Uranium Compounds. National Nuclear Energy Series, Div. IV, Vol. 1 and Div. VI, Vol. 1. McGraw-Hill Book Co., Inc., New York.

Dounce, A. L., E. Roberts, and J. H. Wills. 1951. Catalasuria as a sensitive test for Uranium poisoning. Pages 889-950 in C. Voegtlin and H. C. Hodge, eds. The Pharmacology and Toxicology of Uranium Compounds. National Nuclear Energy Series, Div. IV, Vol. 1 and Div. VI, Vol. 1. McGraw-Hill Book Co., Inc., New York.

Dowdy, S., and S. Wearden. 1983. Statistics for Research. John Wiley and Sons, New York.

Drinker, K. R., P. K. Thompson, and M. Marsh. 1927. "An Investigation of the Effect of Long Continued Ingestion of Zinc, in the Form of Zinc Oxide, by Cats and Dogs, Together with Observations upon the Excretion and Storage of Zinc." Am. J. Physiol. 80, pp. 31-64.

Drinker, K., and P. Drinker. 1928. "Metal Fume Fever: V. Results of the Inhalation by Animals of Zinc and Magnesium Oxide Fumes." J. Ind. Hyg. 10, pp. 56-70.

Dunning, J. B. 1984. Body Weights of 686 Species of North American Birds. Western Bird Banding Association Monograph 1. Eldon Publishing Co., Cave Creek, Arizona.

Dunstone, N. 1993. The mink. T\&AD Poyser, London. 232pp.

Durbin, P. W., and M. E. Wrenn. 1975. Metabolism and effects of Uranium in animals. Pages 68129 in Conference on occupational health experience with Uranium. U.S. Energy Research and Development Administration, Washington, D.C. ERDA 93/UC41.

Edens, F. W., E. Benton, S. J. Bursian, and G. W. Morgan. 1976. "Effect of Dietary Lead on Reproductive Performance in Japanese Quail, Coturnix coturnix japonica." Toxicol. Appl. Pharmacol. 38, pp. 307-314.

Efroymson, R., B.E. Sample, G.W. Suter II and T.L. Ashwood. 1996. Soil-plant contaminant uptake factors: review and recommendations for the Oak Ridge Reservation. ES/ER/TM-198. Oak Ridge National Laboratory, Oak Ridge, TN

Ehrlich, P. R., D. S. Dobkin, and D. Wheye. 1988. The Birder's Handbook: A Field Guide to the Natural History of North American Birds. Simon and Schuster, Inc., New York. 
Eisler, R. 1985a. Cadmium Hazards to Fish, Wildlife, and Invertebrates: A Synoptic Review. U.S. Fish Wildlife Service Biology Report 85(1.2).

Eisler, R. 1985b. Selenium Hazards to Fish, Wildlife, and Invertebrates: A Synoptic Review. U.S. Fish and Wildlife Service Biology Report 85(1.5).

Eisler, R. 1986(a). Chromium hazards to fish, wildlife, and invertebrates: a synoptic review. U.S. Fish Wildl. Serv. Biol. Rep. 85(1.6). 60pp.

Eisler, R. 1986(b). Polychlorinated Biphenyl Hazards to Fish, Wildlife, and Invertebrates: A Synoptic Review. U.S. Fish and Wildlife Service Biology Report 85(1.7).

Eisler, R. 1987. Mercury Hazards to Fish, Wildlife, and Invertebrates: A Synoptic Review.U.S. Fish and Wildife Service Biology Report 85(1.10).

Eisler, R. 1988a. Arsenic Hazards to Fish, Wildlife, and Invertebrates: A Synoptic Review.U.S. Fish and Wildlife Service Biology Report 85(1.12).

Eisler, R. 1988b. Lead Hazards to Fish, Wildlife, and Invertebrates: A Synoptic Review. U.S. Fish Wildife Service Biology Report 85(1.14).

Eisler, R. 1993. Zinc Hazards to Fish, Wildlife, and Invertebrates: A Synoptic Review. U.S. Fish and Wildlife Service Biology Report 85(1.26).

Environmental Sciences Division (ESD). 1993. Final report on the background soil characterization project at the Oak Ridge Reservation, Oak Ridge, Tennessee. DOE/OR/01-1175/V1-V3. Oak Ridge National Laboratory, Oak Ridge, Tenn.

EPA (Environmental Protection Agency). 1980. Ambient Water Quality Criteria for Polychlorinated Biphenyls. U.S. Environ. Protection Agency Rep. 440/5-80-068.

EPA. 1980a. "Guidelines and Methodology Used in the Preparation of Health Effects Assessment Chapters of the Consent Decree Water Quality Criteria Documents." Federal Register 45(231), pp. 79347-79356.

EPA. 1984. Health Effects Assessment for Zinc (and Compounds). EPA/540/1-86-048, U.S Environmental Protection Agency, Office of Research and Development, Washington, D.C.

EPA (U. S. Environmental Protection Agency). 1986. 90-day gavage study in albino rats using acetone. Office of Solid Waste, Washington, D.C.

EPA. 1987. Drinking Water Criteria Document for Copper. ECAO-CIN-417, prepared by the Office of Health and Environmental Assessment, Environmental Criteria and Assessment Office, Cincinnati, Ohio, for the Office of Drinking Water, Washington, D.C.

EPA. 1992. Framework for Ecological Risk Assessment. EPA/630/R-92/001, Risk Assessment Forum, U.S. Environmental Protection Agency, Washington, D.C. 
EPA (U. S. Environmental Protection Agency). 1993. "Great Lakes water quality initiative criteria documents for the protection of wildlife (proposed): DDT, Mercury, 2,3,7,8-TCDD, PCBs." EPA/822/R-93-007. Office Science and Technology Washington, D.C.

EPA. 1993a. Integrated Risk Information System (IRIS)_Carcinogenicity Assessment for Zinc and Compounds, and Oral RFD Assessment for Zinc phosphide. Office of Health and Environmental Assessment, Cincinnati, Ohio.

EPA. 1993b. Wildlife Exposure Factors Handbook, Volume II. EPA/600/R93/187b, Office of Research and Development, Washington, D.C.

EPA. 1993c. Wildlife Criteria Portions of the Proposed Water Quality Guidance for the Great Lakes System. EPA/822/R-93/006, Office of Science and Technology, Washington, D.C.

EPA. 1995. Great Lakes Water Quality Initiative Technical Support Document for Wildlife Criteria. U.S. Environmental Protection Agency, Washington D.C. EPA-820-B-95-009.

Ferm, V. H., and D. P. Hanlon. 1974. "Toxicity of Copper Salts in Hamster Embryonic Development." Biol. Reprod. 11, pp. 97-101.

Ferm, V. H., and W. M. Layton, Jr. 1981. "Teratogenic and Mutagenic Effects of Cadmium," in Cadmium in the Environment, Part 2: Health Effects, J.O. Nriagu, ed. John Wiley, New York, pp. 743-756.

Feron, V.J., C.F.M. Hendriksen, A.J. Speek, et al. 1981. "Lifespan oral toxicity study of vinyl chloride in rats." Food Cosmet. Toxicol. 13: 633-638.

Fimreite, N. 1970. "Effects of Methyl Mercury Treated Feed on the Mortality and Growth of Leghorn Cockerels." Can. J. Anim. Sci. 50, pp. 387-389.

Fimreite, N. 1971. Effects of Dietary Methylmercury on Ringnecked Pheasants. Occasional Paper No. 9, Canadian Wildlife Service.

Fleming, W. J., M. A. Ross Mclane, and E. Cromartie. 1982. "Endrin Decreases Screech Owl Productivity." J. Wildl. Manage. 46, pp. 462-468.

Fitzhugh, O.G. 1948. "Use of DDT insecticides on food products." Ind. Eng. Chem. 40: 704-705.

Food \& Drug Research Laboratory, Inc. 1984. Acute oral toxicity of seventeen nickel/cobalt samples in Sprague-Dawley rats. Report submitted to Nickel Producers Environ. Res. Assoc.

Formigli, L., et al. 1986. "Thallium-induced Testicular Toxicity in the Rat." Environ. Res. 40, pp. 531-539.

Fox, M. R. S., and R. M. Jacobs. 1986. "Zinc: Essentiality, Function, Effects of Deficiency, and Requirements," in Metal Ions in Biological Systems, H. Sigel, ed. Marcel Dekker, Inc., New York. pp. 214-248.

Furness, R. W. 1996. Cadmium in birds. p.389-404. In: W. N. Beyer, G. H. Heinz and A. W. Redmon-Norwood (eds.), Environmental contaminants in wildlife. Lewis Publishers, NY. 
Gale, T.F. 1978. Embryotoxic effects of chromium trioxide in hamsters. Environ. Res. 16: 101-109.

Ganrot, P. O. 1986. "Metabolism and Possible Health Effects of Aluminum." Environ. Health Persp. 65, pp. 363-441.

Gasaway, W. C., and I. O. Buss. 1972. "Zinc Toxicity in the Mallard Duck." J. Wildl. Manage. 36, pp. 1107-1117.

Gerell, R. 1970. "Home Ranges and Movements of the Mink Mustela Vison Schreber in Southern Sweden." Oikos 21, pp. 160-173.

Getz, L. L. 1989. “A 14-year Study of Blarina brevicauda Populations in East-central Illinois." J. Mamm. 70, pp. 8-66.

Giavini, E., C. Vismara, and L. Broccia. 1985. "Teratogenesis study of dioxane in rats." Toxid Lett. 26: 85-88.

Gilani, S.H., and M. Marano. 1979. Chromium poisoning and chick embryogenesis. Environ. Res.19: 427-431.

Golub, M. S., et al. 1987. "Maternal and Developmental Toxicity of Chronic Aluminum Exposure in Mice." Fund. Appl. Toxicol. 8, pp. 346-357.

Good, E. E., and G. W. Ware. 1969. "Effects of Insecticides on Reproduction in the Laboratory Mouse, Iv. Endrin and Dieldrin." Toxicol. Appl. Pharmacol. 14, pp. 201-203.

Gopinath, C., G. A. Hall, and J. M. C. Howell. 1974. [Title not given.] Res. Vet. Sci. 16, pp. 57-69.

Gosselin, R.E. R.P. Smith, H.C. Hodge, et al. 1984. Clinical Toxicology of Commercial Products, 5th ed. Williams and Wilkins, Baltimore, MD. pp. II-148-149.

Goyer, R.A. 1991. Toxic effects of metals. In: Amdur, M.O., J. Doull, and C.D. Klaassen, Eds. Casarett and Doull's toxicology: The basic science of poisons. 4th ed. Pergamon Press, New York. pp. 623-680.

Grandjean, P. 1976. "Possible Effect of Lead on Eggshell Thickness in Kestrels 1874-1974." Bull. Environ. Contam. Toxicol. 16, p. 101

Grant, D.L., W.E.J. Phillips, and G.V. Hatina. 1977. "Effects of hexachlorobenzene on reproduction in the rat." Arch. Environ. Contam. Toxicol. 5:207-216.

Gray, L.E., Jr., J. Ostby, R. Sigmon, J. Ferrell, G. Rehnberg, R. Linder, R. Cooper, J. Goldman, and J. Laskey. 1988. "The development of a protocol to assess reproductive effects of toxicants in the rat." Reprod. Toxicol. 2: 281-287.

Hamilton, W. J., Jr. 1940. "The Summer Food of Minks and Raccoons on the Montezuma Marsh, New York." J. Wildl. Manage. 4, pp. 80-84. 
Hammonds, J. S., F. O. Hoffman, and S. M. Bartell.1994. An Introductory Guide to Uncertainty Analysis in Environmental and Health Risk Assessment. ES/ER/TM-35/R1, Oak Ridge National Laboratory, Oak Ridge, Tennessee.

Harr, J. R. 1978. "Biological Effects of Selenium" in Toxicity of Heavy Metals in the Environment: Part I, F.W. Oehme, ed. Marcel Dekker, Inc., New York, pp. 393-426.

Harris, H. J., T. C. Erdman, G. T. Ankley, and K. B. Lodgel. 1993. "Measures of Reproductive Success and Polychlorinate Biphenyl Residues in Eggs and Chicks of Forster's Terns on Green Bay, Lake Michigan, Wisconsin-1988." Arch. Environ. Contam. Toxicol. 25, pp. 304-314.

Harvey, M. J. 1992. Bats of the Eastern United States. Arkansas Game and Fish Commission, Little Rock, Arkansas.

Haseltine, S.D. and L. Sileo. 1983. Response of American Black Ducks to dietary uranium: a proposed substitute for lead shot. J. Wildl. Manage. 47(4): 1124-1129.

Haseltine, S.D., L. Sileo, D.J. Hoffman, and B.D. Mulhern. 1985. "Effects of chromium on reproduction and growth in black ducks."

Haywood, S. 1985. "Copper Toxicosis and Tolerance in the Rat-I. Changes in Copper Content of the Liver and Kidney." J. Pathol. 145, pp. 149-158.

Heaton S. N., 1992. Effects on reproduction of ranch mink fed carp from Saginaw Bay, Michigan . M. S. Thesis, Department of Animal Science, Michigan State University, East Lansing, MI. 152 pp.

Heinz, G. H. 1979. "Methyl Mercury: Reproduction and Behavioral Effects on Three Generations of Mallard Ducks.” J. Wildl. Mgmt. 43, pp. 394-401.

Heinz, G. H. 1996. Selenium in birds. p. 447-458. In: W. N. Beyer, G. H. Heinz and A. W. Redmon-Norwood (eds.), Environmental contaminants in wildlife. Lewis Publishers, NY, NY.

Heinz, G.H., and S.D. Haseltine. 1981. Avoidance behavior of young black ducks treated with chromium. Toxicol. Lett. 8: 307-310..

Heinz, G. H., and S. D. Haseltine. 1983. "Altered Avoidance Behavior of Young Black Ducks Fed Cadmium." Environ. Toxicol. Chem. 2, pp. 419-421.

Heinz, G. H., D. J. Hoffman, A. J. Krynitsky, and D. M. G. Weller. 1987. "Reproduction in Mallards Fed Selenium." Environ. Toxicol. Chem. 6, pp. 423-433.

Heinz, G. H., D. J. Hoffman, and L. G. Gold. 1989. "Impaired Reproduction of Mallards Fed an Organic Form of Selenium.” J. Wildl. Mgmt. 53, pp. 418-428.

Hill, E.F., and M.B. Camardese. 1986. "Lethal dietary toxicities of environmental contaminants and pesticides to Coturnix" U.S. Fish and Wildlife Service, Fish and Wildlife Tech. Rept. 2. 147 pp. 
Hinzman, R. L., et al. 1995. Report on the biological monitorining and abatement program for Bear Creek at the Oak Ridge Y-12 Plant, Oak Ridge, Tennessee (1989-1994). ORNL/TM-12884. Oak Ridge National Laboratory, Oak Ridge, Tenn.

Hockman, J. G., and J. A. Chapman. 1983. Comparative feeding habits of red foxes (Vulpes vulpes) and gray foxes (Urocyon cinereoargenteus) in Maryland. Amer. Midl. Natur. 110 (2): 276-285.

Hoffman, R. D. 1978. The Diets of Herons and Egrets in Southwestern Lake Erie. National Audubon Society Research Report 7, pp. 365-369.

Hoffman, D. J., and G. H. Heinz. 1988. "Embryotoxic and Teratogenic Effects of Selenium in the Diet of Mallards.” J. Toxicol. Environ. Health 24, pp. 477-490.

Hornshaw, T. C., R. J. Aulerich, and H. E. Johnson. 1983. "Feeding Great Lakes Fish to Mink: Effects on Mink and Accumulation and Elimination of Pcbs by Mink." J. Toxicology and Environ. Health 11, pp. 933-946.

Hudson, R. H., R. K. Tucker, and M. A. Haegele. 1984. "Handbook of toxicity of pesticides to wildlife." 2nd ed. U.S. Fish and Wildl. Serv. Resour. Publ. 153. 90 pp.

Hussein, A. S., A. H. Cantor, and T. H. Johnson. 1988. "Use of High Levels of Dietary Aluminum and Zinc for Inducing Pauses in Egg Production of Japanese Quail.” Poultry Sci. 67, pp. 1157-1165.

International Commission on Radiological Protection (ICRP). 1959. Report of committee II on permissible dose for internal radiation. Health Physics 3:1-380.

Janes, S.W. 1984. Influences of territory compostion and interspecific competition on Red-tailed hawk reproductive success. Ecology. 65: 862-870.

Johnson, D., Jr., A. L. Mehring, Jr., and H. W. Titus. 1960. "Tolerance of Chickens for Barium." Proc. Soc. Exp. Biol. Med. 104, pp. 436-438.

Kazantzis, G. 1979. "Thallium," in Hondbook on the Toxicology of Metals, L. Fribourg, ed. Elsevier Press, New York, pp. 599-612.

Kendall, R. J., and P. F. Scanlon. 1981. "Effects of Chronic Lead Ingestion on Reproductive Characteristics of Ringed Turtle Doves Streptopelia risoria and on Tissue Lead Concentrations of Adults and Progeny." Environ. Poll. Series A, 26, pp. 203-213.

Ketcheson, M. R., G. P. Barron, and D. H. Cox. 1969. "Relationship of Maternal Dietary Zinc During Gestation and Lactation to Development and Zinc, Iron, and Copper Content of the Postnatal Rat." J. Nutr. 98, pp. 303-311.

Kimmel, C. A., L. D. Grant, C. S. Sloan, and B. C. Gladen. 1980. "Chronic Low-level Lead Toxicity in the Rat-I. Maternal Toxicity and Perinatal Effects." Toxicol. Appl. Pharmacol. 56, pp. $28-41$. 
King, K. A., T. W. Custer, and J. S. Quinn. 1991. "Effects of Mercury, Selenium, and Organochlorine Contaminants on Reproduction of Forster's Terns and Black Skimmers Nesting in a Contaminated Texas Bay." Arch. Environ. Contam. Toxicol. 20, pp. 32-40.

Kinnamon, K. E. 1963. "Some Independent and Combined Effects of Copper, Molybdenum, and Zinc on the Placental Transfer of Zinc-65 in the Rat." J. Nutrition 81, pp. 312-320.

Kline, R. D., V. W. Hays and G. L. Cromwell. 1971. "Effects of Copper, Molybdenum and Sulfate on Performance, Hematology and Copper Stores of Pigs and Lambs." J. Animal Sci. 33, pp. 771-779.

Korschgen, L. J. 1958. "December Food Habits of Mink in Missouri." J. Mamm. 39, pp. 521-527.

Krueger, G. L., T. K. Morris, R. R. Suskind, and E. M. Widner. 1984. "The Health Effects of Aluminum Compounds in Mammals." Crit. Rev. Toxicol. 13, pp. 1-24.

Kushlan, J. A. 1978. "Feeding Ecology of Wading Birds" in Wading Birds. National Audubon Society, pp. 249-297.

Lam, H.F., et al. 1985. "Functional and Morphological Changes in the Lungs of Guinea Pigs Exposed to Freshly Generated Ultrafine Zinc Oxide.” Toxicol. Appl. Pharmacol. 78, pp. 29-38.

Lamb, J.C., IV, R.E. Chapin, J. Teague, A.D. Lawton, and J.R. Reel. 1987. "Reproductive effects of four phthalic acid esters in the mouse." Toxicol. Appl. Pharmacol. 88: 255-269.

Landrum, C. L., T. L. Ashwood, and D. K. Cox. 1993. Belted Kingfishers as Ecological Monitors of Contaminations: A Review. ORNL/M-2533, Oak Ridge National Laboratory, Oak Ridge, Tennessee.

Lane, R. W., B. L. Riddle, and J. F. Borzelleca. 1982. " Effects of 1,2-dichloroethane and 1,1,1trichloroethane in drinking water on reproduction and development in mice." Toxicol. Appl. Pharmacol. 63: 409-421.

Larngard, S., and T. Norseth. 1979. Chromium. pp. 383-397. in L. Friberg (ed). Handbook on the toxicology of metals. Elsevier Press, NY. $709 \mathrm{pp}$.

Laskey, J.W., G.L. Rehnberg, J.F. Hein, and S.D. Carter. 1982. Effects of chronic manganese $\left(\mathrm{Mn}_{3} \mathrm{O}_{4}\right)$ exposure on selected reproductive parameters in rats. J. Toxicol. Environ. Health., 9:677-687.

Laskey, J.W., and F.W. Edens. 1985. "Effects of chronic high-level manganese exposure on male behavior in the Japanese Quail (Cotirnix coturnix japonica)." Poult. Sci. 64: 579-584.

Leach, L.J., E.A. Maynard, H.C. Hodge, Scott J.K., C.L. Yuile, G.E. Sylvester, and H.B. Wilson. 1970. A five year inhalation study with uranium dioxide $\left(\mathrm{UO}^{2}\right)$ dust. I. Retention and biologic effect in the monkey, dog, and rat. Health Phys. 18:559-612.

Leach, R. M., K. W.-L. Wang, and D. E. Baker. 1979. Cadmium and the food chain: the effect of dietary cadmium on tissue composition in chicks and laying hens. J. Nutr. 109: 437-443. 
Lecyk, M. 1980. "Toxicity of Cupric Sulfate in Mice Embryonic Development." Zool. Pol. 28, pp. 101-105.

Leonards, P.E.G., M. D. Smit, A. W. J. J. de Jongh, B. van Hattum. 1994. Evaluation of dose-response relationships for the effects of PCBs on the reproduction of mink (Mustela vison). Institute for Environmental Studies, Amsterdam. 50pp.

Lepore, P.D., and R.F. Miller, 1965. "Embryonic viability as influenced by excess molybdenum in chicken breeder diets." Proc. Soc. Exp. Biol. Med. 118: 155-157

Lewis, R. J. and D. V. Sweet, eds. 1984. Registry of Toxic Effects of Chemical Substances, Vol. 1. U.S. Department of Health and Human Services, Public Health Service, Centers for Disease Control, National Institute for Occupational Safety and Health, Cincinnati, Ohio.

Linder, R. E., T. B. Gaines, and R. D. Kimbrough. 1974. "The Effect of PCB on Rat Reproduction." Food Cosmet. Toxicol. 12, p. 63.

Linzey, A. V. 1987. "Effects of Chronic Polychlorinated Biphenyls Exposure on Reproductive Success of White-footed Mice (Peromyscus leucopus)." Arch. Environ. Contam. Toxicol. 16, pp. 455-460.

Lloyd, T. B. 1984. "Zinc Compounds" in Kirk-Othmer Encyclopedia of Chemical Technology, 3rd ed., H. F. Mark, D. F. Othmer, C. G. Overberger, G. T. Seaborg, eds. John Wiley \& Sons, New York, pp. 851-863.

Lo, M. T., and E. Sandi. 1980. Selenium: "Occurrence in Foods and its Toxicological Significance. A Review." J. Environ. Pathol. Toxicol. 4, pp. 193-218.

Loar, J. M. 1990. Fourth annual report on the ORNL biological monitonng and abatement program. Environmental Sciences Division, Oak Ridge National Laboratory, ORNL/TM-Draft.

Loar, J.M., et al. 1992. Second report on the Oak Ridge National Laboratory Biological Monitoring and Abatement Program for White Oak Creek Watershed and the Clinch River. Oak Ridge National Laboratory, Oak Ridge, TN. ORNL/TM-10804.

Ma, W., W. Denneman, and J. Faber. 1991. "Hazardous Exposure of Ground-living Small Mammals to Cadmium and Lead in Contaminated Terrestrial Ecosystems." Arch. Environ. Contam. Toxicol. 20, pp. 266-270.

Mackenzie, K. M., and D. M. Angevine. 1981. "Infertility in Mice Exposed in Utero to Benzo[a]pyrene." Biol. Reprod. 24, pp. 183-191.

Mackenzie, R.D., R.U. Byerrum, C.F. Decker, et al. 1958. Chronic toxicity studies, II.Hexavalent and trivalent chromium administered in drinking water to rats. Am. Med.Assoc. Arch. Ind. Health. 18:232-234.

Maita, K., et al. 1981. "Subacute Toxicity with Zinc Sulfate in Mice and Rats." J. Pest. Sci. 6, pp. 327-336. 
Marathe, M.R., and G.P. Thomas. 1986. "Embryotoxicity and Teratogenicity of Lithium Carbonate in Wistar Rat." Toxicol. Lett. 34, pp. 115-120.

Massie, H.R. and V.R. Aiello. 1984. "Excessive Intake of Copper: Influence on Longevity and Cadmium Accumulation in Mice." Mech. Ageing Dev. 26, pp. 195-203.

Mastromatteo, E. 1986. Nickel. Am. Ind. Hyg. Assoc. J. 47(10):589-601.

Maynard, E.A. and H.C. Hodge. 1949. Studies of the toxicity of various uranium compounds when fed to experimental animals. In: The Pharmacology and Toxicology of Uranium Compounds. C. Voegtlin and H.C. Hodge, eds. McGraw-Hill, New York, pp. 309-376.

Mayo, R.H., et al. 1956. "Copper Tolerance of Young Chickens.” Poult. Sci. 35, pp. 1156-1157.

McCoy, G., et al.-1995: "Chronic Polychlorinated Biphenyls Exposure on Three Generations of Oldfield Mice (Permyscus polionotus): Effects on Reproduction, Growth, and Body Residues." Arch. Environ. Contam. Toxicol. 28, pp. 431-435

McLane, M. A. R., and D. L. Hughes. 1980. "Reproductive Success of Screech Owls Fed Aroclor 1248." Arch. Environm. Contam. Toxicol. 9, pp. 661-665.

Mehring, A. L., Jr., J. H. Brumbaugh, A. J. Sutherland, and H. W. Titus. 1960. "The Tolerance of Growing Chickens for Dietary Copper." Poult. Sci. 39, pp. 713-719.

Melquist, W. E., and M. G. Hornocker. 1983. "Ecology of River Otters in West Central Idaho." Wildl. Monogr. 83, pp. 1-60.

Mendenhall, V. M., E. E. Klaas, and M. A. R. McLane. 1983. "Breeding Success of Barn Owls (Tyto $a l b a)$ Fed Low Levels of Dde and Dieldrin." Arch. Environ. Contam. Toxicol. 12, pp. 235-240.

Merritt, R.C. 1971. The extractive metallurgy of uranium. Colorado School of Mines Research Institute. Atomic Energy Commission.

Meyers-Schone, L. M., and B. T. Walton. 1994. "Turtles as Monitors of Chemical Contaminants in the Environment." Rev. Environ. Contam. Toxicol. 135, pp. 93-153.

Miller, W. J., et al. 1989. "Long-term Feeding of High Zinc Sulfate Diets to Lactating and Gestating Dairy Cows." J. Dairy Sci. 72, pp. 1499-1508.

Mineau, P., B.T. Collins, and A. Baril. 1996. On the use of scaling factors to improve interspecies extrapolation of acute toxicity in birds. Reg. Toxicol. and Pharmacol. In Press.

Mitchell, J. L. 1961."Mink Movements and Population on a Montana River." J. Wildl. Manage. 25, pp. 48-54.

Mumford, R. E., and J. O. Whitaker, Jr. 1982. Mammals of Indiana. Indiana University Press, Bloomington, Indiana.

National Academy of Sciences (NAS) 1977. Arsenic. U.S. National Academy of Sciences, Washington, D.C. 
National Academy of Sciences (NAS). 1979. Zinc. U.S. National Academy of Sciences, National Research Council, Subcommittee on Zinc, University Park Press, Baltimore, Maryland.

National Academy of Sciences (NAS). 1980. Mineral Tolerance of Domestic Animals. National Academy Press, Washington, DC.

National Academy of Sciences (NAS). 1980. Uranium. In: Mineral tolerance of domestic animals. National Academy Press, Washington, DC.

National Coffe Association. 1982. "24-month Chronic Toxicity and Oncogenicity Study of Methylene Chloride in Rats." Final Report, Hazelton Laboratories, Inc., Vienna, Virginia.

NCI (National Cancer Institute). 1978. "Bioassay of Aroclor 1254 for Possible Carcinogenicity."NCI Carcinogenesis Technical Report, Series No. 38, NCI-CG-TR-38, DHEW Pub. No. (NIH) 78-838.

National Geographic Society. 1987. Field Guide to the Birds of North America, 2nd ed.

Nawrot, P.S. and R.E. Staples. 1979. "Embryofetal toxicity and teratogenicity of benzene and toluene in the mouse." Teratology. 19: 41A

Nicholson, J. K., and D. Osborn. 1983. Kidney lesions in pelagic seabirds with high tissue levels of cadmium and mercury. J. Zool. (Lond.) 200: 99-118.

NRC (National Reseach Council), 1982. Nutrient Requirements of Mink and Foxes, No. 7. National Academy of Sciences, Washington, D.C. 72 pp.

NRCC. 1978. Effects of Arsenic in the Canadian Environment. National Research Council of Canada Publication No. NRCC 15391.

Nyholm, N.E.I. 1981. "Evidence of Involvement of Aluminum in Causation of Defective Formation of Eggshells and of Impaired Breeding in Wild Passerine Birds." Environ. Res. 26, pp. 363-371.

Oh, S. H., et al. 1979. "Accumulation and Depletion of Zinc in Chick Tissue Metallothioneins." J. Nutr. 109, pp. 1720-1729.

Ohlendorf, H. M., et al. 1986. "Relationships Between Selenium Concentrations and Avian Reproduction." Trans. N. Am. Wildl. Nat. Res. Conf. 51, pp. 330-342.

Ondreicka, R., E. Ginter, and J. Kortus. 1966. "Chronic Toxicity of Aluminum in Rats and Mice and its Effects on Phosphorus Metabolism.” Brit. J. Indust. Med. 23, pp. 305-313.

Palafox, A. L., and E. Ho-A. 1980. "Effect of Zinc Toxicity in Laying White Leghorn Pullets and Hens." Poultry Sci. 59, pp. 2024-2028.

Palmer, A. K., D. D. Cozens, E. J. F. Spicer, and A. N. Worden. 1978. "Effects of Lindane upon Reproductive Functions in a 3-generation Study in Rats." Toxicology 10, pp. 45-54. 
Palmer, A.K., A.E. Street, F.J.C. Roe, A.N. Worden, and N.J. Van Abbe. 1979. "Safety evaluation of toothpaste containing chloroform, II. Long term studies in rats." J. Environ. Pathol. Toxicol. 2: 821-833.

Paternain, J. L., J. L. Domingo, J. M. Llobet, and J. Corbella. 1988. "Embryotoxic and Teratogenic Effects of Aluminum Nitrate in Rats upon Oral Administration." Teratology 38, pp. 253-257.

Paternain, J. L., J. L. Domingo, A. Ortega, and J. M. Llobet. 1989. "The Effects of Uranium on Reproduction, Gestation, and Postnatal Survival in Mice." Ecotoxicol. Environ. Saf. 17, pp. 291-296.

Pattee, O. H. 1984. "Eggshell Thickness and Reproduction in American Kestrels Exposed to Chronic Dietary Lead." Arch Environ. Contam. Toxicol. 13, pp. 29-34.

Pattee, O.H., S.N. Wiemeyer, and D.M. Swineford. 1988. "Effects of dietary fluoride on reproduction in eastern Screech-Owls." Arch. Environ. Contam. Toxicol. 17: 213-218.

Peakall, D.B. 1974. "Effects of di-N-buylphthalate and di-2-ethylhexylphthalate on the eggs of ring doves." Bull. Environ. Contam. Toxicol. 12: 698-702.

Perry, H. M., E. F. Perry, M. N. Erlanger, and S. J. Kopp. 1983. "Cardiovascular Effects of Chronic Barium Ingestion," in Proceedings of the 17th Annual Conference on Trace Substances in Environmental Health, vòl. 17. University of Missouri Press, Columbia, Missouri.

Peterson, M.A., R.R. Petri, and G.R. Southworth. 1994. Bioaccumulation Studies. In T.L. Ashwood (ed.) Eighth Annual Report on the ORNL Biological Monitoring and Abatement Program. Draft ORNL/TM-12767. Oak Ridge National Laboratory, Oak Ridge, Tennessee.

Phatak, S.S., and V.N. Patwardhan. 1952. Toxicity of nickel -- accumulation of nickel in rats fed on nickel-containing diets and its elimination. J. Sci. Industr. Res. 11b:173-176.

Platonow, N. S., and B. S. Reinhart. 1973. "The Effects of Polychlorinated Biphenyls (Aroclor 1254) on Chicken Egg Production, Fertility and Hatchability." Can. J. Comp. Med. 37, pp. 341-346.

Platonow, N. S., and L. H. Karstad. 1973. "Dietary Effects of Polychlorinated Biphenyls on Mink." Can. J. Comp. Med. 37, pp. 391-400.

Prasad, A. S. 1979. "Clinical, Biochemical, and Pharmacological Role of Zinc." Ann. Rev. Pharmacol. Toxicol. 20, pp. 393-426.

Preston, A.M., R.P. Dowdy, M.A. Preston, and J.N. Freeman. 1976. Effect of dietary chromium on glucose tolerance and serum cholesterol in guinea pigs. J. Nutr. 106: 1391-1397.

Pullar, E. M. 1940. "The Toxicity of Various Copper Compounds and Mixtures for Domesticated Birds. 2." Australian Vet. J. 16, pp. 203-213.

Pullin, B. P. 1990. Size and trends of wading bird populations in Tennessee during 1977-1988. Migrant 61:95-104. 
Quast, J.F., C.G. Humiston, C.E. Wade, et al. 1983. "A chronic toxicity and oncogenicity study in rats and subchronic toxicity in dogs on ingested vinylidene chloride." Fund. Appl. Toxicol. 3: $55-62$.

Rana, S. V. S., and A. Kumar. 1978. "Simultaneous Effects of Dietary Molybdenum and Copper on the Accumulation of Copper in the Liver and Kidney of Copper Poisoned Rats-A Histochemical Study." Ind. Health 18, pp. 9-17.

Ratcliffe, D.A. 1967. "Decease in eggshell weight in certain birds of prey" Nature 215: 208-210.

Reece, R. L., D. B. Dickson, and P. J. Bunowes. 1986."Zinc Toxicity (New Wire Disease) in Aviary Birds." Australian Vet. J. 63, p. 199.

Ringer, R. K., R. J. Aulerich, and M. R. Bleavins. 1981. "Biological Effects of PCBs and PBBs on Mink and Ferrets-A Review" in Halogenated Hydrocarbons: Health and Ecological Effects, M. A. Q. Khan, ed. Permagon Press, Elmsford, New York, pp. 329-343.

Roberson, R. H., and P.J . Schaible. 1960. "The Tolerance of Growing Chicks for High Levels of Different Forms of Zinc.” Poult. Sci. 39, pp. 893-896.

Romoser, G.L., W.A. Dudley, L.J. Machlin, and L. Loveless. 1961. Toxicity of vanadium and chromium for the growing chick. Poultry Sci. 40: 1171-1173.

Rosenfeld, I. and O.A. Beath. 1954. Effect of selenium on reproduction in rats. Proc. Soc. Exp. Biol. Med. 87: 295-297.

Roshchin, I.V. 1967. Toxicity of vanadium compounds used in modern industry. Gig. Sanit. 32: 26-32.

SAIC. 1994. East Fork Poplar Creek - Sewer Line Beltway Remedial Investigation Report. U.S. Department of Energy,, Oak Ridge, TN. DOE/OR/02-1119\&D2\&V2.

Sample, B. E., and G. W. Suter, II. 1994. Estimating Exposure of Terrestrial Wildlife to Contaminants. ES/ER/TM-125, Oak Ridge National Laboratory, Oak Ridge, Tennessee.

Sample, B.E., D.M. Opresko and G.W. Suter II. 1996(a). Toxicological Benchmarks for Wildlife: 1996 Revision. ES/ER/TM-86/R3. Oak Ridge National Laboratory, Oak Ridge, Tennessee.

Sample, B.E., R. Efroymson, G.W. Suter II and T.L. Ashwood. 1996(b). Soil-earthworm and soilsmall mammmal contaminant uptake factors: review and recommendations for the Oak Ridge Reservation. ES/ER/TM-197. Oak Ridge National Laboratory, Oak Ridge, Tennessee.

Sanders, O. T., R. L. Zepp, and R. L. Kirkpatrick. 1974. "Effect of PCB Ingestion on Sleeping Times, Organ Weights, Food Consumption, Serum Corticosterone and Survival of Albino Mice." Bull. Environ. Contam. Toxicol. 12 (4), pp. 394-399.

Sargeant, A.B. 1972. Red fox spatial characteristics in relation to waterfowl predation. J. Wildl. Manage. 36: 225-236. 
Sargeant, A.B. 1978. "Red fox prey demands and implications to prairie duck production." J. Wildl. Manage. 42(3): 520-527.

Schlatterer, B., T.M.M. Coenen, E. Ebert, R. Grau, V. Hilbig, and R. Munk. 1993. "Effects of Bis(tri-n-butyltin)oxide in Japanese Quail exposed during egg laying period: an interlaboratory comparison study." Arch. Environ. Contam. Toxicol. 24: 440-448.

Schlicker, S.A., and D.H. Cox. 1967. "Maternal Dietary Zn in Excess, Fetal Development, and Fe and Cu Metabolism." Abstract, Fed. Amer. Proc. 26, p. 520.

Schlicker, S.A., and D.H. Cox. 1968. "Maternal Dietary Zinc and Development; Zinc, Iron, and Copper Content of the Rat Fetus." J. Nutr. 95, pp. 287-294.

Schroeder, H. A., J. J. Balassa, and W. H. Vinton, Jr. 1965. Chromium, Cadmium and Lead in Rats: Effects on Life Span, Tumors and Tissue Levels. J. Nutr. 86, pp. 51-66.

Schroeder, H. A., and J. J. Balassa. 1967. Arsenic, germanium, tin and vanadium in mice: effects on growth, survival and tissue levels. J. Nutr. 92:245-251.

Schroeder, H.A., M. Kanisawa, D.V. Frost, and M. Mitchener. 1968a. "Germanium, Tin, and Arsenic in Rats: Effects on Growth, Survival and Tissue Levels." J. Nutr. 96, pp. 37-45.

Schroeder, H.A., et al.. 1968b. "Zirconium, Niobium, Antimony, and Fluorine in Mice: Effects on Growth, Survival and Tissue Levels.” J. Nutr. 95, pp. 95-101.

Schroeder, H. A., and M. Mitchener. 1971. Toxic Effects on the Reproduction of Mice and Rats. Arch. Environ. Health. 23, pp. 102-106.

Schroeder, H. A., and M. Mitchener. 1972. "Selenium and Tellurium in Mice." Arch. Environ. Health. 24, pp. 66-71.

Schroeder, H. A., and M. Mitchener. 1975a. "Life-term Studies in Rats: Effects of Aluminum, Barium, Beryllium, and Tungsten.” J. Nutr. 105, pp. 421-427.

Schroeder, H. and M. Mitchener. 1975b. Life-term effects of mercury, methyl mercury and nine other trace metals on mice. J. Nutr. 105: 452-458.

Schroeder, H.A., and M. Mitchener. 1975b. "Life-term Effects of Mercury, Methyl Mercury and Nine Other Trace Metals on Mice." J. Nutr. 105, pp. 452-458.

Schroeder, H., M. Mitchener and A.P. Nason. 1970. Zirconium, niobium, antimony, vanadium and lead in rats: life term studies. J. Nutrit. 100: 59-68.

Schwetz, B.A., J.F. Quast, P.A. Keeler, C.G. Humiston, and R.J. Kociba. 1978. "Results of two-year toxicity and reproduction studies on pentachlorophenol in rats." pp 301-309 in K.R. Rao, ed., Pentachlorophenol: Chemistry, Pharmacology, and Environmental Toxicology. Plenum Press, New York. 401 pp.

Scientifur, 1987. Scientifur Index. I. G. Joergensen (ed.). Scientifur, Hillerod Denmark, 196 pp. 
Sealander, J.A. 1943. "Winter Food Habits of Mink in Southern Michigan." J. Wildl. Manage. 7, pp. $411-417$.

Shaw, P.A. 1933. "Toxicity and Deposition of Thallium in Certain Game Birds." J. Pharmacol. Exp. Ther. 48, pp. 478-487.

Short, H.L. and R.J. Cooper. 1985. Habitat Suitability Index Models: Great Blue Heron. Biological Report 82(10.99), Fish and Wildlife Service, U.S. Department of the Interior.

Skoryna, S.C. 1981. "Effects of oral supplementation with stable strontium." Can. Med. Assoc. J. 125: 703-712.

Sleight, S.D. and O.A. Atallah. 1968. "Reproduction in the guinea pig as affected by chronic administration of potassium nitrate and potassium nitrite." Toxicol. Appl. Pharmacol. 12: 179185.

Smith, G.J., and V.P. Anders. 1989. "Toxic effects of boron on mallard reproduction." Environ. Toxicol. Chem. 8: 943-950.

Smith, H.M. 1967. Handbook of lizards: Lizards of the United States and Canada. Comstock Publ. Assoc., Cornell University Press, Ithaca, New York.

Sommers, L., et al. 1987. "Effects of Soil Properties on Accumulation of Trace Elements by Crops," in Land Application of Sludge, A. L. Page, T. J. Logan, J. A. Ryan, eds., pp. 5-24.

Sorensen, J. R. R., I. R. Campbell, L. B. Tepper, and R. D. Lingg. 1974. "Aluminum in the Environment and Human Health." Environm. Health. Persp. 8, pp. 3-95.

Stahl, J. L., M. E. Cook, M. L. Sunde, and J. L. Greger. 1989."Enhanced Humoral Immunity in Progeny Chicks Fed Practical Diets Supplemented with Zinc,” Appl. Agric. Res. 4, pp. 86-89.

Stahl, J. L., J. L. Greger, and M. E. Cook. 1990. "Breeding-hen and Progeny Performance When Hens Are Fed Excessive Dietary Zinc," Poultry Sci. 69, Pp. 259-263.

Steven, J. D., et al. 1976. Effects of Chromium in the Canadian Environment. NRCC No. 151017.

Steven, J.D., L.J. Davies, E.K. Stanley, R.A. Abbott, M. Ihnat, L. Bidstrup, and J.F. Jaworski. 1976. Effects of chromium in the Canadian environment. NRCC No. 151017. $168 \mathrm{pp}$.

Stevens, R. T., 1995. Heavy Metals and PCBs in Mink (Mustela vison) and Muskrat (Ondatra zibethcus) from the U.S. Department of Energy's Oak Ridge Reservation. Unpublished master's thesis, Tennessee Technological University, Cookeville, Tennessee.

Stickel, L. F., W. H. Stickel, R. A. Dyrland, and D. L. Hughes. 1983. "Oxychlordane, HCS-3260, and Nonachlor in Birds: Lethal Residues and Loss Rates," J. Toxicol. Environ. Health 12, pp. 611-622.

Stokinger, H. E. 1981a. "Copper," in Patty's Industrial Hygiene and Toxicology, Vol. 2A, G. D. Clayton and E. Clayton, eds. John Wiley \& Sons, New York, pp. 1620-1630. 
Stokinger, H.E. 1981b. Vanadium. In: G.D. Clayton and E. Clayton, Eds. Patty's Industrial Hygiene and Toxicology, 3rd rev. ed., vol. 2A. John Wiley and Sons, New York. pp. 2013-2033.

Storm, G.L., R.D. Andrews, R. L. Phillips, R.A. Bishop, D.B. Siniff, and J.R. Tester. 1976. "Morphology, reproduction, dispersal, and mortality of midwestern red fox populations." Wildl. Monogr.

Straube, E. F., N. H. Schuster, and A. J. Sinclair. 1980. "Zinc Toxicity in the Ferret." J. Comparative Pathol. 90, pp. 355-361.

Sundqvist, C., 1989. Mink Encyclopedia Release 1.0 Parts I and II. Mink Encyclopedia Project, Depart. Biology, Abo Akademi, Porthansgatan 3, Turku, Finland. Part I, 391 pp; Part II, $387 \mathrm{pp}$.

Suter, G. W. 1990. Screening level risk assessment for off-site ecological effects in surface waters downstream from the U.S. Department of Energy Oak Ridge Reservation. Environmental Sciences Division Publication 3483. ORNL/ER-8.

Suter, G. W., B. E. Sample, D. S. Jones, and T. L. Ashwood. 1994a. Approach and Strategy for Performing Ecological Risk Assessments for the U.S. Department of Energy's Oak Ridge Reservation: 1994 Revision. ES/ER/TM-33/R1, Oak Ridge National Laboratory, Oak Ridge, Tennessee.

Suter, G. W., et al. 1994b. "Baseline Ecological Risk Assessment," in Remedial Investigation Report for Chestnut Ridge Operable Unit 2 (Filled Coal Ash Pond/Upper McCoy Branch) at the Oak Ridge Y-12 Plant, Oak Ridge. DOE/OR/02-1238\&DO, draft.

Suter, G. W., B. E. Sample, D. S. Jones, and T. L. Ashwood. 1995. Approach and Strategy for Performing Ecological Risk Assessments for the U.S. Department of Energy's Oak Ridge Reservation: 1994 Revision. ES/ER/TM-33/R2, Oak Ridge National Laboratory, Oak Ridge, Tennessee.

Sutton, W. R., and V. E. Nelson. 1937. "Studies on Zinc." Proc. Soc. Exp. Biol. Med. 36, pp. 211-213.

Sutou, S., K. Yamamoto, H. Sendota, and M. Sugiyama. 1980 Toxicity, fertility, teratogenicity, and dominant lethal tests in rats administered cadmium subchronically. I. Fertility, teratogenicity, and dominant lethal tests. Ecotoxicol. Environ. Safety. 4: 51-56.

Tannenbaum, A., and H. Silverstone. 1951. Some aspects of the toxicology of Uranium compounds. Pages 59-96 in A. Tannenbaum, ed. Toxicology of Uranium. National Nuclear Energy Series, Div. IV, Vol. 23, McGraw-Hill Book Co., Inc., New York.

Taylor, J. K. 1987. Quality assurance of chemical measurements. Lewis Publ., Inc., Chelsea, Mich.

Taylor, F.G., Jr., and P.D. Parr. 1978. Distribution of chromium in vegetation and small mammals adjacent to cooling towers. J. Tenn. Acad. Sci. 53: 87-91. 
Tewe, O.O. and J.H. Maner. 1981. "Long-term and carry-over effect of dietary inorganic cyanide $(\mathrm{KCN})$ in the life cycle performance and metabolism of rats." Toxicol. Appl. Pharmacol. 58: $1-7$.

Thompson, D. R. 1996. Mercury in birds and terrestrial mammals. p. 341-356. In: W. N. Beyer, G. H. Heinz, and A. W. Redmon-Norwood (eds.), Environmental contaminants in wildlife. Lewis Publishers, NY, NY.

Travis, C. C., and A. D. Arms. 1988. "Bioconcentration of Organics in Beef, Milk, and Vegetation." Environ. Sci. Technol. 22, pp. 271-274.

Treon, J. F., and F. P. Cleveland. 1955. "Toxicity of Certain Chlorinated Hydrocarbon Insecticides for Laboratory Animals, with Special Reference to Aldrin and Dieldrin." Ag. Food Chem. 3, pp. 402-408.

USAF (U.S. Air Force). 1990. "Copper," in The Installation Program Toxicology Guide, Vol. 5. Wright-Patterson Air Force Base, Ohio, pp. 1-43.

U.S. Fish and Wildlife Service (USFWS). 1964. Pesticide-wildlife Studies, 1963: A Review of Fish and Wildlife Service Investigations During the Calender Year. FWS Circular 199.

Van Daele, L.J., and H.A. Van Daele. 1982. Factors affecting the productivity of ospreys nesting in west-central Idaho. Condor. 84: 292-299.

Venugopal, B., and T. D. Luckey. 1978. Metal Toxicity in Mammals: Vol. 2. Chemical Toxicity of Metals and Metalloids. Plenum press, New York.

Verschuuren, H.G., et al. 1976a. "Toxicity of Methylmercury in Rats-I. Short-term Study." Toxicology 6, pp. 85-96.

Verschuuren, H.G., et al. 1976b. "Toxicity of Methylmercury in Rats -II. Long-term Toxicity Study." Toxicology 6, pp. 107-123.

Verschuuren, H.G., et al. 1976c. "Toxicity of Methylmercury in Rats-I. Reproduction Study." Toxicology 6, pp. 97-106.

Vogtsberger, L.M. and G.W. Barrett. 1973. "Bioenergetics of captive red foxes." J. Wildl. Manage. 37(4): 495-500.

Vohra, P., and F. H. Kratzer. 1968. "Zinc, Copper and Manganese Toxicities in Turkey Poults and Their Alleviation by EDTA." Poult. Sci. 47, pp. 699-704.

Vos, J. G., H. L. Van Der Maas, A.Musch, and E. Ram. 1971. "Toxicity of Hexachlorobenzene in Japanese Quail with Special Reference to Porphyria, Liver Damage, Reproduction, and Tissue Residues." Toxicol. Appl. Pharmacol. 18, pp. 944-957.

Walters, M., and F. J. C. Roe. 1965. "A Study of the Effects of Zinc and Tin Administered Orally to Mice over a Prolonged Period." Food Cosmet. Toxicol. 3, pp. 271-276. 
Washington-Allen, R. A., T. L. Ashwood, S. W. Christensen. 1995. Terrestrial Mapping of the Oak Ridge Reservation: Phase 1. ES/ER/TM-152, Oak Ridge National Laboratory, Oak Ridge, Tennessee.

Ware, G. W. 1978. The Pesticide Book. W. H. Freeman and Co., San Francisco, California.

Weber, C.W. and B.L. Reid. 1968. Nickel toxicity in growing chicks. J. Nutrition 95: 612616.Agency for Toxic Substances and Disease Registry (ATSDR). 1990. Draft toxicological profile for uranium. ATSDR/U.S. Public Health Service, Atlanta, GA.

Weigel, H. J., D. Ilge, I. Elmadfa, and H. J. Jaeger. 1987. "Availability and Toxicological Effects of Low Levels of Biologically Bound Cadmium." Arch. Environ. Contam. Toxicol. 16(1), pp. 85-93.

Weir, R.J., and R.S. Fisher. 1972. "Toxicologica studies on borax and boric acid." Toxicol. Appl. Pharmacol. 23: 351-364.

Westmoreland, N., and W. G. Hoekstra. 1969. "Pathological Defects in the Epiphyseal Cartilage of Zinc-deficient Chicks." J. Nutr. 98, pp. 76-82.

Whanger, P. D. 1973. "Effect of Dietary Cadmium on Intracellular Distribution of Hepatic Iron in Rats." Res. Commum. Chem. Pathol. Pharmacol. 5, pp. 733-740.

White, D.H., and M.P. Dieter. 1978. Effects of dietary vanadium in mallard ducks. J. Toxicol. Environ. Health. 4: 43-50.

White, D. H., and M. T. Finley. 1978. "Uptake and Retention of Dietary Cadmium in Mallard Ducks." Environ. Res. 17, pp. 53-59.

White, D. H., M. T. Finley, and J. F. Ferrell. 1978. "Histopathological Effects of Dietary Cadmium on Kidneys and Testes of Mallard Ducks." J. Toxicol. Environ. Health.

Whitworth, M. R., G. W. Pendleton, D. J. Hoffman, and M. B. Camardese. 1991. "Effects of Dietary Boron and Arsenic on the Behavior of Mallard Ducklings." Environ. Toxicol. Chem. 10, pp. 911-916.

WHO (World Health Organization). 1984. “Chlordane.” Environ. Health Criter. 34.

Wlostowski, T., W. Chetnicki, W. Gierlachowska-Baldyga, and B. Chycak. 1988. "Zinc, Iron, Copper, Manganese, Calcium and Magnesium Supply Status of Free-living Bank Voles." Acta Theriol. 33, pp. 555-573.

Wobeser, G. and M. Swift. 1976. Mercury poisoning in a wild mink. J. Wildl. Dis. 12:335-340.

Wobeser, G., N. O. Nielsen, and B. Schiefer. 1976. "Mercury and Mink-II. Experimental Methylmercury Intoxication." Can. J. Comp. Med. 40, pp. 34-45.

Wren, C.D. 1986. "A Review of Metal Accumulation and Toxicity in Wild Mammals-I. Mercury." Environ. Res. 40, pp. 210-244. 
Wren, C. D., D. B. Hunter, J. F. Leatherland and P. M. Stokes. 1987. "The Effects of Polychlorinated Biphenyls and Methylmercury, Singly and in Combination on Mink-II: Reproduction and Kit Development." Arch. Environ. Contam. Toxicol. 16, pp. 449-454.

Zaporowska, H. and W. Wasilewski. 1991. Significance of reduced food and water consumption in rats intoxicated with vanadium. Comp. Biochem. Physiol. 99C (3): 349-352. 
Appendix A

DATA SURVEY FOR THE OAK RIDGE RESERVATION ECOLOGICAL MONITORING AND ASSESSMENT PROGRAM TERRESTRIAL WILDLIFE RISK ASSESSMENT 


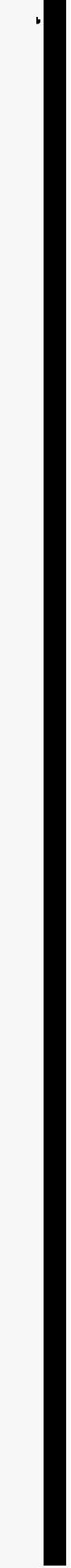




\title{
DATA SURVEY FOR THE OAK RIDGE RESERVATION ECOLOGICAL MONITORING AND ASSESSMENT PROGRAM TERRESTRIAL WILDLIFE RISK ASSESSMENT
}

\author{
Michelle L. Bell and John S. Fackenthal \\ Environmental Assessment and Compliance Group \\ Environmental Sciences Division \\ Oak Ridge National Laboratory
}

\section{INTRODUCTION}

Staff of the Environmental Assessment and Compliance Group were asked to perform a data information survey for the Oak Ridge Reservation Ecological Monitoring and Assessment Program (ORR-EMAP). The survey's purpose was to identify datasets potentially relevant to an upcoming terrestrial wildlife ecological risk assessment.

\section{SURVEY APPROACH}

Primary datasets of interest were soil, sediment, biota, and surface water contaminant concentrations. Radiological studies and air sampling were not of interest to this project. The following Operable Units (OUs) were given priority based on their total non-urban or barren area:

K-25: $\quad$ K-901 (Area 10), K-770, K-33, K-1007

ORNL: $\quad$ WAG 2, WAG 3, WAG 4, WAG 5, WAG 6, WAG 7, WAG 8, WAG 11

Y-12: $\quad$ Bear Creek, LEFPC, Bear Creek OU1, Chestnut Ridge OU2

Other OUs: Freels Bend, South Campus

The survey took a "top-down" approach, starting with ER Program Managers and OU Facility and Project Managers. Most of these people referred to other individuals and programs they thought might have relevant information. (See Fig. 1: Referrals.) It was hoped that this strategy would provide good general coverage of available datasets and allow those with access to datasets the opportunity to contribute.

The survey was conducted by telephone and electronic mail from March 22 through April 6, 1995. After a brief introduction of the survey's purpose, respondents were asked if they were aware of any potentially relevant studies, reports, or research. General information requested from survey participants included the following:

- What OUs are you affiliated with?

- Are you aware of any potentially relevant studies, reports, or research?

- Do you know of any individuals or programs that may have information of interest?

For each person contacted, a survey form was filled out to the extent information was known. (See Fig. A.2: Survey Participant Form.)

If potentially relevant datasets were identified, further questions were asked regarding the nature of the data including the following: 
- Have these datasets been entered into a data management system such as the Oak Ridge Environmental Information System (OREIS) or the Bechtel Environmental Information Data Management System (BEIDMS)?

- What types of samples were taken?

- Who has the data in electronic form?

If most of a dataset was thought to be in a data management system such as OREIS, no further questions regarding that dataset were asked since the findings could be obtained from the system. If a dataset was not thought to be in a data management system, a blank data survey form was faxed to those who might have relevant information. (See Fig. A.3: Dataset Information Form.) Unfortunately, many of these forms were not returned.

\section{PERSONS CONTACTED}

Persons contacted are listed in Table A.1. All are Lockheed Martin Energy Systems, Inc., employees or on-site subcontractors except where indicated.

\section{SURVEY FINDINGS}

Interviews and returned survey forms uncovered the following information regarding OUs of interest.

\section{$\underline{\mathrm{K}-25}$.}

OREIS holds surface water, sediment, toxicity, and biota data for the K-901A holding pond. The K-25 Site Environmental Monitoring program takes monthly surface water and sediment samples from the K-901A pond. SAIC is currently collecting data for K-901. The ORNL Environmental Sciences Division (ESD) sampled Canadian geese near the K-1007 pond for PCBs. SAIC holds surface water, soil, and possibly sediment data for K-770. Additional soil and sediment data for K25 can be found in OREIS.

\section{$\underline{\text { ORNL }}$}

Surface water data from seeps, springs, and tributaries, and sediment and soil data including soil characterizations and core samples have been collected for WAG 2. Results from these studies are intended for inclusion in OREIS. Some Ni sampling has been conducted for WAG 4. Water and soil from Pit 1 of WAG 7 have been sampled. Bechtel holds data regarding WAG 5.

\section{$\underline{Y-12}$}

Surface water, soil, sediment, and biological information for LEFPC are in OREIS. This data includes summaries of $\mathrm{Hg}$ distribution and results of tests for organics. A surface water compliance testing point is located at EFPC. OREIS holds data collected in 1992 and 1993 for the EFPC Remedial Investigation (RI). EFPC data not in OREIS includes pollutant data; old surface water data; and PCB, $\mathrm{Hg}$, and pesticide data for fish and algae. SAIC is currently conducting EFPC studies. CDM obtained Chestnut Ridge soil, sediment, and surface water data. Small mammal and vegetation bioaccumulation studies have been conducted for Chestnut Ridge OU2. Two surface water sampling points for Y-12 surface water compliance are located at Bear Creek. The Bechtel Environmental Information Data Management System (BEIDMS) contains 1994 and 1995 Bear Creek Valley surface water data. A Bear Creek OU1 soils data project being conducted 
by SAIC is almost complete. Future studies for Y-12 include soil and sediment sampling near Bear Creek Road.

A historical data capture being conducted by SAIC has found the following surface water datasets for Bear Creek Valley:

- USGS water quality (inorganics, nitrate), 1984;

- NPDES data (inorganics and organic), 1990-94;

- organics, inorganics, and PCBs, 1990;

- organics, PCBs, inorganics, pesticides, 1993;

- inorganics, organic, 1987; and

- GWQAR data, organics, inorganics. 1986-1994 (in BEIDMS).

The Bear Creek Valley historical data capture contains the following soil and sediment information:

- organics, inorganics, PCBs, 1990 ;

- Upper Bear Creek Valley, inorganics, organics, pesticides, PCBs, 1983-84; and

- well borings, organics, inorganics, pesticides, PCBs, 1983-(unknown).

Other OUs

Jacobs Engineering holds Freels Bend data for soil, water, organics, inorganics, pesticides, PCBs, semi-volatiles, volatiles, and metals. This information is intended for inclusion in OREIS.

Vegetation, soil, sediment, volatiles, and surface water data for South Campus are in OREIS. 
Table A.1. Contacts for data survey for ORR-EMAP terrestrial wildlife risk assessment

\begin{tabular}{|c|c|c|c|c|}
\hline Name & Employer & Phone & UserID & Notes/project affiliation \\
\hline Jane Aiken & & $241-3439$ & XQ9 & In charge of K-901 \\
\hline Terri Ball & & & TLS & WAG 6 \\
\hline Lisa Baron & & $574-7393$ & ISA & \\
\hline Clay Bednarz & & $241-3926$ & NRZ & WAG $4 \& 11$ Project Manager \\
\hline Donna Bennett & & $574-5839$ & DFH & UEFPC \\
\hline Bud Brickeen & & $576-1579$ & WBR & WAG 3 \& 8 Project Manager \\
\hline Jeff Cange & Bechtel & $220-2255$ & & WAG 5 Task Manager \\
\hline Jane Carr & & $241-3542$ & $\mathrm{~J} 5 \mathrm{C}$ & ORNL Document Management Center \\
\hline Jennifer Chason & SAIC & $481-8796$ & & EFPC, Bear Creek \\
\hline Roger Clapp & & $576-6619$ & UVA & WAG 2 Technical Lead \\
\hline Mike Coffey & & $576-5477$ & $\mathrm{C} 3 \mathrm{Y}$ & $\mathrm{K}-1007, \mathrm{~K}-901$ \\
\hline Dennis Cope & & $241-3841$ & DGX & $Y-12$ \\
\hline Barnaby Cornaby & SAIC & $481-8721$ & & LEFPC \\
\hline Chris Dearstone & & $\begin{array}{c}576-5946 \\
574-7449\end{array}$ & KTV & Y-12 Database Administrator \\
\hline John Forstrom & & $576-5640$ & KAF & $\mathrm{K}-25$ \\
\hline Don Garrett & & $241-3501$ & GA4 & WAG 6, WAG 11 \\
\hline Patty Goddard & & $576-3692$ & PG2 & K-25 ER Technical Coordinator \\
\hline Steven Haase & & $241-5258$ & $6 \mathrm{SH}$ & Y-12 Technical Support \\
\hline Chuck Hadden & SAIC & $481-8733$ & & Bear Creek, LEFPC \\
\hline Kim Hanzelka & & $574-4599$ & UKH & Y-12 surface water compliance \\
\hline Al Hardesty & & $576-0311$ & AFQ & WAG 5 \\
\hline Larry Hawk & & $241-4874$ & HKV & Facility Manager (WAG $2,3,8, \ldots$ ) \\
\hline Kelly Henry & Jacobs & $482-5045$ & & Freels Bend, South Campus \\
\hline Steve Herbes & & $574-7336$ & SEH & WAG 2 Project Manager \\
\hline Walter Hill & & $574-2828$ & & LEFPC \\
\hline Judy Hodgins & & $576-2368$ & H9S & $\begin{array}{l}\text { Project Manager for soil sampling at Bear } \\
\text { Creek Road }\end{array}$ \\
\hline
\end{tabular}


Table A.I (continued)

\begin{tabular}{|c|c|c|c|c|}
\hline Name & Employer & Phone & UserID & Notes/project affiliation \\
\hline Jenny Holt & & $\begin{array}{c}574-7336, \\
873-4821 \\
\text { (beeper) }\end{array}$ & VH2 & \\
\hline Rick Howard & & $241-2812$ & HR5 & Facility Manager (WAG 4, 7, 11) \\
\hline Dale Huff & & $574-7859$ & $\mathrm{DDH}$ & WAG 4 \\
\hline Dan Jones & & $241-5247$ & & Y-12 Risk Assessment Group \\
\hline Dick Ketelle & & $574-5762$ & KET & $X-10$ \\
\hline Jim Loar & & $574-7323$ & LOA & \\
\hline John Lyons & & $574-3166$ & L9Y & K-25 ER Program Manager \\
\hline Misty Mayes & SAIC & $481-4617$ & & K-901 pond \\
\hline Wayne McMahon & & $574-7525$ & EIH & Y-12 EM Manager \\
\hline Jerome Miller & & & & LEFPC \\
\hline Jill Mortimore & & $574-1462$ & JAO & Freels Bend, South Campus \\
\hline Allen Motley & & $576-5782$ & $\mathrm{~A} 4 \mathrm{Z}$ & $\mathrm{K}-25$ \\
\hline John Murphy & & $576-7929$ & JMU & X-10 EM Manager \\
\hline Terri Nelson & & $574-7033$ & TRX & $\begin{array}{l}\text { WAG } 7 \text { Facility and Project Manager, WAG } \\
5 \text { Facility Manager }\end{array}$ \\
\hline Rona Painter & & $576-5477$ & RR9 & K-25 Groundwater Program \\
\hline Robert Poling & & $576-5493$ & $\mathrm{P} 80$ & K-25 Groundwater Program \\
\hline Tony Poole & & $241-3591$ & D6P & K-25 ambient monitoring \\
\hline Rob Rich & & $574-0678$ & RA3 & $\begin{array}{l}\text { ambient monitoring of K-901A and K-1007A } \\
\text { ponds; stormwater sampling for Mitchell, } \\
\text { Poplar, Clinch }\end{array}$ \\
\hline Jim Rodgers & & $574-8982$ & JGR & Environmental Compliance for all sites \\
\hline Jean Shaakir-Ali & & $574-5359$ & IJL & WAG 2 \\
\hline Lisa Shipe & & $241-2590$ & OLG & K-25 Monitoring Group \\
\hline Valerie Smith & & $241-3518$ & VD5 & $\mathrm{K}-901$ and other $\mathrm{K}-25$ OUs \\
\hline Brian Spalding & & $574-7265$ & BPS & Pit 1 of WAG 7 \\
\hline Pam Stevens & & $576-5488$ & NPT & $\mathrm{K}-25$ outfalls \\
\hline Jane Tate & Jacobs & $220-4872$ & & South Campus \\
\hline
\end{tabular}


A-8

Table A.1 (continued)

\begin{tabular}{|l|l|c|c|l|}
\hline \multicolumn{1}{|c|}{ Name } & Employer & Phone & UserID & \multicolumn{1}{|c|}{ Notes/project affiliation } \\
\hline Chris Taylor & & $576-6813$ & YLO & WAG 1, WAG 7 \\
\hline Fred Taylor & & $435-3418$ & FGT & Former WAG 7 Project Manager \\
\hline Ralph Turner & & $574-7856$ & RRT & Bear Creek \\
\hline Frank Van Ryn & & $574-1907$ & XS2 & K-770 \\
\hline Ed Vazquez & & $576-1930$ & EAV & Y-12 Data Management Program \\
\hline Steve Walker & & & & $\begin{array}{l}\text { Technical Lead for future soil sampling at } \\
\text { Bear Creek Road }\end{array}$ \\
\hline Ben Watts & & $576-4710$ & BW3 & K-25 Data Management Program \\
\hline Don Watkins & & $576-9931$ & W5T & WAG 2 \\
\hline Darrell West & & $574-7367$ & DAR & \\
\hline Lori Wiley & CDM & & & UEFPC soil sampling \\
\hline Jackie Williams & & $241-5119$ & XLW & K-25 Data Management Program \\
\hline Kirk Wilson & & $576-5290$ & QRG & WAG 6 Facility Manager \\
\hline Pam Wood & & $576-9925$ & PW7 & ORNL editor, Document control \\
\hline Steve Wood & CDM & $482-1065$ & & $\begin{array}{l}\text { Chestnut Ridge OU2: soil, sediment, and } \\
\text { surface water }\end{array}$ \\
\hline
\end{tabular}


FIG. A.1. REFERRALS

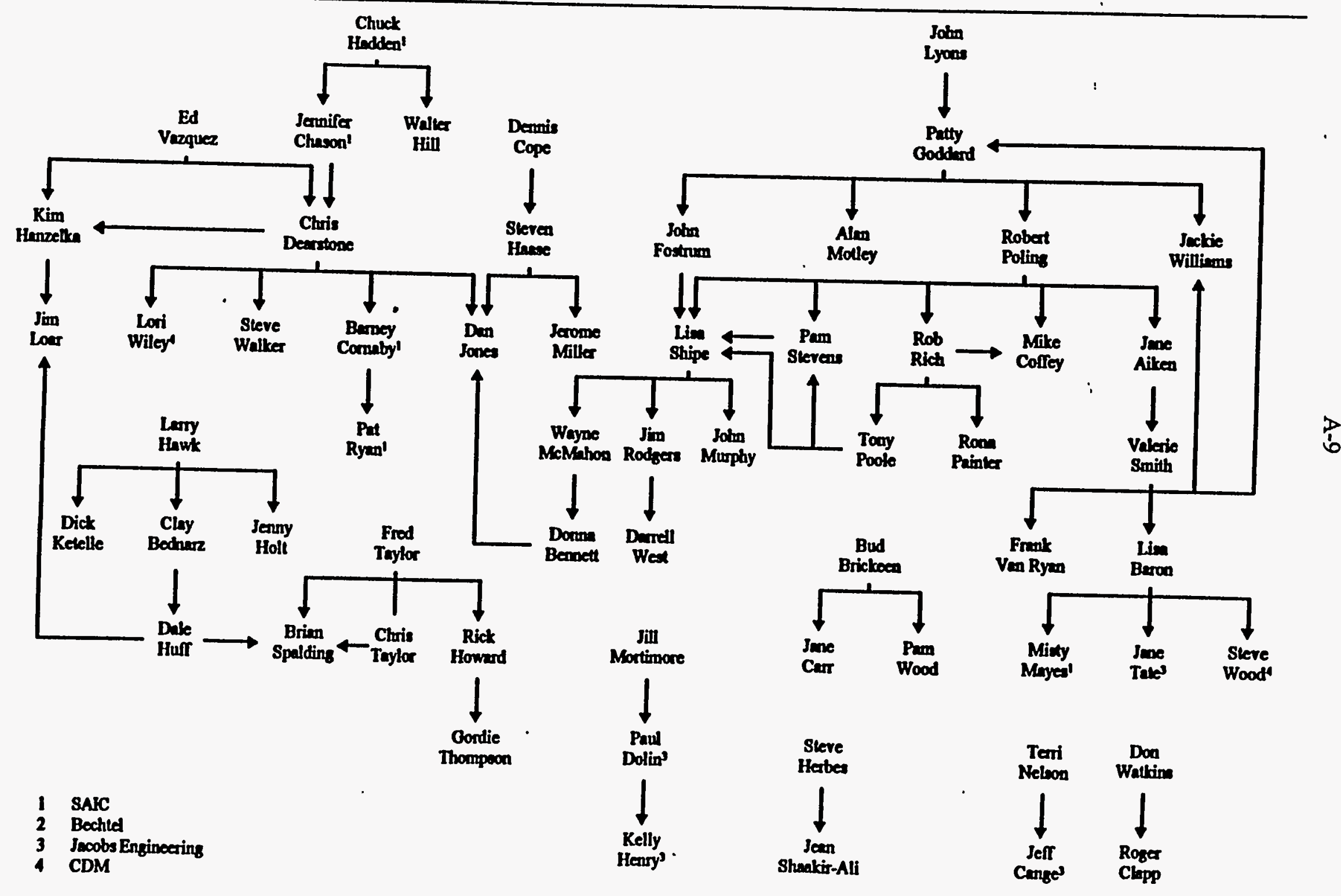


FIG. A.2. SURVEY PARTICIPANT FORM

\section{PROJECT TO LOCATE DATA FOR THE OAK RIDGE RESERVATION \\ WHICH COULD SUPPORT ECOLOGICAL RISK ASSESSMENTS}

\section{INFORMATION ABOUT PERSONS CONTACTED (DRAFT)}

(Complete information is requested only for authorities and custodians of surface water or soil data)

Name of person contacted

(last, first, middle initial)

Job title

Three-character User ID (or E-mail name if person has no User ID)

Phone number

Fax number

How was this person identified to be contacted? (e.g., referred to by program manager; name selected from organizational chart...)

Location

Employer (MMES, SAIC, Bechtel, ...)

Programmatic affiliation (ER, Compliance, BMAP, general research, ...)

Job responsibilities (Free form and flexible)

Operable Unit affiliations (which OU's does this person work with?)

Main role in identifying or providing data (check all that apply):

1. Broad knowledge about multiple data sets

2. Broad knowledge about a major program

3. Detailed knowledge about one or more subprograms or tasks

4. ___ Data system expert

5. Data custodian (of what data?) (Add names of the data authorities)

6. Data authority (of what data?) (Add the name of the person who collected the data for which this person is an authority, or who was in charge of the field teams) 
What programs, subprograms, or data systems is this person knowledgeable about?

What subject areas (and, if relevant, specialties) (e.g., chemistry-mercury, biology-benthic macroinvertebrates, radionuclide concentrations, data management, project management...) is this person knowledgeable about?

Expected usefuiness of this contact in similar future data searches

\section{High Intermediate Low}

Comments on expected usefuiness:

Other comments

Contact made by:

Date(s):

Method (e.g., in person, by phone, E-mail, correspondence): 


\section{DRAFT ORR-EMAP-ORNL Environmental Restoration Data Inventory}

Interview Form for Relevant Data in the 3/95 search for data to support the ORR-EMAP (Terrestrial) Ecological Risk Assessment for the Reservation (As determined by Media/Sample Matrix meeting the filter specifications)

1. Organization (Program/Project/Division):

2. SubProgram or Task:

3. Data File or Model Name:

4. Data Path or Location:

5. Data Purpose:

6. Site Area Description:

7. Location Description:

8. Approximate Date Range: [__

9. Media/Sample Marrix:

10. Primary Custodian of Dataset:

11. Phone Numbers: User ID:

12. Secondary Custodian of Dataset:

13. Phone Numbers: User ID:

14. Primary Data Authority:

15. Phone Numbers: User ID:

16. Secondary Data Authority:

17. Phone Numbers: User ID:

18. Data Generator: (Subcontractor, if applicable)

19. Phone Numbers: User ID:

20. Approximate Time of Last Data Base Update:

21. Intended Frequency of Data Base Update: (Monthly, Quarterly, Annually, etc.) 
FIG. A.3. DATASET INFORMATION FORM (CONTINUED)

22. Abstract:

23. Archive Software:

(Current Database)

25. Presentation Format:

Tabular (Spreadsheet)

Textual (Word Processing)

Graphical (non-spatial raster image)

Spatial (True Earth GIS file)
24. Hardware Used:

$\overline{\text { (Original Platform) }}$

26. Grid System:

(X-10, Admin, TN SP, LavLong)

27. Distribution Point:

(ORNL Domain Name, IP Address)

28. Comments/Other Information:

29. Keywords:

30. Identifiers:

31. Estimated Size:

32. Validation/Evaluation (Yes/No): 33. If "Yes," Describe Type:

34. Data Dictionary (Yes/No):

35. Reports: (attach additional page, if needed)

1) DMC Number: Date Published:

Title:

2) DMC Number: Date Published:

Title:

3) DMC Number: Date Published:

Title: 
This information SUPPLEMENTS that obtained for the Draft ORR-EMAP-ORNL Environmental Restoration Data Inventory Interview Form (from Gordie Thompson) as supported by its "Classification Scheme"

Number (hand-assigned) of the Interview Form which this sheet supplements

Name by which data are known, or a descriptive name for the data. (Example: "BMAP Fish Community sampling data")

Types of samples Contaminant leveis Toxicity General water quality Biota status Other

Types of contaminants, biota, or other measurements represented by the data (e.g., toxicity of noncharacterized water to Ceriodaphnia dubia; levels of $\mathbf{n}$ congeners of PCB's; metals; bioaccumulation study of $x$ in blue herons; ...) (also attach a list of variables or a summary of data if available)

How many stations or locations were sampled? (approximate is OK)?

If soil samples are included, were these Surface? Shallow $\left(<12^{\prime \prime}\right)$ ? Deep $\left(>12^{\prime \prime}\right)$ ?

What is/was the frequency of sampling?

Is sampling ongoing?

If ongoing, provide the scheduled end date if there is one

Sampling method(s) 
Analysis method(s)

Are qualifiers included in the data set $(\mathrm{Y} / \mathrm{N})$ ? Lab? If yes, indicate type(s) included Validation? Other?

Are nondetects included in the data set?

Please characterize the level of data assessment (QA/QC):

Validation/evaluation performed?

(If yes, what type of validation/evaluation was performed?)

_ Are validation/Evaluation results included in the electronic data? Collected under ER standards prevailing at the time of collection?

What approximate percentage of relevant data are in the Oak Ridge Environmental Information System (OREIS)?

Recommended media for transfer (obtain from OREIS; electronically via ftp; diskette(s),...)

Cutoff date for fully validated data

Cutoff date for unvalidated but available data

Any special considerations relating to use of the data? 
Person who compiled this information

Date information was compiled

1.

All persons are thought to be employees of Lockheed Martin Energy Systems, Inc. (LMES) except where indicated.

2.

E-mail address is UserID@ORNL.GoV 


\section{Appendix B}

TABLES FOR CHAPTER 3: EVALUATION OF THE POTENTIAL USE OF OPERABLE UNITS ON THE OAK RIDGE RESERVATION BY WILDLIFE 
- 
Table B.1. Habitat requirements for assessment and measurement endpoints on the ORR

\begin{tabular}{|c|c|c|}
\hline Species & General habitat requirements & Citation \\
\hline Mallard duck & $\begin{array}{l}\text { Ponds, lakes, slow-moving streams or rivers. } \\
\text { shallow water }(<41 \mathrm{~cm}) \text { for feeding }\end{array}$ & DeGraaf and Rudis 1986 \\
\hline Cumberland slider & $\begin{array}{l}\text { Found in shallow freshwaters with lots of } \\
\text { aquatic vegetation. They will inhabit mainly } \\
\text { larger bodies of water with deep water avilable } \\
\text { ( } 3 \text { feet or more). }\end{array}$ & $\begin{array}{l}\text { Meyers-Schone and } \\
\text { Walton } 1994\end{array}$ \\
\hline Mink & $\begin{array}{l}\text { Streambanks, lakeshores, and marshes. Favors } \\
\text { forested wetlands with abundant cover such as } \\
\text { thickets, rocks, or windfalls. }\end{array}$ & DeGraaf and Rudis 1986 \\
\hline River otter & $\begin{array}{l}\text { Borders of streams, lakes or other wetlands in } \\
\text { forested areas. }\end{array}$ & DeGraaf and Rudis 1986 \\
\hline Great blue heron & $\begin{array}{l}\text { All sizes and types of bodies of water that } \\
\text { contain fish }\end{array}$ & DeGraaf and Rudis 1986 \\
\hline Belted kingfisher & $\begin{array}{l}\text { Earthen bank for nesting; pond, lake, stream, or } \\
\text { river for feeding. }\end{array}$ & DeGraaf and Rudis 1986 \\
\hline Bald eagle & $\begin{array}{l}\text { Large bodies of water that contain fish, large } \\
\text { living trees for nesting. Low human } \\
\text { disturbance. }\end{array}$ & DeGraaf and Rudis 1986 \\
\hline Osprey & $\begin{array}{l}\text { Near large bodies of water that support } \\
\text { abundant fish. Along rivers and lakes }\end{array}$ & DeGraaf and Rudis 1986 \\
\hline $\begin{array}{l}\text { Double-crested } \\
\text { cormorant }\end{array}$ & $\begin{array}{l}\text { Found on rocky coasts, beaches, inland lakes } \\
\text { and rivers. }\end{array}$ & $\begin{array}{l}\text { National Geographic } \\
\text { Society } 1987\end{array}$ \\
\hline $\begin{array}{l}\text { Black-crowned night } \\
\text { heron }\end{array}$ & $\begin{array}{l}\text { Ponds, lakes, marshes, slow streams with pools, } \\
\text { or rivers }\end{array}$ & DeGraaf and Rudis 1986 \\
\hline Northern water snake & Aquatic and semi aquatic habitats & DeGraaf and Rudis 1986 \\
\hline Pied-billed grebe & $\begin{array}{l}\text { Lakes, rivers, or ponds with emergent } \\
\text { vegetation and open water }\end{array}$ & DeGraaf and Rudis 1986 \\
\hline Leopard frog & $\begin{array}{l}\text { all types of shallow freshwater habitats; } \\
\text { includes streams, rivers, ponds, or lakes }\end{array}$ & Conant 1986 \\
\hline Hellbender & $\begin{array}{l}\text { Almost always found in rivers and larger } \\
\text { streams where water is running and ample } \\
\text { shelter is available in the form of large rocks, } \\
\text { snags, or debris. }\end{array}$ & Conant 1986 \\
\hline $\begin{array}{l}\text { Rough-winged } \\
\text { swallows }\end{array}$ & $\begin{array}{l}\text { Nearly any open area with adequate nest sites } \\
\text { and a water supply (usually a stream). Often } \\
\text { river valleys and lake shores. }\end{array}$ & DeGraaf and Rudis 1986 \\
\hline
\end{tabular}


Table B.1 (continued)

\begin{tabular}{|c|c|}
\hline Species & General habitat requirements \\
\hline Gray bat & $\begin{array}{l}\text { Cave residents year-round, although different } \\
\text { caves are occupied in summer and winter. } \\
\text { Forage over lakes and rivers. }\end{array}$ \\
\hline Indiana bat & $\begin{array}{l}\text { Favors limestone caves with pools of water. } \\
\text { Solitary females or small maternity colonies } \\
\text { bear young in hollow trees or under loose bark. } \\
\text { Forages over riparian forest and associated } \\
\text { fields }\end{array}$ \\
\hline $\begin{array}{l}\text { Eastern small footed } \\
\text { bat }\end{array}$ & $\begin{array}{l}\text { In or near woodland in caves, mine tunnels, } \\
\text { buildings, crevices in rocks. Maternity } \\
\text { colonies have been observed in buildings. } \\
\text { Forages low over trees and brush }\end{array}$ \\
\hline $\begin{array}{l}\text { Rafinesque's big-eared } \\
\text { bat }\end{array}$ & $\begin{array}{l}\text { Hibernate in caves, mines or similar habitats. } \\
\text { Maternity colonies are usually found in } \\
\text { abandoned buildings. Siuspected to be a } \\
\text { forest-inhabiting bat. }\end{array}$ \\
\hline American toad & $\begin{array}{l}\text { Almost any habitat: gardens, woods, yards with } \\
\text { cover, damp soil, and a food supply } \\
\text { Usually in moist upland woods }\end{array}$ \\
\hline American woodcock & $\begin{array}{l}\text { Moist woodlands in early stages of succession, } \\
\text { swamps, stream banks, bogs, rich bottomlands, } \\
\text { brushy edges of woods, dry open woods and } \\
\text { fields. }\end{array}$ \\
\hline European starling & $\begin{array}{l}\text { Farm, city, orchard, gardens, parks; Prefers } \\
\text { rural areas w/pastures or hayfields; If forests, } \\
\text { prefers stands with low percent canopy cover. } \\
\text { More common in vicinity of human } \\
\text { habitations. }\end{array}$ \\
\hline American robin & $\begin{array}{l}\text { Open woods and fields. Forages primarily in } \\
\text { lawns, gardens, grassy fields, etc. }\end{array}$ \\
\hline Short-tailed shrew & $\begin{array}{l}\text { Both timbered fairly open habitats: deciduous, } \\
\text { mixed, and less often coniferous forests with } \\
\text { moist loose humus; especially common along } \\
\text { banks of streams and in meadows with tall rank } \\
\text { grasses or sedges, brush piles, and stone walls. } \\
\text { Avoids dry, warm sites. }\end{array}$ \\
\hline Long-tailed shrew & found in deciduous and mixed forest. \\
\hline Masked shrew & $\begin{array}{l}\text { Damp deciduous and confiferous woodlands } \\
\text { with grasses, rocks, logs, or stumps for cover; } \\
\text { bogs and other moist areas. }\end{array}$ \\
\hline
\end{tabular}

DeGraaf and Rudis 1986

Mumford and Whitaker

1982

DeGraaf and Rudis 1986

Burt and Grossenheider

1976

Harvey 1992

Mumford and Whitaker

1982

DeGraaf and Rudis 1986

DeGraaf and Rudis 1986

DeGraaf and Rudis 1986

DeGraaf and Rudis 1986

DeGraaf and Rudis 1986

DeGraaf and Rudis 1986

DeGraaf and Rudis 1986 
Table B.1 (continued)

\begin{tabular}{|c|c|c|}
\hline Species & General habitat requirements & Citation \\
\hline Smokey shrew & $\begin{array}{l}\text { Damp, boulder-strewn, upland woods with } \\
\text { thick leafmold. Typically near streams with } \\
\text { moss-covered banks. }\end{array}$ & DeGraaf and Rudis 1986 \\
\hline Southeastern shrew & Open fields and woodlots & $\begin{array}{l}\text { Burt and Grossenheider } \\
1976\end{array}$ \\
\hline Six-line racerunner & $\begin{array}{l}\text { Dry regions in sparse woods with loose/sandy } \\
\text { soil and short grasses. }\end{array}$ & Smith 1967 \\
\hline Slender glass snake & dry grasslands or dry open woods & Conant 1986 \\
\hline $\begin{array}{l}\text { Tennessee cave } \\
\text { salamander }\end{array}$ & caves with water (species has external gills) & Conant 1986 \\
\hline Green salamander & $\begin{array}{l}\text { humid rocky areas where rock faces remain } \\
\text { moist and well protected from sun and direct } \\
\text { rain. }\end{array}$ & Conant 1986 \\
\hline Raccoon & $\begin{array}{l}\text { Wooded areas interrupted by fields and water } \\
\text { courses. Not usually found in dense forests, } \\
\text { commonly found in wetlands near human } \\
\text { habitation. }\end{array}$ & DeGraaf and Rudis 1986 \\
\hline Wood duck & $\begin{array}{l}\text { Shallow waters of ponds, lakes, or marshes } \\
\text { having abundant floating and emergent } \\
\text { vegetation. Wooded swamps or open flooded } \\
\text { lowland forests where food is available. }\end{array}$ & DeGraaf and Rudis 1986 \\
\hline Muskrat & $\begin{array}{l}\text { Marshes, shallow portions of lakes, ponds, } \\
\text { swamps, sluggish streams, drainage ditches. } \\
\text { Most abundant in areas with cattails. }\end{array}$ & DeGraaf and Rudis 1986 \\
\hline White-tailed deer & Mosaic of forests and open areas & DeGraaf and Rudis 1986 \\
\hline Wild turkey & $\begin{array}{l}\text { Mast-producing woodlands. Ideal habitat is a } \\
\text { network of open, mixed forests and fields. }\end{array}$ & DeGraaf and Rudis 1986 \\
\hline Canada goose & $\begin{array}{l}\text { marshes, shores of ponds and lakes, grassy } \\
\text { fields } \\
\text { or agricultural lands that provide additional } \\
\text { grazing areas. }\end{array}$ & DeGraaf and Rudis 1986 \\
\hline Eastern cottontail & $\begin{array}{l}\text { Farmlands, pastures, fallow fields, open } \\
\text { woodlands, thickets along fence rows and stone } \\
\text { walls, edges of forests. swamps and marshes, } \\
\text { suburban areas with adequate food and cover. } \\
\text { Avoids dense woods. }\end{array}$ & DeGraaf and Rudis 1986 \\
\hline Groundhog & $\begin{array}{l}\text { Open land. Edges of woodlands (seldom in } \\
\text { interior), open cultivated land, pastures, } \\
\text { meadows, open brushy hillsides. }\end{array}$ & DeGraaf and Rudis 1986 \\
\hline
\end{tabular}


Table B.1 (continued)

\begin{tabular}{|c|c|}
\hline Species & General habitat requirements \\
\hline Grasshopper sparrow & $\begin{array}{l}\text { Hayfields, weedy fallow fields, prairies. } \\
\text { Avoids shrubby fields. Birds favor uplands } \\
\text { with ground vegetation of various densities. }\end{array}$ \\
\hline Henslow's sparrow & $\begin{array}{l}\text { Neglected weedy fields-commonly of } \\
\text { broomsedge-wet meadows, saltmarsh edges. } \\
\text { Occaisionally in dry and cultivated uplands. } \\
\text { May fovor moist lowland habitat and may use } \\
\text { areas with widely scattered shrubs. }\end{array}$ \\
\hline Lark sparrow & $\begin{array}{l}\text { generally prefers sites with grasslands or open } \\
\text { woodlands }\end{array}$ \\
\hline Vesper sparrow & $\begin{array}{l}\text { Breed in short-grass meadows, pastures, } \\
\text { hayfields, cultivated grain fields, dry open } \\
\text { uplands, bumed and cut-over areas in forests, } \\
\text { country roadsides. Birds favor sparsely } \\
\text { vegetated uplands and may use areas with } \\
\text { widely scattered shrubs. }\end{array}$ \\
\hline Red-tailed hawk & $\begin{array}{l}\text { Deciduous and mixed woodlands interspersed } \\
\text { with meadows, brushy pastures, open bogs, and } \\
\text { swampy areas. Large openings for foraging. }\end{array}$ \\
\hline Golden eagle & $\begin{array}{l}\text { Elevated nest sites, especially cliffs. Broad } \\
\text { expanses of open land for hunting. } \\
50 \text { to } 100 \text { square mile home range. }\end{array}$ \\
\hline Northern harrier & $\begin{array}{l}\text { Open country with herbaceous or low woody } \\
\text { vegetation for nest concealment. }\end{array}$ \\
\hline Cooper's hawk & $\begin{array}{l}\text { Extensive deciduous or mixed woodlands that } \\
\text { are dense or open, scattered woodlots } \\
\text { interspersed with open fields. Occupies similar } \\
\text { forest niche as Sharp-shinned Hawk but has } \\
\text { broadened its habitat by moving into more } \\
\text { open agricultural areas. Flood plain forests and } \\
\text { wooded swamps. }\end{array}$ \\
\hline Red-shouldered hawk & $\begin{array}{l}\text { Moist hardwood or mixed woodlands, wooded } \\
\text { swamps, bottomlands and wooded margins of } \\
\text { marshes often close to cultivated fields. }\end{array}$ \\
\hline Sharp-shinned hawk & $\begin{array}{l}\text { Open mixed or coniferous woodlands, clearing, } \\
\text { edges. Extensive open mixed woodlands that } \\
\text { are free from human disturbance. }\end{array}$ \\
\hline Barn owl & $\begin{array}{l}\text { Almost anywhere in open country but prefers } \\
\text { vicinity of farms and villages. Avoids } \\
\text { woodlands and higher elevations. }\end{array}$ \\
\hline Black vulture & $\begin{array}{l}\text { Common in open country and around human } \\
\text { settlements, avoids heavily forested areas }\end{array}$ \\
\hline
\end{tabular}

DeGraaf and Rudis 1986

National Geographc

Society 1987

DeGraaf and Rudis 1986

DeGraaf and Rudis 1986

DeGraaf and Rudis 1986

DeGraaf and Rudis 1986

DeGraaf and Rudis 1986

DeGraaf and Rudis 1986

DeGraaf and Rudis 1986

DeGraaf and Rudis 1986

Ehrlich et al. 1988 
Table B.1 (continued)

\begin{tabular}{lll}
\hline \multicolumn{1}{c}{ Species } & \multicolumn{1}{c}{ General habitat requirements } & \multicolumn{1}{c}{ Citation } \\
\hline Cougar & $\begin{array}{l}\text { Found throughout all habitat types and } \\
\text { successional stages. } \\
\text { Requires isolation away from human } \\
\text { disturbance. }\end{array}$ & DeGraaf and Rudis 1986 \\
& $\begin{array}{l}\text { Home ranges may vary in size from } 5 \text { to } 96 \\
\text { square miles. }\end{array}$ & \\
A mixture of forest and open areas is preferred. & DeGraaf and Rudis 1986 \\
Red fox & $\begin{array}{l}\text { Unbroken fields and dense forests avoided. } \\
\text { Edges used heavily. }\end{array}$ & \\
Snapping turtle & $\begin{array}{l}\text { Any permanent body of freshwater, large or } \\
\text { small. }\end{array}$ & DeGraaf and Rudis 1986 \\
Black rat snake & $\begin{array}{l}\text { Variety of habitats including woodlands, } \\
\text { thickets, field edges, farmlands, rocky hillsides, } \\
\text { river bottoms, old barns. }\end{array}$ & DeGraaf and Rudis 1986 \\
Northern pine snake & $\begin{array}{l}\text { Flat, sandy pine barrens, sandhills, and dry } \\
\text { mountain ridges, most often in or near pine } \\
\text { woods. }\end{array}$ & Conant 1986 \\
\hline
\end{tabular}


Table B.2. Summary of landcover types identified on the ORR and expected use by assessment and measurement endpoints

\begin{tabular}{|c|c|c|c|c|c|c|c|c|c|c|}
\hline \multirow[b]{2}{*}{ Species } & \multicolumn{10}{|c|}{ Landcover types" on the ORR } \\
\hline & Urban & Water & $\begin{array}{l}\text { Pine } \\
\text { forest }\end{array}$ & Pine plant. & $\begin{array}{l}\text { Decid. } \\
\text { forest }\end{array}$ & $\begin{array}{l}\text { Mixed } \\
\text { forest }\end{array}$ & Pasture & Trans. & Barren & Other \\
\hline Mallard duck & & $\mathrm{X}$ & & & & & & & & \\
\hline Cumberland slider & & $\mathrm{X}$ & & & & & & & & \\
\hline Mink & & $\mathrm{X}$ & & & $\mathrm{X}$ & $\mathrm{X}$ & & & & $\begin{array}{l}\text { water primary; } \\
\text { forest secondary }\end{array}$ \\
\hline River otter & & $\mathrm{X}$ & & & $\mathrm{x}$ & $\mathrm{X}$ & & & & $\begin{array}{l}\text { water primary; } \\
\text { forest secondary }\end{array}$ \\
\hline Great blue heron & & $\mathbf{X}$ & & & & & & & & \\
\hline Belted kingfisher & & $\mathrm{X}$ & & & & & & & & \\
\hline Bald eagle & & $\mathrm{X}$ & & & & & & & & $\begin{array}{c}\text { large bodies of } \\
\text { water }\end{array}$ \\
\hline Osprey & & $\mathrm{x}$ & & & & & & & & $\begin{array}{c}\text { large bodies of } \\
\text { water }\end{array}$ \\
\hline Double-crested cormorant & & $\mathrm{X}$ & & & & & & & & $\begin{array}{c}\text { large bodies of } \\
\text { water }\end{array}$ \\
\hline Black-crowned night heron & & $\mathrm{X}$ & & & & & & & & \\
\hline Northern water snake & & $\mathrm{X}$ & & & & & & & & \\
\hline Pied-billed grebe & & $\mathrm{X}$ & & & & & & & & \\
\hline Leopard frog & & $\mathrm{X}$ & & & & & & & & \\
\hline Hellbender & & $\mathrm{X}$ & & & & & & & & \\
\hline
\end{tabular}


Table B.2 (continued)

\begin{tabular}{|c|c|c|c|c|c|c|c|c|c|c|}
\hline \multirow[b]{2}{*}{ Species } & \multicolumn{10}{|c|}{ Landcover types" on the ORR } \\
\hline & Urban & Water & $\begin{array}{c}\text { Pine } \\
\text { forest }\end{array}$ & Pine plant. & $\begin{array}{l}\text { Decid. } \\
\text { forest }\end{array}$ & $\begin{array}{l}\text { Mixed } \\
\text { forest } \\
\end{array}$ & Pasture & Trans. & Barren & Other \\
\hline Rough-winged swallows & & $\mathrm{x}$ & & & & & $\mathrm{x}$ & $\mathrm{X}$ & & Earthen Banks \\
\hline Gray bat & & $\mathrm{x}$ & & & & & & & & $\begin{array}{l}\text { large bodies of } \\
\text { water, caves }\end{array}$ \\
\hline Indiana bat & & $\mathrm{X}$ & & & $\mathrm{X}$ & $\mathrm{X}$ & $\mathrm{X}$ & $\mathrm{X}$ & & \\
\hline Eastern small footed bat & & & & & $\mathrm{X}$ & & $\mathrm{X}$ & $\mathrm{X}$ & & \\
\hline Rafinesque's big-eared bat & $\begin{array}{c}\mathrm{X} \\
\text { (buiildings) }\end{array}$ & & $\mathrm{X}$ & $\mathrm{X}$ & $\mathrm{X}$ & $\mathrm{X}$ & & & & Caves \\
\hline American toad & & $\mathrm{X}$ & $\mathrm{X}$ & $\mathrm{X}$ & $\mathrm{X}$ & $\mathrm{X}$ & & & & $\begin{array}{l}\text { forest primary; } \\
\text { water secondary }\end{array}$ \\
\hline American woodcock & & & & & $\mathrm{X}$ & $\mathrm{x}$ & $\mathrm{X}$ & $\mathrm{X}$ & & \\
\hline European starling & $\mathrm{X}$ & & $\mathrm{X}$ & $\mathbf{x}$ & $\mathrm{X}$ & $\mathrm{X}$ & $\mathrm{X}$ & $\mathrm{X}$ & & \\
\hline American robin & $\mathrm{X}$ & & $\mathrm{X}$ & $\mathrm{X}$ & $\mathrm{X}$ & $\mathbf{X}$ & $\mathrm{x}$ & $\mathrm{X}$ & & \\
\hline Short-tailed shrew & & & $\mathrm{X}$ & $\mathrm{X}$ & $\mathrm{X}$ & $\mathrm{X}$ & & $\mathrm{X}$ & & \\
\hline Long-tailed shrew & & & & & $\mathrm{X}$ & $\mathrm{X}$ & & & & \\
\hline Masked shrew & & & & & $\mathrm{X}$ & $\mathrm{X}$ & & & & \\
\hline Smokey shrew & & & & & $\mathrm{X}$ & $\mathrm{x}$ & & & & \\
\hline Southeastern shrew & & & $\mathrm{X}$ & $\mathrm{X}$ & $\mathrm{X}$ & $\mathrm{X}$ & $\mathrm{X}$ & $\mathrm{X}$ & & \\
\hline Six-line racerunner & & & $\mathrm{X}$ & $\mathrm{X}$ & $\mathrm{X}$ & $\mathrm{X}$ & $\mathrm{X}$ & $\mathrm{X}$ & & \\
\hline Slender glass snake & & & $\mathbf{x}$ & $\mathrm{X}$ & $\mathrm{X}$ & $\mathbf{x}$ & $\mathrm{X}$ & $\mathrm{X}$ & & \\
\hline
\end{tabular}


Table B.2 (continued)

\begin{tabular}{|c|c|c|c|c|c|c|c|c|c|c|}
\hline \multirow[b]{2}{*}{ Species } & \multicolumn{10}{|c|}{ Landcover types on the ORR } \\
\hline & Urban & Water & $\begin{array}{c}\text { Pine } \\
\text { forest }\end{array}$ & Pine plant. & $\begin{array}{l}\text { Decid. } \\
\text { forest }\end{array}$ & $\begin{array}{l}\text { Mixed } \\
\text { forest } \\
\end{array}$ & Pasture & Trans. & Barren & Other \\
\hline Tennessee cave salamander & & & & & & & & & & Caves \\
\hline Green salamander & & & & & & & & & & moist, rocky sites \\
\hline Raccoon & $\mathrm{X}$ & $\mathrm{X}$ & $\mathrm{X}$ & $\mathrm{X}$ & $\mathrm{X}$ & $\mathrm{X}$ & $\mathrm{x}$ & $\mathrm{X}$ & & \\
\hline Wood duck & & $\mathrm{X}$ & & & $\mathrm{X}$ & $\mathrm{x}$ & & & & \\
\hline Muskrat & & $\mathrm{X}$ & & & & & & & & \\
\hline White-tailed deer & & & $\mathrm{X}$ & $\mathrm{X}$ & $\mathrm{X}$ & $\mathrm{X}$ & $\mathrm{X}$ & $\mathrm{X}$ & & \\
\hline Wild turkey & & & $\mathrm{X}$ & $\mathrm{x}$ & $\mathrm{X}$ & $\mathrm{x}$ & $\mathrm{X}$ & $\mathrm{X}$ & & \\
\hline Canada goose & $\mathrm{X}$ & $\mathrm{X}$ & & & & & $\mathrm{X}$ & & & \\
\hline Eastern cottontail & $\mathrm{X}$ & & & & & & $\mathrm{X}$ & $\mathrm{x}$ & & \\
\hline Groundhog & $\mathrm{X}$ & & & & & & $\mathrm{X}$ & $\mathrm{X}$ & & \\
\hline Grasshopper sparrow & & & & & & & $\mathrm{x}$ & $\mathrm{x}$ & & \\
\hline Henslow's sparrow & & & & & & & $\mathrm{X}$ & $\mathrm{X}$ & & \\
\hline Lark sparrow & & & & & $\mathrm{X}$ & $\mathrm{X}$ & $\mathrm{X}$ & $\mathrm{X}$ & & \\
\hline Vesper sparrow & & & & & & & $X$ & $\mathrm{X}$ & & \\
\hline Red-tailed hawk & & & $\mathrm{X}$ & $\mathrm{X}$ & $\mathrm{X}$ & $\mathrm{X}$ & $\mathrm{X}$ & $\mathrm{X}$ & & \\
\hline Golden eagle & & & & & & & & & & $\begin{array}{c}\text { use of ORR } \\
\text { unlikely }^{\mathrm{B}}\end{array}$ \\
\hline Northern harrier & & & & & & & $\mathrm{X}$ & $\mathrm{X}$ & & \\
\hline
\end{tabular}


Table B.2 (continued)

\begin{tabular}{|c|c|c|c|c|c|c|c|c|c|c|}
\hline \multirow[b]{2}{*}{ Species } & \multicolumn{10}{|c|}{ Landcover types" on the ORR } \\
\hline & Urban & Water & $\begin{array}{c}\text { Pine } \\
\text { forest }\end{array}$ & Pine plant. & $\begin{array}{l}\text { Decid. } \\
\text { forest }\end{array}$ & $\begin{array}{l}\text { Mixed } \\
\text { forest }\end{array}$ & Pasture & Trans. & Barren & Other \\
\hline Cooper's hawk & & & & & $\mathrm{x}$ & $\mathrm{X}$ & $\mathrm{X}$ & $\mathrm{X}$ & & \\
\hline Red-shouldered hawk & & & & & $\mathrm{X}$ & $\mathbf{X}$ & & & & \\
\hline Sharp-shinned hawk & & & & & $\mathbf{X}$ & $\mathrm{X}$ & & & & \\
\hline Barn owl & $\mathrm{X}$ & & & & & & $\mathrm{X}$ & $\mathrm{X}$ & & \\
\hline Black vulture & & & & & & & $\mathrm{X}$ & $\mathrm{x}$ & & \\
\hline Cougar & & & $\mathrm{X}$ & $\mathrm{X}$ & $\mathrm{x}$ & $\mathbf{X}$ & $\mathrm{X}$ & $\mathrm{X}$ & & $\begin{array}{c}\text { use of ORR } \\
\text { unlikelyc }\end{array}$ \\
\hline Red fox & & & $\mathrm{x}$ & $\mathrm{X}$ & $\mathrm{x}$ & $\mathrm{x}$ & $\mathrm{X}$ & $\mathrm{X}$ & & \\
\hline Snapping turtle & & $\mathbf{x}$ & & & & & & & & \\
\hline Black rat snake & $\mathrm{X}$ & & $\mathrm{X}$ & $\mathrm{X}$ & $\mathrm{x}$ & $\mathrm{X}$ & $\mathrm{X}$ & $\mathbf{X}$ & & \\
\hline Northern pine snake & & & $\mathrm{X}$ & $\mathrm{X}$ & & $\mathrm{X}$ & & & & \\
\hline
\end{tabular}

Definitions of habitat types are presnted in Table $1 . \mathrm{X}$ in cell indicates use of habitat by listed endpoint species.

${ }^{B}$ While golden eagles may migrate through the ORR, because the ORR does not contain large expanses of open habitat, significant use of any area on the ORR is highly unlikely.

${ }^{c}$ Because the ORR does not contain large expanses of habitat away from human disturbance, significant use of any area on the ORR is highly unlikely. 
Table B.3. Summary of landcover types identified on OUs on the ORR

\begin{tabular}{|c|c|c|c|c|c|c|c|c|c|c|}
\hline \multirow[b]{2}{*}{$\mathbf{O U}$} & \multicolumn{10}{|c|}{ Area (ha) by landcover type } \\
\hline & Urban & Water & $\begin{array}{c}\text { Pine } \\
\text { forest }\end{array}$ & Pine plant. & $\begin{array}{l}\text { Decid. } \\
\text { forest }\end{array}$ & $\begin{array}{l}\text { Mixed } \\
\text { forest } \\
\end{array}$ & Pasture & Trans. & Barren & Total \\
\hline Area $10(\mathrm{~K}-901)$ & 15.94 & 3.56 & 1.75 & 0.31 & 6.87 & 7.62 & 3.19 & 38.31 & & 77.5 \\
\hline $\mathrm{K}-33$ & 65 & 0.12 & & & 2.94 & 0.87 & 5.06 & 13.94 & 0.37 & 88.3 \\
\hline K-1064 & 110.6 & & & & & & 0.19 & 3.56 & 0.06 & 14.87 \\
\hline $\mathrm{K}-1410$ & 3.19 & & & & & & & 0.31 & & 3.5 \\
\hline $\mathrm{K}-29$ & 25.62 & & & & & & 0.62 & 0.88 & & 27.12 \\
\hline K-1007 & 13.75 & 7.62 & & & & & 0.19 & 0.75 & & 22.31 \\
\hline $\mathrm{K}-1413$ & 1.31 & & & & & & & & & 1.31 \\
\hline $\mathrm{K}-1004$ & 2.94 & & & & & & & & & 2.94 \\
\hline $\mathrm{K}-1070-\mathrm{C} / \mathrm{D}$ & 6.56 & & & & 1.69 & 0.19 & 0.25 & 4.37 & & 13.06 \\
\hline $\mathrm{K}-1401$ & 8.06 & & & & & & & & & 8.06 \\
\hline $\mathrm{K}-1420$ & 2.31 & & & & & & & & & 2.31 \\
\hline K-1407 & 12.31 & $0^{\mathrm{a}}$ & & & & & & 4.19 & & 16.5 \\
\hline $\mathrm{K}-770$ & 43.81 & 2 & 2.37 & 1.06 & 4.37 & 3.12 & 4.19 & 28 & 0.06 & 88.98 \\
\hline WAG 1 & 48.18 & $0^{\mathrm{a}}$ & 0.81 & & 1.25 & 0.81 & 0.94 & & & 51.99 \\
\hline WAG 2 & 13 & 9 & 1 & & 15.75 & 29 & 0.06 & 14.81 & & 82.62 \\
\hline WAG 3 & 0.56 & & 0.19 & & 1.06 & 2.19 & 0.06 & 8.12 & & 12.18 \\
\hline WAG 4 & 6.37 & $0^{\mathrm{a}}$ & & & 2.19 & 1.19 & 4.5 & 1.06 & & 15.31 \\
\hline
\end{tabular}


Table B.3 (continued)

\begin{tabular}{|c|c|c|c|c|c|c|c|c|c|c|}
\hline \multirow[b]{2}{*}{$\mathbf{O U}$} & \multicolumn{10}{|c|}{ Area (ha) by landcover type } \\
\hline & Urban & Water & $\begin{array}{c}\text { Pine } \\
\text { forest }\end{array}$ & Pine plant. & $\begin{array}{l}\text { Decid. } \\
\text { forest }\end{array}$ & $\begin{array}{l}\text { Mixed } \\
\text { forest }\end{array}$ & Pasture & Trans. & Barren & Total \\
\hline WAG 5 & 10.19 & $0^{\mathrm{a}}$ & 0.25 & & 3.56 & 6.44 & 7.69 & 9.06 & & 37.19 \\
\hline WAG 6 & 25.5 & 0.75 & & & 5.06 & 2.06 & 0.5 & 2.94 & & 36.81 \\
\hline WAG 7 & 5.37 & $0^{2}$ & 1.44 & & 17.25 & 25.31 & 0.12 & 8.31 & & 57.8 \\
\hline WAG 8 & 17.81 & & 3.44 & & 1.44 & 3.785 & & 5.12 & & 31.56 \\
\hline WAG 9 & 1.37 & & & & 0.25 & 0.06 & & 0.31 & & 1.99 \\
\hline WAG 10 & 0.5 & & 0.12 & & 0.06 & 0.19 & & 0.25 & & 1.12 \\
\hline WAG 11 & 0.31 & & 4.56 & & 0.81 & 3.81 & 0.37 & 5.12 & & 14.98 \\
\hline WAG 13 & 0.56 & & 0.12 & & 0.18 & 0.44 & 0.37 & 1.81 & & 3.48 \\
\hline Bear Creek & 85.37 & $0^{\mathrm{s}}$ & 37.37 & 20.94 & 192.81 & 140.56 & 14.62 & 246.06 & 0.44 & 738.17 \\
\hline BC OU1 & 9.5 & & & & 8.19 & 0.25 & 9.19 & 24 & 0.25 & 51.38 \\
\hline $\mathrm{BC}$ OU2 & 4.12 & & & & & & & 0.62 & 0.06 & 4.8 \\
\hline CR OU1 & 1.5 & & & & & 0.19 & 2.5 & 2.06 & & 6.25 \\
\hline CR OU2 & 0.94 & 0.06 & & & 3.81 & 0.38 & & 2.62 & & 7.81 \\
\hline CR OU3 & 0.31 & & & & & & 0.19 & & & 0.5 \\
\hline CR OU4 & 1.44 & 3.94 & & & 0.06 & 0.06 & 0.19 & 0.56 & 0.31 & 6.56 \\
\hline Lower East Fork Poplar Creek & 99.81 & 0.19 & 7.37 & 2.62 & 41.06 & 50.87 & 8.5 & 133.87 & 2 & 344.29 \\
\hline UEFPC OU2 & 3.56 & & & & & & & & & 3.56 \\
\hline UEFPC OU3 & 5.19 & & & & & & & & & 5.19 \\
\hline
\end{tabular}


Table B.3 (continued)

\begin{tabular}{|c|c|c|c|c|c|c|c|c|c|c|}
\hline \multirow[b]{2}{*}{$\mathbf{O U}$} & \multicolumn{10}{|c|}{ Area (ha) by landcover type } \\
\hline & Urban & Water & $\begin{array}{c}\text { Pine } \\
\text { forest }\end{array}$ & Pine plant. & $\begin{array}{l}\text { Decid. } \\
\text { forest }\end{array}$ & $\begin{array}{l}\text { Mixed } \\
\text { forest } \\
\end{array}$ & Pasture & Trans. & Barren & Total \\
\hline Freels Bend & 0.75 & 1.12 & & 0.06 & 2.06 & 3.88 & 0.81 & 4.56 & & 13.49 \\
\hline South Campus Facility & 9.81 & 0.44 & 0.06 & 0.06 & & & 13.25 & 4.5 & 0.44 & 28.56 \\
\hline
\end{tabular}

a While no surface water was observed in the satellite image, surface water is known to be present at this site. 
Table B.4. Summary of habitat availability for assessment and measurment endpoints at K-25 OUs."

\begin{tabular}{|c|c|c|c|c|c|c|c|c|c|c|c|c|c|}
\hline & K-901 & K-33 & K-1064 & $\mathrm{K}-1410$ & K-29 & K-1007 & K-1413 & K-1004 & $\mathrm{K}-1070-\mathrm{C} / \mathrm{D}$ & K-1401 & K-1420 & K-1407 & $\mathrm{K}-770$ \\
\hline Mallard duck & $\mathbf{x}$ & $\mathbf{x}$ & & & & $x$ & & & & & & $\mathrm{x}$ & $\mathrm{x}$ \\
\hline Cumberland slider & $\mathrm{x}$ & $\mathrm{x}$ & & & & $\mathrm{x}$ & & & & & & $\mathrm{x}$ & $\mathrm{x}$ \\
\hline Mink & $x$ & $x$ & & & & $\mathrm{x}$ & & & & & & $\mathrm{x}$ & $\mathrm{x}$ \\
\hline River otter & $x$ & $\mathrm{x}$ & & & & $\mathrm{x}$ & & & & & & $\mathrm{x}$ & $\mathrm{x}$ \\
\hline Great blue heron & $\mathrm{x}$ & $\mathrm{x}$ & & & & $\mathrm{x}$ & & & & & & $\mathrm{x}$ & $\mathrm{x}$ \\
\hline Belted kingfisher & $\mathrm{x}$ & $\mathrm{x}$ & & & & $\mathrm{x}$ & & & & & & $\mathrm{x}$ & $\mathbf{x}$ \\
\hline Bald eagle & $\mathrm{x}$ & & & & & $x$ & & & & & & & \\
\hline Osprey & $\mathrm{x}$ & & & & & $\mathrm{x}$ & & & & & & & \\
\hline $\begin{array}{l}\text { Double-crested } \\
\text { cormorant }\end{array}$ & $\mathrm{x}$ & & & & & $\mathbf{x}$ & & & & & & & \\
\hline $\begin{array}{l}\text { Black-crowned night } \\
\text { heron }\end{array}$ & $\mathrm{x}$ & $\mathrm{x}$ & & & & $\mathrm{x}$ & & & & & & $\mathrm{x}$ & $\mathrm{x}$ \\
\hline Northern Water snake & $\mathrm{x}$ & $\mathrm{x}$ & & & & $\mathrm{x}$ & & & & & & $\mathrm{x}$ & $x$ \\
\hline Pied-billed grebe & $\mathrm{x}$ & $\mathrm{x}$ & & & & $\mathrm{x}$ & & & & & & $\mathrm{x}$ & $\mathrm{x}$ \\
\hline Leopard frog & $\mathrm{x}$ & $\mathrm{x}$ & & & & $\mathrm{x}$ & & & & & & $\mathrm{x}$ & $x$ \\
\hline \multicolumn{14}{|l|}{ Hellbender } \\
\hline $\begin{array}{l}\text { Rough-winged } \\
\text { swallows }\end{array}$ & $\mathrm{x}$ & $\mathrm{x}$ & & & & $\mathrm{x}$ & & & $\mathrm{x}$ & & & $\mathrm{x}$ & $\mathrm{x}$ \\
\hline Gray bat & $\mathrm{x}$ & & & & & $\mathrm{x}$ & & & & & & & \\
\hline Indiana bat & $\mathrm{x}$ & $\mathrm{x}$ & $x$ & $\mathrm{x}$ & $\mathrm{x}$ & $\mathrm{x}$ & & & $\mathrm{x}$ & & & $\mathrm{x}$ & $\mathrm{x}$ \\
\hline Eastern small footed bat & $\mathrm{x}$ & $\mathbf{x}$ & $\mathrm{x}$ & $\mathrm{x}$ & $x$ & $\mathrm{x}$ & & & $\mathbf{x}$ & & & $x$ & $\mathbf{x}$ \\
\hline
\end{tabular}


Table B.4 (continued)

\begin{tabular}{|c|c|c|c|c|c|c|c|c|c|c|c|c|c|}
\hline & K-901 & K-33 & K-1064 & K-1410 & K-29 & K-1007 & $K-1413$ & K-1004 & K-1070-C/D & K-1401 & $K-1420$ & K-1407 & K-770 \\
\hline $\begin{array}{l}\text { Rafinesque's } \\
\text { big-eared bat }\end{array}$ & $x$ & $x$ & $x$ & $x$ & $\mathrm{x}$ & $\mathrm{x}$ & $x$ & $x$ & $x$ & $\mathrm{x}$ & $\mathrm{x}$ & $\mathrm{x}$ & $\mathrm{x}$ \\
\hline American toad & $\mathrm{x}$ & $\mathrm{x}$ & & & & & & & $\mathrm{x}$ & & & & $\mathrm{x}$ \\
\hline American woodcock & $\mathrm{x}$ & $\mathrm{x}$ & $\mathrm{x}$ & $\mathrm{x}$ & $\mathrm{x}$ & $\mathrm{x}$ & & & $\mathrm{x}$ & & & $\mathrm{x}$ & $\mathrm{x}$ \\
\hline European starling & $\mathrm{x}$ & $\mathrm{x}$ & $\mathrm{x}$ & $\mathrm{x}$ & $\mathrm{x}$ & $\mathrm{x}$ & $\mathrm{x}$ & $\mathrm{x}$ & $\mathrm{x}$ & $x$ & $x$ & $\mathrm{x}$ & $x$ \\
\hline American robin & $\mathrm{x}$ & $\mathrm{x}$ & $\mathrm{x}$ & $x$ & $\mathrm{x}$ & $\mathrm{x}$ & $x$ & $\mathrm{x}$ & $\mathbf{x}$ & $x$ & $\mathrm{x}$ & $\mathrm{x}$ & $\mathrm{x}$ \\
\hline Short-tailed shrew & $\mathrm{x}$ & $x$ & & & & & & & $\mathrm{x}$ & & & & $\mathrm{x}$ \\
\hline Long-tailed shrew & $\mathrm{x}$ & $\mathrm{x}$ & & & & & & & $\mathrm{x}$ & & & & $\mathrm{x}$ \\
\hline Masked shrew & $\mathrm{x}$ & $\mathrm{x}$ & & & & & & & $\mathrm{x}$ & & & & $\mathrm{x}$ \\
\hline Smokey shrew & $\mathrm{x}$ & $\mathrm{x}$ & & & & & & & $\mathrm{x}$ & & & & $\mathrm{x}$ \\
\hline Southeastern shrew & $\mathrm{x}$ & $x$ & $\mathrm{x}$ & $x$ & $\mathrm{x}$ & $\mathrm{x}$ & & & $x$ & & & $\mathrm{x}$ & $\mathrm{x}$ \\
\hline Six-line racerunner & $\mathrm{x}$ & $\mathrm{x}$ & $\mathrm{x}$ & $\mathrm{x}$ & $\mathrm{x}$ & $\mathrm{x}$ & & & $\mathrm{x}$ & & & $\mathrm{x}$ & $x$ \\
\hline Slender glass snake & $\mathrm{x}$ & $\mathrm{x}$ & $\mathrm{x}$. & $\mathrm{x}$ & $\mathrm{x}$ & $\mathrm{x}$ & & & $x$ & & & $x$ & $\mathrm{x}$ \\
\hline \multicolumn{14}{|l|}{$\begin{array}{l}\text { Tennessee cave } \\
\text { salamander }\end{array}$} \\
\hline \multicolumn{14}{|l|}{ Green salamander } \\
\hline Raccoon & $\mathrm{x}$ & $\mathrm{x}$ & $\mathrm{x}$ & $\mathrm{x}$ & $\mathrm{x}$ & $\mathrm{x}$ & $\mathrm{x}$ & $\mathrm{x}$ & $\mathrm{x}$ & $\mathrm{x}$ & $\mathrm{x}$ & $\mathrm{x}$ & $\mathrm{x}$ \\
\hline Wood duck & $x$ & $\mathrm{x}$ & & & & $\mathrm{x}$ & & & & & & $\mathrm{x}$ & $\mathrm{x}$ \\
\hline Muskrat & $\mathrm{x}$ & $\mathrm{x}$ & & & & $\mathrm{x}$ & & & & & & $x$ & $x$ \\
\hline White-tailed deer & $\mathrm{x}$ & $\mathrm{x}$ & $\mathrm{x}$ & $x$ & $\mathbf{x}$ & $\mathrm{x}$ & & & $x$ & & & $\mathrm{x}$ & $\mathrm{x}$ \\
\hline Wild turkey & $\mathrm{x}$ & $\mathrm{x}$ & $\mathrm{x}$ & $\mathrm{x}$ & $\mathbf{x}$ & $\mathrm{x}$ & & & $\mathrm{x}$ & & & $\mathrm{x}$ & $\mathrm{x}$ \\
\hline Canada goose & $\mathrm{x}$ & $\mathrm{x}$ & $\mathrm{x}$ & $\mathrm{x}$ & $\mathrm{x}$ & $\mathrm{x}$ & $\mathrm{x}$ & $\mathrm{x}$ & $\mathrm{x}$ & $\mathrm{x}$ & $\mathrm{x}$ & $\mathrm{x}$ & $\mathrm{x}$ \\
\hline
\end{tabular}




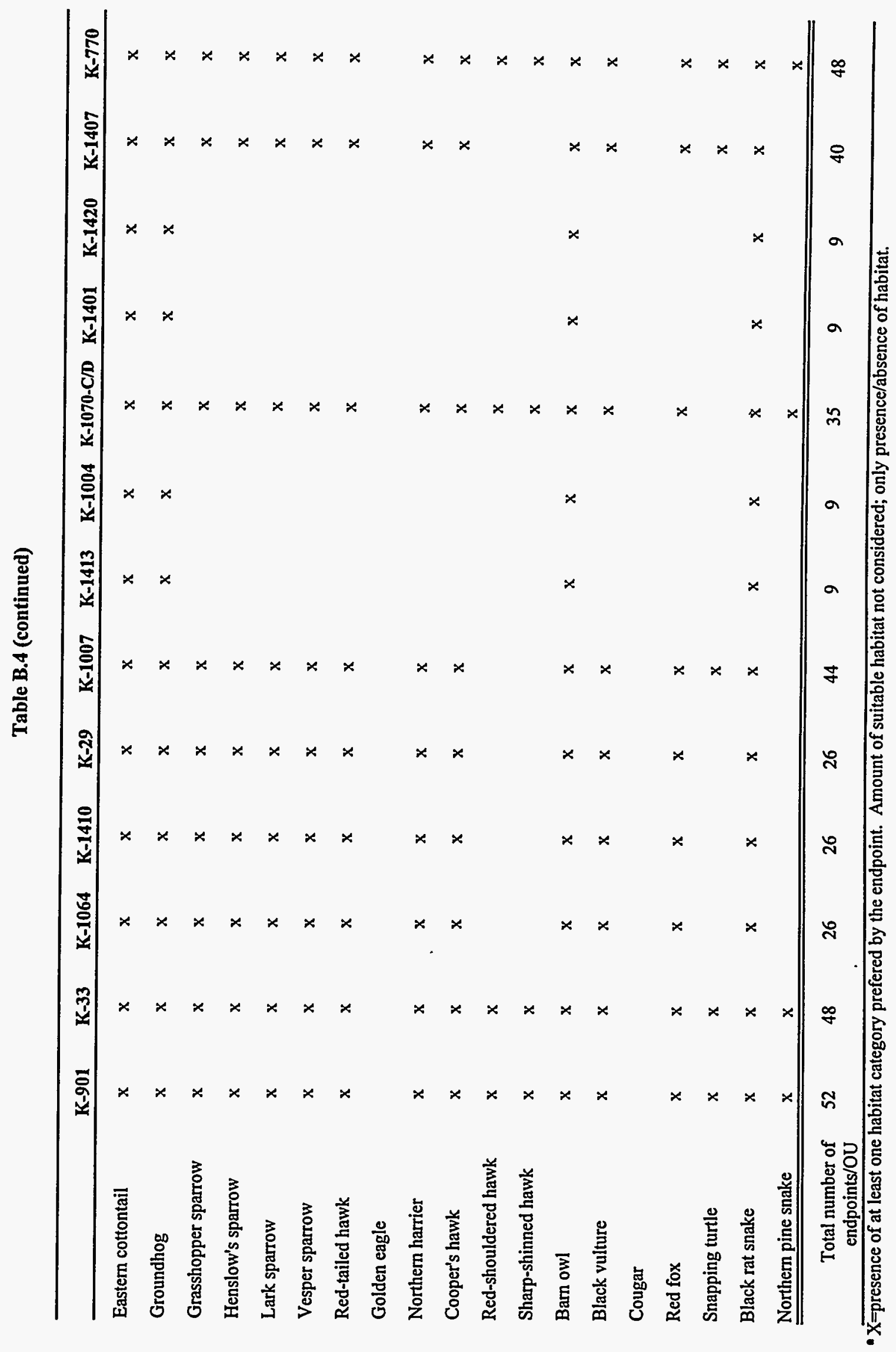


Table B.5. Summary of habitat availability for assessment and measurment endpoints at X-10 OUs ${ }^{\wedge}$

\begin{tabular}{|c|c|c|c|c|c|c|c|c|c|c|c|c|}
\hline & WAG 1 & WAG 2 & WAG 3 & WAG 4 & WAG 5 & WAG 6 & WAG 7 & WAG 8 & WAG 9 & WAG 10 & WAG 11 & WAG 13 \\
\hline Mallard duck & $\mathbf{x}$ & $\mathrm{x}$ & & $\mathrm{x}$ & $\mathrm{x}$ & $\mathrm{x}$ & $\mathrm{x}$ & & & & & \\
\hline Cumberland slider & $x$ & $\mathrm{x}$ & & $\mathrm{x}$ & $x$ & $\mathrm{x}$ & $\mathrm{x}$ & & & & & \\
\hline Mink & $\mathrm{x}$ & $\mathrm{x}$ & & $\mathrm{x}$ & $\mathrm{x}$ & $\mathrm{x}$ & $\mathrm{x}$ & & & & & \\
\hline River otter & & $\mathrm{x}$ & & $x$ & $x$ & $\mathrm{x}$ & $\mathrm{x}$ & & & & & \\
\hline Great blue heron & $\mathrm{x}$ & $\mathrm{x}$ & & $\mathrm{x}$ & $\mathrm{x}$ & $\mathrm{x}$ & $\mathrm{x}$ & & & & & \\
\hline Belted kingfisher & $\mathrm{x}$ & $\mathrm{x}$ & & $\mathrm{x}$ & $\mathrm{x}$ & $\mathrm{x}$ & $\mathrm{x}$ & & & & & \\
\hline Bald eagle & & $\begin{array}{c}\mathbf{x} \\
\text { (WOL) }^{b}\end{array}$ & & & & & & & & & & \\
\hline Osprey & & $\stackrel{x}{\text { (WOL) }^{b}}$ & & & & & & & & & & \\
\hline Double-crested cormorant & & $\begin{array}{c}x \\
(\text { WOL })^{b}\end{array}$ & & & & & & & & & & \\
\hline Black-crowned night heron & $\mathrm{x}$ & $\mathrm{x}$ & & $\mathrm{x}$ & $\mathrm{x}$ & $\mathrm{x}$ & $\mathrm{x}$ & & & & & \\
\hline Northern water snake & $\mathrm{x}$ & $\mathrm{x}$ & & $\mathrm{x}$ & $\mathbf{x}$ & $\mathrm{x}$ & $\mathrm{x}$ & & & & & \\
\hline Pied-billed grebe & $\mathrm{x}$ & $\mathrm{x}$ & & $\mathrm{x}$ & $\mathrm{x}$ & $\mathrm{x}$ & $\mathrm{x}$ & & & & & \\
\hline Leopard frog & $\mathrm{x}$ & $\mathrm{x}$ & & $\mathrm{x}$ & $\mathrm{x}$ & $\mathrm{x}$ & $\mathrm{x}$ & & & & & \\
\hline Hellbender & & $\mathrm{x}$ & & $\mathrm{x}$ & $\mathrm{x}$ & $\mathrm{x}$ & $\mathbf{x}$ & & & & & \\
\hline Rough-winged swallows & $\mathrm{x}$ & $\mathrm{x}$ & $\mathrm{x}$ & $\mathrm{x}$ & $\mathrm{x}$ & $\mathrm{x}$ & $\mathrm{x}$ & $\mathrm{x}$ & $\mathrm{x}$ & $\mathrm{x}$ & $\mathrm{x}$ & $\mathrm{x}$ \\
\hline Gray bat & & $\begin{array}{c}x \\
(\text { WOL) }\end{array}$ & & & & & & & & & & \\
\hline Indiana bat & $\mathrm{x}$ & $\mathbf{x}$ & $\mathrm{x}$ & $\mathrm{x}$ & $\mathrm{x}$ & $\mathrm{x}$ & $\mathrm{x}$ & $\mathbf{x}$ & $\mathrm{x}$ & $\mathrm{x}$ & $\mathrm{x}$ & $\mathrm{x}$ \\
\hline
\end{tabular}


Table B.5 (continued)

\begin{tabular}{|c|c|c|c|c|c|c|c|c|c|c|c|c|}
\hline & WAG 1 & WAG 2 & WAG 3 & WAG 4 & WAG 5 & WAG 6 & WAG 7 & WAG 8 & WAG 9 & WAG 10 & WAG 11 & WAG 13 \\
\hline Eastern small footed bat & $x$ & $\mathbf{x}$ & $\mathrm{x}$ & $\mathrm{x}$ & $x$ & $\mathrm{x}$ & $\mathrm{x}$ & $\mathbf{x}$ & $\mathbf{x}$ & $\mathrm{x}$ & $\mathbf{x}$ & $x$ \\
\hline Rafinesque's big-eared bat & $\mathbf{x}$ & $\mathbf{x}$ & $\mathbf{x}$ & $\mathbf{x}$ & $\mathbf{x}$ & $x$ & $\mathrm{x}$ & $\mathbf{x}$ & $\mathbf{x}$ & $\mathrm{x}$ & $\mathbf{x}$ & $\mathbf{x}$ \\
\hline American toad & $x$ & $x$ & $\mathrm{x}$ & $\mathbf{x}$ & $x$ & $\mathrm{x}$ & $\mathrm{x}$ & $\mathbf{x}$ & $\mathbf{x}$ & $\mathrm{x}$ & $\mathrm{x}$ & $\mathrm{x}$ \\
\hline American woodcock & $\mathbf{x}$ & $\mathbf{x}$ & $\mathrm{x}$ & $\mathbf{x}$ & $\mathrm{x}$ & $\mathbf{x}$ & $\mathbf{x}$ & $\mathbf{x}$ & $\mathbf{x}$ & $\mathbf{x}$ & $\mathbf{x}$ & $\mathbf{x}$ \\
\hline European starling & $\mathrm{x}$ & $\mathrm{x}$ & $\mathbf{x}$ & $\mathrm{x}$ & $\mathbf{x}$ & $\mathrm{x}$ & $\mathbf{x}$ & $\mathbf{x}$ & $\mathbf{x}$ & $\mathrm{x}$ & $\mathbf{x}$ & $\mathrm{x}$ \\
\hline American robin & $\mathrm{x}$ & $\mathrm{x}$ & $x$ & $\mathrm{x}$ & $\mathrm{x}$ & $\mathrm{x}$ & $\mathrm{x}$ & $\mathbf{x}$ & $\mathbf{x}$ & $\mathrm{x}$ & $\mathbf{x}$ & $\mathrm{x}$ \\
\hline Short-tailed shrew & $\mathrm{x}$ & $\mathrm{x}$ & $x$ & $\mathrm{x}$ & $\mathrm{x}$ & $\mathrm{x}$ & $\mathrm{x}$ & $\mathbf{x}$ & $x$ & $\mathrm{x}$ & $\mathrm{x}$ & $\mathbf{x}$ \\
\hline Long-tailed shrew & $x$ & $\mathrm{x}$ & $x$ & $\mathbf{x}$ & $\mathbf{x}$ & $\mathbf{x}$ & $x$ & $\mathrm{x}$ & $x$ & $\mathrm{x}$ & $x$ & $\mathrm{x}$ \\
\hline Masked shrew & $\mathbf{x}$ & $\mathbf{x}$ & $\mathbf{x}$ & $\mathbf{x}$ & $x$ & $\mathbf{x}$ & $x$ & $\mathbf{x}$ & $\mathrm{x}$ & $x$ & $x$ & $x$ \\
\hline Smokey shrew & $x$ & $\mathbf{x}$ & $x$ & $\mathbf{x}$ & $\mathbf{x}$ & $x$ & $x$ & $\mathbf{x}$ & $\mathrm{x}$ & $\mathrm{x}$ & $x$ & $\mathrm{x}$ \\
\hline Southeastern shrew & $\mathbf{x}$ & $\mathbf{x}$ & $\mathbf{x}$ & $\mathbf{x}$ & $\mathbf{x}$ & $x$ & $\mathrm{x}$ & $\mathbf{x}$ & $\mathbf{x}$ & $\mathrm{x}$ & $\mathbf{x}$ & $\mathrm{x}$ \\
\hline Six-line racerunner & $\mathrm{x}$ & $\mathbf{x}$ & $\mathbf{x}$ & $\mathrm{x}$ & $\mathrm{x}$ & $\mathrm{x}$ & $\mathbf{x}$ & $\mathrm{x}$ & $\mathrm{x}$ & $x$ & $\mathrm{x}$ & $\mathbf{x}$ \\
\hline Slender glass snake & $x$ & $\mathrm{x}$ & $\mathbf{x}$ & $\mathbf{x}$ & $\mathbf{x}$ & $\mathrm{x}$ & $x$ & $\mathbf{x}$ & $\mathrm{x}$ & $\mathbf{x}$ & $\mathrm{x}$ & $\mathrm{x}$ \\
\hline \multicolumn{13}{|l|}{ Tennessee cave salamander } \\
\hline \multicolumn{13}{|l|}{ Green salamander } \\
\hline Raccoon & $\mathrm{x}$ & $x$ & $\mathrm{x}$ & $\mathbf{x}$ & $\mathrm{x}$ & $\mathrm{x}$ & $\mathrm{x}$ & $\mathrm{x}$ & $\mathrm{x}$ & $\mathbf{x}$ & $x$ & $x$ \\
\hline Wood duck & $x$ & $\mathbf{x}$ & & $\mathbf{x}$ & $\mathrm{x}$ & $x$ & $\mathbf{x}$ & & & & & \\
\hline Muskrat & $x$ & $\mathbf{x}$ & & $\mathbf{x}$ & $\mathbf{x}$ & $\mathrm{x}$ & $\mathrm{x}$ & & & & & \\
\hline White-tailed deer & $\mathrm{x}$ & $\mathbf{x}$ & $x$ & $\mathbf{x}$ & $\mathbf{x}$ & $x$ & $\mathbf{x}$ & $\mathrm{x}$ & $x$ & $\mathrm{x}$ & $\mathrm{x}$ & $\mathrm{x}$ \\
\hline Wild turkey & $\mathbf{x}$ & $\mathrm{x}$ & $\mathrm{x}$ & $\mathrm{x}$ & $\mathbf{x}$ & $\mathrm{x}$ & $\mathrm{x}$ & $\mathrm{x}$ & $\mathrm{x}$ & $\mathrm{x}$ & $\mathbf{x}$ & $x$ \\
\hline Canada goose & $x$ & $\mathrm{x}^{\cdot}$ & $x$ & $\mathbf{x}$ & $\mathrm{x}$ & $x$ & $\mathbf{x}$ & $\mathrm{x}$ & $\mathbf{x}$ & $x$ & $\mathrm{x}$ & $\mathrm{x}$ \\
\hline
\end{tabular}


Table B.5 (continued)

\begin{tabular}{|c|c|c|c|c|c|c|c|c|c|c|c|c|}
\hline & WAG 1 & WAG 2 & WAG 3 & WAG 4 & WAG 5 & WAG 6 & WAG 7 & WAG 8 & WAG 9 & WAG 10 & WAG 11 & WAG 13 \\
\hline Eastern cottontail & $\mathbf{x}$ & $x$ & $\mathbf{x}$ & $\mathbf{x}$ & $\mathrm{x}$ & $\mathrm{x}$ & $\mathbf{x}$ & $\mathbf{x}$ & $x$ & $\mathbf{x}$ & $\mathbf{x}$ & $\mathbf{x}$ \\
\hline Groundhog & $\mathrm{x}$ & $\mathbf{x}$ & $\mathbf{x}$ & $\mathbf{x}$ & $\mathrm{x}$ & $\mathrm{x}$ & $x$ & $x$ & $\mathbf{x}$ & $\mathbf{x}$ & $\mathbf{x}$ & $\mathbf{x}$ \\
\hline Grasshopper sparrow & $\mathrm{x}$ & $\mathbf{x}$ & $x$ & $\mathbf{x}$ & $\mathrm{x}$ & $\mathrm{x}$ & $x$ & $\mathrm{x}$ & $\mathrm{x}$ & $\mathrm{x}$ & $\mathrm{x}$ & $\mathbf{x}$ \\
\hline Henslow's sparrow & $\mathbf{x}$ & $\mathrm{x}$ & $\mathbf{x}$ & $\mathbf{x}$ & $\mathbf{x}$ & $\mathbf{x}$ & $\mathbf{x}$ & $\mathbf{x}$ & $\mathbf{x}$ & $\mathrm{x}$ & $\mathbf{x}$ & $\mathbf{x}$ \\
\hline Lark sparrow & $\mathrm{x}$ & $x$ & $\mathbf{x}$ & $\mathbf{x}$ & $\mathrm{x}$ & $x$ & $\mathbf{x}$ & $\mathrm{x}$ & $\mathbf{x}$ & $\mathrm{x}$ & $\mathbf{x}$ & $x$ \\
\hline Vesper sparrow & $x$ & $\mathbf{x}$ & $\mathbf{x}$ & $x$ & $\mathbf{x}$ & $\mathbf{x}$ & $\mathbf{x}$ & $x$ & $\mathbf{x}$ & $\mathbf{x}$ & $\mathbf{x}$ & $\mathbf{x}$ \\
\hline Red-tailed hawk & $\mathbf{x}$ & $\mathbf{x}$ & $\mathbf{x}$ & $x$ & $\mathrm{x}$ & $\mathbf{x}$ & $\mathrm{x}$ & $\mathbf{x}$ & $\mathbf{x}$ & $\mathrm{x}$ & $\mathbf{x}$ & $\mathbf{x}$ \\
\hline \multicolumn{13}{|l|}{ Golden eagle } \\
\hline Northern harrier & $x$ & $\mathbf{x}$ & $x$ & $\mathrm{x}$ & $\mathrm{x}$ & $\mathbf{x}$ & $\mathbf{x}$ & $\mathbf{x}$ & $\mathbf{x}$ & $\mathrm{x}$ & $\mathbf{x}$ & $\mathbf{x}$ \\
\hline Cooper's hawk & $\mathbf{x}$ & $\mathrm{x}$ & $\mathbf{x}$ & $x$ & $\mathbf{x}$ & $\mathbf{x}$ & $\mathrm{x}$ & $\mathrm{x}$ & $\mathrm{x}$ & $x$ & $\mathrm{x}$ & $\mathrm{x}$ \\
\hline Red-shouldered hawk & $\mathbf{x}$ & $\mathrm{x}$ & $\mathrm{x}$ & $\mathrm{x}$ & $x$ & $\mathbf{x}$ & $\mathbf{x}$ & $\mathbf{x}$ & $x$ & $\mathbf{x}$ & $\mathrm{x}$ & $x$ \\
\hline Sharp-shinned hawk & $\mathbf{x}$ & $\mathrm{x}$ & $\mathrm{x}$ & $\mathbf{x}$ & $\mathrm{x}$ & $\mathrm{x}$ & $\mathbf{x}$ & $x$ & $\mathbf{x}$ & $\mathrm{x}$ & $\mathbf{x}$ & $x$ \\
\hline Barn owl & $\mathrm{x}$ & $\mathrm{x}$ & $\mathrm{x}$ & $x$ & $x$ & $\mathbf{x}$ & $\mathbf{x}$ & $\mathbf{x}$ & $\mathbf{x}$ & $\mathrm{x}$ & $\mathrm{x}$ & $\mathrm{x}$ \\
\hline Black vulture & $x$ & $\mathrm{x}$ & $x$ & $\mathrm{x}$ & $\mathrm{x}$ & $\mathbf{x}$ & $\mathbf{x}$ & $\mathbf{x}$ & $\mathrm{x}$ & $\mathrm{x}$ & $\mathrm{x}$ & $\mathrm{x}$ \\
\hline Cougar & - & & & & & & & & & & & \\
\hline Red fox & $\mathbf{x}$ & $x$ & $\mathrm{x}$ & $\mathrm{x}$ & $\mathrm{x}$ & $\mathrm{x}$ & $x$ & $\mathbf{x}$ & $\mathbf{x}$ & $\mathrm{x}$ & $\mathbf{x}$ & $\mathrm{x}$ \\
\hline Snapping turtle & $\mathbf{x}$ & $\mathrm{x}$ & & $\mathbf{x}$ & $\mathbf{x}$ & $x$ & $x$ & & & & & \\
\hline Black rat snake & $x$ & $\mathrm{x}$ & $\mathrm{x}$ & $\mathrm{x}$ & $\mathrm{x}$ & $x$ & $x$ & $\mathbf{x}$ & $\mathbf{x}$ & $\mathrm{x}$ & $x$ & $x$ \\
\hline Northern pine snake & $x$ & $\mathrm{x}$ & $\mathrm{x}$ & $\mathrm{x}$ & $\mathrm{x}$ & $x$ & $\mathbf{x}$ & $\mathrm{x}$ & $\mathrm{x}$ & $\mathrm{x}$ & $\mathrm{x}$ & $\mathrm{x}$ \\
\hline $\begin{array}{r}\text { Total number of } \\
\text { endpoints/OU }\end{array}$ & 47 & 53 & 35 & 49 & 49 & 49 & 49 & 35 & 35 & 35 & 35 & 35 \\
\hline
\end{tabular}

$2 \mathrm{X}=$ presence of at least one habitat category prefered by the endpoint. Amount of suitable habitat not considered; only presence/absence of habitat.

b $\mathrm{WOL}=$ suitable habitat only at White Oak Lake. 
Table B.6. Summary of habitat availability for assessment and measurment endpoints at Y-12 OUs, Freel's Bend, and the South Campus Facility

\begin{tabular}{|c|c|c|c|c|c|c|c|c|c|c|c|c|}
\hline & $\begin{array}{l}\text { Bear } \\
\text { Creek } \\
\end{array}$ & $\begin{array}{l}\text { BC } \\
\text { OU1 }\end{array}$ & $\begin{array}{l}\text { BC } \\
\text { OU2 } \\
\end{array}$ & $\begin{array}{l}\text { CR } \\
\text { OU1 } \\
\end{array}$ & $\begin{array}{l}\text { CR } \\
\text { OU2 } \\
\end{array}$ & $\begin{array}{l}\text { CR } \\
\text { OU3 } \\
\end{array}$ & $\begin{array}{l}\text { CR } \\
\text { OU4 } \\
\end{array}$ & LEFPC & $\begin{array}{l}\text { UEFPC } \\
\text { OU2 } \\
\end{array}$ & $\begin{array}{l}\text { UEFPC } \\
\text { OU3 } \\
\end{array}$ & $\begin{array}{l}\text { Freels } \\
\text { Bend }\end{array}$ & SCF \\
\hline Mallard duck & $x$ & & & & & & $\mathbf{x}$ & $x$ & & & $\mathrm{x}$ & $x$ \\
\hline Cumberland slider & $\mathbf{x}$ & & & & & & $\mathbf{x}$ & $\mathrm{x}$ & & & $\mathbf{x}$ & $\mathbf{x}$ \\
\hline Mink & $\mathbf{x}$ & & & & & & $\mathrm{x}$ & $x$ & & & $\mathrm{x}$ & $x$ \\
\hline River otter & $\mathbf{x}$ & & & & & & $\mathbf{x}$ & $\mathrm{x}$ & & & $\mathbf{x}$ & $\mathrm{x}$ \\
\hline Great blue heron & $\mathrm{x}$ & & & & & & $\mathrm{x}$ & $x$ & & & $x$ & $\mathrm{x}$ \\
\hline Belted kingfisher & $\mathrm{x}$ & & & & & & $\mathrm{x}$ & $x$ & & & $\mathrm{x}$ & $\mathbf{x}$ \\
\hline \multicolumn{13}{|l|}{ Bald eagle } \\
\hline \multicolumn{13}{|l|}{ Osprey } \\
\hline \multicolumn{13}{|l|}{ Double-crested cormorant } \\
\hline $\begin{array}{l}\text { Black-crowned night } \\
\text { heron }\end{array}$ & $x$ & · & & & & & $\mathrm{x}$ & $\mathrm{x}$ & & & $x$ & $\mathrm{x}$ \\
\hline Northern water snake & $\mathbf{x}$ & & & & & & $\mathbf{x}$ & $x$ & & & $\mathrm{x}$ & $\mathrm{x}$ \\
\hline Pied-billed grebe & $\mathrm{x}$ & & & & & & $\mathrm{x}$ & $x$ & & & $x$ & $\mathrm{x}$ \\
\hline Leopard frog & $x$ & & & & & & $\mathbf{x}$ & $x$ & & & $x$ & $\mathbf{x}$ \\
\hline Hellbender & $x$ & & & & & & & $\mathrm{x}$ & & & & \\
\hline Rough-winged swallows & $x$ & $\mathbf{x}$ & $x$ & $\mathrm{x}$ & $\mathrm{x}$ & & $\mathrm{x}$ & $\mathrm{x}$ & & & $x$ & $\mathbf{x}$ \\
\hline \multicolumn{13}{|l|}{ Gray bat } \\
\hline Indiana bat & $\mathbf{x}$ & $\mathbf{x}$ & $\mathbf{x}$ & $\mathbf{x}$ & $\mathbf{x}$ & $\mathbf{x}$ & $\mathbf{x}$ & $\mathbf{x}$ & & & $x$ & $\mathbf{x}$ \\
\hline Eastern small footed bat & $x$ & $\mathbf{x}$ & $\mathrm{x}$ & $\mathrm{x}$ & $\mathrm{x}$ & $\mathrm{x}$ & $\mathrm{x}$ & $\mathrm{x}$ & & & $x$ & $\mathrm{x}$ \\
\hline Rafinesque's big-eared bat & $\mathbf{x}$ & $\mathbf{x}$ & $\mathbf{x}$ & $\mathbf{x}$ & $\mathbf{x}$ & $\mathbf{x}$ & $\mathbf{x}$ & $\mathbf{x}$ & $\mathrm{x}$ & $x$ & $x$ & $\mathbf{x}$ \\
\hline
\end{tabular}


Table B.6 (continued)

\begin{tabular}{|c|c|c|c|c|c|c|c|c|c|c|c|c|}
\hline & $\begin{array}{l}\text { Bear } \\
\text { Creek } \\
\end{array}$ & $\begin{array}{l}\text { BC } \\
\text { oU1 } \\
\end{array}$ & $\begin{array}{l}\text { BC } \\
\text { OU2 } \\
\end{array}$ & $\begin{array}{l}\text { CR } \\
\text { OU1 } \\
\end{array}$ & $\begin{array}{l}\text { CR } \\
\text { OU2 } \\
\end{array}$ & $\begin{array}{l}\text { CR } \\
\text { OU3 } \\
\end{array}$ & $\begin{array}{l}\text { CR } \\
\text { OU4 } \\
\end{array}$ & LEFPC & $\begin{array}{l}\text { UEFPC } \\
\text { OU2 }\end{array}$ & $\begin{array}{l}\text { UEFPC } \\
\text { OU3 }\end{array}$ & $\begin{array}{l}\text { Freels } \\
\text { Bend } \\
\end{array}$ & SCF \\
\hline American toad & $x$ & $\mathrm{x}$ & & $\mathrm{x}$ & $\mathrm{x}$ & & $x$ & $\mathrm{x}$ & & & $x$ & $\mathrm{x}$ \\
\hline American woodcock & $\mathrm{x}$ & $x$ & $\mathrm{x}$ & $\mathrm{x}$ & $x$ & $x$ & $\mathrm{x}$ & $\mathrm{x}$ & & & $x$ & $x$ \\
\hline European starling & $\mathrm{x}$ & $\mathrm{x}$ & $\mathbf{x}$ & $\mathrm{x}$ & $\mathrm{x}$ & $\mathbf{x}$ & $\mathrm{x}$ & $\mathrm{x}$ & $\mathbf{x}$ & $\mathrm{x}$ & $\mathrm{x}$ & $x$ \\
\hline American robin & $\mathrm{x}$ & $\mathrm{x}$ & $\mathbf{x}$ & $x$ & $x$ & $x$ & $x$ & $x$ & $\mathbf{x}$ & $\mathrm{x}$ & $\mathbf{x}$ & $x$ \\
\hline Short-tailed shrew & $\mathrm{x}$ & $\mathbf{x}$ & & $\mathrm{x}$ & $\mathrm{x}$ & & $\mathbf{x}$ & $\mathbf{x}$ & & & $\mathrm{x}$ & $\mathrm{x}$ \\
\hline Long-tailed shrew & $\mathrm{x}$ & $\mathrm{x}$ & & $x$ & $\mathrm{x}$ & & $\mathbf{x}$ & $x$ & & & $x$ & \\
\hline Masked shrew & $\mathbf{x}$ & $\mathbf{x}$ & & $\mathbf{x}$ & $\mathrm{x}$ & & $\mathrm{x}$ & $x$ & & & $\mathrm{x}$ & \\
\hline Smokey shrew & $\mathrm{x}$ & $\mathbf{x}$ & & $x$ & $\mathrm{x}$ & & $\mathbf{x}$ & $x$ & & & $\mathrm{x}$ & \\
\hline Southeastern shrew & $\mathrm{x}$ & $\mathbf{x}$ & $x$ & $\mathbf{x}$ & $\mathrm{x}$ & $x$ & $\mathbf{x}$ & $\mathrm{x}$ & & & $\mathrm{x}$ & $\mathrm{x}$ \\
\hline Six-line racerunner & $\mathbf{x}$ & $\mathrm{x}$ & $\mathbf{x}$ & $\mathbf{x}$ & $\mathbf{x}$ & $\mathrm{x}$ & $\mathbf{x}$ & $\mathrm{x}$ & & & $\mathrm{x}$ & $x$ \\
\hline $\begin{array}{l}\text { Slender glass snake } \\
\text { Tennessee cave } \\
\text { salamander }\end{array}$ & $\mathrm{x}$ & $\mathbf{x}$ & $\mathbf{x}$ & $\mathbf{x}$ & $\mathbf{x}$ & $x$ & $\mathbf{x}$ & $\mathbf{x}$ & & & $\mathbf{x}$ & $\mathrm{x}$ \\
\hline \multicolumn{13}{|l|}{ Green salamander } \\
\hline Raccoon & $x$ & $\mathrm{x}$ & $\mathrm{x}$ & $\mathbf{x}$ & $\mathrm{x}$ & $\mathrm{x}$ & $\mathrm{x}$ & $\mathrm{x}$ & $\mathrm{x}$ & $\mathrm{x}$ & $\mathrm{x}$ & $\mathrm{x}$ \\
\hline Wood duck & $\mathrm{x}$ & & & & & & $\mathrm{x}$ & $x$ & & & $\mathbf{x}$ & $\mathrm{x}$ \\
\hline Muskrat & $\mathbf{x}$ & & & & & & $\mathrm{x}$ & $\mathrm{x}$ & & & $x$ & $\mathrm{x}$ \\
\hline White-tailed deer & $\mathbf{x}$ & $\mathbf{x}$ & $x$ & $\mathrm{x}$ & $x$ & $\mathrm{x}$ & $\mathrm{x}$ & $\mathrm{x}$ & & & $x$ & $\mathrm{x}$ \\
\hline Wild turkey & $\mathrm{x}$ & $\mathbf{x}$ & $\mathrm{x}$ & $\mathrm{x}$ & $\mathrm{x}$ & $\mathrm{x}$ & $\mathrm{x}$ & $\mathrm{x}$ & & & $x$ & $\mathrm{x}$ \\
\hline Canada goose & $\mathbf{x}$ & $x$ & $x$ & $x$ & $x$ & $\mathrm{x}$ & $x$ & $\mathrm{x}$ & $\mathrm{x}$ & $\mathrm{x}$ & $x$ & $x$ \\
\hline Eastern cottontail & $\mathrm{x}$ & $\mathrm{x}$ & $\mathrm{x}$ & $\mathrm{x}$ & $\mathrm{x}$ & $\mathrm{x}$ & $\mathrm{x}$ & $x$ & $\mathbf{x}$ & $\mathbf{x}$ & $\mathrm{x}$ & $x$ \\
\hline
\end{tabular}


Table B.6 (continued)

\begin{tabular}{|c|c|c|c|c|c|c|c|c|c|c|c|c|}
\hline & $\begin{array}{l}\text { Bear } \\
\text { Creek }\end{array}$ & $\begin{array}{l}\text { BC } \\
\text { OU1 }\end{array}$ & $\begin{array}{l}\text { BC } \\
\text { OU2 }\end{array}$ & $\begin{array}{l}\text { CR } \\
\text { OU1 }\end{array}$ & $\begin{array}{l}\text { CR } \\
\text { OU2 }\end{array}$ & $\begin{array}{l}\text { CR } \\
\text { OU3 }\end{array}$ & $\begin{array}{l}\text { CR } \\
\text { OU4 } \\
\end{array}$ & LEFPC & $\begin{array}{l}\text { UEFPC } \\
\text { OU2 }\end{array}$ & $\begin{array}{l}\text { UEFPC } \\
\text { OU3 }\end{array}$ & $\begin{array}{l}\text { Freels } \\
\text { Bend } \\
\end{array}$ & SCF \\
\hline Groundhog & $\mathrm{x}$ & $\mathrm{x}$ & $\mathrm{x}$ & $x$ & $x$ & $\mathrm{x}$ & $\mathbf{x}$ & $\mathrm{x}$ & $\mathbf{x}$ & $\mathrm{x}$ & $\mathbf{x}$ & $\mathbf{x}$ \\
\hline Grasshopper sparrow & $\mathrm{x}$ & $\mathrm{x}$ & $\mathrm{x}$ & $\mathrm{x}$ & $\mathbf{x}$ & $\mathbf{x}$ & $\mathrm{x}$ & $\mathrm{x}$ & & & $\mathbf{x}$ & $\mathrm{x}$ \\
\hline Henslow's sparrow & $\mathrm{x}$ & $\mathbf{x}$ & $\mathrm{x}$ & $\mathbf{x}$ & $\mathrm{x}$ & $\mathbf{x}$ & $\mathrm{x}$ & $x$ & & & $\mathrm{x}$ & $\mathrm{x}$ \\
\hline Lark sparrow & $\mathbf{x}$ & $\mathbf{x}$ & $\mathrm{x}$ & $\mathbf{x}$ & $\mathrm{x}$ & $\mathbf{x}$ & $\mathrm{x}$ & $\mathrm{x}$ & & & $\mathbf{x}$ & $\mathrm{x}$ \\
\hline Vesper sparrow & $\mathrm{x}$ & $\mathbf{x}$ & $\mathrm{x}$ & $\mathbf{x}$ & $\mathrm{x}$ & $\mathrm{x}$ & $x^{\prime}$ & $\mathrm{x}$ & & & $x$ & $\mathrm{x}$ \\
\hline Red-tailed hawk & $\mathrm{x}$ & $\mathrm{x}$ & $\mathrm{x}$ & $\mathbf{x}$ & $\mathrm{x}$ & $\mathrm{x}$ & $\mathrm{x}$ & $\mathbf{x}$ & & & $\mathbf{x}$ & $\mathrm{x}$ \\
\hline \multicolumn{13}{|l|}{ Golden eagle } \\
\hline Northem harrier & $\mathrm{x}$ & $\mathbf{x}$ & $\mathrm{x}$ & $x$ & $\mathbf{x}$ & $x$ & $\mathrm{x}$ & $\mathbf{x}$ & & & $x$ & $\mathrm{x}$ \\
\hline Cooper's hawk & $\mathrm{x}$ & $x$ & $\mathrm{x}$ & $\mathbf{x}$ & $\mathrm{x}$ & $\mathrm{x}$ & $\mathrm{x}$ & $x$ & & & $x$ & $\mathrm{x}$ \\
\hline Red-shouldered hawk & $x$ & $x$ & & $\mathbf{x}$ & $\mathbf{x}$ & & $x$ & $\mathbf{x}$ & & & $\mathrm{x}$ & \\
\hline Sharp-shinned hawk & $\mathrm{x}$ & $x$ & & $\mathrm{x}$ & $\mathrm{x}$ & & $\mathbf{x}$ & $x$ & & & $\mathrm{x}$ & \\
\hline Barn owl & $\mathrm{x}$ & $\mathrm{x}$ & $\mathrm{x}$ & $x$ & $\mathrm{x}$ & $\mathrm{x}$ & $\mathrm{x}$ & $\mathrm{x}$ & $x$ & $x$ & $\mathrm{x}$ & $x$ \\
\hline Black vulture & $\mathrm{x}$ & $\mathbf{x}$ & $\mathrm{x}$ & $x$ & $\mathbf{x}$ & $\mathrm{x}$ & $x$ & $\mathrm{x}$ & & & $\mathrm{x}$ & $\mathrm{x}$ \\
\hline \multicolumn{13}{|l|}{ Cougar } \\
\hline Red fox & $\mathrm{x}$ & $\mathrm{x}$ & $\mathrm{x}$ & $x$ & $\mathbf{x}$ & $x$ & $\mathrm{x}$ & $\mathbf{x}$ & & & $x$ & $\mathrm{x}$ \\
\hline Snapping turtle & $\mathrm{x}$ & & & & & & $\mathrm{x}$ & $\mathrm{x}$ & & & $\mathbf{x}$ & $x$ \\
\hline Black rat snake & $\mathrm{x}$ & $x$ & $\mathrm{x}$ & $\mathrm{x}$ & $x$ & $x$ & $\mathrm{x}$ & $x$ & $\mathrm{x}$ & $\mathrm{x}$ & $\mathbf{x}$ & $\mathrm{x}$ \\
\hline Northern pine snake & $\mathrm{x}$ & $x$ & & $\mathrm{x}$ & $\mathrm{x}$ & & $\mathrm{x}$ & $\mathrm{x}$ & & & $x$ & $x$ \\
\hline $\begin{array}{r}\text { Total number of } \\
\text { endpoints/OU }\end{array}$ & 49 & 35 & 27 & 35 & 35 & 26 & 48 & 49 & 9 & 9 & 48 & 43 \\
\hline
\end{tabular}

- $X=$ presence of at least one habitat category prefered by the endpoint. Amount of suitable habitat not considered; only presence/absence of habitat. 
Table B.7. Ranking of endpoint species by the number of OUs that provide at least one favored habitat type

\begin{tabular}{|c|c|c|c|}
\hline Endpoint Species & $\begin{array}{l}\text { Total OUs } \\
\text { W/habitat }\end{array}$ & Endpoint Species & $\begin{array}{l}\text { Total OUs } \\
\text { W/habitat }\end{array}$ \\
\hline Barn owl & 37 & American Toad & 24 \\
\hline Groundhog & 37 & Long-tailed shrew & 23 \\
\hline European starling & 37 & Red-shouldered hawk & 23 \\
\hline American robin & 37 & Sharp-shinned hawk & 23 \\
\hline Rafinesque's big-eared bat & 37 & Masked shrew & 23 \\
\hline Raccoon & 37 & Smokey shrew & 23 \\
\hline Eastern cottontail & 37 & Snapping turtle & 16 \\
\hline Black rat snake & 37 & Mallard duck & 16 \\
\hline Canada goose & 37 & Muskrat & 16 \\
\hline American woodcock & 31 & Pied-billed grebe & 16 \\
\hline Henslow's sparrow & 31 & Mink & 16 \\
\hline Southeastern shrew & 31 & Great blue heron & 16 \\
\hline Wild turkey & 31 & Belted kingfisher & 16 \\
\hline Slender glass snake & 31 & Black-crowned night heron & 16 \\
\hline Grasshopper sparrow & 31 & Wood duck & 16 \\
\hline Six-line racerunner & 31 & Northern Water snake & 16 \\
\hline Eastern small footed bat & 31 & Leopard frog & 16 \\
\hline Indiana bat & 31 & Cumberland slider & 16 \\
\hline Lark sparrow & 31 & River otter & 15 \\
\hline Red fox & 31 & Hellbender & 7 \\
\hline Black vulture & 31 & Bald eagle & 3 \\
\hline Cooper's hawk & 31 & Gray bat & 3 \\
\hline Northern harrier & 31 & Double-crested cormorant & 3 \\
\hline White-tailed deer & 31 & Osprey & 3 \\
\hline Red-tailed hawk & 31 & Green salamander & 0 \\
\hline Vesper sparrow & 31 & Golden eagle & 0 \\
\hline Rough-winged swallows & 27 & Tennessee cave salamander & 0 \\
\hline Short-tailed shrew & 24 & Cougar & 0 \\
\hline Northern pine snake & 24 & & \\
\hline
\end{tabular}




\section{B-25}

Table B.8. Ranking of OUs on the ORR by the number of species for which they provide habitat

\begin{tabular}{|c|c|c|c|}
\hline OUs & $\begin{array}{c}\text { Total species } \\
\text { per OU }\end{array}$ & Ous & $\begin{array}{c}\text { Total species } \\
\text { per OU }\end{array}$ \\
\hline WAG 2 & 53 & WAG 9 & 35 \\
\hline $\mathrm{K}-901$ & 52 & WAG 10 & 35 \\
\hline Lower East Fork Poplar Creek & 49 & WAG 11 & 35 \\
\hline Bear Creek & 49 & WAG 13 & 35 \\
\hline WAG 4 & 49 & BC OU1 & 35 \\
\hline WAG 5 & 49 & CR OU1 & 35 \\
\hline WAG 6 & 49 & CR OU2 & 35 \\
\hline WAG 7 & 49 & $\mathrm{BC}$ OU2 & 27 \\
\hline $\mathrm{K}-33$ & 48 & K-1064 & 26 \\
\hline $\mathrm{K}-770$ & 48 & $\mathrm{~K}-1410$ & 26 \\
\hline CR OU4 & 48 & $\mathrm{~K}-29$ & 26 \\
\hline Freel's Bend & 48 & CR OU3 & 26 \\
\hline WAG 1 & 47 & $\mathrm{~K}-1413$ & 9 \\
\hline $\mathrm{K}-1007$ & 44 & K-1004 & 9 \\
\hline South Campus Facility & 43 & $\mathrm{~K}-1401$ & 9 \\
\hline K-1407 & 40 & $\mathrm{~K}-1420$ & 9 \\
\hline $\mathrm{K}-1070-\mathrm{C} / \mathrm{D}$ & 35 & UEFPC OU2 & 9 \\
\hline WAG 3 & 35 & UEFPC OU3 & 9 \\
\hline WAG 8 & 35 & & \\
\hline
\end{tabular}



Appendix C

TABLES AND FIGURES FOR CHAPTER 4: ASSESSMENT OF RISK TO PISCIVORES ON THE OAK RIDGE RESERVATION 


$$
\text { C-3 }
$$

Table C.1. Life history parameters for mink

\begin{tabular}{|c|c|c|c|}
\hline Parameter & Value & Comments & Reference \\
\hline Body Weight & $1.0 \mathrm{~kg}\left(\right.$ mean $\left.\sigma^{r}+q\right)$ & & EPA 1993b \\
\hline $\begin{array}{l}\text { Food Consumption } \\
\text { Rate }\end{array}$ & $0.137 \mathrm{~kg} / \mathrm{d}$ (mean ơ+ㅇ) & & $\begin{array}{l}\text { Bleavins and Aulerich } \\
1981\end{array}$ \\
\hline $\begin{array}{l}\text { Water } \\
\text { Consumption Rate }\end{array}$ & $0.099 \mathrm{~L} / \mathrm{d}$ & $\begin{array}{l}\text { estimated using } \\
\text { allometric } \\
\text { equation }^{\mathrm{a}} \\
\text { assuming } 1.0 \mathrm{~kg} \\
\text { bw }\end{array}$ & $\begin{array}{l}\text { After Calder and Braun } \\
1983\end{array}$ \\
\hline \multirow[t]{2}{*}{ Diet Composition } & $\begin{array}{l}\text { Diverse diet includes: mammals, } \\
\text { fish, } \\
\text { aquatic invertebrates, } \\
\text { amphibians, } \\
\text { and birds }\end{array}$ & & $\begin{array}{l}\text { Hamilton } 1940, \\
\text { Sealander } 1943, \\
\text { Korschgen } 1958, \\
\text { Burgess and Bider } \\
1980 \\
\text { Alexander } 1977\end{array}$ \\
\hline & $\begin{array}{l}\text { Proportion of aquatic prey (fish, } \\
\text { amphibians, inverts, etc.) }= \\
0.546 \pm 0.21 \\
\text { fish sizes: } \\
0-10 \mathrm{~cm}=72 \% \\
11-20 \mathrm{~cm}=28 \%\end{array}$ & $\begin{array}{l}\text { Proportion } \\
\text { represents means } \\
\text { of values from five } \\
\text { studies }\end{array}$ & \\
\hline \multirow[t]{3}{*}{ Home Range } & $\begin{array}{l}2.63 \mathrm{~km}\left(\sigma^{7}\right) \\
1.85 \mathrm{~km}(\%)\end{array}$ & stream - Sweden & Gerell 1970 \\
\hline & 770 ha $\left(\sigma^{7}\right)$ & $\begin{array}{l}\text { prairie potholes, } \\
\text { Manitoba }\end{array}$ & $\begin{array}{l}\text { Amold and Fritzell } \\
1987\end{array}$ \\
\hline & & $\begin{array}{l}\text { range size and } \\
\text { shape depends on } \\
\text { habitat - linear } \\
\text { along streams, } \\
\text { circular in marshes }\end{array}$ & EPA 1993a. \\
\hline $\begin{array}{l}\text { Habitat } \\
\text { Requirements }\end{array}$ & $\begin{array}{l}\text { aquatic habitats - streams, lakes, } \\
\text { marshes; }\end{array}$ & & $\begin{array}{l}\text { Burt and Grossenheider } \\
1976\end{array}$ \\
\hline Population Density & $0.03-0.085 / \mathrm{ha}$ & river - Montana & Mitchell 1961 \\
\hline & $0.6 / \mathrm{km}$ & river - Michigan & EPA 1993a \\
\hline Behavior & $\begin{array}{l}\text { nocturnal } \\
\text { active year-round, } \\
\text { does not hibernate }\end{array}$ & & EPA 1993a \\
\hline
\end{tabular}




$$
\text { C-4 }
$$

Table C.2. Life history parameters for river otter

\begin{tabular}{|c|c|c|c|}
\hline Parameter & Value & Comments & Reference \\
\hline Body Weight & $8.0 \mathrm{~kg}\left(\right.$ mean $\left.\sigma^{x}+9\right)$ & & EPA 1993b \\
\hline $\begin{array}{l}\text { Food Consumption } \\
\text { Rate }\end{array}$ & $0.9 \mathrm{~kg} / \mathrm{d}\left(\right.$ mean $\left.\sigma^{2}+q\right)$ & & EPA 1993b \\
\hline $\begin{array}{l}\text { Water Consumption } \\
\text { Rate }\end{array}$ & $0.64 \mathrm{~L} / \mathrm{d}$ & & EPA 1993b \\
\hline \multirow[t]{2}{*}{ Diet Composition } & $\begin{array}{l}\text { Almost exclusively fish } \\
2-50 \mathrm{~cm} \text { in size; most } \geq 30 \\
\mathrm{~cm} \text {. }\end{array}$ & & $\begin{array}{l}\text { Melquist and } \\
\text { Hornocker } 1983\end{array}$ \\
\hline & $\begin{array}{l}50 \% \text { large and } 50 \% \text { small } \\
\text { fish }\end{array}$ & & EPA 1993b \\
\hline Home Range & $10-78 \mathrm{~km}$ & $\begin{array}{l}\text { river-Idaho } \\
\text { range size and } \\
\text { shape depends on } \\
\text { habitat - linear } \\
\text { along streams, } \\
\text { circular in marshes }\end{array}$ & $\begin{array}{l}\text { Melquist and } \\
\text { Hornocker } 1983 \\
\text { EPA 1993b }\end{array}$ \\
\hline $\begin{array}{l}\text { Habitat } \\
\text { Requirements }\end{array}$ & $\begin{array}{l}\text { aquatic habitats - streams, } \\
\text { lakes, marshes; }\end{array}$ & & EPA 1993b \\
\hline \multirow[t]{2}{*}{ Population Density } & $0.17-0.37 / \mathrm{km}$ & river-Idaho & $\begin{array}{l}\text { Melquist and } \\
\text { Hornocker } 1983\end{array}$ \\
\hline & $0.0094-0.014 / \mathrm{ha}$ & & EPA 1993b \\
\hline \multirow[t]{2}{*}{ Behavior } & $\begin{array}{l}\text { Generally most active } \\
\text { morning and evening, but } \\
\text { may be active at any time in } \\
\text { day. }\end{array}$ & & $\begin{array}{l}\text { Melquist and } \\
\text { Hornocker } 1983\end{array}$ \\
\hline & $\begin{array}{l}\text { active year-round, } \\
\text { does not hibernate }\end{array}$ & & EPA 1993b \\
\hline
\end{tabular}


Table C.3. Life history parameters for belted kingfisher

\begin{tabular}{|c|c|c|c|}
\hline Parameter & Value & Comments & Reference \\
\hline Body Weight & $0.148 \mathrm{~kg}$ & & Dunning 1984 \\
\hline \multirow{2}{*}{$\begin{array}{l}\text { Food Consumption } \\
\text { Rate }\end{array}$} & $50 \%$ bw & & Alexander 1977 \\
\hline & $0.075 \mathrm{~kg} / \mathrm{d}$ & assuming $0.148 \mathrm{~kg}$ bw & \\
\hline $\begin{array}{l}\text { Water Consumption } \\
\text { Rate }\end{array}$ & $0.016 \mathrm{~L} / \mathrm{d}$ & $\begin{array}{l}\text { estimated using } \\
\text { allometric equation } \\
\text { assuming } 0.148 \mathrm{~kg} \mathrm{bw}\end{array}$ & \\
\hline $\begin{array}{l}\text { Soil Consumption } \\
\text { Rate }\end{array}$ & $\begin{array}{l}\text { as a piscivore, assumed to } \\
\text { be negligible }\end{array}$ & & \\
\hline \multirow[t]{2}{*}{ Diet Composition } & $\begin{array}{l}\text { Cyprinids - } 76.4 \% \\
\text { other fish }-10.2 \% \\
\text { crayfish }-13.3 \%\end{array}$ & Ohio - creek & Davis 1982 \\
\hline & $\begin{array}{l}\text { lizards, small snakes, } \\
\text { frogs, salamanders, and } \\
\text { insects may be consumed } \\
\text { if fish are unavailable }\end{array}$ & & Landrum et al. 1993 \\
\hline \multirow[t]{2}{*}{ Home Range } & $\begin{array}{l}1.03 \mathrm{~km} \text { (breeding) } \\
0.39 \mathrm{~km} \text { (non-breeding) }\end{array}$ & Ohio - creek & Davis 1982 \\
\hline & $2.19 \mathrm{~km}$ (breeding) & $\begin{array}{l}\text { Pennsylvania - stream } \\
\text { summer }\end{array}$ & Brooks and Davis 1987 \\
\hline \multirow[t]{3}{*}{ Habitat Requirements } & $\begin{array}{l}\text { uses a diverse aquatic } \\
\text { habitats (stream, river, } \\
\text { lake, marsh, coastline) }\end{array}$ & & Brooks and Davis 1987 \\
\hline & $\begin{array}{l}\text { require high vertical } \\
\text { banks composed of } \\
>75 \% \text { sand and }<7 \% \text { clay } \\
\text { for nest construction }\end{array}$ & & \\
\hline & $\begin{array}{l}\text { prefer relatively clear } \\
\text { waters free of thick } \\
\text { vegetation }\end{array}$ & & Bent 1940. \\
\hline Population Density & $0.11-0.19$ pairs $/ \mathrm{km}$ shore & $\begin{array}{l}\text { Pennsylvania - stream } \\
\text { summer }\end{array}$ & Brooks and Davis 1987 \\
\hline Behavior & $\begin{array}{l}\text { while most migrate from } \\
\text { northern parts of range, } \\
\text { some may stay in areas } \\
\text { where water remains ice- } \\
\text { free }\end{array}$ & & Bent 1940. \\
\hline
\end{tabular}


Table C.4. Life history parameters for great blue heron

\begin{tabular}{|c|c|c|c|}
\hline Parameter & Value & Comments & Reference \\
\hline Body Weight & $\begin{array}{l}2.576 \mathrm{~kg}\left(\sigma^{\pi}\right) \\
2.204 \mathrm{~kg}(+) \\
2.39 \mathrm{~kg}\left(\operatorname{mean} \sigma^{x}+\%\right)\end{array}$ & & Dunning 1984 \\
\hline $\begin{array}{l}\text { Food Consumption } \\
\text { Rate }\end{array}$ & $0.42 \mathrm{~kg} / \mathrm{d}$ & $\begin{array}{l}\text { estimated using } \\
\text { allometric equation }{ }^{\mathrm{a}} \\
\text { specific for herons and } \\
\text { egrets } \\
\text { assuming } 2.39 \mathrm{~kg} \mathrm{bw}\end{array}$ & Kushlan 1978 \\
\hline $\begin{array}{l}\text { Water Consumption } \\
\text { Rate }\end{array}$ & $0.1058 \mathrm{~L} / \mathrm{d}$ & $\begin{array}{l}\text { estimated using } \\
\text { allometric equation } \\
\text { assuming } 2.39 \mathrm{~kg} \mathrm{bw}\end{array}$ & $\begin{array}{l}\text { After Calder and } \\
\text { Braun } 1983\end{array}$ \\
\hline \multirow[t]{2}{*}{ Diet Composition } & $\begin{array}{l}\text { diet predominantly fish } \\
\text { but may include } \\
\text { crustaceans, insects, } \\
\text { snails, amphibians, } \\
\text { reptiles, birds, and } \\
\text { mammals }\end{array}$ & & $\begin{array}{l}\text { Kushlan } 1978 \\
\text { Callazo } 1985 \\
\text { Hoffman } 1978\end{array}$ \\
\hline & $\begin{array}{l}\text { fish sizes: } \\
0-10 \mathrm{~cm}=39.2 \% \\
11-20 \mathrm{~cm}=47.1 \% \\
21-30 \mathrm{~cm}=13.7 \%\end{array}$ & & Alexander 1977 \\
\hline \multirow{2}{*}{$\begin{array}{l}\text { Home Range } \\
\text { (foraging distance } \\
\text { from colony) }\end{array}$} & $3.1 \mathrm{~km}$ & $\begin{array}{l}\text { up to } 24.2 \mathrm{~km} \text { - } \\
\text { S. Dakota - river }\end{array}$ & EPA 1993a. \\
\hline & $7-8 \mathrm{~km}$ & N. Carolina - coastal & Short and Cooper 1985 \\
\hline \multirow[t]{3}{*}{$\begin{array}{l}\text { Habitat } \\
\text { Requirements }\end{array}$} & $\begin{array}{l}\text { use both coastal and } \\
\text { inland water-associated } \\
\text { habitats }\end{array}$ & . & Short and Cooper 1985 \\
\hline & $\begin{array}{l}\text { Foraging: shallow } \\
\text { shores of ponds, lakes, } \\
\text { streams, wet meadows, } \\
\text { wooded swamps, bays, } \\
\text { and marshes }\end{array}$ & & DeGraaf et al. 1981 \\
\hline & $\begin{array}{l}\text { breeding: trees for } \\
\text { rookery sites. In } \\
\text { absence of trees will } \\
\text { use rock ledges, cliffs, } \\
\text { and artificial structures }\end{array}$ & & Short and Cooper 1985 \\
\hline
\end{tabular}




\section{C-7}

Table C.4 (continued)

\begin{tabular}{llll}
\hline \multicolumn{1}{c}{ Parameter } & \multicolumn{1}{c}{ Value } & Comments & Reference \\
\hline Population Density & $\begin{array}{l}\text { nest colonially, } \\
\text { therefore population } \\
\text { density depends on } \\
\text { availability of nest } \\
\text { habitat and suitable } \\
\text { foraging habitat }\end{array}$ & EPA 1993a \\
& $\begin{array}{l}\text { 2.3 - 3.6 /km } \\
\text { Behavior }\end{array}$ & $\begin{array}{l}\text { North Dakota rivers and } \\
\text { streams }\end{array}$ & \\
& $\begin{array}{l}\text { may or may not defend } \\
\text { a feeding territory } \\
\text { depending on local } \\
\text { population size and } \\
\text { food availability }\end{array}$ & Kushlan 1978 \\
& $\begin{array}{l}\text { Migrates in northern } \\
\text { U.S. and southern } \\
\text { Canada; year round } \\
\text { resident from WV, PA } \\
\text { south. }\end{array}$ & National Geographic \\
\hline
\end{tabular}


C-8

Table C.5. Life history parameters for osprey

\begin{tabular}{|c|c|c|c|}
\hline Parameter & Value & Comments & Reference \\
\hline Body Weight & $1.5 \mathrm{~kg}\left(0^{\pi}+q\right)$ & & EPA $1993 c$ \\
\hline Food Consumption Rate & $0.3 \mathrm{~kg} / \mathrm{d}$ & fresh weight & EPA $1993 c$ \\
\hline Water Consumption Rate & $0.077 \mathrm{~L} / \mathrm{d}$ & & EPA $1993 c$ \\
\hline \multirow[t]{2}{*}{ Diet Composition } & almost $100 \%$ fish & $\begin{array}{l}\text { all parts of fish } \\
\text { consumed except } \\
\text { large bones }\end{array}$ & EPA $1993 c$ \\
\hline & $\begin{array}{l}\text { fish sizes: } \\
0-10 \mathrm{~cm}=3.3 \% \\
11-20 \mathrm{~cm}=42.1 \% \\
21-30 \mathrm{~cm}=46.7 \% \\
31-40 \mathrm{~cm}=6.6 \% \\
>41 \mathrm{~cm}=1.3 \%\end{array}$ & & $\begin{array}{l}\text { Van Daele and } \\
\text { Van Daele } 1982\end{array}$ \\
\hline $\begin{array}{l}\text { Home Range } \\
\text { (foraging distance from } \\
\text { nest site) }\end{array}$ & $10-15 \mathrm{~km}$ & & $\begin{array}{l}\text { VanDaele and } \\
\text { VanDaele } 1982\end{array}$ \\
\hline \multirow[t]{3}{*}{ Habitat Requirements } & $\begin{array}{l}\text { Coastal areas plus large } \\
\text { rivers and lakes }\end{array}$ & & EPA $1993 b$ \\
\hline & $\begin{array}{l}\text { Nesting habitat requires } \\
\text { open, shallow water } \\
\text { nearby plus abundant } \\
\text { fish. }\end{array}$ & & \\
\hline & $\begin{array}{l}\text { Nests atop isolated (often } \\
\text { dead) trees and man- } \\
\text { made structures }\end{array}$ & & \\
\hline Population Density & $0.005-0.1$ nests $/ \mathrm{ha}$ & & EPA $1993 b$ \\
\hline Behavior & $\begin{array}{l}\text { year-round resident in } \\
\text { southern part of range } \\
\text { (i.e. Florida) }\end{array}$ & & EPA $1993 b$ \\
\hline & Migratory in Tennessee & & \\
\hline
\end{tabular}


Table C.6. Summary statistics for fish data from the ORR

\begin{tabular}{|c|c|c|c|c|c|c|c|c|c|c|c|}
\hline \multirow[b]{2}{*}{ Analyte } & \multirow[b]{2}{*}{ Location } & \multirow[b]{2}{*}{ Watershed } & \multirow[b]{2}{*}{ Size } & \multirow[b]{2}{*}{ Obs } & \multirow[b]{2}{*}{ Det } & \multicolumn{6}{|c|}{ Contaminant concentrations in fish $(\mathrm{mg} / \mathrm{kg})$} \\
\hline & & & & & & Mean & $\begin{array}{l}\text { Standard } \\
\text { error }\end{array}$ & $\begin{array}{l}95 \% \\
\text { UCL }\end{array}$ & Maximum & $\begin{array}{l}\text { Lognormal } \\
\text { mean }\end{array}$ & $\begin{array}{l}\text { Lognormal } \\
\text { standard } \\
\text { deviation }\end{array}$ \\
\hline Mercury & BCK 0.6 & Bear Creek & small & 24 & 24 & 0.269 & 0.020 & 0.304 & 0.549 & 0.269 & 0.091 \\
\hline Mercury & BCK 3.3 & Bear Creek & small & 8 & 8 & 0.060 & 0.006 & 0.071 & 0.086 & 0.060 & 0.016 \\
\hline Mercury & BCK 4.5 & Bear Creek & small & 11 & 11 & 0.194 & 0.021 & 0.233 & 0.339 & 0.195 & 0.067 \\
\hline Mercury & BCK 9.4 & Bear Creek & small & 8 & 8 & 0.079 & 0.006 & 0.090 & 0.110 & 0.079 & 0.015 \\
\hline Mercury & BCK 12.4 & Bear Creek & small & 8 & 8 & 0.120 & 0.010 & 0.139 & 0.170 & 0.120 & 0.026 \\
\hline Mercury & EFK 2.1 & East Fork & small & 28 & 28 & 0.281 & 0.012 & 0.301 & 0.436 & 0.281 & 0.065 \\
\hline Mercury & EFK 6.3 & East Fork & small & 24 & 24 & 0.420 & 0.016 & 0.447 & 0.549 & 0.420 & 0.082 \\
\hline Mercury & EFK 13.8 & East Fork & small & 24 & 24 & 0.425 & 0.022 & 0.462 & 0.612 & 0.426 & 0.112 \\
\hline Mercury & EFK 18.2 & East Fork & small & 25 & 25 & 0.430 & 0.014 & 0.454 & 0.549 & 0.430 & 0.069 \\
\hline Mercury & EFK 24.0 & East Fork & small & 24 & 24 & 0.411 & 0.028 & 0.459 & 0.761 & 0.410 & 0.125 \\
\hline Mercury & EFK 23.4 & East Fork & small & 24 & 24 & 0.420 & 0.028 & 0.467 & 1.009 & 0.418 & 0.099 \\
\hline Mercury & EFK 24.5 & East Fork & small & 24 & 24 & 0.762 & 0.031 & 0.815 & 0.956 & 0.766 & 0.187 \\
\hline Mercury & EFK 6.3 & East Fork & large & 12 & 12 & 0.339 & 0.036 & 0.403 & 0.580 & 0.341 & 0.128 \\
\hline Mercury & EFK 13.8 & East Fork & large & 12 & 12 & 0.307 & 0.023 & 0.348 & 0.418 & 0.310 & 0.096 \\
\hline Mercury & EFK 18.2 & East Fork & large & 12 & 12 & 0.300 & 0.037 & 0.366 & 0.580 & 0.301 & 0.126 \\
\hline Mercury & EFK 24.0 & East Fork & large & 4 & 4 & 0.400 & 0.029 & 0.467 & 0.483 & 0.401 & 0.055 \\
\hline Mercury & K-901 & $\mathrm{K}-25$ & small & 8 & 8 & 0.035 & 0.004 & 0.042 & 0.050 & 0.035 & 0.012 \\
\hline Mercury & $\mathrm{K}-710$ & $\mathrm{~K}-25$ & small & 8 & 8 & 0.089 & 0.004 & 0.097 & 0.106 & 0.089 & 0.013 \\
\hline Mercury & $\mathrm{K}-1007 \mathrm{~b} P 1$ & $\mathrm{~K}-25$ & small & 8 & 8 & 0.070 & 0.003 & 0.075 & 0.078 & 0.070 & 0.009 \\
\hline Mercury & $\mathrm{K}-1007 \mathrm{~b}$ P5 & $\mathrm{K}-25$ & small & 8 & 8 & 0.047 & 0.005 & 0.055 & 0.072 & 0.047 & 0.013 \\
\hline Mercury & CRK 15 & $\mathrm{~K}-25$ & small & 29 & 29 & 0.112 & 0.008 & 0.126 & 0.245 & 0.113 & 0.046 \\
\hline Mercury & MIK 0.2 & $\mathrm{~K}-25$ & small & 8 & 8 & 0.219 & 0.030 & 0.276 & 0.354 & 0.221 & 0.090 \\
\hline Mercury & PCK 1.6 & $\mathrm{~K}-25$ & small & 28 & 27 & 0.179 & 0.014 & 0.202 & 0.383 & 0.179 & 0.075 \\
\hline
\end{tabular}


Table C.6 (continued)

\begin{tabular}{|c|c|c|c|c|c|c|c|c|c|c|c|}
\hline \multirow[b]{2}{*}{ Analyte } & \multirow[b]{2}{*}{ Location } & \multirow[b]{2}{*}{ Watershed } & \multirow[b]{2}{*}{ Size } & \multirow[b]{2}{*}{ Obs } & \multirow[b]{2}{*}{ Det } & \multicolumn{6}{|c|}{ Contaminant concentrations in fish (mg/kg) } \\
\hline & & & & & & Mean & $\begin{array}{l}\text { Standard } \\
\text { error }\end{array}$ & $\begin{array}{l}95 \% \\
\text { UCL }\end{array}$ & Maximum & $\begin{array}{c}\text { Lognormal } \\
\text { mean }\end{array}$ & $\begin{array}{c}\text { Lognormal } \\
\text { standard } \\
\text { deviation }\end{array}$ \\
\hline Mercury & PCK 2.3 & $\mathrm{~K}-25$ & small & 11 & 11 & 0.183 & 0.016 & 0.211 & 0.247 & 0.187 & 0.075 \\
\hline Mercury & PCK 6.9 & $\mathrm{~K}-25$ & small & 8 & 8 & 0.203 & 0.009 & 0.220 & 0.237 & 0.203 & 0.026 \\
\hline Mercury & PCK 7.2 & $\mathrm{~K}-25$ & small & 12 & 12 & 0.278 & 0.025 & 0.323 & 0.361 & 0.288 & 0.142 \\
\hline Mercury & PCK 7.4 & $\mathrm{~K}-25$ & small & 12 & 12 & 0.212 & 0.019 & 0.246 & 0.394 & 0.212 & 0.056 \\
\hline Mercury & PCK 8.2 & $\mathrm{~K}-25$ & small & 16 & 16 & 0.251 & 0.017 & 0.281 & 0.443 & 0.252 & 0.063 \\
\hline Mercury & PCK 8.5 & $\mathrm{~K}-25$ & small & 9 & 7 & 0.233 & 0.021 & 0.272 & 0.335 & 0.223 & 0.096 \\
\hline Mercury & PCK 8.9 & $\mathrm{~K}-25$ & small & 9 & 9 & 0.290 & 0.030 & 0.346 & 0.408 & 0.294 & 0.111 \\
\hline Mercury & PCK 9.7 & $\mathrm{~K}-25$ & small & 10 & 10 & 0.108 & 0.032 & 0.167 & 0.311 & 0.105 & 0.086 \\
\hline Mercury & PCK 18.2 & $\mathrm{~K}-25$ & small & 8 & 8 & 0.052 & 0.003 & 0.058 & 0.066 & 0.052 & 0.009 \\
\hline Mercury & K-901 & $\mathrm{K}-25$ & large & 18 & 18 & 0.174 & 0.025 & 0.223 & 0.483 & 0.171 & 0.084 \\
\hline Mercury & CRK 15 & $\mathrm{~K}-25$ & large & 20 & 15 & 0.146 & 0.018 & 0.178 & 0.343 & 0.149 & 0.092 \\
\hline Mercury & PCK 1.6 & $\mathrm{~K}-25$ & large & 20 & 20 & 0.284 & 0.031 & 0.337 & 0.645 & 0.282 & 0.121 \\
\hline Mercury & PCK 2.3 & $\mathrm{~K}-25$ & large & 2 & 2 & 0.269 & 0.019 & 0.392 & 0.288 & 0.269 & 0.028 \\
\hline Mercury & PCK 7.2 & $\mathrm{~K}-25$ & large & 1 & 1 & 0.321 & 0.321 & & & & \\
\hline Mercury & PCK 7.4 & $\mathrm{~K}-25$ & large & 5 & 5 & 0.376 & 0.078 & 0.543 & 0.602 & 0.387 & 0.203 \\
\hline Mercury & PCK 8.5 & $\mathrm{~K}-25$ & large & 2 & 2 & 0.531 & 0.192 & 1.744 & 0.723 & 0.571 & 0.330 \\
\hline Mercury & MEK 0.2 & White Oak & small & 24 & 24 & 0.090 & 0.006 & 0.099 & 0.161 & 0.090 & 0.025 \\
\hline Mercury & NTK 0.2 & White Oak & small & 8 & 8 & 0.123 & 0.008 & 0.139 & 0.157 & 0.124 & 0.026 \\
\hline Mercury & WCK 0.9 & White Oak & small & 16 & 16 & 0.103 & 0.006 & 0.114 & 0.161 & 0.103 & 0.024 \\
\hline Mercury & WCK 1.5 & White Oak & small & 16 & 16 & 0.096 & 0.009 & 0.111 & 0.166 & 0.096 & 0.035 \\
\hline Mercury & WCK 2.3 & White Oak & small & 8 & 8 & 0.154 & 0.020 & 0.191 & 0.261 & 0.155 & 0.052 \\
\hline Mercury & WCK 2.9 & White Oak & small & 8 & 8 & 0.176 & 0.016 & 0.207 & 0.245 & 0.177 & 0.046 \\
\hline Mercury & WCK 3.5 & White Oak & small & 16 & 16 & 0.111 & 0.007 & 0.124 & 0.166 & 0.112 & 0.033 \\
\hline Mercury & WCK 1.5 & White Oak & large & 16 & 16 & 0.154 & 0.018 & 0.185 & 0.301 & 0.155 & 0.082 \\
\hline
\end{tabular}


Table C.6 (continued)

\begin{tabular}{|c|c|c|c|c|c|c|c|c|c|c|c|}
\hline \multirow[b]{2}{*}{ Analyte } & \multirow[b]{2}{*}{ Location } & \multirow[b]{2}{*}{ Watershed } & \multirow[b]{2}{*}{ Size } & \multirow[b]{2}{*}{ Obs } & \multirow[b]{2}{*}{ Det } & \multicolumn{6}{|c|}{ Contaminant concentrations in fish (mg/kg) } \\
\hline & & & & & & Mean & $\begin{array}{l}\text { Standard } \\
\text { error }\end{array}$ & $\begin{array}{l}95 \% \\
\text { UCL }\end{array}$ & Maximum & $\begin{array}{c}\text { Lognormal } \\
\text { mean }\end{array}$ & $\begin{array}{l}\text { Lognormal } \\
\text { standard } \\
\text { deviation }\end{array}$ \\
\hline PCBs & BCK 0.6 & Bear Creek & small & 24 & 24 & 0.718 & 0.083 & 0.860 & 1.703 & 0.727 & 0.464 \\
\hline PCBs & BCK 3.3 & Bear Creek & small & 8 & 8 & 0.978 & 0.150 & 1.272 & 1.750 & 0.978 & 0.417 \\
\hline PCBs & BCK 4.5 & Bear Creek & small & 11 & 11 & 1.951 & 0.368 & 2.618 & 3.766 & 2.342 & 3.011 \\
\hline PCBs & BCK 9.4 & Bear Creek & small & 8 & 8 & 2.855 & 0.494 & 3.823 & 4.500 & 2.961 & 2.004 \\
\hline PCBs & BCK 12.4 & Bear Creek & small & 8 & 8 & 0.275 & 0.066 & 0.403 & 0.610 & 0.285 & 0.250 \\
\hline PCBs & EFK 2.1 & East Fork & small & 28 & 28 & 0.613 & 0.063 & 0.720 & 1.564 & 0.644 & 0.489 \\
\hline PCBs & EFK 6.3 & East Fork & small & 24 & 24 & 0.663 & 0.086 & 0.810 & 2.166 & 0.658 & 0.363 \\
\hline PCBs & EFK 13.8 & East Fork & small & 24 & 24 & 0.869 & 0.138 & 1.106 & 3.360 & 0.864 & 0.620 \\
\hline PCBs & EFK 18.2 & East Fork & small & 24 & 24 & 1.364 & 0.181 & 1.673 & 3.856 & 1.373 & 0.938 \\
\hline PCBs & EFK 24.0 & East Fork & small & 24 & 24 & 5.705 & 0.852 & 7.165 & 17.430 & 6.217 & 7.126 \\
\hline PCBs & EFK 23.4 & East Fork & small & 24 & 24 & 2.543 & 0.629 & 3.620 & 15.746 & 2.372 & 1.922 \\
\hline PCBs & EFK 24.5 & East Fork & small & 24 & 24 & 7.479 & 2.208 & 11.264 & 53.442 & 7.268 & 9.933 \\
\hline PCBs & EFK 6.3 & East Fork & large & 12 & 12 & 2.281 & 0.664 & 3.473 & 7.514 & 2.442 & 3.539 \\
\hline PCBs & EFK 13.8 & East Fork & large & 12 & 12 & 3.225 & 0.636 & 4.368 & 8.185 & 3.268 & 2.367 \\
\hline PCBs & EFK 18.2 & East Fork & large & 12 & 12 & 2.410 & 0.347 & 3.033 & 5.007 & 2.454 & 1.377 \\
\hline PCBs & EFK 24.0 & East Fork & large & 4 & 4 & 10.920 & 0.911 & 13.063 & 12.770 & 10.961 & 1.878 \\
\hline PCBs & $\mathrm{K}-901$ & $\mathrm{~K}-25$ & small & 8 & 8 & 6.338 & 1.470 & 9.218 & 15.000 & 6.346 & 4.186 \\
\hline PCBs & $\mathrm{K}-1007 \mathrm{~b}$ P1 & $\mathrm{K}-25$ & small & 4 & 4 & 4.538 & 1.773 & 8.710 & 8.597 & 5.805 & 8.868 \\
\hline PCBs & K-1007b P5 & $\mathrm{K}-25$ & small & 4 & 4 & 0.123 & 0.018 & 0.165 & 0.164 & 0.124 & 0.040 \\
\hline PCBs & CRK 15 & $\mathrm{~K}-25$ & small & 6 & 6 & 0.870 & 0.057 & 0.985 & 1.110 & 0.872 & 0.136 \\
\hline PCBs & MIK 0.2 & $\mathrm{~K}-25$ & small & 3 & 3 & 3.099 & 0.262 & 3.864 & 3.464 & 3.112 & 0.477 \\
\hline PCBs & PCK 1.6 & $\mathrm{~K}-25$ & small & 14 & 13 & 0.984 & 0.106 & 1.172 & 1.830 & 0.978 & 0.378 \\
\hline PCBs & PCK 7.4 & $\mathrm{~K}-25$ & small & 2 & 2 & 2.460 & 0.459 & 5.358 & 2.919 & 2.504 & 0.681 \\
\hline PCBs & K-901 & $\mathrm{K}-25$ & large & 9 & 9 & 1.013 & 0.321 & 1.641 & 2.884 & 0.972 & 0.834 \\
\hline
\end{tabular}


Table C.6 (continued)

\begin{tabular}{|c|c|c|c|c|c|c|c|c|c|c|c|}
\hline \multirow[b]{2}{*}{ Analyte } & \multirow[b]{2}{*}{ Location } & \multirow[b]{2}{*}{ Watershed } & \multirow[b]{2}{*}{ Size } & \multirow[b]{2}{*}{ Obs } & \multirow[b]{2}{*}{ Det } & \multicolumn{6}{|c|}{ Contaminant concentrations in fish (mg/kg) } \\
\hline & & & & & & Mean & $\begin{array}{l}\text { Standard } \\
\text { error }\end{array}$ & $\begin{array}{l}95 \% \\
\text { UCL }\end{array}$ & Maximum & $\begin{array}{l}\text { Lognormal } \\
\text { mean }\end{array}$ & $\begin{array}{l}\text { Lognormal } \\
\text { standard } \\
\text { deviation }\end{array}$ \\
\hline PCBs & $\mathrm{K}-710$ & $\mathrm{~K}-25$ & large & 4 & 4 & 0.806 & 0.237 & 1.363 & 1.481 & 0.835 & 0.502 \\
\hline PCBs & $\mathrm{K}-1007 \mathrm{~b} \mathrm{Pl}$ & $\mathrm{K}-25$ & large & 14 & 14 & 29.964 & 3.346 & 35.890 & 58.212 & 30.166 & 13.015 \\
\hline PCBs & $\mathrm{K}-1007 \mathrm{~b}$ P5 & $\mathrm{K}-25$ & large & 2 & 2 & 1.327 & 0.962 & 7.403 & 2.290 & 2.124 & 4.453 \\
\hline PCBs & CRK 15 & $\mathrm{~K}-25$ & large & 38 & 38 & 2.509 & 0.134 & 2.734 & 4.036 & 2.528 & 0.965 \\
\hline PCBs & PCK 1.1 & $\mathrm{~K}-25$ & large & 10 & 10 & 0.937 & 0.078 & 1.080 & 1.328 & 0.940 & 0.244 \\
\hline PCBs & PCK 1.6 & $\mathrm{~K}-25$ & large & 40 & 39 & 3.242 & 0.143 & 3.482 & 5.281 & 3.245 & 1.019 \\
\hline PCBs & PCK 2.3 & $\mathrm{~K}-25$ & large & 10 & 10 & 1.073 & 0.112 & 1.278 & 1.840 & 1.075 & 0.332 \\
\hline PCBs & PCK 6.9 & $\mathrm{~K}-25$ & large & 8 & 8 & 1.988 & 0.178 & 2.326 & 2.715 & 1.996 & 0.513 \\
\hline PCBs & PCK 7.2 & $\mathrm{~K}-25$ & large & 8 & 8 & 1.554 & 0.184 & 1.901 & 2.575 & 1.566 & 0.544 \\
\hline PCBs & PCK 7.4 & $\mathrm{~K}-25$ & large & 8 & 8 & 2.789 & 0.254 & 3.271 & 3.808 & 2.807 & 0.793 \\
\hline PCBs & PCK 8.5 & $\mathrm{~K}-25$ & large & 12 & 11 & 2.916 & 0.184 & 3.247 & 3.512 & 2.931 & 0.810 \\
\hline PCBs & PCK 8.9 & $\mathrm{~K}-25$ & large & 8 & 8 & 0.842 & 0.097 & 1.025 & 1.128 & 0.859 & 0.361 \\
\hline PCBs & PCK 9.7 & $\mathrm{~K}-25$ & large & 4 & 4 & 0.776 & 0.130 & 1.081 & 1.102 & 0.789 & 0.282 \\
\hline PCBs & MEK 0.2 & White Oak & small & 20 & 15 & 0.247 & 0.062 & 0.355 & 1.330 & 0.257 & 0.384 \\
\hline PCBs & NTK 0.2 & White Oak & small & 8 & 8 & 0.290 & 0.108 & 0.495 & 0.992 & 0.300 & 0.344 \\
\hline PCBs & WCK 0.9 & White Oak & small & 13 & 13 & 0.587 & 0.110 & 0.783 & 1.724 & 0.609 & 0.470 \\
\hline PCBs & WCK 1.5 & White Oak & small & 24 & 24 & 2.097 & 0.284 & 2.584 & 6.587 & 2.100 & 1.371 \\
\hline PCBs & WCK 2.3 & White Oak & small & 8 & 8 & 1.592 & 0.304 & 2.169 & 3.502 & 1.603 & 0.805 \\
\hline PCBs & WCK 2.9 & White Oak & small & 16 & 16 & 1.107 & 0.195 & 1.448 & 2.915 & 1.141 & 0.978 \\
\hline PCBs & WCK 3.5 & White Oak & small & 16 & 16 & 1.300 & 0.160 & 1.580 & 2.303 & 1.349 & 0.889 \\
\hline PCBs & WCK 0.9 & White Oak & large & 10 & 10 & 6.483 & 1.236 & 8.748 & 13.008 & 7.501 & 8.244 \\
\hline PCBs & WCK 1.5 & White Oak & large & 16 & 16 & 13.149 & 1.814 & 16.329 & 28.445 & 13.520 & 9.065 \\
\hline PCBs & WCK 0.3 & White Oak & large & 4 & 4 & 5.829 & 0.421 & 6.819 & 6.702 & 5.847 & 0.887 \\
\hline
\end{tabular}




\section{C-13}

Table C.7. Estimated exposure of mink on the ORR to mercury and PCBs

\begin{tabular}{|c|c|c|c|c|c|}
\hline Analyte & Drainage & $\begin{array}{l}\text { Sampling } \\
\text { station }\end{array}$ & $\begin{array}{c}\text { Dietary } \\
\text { exposure } \\
\text { (mg/kg-d) }\end{array}$ & $\begin{array}{c}\text { NOAEL } \\
\text { HQ }\end{array}$ & $\begin{array}{c}\text { LOAEL } \\
\text { HQ }\end{array}$ \\
\hline Mercury & East Fork & EFK 2.1 & 0.0225 & 1.50 & 0.90 \\
\hline Mercury & East Fork & EFK 6.3 & 0.0334 & 2.23 & 1.34 \\
\hline Mercury & East Fork & EFK 13.8 & 0.0346 & 2.31 & 1.38 \\
\hline Mercury & East Fork & EFK 18.2 & 0.0339 & 2.26 & 1.36 \\
\hline Mercury & East Fork & EFK 23.4 & 0.0349 & 2.33 & 1.40 \\
\hline Mercury & East Fork & EFK 24.0 & 0.0343 & 2.29 & 1.37 \\
\hline Mercury & East Fork & EFK 24.5 & 0.0609 & 4.06 & 2.44 \\
\hline Mercury & Bear Creek & BCK 0.6 & 0.0227 & 1.51 & 0.91 \\
\hline Mercury & Bear Creek & BCK 3.3 & 0.0053 & 0.35 & 0.21 \\
\hline Mercury & Bear Creek & BCK 4.5 & 0.0174 & 1.16 & 0.70 \\
\hline Mercury & Bear Creek & BCK 9.4 & 0.0067 & 0.45 & 0.27 \\
\hline Mercury & Bear Creek & BCK 12.4 & 0.0104 & 0.69 & 0.42 \\
\hline Mercury & $\mathrm{K}-25$ & CRK 15 & 0.0094 & 0.63 & 0.38 \\
\hline Mercury & $\mathrm{K}-25$ & $\mathrm{~K}-901$ & 0.0032 & 0.21 & 0.13 \\
\hline Mercury & $\mathrm{K}-25$ & $\mathrm{~K}-710$ & 0.0073 & 0.48 & 0.29 \\
\hline Mercury & $\mathrm{K}-25$ & PCK 1.6 & 0.0151 & 1.01 & 0.61 \\
\hline Mercury & $\mathrm{K}-25$ & $\mathrm{~K}-1007 \mathrm{~b}$ P1 & 0.0056 & 0.37 & 0.22 \\
\hline Mercury & $\mathrm{K}-25$ & K-1007b P5 & 0.0041 & 0.28 & 0.17 \\
\hline Mercury & $\mathrm{K}-25$ & PCK 2.3 & 0.0158 & 1.05 & 0.63 \\
\hline Mercury & $\mathrm{K}-25$ & PCK 6.9 & 0.0165 & 1.10 & 0.66 \\
\hline Mercury & $\mathrm{K}-25$ & PCK 7.2 & 0.0242 & 1.61 & 0.97 \\
\hline Mercury & $\mathrm{K}-25$ & PCK 7.4 & 0.0184 & 1.22 & 0.73 \\
\hline Mercury & $\mathrm{K}-25$ & MIK 0.2 & 0.0206 & 1.37 & 0.82 \\
\hline Mercury & $\mathrm{K}-25$ & PCK 8.2 & 0.0210 & 1.40 & 0.84 \\
\hline Mercury & $\mathrm{K}-25$ & PCK 8.5 & 0.0203 & 1.36 & 0.81 \\
\hline Mercury & $\mathrm{K}-25$ & PCK 8.9 & 0.0259 & 1.72 & 1.04 \\
\hline Mercury & $\mathrm{K}-25$ & PCK 9.7 & 0.0125 & 0.83 & 0.50 \\
\hline Mercury & $\mathrm{K}-25$ & PCK 18.2 & 0.0043 & 0.29 & 0.17 \\
\hline Mercury & White Oak & WCK 0.9 & 0.0085 & 0.57 & 0.34 \\
\hline Mercury & White Oak & WCK 1.5 & 0.0083 & 0.55 & 0.33 \\
\hline Mercury & White Oak & WCK 2.3 & 0.0143 & 0.95 & 0.57 \\
\hline Mercury & White Oak & MEK 0.2 & 0.0074 & 0.49 & 0.30 \\
\hline Mercury & White Oak & WCK 2.9 & 0.0155 & 1.03 & 0.62 \\
\hline Mercury & White Oak & WCK 3.5 & 0.0093 & 0.62 & 0.37 \\
\hline Mercury & White Oak & NTK 0.2 & 0.0104 & 0.69 & 0.42 \\
\hline PCBs & East Fork & EFK 2.1 & 0.0538 & 0.38 & 0.08 \\
\hline PCBs & East Fork & EFK 6.3 & 0.0606 & 0.43 & 0.09 \\
\hline PCBs & East Fork & EFK 13.8 & 0.0827 & 0.59 & 0.12 \\
\hline PCBs & East Fork & EFK 18.2 & 0.1251 & 0.89 & 0.18 \\
\hline PCBs & East Fork & EFK 23.4 & 0.2708 & 1.93 & 0.39 \\
\hline
\end{tabular}


Table C.7 (continued)

\begin{tabular}{|c|c|c|c|c|c|}
\hline Analyte & Drainage & $\begin{array}{l}\text { Sampling } \\
\text { station }\end{array}$ & $\begin{array}{c}\text { Dietary } \\
\text { exposure } \\
\text { (mg/kg-d) }\end{array}$ & $\begin{array}{c}\text { NOAEL } \\
\text { HQ }\end{array}$ & $\begin{array}{c}\text { LOAEL } \\
\text { HQ }\end{array}$ \\
\hline PCBs & East Fork & EFK 24.0 & 0.5360 & 3.83 & 0.78 \\
\hline PCBs & East Fork & EFK 24.5 & 0.8426 & 6.02 & 1.22 \\
\hline PCBs & Bear Creek & BCK 0.6 & 0.0644 & 0.46 & 0.09 \\
\hline PCBs & Bear Creek & BCK 3.3 & 0.0951 & 0.68 & 0.14 \\
\hline PCBs & Bear Creek & BCK 4.5 & 0.1959 & 1.40 & 0.28 \\
\hline PCBs & Bear Creek & BCK 9.4 & 0.2860 & 2.04 & 0.41 \\
\hline PCBs & Bear Creek & BCK 12.4 & 0.0301 & 0.22 & 0.04 \\
\hline PCBs & $\mathrm{K}-25$ & CRK 15 & 0.0736 & 0.53 & 0.11 \\
\hline PCBs & $\mathrm{K}-25$ & K-901 & 0.6895 & 4.93 & 1.00 \\
\hline PCBs & $\mathrm{K}-25$ & $\mathrm{~K}-710$ & 0.1020 & 0.73 & 0.15 \\
\hline PCBs & $\mathrm{K}-25$ & PCK 1.1 & 0.0808 & 0.58 & 0.12 \\
\hline PCBs & $\mathrm{K}-25$ & PCK 1.6 & 0.0876 & 0.63 & 0.13 \\
\hline PCBs & $\mathrm{K}-25$ & $\mathrm{~K}-1007 \mathrm{~b} \mathrm{P} 1$ & 0.6516 & 4.65 & 0.94 \\
\hline PCBs & $\mathrm{K}-25$ & $\mathrm{~K}-1007 \mathrm{~b}$ P5 & 0.0123 & 0.09 & 0.02 \\
\hline PCBs & $\mathrm{K}-25$ & PCK 2.3 & 0.0956 & 0.68 & 0.14 \\
\hline PCBs & $\mathrm{K}-25$ & PCK 6.9 & 0.1740 & 1.24 & 0.25 \\
\hline PCBs & $\mathrm{K}-25$ & PCK 7.2 & 0.1422 & 1.02 & 0.21 \\
\hline PCBs & $\mathrm{K}-25$ & PCK 7.4 & 0.4008 & 2.86 & 0.58 \\
\hline PCBs & $\mathrm{K}-25$ & MIK 0.2 & 0.2891 & 2.06 & 0.42 \\
\hline PCBs & $\mathrm{K}-25$ & PCK 8.5 & 0.2429 & 1.73 & 0.35 \\
\hline PCBs & $\mathrm{K}-25$ & PCK 8.9 & 0.0767 & 0.55 & 0.11 \\
\hline PCBs & $\mathrm{K}-25$ & PCK 9.7 & 0.0809 & 0.58 & 0.12 \\
\hline PCBs & White Oak & WCK 0.3 & 0.5101 & 3.64 & 0.74 \\
\hline PCBs & White Oak & WCK 0.9 & 0.0586 & 0.42 & 0.08 \\
\hline PCBs & White Oak & WCK 1.5 & 0.1933 & 1.38 & 0.28 \\
\hline PCBs & White Oak & WCK 2.3 & 0.1622 & 1.16 & 0.24 \\
\hline PCBs & White Oak & MEK 0.2 & 0.0265 & 0.19 & 0.04 \\
\hline PCBs & White Oak & WCK 2.9 & 0.1083 & 0.77 & 0.16 \\
\hline PCBs & White Oak & WCK 3.5 & 0.1182 & 0.84 & 0.17 \\
\hline PCBs & White Oak & NTK 0.2 & 0.0370 & 0.26 & 0.05 \\
\hline
\end{tabular}


Table C.8. Estimated exposure of river otter on the ORR to mercury and PCBs

\begin{tabular}{|c|c|c|c|c|c|}
\hline Analyte & Drainage & $\begin{array}{l}\text { Sampling } \\
\text { station }\end{array}$ & $\begin{array}{c}\text { Dietary } \\
\text { exposure } \\
\text { (mg/kg-d) }\end{array}$ & $\begin{array}{c}\text { NOAEL } \\
\text { HQ }\end{array}$ & $\begin{array}{c}\text { LOAEL } \\
\text { HQ }\end{array}$ \\
\hline Mercury & EFK 2.1 & East Fork & 0.0339 & 3.77 & 2.26 \\
\hline Mercury & EFK 6.3 & East Fork & 0.0478 & 5.31 & 3.19 \\
\hline Mercury & EFK 13.8 & East Fork & 0.0456 & 5.07 & 3.04 \\
\hline Mercury & EFK 18.2 & East Fork & 0.0461 & 5.12 & 3.07 \\
\hline Mercury & EFK 23.4 & East Fork & 0.0526 & 5.84 & 3.50 \\
\hline Mercury & EFK 24.0 & East Fork & 0.0521 & 5.79 & 3.47 \\
\hline Mercury & EFK 24.5 & East Fork & 0.0917 & 10.18 & 6.11 \\
\hline Mercury & BCK 0.6 & Bear Creek & 0.0342 & 3.80 & 2.28 \\
\hline Mercury & BCK 3.3 & Bear Creek & 0.0080 & 0.89 & 0.53 \\
\hline Mercury & BCK 4.5 & Bear Creek & 0.0262 & 2.91 & 1.74 \\
\hline Mercury & BCK 9.4 & Bear Creek & 0.0101 & 1.13 & 0.68 \\
\hline Mercury & BCK 12.4 & Bear Creek & 0.0156 & 1.74 & 1.04 \\
\hline Mercury & CRK 15 & $\mathrm{~K}-25$ & 0.0171 & 1.90 & 1.14 \\
\hline Mercury & $\mathrm{K}-901$ & $\mathrm{~K}-25$ & 0.0149 & 1.66 & 0.99 \\
\hline Mercury & $\mathrm{K}-710$ & $\mathrm{~K}-25$ & 0.0109 & 1.22 & 0.73 \\
\hline Mercury & PCK 1.6 & $\mathrm{~K}-25$ & 0.0303 & 3.37 & 2.02 \\
\hline Mercury & $\mathrm{K}-1007 \mathrm{~b} \mathrm{Pl}$ & $\mathrm{K}-25$ & 0.0084 & 0.94 & 0.56 \\
\hline Mercury & K-1007b P5 & $\mathrm{K}-25$ & 0.0062 & 0.69 & 0.42 \\
\hline Mercury & PCK 2.3 & $\mathrm{~K}-25$ & 0.0339 & 3.77 & 2.26 \\
\hline Mercury & PCK 6.9 & $\mathrm{~K}-25$ & 0.0248 & 2.76 & 1.65 \\
\hline Mercury & PCK 7.2 & $\mathrm{~K}-25$ & 0.0363 & 4.03 & 2.42 \\
\hline Mercury & PCK 7.4 & $\mathrm{~K}-25$ & 0.0443 & 4.93 & 2.96 \\
\hline Mercury & MIK 0.2 & $\mathrm{~K}-25$ & 0.0310 & 3.45 & 2.07 \\
\hline Mercury & PCK 8.2 & $\mathrm{~K}-25$ & 0.0316 & 3.51 & 2.11 \\
\hline Mercury & PCK 8.5 & $\mathrm{~K}-25$ & 0.1134 & 12.60 & 7.56 \\
\hline Mercury & PCK 8.9 & $\mathrm{~K}-25$ & 0.0389 & 4.32 & 2.59 \\
\hline Mercury & PCK 9.7 & $\mathrm{~K}-25$ & 0.0188 & 2.09 & 1.25 \\
\hline Mercury & PCK 18.2 & $\mathrm{~K}-25$ & 0.0065 & 0.73 & 0.44 \\
\hline Mercury & WCK 0.9 & White Oak & 0.0128 & 1.43 & 0.86 \\
\hline Mercury & WCK 1.5 & White Oak & 0.0166 & 1.85 & 1.11 \\
\hline Mercury & WCK 2.3 & White Oak & 0.0215 & 2.39 & 1.43 \\
\hline Mercury & MEK 0.2 & White Oak & 0.0111 & 1.24 & 0.74 \\
\hline Mercury & WCK 2.9 & White Oak & 0.0233 & 2.59 & 1.55 \\
\hline Mercury & WCK 3.5 & White Oak & 0.0140 & 1.55 & 0.93 \\
\hline Mercury & NTK 0.2 & White Oak & 0.0157 & 1.74 & 1.04 \\
\hline PCBs & BCK 0.6 & Bear Creek & 0.0968 & 1.17 & 0.24 \\
\hline PCBs & BCK 3.3 & Bear Creek & 0.1431 & 1.72 & 0.35 \\
\hline PCBs & BCK 4.5 & Bear Creek & 0.2946 & 3.55 & 0.72 \\
\hline PCBs & BCK 9.4 & Bear Creek & 0.4301 & 5.18 & 1.05 \\
\hline PCBs & BCK 12.4 & Bear Creek & 0.0453 & 0.55 & 0.11 \\
\hline
\end{tabular}




$$
\text { C-16 }
$$

Table C.8 (continued)

\begin{tabular}{|c|c|c|c|c|c|}
\hline Analyte & Drainage & $\begin{array}{l}\text { Sampling } \\
\text { station }\end{array}$ & $\begin{array}{c}\text { Dietary } \\
\text { exposure } \\
\text { (mg/kg-d) }\end{array}$ & $\begin{array}{c}\text { NOAEL } \\
\text { HQ }\end{array}$ & $\begin{array}{c}\text { LOAEL } \\
\text { HQ }\end{array}$ \\
\hline PCBs & EFK 2.1 & East Fork & 0.0810 & 0.98 & 0.20 \\
\hline PCBs & EFK 6.3 & East Fork & 0.2409 & 2.90 & 0.59 \\
\hline PCBs & EFK 13.8 & East Fork & 0.3079 & 3.71 & 0.75 \\
\hline PCBs & EFK 18.2 & East Fork & 0.2647 & 3.19 & 0.65 \\
\hline PCBs & EFK 23.4 & East Fork & 0.4073 & 4.91 & 0.99 \\
\hline PCBs & EFK 24.0 & East Fork & 1.1379 & 13.71 & 2.78 \\
\hline PCBs & EFK 24.5 & East Fork & 1.2672 & 15.27 & 3.09 \\
\hline PCBs & CRK 15 & $\mathrm{~K}-25$ & 0.2092 & 2.52 & 0.51 \\
\hline PCBs & K-901 & $\mathrm{K}-25$ & 0.6108 & 7.36 & 1.49 \\
\hline PCBs & $\mathrm{K}-710$ & $\mathrm{~K}-25$ & 0.1533 & 1.85 & 0.37 \\
\hline PCBs & PCK 1.1 & $\mathrm{~K}-25$ & 0.1215 & 1.46 & 0.30 \\
\hline PCBs & PCK 1.6 & $\mathrm{~K}-25$ & 0.2618 & 3.15 & 0.64 \\
\hline PCBs & K-1007b P1 & $\mathrm{K}-25$ & 2.5088 & 30.23 & 6.12 \\
\hline PCBs & $\mathrm{K}-1007 \mathrm{~b}$ P5 & $\mathrm{K}-25$ & 0.4257 & 5.13 & 1.04 \\
\hline PCBs & PCK 2.3 & $\mathrm{~K}-25$ & 0.1438 & 1.73 & 0.35 \\
\hline PCBs & PCK 6.9 & $\mathrm{~K}-25$ & 0.2616 & 3.15 & 0.64 \\
\hline PCBs & PCK 7.2 & $\mathrm{~K}-25$ & 0.2139 & 2.58 & 0.52 \\
\hline PCBs & PCK 7.4 & $\mathrm{~K}-25$ & 0.4853 & 5.85 & 1.18 \\
\hline PCBs & MIK 0.2 & $\mathrm{~K}-25$ & 0.4347 & 5.24 & 1.06 \\
\hline PCBs & PCK 8.5 & $\mathrm{~K}-25$ & 0.3653 & 4.40 & 0.89 \\
\hline PCBs & PCK 8.9 & $\mathrm{~K}-25$ & 0.1154 & 1.39 & 0.28 \\
\hline PCBs & PCK 9.7 & $\mathrm{~K}-25$ & 0.1216 & 1.47 & 0.30 \\
\hline PCBs & WCK 0.3 & White Oak & 0.7671 & 9.24 & 1.87 \\
\hline PCBs & WCK 0.9 & White Oak & 0.5362 & 6.46 & 1.31 \\
\hline PCBs & WCK 1.5 & White Oak & 1.0638 & 12.82 & 2.59 \\
\hline PCBs & WCK 2.3 & White Oak & 0.2440 & 2.94 & 0.60 \\
\hline PCBs & MEK 0.2 & White Oak & 0.0399 & 0.48 & 0.10 \\
\hline PCBs & WCK 2.9 & White Oak & 0.1629 & 1.96 & 0.40 \\
\hline PCBs & WCK 3.5 & White Oak & 0.1777 & 2.14 & 0.43 \\
\hline PCBs & NTK 0.2 & White Oak & 0.0557 & 0.67 & 0.14 \\
\hline
\end{tabular}


Table C.9. Estimated exposure of belted kingfisher on the ORR to mercury and PCBs

\begin{tabular}{|c|c|c|c|c|c|}
\hline Analyte & Drainage & $\begin{array}{l}\text { Sampling } \\
\text { station }\end{array}$ & $\begin{array}{c}\text { Dietary } \\
\text { exposure } \\
\text { (mg/kg-d) } \\
\end{array}$ & $\begin{array}{c}\text { NOAEL } \\
\text { HQ }\end{array}$ & $\begin{array}{c}\text { LOAEL } \\
\text { HQ }\end{array}$ \\
\hline Mercury & EFK 2.1 & East Fork & 0.1527 & 25.46 & 2.39 \\
\hline Mercury & EFK 6.3 & East Fork & 0.2264 & 37.73 & 3.54 \\
\hline Mercury & EFK 13.8 & East Fork & 0.2343 & 39.05 & 3.66 \\
\hline Mercury & EFK 18.2 & East Fork & 0.2299 & 38.32 & 3.59 \\
\hline Mercury & EFK 23.4 & East Fork & 0.2368 & 39.46 & 3.70 \\
\hline Mercury & EFK 24.0 & East Fork & 0.2327 & 38.78 & 3.64 \\
\hline Mercury & EFK 24.5 & East Fork & 0.4129 & 68.81 & 6.45 \\
\hline Mercury & BCK 0.6 & Bear Creek & 0.1539 & 25.64 & 2.40 \\
\hline Mercury & BCK 3.3 & Bear Creek & 0.0360 & 6.00 & 0.56 \\
\hline Mercury & BCK 4.5 & Bear Creek & 0.1178 & 19.64 & 1.84 \\
\hline Mercury & BCK 9.4 & Bear Creek & 0.0456 & 7.60 & 0.71 \\
\hline Mercury & BCK 12.4 & Bear Creek & 0.0704 & 11.74 & 1.10 \\
\hline Mercury & CRK 15 & $\mathrm{~K}-25$ & 0.0638 & 10.63 & 1.00 \\
\hline Mercury & K-901 & $\mathrm{K}-25$ & 0.0215 & 3.58 & 0.34 \\
\hline Mercury & $\mathrm{K}-710$ & $\mathrm{~K}-25$ & 0.0493 & 8.21 & 0.77 \\
\hline Mercury & PCK 1.6 & $\mathrm{~K}-25$ & 0.1025 & 17.08 & 1.60 \\
\hline Mercury & $\mathrm{K}-1007 \mathrm{~b} P 1$ & $\mathrm{~K}-25$ & 0.0381 & 6.34 & 0.59 \\
\hline Mercury & $\mathrm{K}-1007 \mathrm{~b}$ P5 & $\mathrm{K}-25$ & 0.0281 & 4.68 & 0.44 \\
\hline Mercury & PCK 2.3 & $\mathrm{~K}-25$ & 0.1070 & 17.83 & 1.67 \\
\hline Mercury & PCK 6.9 & $\mathrm{~K}-25$ & 0.1117 & 18.61 & 1.75 \\
\hline Mercury & PCK 7.2 & $\mathrm{~K}-25$ & 0.1639 & 27.31 & 2.56 \\
\hline Mercury & PCK 7.4 & $\mathrm{~K}-25$ & 0.1244 & 20.73 & 1.94 \\
\hline Mercury & MIK 0.2 & $\mathrm{~K}-25$ & 0.1397 & 23.28 & 2.18 \\
\hline Mercury & PCK 8.2 & $\mathrm{~K}-25$ & 0.1423 & 23.72 & 2.22 \\
\hline Mercury & PCK 8.5 & $\mathrm{~K}-25$ & 0.1377 & 22.96 & 2.15 \\
\hline Mercury & PCK 8.9 & $\mathrm{~K}-25$ & 0.1753 & 29.21 & 2.74 \\
\hline Mercury & PCK 9.7 & $\mathrm{~K}-25$ & 0.0846 & 14.10 & 1.32 \\
\hline Mercury & PCK 18.2 & $\mathrm{~K}-25$ & 0.0294 & 4.90 & 0.46 \\
\hline Mercury & WCK 0.9 & White Oak & 0.0579 & 9.65 & 0.90 \\
\hline Mercury & WCK 1.5 & White Oak & 0.0560 & 9.34 & 0.88 \\
\hline Mercury & WCK 2.3 & White Oak & 0.0969 & 16.16 & 1.51 \\
\hline Mercury & MEK 0.2 & White Oak & 0.0502 & 8.37 & 0.78 \\
\hline Mercury & WCK 2.9 & White Oak & 0.1048 & 17.47 & 1.64 \\
\hline Mercury & WCK 3.5 & White Oak & 0.0630 & 10.50 & 0.98 \\
\hline Mercury & NTK 0.2 & White Oak & 0.0706 & 11.77 & 1.10 \\
\hline PCBs & BCK 0.6 & Bear Creek & 0.4360 & 2.42 & 0.24 \\
\hline PCBs & BCK 3.3 & Bear Creek & 0.6446 & 3.58 & 0.36 \\
\hline PCBs & BCK 4.5 & Bear Creek & 1.3269 & 7.37 & 0.74 \\
\hline PCBs & BCK 9.4 & Bear Creek & 1.9373 & 10.76 & 1.08 \\
\hline PCBs & BCK 12.4 & Bear Creek & 0.2042 & 1.13 & 0.11 \\
\hline
\end{tabular}


C-18

Table C.9 (continued)

\begin{tabular}{|c|c|c|c|c|c|}
\hline Analyte & Drainage & $\begin{array}{l}\text { Sampling } \\
\text { station }\end{array}$ & $\begin{array}{c}\text { Dietary } \\
\text { exposure } \\
\text { (mg/kg-d) }\end{array}$ & $\begin{array}{l}\text { NOAEL } \\
\text { HQ }\end{array}$ & $\begin{array}{c}\text { LOAEL } \\
\text { HQ }\end{array}$ \\
\hline PCBs & EFK 2.1 & East Fork & 0.3647 & 2.03 & 0.20 \\
\hline PCBs & EFK 6.3 & East Fork & 0.4105 & 2.28 & 0.23 \\
\hline PCBs & EFK 13.8 & East Fork & 0.5602 & 3.11 & 0.31 \\
\hline PCBs & EFK 18.2 & East Fork & 0.8478 & 4.71 & 0.47 \\
\hline PCBs & EFK 23.4 & East Fork & 1.8345 & 10.19 & 1.02 \\
\hline PCBs & EFK 24.0 & East Fork & 3.6311 & 20.17 & 2.02 \\
\hline PCBs & EFK 24.5 & East Fork & 5.7083 & 31.71 & 3.17 \\
\hline PCBs & CRK 15 & $\mathrm{~K}-25$ & 0.4989 & 2.77 & 0.28 \\
\hline PCBs & K-901 & $\mathrm{K}-25$ & 4.6713 & 25.95 & 2.60 \\
\hline PCBs & $\mathrm{K}-710$ & $\mathrm{~K}-25$ & 0.6907 & 3.84 & 0.38 \\
\hline PCBs & PCK 1.1 & $\mathrm{~K}-25$ & 0.5473 & 3.04 & 0.30 \\
\hline PCBs & PCK 1.6 & $\mathrm{~K}-25$ & 0.5937 & 3.30 & 0.33 \\
\hline PCBs & K-1007b P1 & $\mathrm{K}-25$ & 4.4141 & 24.52 & 2.45 \\
\hline PCBs & $\mathrm{K}-1007 \mathrm{~b}$ P5 & $\mathrm{K}-25$ & 0.0836 & 0.46 & 0.05 \\
\hline PCBs & PCK 2.3 & $\mathrm{~K}-25$ & 0.6476 & 3.60 & 0.36 \\
\hline PCBs & PCK 6.9 & $\mathrm{~K}-25$ & 1.1786 & 6.55 & 0.65 \\
\hline PCBs & PCK 7.2 & $\mathrm{~K}-25$ & 0.9635 & 5.35 & 0.54 \\
\hline PCBs & PCK 7.4 & $\mathrm{~K}-25$ & 2.7151 & 15.08 & 1.51 \\
\hline PCBs & MIK 0.2 & $\mathrm{~K}-25$ & 1.9583 & 10.88 & 1.09 \\
\hline PCBs & PCK 8.5 & $\mathrm{~K}-25$ & 1.6453 & 9.14 & 0.91 \\
\hline PCBs & PCK 8.9 & $\mathrm{~K}-25$ & 0.5196 & 2.89 & 0.29 \\
\hline PCBs & PCK 9.7 & $\mathrm{~K}-25$ & 0.5480 & 3.04 & 0.30 \\
\hline PCBs & WCK 0.3 & White Oak & 3.4556 & 19.20 & 1.92 \\
\hline PCBs & WCK 0.9 & White Oak & 0.3969 & 2.21 & 0.22 \\
\hline PCBs & WCK 1.5 & White Oak & 1.3093 & 7.27 & 0.73 \\
\hline PCBs & WCK 2.3 & White Oak & 1.0990 & 6.11 & 0.61 \\
\hline PCBs & MEK 0.2 & White Oak & 0.1797 & 1.00 & 0.10 \\
\hline PCBs & WCK 2.9 & White Oak & 0.7339 & 4.08 & 0.41 \\
\hline PCBs & WCK 3.5 & White Oak & 0.8005 & 4.45 & 0.44 \\
\hline PCBs & NTK 0.2 & White Oak & 0.2508 & 1.39 & 0.14 \\
\hline
\end{tabular}


Table C.10. Estimated exposure of great blue heron on the ORR to mercury and PCBs

\begin{tabular}{|c|c|c|c|c|c|}
\hline Analyte & Drainage & $\begin{array}{l}\text { Sampling } \\
\text { station }\end{array}$ & $\begin{array}{c}\text { Dietary } \\
\text { exposure } \\
\text { (mg/kg-d) }\end{array}$ & $\begin{array}{c}\text { NOAEL } \\
\text { HQ }\end{array}$ & $\begin{array}{c}\text { LOAEL } \\
\text { HQ }\end{array}$ \\
\hline Mercury & EFK 2.1 & East Fork & 0.0530 & 8.83 & 0.83 \\
\hline Mercury & EFK 6.3 & East Fork & 0.0785 & 13.08 & 1.23 \\
\hline Mercury & EFK 13.8 & East Fork & 0.0812 & 13.54 & 1.27 \\
\hline Mercury & EFK 18.2 & East Fork & 0.0797 & 13.29 & 1.25 \\
\hline Mercury & EFK 23.4 & East Fork & 0.0821 & 13.68 & 1.28 \\
\hline Mercury & EFK 24.0 & East Fork & 0.0807 & 13.45 & 1.26 \\
\hline Mercury & EFK 24.5 & East Fork & 0.1432 & 23.86 & 2.24 \\
\hline Mercury & BCK 0.6 & Bear Creek & 0.0534 & 8.89 & 0.83 \\
\hline Mercury & BCK 3.3 & Bear Creek & 0.0125 & 2.08 & 0.20 \\
\hline Mercury & BCK 4.5 & Bear Creek & 0.0409 & 6.81 & 0.64 \\
\hline Mercury & BCK 9.4 & Bear Creek & 0.0158 & 2.64 & 0.25 \\
\hline Mercury & BCK 12.4 & Bear Creek & 0.0244 & 4.07 & 0.38 \\
\hline Mercury & CRK 15 & $\mathrm{~K}-25$ & 0.0221 & 3.68 & 0.35 \\
\hline Mercury & $\mathrm{K}-901$ & $\mathrm{~K}-25$ & 0.0075 & 1.24 & 0.12 \\
\hline Mercury & $\mathrm{K}-710$ & $\mathrm{~K}-25$ & 0.0171 & 2.85 & 0.27 \\
\hline Mercury & PCK 1.6 & $\mathrm{~K}-25$ & 0.0355 & 5.92 & 0.56 \\
\hline Mercury & $\mathrm{K}-1007 \mathrm{~b}$ P1 & $\mathrm{K}-25$ & 0.0132 & 2.20 & 0.21 \\
\hline Mercury & $\mathrm{K}-1007 \mathrm{~b}$ P5 & $\widehat{K-25}$ & 0.0097 & 1.62 & 0.15 \\
\hline Mercury & PCK 2.3 & $\mathrm{~K}-25$ & 0.0371 & 6.18 & 0.58 \\
\hline Mercury & PCK 6.9 & $\mathrm{~K}-25$ & 0.0387 & 6.46 & 0.61 \\
\hline Mercury & PCK 7.2 & $\mathrm{~K}-25$ & 0.0568 & 9.47 & 0.89 \\
\hline Mercury & PCK 7.4 & $\mathrm{~K}-25$ & 0.0431 & 7.19 & 0.67 \\
\hline Mercury & MIK 0.2 & $\mathrm{~K}-25$ & 0.0484 & 8.07 & 0.76 \\
\hline Mercury & PCK 8.2 & $\mathrm{~K}-25$ & 0.0493 & 8.22 & 0.77 \\
\hline Mercury & PCK 8.5 & $\mathrm{~K}-25$ & 0.0478 & 7.96 & 0.75 \\
\hline Mercury & PCK 8.9 & $\mathrm{~K}-25$ & 0.0608 & 10.13 & 0.95 \\
\hline Mercury & PCK 9.7 & $\mathrm{~K}-25$ & 0.0293 & 4.89 & 0.46 \\
\hline Mercury & PCK 18.2 & $\mathrm{~K}-25$ & 0.0102 & 1.70 & 0.16 \\
\hline Mercury & WCK 0.9 & White Oak & 0.0201 & 3.34 & 0.31 \\
\hline Mercury & WCK 1.5 & White Oak & 0.0194 & 3.24 & 0.30 \\
\hline Mercury & WCK 2.3 & White Oak & 0.0336 & 5.60 & 0.53 \\
\hline Mercury & MEK 0.2 & White Oak & 0.0174 & 2.90 & 0.27 \\
\hline Mercury & WCK 2.9 & White Oak & 0.0364 & 6.06 & 0.57 \\
\hline Mercury & WCK 3.5 & White Oak & 0.0218 & 3.64 & 0.34 \\
\hline Mercury & NTK 0.2 & White Oak & 0.0245 & 4.08 & 0.38 \\
\hline PCBs & EFK 2.1 & East Fork & 0.1265 & 0.70 & 0.07 \\
\hline PCBs & EFK 6.3 & East Fork & 0.1424 & 0.79 & 0.08 \\
\hline PCBs & EFK 13.8 & East Fork & 0.1943 & 1.08 & 0.11 \\
\hline PCBs & EFK 18.2 & East Fork & 0.2940 & 1.63 & 0.16 \\
\hline PCBs & EFK 23.4 & East Fork & 0.6362 & 3.53 & 0.35 \\
\hline
\end{tabular}


Table C.10 (continued)

\begin{tabular}{|c|c|c|c|c|c|}
\hline Analyte & Drainage & $\begin{array}{l}\text { Sampling } \\
\text { station }\end{array}$ & $\begin{array}{c}\text { Dietary } \\
\text { exposure } \\
\text { (mg/kg-d) }\end{array}$ & $\begin{array}{c}\text { NOAEL } \\
\text { HQ }\end{array}$ & $\begin{array}{c}\text { LOAEL } \\
\text { HQ }\end{array}$ \\
\hline PCBs & EFK 24.0 & East Fork & 1.2592 & 7.00 & 0.70 \\
\hline PCBs & EFK 24.5 & East Fork & 1.9795 & 11.00 & 1.10 \\
\hline PCBs & BCK 0.6 & Bear Creek & 0.1512 & 0.84 & 0.08 \\
\hline PCBs & BCK 3.3 & Bear Creek & 0.2235 & 1.24 & 0.12 \\
\hline PCBs & BCK 4.5 & Bear Creek & 0.4601 & 2.56 & 0.26 \\
\hline PCBs & BCK 9.4 & Bear Creek & 0.6718 & 3.73 & 0.37 \\
\hline PCBs & BCK 12.4 & Bear Creek & 0.0708 & 0.39 & 0.04 \\
\hline PCBs & CRK 15 & $\mathrm{~K}-25$ & 0.1730 & 0.96 & 0.10 \\
\hline PCBs & K-901 & $K-25$ & 1.6199 & 9.00 & 0.90 \\
\hline PCBs & $\mathrm{K}-710$ & $\mathrm{~K}-25$ & 0.2395 & 1.33 & 0.13 \\
\hline PCBs & PCK 1.1 & $\mathrm{~K}-25$ & 0.1898 & 1.05 & 0.11 \\
\hline PCBs & PCK 1.6 & $\mathrm{~K}-25$ & 0.2059 & 1.14 & 0.11 \\
\hline PCBs & K-1007b P1 & $\mathrm{K}-25$ & 1.5307 & 8.50 & 0.85 \\
\hline PCBs & K-1007b P5 & $\mathrm{K}-25$ & 0.0290 & 0.16 & 0.02 \\
\hline PCBs & PCK 2.3 & $\mathrm{~K}-25$ & 0.2246 & 1.25 & 0.12 \\
\hline PCBs & PCK 6.9 & $\mathrm{~K}-25$ & 0.4087 & 2.27 & 0.23 \\
\hline PCBs & PCK 7.2 & $\mathrm{~K}-25$ & 0.3341 & 1.86 & 0.19 \\
\hline PCBs & PCK 7.4 & $\mathrm{~K}-25$ & 0.9415 & 5.23 & 0.52 \\
\hline PCBs & MIK 0.2 & $\mathrm{~K}-25$ & 0.6791 & 3.77 & 0.38 \\
\hline PCBs & PCK 8.5 & $\mathrm{~K}-25$ & 0.5706 & 3.17 & 0.32 \\
\hline PCBs & PCK 8.9 & $\mathrm{~K}-25$ & 0.1802 & 1.00 & 0.10 \\
\hline PCBs & PCK 9.7 & $\mathrm{~K}-25$ & 0.1900 & 1.06 & 0.11 \\
\hline PCBs & WCK 0.3 & White Oak & 1.1983 & 6.66 & 0.67 \\
\hline PCBs & WCK 0.9 & White Oak & 0.1377 & 0.76 & 0.08 \\
\hline PCBs & WCK 1.5 & White Oak & 0.4540 & 2.52 & 0.25 \\
\hline PCBs & WCK 2.3 & White Oak & 0.3811 & 2.12 & 0.21 \\
\hline PCBs & MEK 0.2 & White Oak & 0.0623 & 0.35 & 0.03 \\
\hline PCBs & WCK 2.9 & White Oak & 0.2545 & 1.41 & 0.14 \\
\hline PCBs & WCK 3.5 & White Oak & 0.2776 & 1.54 & 0.15 \\
\hline PCBs & NTK 0.2 & White Oak & 0.0870 & 0.48 & 0.05 \\
\hline
\end{tabular}




\section{C-21}

Table C.11. Estimated exposure of osprey on the ORR to mercury and PCBs

\begin{tabular}{|c|c|c|c|c|c|}
\hline Analyte & Drainage & $\begin{array}{l}\text { Sampling } \\
\text { station }\end{array}$ & $\begin{array}{c}\text { Dietary } \\
\text { exposure } \\
\text { (mg/kg-d) }\end{array}$ & $\begin{array}{c}\text { NOAEL } \\
\text { HQ }\end{array}$ & $\begin{array}{c}\text { LOAEL } \\
\text { HQ }\end{array}$ \\
\hline Mercury & CRK 15 & $\mathrm{~K}-25$ & 0.0260 & 4.33 & 0.41 \\
\hline Mercury & K-901 & $\mathrm{K}-25$ & 0.0113 & 1.89 & 0.18 \\
\hline Mercury & $\mathrm{K}-710$ & $\mathrm{~K}-25$ & 0.0194 & 3.24 & 0.30 \\
\hline Mercury & PCK 1.6 & $\mathrm{~K}-25$ & 0.0426 & 7.10 & 0.67 \\
\hline Mercury & K-1007b P1 & $\mathrm{K}-25$ & 0.0150 & 2.50 & 0.23 \\
\hline Mercury & $\mathrm{K}-1007 \mathrm{~b}$ P5 & $\mathrm{K}-25$ & 0.0111 & 1.85 & 0.17 \\
\hline Mercury & PCK 2.3 & $\mathrm{~K}-25$ & 0.0451 & 7.51 & 0.70 \\
\hline Mercury & PCK 6.9 & $\mathrm{~K}-25$ & 0.0441 & 7.35 & 0.69 \\
\hline Mercury & PCK 7.2 & $\mathrm{~K}-25$ & 0.0646 & 10.77 & 1.01 \\
\hline Mercury & PCK 7.4 & $\mathrm{~K}-25$ & 0.0538 & 8.97 & 0.84 \\
\hline Mercury & MIK 0.2 & $\mathrm{~K}-25$ & 0.0551 & 9.19 & 0.86 \\
\hline Mercury & PCK 8.2 & $\mathrm{~K}-25$ & 0.0562 & 9.36 & 0.88 \\
\hline Mercury & PCK 8.5 & $\mathrm{~K}-25$ & 0.0776 & 12.94 & 1.21 \\
\hline Mercury & PCK 8.9 & $\mathrm{~K}-25$ & 0.0692 & 11.53 & 1.08 \\
\hline Mercury & PCK 9.7 & $\mathrm{~K}-25$ & 0.0334 & 5.56 & 0.52 \\
\hline Mercury & PCK 18.2 & $\mathrm{~K}-25$ & 0.0116 & 1.93 & 0.18 \\
\hline Mercury & WCK 0.9 & White Oak & 0.0228 & 3.81 & 0.36 \\
\hline Mercury & WCK $1 . \dot{5}$ & White Oak & 0.0233 & 3.88 & 0.36 \\
\hline PCBs & CRK 15 & $\mathrm{~K}-25$ & 0.2245 & 1.25 & 0.12 \\
\hline PCBs & K-901 & $\mathrm{K}-25$ & 1.7239 & 9.58 & 0.96 \\
\hline PCBs & $\mathrm{K}-710$ & $\mathrm{~K}-25$ & 0.2726 & 1.51 & 0.15 \\
\hline PCBs & PCK 1.1 & $\mathrm{~K}-25$ & 0.2160 & 1.20 & 0.12 \\
\hline PCBs & PCK 1.6 & $\mathrm{~K}-25$ & 0.2708 & 1.50 & 0.15 \\
\hline PCBs & K-1007b P1 & $\mathrm{K}-25$ & 2.1715 & 12.06 & 1.21 \\
\hline PCBs & K-1007b P5 & $\mathrm{K}-25$ & 0.1474 & 0.82 & 0.08 \\
\hline PCBs & PCK 2.3 & $\mathrm{~K}-25$ & 0.2556 & 1.42 & 0.14 \\
\hline PCBs & PCK 6.9 & $\mathrm{~K}-25$ & 0.4651 & 2.58 & 0.26 \\
\hline PCBs & PCK 7.2 & $\mathrm{~K}-25$. & 0.3803 & 2.11 & 0.21 \\
\hline PCBs & PCK 7.4 & $\mathrm{~K}-25$ & 1.0386 & 5.77 & 0.58 \\
\hline PCBs & MIK 0.2 & $\mathrm{~K}-25$ & 0.7729 & 4.29 & 0.43 \\
\hline PCBs & PCK 8.5 & $\mathrm{~K}-25$ & 0.6493 & 3.61 & 0.36 \\
\hline PCBs & PCK 8.9 & $\mathrm{~K}-25$ & 0.2051 & 1.14 & 0.11 \\
\hline PCBs & PCK 9.7 & $\mathrm{~K}-25$ & 0.2163 & 1.20 & 0.12 \\
\hline PCBs & WCK 0.3 & White Oak & 1.3638 & 7.58 & 0.76 \\
\hline PCBs & WCK 0.9 & White Oak & 0.2825 & 1.57 & 0.16 \\
\hline PCBs & WCK 1.5 & White Oak & 0.7339 & 4.08 & 0.41 \\
\hline
\end{tabular}




$$
\text { C-22 }
$$

Table C.12. Biomass of fish observed at fish sampling locations in Bear Creek in 1993

\begin{tabular}{llrrrrrr}
\hline \multicolumn{2}{c}{ Sample location } & & \multicolumn{3}{c}{ Fish biomass $\left(\mathrm{g} / \mathrm{m}^{2}\right)$} & & \\
\cline { 1 - 1 } $\begin{array}{c}\text { Fish } \\
\text { Community }\end{array}$ & Bioaccumulation & & Spring & Fall & $\begin{array}{c}\text { Mean } \\
\text { annual } \\
\text { biomass }\end{array}$ & $\begin{array}{c}\text { Proportion of } \\
\text { total biomass at } \\
\text { sampled locations }\end{array}$ \\
\hline BCK 0.7 & BCK 0.6 & 5.84 & 4.73 & 5.29 & 0.18 \\
BCK 3.25 & BCK 3.3 & & 2.57 & 3.29 & 2.93 & 0.1 \\
BCK 3.25 & BCK 4.5 & & 2.57 & 3.29 & 2.93 & 0.1 \\
BCK 9.4 & BCK 9.4 & & 5.37 & 12.59 & 8.98 & 0.30 \\
BCK 12.36 & BCK 12.4 & & 14.43 & 4.43 & 9.43 & 0.32 \\
\hline
\end{tabular}

Source: Hinzman et al. 1995. 


$$
\text { C-23 }
$$

Table C.13. Density of fish observed at fish sampling locations in East Fork Poplar Creek

\begin{tabular}{|c|c|c|c|c|}
\hline \multicolumn{2}{|c|}{ Sample location } & \multicolumn{2}{|c|}{ Fish Density (no./m²) } & \multirow{2}{*}{$\begin{array}{c}\text { Proportion of total } \\
\text { density at sampled } \\
\text { locations }\end{array}$} \\
\hline $\begin{array}{c}\text { Fish } \\
\text { community }\end{array}$ & Bioaccumulation & Year & $\begin{array}{c}\text { Mean annual } \\
\text { density }\end{array}$ & \\
\hline EFK $2.3^{\circ}$ & EFK 2.1 & 1991 & 16.4 & 0.25 \\
\hline EFK $7.3^{2}$ & EFK 6.3 & 1991 & 4.4 & 0.067 \\
\hline EFK 10.8 & EFK 13.8 & 1991 & 16.6 & 0.253 \\
\hline EFK $17.6^{\mathrm{b}}$ & EFK 18.2 & 1991 & 2.8 & 0.043 \\
\hline EFK $23.4^{b}$ & EFK 23.4 & $\begin{array}{r}1993- \\
1995\end{array}$ & 11.1 & 0.169 \\
\hline $\begin{array}{l}\text { EFK } \\
23.4+24.4^{b}\end{array}$ & EFK 24.0 & $\begin{array}{r}1993- \\
1995\end{array}$ & 8.5 & 0.129 \\
\hline EFK $24.4^{b}$ & EFK 24.5 & $\begin{array}{r}1993- \\
1995\end{array}$ & 5.9 & 0.09 \\
\hline
\end{tabular}

"Source:SAIC. 1994.

' Source: unpublished UEFPC BMAP data (to be in UEFPC RI workplan) 


\section{C-24}

Table C.14. Total biomass of fish observed at fish sampling locations in White Oak Creek Watershed

\begin{tabular}{|c|c|c|c|c|c|c|c|}
\hline \multicolumn{2}{|c|}{ Sample location } & \multicolumn{4}{|c|}{ Fish biomass $\left(\mathrm{g} / \mathrm{m}^{2}\right)$} & \multicolumn{2}{|c|}{$\begin{array}{c}\text { Proportion of total } \\
\text { biomass at sampled } \\
\text { locations }\end{array}$} \\
\hline $\begin{array}{c}\text { Fish } \\
\text { community }\end{array}$ & Bioaccumulation & Spring & Fall & Year & $\begin{array}{c}\text { Mean } \\
\text { annual } \\
\text { biomass }\end{array}$ & $\begin{array}{l}\text { data from } \\
\text { all } 8 \\
\text { locations } \\
\end{array}$ & $\begin{array}{c}\text { data from } \\
\text { only } 7 \\
\text { locations } \\
\end{array}$ \\
\hline WOL a & WCK 0.3 & - & - & 1987 & 53.66 & 0.248 & \\
\hline WOL $^{2}$ & WCK 0.9 & - & - & 1987 & 53.66 & 0.248 & 0.33 \\
\hline WOL ${ }^{2}$ & WCK 1.5 & - & - & 1987 & 53.66 & 0.248 & 0.33 \\
\hline WCK $2.3^{\circ}$ & WCK 2.3 & 10.49 & 17.06 & 1993 & 13.78 & 0.064 & 0.085 \\
\hline MEK $0.6^{b}$ & MEK 0.2 & 10.52 & 9.6 & 1993 & 10.06 & 0.046 & 0.062 \\
\hline WCK $2.9^{b}$ & WCK 2.9 & 10.80 & 13.34 & 1993 & 12.07 & 0.056 & 0.075 \\
\hline WCK $3.4^{b}$ & WCK 3.5 & 17.16 & 14.30 & 1993 & 15.73 & 0.073 & 0.097 \\
\hline NTK $0.3^{b}$ & NTK 0.2 & 3.27 & 4.50 & 1993 & 3.89 & 0.018 & 0.024 \\
\hline
\end{tabular}

s Source:Loar et al. 1992.

${ }^{\mathrm{b}}$ Source:Ashwood et al. 1994. 


\section{C-25}

Table C.15. Results of Monte Carlo simulation of exposure for piscivores on the ORR

\begin{tabular}{|c|c|c|c|c|c|c|c|c|}
\hline Location & Analyte & Species & $\begin{array}{c}\text { No. of } \\
\text { sampling } \\
\text { locations }\end{array}$ & Mean & $\begin{array}{l}\text { Standard } \\
\text { deviation }\end{array}$ & $\begin{array}{c}\text { 80th } \\
\text { percentile }\end{array}$ & $\begin{array}{c}\%> \\
\text { NOAEL }\end{array}$ & $\begin{array}{c}\%> \\
\text { LOAEL }\end{array}$ \\
\hline Bear Creek & Mercury & Mink & 5 & 0.0102 & 0.0025 & 0.0121 & $5 \%$ & $<5 \%$ \\
\hline $\begin{array}{l}\text { East Fork Poplar } \\
\text { Creek }\end{array}$ & Mercury & Mink & 7 & 0.0310 & 0.0060 & 0.0361 & $>95 \%$ & $80 \%$ \\
\hline $\mathrm{K}-25$ & Mercury & Mink & 17 & 0.0119 & 0.0019 & 0.0135 & $5 \%$ & $<5 \%$ \\
\hline White Oak Creek & Mercury & Mink & 7 & 0.0083 & 0.0019 & 0.0098 & $<5 \%$ & $<5 \%$ \\
\hline Bear Creek & Mercury & Otter & 5 & 0.0153 & 0.0022 & 0.0170 & $>95 \%$ & $50 \%$ \\
\hline $\begin{array}{l}\text { East Fork Poplar } \\
\text { Creek }\end{array}$ & Mercury & Otter & 7 & 0.0447 & 0.0034 & 0.0477 & $>95 \%$ & $>95 \%$ \\
\hline $\mathrm{K}-25$ & Mercury & Otter & 17 & 0.0213 & 0.0020 & 0.0228 & $>95 \%$ & $>95 \%$ \\
\hline White Oak Creek & Mercury & Otter & 7 & 0.0136 & 0.0018 & 0.0150 & $>95 \%$ & $25 \%$ \\
\hline Bear Creek & Mercury & Kingfisher & 5 & 0.0691 & 0.0101 & 0.0769 & $>95 \%$ & $65-70 \%$ \\
\hline $\begin{array}{l}\text { East Fork Poplar } \\
\text { Creek }\end{array}$ & Mercury & Kingfisher & 7 & 0.2118 & 0.0230 & 0.2308 & $>95 \%$ & $>95 \%$ \\
\hline $\mathrm{K}-25$ & Mercury & Kingfisher & 17 & 0.0816 & 0.0091 & 0.0889 & $>95 \%$ & $>95 \%$ \\
\hline White Oak Creek & Mercury & Kingfisher & 7 & 0.0564 & 0.0077 & 0.0625 & $>95 \%$ & $15 \%$ \\
\hline Bear Creek & Mercury & Heron & 5 & 0.0238 & 0.0034 & 0.0263 & $>95 \%$ & $<5 \%$ \\
\hline $\begin{array}{l}\text { East Fork Poplar } \\
\text { Creek }\end{array}$ & Mercury & Heron & 7 & 0.0792 & 0.0074 & 0.0851 & $>95 \%$ & $>95 \%$ \\
\hline$K-25$ & Mercury & Heron & 17 & 0.0282 & 0.0031 & 0.0306 & $>95 \%$ & $<5 \%$ \\
\hline White Oak Creek & Mercury & Heron & 7 & 0.0198 & 0.0028 & 0.0220 & $>95 \%$ & $<5 \%$ \\
\hline $\mathrm{K}-25$ & Mercury & Osprey & 17 & 0.0330 & 0.0033 & 0.0355 & $>95 \%$ & $<5 \%$ \\
\hline White Oak Creek & Mercury & Osprey & 7 & 0.0202 & 0.0037 & 0.0229 & $>95 \%$ & $<5 \%$ \\
\hline Bear Creek & PCBs & Mink & 5 & 0.1102 & 0.0610 & 0.1481 & $20-25 \%$ & $<5 \%$ \\
\hline $\begin{array}{l}\text { East Fork Poplar } \\
\text { Creek }\end{array}$ & PCBs & Mink & 7 & 0.1735 & 0.1021 & 0.2301 & $50-55 \%$ & $<5 \%$ \\
\hline$K-25$ & PCBs & Mink & 17 & 0.1476 & 0.0406 & 0.1752 & $50 \%$ & $<5 \%$ \\
\hline White Oak Creek & PCBs & Mink & 8 & 0.1785 & 0.0563 & 0.2194 & $75 \%$ & $<5 \%$ \\
\hline
\end{tabular}




\section{C-26}

Table C.15 (continued)

\begin{tabular}{|c|c|c|c|c|c|c|c|c|}
\hline Location & Analyte & Species & $\begin{array}{c}\text { No. of } \\
\text { sampling } \\
\text { locations }\end{array}$ & Mean & $\begin{array}{l}\text { Standard } \\
\text { deviation }\end{array}$ & $\begin{array}{c}\text { 80th } \\
\text { percentile }\end{array}$ & $\begin{array}{c}\%> \\
\text { NOAEL }\end{array}$ & $\begin{array}{c}\%> \\
\text { LOAEL }\end{array}$ \\
\hline Bear Creek & PCBs & Otter & 5 & 0.1627 & 0.0752 & 0.2067 & $90-95 \%$ & $<5 \%$ \\
\hline $\begin{array}{l}\text { East Fork Poplar } \\
\text { Creek }\end{array}$ & PCBs & Otter & 7 & 0.3483 & 0.1038 & 0.4057 & $>95 \%$ & $15-20 \%$ \\
\hline $\mathrm{K}-25$ & PCBs & Otter & 17 & 0.3222 & 0.0659 & 0.3638 & $>95 \%$ & $5-10 \%$ \\
\hline White Oak Creek & PCBs & Otter & 8 & 0.5242 & 0.1784 & 0.6249 & $>95 \%$ & $70-75 \%$ \\
\hline Bear Creek & PCBs & Kingfisher & 5 & 0.7212 & 0.3406 & 0.9271 & $>95 \%$ & $<5 \%$ \\
\hline $\begin{array}{l}\text { East Fork Poplar } \\
\text { Creek }\end{array}$ & PCBs & Kingfisher & 7 & 1.1850 & 0.6537 & 1.5290 & $>95 \%$ & $10-15 \%$ \\
\hline $\mathrm{K}-25$ & PCBs & Kingfisher & 17 & 1.0332 & 0.3337 & 1.1631 & $>95 \%$ & $<5 \%$ \\
\hline White Oak Creek & PCBs & Kingfisher & 8 & 1.2136 & 0.2056 & 1.3590 & $>95 \%$ & $<5 \%$ \\
\hline Bear Creek & PCBs & Heron & 5 & 0.2532 & 0.1169 & 0.3225 & $70-75 \%$ & $<5 \%$ \\
\hline $\begin{array}{l}\text { East Fork Poplar } \\
\text { Creek }\end{array}$ & PCBs & Heron & 7 & 0.5017 & 0.3609 & 0.6358 & $>95 \%$ & $<5 \%$ \\
\hline $\mathrm{K}-25$ & PCBs & Heron & 17 & 0.3573 & 0.1075 & 0.4051 & $>95 \%$ & $<5 \%$ \\
\hline White Oak Creek & PCBs & Heron & 8 & 0.4202 & 0.0753 & 0.4721 & $>95 \%$ & $<5 \%$ \\
\hline $\mathrm{K}-25$ & PCBs & Osprey & 17 & 0.4318 & 0.1073 & 0.4859 & $>95 \%$ & $<5 \%$ \\
\hline White Oak Creek & PCBs & Osprey & 8 & 0.6605 & 0.1144 & 0.7489 & $>95 \%$ & $<5 \%$ \\
\hline
\end{tabular}


Table C.16. Estimated NOAELs and LOAELs for mink and river otter

\begin{tabular}{|c|c|c|c|c|c|c|c|c|c|c|}
\hline \multirow{2}{*}{ Contaminant } & \multicolumn{6}{|c|}{ Experimental information } & \multicolumn{2}{|c|}{$\begin{array}{c}\text { Estimated } \\
\text { NOAEL } \\
\text { (mg/kg/d) }\end{array}$} & \multicolumn{2}{|c|}{$\begin{array}{c}\text { Estimated } \\
\text { LOAEL } \\
(\mathrm{mg} / \mathrm{kg} / \mathrm{d})\end{array}$} \\
\hline & Form & Test species & $\begin{array}{c}\text { NOAEL } \\
\text { (mg/kg/d) } \\
\text { and duration }\end{array}$ & $\begin{array}{c}\text { LOAEL } \\
\text { (mg/kg/d) } \\
\text { and duration }\end{array}$ & Endpoint & Citation & mink & otter & mink & otter \\
\hline Mercury & methyl & mink & $\begin{array}{c}0.015^{2} \\
93 \mathrm{~d}\end{array}$ & $\begin{array}{c}0.025^{2} \\
93 \mathrm{~d}\end{array}$ & mortality & Wobeser et al. 1976 & $\begin{array}{c}0.01 \\
5\end{array}$ & 0.009 & 0.025 & 0.015 \\
\hline PCB's & $\begin{array}{c}\text { Aroclor } \\
1254\end{array}$ & $\operatorname{mink}$ & $\begin{array}{c}0.14 \\
4.5 \mathrm{mo} . \\
\end{array}$ & $\begin{array}{r}0.69 \\
4.5 \mathrm{mo} \\
\end{array}$ & reproduction & $\begin{array}{c}\text { Aulerich and Ringer } \\
1987\end{array}$ & 0.14 & 0.083 & 0.69 & 0.41 \\
\hline
\end{tabular}


Table C.17. Estimated NOAELs and LOAELs for belted kingfisher, great blue heron, and osprey

\begin{tabular}{|c|c|c|c|c|c|c|c|c|}
\hline \multirow[b]{2}{*}{ Contaminant } & \multicolumn{6}{|c|}{ Experimental information } & \multicolumn{2}{|c|}{$\begin{array}{c}\text { Estimated Values } \\
(\mathrm{mg} / \mathrm{kg} / \mathrm{d})\end{array}$} \\
\hline & Form & Test species & $\begin{array}{c}\text { NOAEL } \\
\text { (mg/kg/d) } \\
\text { and duration }\end{array}$ & $\begin{array}{c}\text { LOAEL } \\
\text { (mg/kg/d) } \\
\text { and duration }\end{array}$ & Endpoint & Citation & NOAEL & LOAEL \\
\hline Mercury & methyl & mallard duck & $\begin{array}{l}0.006^{2} \\
3 \text { gen. }\end{array}$ & $\begin{array}{l}0.064 \\
3 \text { gen. }\end{array}$ & reproduction & Heinz 1979 & 0.006 & 0.064 \\
\hline PCB's & Aroclor 1254 & $\begin{array}{c}\text { Ring-necked } \\
\text { Pheasant }\end{array}$ & $\begin{array}{l}0.18^{2} \\
17 \mathrm{wk}\end{array}$ & $\begin{array}{c}1.8 \\
17 \mathrm{wk}\end{array}$ & reproduction & $\begin{array}{c}\text { Dahlgren et al. } \\
1972\end{array}$ & 0.18 & 1.8 \\
\hline
\end{tabular}

${ }^{2}$ Estimated NOAEL: LOAEL-NOAEL factor of 10 applied. 
Table C.18 Contaminant concentrations (mg/kg) found in Kingfisher egg shells and feathers found on the ORR

\begin{tabular}{lcccccccc}
\hline Matrix & Burrow a & As & Cd & Se & Pb & Hg & $\begin{array}{c}{ }^{60 C o} \\
(\mathrm{pCi} / \mathrm{g})\end{array}$ & $\begin{array}{c}{ }^{137} \mathrm{Cs} \\
(\mathrm{pCi} / \mathrm{g})\end{array}$ \\
\hline egg shell & CRD & 0.135 & $<0.0333 \mathrm{~b}$ & 1.58 & 2.0 & $<0.020$ & $<7.45$ & $<9.09$ \\
egg shell & WOC & 0.0536 & 0.0583 & 1.41 & 5.31 & 0.182 & $<1.89$ & $58.1-1.7$ \\
feathers & CRU & 0.074 & 0.0132 & 5.72 & 0.657 & 1.03 & $<0.21$ & $<0.18$ \\
feathers & CRU & 0.0449 & $<0.0102$ & 6.54 & 1.42 & 1.01 & $<0.18$ & $<0.19$ \\
feathers & CRU & 0.052 & $<0.010$ & 5.72 & 1.67 & 1.04 & $<0.17$ & $<0.18$ \\
feathers & CRU & 0.0755 & 0.0755 & 6.83 & 1.91 & 0.726 & $<0.25$ & $<0.16$ \\
\hline
\end{tabular}

${ }^{2} \mathrm{CRD}=$ Clinch River downstream of WOL Embayment; WOC = White Oak Creek downstream of WCK 3.5; $\mathrm{CRU}=$ Clinch River upstream of Oak Ridge Reservation.

bLess than values are below minimum detection limit. 


$$
\text { C-30 }
$$

Table C.19 Contaminant concentrations in tissues of the three kingfishers found on the ORR

\begin{tabular}{|c|c|c|c|c|c|c|c|}
\hline $\begin{array}{l}\text { Bird } \\
\text { No. }\end{array}$ & $\begin{array}{l}\text { Watershed and } \\
\text { Location }\end{array}$ & Organ & $\begin{array}{c}{ }_{137 \mathrm{Cs}} \\
(\mathrm{pCi} / \mathrm{g})\end{array}$ & $\begin{array}{c}\mathrm{Cd} \\
(\mathrm{mg} / \mathrm{kg})^{2}\end{array}$ & $\begin{array}{c}\text { Pb } \\
(\mathrm{mg} / \mathrm{kg})^{n}\end{array}$ & $\underset{(\mathrm{mg} / \mathrm{kg})}{\mathrm{Se}}$ & $\underset{(\mathrm{mg} / \mathrm{kg})}{\mathrm{Hg}}$ \\
\hline \multirow[t]{5}{*}{1} & \multirow[t]{5}{*}{$\begin{array}{l}\text { East Fork Poplar } \\
\text { Creek, } \\
\text { Lake Reality }\end{array}$} & $\begin{array}{c}\text { whole body } \\
\text { feathers }\end{array}$ & $<2$ & ND & 2.67 & 5.38 & 13.9 \\
\hline & & kidney & & 4.04 & ND & 5.81 & 8.65 \\
\hline & & liver & & 0.95 & ND & 2.71 & 3.69 \\
\hline & & heart & & $\mathrm{ND}$ & ND & 1.25 & 1.1 \\
\hline & & muscle & & ND & ND & ND & 0.572 \\
\hline \multirow[t]{5}{*}{2} & \multirow{5}{*}{$\begin{array}{l}\text { East Fork Poplar } \\
\text { Creek }\end{array}$} & feathers & & 7.21 & 1.86 & 5.63 & 4.55 \\
\hline & & kidney & & 0.40 & ND & 3.14 & 1.46 \\
\hline & & liver & & 0.23 & ND & 3.45 & 0.955 \\
\hline & & heart & & ND & ND & 2.01 & 0.594 \\
\hline & & muscle & 3 & ND & ND & 1.04 & 0.805 \\
\hline \multirow[t]{5}{*}{3} & \multirow[t]{5}{*}{$\begin{array}{l}\text { White Oak } \\
\text { Creek, } \\
\text { Bldg. } 4505\end{array}$} & $\begin{array}{l}\text { whole body } \\
\text { feathers }\end{array}$ & 13,690 & 0.34 & 4.88 & 7.29 & 2.72 \\
\hline & & kidney & 69 & 1.53 & 0.42 & 6.01 & 26.8 \\
\hline & & liver & 76 & 0.90 & 0.40 & 7.5 & 17.6 \\
\hline & & heart & 81 & ND & ND & 2.2 & 9.52 \\
\hline & & muscle & 151 & ND & 0.58 & 1.84 & 6.34 \\
\hline
\end{tabular}

${ }^{2} \mathrm{ND}=$ Nondetect: As- $<0.40 \mathrm{mg} / \mathrm{kg}, \mathrm{Cd}-<0.20 \mathrm{mg} / \mathrm{kg}, \mathrm{Pb}-<0.40 \mathrm{mg} / \mathrm{kg}$, and Se- $<0.40 \mathrm{mg} / \mathrm{kg}$. 
C-31

Table C.20. Summary of number of locations where HQs $>1$ were observed

\begin{tabular}{|c|c|c|c|c|}
\hline Watershed & Endpoint & Analyte & $\begin{array}{c}\text { No. locations where } \\
\text { NOAEL-based } \\
\text { HQ }>1\end{array}$ & $\begin{array}{c}\text { No. locations where } \\
\text { LOAEL-based } \\
\text { HQ }>1\end{array}$ \\
\hline \multirow[t]{8}{*}{ Bear Creek } & Mink & $\mathrm{Hg}$ & 2 & 0 \\
\hline & & PCBs & 2 & 0 \\
\hline & River Otter & $\mathrm{Hg}$ & 4 & 3 \\
\hline & & PCBs & 4 & 1 \\
\hline & Kingfisher & $\mathrm{Hg}$ & 5 & 3 \\
\hline & & PCBs & 5 & 1 \\
\hline & Heron & $\mathrm{Hg}$ & 5 & 0 \\
\hline & & PCBs & 3 & 0 \\
\hline \multirow{8}{*}{$\begin{array}{c}\text { East Fork } \\
\text { Poplar Creek }\end{array}$} & Mink & $\mathrm{Hg}$ & 7 & 6 \\
\hline & & PCBs & 3 & 1 \\
\hline & Otter & $\mathrm{Hg}$ & 7 & 7 \\
\hline & & PCBs & 6 & 2 \\
\hline & Kingfisher & $\mathrm{Hg}$ & 7 & 7 \\
\hline & & PCBs & 7 & 3 \\
\hline & Heron & $\mathrm{Hg}$ & 7 & 6 \\
\hline & & PCBs & 5 & 1 \\
\hline \multirow[t]{10}{*}{$\mathrm{K}-25$} & Mink & $\mathrm{Hg}$ & 9 & 1 \\
\hline & & PCBs & 7 & 0 \\
\hline & Otter & $\mathrm{Hg}$ & 13 & 11 \\
\hline & & PCBs & 15 & 5 \\
\hline & Kingfisher & $\mathrm{Hg}$ & 16 & 10 \\
\hline & & PCBs & 14 & 4 \\
\hline & Heron & $\mathrm{Hg}$ & 16 & 0 \\
\hline & & PCBs & 13 & 0 \\
\hline & Osprey & $\mathrm{Hg}$ & 16 & 3 \\
\hline & & PCBs & 14 & 1 \\
\hline \multirow{3}{*}{$\begin{array}{l}\text { White Oak } \\
\text { Creek }\end{array}$} & Mink & $\mathrm{Hg}$ & 1 & 0 \\
\hline & & PCBs & 3 & 0 \\
\hline & Otter & $\mathrm{Hg}$ & 7 & 3 \\
\hline
\end{tabular}




\section{C-32}

Table C.20 (continued)

\begin{tabular}{ccccc}
\hline Watershed & Endpoint & Analyte & $\begin{array}{c}\text { No. locations where } \\
\text { NOAEL-based } \\
\text { HQ }>\text { 1 }\end{array}$ & $\begin{array}{c}\text { No. locations where } \\
\text { LOAEL-based } \\
\text { HQ > 1 }\end{array}$ \\
\hline \multirow{3}{*}{ Kingfisher } & PCBs & 6 & 3 \\
& Hg & 7 & 3 \\
& PCBs & 7 & 1 \\
& Hg & 7 & 0 \\
& Osprey & PCBs & 5 & 0 \\
& Hg & 2 & 0 \\
\hline
\end{tabular}


Table C.21. Summary of number of individuals of piscivore endpoint species estimated to be experiencing adverse effects by watershed and for the ORR

\begin{tabular}{|c|c|c|c|c|c|c|}
\hline Location & Analyte & Species & $\begin{array}{c}\%> \\
\text { LOAEL }\end{array}$ & $\begin{array}{l}\text { Number in } \\
\text { Watershed }\end{array}$ & $\begin{array}{l}\text { Number } \\
\text { Adversely } \\
\text { Affected }\end{array}$ & $\begin{array}{c}\text { Percent } \\
\text { Adversely } \\
\text { Affected } \\
\end{array}$ \\
\hline Bear Creek & Mercury & Mink & $<5 \%$ & 7 & 0 & $0 \%$ \\
\hline $\begin{array}{l}\text { East Fork Poplar } \\
\text { Creek }\end{array}$ & Mercury & Mink & $80 \%$ & 15 & 12 & $80 \%$ \\
\hline $\mathrm{K}-25$ & Mercury & Mink & $<5 \%$ & 14 & 0 & $0 \%$ \\
\hline White Oak Creek & Mercury & Mink & $<5 \%$ & 4 & 0 & $0 \%$ \\
\hline ORR-wide & Mercury & Mink & & 40 & 12 & $30 \%$ \\
\hline Bear Creek & Mercury & Otter & $50 \%$ & 5 & 2 & $40 \%$ \\
\hline $\begin{array}{l}\text { East Fork Poplar } \\
\text { Creek }\end{array}$ & Mercury & Otter & $>95 \%$ & 9 & 9 & $100 \%$ \\
\hline $\mathrm{K}-25$ & Mercury & Otter & $>95 \%$ & 9 & 9 & $100 \%$ \\
\hline White Oak Creek & Mercury & Otter & $25 \%$ & 2 & 0 & $0 \%$ \\
\hline ORR-wide & Mercury & Otter & & 25 & 20 & $80 \%$ \\
\hline Bear Creek & Mercury & Kingfisher & $65-70 \%$ & 5 & 3 & $60 \%$ \\
\hline $\begin{array}{l}\text { East Fork Poplar } \\
\text { Creek }\end{array}$ & Mercury & Kingfisher & $>95 \%$ & 10 & 10 & $100 \%$ \\
\hline $\mathrm{K}-25$ & Mercury & Kingfisher & $>95 \%$ & 9 & 9 & $100 \%$ \\
\hline White Oak Creek & Mercury & Kingfisher & $15 \%$ & 3 & 0 & $0 \%$ \\
\hline ORR-wide & Mercury & Kingfisher & & 27 & 22 & $81.5 \%$ \\
\hline Bear Creek & Mercury & Heron & $<5 \%$ & 29 & 0 & $0 \%$ \\
\hline $\begin{array}{l}\text { East Fork Poplar } \\
\text { Creek }\end{array}$ & Mercury & Heron & $>95 \%$ & 57 & 57 & $100 \%$ \\
\hline $\mathrm{K}-25$ & Mercury & Heron & $<5 \%$ & 54 & 0 & $0 \%$ \\
\hline White Oak Creek & Mercury & Heron & $<5 \%$ & 15 & 0 & $0 \%$ \\
\hline ORR-wide & Mercury & Heron & & 155 & 57 & $36.8 \%$ \\
\hline $\mathrm{K}-25$ & Mercury & Osprey & $<5 \%$ & & 0 & $0 \%$ \\
\hline White Oak Creek & Mercury & Osprey & $<5 \%$ & & 0 & $0 \%$ \\
\hline Bear Creek & PCBs & Mink & $<5 \%$ & 7 & 0 & $0 \%$ \\
\hline
\end{tabular}


Table C.21 (continued)

\begin{tabular}{|c|c|c|c|c|c|c|}
\hline Location & Analyte & Species & $\begin{array}{c}\%> \\
\text { LOAEL }\end{array}$ & $\begin{array}{l}\text { Number in } \\
\text { Watershed }\end{array}$ & $\begin{array}{c}\text { Number } \\
\text { Adversely } \\
\text { Affected } \\
\end{array}$ & $\begin{array}{c}\text { Percent } \\
\text { Adversely } \\
\text { Affected } \\
\end{array}$ \\
\hline $\begin{array}{l}\text { East Fork Poplar } \\
\text { Creek }\end{array}$ & PCBs & Mink & $<5 \%$ & 15 & 0 & $0 \%$ \\
\hline $\mathrm{K}-25$ & PCBs & Mink & $<5 \%$ & 14 & 0 & $0 \%$ \\
\hline White Oak Creek & PCBs & Mink & $<5 \%$ & 4 & 0 & $0 \%$ \\
\hline ORR-wide & PCBs & Mink & & 40 & 0 & $0 \%$ \\
\hline Bear Creek & PCBs & Otter & $<5 \%$ & 5 & 0 & $0 \%$ \\
\hline $\begin{array}{l}\text { East Fork Poplar } \\
\text { Creek }\end{array}$ & PCBs & Otter & $15-20 \%$ & 9 & 1 & $11 \%$ \\
\hline $\mathrm{K}-25$ & PCBs & Otter & $5-10 \%$ & 9 & 0 & $0 \%$ \\
\hline White Oak Creek & PCBs & Otter & $70-75 \%$ & 2 & 1 & $50 \%$ \\
\hline ORR-wide & PCBs & Otter & & 25 & 2 & $8 \%$ \\
\hline Bear Creek & PCBs & Kingfisher & $<5 \%$ & 5 & 0 & $0 \%$ \\
\hline $\begin{array}{l}\text { East Fork Poplar } \\
\text { Creek }\end{array}$ & PCBs & Kingfisher & $10-15 \%$ & 10 & 0 & $0 \%$ \\
\hline $\mathrm{K}-25$ & PCBs & Kingfisher & $<5 \%$ & 9 & 0 & $0 \%$ \\
\hline White Oak Creek & PCBs & Kingfisher & $<5 \%$ & 3 & 0 & $0 \%$ \\
\hline ORR-wide & PCBs & Kingfisher & & 27 & 0 & $0 \%$ \\
\hline Bear Creek & PCBs & Heron & $<5 \%$ & 29 & 0 & $0 \%$ \\
\hline $\begin{array}{l}\text { East Fork Poplar } \\
\text { Creek }\end{array}$ & PCBs & Heron & $<5 \%$ & 57 & 0 & $0 \%$ \\
\hline $\mathrm{K}-25$ & PCBs & Heron & $<5 \%$ & 54 & 0 & $0 \%$ \\
\hline White Oak Creek & PCBs & Heron & $<5 \%$ & 15 & 0 & $0 \%$ \\
\hline ORR-wide & PCBs & Heron & & 155 & 0 & $0 \%$ \\
\hline $\mathrm{K}-25$ & PCBs & Osprey & $<5 \%$ & & 0 & $0 \%$ \\
\hline White Oak Creek & PCBs & Osprey & $<5 \%$ & & 0 & $0 \%$ \\
\hline
\end{tabular}


Table C.22. Simulation of exposure of mink to mercury and PCBs in toxicity test diets

\begin{tabular}{|c|c|c|c|c|c|c|c|c|c|c|c|}
\hline \multirow[b]{2}{*}{ Diet } & \multirow[b]{2}{*}{ Analyte } & \multicolumn{4}{|c|}{ Concentration in diet } & \multirow{2}{*}{$\begin{array}{l}\text { Distribution } \\
\text { used in } \\
\text { simulation }\end{array}$} & \multicolumn{3}{|c|}{ Modeled exposure (mg/kg-d) } & \multirow{2}{*}{$\begin{array}{c}\%> \\
\text { NOAEL }\end{array}$} & \multirow{2}{*}{$\begin{array}{c}\%> \\
\text { LOAEL }\end{array}$} \\
\hline & & Mean & STD & Min & Max & & Mean & STD & $\begin{array}{c}\text { 80th } \\
\text { percentile }\end{array}$ & & \\
\hline A & Mercury & 0.02 & $\mathbf{0}$ & 0.02 & 0.03 & Triangular & 0.0034 & 0.0009 & 0.0042 & $<5 \%$ & $<5 \%$ \\
\hline B & Mercury & 0.05 & 0 & 0.04 & 0.06 & Triangular & 0.0074 & 0.0019 & 0.0088 & $<5 \%$ & $<5 \%$ \\
\hline $\mathrm{C}$ & Mercury & 0.09 & $\mathbf{0}$ & 0.08 & 0.11 & Triangular & 0.0138 & 0.0035 & 0.016 & $30 \%$ & $<5 \%$ \\
\hline $\mathrm{D}$ & Mercury & 0.15 & 0.01 & & & Normal & 0.022 & 0.0059 & 0.026 & $>95 \%$ & $25 \%$ \\
\hline $\mathrm{E}$ & Mercury & 0.22 & 0.01 & & & Normal & 0.033 & 0.008 & 0.038 & $>95 \%$ & $85 \%$ \\
\hline A & PCB 1260 & 0.169 & 0.002 & & & Normal & 0.025 & 0.0063 & 0.029 & $<5 \%$ & $<1 \%$ \\
\hline B & PCB 1260 & 11.44 & 0.327 & & & Normal & 1.70 & 0.43 & 1.97 & $>95 \%$ & $>95 \%$ \\
\hline $\mathrm{C}$ & РCB 1260 & 4.697 & 0.174 & & & Normal & 0.698 & 0.18 & 0.82 & $>95 \%$ & $40-45 \%$ \\
\hline $\mathrm{D}$ & PCB 1260 & 10.41 & 0.25 & & & Normal & 1.54 & 0.39 & 1.79 & $>95 \%$ & $>95 \%$ \\
\hline $\mathrm{E}$ & PCB 1260 & 20.67 & 0.458 & & & Normal & 3.07 & 0.77 & 3.55 & $>95 \%$ & $>95 \%$ \\
\hline
\end{tabular}




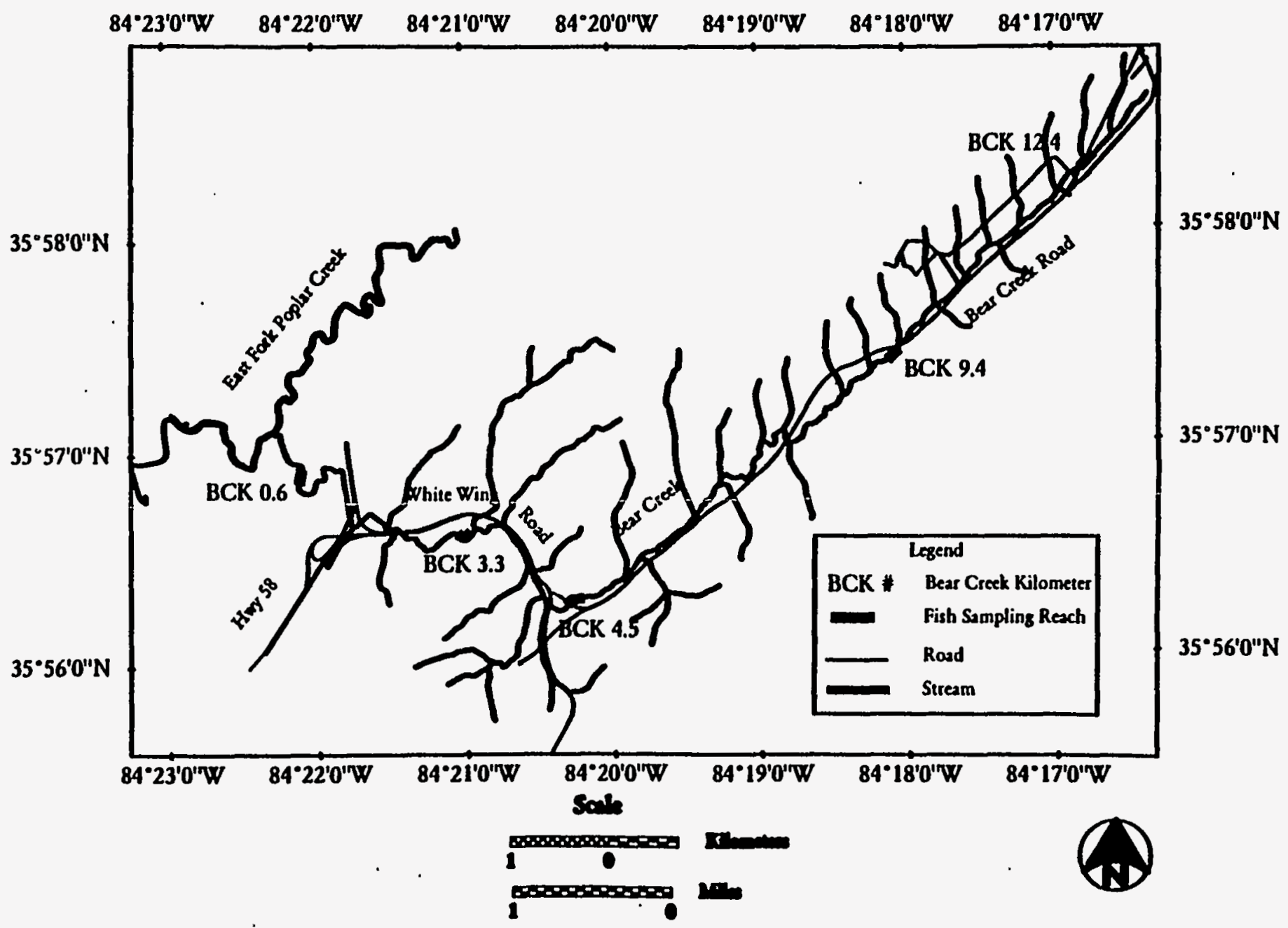

Fig. C.1. The Bear Creek fish sampling locations used in the ORR-wide ecological risk assessment. The map projection is Tennessee State Plane (TSP) meters, Zone 5301, and NAD 83. The study site location data is from BMAP and OREIS spatial database. The map was prepared by R.A. Washington-Allen, Environmental Sciences Division (ESD) ORNL on July 27, 1995. 


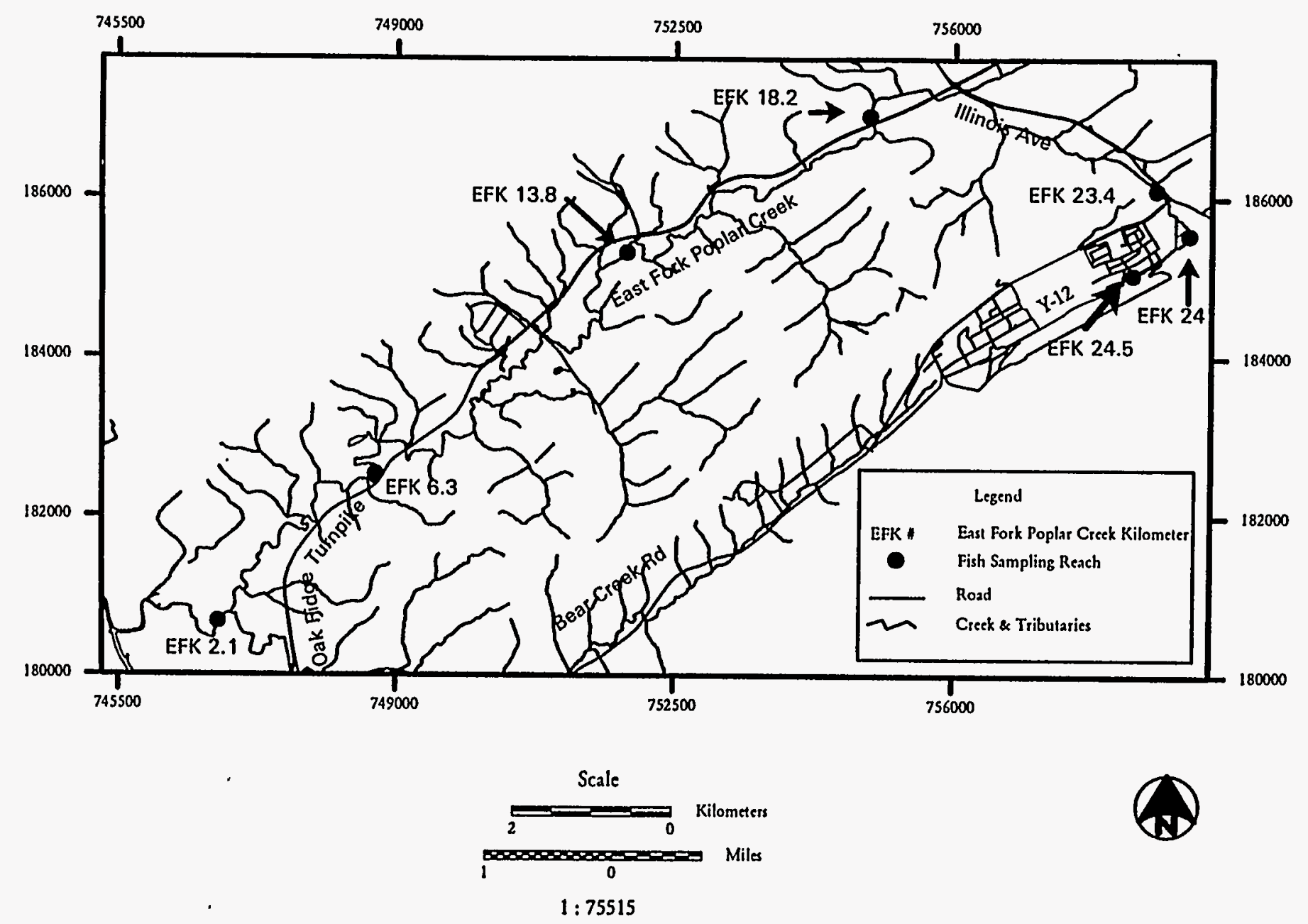

Fig. C.2. The East Fork Poplar Creek fish and ecological sampling locations (from EFPC RI) used in the ORR-wide ecological risk assessement. The map projection is Tennessee State Plane meters, Zone 5301, and NAD 83. The study site location data is from SAIC, BMAP, and OREIS spatial database. The map was prepared by R. A. Washington-Allen, Environmental Sciences Division, ORNL on September 11, 1996. 


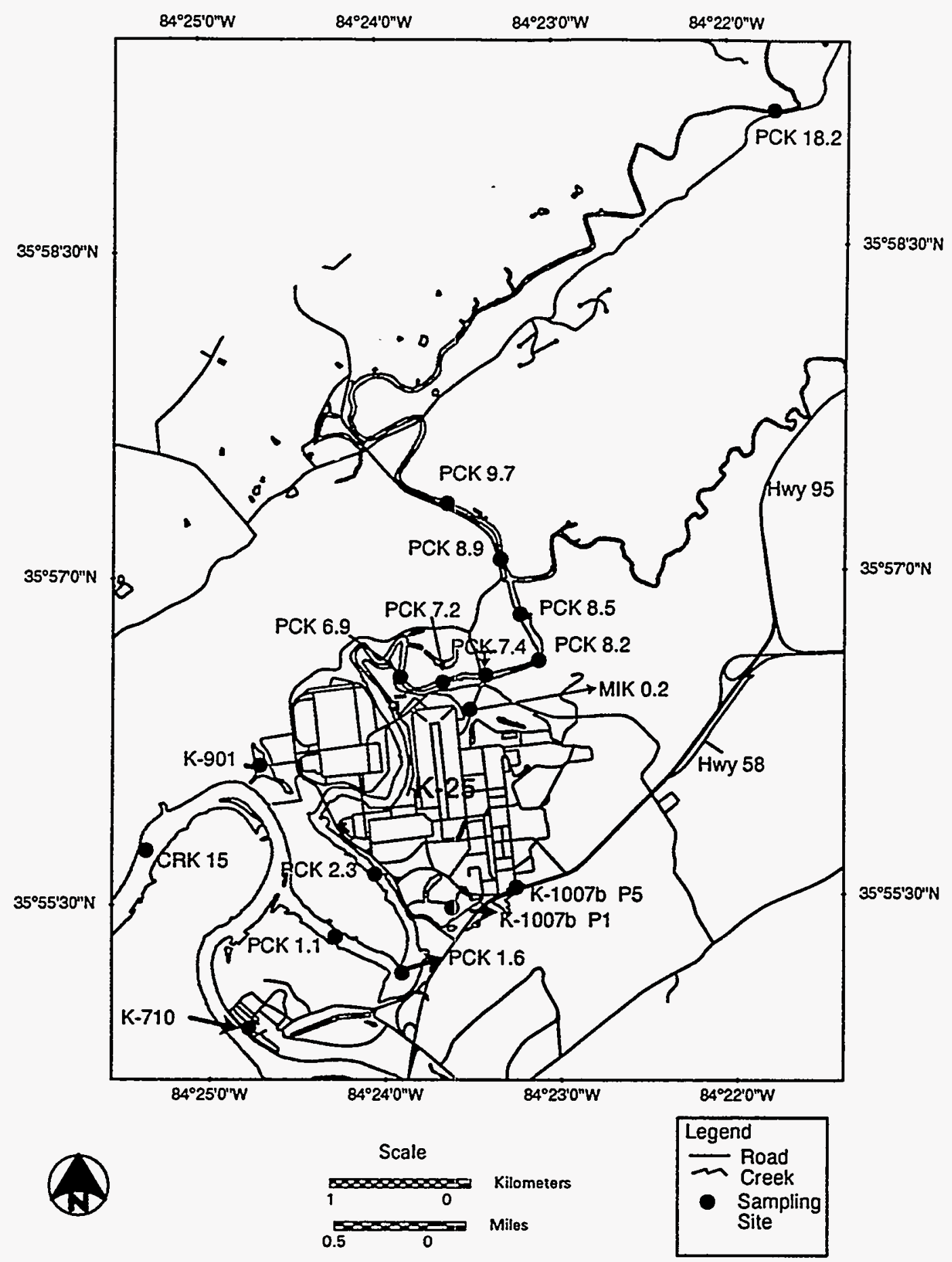

Fig. C.3. The Poplar Creek sampling locations and ponds used to evaluate risks in the K-25 vicinity for the ORR-wide ecological risk assessment. The map projection is Tennessee State Plane meters, Zone 5301, and NAD 83. The study site location data is from BMAP and OREIS spatial database. The map was prepared by R. A. Washington-Allen, Environmental Sciences Division, ORNL on September 11, 1996. 

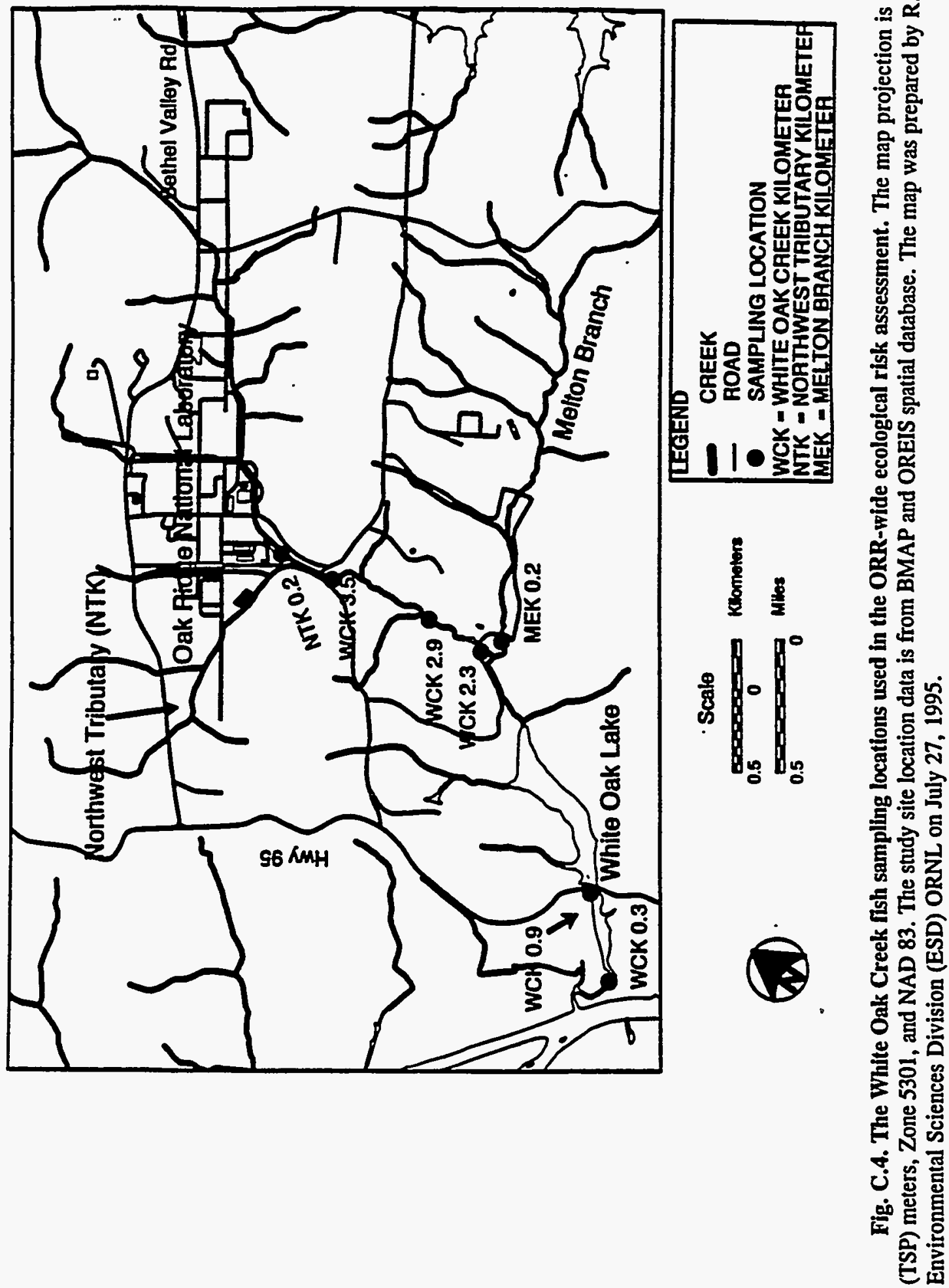

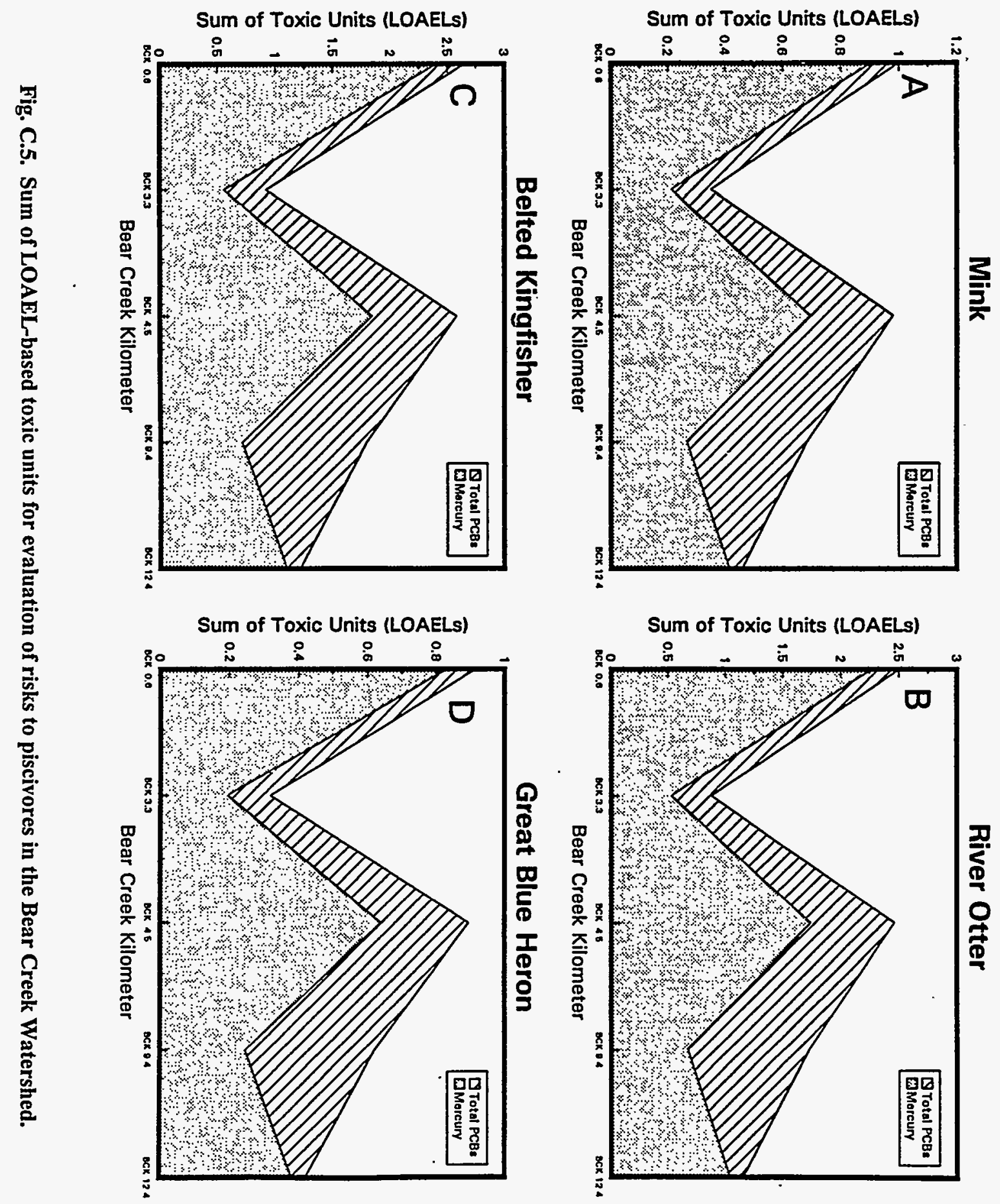


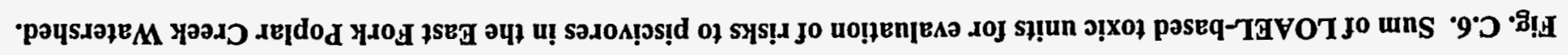
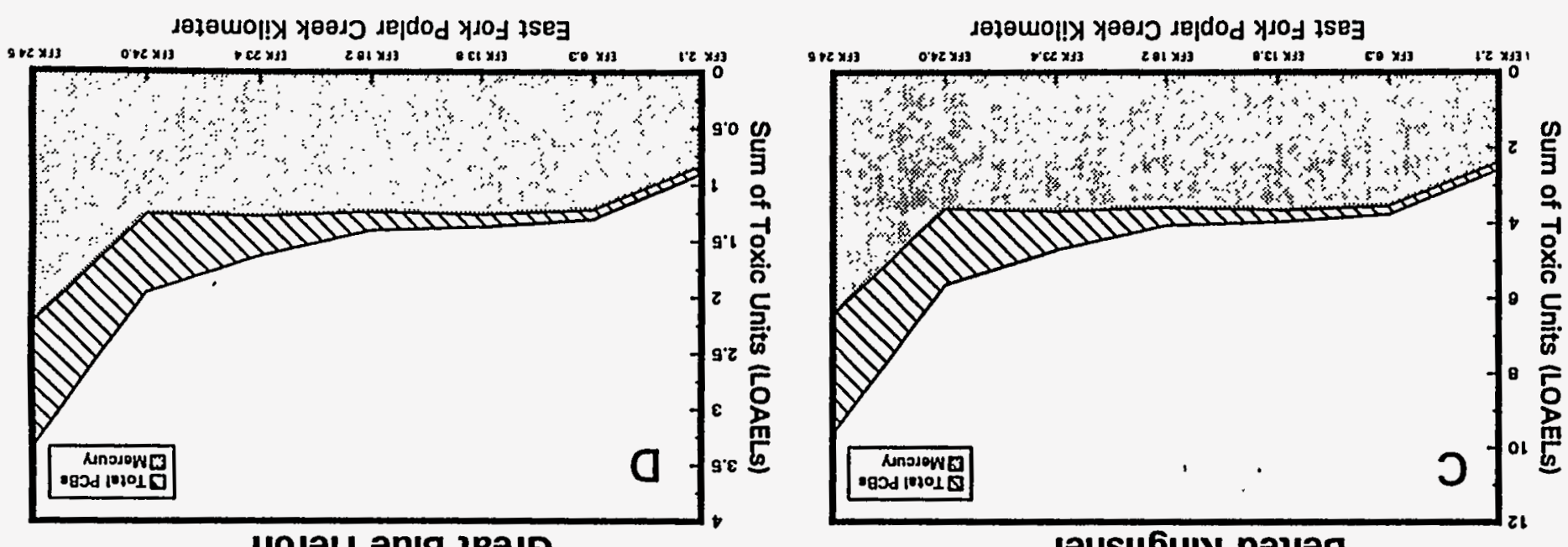

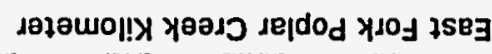

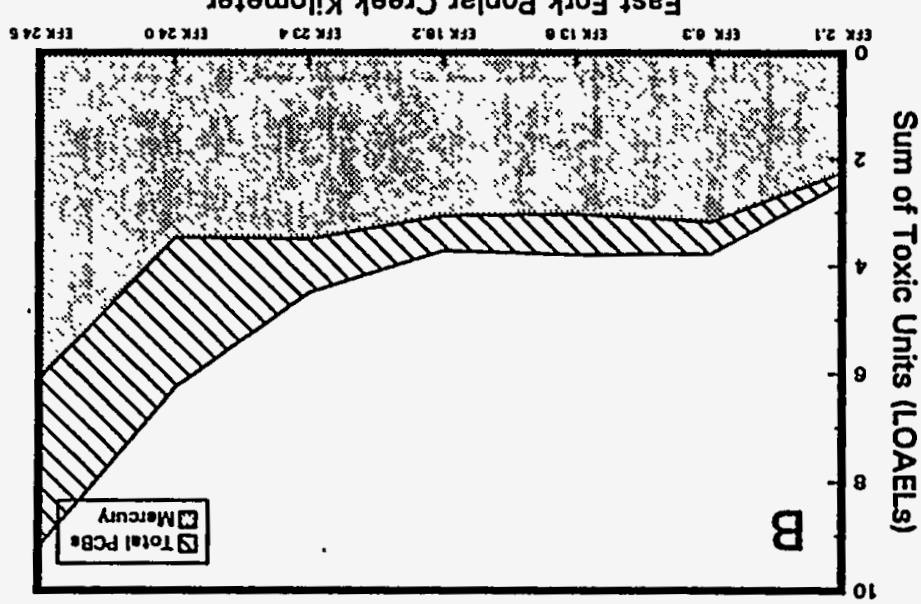

Jә¥10 dəก!บ

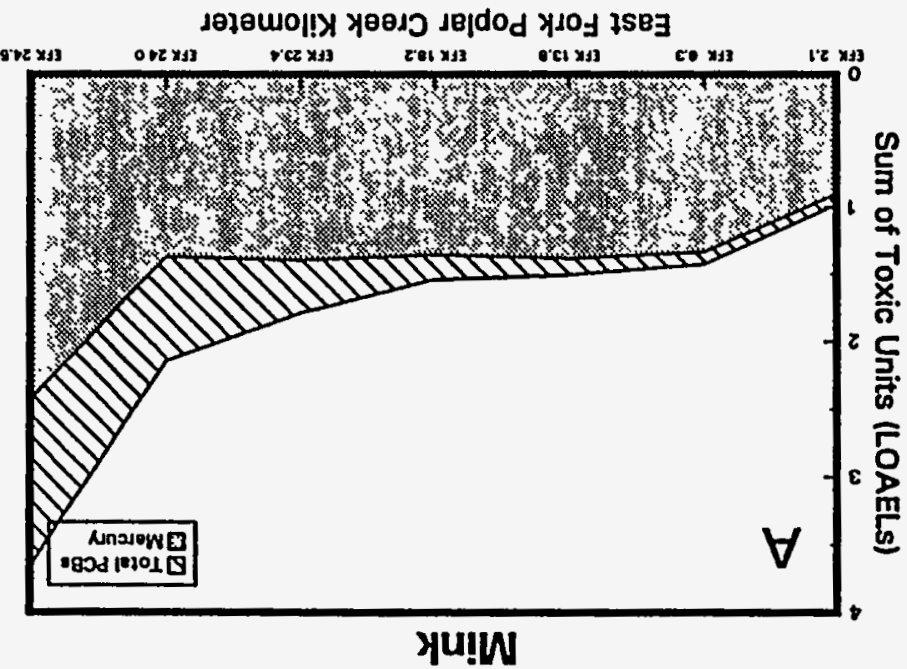


Mink

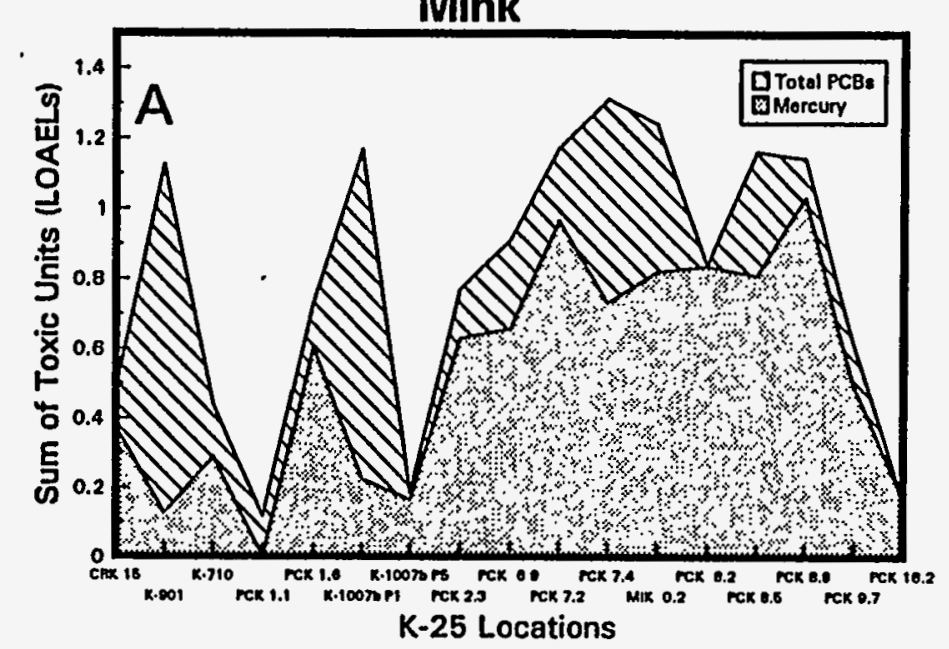

Belted Kingfisher

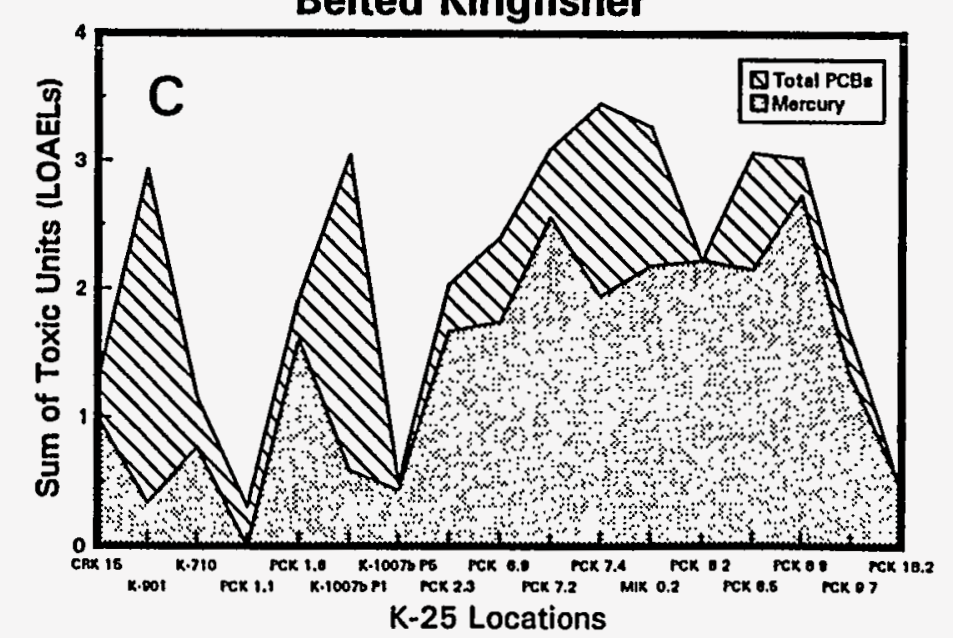

River Otter

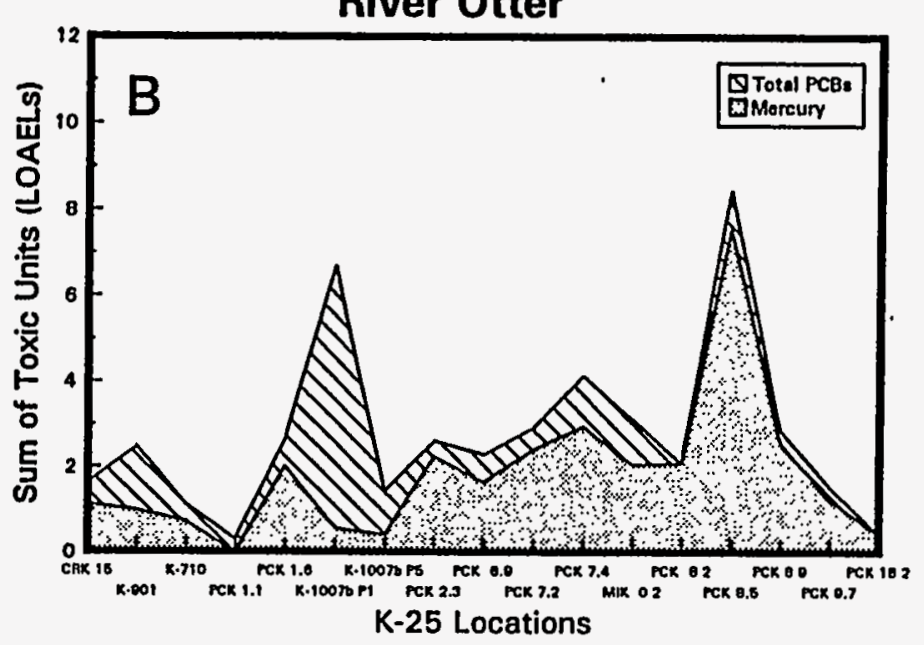

Great Blue Heron

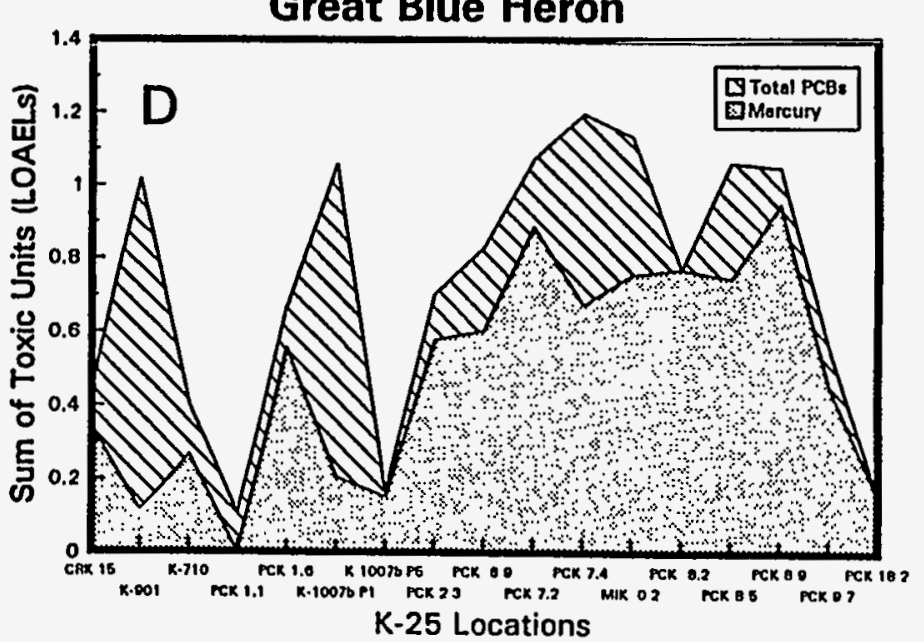

Fig. C.7. Sum of LOAEL-based toxic units for evaluation of risks to piscivores in the K-25 vicinity . 


\section{C-43}

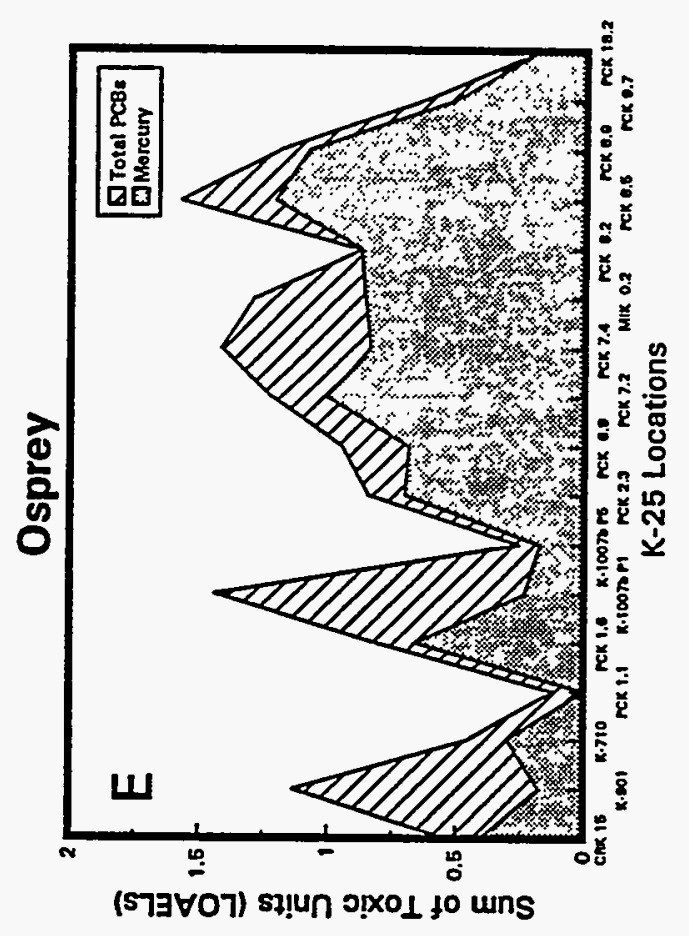

ن 

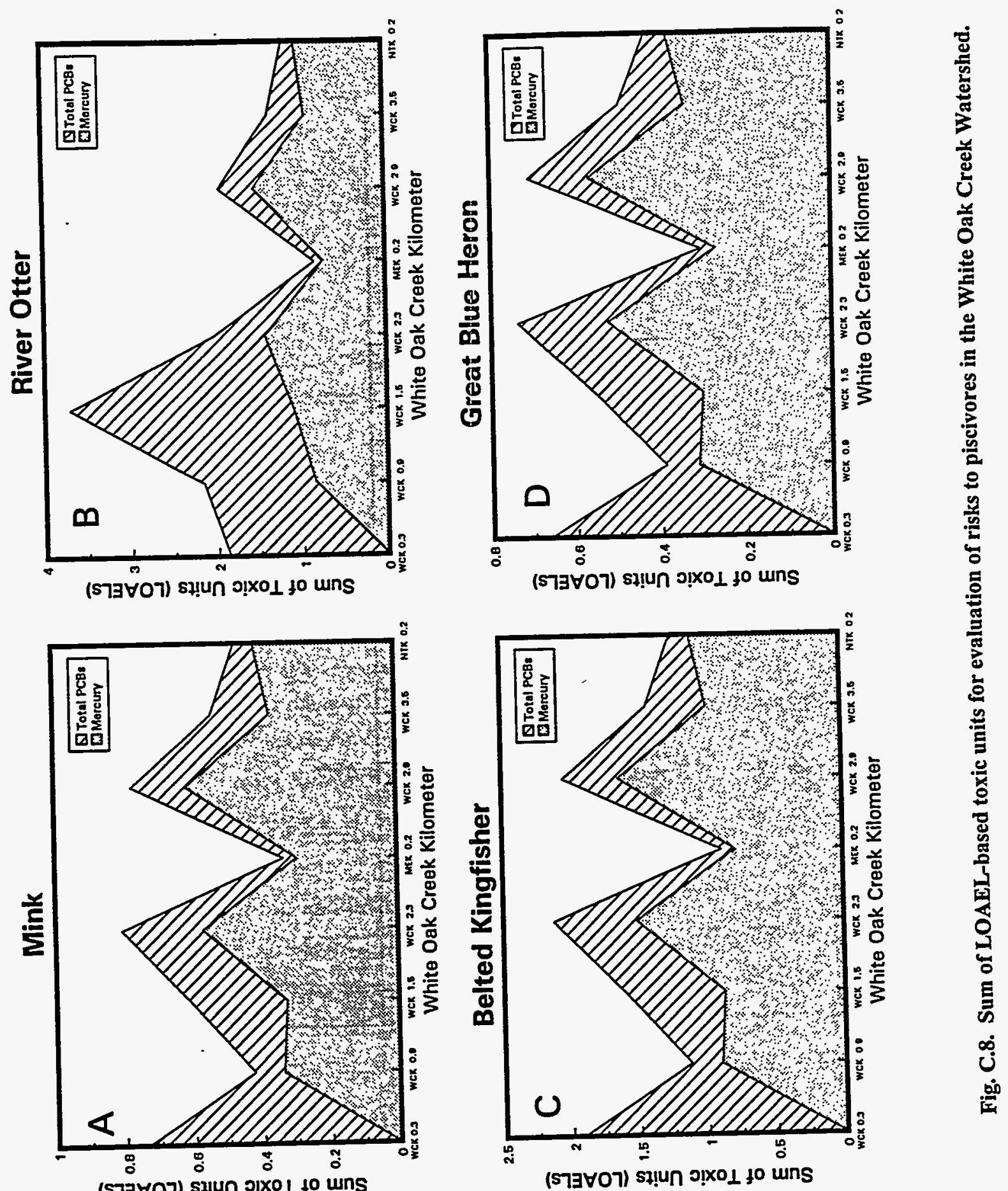


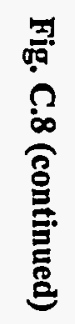

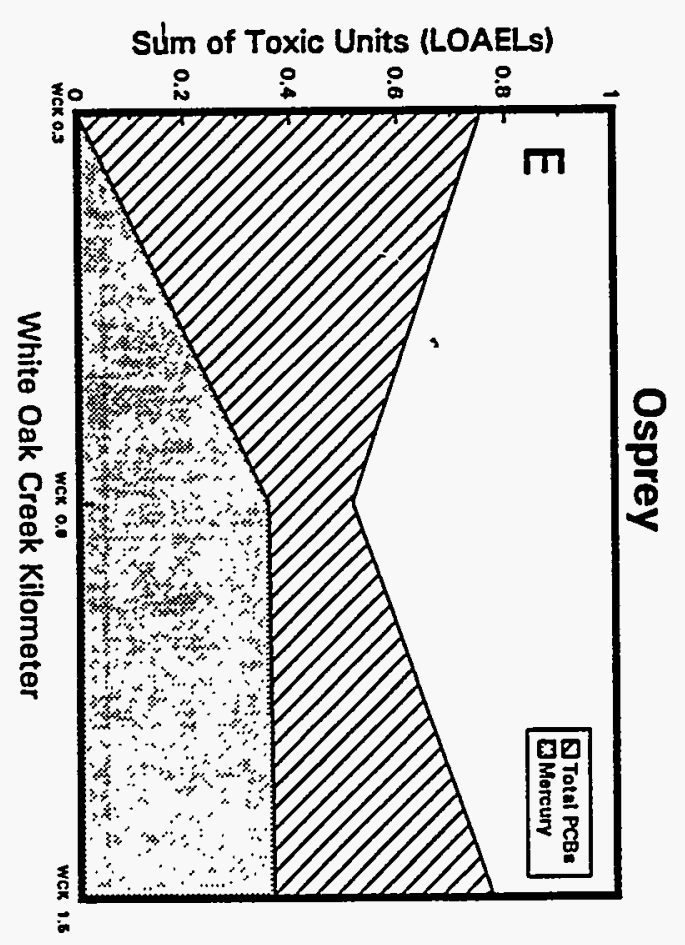




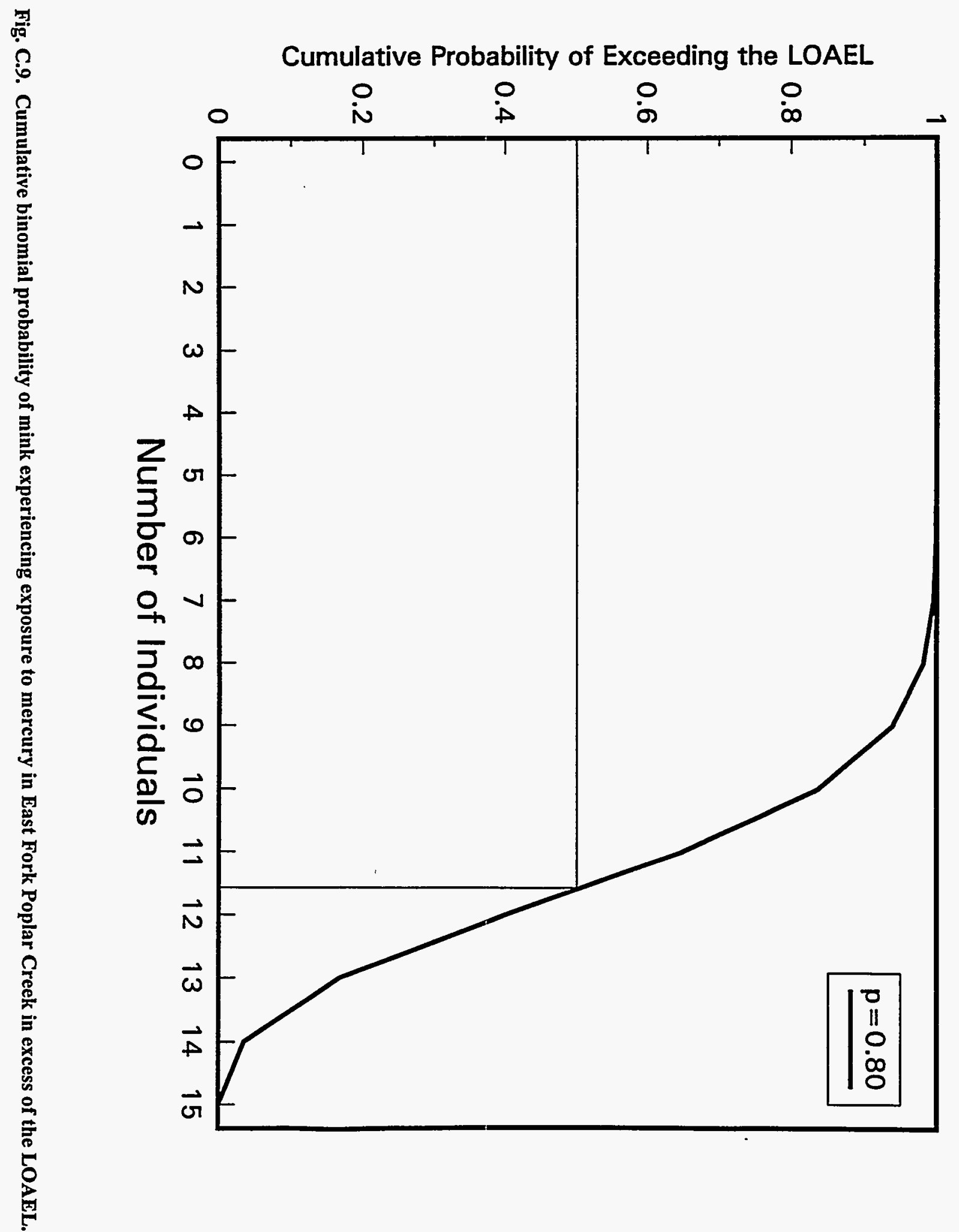


C-47

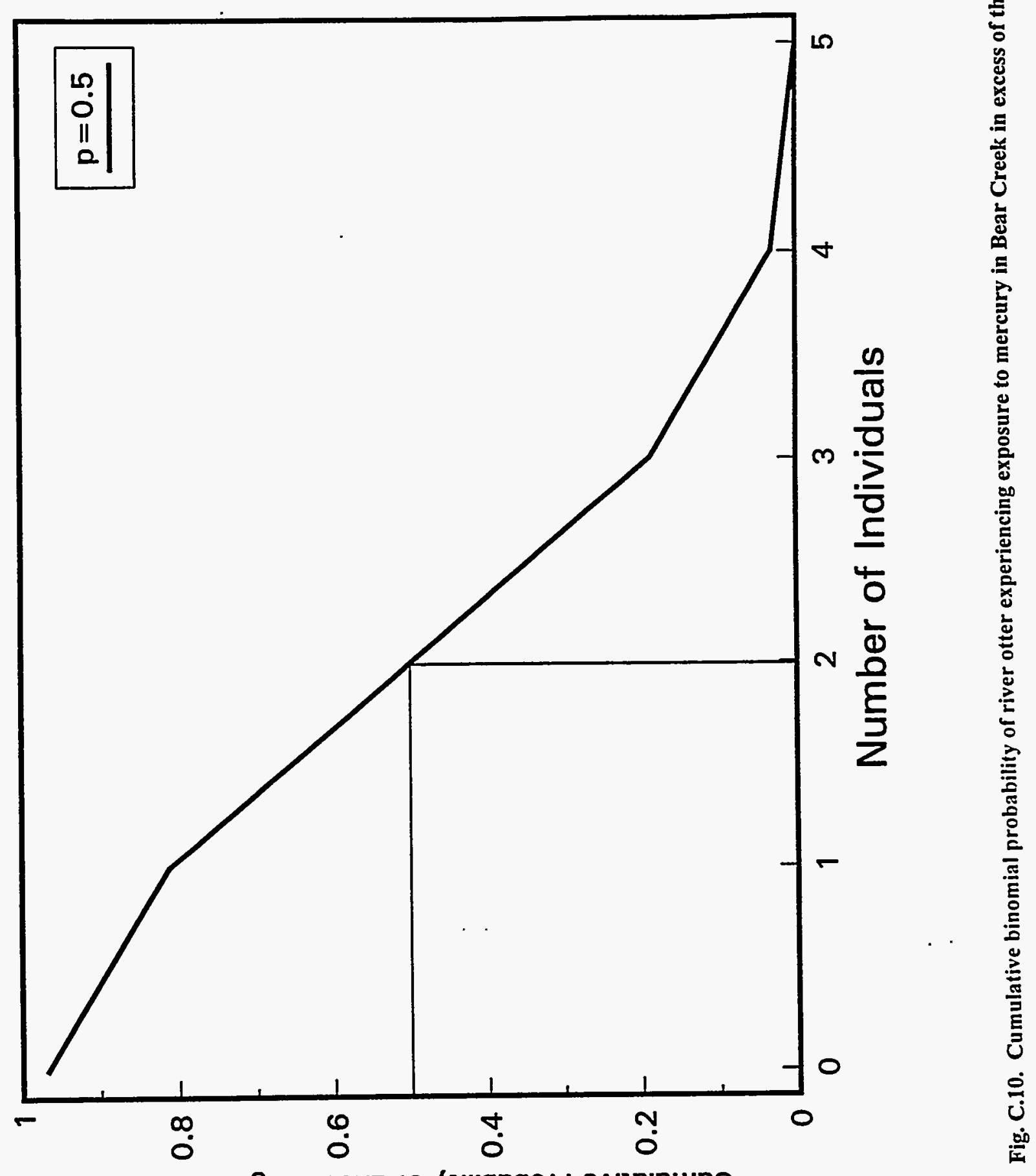

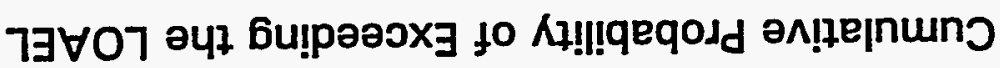



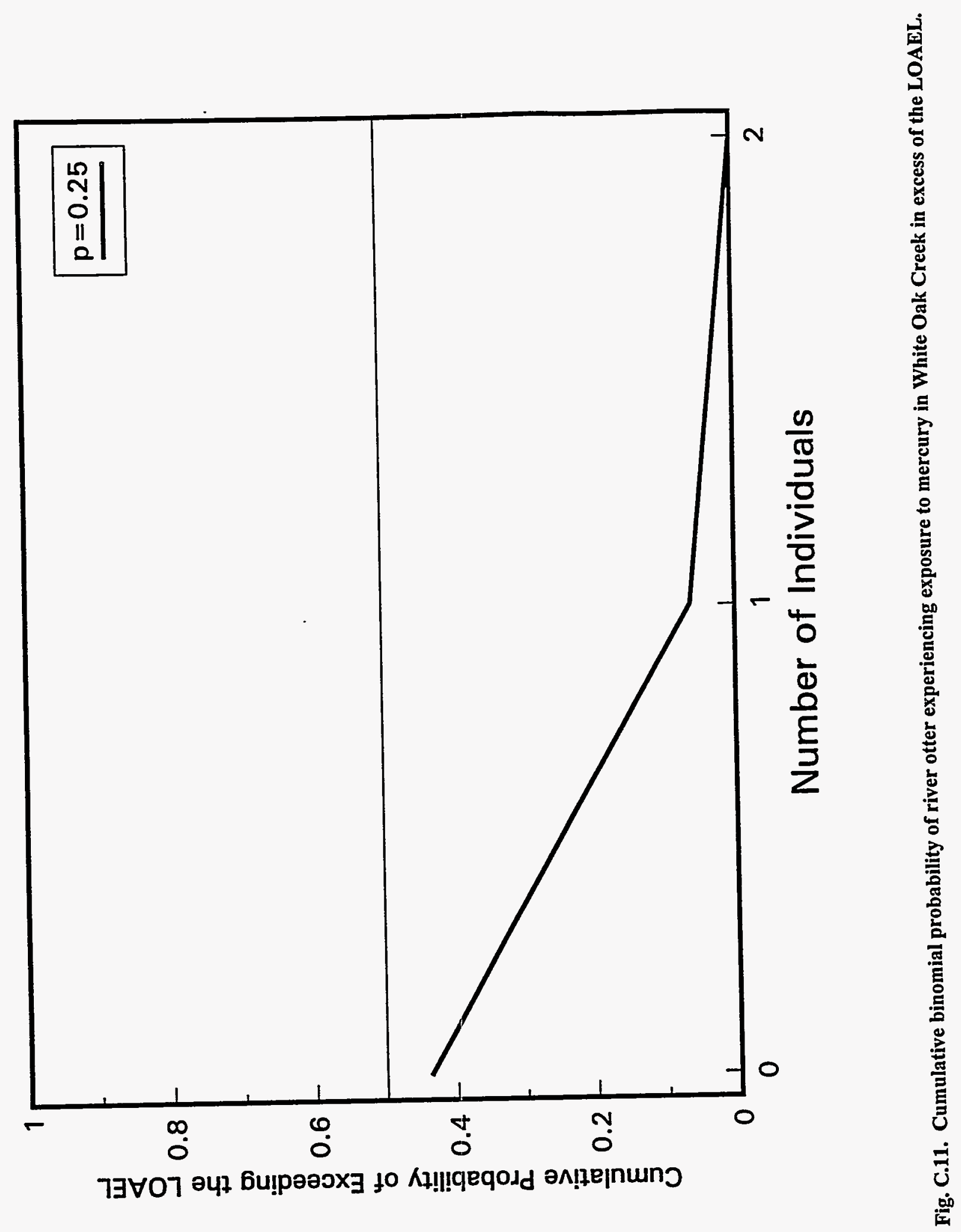
C-49

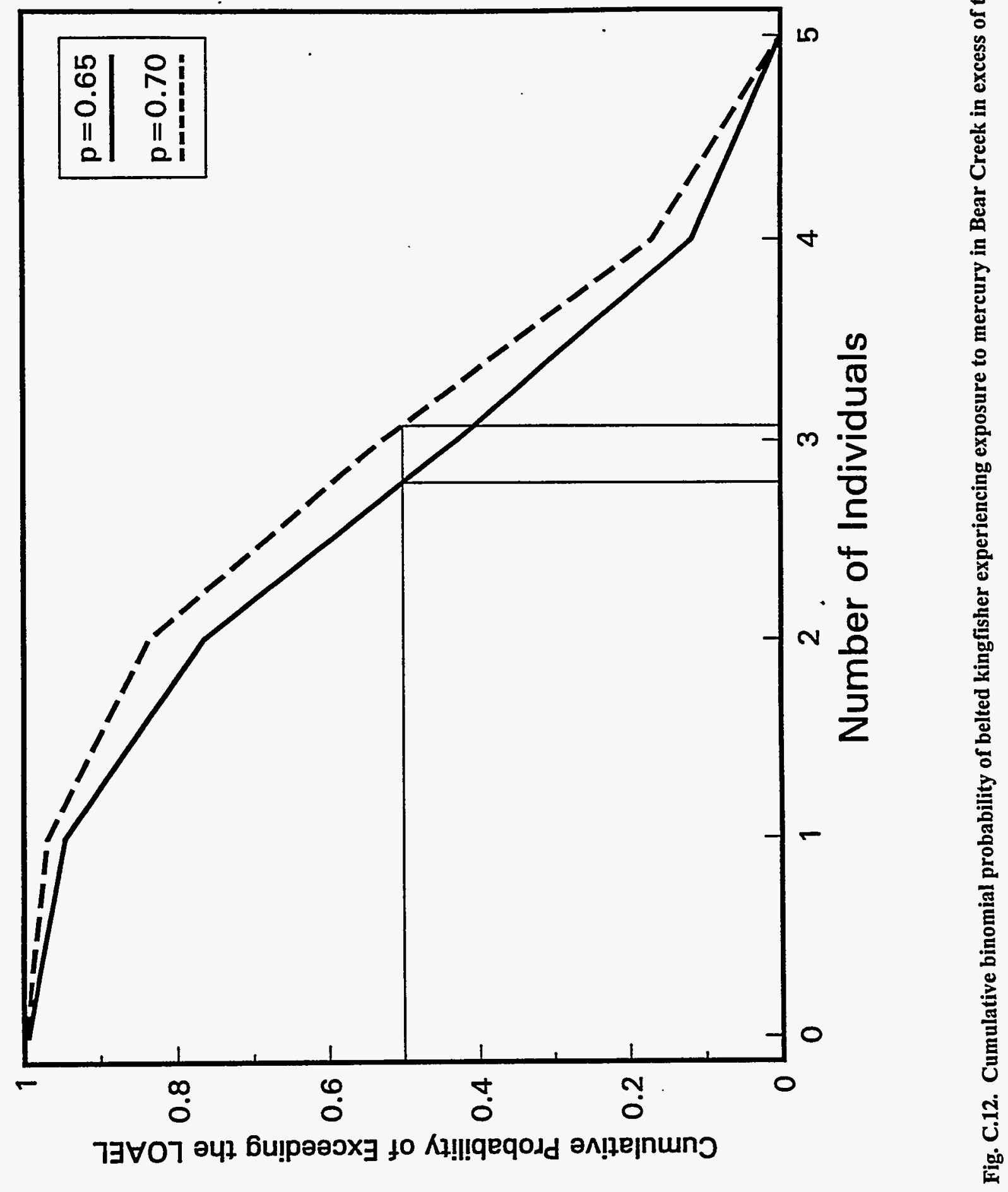




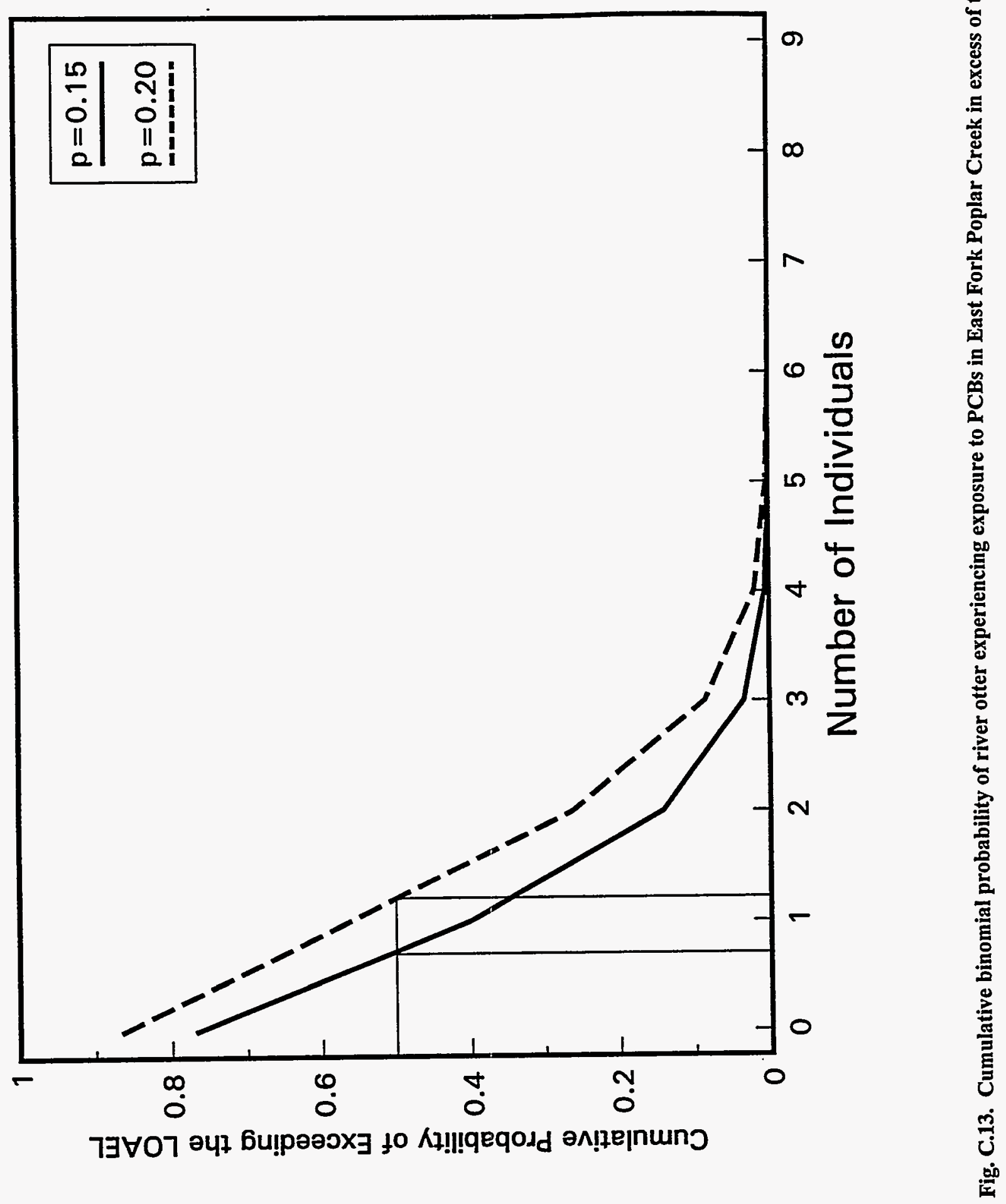




\section{C-51}
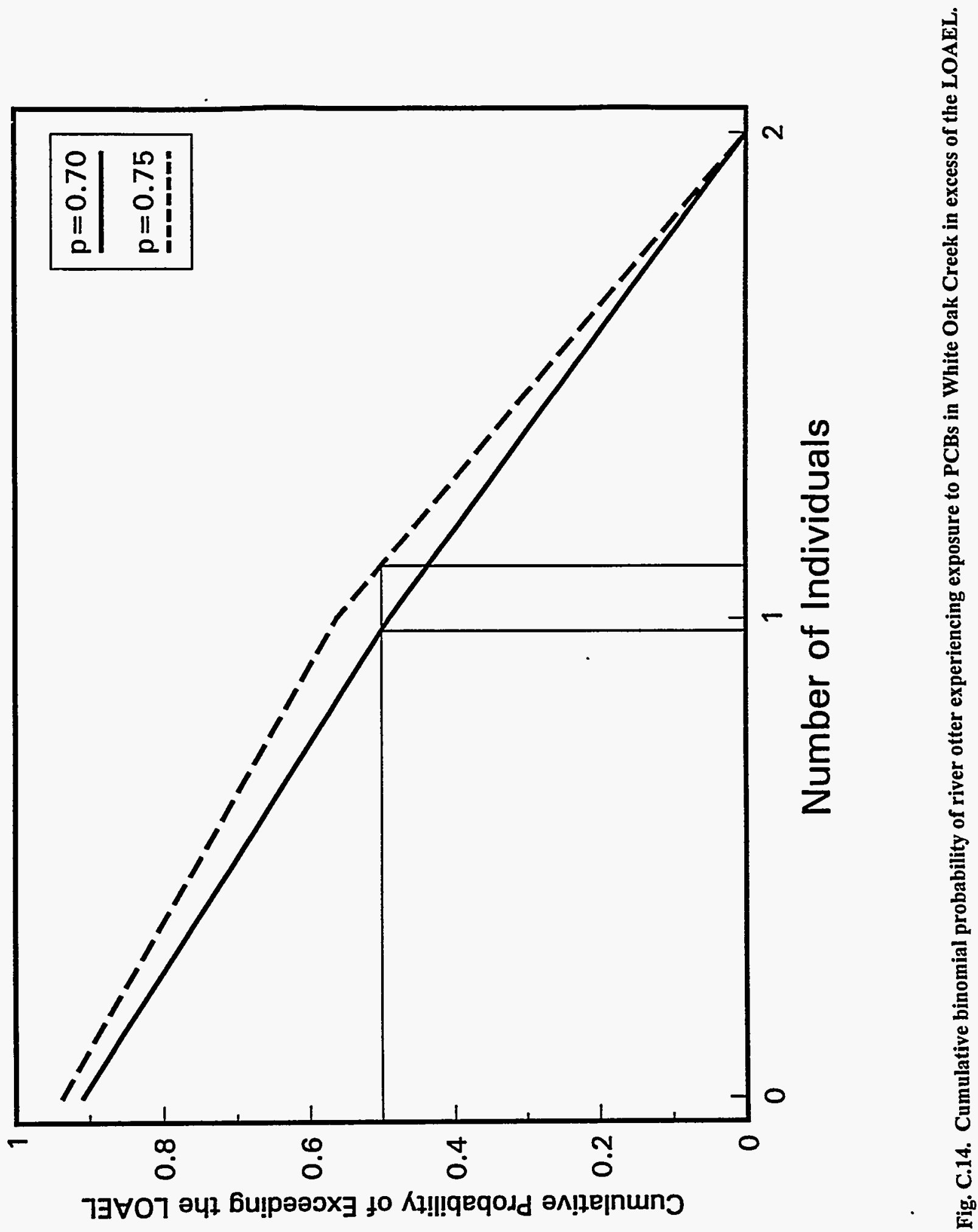

Appendix D

\section{TOXICOLOGICAL PROFILES}




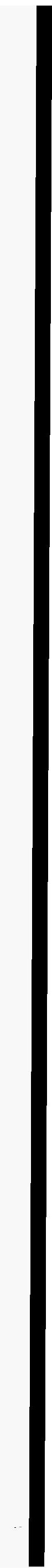




\section{TOXICOLOGICAL PROFILES}

Aluminum. Aluminum is an ubiquitous metal, being the third most abundant element in the earth's crust (Krueger et al. 1984). Relative to other metals, the toxicity of aluminum is low (Sorensen et al. 1974). The oral $L D_{50}$ for mice ranges from 770 to $980 \mathrm{mg}$ aluminum/kg body weight (Ondreicka et al. 1966). The principal effect of aluminum is to interfere with phosphorous metabolism; in the alimentary canal, aluminum forms insoluble compounds with phosphorous resulting in an imbalance of calcium and phosphorous (Carrerie et al. 1986). Other effects of aluminum include neurotoxicity. Rats exposed to aluminum display behavioral abnormalities and have reduced acetylcholinesterase activity (Krueger et al. 1984). Mice consuming diets containing 500 to $1000 \mathrm{ppm}$ aluminum displayed ataxia and paralysis of the hind limbs (Golub et al. 1987). In humans, aluminum has been associated with several degenerative diseases of the nervous system, including Alzheimer's disease, Parkinson's disease, and amyotrophic lateral sclerosis (Ganrot 1986).

Ondreicka et al. (1966) evaluated the effects of aluminum on mammalian reproduction. Mice received $19.3 \mathrm{mg}$ aluminum $/ \mathrm{kg}$ bodyweight/day (as $\mathrm{AlCl}_{3}$ ) in drinking water for three generations. While the number of litters and offspring per litter was not reduced, growth was significantly reduced among all offspring in the second and third generations. In a similar study, rats received daily intragastric doses of $0,180,360$, or $720 \mathrm{mg}$ aluminum/ $\mathrm{kg}$ body weight/day (Domingo et al. 1987) for one generation. Growth and survival of young was reduced among the groups that received 360 and $720 \mathrm{mg}$ aluminum/kg/day. Other studies also report that while aluminum does not appear to affect the number of litters or number of offspring/litter, growth and survival of offspring of aluminum exposed parents is reduced (Golub et al. 1987; Paternain et al. 1988).

Due to it's interference with phosphorous and calcium metabolism, it has been suggested that aluminum may impair eggshell formation by birds, resulting in eggshell thinning (Nyholm 1981). To test this hypothesis, Carriere et al. (1986) fed breeding ring doves (Streptopelia risoria) a diet containing $1000 \mathrm{ppm}$ aluminum (and adequate but reduced calcium and phosphorous) and observed reproduction. While no reproductive effects or embryonic malformations were observed at this dosage level, significant reproductive effects resulted when birds were fed a diet deficient in calcium and phosphorous that contained $750 \mathrm{ppm}$ aluminum. Therefore, among birds it appears that the manifestation of toxic effects of aluminum are dependent upon the nutritional quality of their diet.

Arsenic. Arsenic is present in the earth's crust at approximately $2 \mathrm{ppm}$, but tissues of animals generally contain an average of $<0.5 \mathrm{ppm}$ (Venugopal and Luckey 1978). Arsenic may be a required micronutrient; growth, survival, and reproduction of goats is poor if the diet contains $<0.05 \mathrm{ppm} A s$ (NAS 1977).

Arsenic is a carcinogen and teratogen. Other effects include reduced growth, hearing/sight loss, liver/kidney damage, and death (Eisler 1988a). Inorganic arsenic is usually more toxic than organic arsenic compounds. Wildlife mortality and malformations have been observed for chronic doses of $1-10 \mathrm{mg} \mathrm{As} / \mathrm{kg} \mathrm{bw}$ and dietary concentrations of 5-50 ppm (Eisler 1988a). Acute $\mathrm{LD}_{50} \mathrm{~s}$ for mammals of 35-100 mg calcium arsenate/ $\mathrm{kg}$ body weight and $10-50 \mathrm{mg}$ lead arsenate $/ \mathrm{kg}$ body weight have been reported (NRCC 1978).

Schroeder and Mitchner (1971) exposed mice to $5 \mathrm{ppm}$ sodium arsenite in drinking water for three generations. While mice fed arsenic survived well, litter size decreased in subsequent generations. A dose of $0.38 \mathrm{mg}$ arsenic/kg over a lifetime was sufficient to cause a slight decrease 
in the median lifespan of laboratory mice (Schroeder and Balassa 1967), but it had no effect on growth. As little as $3 \mathrm{mg}$ arsenic trioxide/kg body weight or $1 \mathrm{mg}$ sodium arsenite $/ \mathrm{kg}$ body weight can be lethal (NAS 1977).

Because metabolism of arsenic in rats is unlike that in other animals, results of toxicity studies using rats generally should not be extrapolated to other species (Eisler 1988a).

Among birds, $\mathrm{LD}_{50} \mathrm{~s}$ for arsenic compounds range from 17.4 to $3300 \mathrm{mg} / \mathrm{kg}$ bw (Eisler, 1988a). While no mortality was observed among mallard ducks fed a diet containing $100 \mathrm{ppm}$ sodium arsenite for 128 days, $12 \%$ to $92 \%$ mortality was observed for ducks fed diets containing 250 to $1000 \mathrm{ppm}$ arsenite (USFWS 1964). Camardese et al. (1990) and Whitworth et al. (1991) fed mallards diets containing 30,100 , or $300 \mathrm{ppm}$ sodium arsenate. While no effects were observed on behavior, growth was reduced for male ducks consuming $300 \mathrm{ppm}$ arsenic and for female ducks at all exposure levels.

Barium. The soluble salts of barium, an alkaline earth metal, are toxic in mammalian systems. At low doses, barium acts as a muscle stimulant and at higher doses affects the nervous system eventually leading to paralysis. The $\mathrm{LD}_{50}$ for rats is listed as $630 \mathrm{mg} / \mathrm{kg}$ for barium carbonate, 118 $\mathrm{mg} / \mathrm{kg}$ for barium chloride, and $921 \mathrm{mg} / \mathrm{kg}$ for barium acetate (Lewis and Sweet 1984).

Schroeder and Mitchener (1975a, b) exposed rats and mice to $5 \mathrm{mg}$ barium $/ \mathrm{L}$ in drinking water for their lifetime. There was a slight but significant reduction in longevity of treated male mice when measured as the mean age at death of the last surviving $10 \%$ of animals. The overall average life span of the group, however, was about the same as the control group. In another study, Perry et al. (1983) exposed rats to $0,1,10$, or $100 \mathrm{ppm}$ barium for up to 16 months. A significant increase in average blood pressure was observed in the highest dose group; a slight but statistically significant increase was seen in the $10 \mathrm{ppm}$ dose group. Information on developmental and reproductive toxicity of barium to mammals is not available.

The $\mathrm{LD}_{\mathrm{s0}}$ of barium to chickens is $623 \mathrm{mg} / \mathrm{kg}$ (Johnson et al. 1960). Johnson et al. (1960) report that while chickens will tolerate $1000 \mathrm{ppm}$ barium in their diet without adverse effects, $2000 \mathrm{ppm}$ reduces growth, $8000 \mathrm{ppm}$ produces $50 \%$ mortality in 4 weeks, and diets containing 16,000 or $32,000 \mathrm{ppm}$ barium are $100 \%$ lethal.

Cadmium. While there is little information to indicate that this relatively rare metal is biologically essential or beneficial, $\mathrm{Cd}$ has been suggested as the cause of various deleterious effects to wildlife (Eisler 1985a). Mammals and birds are comparatively resistant to the biocidal properties of $\mathrm{Cd}$, which include growth retardation, anemia, and testicular damage. $\mathrm{Cd}$ tends to bioaccumulation the liver and kidney, eventually acting as a cumulative toxin. Cd residues of $2 \mathrm{ppm}$ whole body fresh weight are evidence of $\mathrm{Cd}$ contamination, and residues $>5 \mathrm{ppm}$ whole animal fresh weight may be life-threatening (Eisler 1985a).

The lowest oral dose resulting in death for rats was $250 \mathrm{mg} \mathrm{Cd} / \mathrm{kg}$ body weight (EPA 1980a). Weigel et al. (1987) fed rats $0.24,0.85$, or $2.25 \mathrm{mg} / \mathrm{kg} \mathrm{Cd}$ in diet for 8 weeks. Concentrations $\geq 0.85$ $\mathrm{mg} / \mathrm{kg}$ resulted in reduced food intake, reduced body weights, and reduced enzyme activity, but no hematological effects were noted. Ma et al. (1991) determined that an average cadmium intake of $15 \mathrm{mg} / \mathrm{kg} /$ day corresponded with critical renal metal loads of $120 \mathrm{mg} / \mathrm{kg}$, a level indicative of adverse health effects. Rats on a diet with $5 \mathrm{ppm}$ Cd suffered shortened lifespans (Schroeder et al. 1965). Cd at $50 \mathrm{ppm}$ in the diet depleted iron from rat livers (Whanger 1973). Rats eating diets with 
$7.15 \mathrm{ppm} \mathrm{Cd}$ (as CdO) exhibited growth reductions, but those consuming a diet with $2.80 \mathrm{ppm} \mathrm{Cd}$ did not (Weigel et al. 1987). In a 3 generation reproductive study, the population of mice exposed to $1 \mathrm{ppm} \mathrm{CdCl}_{2}$ in their drinking water died out after the second generation (Schroeder and Mitchner 1971). Rats receiving $>6 \mathrm{mg} \mathrm{Cd} / \mathrm{kg}$ body weight daily during pregnancy gave birth to malformed fetuses (Ferm and Layton 1981).

No mortality was observed among adult mallard ducks fed diets containing $0,2,20$, and 200 ppm Cd, however egg production was significantly reduced in the group consuming $200 \mathrm{ppm} \mathrm{Cd}$ (White and Finley 1978). In addition, the testes of males in the $200 \mathrm{ppm} \mathrm{Cd}$ group atrophied and the spermatogenic process was disrupted (White et al. 1978). Among mallard ducklings, $20 \mathrm{ppm}$ $\mathrm{Cd}$ in the diet produces mild to severe kidney lesions, reduces packed cell volume and hemoglobin concentrations in the blood (Cain et al. 1983). Avoidance behavior of black ducklings is impaired by diets containing $40 \mathrm{ppm} \mathrm{Cd}$ (Heinz and Haseltine 1983).

Copper. Copper occurs naturally in elemental form and as a component of many minerals. It is an essential nutrient that is normally present in a wide variety of tissues (ATSDR 1990; EPA 1987). Because of its high electrical and thermal conductivity, it is widely used in the manufacture of electrical equipment. Common copper salts, such as the sulfate, carbonate, cyanide, oxide, and sulfide are used as fungicides, as components of ceramics and pyrotechnics, for electroplating, and for numerous other industrial applications (ACGIH 1986). The largest anthropogenic releases of copper to the environment result from mining operations, agriculture, solid waste, and sludge from sewage treatment plants. Natural discharges to air and water, such as windblown dust and volcanic eruptions, may be significant (ATSDR 1990).

Copper is a component of a number of metalloenzymes such as catalase, peroxidases, and cytochrome oxidase and is essential for the utilization of iron (Goyer 1991; Stokinger 1981a). Although most copper salts occur in two valence states, as cuprous $\left(\mathrm{Cu}^{+}\right)$or cupric $\left(\mathrm{Cu}^{2+}\right)$ ions, the biological availability and toxicity of copper is most likely associated with the divalent state (ATSDR 1990). Copper sulfate is the most common copper salt. Copper is soluble in nitric acid and hot sulfuric acid, very slightly soluble in hydrochloric acid and ammonia, and insoluble in water (Stokinger 1981a).

The metabolism of copper involves mainly its transfer to and from various organic ligands, most notably sulfhydryl and imidazole groups on amino acids and proteins (ATSDR 1990). The liver is one of the main organs involved in the storage and metabolism of copper. Absorption of ingested copper occurs primarily in the upper gastrointestinal tract (EPA 1987). Soluble copper compounds (oxides, hydroxides, citrates) are readily absorbed but water-insoluble compounds (sulfides) are poorly absorbed (Venugopal and Luckey 1978). Zinc, molybdenum, and other metals may decrease dietary copper absorption (USAF 1990).

In animal studies, oral exposure to copper caused hepatic and renal accumulation of copper, liver and kidney necrosis at doses of $\geq 100 \mathrm{mg} / \mathrm{kg} /$ day, and hematological effects at doses of 40 mg/kg/day (EPA 1986; Haywood 1985; Rana and Kumar 1978; Gopinath et al. 1974; Kline et al. 1971). Oral or intravenous administration of copper sulfate can increase fetal mortality and developmental abnormalities in experimental animals (Lecyk 1980; Ferm and Hanlon 1974). Rat oral $\mathrm{LD}_{50}$ values for various copper compounds are $140 \mathrm{mg} / \mathrm{kg}$ for copper chloride $\left(\mathrm{CuCl}_{2}\right) ; 470$ $\mathrm{mg} / \mathrm{kg}$ for copper oxide $\left(\mathrm{Cu}_{2} \mathrm{O}\right) ; 940 \mathrm{mg} / \mathrm{kg}$ for copper nitrate $\left(\mathrm{Cu}\left(\mathrm{NO}_{3}\right)_{2} \cdot 3 \mathrm{H}_{2} \mathrm{O}\right)$; and $960 \mathrm{mg} / \mathrm{kg}$ for copper sulfate $\left(\mathrm{CuSO}_{4} \cdot 5 \mathrm{H}_{2} \mathrm{O}\right.$ ) (Stokinger 1981a). Deaths in animals given lethal doses of copper have been attributed to extensive hepatic centrilobular necrosis (USAF 1990). 
In a 90-day subchronic study with copper cyanide $(\mathrm{CuCN})$, high mortality, attributed to hemolytic anemia, was seen in both male and female rats receiving $50 \mathrm{mg} / \mathrm{kg} /$ day by gavage, but not in those receiving $\leq 5 \mathrm{mg} / \mathrm{kg} /$ day (EPA 1986). In general, male rats appeared to be more sensitive to the effects of $\mathrm{CuCN}$ than female rats. Rats receiving $500 \mathrm{ppm}$ copper in their diet (about 5 $\mathrm{mg} /$ day) appeared normal, while rats receiving $1000 \mathrm{ppm}$ exhibited depressed growth, those at 2000 ppm hardly grew at all, and those on a $4000 \mathrm{ppm}$ diet lost weight rapidly and died (Boyden et al. 1938). Salt licks containing 5-9\% copper sulfate caused anorexia, hemolytic anemia, icterus, and hemoglobinuria, followed by death within 2 days in sheep using the licks (Gopinath et al. 1974). The estimated ingested dose was $40-49 \mathrm{~g}$ over a 25 - to 86-day period. Lecyk (1980) observed reduced litter size, decreased fetal weights, and skeletal abnormalities in the offspring of mice fed diets supplemented with 3000 or 4000 ppm copper sulfate (155 or $207 \mathrm{mg}$ copper/kg/day, respectively) for one month prior to gestation and on days $0-19$ of gestation.

Aulerich et al. (1982) reported an increased mortality rate in the offspring of minks fed a diet supplemented with $>3 \mathrm{mg}$ copper/kg/day as copper sulfate for 50 weeks. Although kit mortality was greater and litter mass was reduced relative to controls, reproductive performance of mink fed diets supplemented with up to $200 \mathrm{ppm}$ copper for 357 days was within the normal range for the species (Aulerich et al. 1982). Lifetime exposure to $42.4 \mathrm{mg}$ copper/ $\mathrm{kg} /$ day (as copper gluconate) in drinking water caused a $12.8 \%$ decrease in the maximal lifespan in mice (Massie and Aiello 1984).

Domestic chicks on diets 2324 ppm copper grew slowly; mortality increased with dietary copper concentrations of $1270 \mathrm{ppm}$ (Mayo et al. 1956). Arthur et al. (1958) observed no ill effects in chicks fed $\leq 500 \mathrm{ppm}$ copper in diet up to 8 weeks of age. Dietary copper levels from 588-1176 ppm for 10 weeks exerted a toxic effect on chick growth; the minimum toxic level of copper appeared to be about $500 \mathrm{ppm}$ (Mehring et al. 1960). Turkey poults tolerated $676 \mathrm{ppm}$ copper in starter diets for 21 days with no deleterious effects, but copper was definitely toxic at levels $>1620$ ppm (Vohra and Kratzer 1968). Chickens given a daily dose of $>70 \mathrm{mg} / \mathrm{kg}$ of $\mathrm{CuCO}_{3}$ died while those receiving $<60 \mathrm{mg} / \mathrm{kg}$ exhibited slight symptoms of copper poisoning but survived (Pullar 1940). No symptoms of copper poisoning were observed in domestic mallards ingesting $\leq 29$ $\mathrm{mg} / \mathrm{kg} /$ day of $\mathrm{CuCO}_{3}$, but daily intakes $255 \mathrm{mg} / \mathrm{kg} /$ day were toxic (Pullar 1940).

Chromium. Chromium occurs as either chromium (III) or chromium (VI). Trivalent chromium is an essential metal in man and wildlife, playing an important role in insulin metabolism (Larngard and Norseth 1979). Hexavalent chromium is more toxic than chromium (III) because of its high oxidation potential and the ease with which it penetrates biological membranes (Steven et al. 1976; Taylor and Parr 1978). However, it is unlikely that all chromium in soil would be chromium (VI) because it is a highly oxidizing chemical species which is usually reduced by soil organic matter to chromium (III). Chromium (III) solubility decreases with increasing $\mathrm{pH}$, and it is completely precipitated at $\mathrm{pH}$ above 5.5. In most soils, chromium is primarily present as precipitated chromium (III) and is not bioavailable. Most chromium in soil and sediments is unavailable to living organisms, and there is little evidence of chromium biomagnifying through food chains in its inorganic form (Eisler 1986a). Concentrations of total chromium $>4.0 \mathrm{mg} / \mathrm{kg}$ dry weight should be viewed as presumptive evidence of chromium contamination (Eisler 1986a).

At high concentrations, chromium is a mutagen, teratogen and carcinogen (Eisler 1986a). The $\mathrm{LD}_{50}$ for chromium (III) in mice is $260 \mathrm{mg} / \mathrm{kg}$ bw and $5 \mathrm{mg} / \mathrm{kg}$ bw for chromium (VI) (Steven et al. 1976). Rats fed chromium (VI) reached a toxic threshold at $1000 \mathrm{ppm}$ (Steven et al. 1976). Pregnant hamsters injected with 5 to $15 \mathrm{mg} \mathrm{CrO}$ [chromium (VI)]/kg bw displayed a dosedependent increase in the number of resorbed and malformed fetuses (Gale, 1978). Guinea pigs fed 
$50 \mathrm{ppm}$ chromium (III) for 21 weeks showed no adverse effects (Preston et al. 1976). Similar results were observed among rats consuming water containing $25 \mathrm{ppm}$ chromium (VI) for 1 year (Mackenzie et al. 1958).

Injection of 0.002 to $0.05 \mathrm{mg} \mathrm{CrO}_{3}$ [chromium (VI)]/chicken egg produced a dose-dependent decrease in egg viability and increased frequency of malformed embryos (Gilani and Marano, 1979). In contrast, adult black ducks fed a diet containing 0,10 , or 50 ppm chromium (III) for 10 months displayed normal growth and reproduction (Haseltine et al., unpublished manuscript). While no malformations were observed among ducklings from treated birds, growth and survivorship was reduced. Heinz and Haseltine (1981) observed no effects on avoidance behavior of black ducklings fed a diet containing 20 or 200 ppm chromium (III).

DDT. DDT (1,1,1-trichloro-2,2-bis(p-chlorophenyl)ethane) is an organochlorine insecticide that was banned for use in the United States in 1972. DDT, and its metabolites, DDE and DDD, are highly persistent. The half-life of DDT in soil is reported to range from 2 to 15 years (ATSDR 1993). DDT and it's metabolites are also highly lipophilic and have a high bioaccumulation potential. A bioconcentration factor for rainbow trout is reported to be 12000 (ATSDR 1993). Braune and Norstrom (1989) found DDE concentrations in herring gills to be 85 times higher than fish in their diet.

Acute oral toxicity of DDT and its metabolites is relatively low. Mammalian oral $\mathrm{LD}_{50}$ values range from $87 \mathrm{mg} / \mathrm{kg}$ for rats to $>5000 \mathrm{mg} / \mathrm{kg}$ for hamsters (EPA 1993). Avian oral $L D_{50}$ values range from $595 \mathrm{mg} / \mathrm{kg}$ for California quail to $>4000 \mathrm{mg} / \mathrm{kg}$ for rock doves (Hudson et al. 1984). Hill and Camardese (1986) report 5-day dietary $\mathrm{LC}_{50} \mathrm{~s}$ for DDT and DDE to be $416 \mathrm{mg} / \mathrm{kg}$ and 859 $\mathrm{mg} / \mathrm{kg}$, respectively.

Despite low acute toxicity, chronic exposure to low levels of DDT in food has adverse effects of reproduction in wildlife. The primary adverse effect among birds is eggshell thinning and decreased reproductive success (Ratcliffe 1967). Anderson et al. (1975) studied the reproductive success of pelicans from 1969 through 1974. During this time, DDT residues in anchovies, their primary food, declined from $4.27 \mathrm{ppm}$ (wet weight) to $0.15 \mathrm{ppm}$ (wet weight). While reproductive success improved from 1969 to 1974, in 1974 the fledgling rate was still $30 \%$ below that needed to maintain a stable population. Because this study was long-term and considered reproductive effects in a wildlife species, EPA (1993) judged this study to be the most appropriate to evaluate DDT effects to avian wildlife. Therefore the $0.15 \mathrm{ppm}$ DDT value was considered to be a chronic LOAEL.

In a study of the effects of DDT on reproduction in mammals, Fitzhugh (1948) exposed rats to $10,50,100$, or $600 \mathrm{ppm}$ DDT in their diet for two years. While consumption of $50 \mathrm{ppm}$ or more DDT in the diet reduced the number of young produced, no adverse effects were observed at the 10 ppm DDT dose level. Because the study considered exposure throughout 2 years and reproduction, the 10 and $50 \mathrm{ppm}$ DDT doses were considered to be chronic NOAELs and LOAELs, respectively.

Lead. Lead is a comparatively rare metal, averaging $16 \mathrm{ppm}$ in the earth's crust, that is neither essential nor beneficial in living organisms (Eisler 1988b). Lead has adverse effects on survival, growth, reproduction, development, behavior, learning, and metabolism. In general, organic lead compounds are more toxic than inorganic compounds, biomagnification of lead is minimal, and younger organisms are more susceptible to lead toxicity (Eisler 1988b). 
Acute oral doses of 5-108 $\mathrm{mg}$ lead/kg bw reduced rat survival (Eisler 1988b), and rats fed diets with $5 \mathrm{ppm}$ lead had shortened life spans (Schroeder et al. 1965). An acute $L D_{50}$ based on a single oral dose of $12 \mathrm{mg}$ tetraethyllead/kg body weight was reported by Branica and Konrad (1980). Rats fed $0.5,5,25$, or $250 \mathrm{ppm}$ inorganic lead in diets over two generations exhibited no substantial developmental effects (Kimmel et al. 1980). In another study, Azar et al. (1973) fed rats a diet containing $0,10,50,100,1000$, or $2000 \mathrm{ppm}$ lead acetate for three generations. While the number of litters and young/litter was not affected by any dose level, growth was reduced and kidney histopathologies were observed among offspring in the 1000 and $2000 \mathrm{ppm}$ treatments. Frequency of pregnancy was reduced in mice ingesting $3 \mathrm{mg} / \mathrm{kg}$ body weight tetraethyllead daily, and daily ingestion of $1.5 \mathrm{mg} / \mathrm{kg}$ tetraethyllead chloride resulted in a reduction in the success of implanted ova (Clark 1979).

Anemia and other hematological effects were induced among pigeons orally dosed with $6.25 \mathrm{mg} \mathrm{lead} / \mathrm{kg}$ bw/day (Anders et al. 1982). Kendall and Scanlon (1981) exposed ring doves to drinking water containing 0 or $100 \mathrm{ppm}$ lead and observed no effects on time to produce eggs, egg production, or fertility. However, testes weight and sperm count was decreased among lead-exposed males. Grandjean (1976) correlated eggshell thickness and eggshell lead levels in European kestrels (Falco tinnunculus), suggesting that lead may cause eggshell thinning. Among American kestrels (Falco sparvarius) fed diets containing 0,10 , or $50 \mathrm{ppm}$ lead, no adverse effects survival, egglaying, initiation of incubation, egg fertility, or eggshell thickness were observed (Pattee 1984).

Mercury. Mercury has no known biological function and is potentially toxic to fish and wildlife. Mercury is a mutagen, teratogen, and carcinogen that adversely affects the central nervous, renal, and reproductive systems of wildlife (Eisler 1987). Inorganic mercury compounds in aquatic systems are readily converted to organomercury by microbial action (Berlin 1979), with organomercury compounds being more toxic than inorganic mercury compounds. Biota bioconcentrate mercury compounds which can be further biomagnified through food chains (Wren, 1986).

Daily doses of $0.1-0.5 \mathrm{mg} / \mathrm{kg}$ bw/day and dietary concentrations of $1.0-5.0 \mathrm{ppm}$ are lethal to sensitive mammals (Eisler 1987). Central nervous system toxicity, weight loss, and mortality were observed among rats fed a diet containing $250 \mathrm{ppm}$ methyl mercury (MeHg) for 2 weeks (Verschuuren et al. 1976a). Rats consuming $2.5 \mathrm{ppm} \mathrm{MeHg}$ in the diet for 2 years displayed reduced growth, increased kidney weight, and altered kidney histochemistry (Verschuuren et al. 1976b). To study effects on reproduction, Verschuuren et al. (1976c) fed rats a diet containing $0,0.1,0.5$, and $2.5 \mathrm{ppm} \mathrm{MeHg}$ for three generations. While no effects were observed among rats fed 0.1 or $0.5 \mathrm{ppm}$ $\mathrm{MeHg}$, offspring viability was reduced among rats in the $2.5 \mathrm{ppm}$ treatment. Among mink, 93-day consumption of diets containing 1.8 to $15.0 \mathrm{ppm} \mathrm{MeHg}$ produced mortality, ataxia, anorexia, and paralysis (Wobeser et al. 1976), with the highest exposures showing the greatest effects.

The $\mathrm{LD}_{50}$ for MeHg for Coturnix quail ranges from 14.4 to $33.7 \mathrm{mg} / \mathrm{kg}$ bw (Eisler 1987). Growth was decreased and mortality increased among leghorn cockerels fed diets containing 6 to $18 \mathrm{ppm} \mathrm{MeHg}$ (Fimreite 1970). Ring-necked pheasants fed diets of MeHg-treated grains displayed reduced egg production and hatchability and laid more shell-less eggs than controls (Fimreite 1971). Heinz (1979) fed mallard ducks a diet containing $0.5 \mathrm{ppm} \mathrm{MeHg}$ for three generations. While $\mathrm{MeHg}$ consumption did not affect adult weights or weight change during the reproductive season, MeHgexposed females laid fewer eggs (with more eggs outside the nest box), produced fewer young, and displayed slightly thinner eggshells. Young of MeHg-treated adults were less responsive to maternal calls and hyper-responsive to fright stimuli. 
Nickel. Nickel is a naturally occurring element that may exist in various mineral forms. It forms $0.008 \%$ of the earth's crust (NAS 1980). Soil and sediment are the primary receptacles for nickel, but mobilization may occur depending on physico-chemical characteristics of the soil (ATSDR 1988; USAF 1990). Nickel is used in a wide variety of applications including metallurgical processes and electrical components, such as batteries (ATSDR 1988; USAF 1990). There is some evidence that nickel may be an essential trace element for mammals.

Nickel occurs in nature in the nonionic and divalent states; other valence states occur very infrequently (Mastromatteo 1986).

The absorption of nickel is dependent on its physico-chemical form, with water soluble forms being more readily absorbed. Soluble nickel compounds tend to be more toxic than insoluble compounds (Goyer 1991). The metabolism of nickel involves conversion to various chemical forms and binding to various ligands (ATSDR 1988). Nickel is excreted in the urine and feces with relative amounts for each route being dependent on the route of exposure and chemical form. Most nickel enters the body via food and water consumption.

Oral $\mathrm{LD}_{50}$ values for rats range from $67 \mathrm{mg}$ nickel $/ \mathrm{kg}$ (nickel sulfate hexahydrate) to $>9000 \mathrm{mg}$ nickel/kg (nickel powder) (ATSDR 1988). The Food and Drug Research Laboratories, Inc. (1984) reported an acute oral $L_{50}$ of $175 \mathrm{mg} / \mathrm{kg}$ for female rats exposed to nickel dioxide hexahydrate; acute oral $\mathrm{LD}_{50} \mathrm{~s}$ for 11 other nickel compounds ranged from 275 to $>9000 \mathrm{mg} / \mathrm{kg}$. Toxic effects of oral exposure to nickel usually involve the kidneys with some evidence from animal studies showing a possible developmental/reproductive toxicity effect (ATSDR 1988; Goyer 1991).

Inorganic nickel compounds are well-tolerated when taken orally by rodents in doses up to 500 $\mathrm{mg} / \mathrm{kg}$ (Mastromatteo 1986). Rats continually fed a $250 \mathrm{ppm}$ nickel diet for 16 months suffered no deleterious effects and were considered in excellent condition (Phatak and Patwardhan 1952). Progressive accumulation of nickel was not observed in the tissues assayed. In a three-generation study of rats, Ambrose et al. (1976) reported a no-observed-adverse-effects level (NOAEL) and lowest-observed-adverse-effects level (LOAEL) of $5 \mathrm{mg} / \mathrm{kg} /$ day and $50 \mathrm{mg} / \mathrm{kg} /$ day, respectively. Doses of $24.15 \mathrm{mg} / \mathrm{kg}$-day administered as nickel sulfate in the diet had no adverse effects on reproduction of the rats. Growth in dogs was depressed by dietary concentrations of $2500 \mathrm{ppm}$ nickel sulfate hexahydrate; in the rats, growth was depressed at dietary concentrations $>1000 \mathrm{ppm}$ (Ambrose et al. 1976).

Weber and Reid (1968) fed a basal diet of up to $1300 \mathrm{ppm}$ nickel sulfate or nickel acetate to domestic chicks for 4 weeks. Growth of chicks was significantly depressed at $700 \mathrm{ppm}$ nickel and above. Doses of $21.4 \mathrm{mg} / \mathrm{kg}$-day administered as nickel sulfate in the diet had no adverse effects on weight gain after 4 weeks. Mallard ducklings on diets with $\geq 800 \mathrm{ppm}$ nickel would be adversely affected (Cain and Pafford 1981).

PCBs. Polychlorinated biphenyls (PCBs) are a family of man-made chemicals consisting of 209 individual compounds with varying toxicity (ATSDR 1989a). Aroclor is the trade name for PCBs made by Monsanto. Because of their insulating and nonflammable properties, PCBs were widely used in industrial applications such as coolants and lubricants in transformers, capacitors, and electrical equipment (ATSDR 1989a). The United States stopped manufacturing PCBs in 1977 due to evidence that they accumulate in the environment. PCBs have become widespread environmental contaminants. 
Most exposures to PCBs are oral. Absorption of PCBs following oral exposure is often $>90 \%$ (ATSDR 1989a). PCBs are preferentially stored in adipose tissues in animals. They may cross the placenta or be transferred to offspring through milk. PCBs with higher chlorine content (the last 2 digits of the Aroclor designation indicate the percent $\mathrm{Cl}$ content of the compound) tend to persist in the environment longer than those with lower $\mathrm{Cl}$ content, and PCBs are known to bioaccumulate and biomagnify to toxic concentrations in animals (Eisler 1986b; ATSDR 1989a). Chronic exposures are of particular concern. PCBs with high $\mathrm{K}_{\text {ow }}$ values and high numbers of chlorines in adjacent positions are generally the most toxic. Although relatively insoluble in water, PCBs are generally freely soluble in nonpolar organic solvents and in biological lipids (EPA 1980).

Sixty percent of mice fed diets containing 1,000 ppm Aroclor 1254 for 14 days died within 15 days, but none of the mice fed diets with only $250 \mathrm{ppm}$ Aroclor for 14 days died (Sanders et al. 1974). These diets translate to doses of 130 and $32.5 \mathrm{mg} / \mathrm{kg} /$ day, respectively (ATSDR 1989a). White-footed mice fed $10 \mathrm{ppm}$ Aroclor 1254 for 18 months had fewer offspring produced and a longer time between litters than control mice (Linzey 1987).

Feeding studies suggest a total intake of $500-2,000 \mathrm{mg} / \mathrm{kg}$ of Aroclor 1254 obtained through the diet over 1 to 7 weeks is lethal in rats (Hudson et al. 1984). Male rats consuming diets containing 0-100 ppm Aroclor 1254 for 104 weeks suffered dose-related reduced survival (NCI 1978); however, there was no effect on similarly treated female rats. Dietary concentrations of $\geq 20$ ppm Aroclor 1254 reduced litter sizes in one- and two-generation reproduction studies with rats; concentrations $<5$ ppm had no effect (Linder et al. 1974).

Mink are one of the most susceptible mammals; dietary levels as low as $0.1 \mathrm{ppm}$ fresh weight have caused death and reproductive toxicity (Eisler 1986b). Diets containing $20 \mathrm{ppm}$ Aroclor 1242 were lethal to mink in a 247-day experiment. The $\mathrm{LC}_{50}$ for chronic exposures is $6.65 \mathrm{ppm}$ Aroclor 1254 for mink over a 8 month period (Ringer et al. 1981). Diets containing 5 ppm Aroclor 1242 caused complete reproductive failure (Bleavins et al. 1980). Exposure for 160 days to $3.57 \mathrm{ppm}$ Aroclor 1254 resulted in $100 \%$ mortality of adult mink (Platonow and Karstad 1973).

A chronic study was conducted over 4.5 months exposing mink to 1,5 and 15 ppm Aroclor 1254 in the diet. There was a significant reduction in the number of offspring born alive at the 5 and $15 \mathrm{mg} / \mathrm{kg}$ exposures (Aulerich and Ringer 1977). Mink fed carp containing $1.5 \mathrm{ppm}$ Aroclor 1254 for 6 months produced no offspring that survived to 24 hours (Hornshaw et al. 1983). No effects were observed in mink fed $0.64 \mathrm{ppm}$ Aroclor 1254 for 160 days (Platonow and Karstad 1973). Exposure of mink for 6 months to $1 \mathrm{ppm}$ Aroclor 1254 resulted in no significant difference from controls in number of offspring, or offspring mortality (Wren et al. 1987). Therefore, the $1 \mathrm{ppm}$ dose was considered to be a chronic NOAEL.

A dietary dose of $25 \mathrm{ppm}$ Aroclor 1254 fed for at lease a month before egg-laying in mallard ducks had no detrimental effect on reproductive success (Custer and Heinz 1980). Dietary exposure of $5 \mathrm{ppm}$ Aroclor 1254 for 39 weeks to laying hens and roosters resulted in reduced egg production, although hatchability of fertile eggs was not affected (Platonow and Reinhart 1973). Screech owls fed $3 \mathrm{ppm}$ Aroclor 1248 through two breeding seasons did not have significantly different reproductive success, relative to controls (McLane and Hughes 1980). Exposure of pheasants to $12.5 \mathrm{mg} / \mathrm{bird} /$ week $(1.8 \mathrm{mg} / \mathrm{kg} / \mathrm{d}$ ) of Aroclor 1254 for 17 weeks resulted in significantly reduced egg hatchability (Dahlgren et al. 1972). Because this study considered exposure throughout a critical lifestage (reproduction), the $12.5 \mathrm{mg} / \mathrm{bird} /$ week dose was considered to be a chronic LOAEL. 
Selenium. While selenium is an essential nutrient that interacts with Vitamin $\mathrm{E}$ and maintains muscle integrity, $t$ has a very narrow tolerance range; in humans, while 0.04-0.1 ppm is required in diet, $4 \mathrm{ppm}$ may produce toxic effects (Eisler 1985b). In mammals, chronic selenium poisoning is induced by diets containing 1-44 ppm selenium (Harr 1978). Symptoms include liver cirrhosis, lameness, loss of hair, emaciation, reduced conception, and increased fetal resorption. Plants convert inorganic selenium to organic selenium compounds, thereby increasing their biological availability (Lo and Sandi 1980).

To evaluate the effects of selenium on reproduction, Schroeder and Mitchner (1971) exposed mice to $3 \mathrm{ppm}$ selenate in drinking water for three generations. This dosage level increased juvenile mortality, number of runts, and resulted in reproductive failure by the third generation. In another study, exposure to $3 \mathrm{ppm}$ selenate or selenite in water for a lifetime had no effect on mouse longevity and no tumorigenicity was observed (Schroeder and Mitchner 1972).

Selenium is both embryotoxic and teratogenic to birds, with organic selenium (selenomethionine) being more toxic than inorganic selenium (Hoffman and Heinz 1988). Mallard ducks were fed diets containing 1,5,10,25, or $100 \mathrm{ppm}$ selenite (Heinz et al. 1987) or 1, 2, 4, 8, or $16 \mathrm{ppm}$ selenomethionine (Heinz et al. 1989) for about 10 weeks. Exposure to 1, 5, or $10 \mathrm{ppm}$ selenite or 1,2 , or $4 \mathrm{ppm}$ selenomethionine in the diet had no effect on survival, growth, or reproductive success of adults. The diet containing $100 \mathrm{ppm}$ selenite killed 11 of 12 adults. While only one adult receiving the $25 \mathrm{ppm}$ diet died, time to laying, interval between eggs was increased, and duckling survivorship was reduced in this treatment (Heinz et al. 1987). Diets containing 8 and $16 \mathrm{ppm}$ selenomethionine resulted in $6.8 \%$ and $67.9 \%$ malformed embryos, respectively. In addition, duckling survival was significantly reduced (Heinz et al. 1989).

The most visible incident of environmental selenium toxicity occurred at the Kesterson National Wildlife Refuge in California. Agricultural wastewater containing approximately $0.3 \mathrm{ppm}$ selenium was used for marsh management at the refuge (Ohlendorf et al. 1986). Mean selenium concentrations in plants, invertebrates, and fish at the site were $22-175 \mathrm{ppm}$ (dry weight). As a result, reproductive success among water birds was poor, and the incidence of embryo mortality and developmental abnormalities was dramatically increased. Raccoons on the refuge were found to bioaccumulate selenium (Clark et al. 1989). While peak births at the refuge was 2 months later than reported at other locations, no adverse effects on raccoon reproduction were observed.

Metabolism of selenium may be significantly modified through interactions with heavy metals, and selenium may provide some protection from adverse effects associated with various metals, including cadmium and mercury (Eisler 1985b). Arsenite inhibits methylation of selenium but increases fecal excretion of selenite (Venugopal and Luckey 1978).

Thallium. Thallium is a widely distributed metal, occurring at concentrations of approximately $1 \mathrm{ppm}$ in the earths crust (Kazantzis 1979). Principal systems affected by $\mathrm{Tl}$ exposure include nervous and digestive; renal damage and hair loss have also been observed. Thallium sulfate, which has been widely used as a rodenticide, has an acute oral $\mathrm{LD}_{50}$ of $16 \mathrm{mg} / \mathrm{kg}$ (Ware 1978). In chronic studies, rats tolerated a dose of $10 \mathrm{mg} \mathrm{Tl}$ acetate/ $\mathrm{kg}$, while $30 \mathrm{mg} / \mathrm{kg}$ was lethal to males by 15 weeks. All rats fed a daily dose of $0.45 \mathrm{mg} \mathrm{Tl} / \mathrm{kg}$ died after 4 months (Kazantzis 1979). Rats exposed to $10 \mathrm{ppm} \mathrm{Tl}$ in drinking water for 2 mo accumulated $\mathrm{Tl}$ in testis and exhibited signs of testicular toxicity including reduced sperm motility (Formigli et al. 1986). 
Bean and Hudson (1976) orally dosed 3 golden eagles with 60 and $120 \mathrm{mg} \mathrm{Tl}_{2} \mathrm{SO}_{4} / \mathrm{kg}$ bw; the bird receiving $60 \mathrm{mg} \mathrm{Tl} \mathrm{SO}_{4} / \mathrm{kg}$ survived while the two dosed with $120 \mathrm{mg} \mathrm{Tl} \mathrm{SO}_{4} / \mathrm{kg}$ died, suggesting an $L D_{50}$ between the doses. Oral $L D_{50}$ 's for quail, geese, and ducks are 12,15 , and 30 $\mathrm{mg} / \mathrm{kg}$ respectively (Shaw 1933). No long-term studies of thallium toxicity to birds are currently available.

Uranium. Uranium is an element used as a nuclear fuel, in nuclear weapons production, and in its natural or depleted form as counterweights for airplanes and as shielding material (Burkart 1991). Its average concentration in the earth's crust is approximately 3-4 ppm (Merritt 1971).

Except for their radioactivity, metallic uranium and particles of insoluble uranium compounds are biologically inert. The chemical toxicity of uranium is exerted only by its aqueous ions (Durbin and Wrenn 1975). Aqueous ions have been identified for uranium (II), uranium (IV), uranium (V), and uranium (VI), but only uranium (IV) and uranium (VI) are stable in solution. In a solution of low acidity, uranium (IV) hydrolyzes to form insoluble hydroxides (Durbin and Wrenn 1975). Uranium (VI) is the most frequently encountered oxidation state in nuclear fuel cycles. Uranyl nitrate and uranyl fluoride are 1.4-2 times more toxic than $\mathrm{UCl}_{5}, \mathrm{UCl}_{4}, \mathrm{UO}_{3}$, or $\mathrm{NO}_{2} \mathrm{U}_{2} \mathrm{O}_{7}$ and 3 times more toxic than $\left(\mathrm{NH}_{4}\right)_{2} \mathrm{U}_{2} \mathrm{O}_{7}$ (Durbin and Wrenn 1975). Uranium-235 is the most radioactive of the uranium isotopes. Other uranium isotopes including uranium-233, -234 , and -238 have low specific activities, long half-lives, and have lower potential to cause radiation induced diseases (ATSDR 1990).

The absorption level of uranium compounds following oral exposure is generally considered to be quite low. In animals, once uranium has been absorbed following inhalation exposures, it leaves the blood very quickly for distribution to body tissues (ATSDR 1990). Some of the uranium reacts with the protein surface of the columnular cells lining the renal tubule and injures or kills these cells. With small or moderate doses, the distal portion of the proximal convoluted tubule receives the severest injury. If death ensues, it follows a typical uremia caused by kidney dysfunction. If the animal survives, cellular regeneration restores much of the kidney tissue and function (NAS 1980). Most of the absorbed uranium is excreted in the urine, and renal clearance of uranium (VI) in cats, dogs, humans, and rabbits is high (Durbin and Wrenn 1975). About 60\% is excreted as a soluble bicarbonate complex, whereas the remainder is bound to plasma protein. Sixty percent is excreted in the urine within 24 hours. About $25 \%$ may be fixed in the bone (Chen et al. 1961).

The toxicity of uranium compounds depends on the degree of solubility, transport across cellular barriers, and absorption into blood. Toxicological effects from the ingestion of uranium are the result of the action of uranium as a metal and its radioactive properties. For humans and animals, uranium and its salts are highly toxic. Dermatitis, renal damage, and acute arterial lesions may occur. Acute intoxication may lead to irreversible damage and to death due to renal dysfunction (Burkart 1991). The primary toxic chemical effect of uranium is seen in kidney damage, but bone is considered the critical tissue for long-term radiation effects (ICRP 1959). Studies in rabbits, mice, and dogs showed kidney damage in a dose-related effect. Fetal skeletal abnormalities and fetal death were found in pregnant mice exposed to $6 \mathrm{mg} / \mathrm{kg}$ of uranyl acetate dihydrate (ATSDR 1990). Uranium toxicity is dependent upon and modified by many factors and most of the reported studies have been conducted with laboratory animals, primarily mice (NAS 1980). Herbivores may be highly sensitive because of the acidity of their urine (Dounce, 1951). 
The acute $L D_{50}$ for natural uranium injected in mice varies with strain and sex from 6-25 mg uranium $/ \mathrm{kg}$ (Dounce et al. 1951; Tannenbaum and Silverstone 1951). It is somewhat lower for ${ }^{233} \mathrm{UO}_{2}\left(\mathrm{NO}_{3}\right)_{2}: 4.5 \mathrm{mg}{ }^{233} \mathrm{U} / \mathrm{kg}$ (Durbin and Wrenn 1975). The toxicity benchmark for mammals is based on a 30-day study involving rabbits (Maynard and Hodge 1949). Doses of $2.8 \mathrm{mg} / \mathrm{kg}$-day administered as uranium soluble salts in the diet had adverse effects on the kidneys of the rats. However, a dietary level of $400 \mathrm{ppm}$ uranium appears to be safe for rats, even when the uranium is in a soluble form (NAS 1980).

Inhalation of uranium dioxide dust by rats, dogs, and monkeys at a concentration of $5 \mathrm{mg}$ uranium $/ \mathrm{m}^{3}$ for up to 5 years produced accumulation in the lungs and tracheobronchial lymph nodes that accounted for $90 \%$ of the body burden. No evidence of toxicity was observed despite the long duration of observation (Leach et al. 1970). Doses up to $10 \mathrm{mg}$ uranium/ $\mathrm{m}^{3}$ failed to cause excess mortality in dogs subjected to one year of continual inhalation (36 hrs/wk) (Durbin and Wrenn 1975). Following inhalation of the insoluble uranium salts, retention by the lungs is prolonged (Goyer 1991).

In a 6-week study of black ducks fed 0-1600 ppm powdered uranium in their feed, Haseltine and Sileo (1983) found no alterations in kidney or liver weights, no significant lesions, and no increase in mortality relative to controls. Doses of $86 \mathrm{mg} / \mathrm{kg}$-day administered as depleted metallic uranium in the diet caused no adverse effects on the liver, kidney, or mortality rates of the ducks.

Vanadium. Vanadium is a metallic element that occurs in six oxidation states and numerous inorganic compounds. The toxicity of vanadium depends on its physico-chemical state, particularly on its valence state and solubility. Based on acute toxicity, pentavalent $\mathrm{NH}_{4} \mathrm{VO}_{3}$ has been reported to be more than twice as toxic as trivalent $\mathrm{VCl}_{3}$ and more than 6 times as toxic as divalent $\mathrm{VI}_{2}$. Pentavalent $\mathrm{V}_{2} \mathrm{O}_{5}$ has been reported to be more than 5 times as toxic as trivalent $\mathrm{V}_{2} \mathrm{O}_{3}$ (Roshchin 1967). In animals, acutely toxic oral doses cause vasoconstriction, diffuse desquamative enteritis, congestion and fatty degeneration of the liver, congestion and focal hemorrhages in the lungs and adrenal cortex (Gosselin et al. 1984). Minimal effects seen after subchronic oral exposures to animals include diarrhea, altered renal function, and decreases in erythrocyte counts, hemoglobin, and hematocrit (Domingo et al. 1985; Zaporowska and Wasilewski 1991).

A vanadyl sulfate concentration of $5 \mu \mathrm{g} / \mathrm{mL}$ in drinking water, plus a vanadium level of $3.2 \mu \mathrm{g} / \mathrm{g}$ in the diet $(4.1 \mathrm{mg} \mathrm{V} / \mathrm{kg}$ total) of mice, was reported to cause no adverse effects over a lifetime exposure period (Schroeder and Balassa 1967). In similar lifetime studies, rats and mice exhibited no adverse effects when exposed to $5 \mathrm{ppm}$ vanadium (as vanadyl sulfate) in drinking water (Schroeder et al. 1970; Schroeder and Mitchner 1975b). The estimated dose levels were $0.7 \mathrm{mg}$. $\mathrm{V} / \mathrm{kg} /$ day for rats and $0.9 \mathrm{mg} \mathrm{V} / \mathrm{kg} /$ day for mice. Vanadium pentoxide in the diet of rats at levels of 10 and $100 \mathrm{ppm}$ for their entire lifetime resulted in no significant toxicological effects except for a reduction in hair cystine content (Stokinger 1981b).

White and Dieter (1978) observed no mortality among mallard ducks fed diets containing 1 , 10 , or $100 \mathrm{ppm}$ vanadyl sulfate for 12 weeks. Altered lipid metabolism was observed among birds fed $100 \mathrm{ppm}$ vanadium; no other effects were observed. Among chickens, 200 to $400 \mathrm{ppm}$ $\mathrm{Ca}_{2}\left(\mathrm{VO}_{4}\right)_{2}$ in the diet produced $100 \%$ mortality; weight gain decreased among chicks fed 20 to 40 ppm Ca ${ }_{2}\left(\mathrm{VO}_{4}\right)_{2}$ (Romoser et al. 1961).

Zinc. Zinc makes up about $0.002 \%$ of the earth's crust (NAS 1980). Zinc is an essential trace element in all living organisms; it assures the stability of biological molecules and structures such 
as DNA, membranes, and ribosomes (Eisler 1993). It is used commercially primarily in galvanized metals and metal alloys, but zinc compounds also have wide applications as chemical intermediates, catalysts, pigments, vulcanization activators and accelerators in the rubber industry, UV stabilizers, and supplements in animal feeds and fertilizers. Zinc compounds are also used in rayon manufacture, smoke bombs, soldering fluxes, mordants for printing and dyeing, wood preservatives, mildew inhibitors, deodorants, antiseptics, and astringents (Lloyd 1984; ATSDR 1989b). In addition, zinc phosphide is used as a rodenticide.

Zinc occurs in nature as a sulfide, oxide, or carbonate (Eisler 1993). It is divalent in solution. In freshwater with $\mathrm{pH}>4$ and $<7$ it exists almost exclusively as the aquo ion $\left(\mathrm{Zn}\left(\mathrm{H}_{2} \mathrm{O}\right)_{6}\right)^{2+}(\mathrm{Campbell}$ and Stokes 1985). Zinc interacts with many chemicals, and it may diminish the toxic effects of cadmium and protects against lead toxicosis in terrestrial animals (Eisler 1993). Background concentrations seldom exceed $0.040 \mathrm{mg} / \mathrm{L}$ in water or $200 \mathrm{mg} / \mathrm{kg}$ in soil or sediment (Eisler 1993).

Although it is essential for normal growth and reproduction (Prasad 1979; Stahl et al. 1989) and important to central nervous system function (Eisler 1993), the primary toxic effect of zinc is on zinc-dependent enzymes that regulate RNA and DNA. It is most harmful to aquatic life in conditions of low $\mathrm{pH}$, low alkalinity, low dissolved oxygen, and elevated temperature. Zinc is relatively nontoxic in mammals, but excessive intake can cause a variety of effects. It is not known to be carcinogenic by normal exposure routes (Eisler 1993).

Gastrointestinal absorption of zinc is variable (20-80\%) and depends on the chemical compound as well as on zinc levels in the body and on dietary concentrations of other nutrients (EPA 1984). Information on pulmonary absorption is limited and complicated by the potential for gastrointestinal absorption due to mucociliary clearance from the respiratory tract and subsequent swallowing. Pulmonary inflammation and changes in lung function have been observed in inhalation studies on animals (Amur et al. 1982; Lam et al. 1985; Drinker and Drinker 1928). Zinc is present in all tissues with the highest concentrations in the prostate, kidney, liver, heart, and pancreas. Zinc is a vital component of many metalloenzymes such as carbonic anhydrase, which regulates $\mathrm{CO}_{2}$ exchange (Stokinger 1981).

In animals, gastrointestinal and hepatic lesions (Allen et al. 1983; Brink et al. 1959), pancreatic lesions (Maita et al. 1981; Drinker et al. 1927), anemia (ATSDR 1989b; Fox and Jacobs 1986; Maita et al. 1981), and diffuse nephrosis (Maita et al. 1981; Allen et al. 1983) have been observed following subchronic oral exposures. Anemia and pancreatitis were the major adverse effects observed in chronic animal studies (Aughey et al. 1977; Drinker et al. 1927; Walters and Roe 1965; Sutton and Nelson 1937). Teratogenic effects have not been seen in animals exposed to zinc; however, high oral doses can affect reproduction and fetal growth (Ketcheson et al. 1969; Schlicker and Cox 1967, 1968; Sutton and Nelson 1937).

Livestock and small mammals are tolerant of extended dietary loadings $>100$ times the minimum recommended daily zinc requirement (Eisler 1993). No adverse effects on general health or reproduction were observed in dairy cows fed $1310 \mathrm{mg}$ zinc/ $\mathrm{kg}$ food (Miller et al., 1989). A diet of 4000-5000 mg zinc/kg food for 18 days resulted in fetotoxicity and poor reproduction in rats (NAS 1979). Acute oral $\mathrm{LD}_{50}$ doses of $350-800 \mathrm{mg}$ zinc/ $\mathrm{kg}$ body weight have been reported for rats (Eisler 1993). Wlostowski et al. (1988) recommended $30 \mathrm{mg}$ zinc/kg in the diet of bank voles.

Dogs on diets with up to $1000 \mathrm{mg}$ zinc/kg of food for up to one year showed no measurable signs of damage (NAS 1979). Horses ingesting $>90 \mathrm{mg}$ zinc/kg body weight daily in the vicinity 
of a lead-zinc smelter exhibited decreased growth and death (NAS 1979). No effects were observed in mice fed $<682 \mathrm{mg}$ zinc/ $\mathrm{kg}$ food ( $<109 \mathrm{mg}$ zinc/kg body weight daily) for 13 weeks, but at 6820 $\mathrm{mg}$ zinc/kg food adverse effects on growth and survival were documented (Maita et al. 1981). In a 37-day study involving rats, doses of $97 \mathrm{mg} / \mathrm{kg}$-day administered as zinc carbonate in the diet had no adverse effects on the reproductivity of rats (Kinnamon 1963). European ferrets (Mustela putorius furo) fed up to $500 \mathrm{mg}$ zinc/ $\mathrm{kg}$ for up to 197 days all survived with no significant histopathologies, but those fed 1500 or $3000 \mathrm{mg} / \mathrm{kg}$ diet died within 21 days (Straube et al. 1980; Reece et al. 1986). Reproduction ceased entirely in female rats ingesting a diet with $500 \mathrm{mg}$ zinc/kg/day (Sutton and Nelson 1937), possibly a result of zinc-induced anemia.

Mallards (Anas platyrhynchos) fed diets containing $>3000 \mathrm{mg}$ zinc/kg for 30 or 60 days suffered leg paralysis, decreased food consumption, and high mortality (Gasaway and Buss 1972; NAS 1979). Egg production in Japanese quail (Coturnix coturnix japonica) hens fed 15,000 mg zinc (as $\mathrm{ZnO}$ )/kg feed for 7 days decreased to near zero within 3 days (Hussein et al. 1988). Seven percent of 14-day old quail fed $600 \mathrm{mg}$ zinc (as zinc phosphide) $\mathrm{kg}$ feed over 5 days died, $53 \%$ of those fed $990 \mathrm{mg} / \mathrm{kg}$ died, and $93 \%$ of those fed $1634 \mathrm{mg} / \mathrm{kg}$ died (Hill and Camardese, 1986). Domestic chicken pullets and hens on a diet with $20,000 \mathrm{mg}$ zinc/kg feed for 5 days were lighter weight by day 5 and produced significantly fewer eggs for 4 weeks following treatment (Palafox and Ho-A 1980). Eggs collected 14-28 days post-treatment had reduced fertility and hatchability. However, normal growth, egg production, fertility, and hatchability was observed 4-12 weeks posttreatment. Acute oral $L D_{50}$ values for zinc phosphide, a rodenticide, were between 16 and $47 \mathrm{mg} / \mathrm{kg}$ body weight in ring-necked pheasants (Phasianus colchicus), golden eagles (Aquila chrysaetos), mallards, and homed larks (Eremophila alpestris) (Hudson et al. 1984), but much of the biocidal action is attributed to the phosphide rather than the zinc (Eisler 1993).

Diets containing $28,48,228$, or $2028 \mathrm{mg}$ zinc/ $\mathrm{kg}$ for $12-44$ weeks had no effect on overall egg production by domestic chickens although zinc levels were elevated in hens on the highest zinc diet (Stahl et al. 1990). All day-old chicks fed diets containing 16,000 mg zinc/kg feed for 5 weeks and $80 \%$ of those fed $8000 \mathrm{mg} / \mathrm{kg}$ died; those on a $4000 \mathrm{mg}$ zinc/kg diet showed no significant reductions in growth or survival ( $\mathrm{Oh}$ et al. 1979). In a 60 -day study, doses of $170 \mathrm{mg} / \mathrm{kg}$-day administered as zinc carbonate in the diet caused increased mortality and altered blood chemistry in mallards (Gasaway and Buss 1972).

In chickens, adverse effects associated with zinc deficiency have been observed at $<38 \mathrm{mg}$ zinc/kg dry weight feed (Blamberg et al. 1960; Westmoreland and Hoekstra 1969; Stahl et al., 1989), but concentrations of $93-120 \mathrm{mg} / \mathrm{kg}$ are suggested as adequate in the diet (Blamberg et al. 1960; Westmoreland and Hoekstra 1969). Greater than $178 \mathrm{mg} / \mathrm{kg}$ dry weight feed is considered excessive (Stahl et al. 1989), and dietary concentrations $>2000 \mathrm{mg} / \mathrm{kg}$ dry weight feed are considered toxic (NAS 1979; Oh et al. 1979; Stahl et al. 1990). Turkey poults tolerated zinc levels up to $2000 \mathrm{ppm}$ in starter diets for 21 days with no deleterious effects, but levels $24000 \mathrm{ppm}$ resulted in marked growth depression (Vohra and Kratzer 1968). No mortality was observed in poults on a diet containing 10,000 ppm zinc (Vohra and Kratzer, 1968), but increased mortality has been observed for chickens on diets with 3000 ppm zinc (Roberson and Schaible 1960). 

Appendix E

REPRODUCTIVE PERFORMANCE OF MINK 


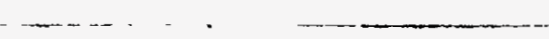




\title{
REPRODUCTIVE PERFORMANCE OF MINK
}

\author{
Richard S. Halbrook \\ Cooperative Wildlife Research Laboratory \\ Southern Illinois University
}

\section{INTRODUCTION}

Plant operations and waste disposal at the Oak Ridge National Laboratory (ORNL), the Gaseous Diffusion Plant (ORGDP), and the Weapons Plant (Y-12) have introduced an assortment of potentially harmful contaminants into the surrounding environment (Ashwood et al. 1986, Suter 1990). The potential for off-reservation transport of contaminants by streams on the Oak Ridge Reservation (ORR) that empty into the Clinch and Tennessee River systems is a concern.

Contaminants of special concern include mercury $(\mathrm{Hg})$ and polychlorinated biphenyls (PCB's) (Suter 1990). Elevated concentrations of Hg and PCB's have been found in fish collected from East Fork Poplar Creek (EFPC) and Bear Creek, and elevated concentrations of PCB's also have been found in fish from White Oak Creek (Loar 1990). East Fork Poplar Creek and Bear Creek originate within the Y-12 Plant and flow into Poplar Creek north of the K-25 Plant and White Oak Creek flows through ORNL. Both creeks empty into the Clinch River on the upper reach of Watts Bar Lake. In the Screening Level Risk Assessment for the Off-Site Ecological Effects in Surface Waters Downstream from the U.S. Department of Energy Oak Ridge Reservation, Suter (1990) indicated that piscivorous wildlife along the Clinch River are at risk.

Mink (Mustela vison) have been shown to be among the most sensitive, if not the single most sensitive, mammalian species to polychlorinated biphenyl (PCB) toxicity (Aulerich and Ringer 1977). Feeding studies conducted by Aulerich et al. (1971, 1973), Hornshaw et al. (1983), and Heaton (1992) have demonstrated the extreme sensitivity of mink to chlorinated hydrocarbon contaminants, especially PCBs, contained in fish taken from the Great Lakes. Additional studies have shown this species also to be sensitive to other halogenated hydrocarbons, including polybrominated biphenyls (Aulerich and Ringer 1979), hexachlorobenzene (Bleavins et al. 1988) and mercury (Hg) (Aulerich et al. 1974, Wobeser and Swift 1976, Wobeser et al. 1976). Numerous other toxicological studies with mink have been reported in the literature (Scientifur 1987, Sundqvist 1989, Leonards et al. 1994) and summarized by Calabrese et al. (1992). In addition, mink have been recommended as an indicator species for the goal of virtual elimination of persistent toxic substances in the Great Lakes by the International Joint Commission Virtual Elimination Task Force Biomarker Workshop (personal communication from Glen Fox, Environment Canada, Ottawa, Ontario).

Because mink are sensitive to PCB and Hg toxicity and inhabit wetland areas, they are potentially good indicators of environmental effects of these chemicals in aquatic habitats. However, mink are secretive and population densities tend to be low (male home ranges average $2,600 \mathrm{~m}$ in stream length, Dunstone 1993), making assessment of environmental contaminant effects in natural populations difficult. Since it is known that fish inhabiting aquatic systems downstream from the Oak Ridge Reservation (ORR) contain elevated concentrations of PCBs and Hg (Sect. 3.5.1), and that fish are a major food item of mink, the objectives of this study were to compare biological accumulation of environmental contaminants and reproductive effects in mink fed fish collected on the ORR to accumulation and effects in mink fed fish collected from the Clinch River above the ORR, or from the ocean. 


\section{MATERIALS AND METHODS}

\subsection{Fish Collection and Diet Preparation}

Fish used in mink diets were collected from the reach of Poplar Creek between East Fork Poplar Creek and the confluence of Poplar Creek with the Clinch River (on the ORR) and from the Clinch River above Melton Hill Dam near Bull Run Power Plant (above the ORR), or were ocean fish (mackerel) obtain from a commercial supplier. Fish collected on the ORR and above the ORR were identified, weighted, placed in labeled plastic bags, frozen and shipped on dry ice for overnight delivery to the Michigan State University (MSU) Experimental Fur Farm. Ocean fish were frozen and shipped directly to MSU by a commercial supplier. At MSU, fish collected from the same location were ground through a $3 / 8$ inch plate and mixed in a paddle mixer. This process was repeated until all fish from the same location were ground and mixed together so that a homogeneous mixture was obtained. Ten aliquots of the homogeneous mixture were placed in whirlpac bags, labelled, and frozen for contaminant analyses. This process was repeated for fish collected from each source.

Five diets, each composed of $75 \%$ fish and $25 \%$ normal ranch mink chow, were prepared. Appropriate proportions of homogenized fish from prescribed locations were blended with components of normal mink diet (eggs, liver, vitamin and mineral premix, d-biotin, and cereal). The fish portion of 2 diets (A and B) contained 75\% ocean fish and 75\% fish collected above the ORR (Clinch River above Melton Hill Dam), respectively. These served as reference diets for this study. The fish portion of the remaining 3 diets ( $C, D$, and $E$ ) contained 25,50 and $75 \%$ fish collected on the ORR and 50,25, and $0 \%$ ocean fish, respectively. All diets were formulated to meet the nutrient requirements of the mink (NRC, 1982). Diet proximate analyses were determined by MSU. Ten aliquots of each diet were placed in whirlpac bags, labelled, and frozen for contaminant analyses.

\subsection{Mink Feeding Experiment}

Fifty adult, natural dark mink from the MSU Experimental Fur Farm, Michigan State University (MSU), East Lansing, Michigan were uniquely identified and randomly divided into 5 groups of 2 males and 8 females per group. Mink were housed individually in wire cages $(61 \times 76$ $\times 46 \mathrm{~cm}$ ) with attached nest boxes $(38 \times 28 \times 27 \mathrm{~cm})$. Cages were suspended above the ground in open-sided sheds. Throughout the study, mink were provided food and drinking water at libitum and exposed to ambient temperature and photoperiod. Mink were immunized against canine distemper, virus enteritis, infectious pneumonia, and botulism, and provided thiamine daily to prevent thiamine deficiency resulting form thiaminase in fish. Mink were acclimated to the test facilities for at least one week prior to the definitive test.

Each mink group was fed one of the prepared diets from December 1, 1993 (approximately 3 months prior to breeding) through approximately June 30, 1993 (6 weeks postpartum). Mink were weighed at the beginning of the feeding trials and at monthly intervals thereafter (except during the gestation period). They were observed daily and any behavioral changes or clinical signs of toxicity recorded.

Mating began March 1, 1994 and was confined within the respective groups. Females were given an opportunity to mate every fourth day until a confirmed mating (presence of motile spermatozoa in vaginal aspirations) was obtained. The mated females were given an opportunity for a second mating the day following the initial mating or eight days later (a standard commercial 
mink ranch practice). The bred females were checked daily during gestation for evidence of whelping. The gestation period of mink averages 51 days but is highly variable ( 42 to 65 days) due to delayed implantation. Whelped kits were counted, sexed, and weighed on the day of birth and at three and six weeks of age. Mink kits begin to consume solid feed at 21 to 24 days of age and are weaned at 6 weeks. Thus, kit body weight at 3 weeks of age provides a good indication of the lactational performance of the female. Reproductive indices measured included: number of females mated; number of females whelping; length of gestation; number of kits whelped (alive, dead); kit sex ratio; average kit body weight at birth, 3, and 6 weeks of age; and kit survival to 3 and 6 weeks of age.

Adult mink with $>30 \%$ decrease in original body weight and all adults at the termination of the study were euthanized $\left(\mathrm{CO}_{2}\right)$. All adult mink were necropsied, organ (brain, liver, kidneys, heart, lungs, gonads, and adrenal glands) weights were recorded and samples of adipose, liver, kidney, and hair collected for residue analysis. At 6 weeks of age, 3 kits each from 3 randomly selected females from dietary groups A, B, C, and E were euthanized, liver, spleen, and kidneys weighed, and samples (liver, kidney, and remaining carcass) collected for residue analyses. Tissue samples (brain, liver, kidney, heart, lungs, and adrenal gland) also were collected from adult mink and preserved in $10 \%$ formalin for histopathologic examination.

Ten aliquots, each, of homogenized fish and mink diets, and collected mink tissues were shipped frozen to the Southwest Research Institute, San Antonio, TX for PCB (Aroclors), CB (congeners) and mercury concentration determination. Adult mink liver and fat tissues and kidney, liver, and hair tissues were analyzed for Aroclor and CB concentrations, and mercury concentration, respectively. Liver tissue also was analyzed for ethoxyresorufin-o-deethylase (EROD) activity. Kit whole carcass and liver tissue, and whole carcass and kidney tissues were analyzed for PCB and CB concentrations, and mercury concentration, respectively. Lipid concentration (\% lipid) was determined for all samples analyzed for PCBs

PCB Aroclor and congener results were adjusted for lipid concentration (tissue concentrations divided by the \% lipid) prior to statistical analysis. Results of contaminant analyses, physiological measurements, and reproductive parameters were statistically evaluated for differences among diet groups and between diet groups A or B and E using non-parametric (Wilcoxon or Kruskel-Wallis) and gausian (t-test or ANOVA) tests.

\section{RESULTS}

The species composition of fish collected from the ORR and the Clinch River above Melton Hill Dam were similar and consisted mostly of benthic species (Table E.1). Mean mercury concentrations were significantly different among fish collected from the ORR, Clinch River, or ocean (Table E.2). Mean mercury concentrations in mink diets increased progressively from diet A through diet E (Table E.2). Correspondingly, mercury concentrations in liver, kidney, and hair of adult female mink increased progressively in mink fed diets $A$ through $E$ (Table E.3). Mercury concentrations in kit kidney tissue and homogenized carcass were not significantly different in offspring of mink fed diets $A, B$, or $C$, but were significantly greater $(P<0.05)$ in offspring of mink fed diet $E$ (Table E.3). 


\subsection{PCB and Congener Profiles in Fish and Mink Diets}

Aroclor 1260 was the dominant Aroclor detected in aliquots of homogenized fish, mink diets, and tissues of adult mink and kits, although Aroclor 1254 also was quantified in several tissue samples. Aroclor 1260 was quantified in aliquots of all diets except for diet A ( $75 \%$ ocean fish), in fat tissue from mink in all diet groups except diet group $C$, and in liver tissue of mink from diet groups $\mathrm{D}$ and $\mathrm{E}$. Twenty-three specific congeners, including 8 coplanar congeners (non-ortho or mono-ortho congeners), were evaluated in homogenized fish, diets, liver and fat tissues of adult mink, and liver tissue and carcass of kits. Ninety-six percent of congener concentrations were significantly different among ocean, $O R R$, and Clinch River homogenized fish, including all but one coplanar congeners (Table E.4). In all cases where significant differences existed in homogenized fish congener concentrations among collection sites, the greatest concentrations were in fish collected from the ORR. Aroclor 1260 and $87 \%$ of the congener evaluated also were quantified in mink diets (Table E.5). Mean Aroclor 1260 concentration was significantly greater $(\mathrm{P}<0.01)$ in diet E compared to concentrations other diets. Coplanar CBs 126 and 189 were not detected in any diets, CB 156 was detected in low concentrations in diets $B, C$, and D, and $C B s 77$ and 81 were quantified in low concentrations in diets C, D, and E, while CB 167 was only quantified in diets D and $E$. Concentrations of coplanar CB 118 were significantly greater $(P<0.01)$ in aliquots of diet $E$ compared to aliquots of the other diets. Mean concentrations of $C B 123$ progressively increased from diet $C$ to $D$, however, quantified concentrations in diet $E$ were surprisingly lower than concentrations in diet $\mathrm{C}$. Low concentrations of this $\mathrm{CB}$ in diet $\mathrm{E}$ are thought to result from matrix interference in this diet. Similarly, lower than expected concentrations were quantified for CBs 99, 101,156 , and 171 in diet $\mathrm{E}$. The remaining non-plainer congener concentrations were generally greatest in aliquots from diet $\mathrm{E}$ (Table E.5).

\subsection{PCB and Congener Profile in Mink Tissues}

Mean Aroclor 1260 concentration was significantly greater in liver tissue of female mink fed $\operatorname{diet}$ E (Table E.6). Coplanar CB 189 was quantified at low concentrations ( $<21 \mathrm{ppb})$ in liver tissue from all mink fed diet E, $50 \%$ of those fed diet $\mathrm{D}$, and less than $10 \%$ of those fed diets $\mathrm{A}, \mathrm{B}$, or $\mathrm{C}$. Liver concentrations of $C B 126$ were significantly greater $(P<0.01)$ in samples collected from female mink fed diet $\mathrm{E}$. Low concentrations ( $<32 \mathrm{ppb}$ ) of CB 126 also were quantified in liver tissue from female mink fed diets B and D. Mean liver concentrations of coplanar CBs 77 and 81 were $\leq 6 \mathrm{ppb}$ in all female mink regardless of diet. Mean concentrations of CBs 156 and 167 increased progressive in liver tissue from female mink fed diets $A-E$ and were significantly greater $(P<0.01)$ in mink fed diet $E$ compared to those fed diets A or B. Mean concentration of coplanar CBs 118 and 123 were significantly greater in liver tissue from female mink on diet $\mathrm{E}$ compared to concentrations in liver tissue from mink fed diets $A$ or $B$. There were significant differences $(P<0.05)$ in all female mink liver tissue non-planar congener concentrations among diet groups. For all non-planar congener in female liver tissue, concentrations were significantly greater $(P<0.05)$ in tissues from diet $\mathrm{E}$ mink compared to diet A mink, except for concentrations of CBs 195 and 196 which were not significantly different. Similarly, mean female mink liver concentrations of all non-planar congeners were significantly greater in female mink liver from diet group $\mathrm{E}$ mink compared to diet group B mink, except for CBs 146, 153, 170, 180, 183, and 201 which were not significantly different between these diet groups.

Mean Aroclor 1260 concentration in fat tissue from female mink fed diet $\mathrm{E}$ were significantly greater than mean concentrations from female mink fed diets A or B (Table E.7). Mean concentrations of all coplanar CBs were significantly greater $(P<0.05)$ in fat tissue from female 
mink fed diet $\mathrm{E}$ compared to mean concentrations in mink fed diets $\mathrm{A}$ or $\mathrm{B}$, except that there was no difference in CB 126 fat concentration between female mink fed diets $E$ and $B$. Non-planar CB mean concentrations were significantly greater $(P<0.05)$ in fat tissue from female mink fed diet $E$ compared to mean concentrations in mink fed diets A or B, except CBs 170, 194, and 195. There was no difference between CB 170 or 194 mean fat concentrations between female mink fed diets $B$ or $E$, and mean fat concentration of CB 195 in female mink was significantly greater $(P<0.05)$ in female mink fed diet $\mathrm{B}$ compared to diet $\mathrm{E}$.

Concentrations of coplanar CBs 77, 81, 123,156, and 189 were $<20 \mathrm{ppb}$ in liver tissue from kits in all diet groups (Table E.8). Concentrations of coplanar CBs 118, 126, and 167 were significantly greater $(P<0.05)$ in liver from diet $E$ kits compared to those from diets $A, B$, or $C$. Concentrations of non-planar CBs 101, 151,171, and 195 were $<15 \mathrm{ppb}$ in liver tissue from kits in all diet groups. Concentrations of the remaining non-planar $\mathrm{CBs}$ quantified were greater in liver tissue of diet $E$ kits.

The pattern of concentrations of coplanar CBs in kit carcass homogenates from the various diets were similar to those observed in kit liver tissue (Table E.9). Except, the concentration of coplanar CB 126 was $<25 \mathrm{ppb}$ in kit carcass homogenates and the concentration of CB 156 was significantly greater $(P<0.05)$ in kit carcass homogenates from diet group $E$ compared to other diet groups. Concentration patterns of non-planar CBs in the various diet groups also were similar in carcass homogenates compared to concentrations in liver tissue. Except concentrations of CBs 151 and 196 were the only $\mathrm{CBs}$ with concentrations $<25 \mathrm{ppb}$. Concentrations of all other CBs quantified were greater in homogenized carcasses of kits from diet group $\mathrm{E}$.

\subsection{Physiological and Reproductive Effects}

Two mink from diet group A, one male and one female, died during the experimental period. The male died on March 18, 1994 from hemorrhagic and necrotizing cystitis and the female died on April 24, 1994 due to complications during parturition. In addition to these adult mink, kits from one female in diet group B developed staph infections and all but one diet prior to 6 weeks of age.

One, 2, and 4 females did not whelp in diet groups A and B, D, and C, respectively (Table E.10) - Two females that did not whelp ( 1 from diet group $A$ and 1 from diet group $C$ ) had cyst in the reproductive tracts that probably interfered with normal reproduction. Two females that did not whelp ( 1 from diet group $C$ and 1 from diet group $D$ ) had no placental scars in the uterus and therefore probably were not pregnant. The 'reason the remaining 4 females did not whelp is unknown.

Mean whole body weights of female mink were not significantly different among diet groups at the beginning of the experimental period, however, mean weights of females in diet group $E$ were significantly less $(P=0.03)$ than mean weights of females in diet group $A$ at the end of the experimental period (Table E.10). Mean female relative organ weights (organ weights/body weight) were not significantly different among diet groups. At 6 weeks of age, mean whole body weights were significantly lower $(\mathrm{P}=0.004)$ in male kits from diet group $\mathrm{E}$ compared to those from diet group A. A similar trend was observed in 6 week old female kits, although differences were not statistically significant. Mean relative kidney weights were significantly lower $(\mathrm{P}=0.003)$ in kits from diet group $B(\bar{x}=1.0 \mathrm{~g})$ compared to those from diet group $E(\bar{x}=1.3 \mathrm{~g})$. Kit mean relative liver and spleen weights were not significantly different among diet groups. No histological lesions were attributed to diets. 


\section{E-8}

Mean litter size was significantly reduced $(\mathrm{P}=0.01)$ in $\operatorname{diet}$ group $\mathrm{E}$ compared to $\operatorname{diet}$ groups $\mathrm{A}$, $\mathrm{B}$, and $\mathrm{C}$ but not diet group D (Table E.10). Liver EROD activity was significantly increased in adult female mink from diet groups $\mathrm{D}$ and $\mathrm{E}$ compared to those from diet group A (Table E.10).

Although concentrations of mercury and PCBs were greater in fish collected from streams located on the ORR and these contaminants were higher in diets fed to mink with increasing percentage of ORR fish, reproductive effects were only noted in mink fed $75 \%$ ORR fish. Liver EROD activity, a sensitive biomarker of exposure to PCBs increased in mink fed diets containing $50 \%$ and $75 \%$ fish collected from the ORR.

Although fish are a major food item in the diet of wild mink, the proportion of fish in their diets normally does not exceed $40-60 \%$. However, in addition to fish, concentrations of contaminants in other food items (crayfish, frogs, muskrat, ducks, and reodents) need to be evaluated in assessing effects of contaminants on mink living on the ORR. 
E-9

Table E.1. Percent by weight of the most common fish species collected from the ORR and Clinch River above Melton Hill Dam

\begin{tabular}{lcccc}
\hline Common name & $\begin{array}{c}\text { ORR } \\
\%\end{array}$ & $\begin{array}{c}\text { Weight } \\
\text { kg }\end{array}$ & $\begin{array}{c}\text { Clinch River } \\
\%\end{array}$ & $\begin{array}{c}\text { Weight } \\
\text { kg }\end{array}$ \\
\hline Sucker & & & & \\
Carp & 17 & 280 & 3 & 12 \\
Catfish & 20 & 330 & 24 & 97 \\
Shad & 15 & 248 & 13 & 53 \\
Buffalo & 7 & 116 & 6 & 24 \\
Other species & 17 & 280 & 42 & 170 \\
\multicolumn{1}{c}{ TOTALS } & 24 & 396 & 12 & 49 \\
\hline
\end{tabular}


Table E.2. Mean mercury concentrations (ppm, wet wt) in homogenized fish ${ }^{1}$ collected on the $\mathrm{ORR}^{2}$, Clinch River above the $O R R^{3}$, and from the ocean ${ }^{4}$ and diets fed to mink

\begin{tabular}{llllll}
\hline & $N^{5}$ & MEAN $^{6}$ & SE & MIN & MAX \\
\hline LOCATION & & & & & \\
On the ORR & 10 & $0.35^{\mathrm{a}}$ & 0.03 & 0.17 & 0.43 \\
Clinch River & 10 & $0.07^{\mathrm{b}}$ & 0.00 & 0.05 & 0.09 \\
Ocean & 10 & $0.03^{\mathrm{c}}$ & 0.00 & 0.02 & 0.04 \\
& & & & & \\
DIET & & & & & \\
$\mathrm{A}^{7}$ & 10 & $0.02^{\mathrm{a}}$ & 0.00 & 0.02 & 0.03 \\
$\mathrm{~B}^{8}$ & 10 & $0.05^{\mathrm{b}}$ & 0.00 & 0.04 & 0.06 \\
$\mathrm{C}^{9}$ & 10 & $0.09^{\mathrm{c}}$ & 0.00 & 0.08 & 0.11 \\
$\mathrm{D}^{10}$ & 10 & $0.15^{\mathrm{d}}$ & 0.01 & 0.12 & 0.18 \\
$\mathrm{E}^{11}$ & 10 & $0.22^{\mathrm{e}}$ & 0.01 & 0.16 & 0.24 \\
\hline
\end{tabular}

'Various fish species.

${ }^{2}$ Poplar Creek between East Fork Poplar Creek and confluence with the Clinch River.

${ }^{3}$ Above Melton Hill Dam near Bull Run Power Plant.

${ }^{4}$ Mackerel purchased from commercial supplier.

${ }^{5}$ Number of aliquots analyzed.

${ }^{6} \mathrm{Means}$ followed by different letters are significantly different, $\mathrm{P}<0.05$.

${ }^{7} 75 \%$ ocean fish, $25 \%$ ranch mink diet.

${ }^{8} 75 \%$ fish collected from the Clinch River above the Oak Ridge Reservation (ORR), $25 \%$ ranch mink diet.

${ }^{9} 25 \%$ fish collected from Poplar Creek on the ORR, $50 \%$ ocean fish, $25 \%$ ranch mink diet.

${ }^{10} 50 \%$ fish collected from Poplar Creek on the ORR, 25\% ocean fish, $25 \%$ ranch mink diet.

${ }^{11} 75 \%$ fish collected from Poplar Creek on the ORR, 25\% ranch mink diet. 
E-11

Table E.3. Mercury concentration (ppm, wet wt) in tissues from female mink fed ( $\mathrm{n}=8 /$ diet) various diets $^{1}$ and their 6-week-old kits

\begin{tabular}{|c|c|c|c|c|c|c|}
\hline & & Diet A & Diet B & Diet C & Diet D & Diet E \\
\hline \multicolumn{7}{|c|}{ ADULT FEMALE MINK } \\
\hline \multirow[t]{3}{*}{ Liver $\mathrm{Hg}$} & Mean $^{2}$ & $0.41^{2}$ & $0.61^{\mathrm{a}}$ & $1.06^{\mathrm{a}}$ & $1.93^{b}$ & $3.67^{c}$ \\
\hline & $\mathrm{SE}$ & 0.07 & 0.06 & 0.10 & 0.15 & 0.32 \\
\hline & Range & $0.17-0.8$ & $0.47-0.87$ & $0.74-1.49$ & $1.26-2.47$ & $2.52-5.20$ \\
\hline \multirow[t]{3}{*}{ Kidney } & Mean & $0.84^{\mathrm{a}}$ & $1.25^{\mathrm{ab}}$ & $2.22^{\mathrm{bc}}$ & $3.47^{\text {ed }}$ & $4.35^{\mathrm{d}}$ \\
\hline & SE & 0.13 & 0.18 & 0.35 & 0.52 & 0.34 \\
\hline & Range & $0.25-1.46$ & $0.53-1.96$ & $1.24-4.22$ & $2.38-7.00$ & $3.33-6.25$ \\
\hline \multirow[t]{3}{*}{ Hair Hg } & Mean & $3.79^{\mathrm{a}}$ & $7.43^{b}$ & $7.71^{b}$ & $13.44^{c}$ & $19.03^{d}$ \\
\hline & $\mathrm{SE}$ & 0.26 & 0.55 & 0.63 & 0.79 & 0.57 \\
\hline & Range & $2.20-4.61$ & $5.05-9.70$ & $4.38-9.62$ & $10.2-15.6$ & $16.8-21.4$ \\
\hline \multicolumn{7}{|l|}{ KITS } \\
\hline \multirow[t]{4}{*}{ Carcass } & Mean & $0.02^{\mathrm{a}}$ & $0.03^{2}$ & $0.05^{2}$ & & $0.20^{\mathrm{b}}$ \\
\hline & $\mathrm{SE}$ & 0.004 & 0.003 & 0.003 & & 0.02 \\
\hline & Range & $0.01-0.05$ & $0.02-0.05$ & $0.04-0.06$ & & $0.10-0.30$ \\
\hline & $\mathbf{N}$ & 9 & 9 & 8 & & 9 \\
\hline \multirow[t]{4}{*}{ Kidney } & Mean & $0.03^{2}$ & $0.03^{\mathrm{a}}$ & $0.06^{2}$ & & $0.19^{b}$ \\
\hline & SE & 0.001 & 0.003 & 0.003 & & 0.02 \\
\hline & Range & $0.02-0.04$ & $0.02-0.04$ & $0.05-0.07$ & & $0.11-0.31$ \\
\hline & $\mathrm{N}$ & 9 & 9 & 8 & & 9 \\
\hline
\end{tabular}

'Diet $A=75 \%$ ocean fish, Diet $B=75 \%$ fish collected above the Oak Ridge Reservation, Diet $C=25 \%$ fish collected on the Oak Ridge Reservation and $50 \%$ ocean fish, Diet $\mathrm{D}=50 \%$ fish collected on the Oak Ridge Reservation and $25 \%$ ocean fish, Diet $\mathrm{E}=\mathbf{7 5} \%$ fish collected on the Oak Ridge Reservation.

${ }^{2}$ Means with different superscripts are significantly different, $\mathrm{P}<0.05$. 
E-12

Table E.4. Mean ${ }^{1} \pm$ SE lipid adjusted Aroclor 1260 and PCB congener concentrations (ppm, wet wt) in homogenized fish ${ }^{2}$ collected on the $\mathbf{O R R}^{3}$, Clinch River above the $\mathrm{ORR}^{4}$, and from the ocean ${ }^{5}$

\begin{tabular}{|c|c|c|c|}
\hline & Ocean & Clinch River & ORR \\
\hline CB 77 & $0.022^{4} \pm 0.000(10)$ & $0.039^{b} \pm 0.001(10)$ & $0.190^{\complement} \pm 0.004(10)$ \\
\hline CB 81 & $0.053^{2} \pm 0.001(10)$ & $0.592^{b} \pm 0.062(10)$ & $1.419^{c} \pm 0.262(9)$ \\
\hline CB 99 & $0.022^{2} \pm 0.000(10)$ & $0.076^{b} \pm 0.011(10)$ & $0.894^{c} \pm 0.015(10)$ \\
\hline CB 101 & $0.022^{\mathrm{a}} \pm 0.000(10)$ & $0.142^{b} \pm 0.022(10)$ & $0.609^{c} \pm 0.010(10)$ \\
\hline CB 118 & $0.022^{ \pm} \pm 0.000(10)$ & $0.468^{\mathrm{ab}} \pm 0.219(10)$ & $1.150^{b} \pm 0.030(9)$ \\
\hline CB 123 & $0.022^{2} \pm 0.000(10)$ & $0.039^{a b} \pm 0.001(10)$ & $0.051^{b} \pm 0.010(10)$ \\
\hline CB 126 & $0.022^{2} \pm 0.000(10)$ & $0.039^{b} \pm 0.001(10)$ & $0.041^{b} \pm 0.001(10)$ \\
\hline CB 128 & $0.022^{2} \pm 0.000(10)$ & $0.178^{b} \pm 0.003(10)$ & $0.636^{c} \pm 0.012(10)$ \\
\hline CB 138 & $0.022^{2} \pm 0.000(10)$ & $0.706^{b} \pm 0.014(10)$ & $1.611^{\mathrm{c}} \pm 0.052(9)$ \\
\hline CB 146 & $0.022^{2} \pm 0.000(10)$ & $0.388^{b} \pm 0.007(10)$ & $0.822^{c} \pm 0.023(10)$ \\
\hline CB 151 & $0.039^{2} \pm 0.002(10)$ & $0.496^{b} \pm 0.008(10)$ & $1.731^{c} \pm 0.048(10)$ \\
\hline CB 153 & $0.074^{2} \pm 0.002(10)$ & $2.813^{b} \pm 0.082(10)$ & $4.733^{c} \pm 0.123(9)$ \\
\hline CB 156 & $0.022^{2} \pm 0.000(10)$ & $0.039^{b} \pm 0.001(10)$ & $0.078^{b} \pm 0.037(10)$ \\
\hline CB 167 & $0.022^{ \pm} \pm 0.000(10)$ & $0.044^{b} \pm 0.003(10)$ & $0.193^{c} \pm 0.003(10)$ \\
\hline CB 170 & $0.022^{ \pm} \pm 0.000(10)$ & $0.455^{b} \pm 0.010(10)$ & $1.315^{c} \pm 0.025(10)$ \\
\hline CB 171 & $0.022^{2} \pm 0.000(10)$ & $0.039^{b} \pm 0.001(10)$ & $0.041^{b} \pm 0.001(10)$ \\
\hline CB 180 & $0.022^{2} \pm 0.000(10)$ & $3.021^{b} \pm 0.099(10)$ & $3.592^{\complement} \pm 0.088(10)$ \\
\hline CB 183 & $0.022^{2} \pm 0.000(10)$ & $0.690^{b} \pm 0.012(10)$ & $1.000^{c} \pm 0.016(10)$ \\
\hline CB 189 & $0.022^{2} \pm 0.000(10)$ & $0.039^{b} \pm 0.001(10)$ & $0.041^{b} \pm 0.001(10)$ \\
\hline CB 194 & $0.022^{4} \pm 0.000(10)$ & $0.376^{b} \pm 0.009(10)$ & $0.430^{\circ} \pm 0.006(10)$ \\
\hline CB 195 & $0.022^{4} \pm 0.000(10)$ & $0.042^{b} \pm 0.002(10)$ & $0.043^{b} \pm 0.002(10)$ \\
\hline CВ 196 & $0.022^{2} \pm 0.000(10)$ & $0.570^{b} \pm 0.014(10)$ & $1.660^{c} \pm 0.041(10)$ \\
\hline CB 201 & $0.022^{2} \pm 0.000(10)$ & $0.486^{b} \pm 0.009(10)$ & $0.605^{c} \pm 0.008(10)$ \\
\hline Aroclor 1260 & $0.379^{2} \pm 0.008(10)$ & $21.917^{b} \pm 0.681(10)$ & $28.997^{c} \pm 0.659(10)$ \\
\hline
\end{tabular}

${ }^{1}$ Means with different superscripts are significantly different, $\mathrm{P}<0.05$.

${ }^{2}$ Various fish species.

${ }^{3}$ Poplar Creek between East Fork Poplar Creek and confluence with the Clinch River.

${ }^{4}$ Above Melton Hill Dam near Bull Run Power Plant.

${ }^{5}$ Mackerel purchased from commercial supplier. 
Table E.5. Mean \pm SE lipid adjusted Aroclor 1260 and PCB congener concentrations (ppm, wet wt) in mink diets ${ }^{1}(\mathrm{n}=10 /$ diet $)$

\begin{tabular}{|c|c|c|c|c|c|}
\hline & Diet A & Diet B & Diet C & Diet D & Diet E \\
\hline CB 77 & $0.025 \pm 0.000$ & $0.037 \pm 0.001$ & $0.046 \pm 0.003$ & $0.102 \pm 0.002$ & $0.116 \pm 0.005$ \\
\hline CB 81 & $0.027 \pm 0.002$ & $0.337 \pm 0.051$ & $0.507 \pm 0.011$ & $0.873 \pm 0.022$ & $1.158 \pm 0.033$ \\
\hline CB 99 & $0.025 \pm 0.000$ & $0.037 \pm 0.001$ & $0.276 \pm 0.011$ & $0.531 \pm 0.014$ & $0.520 \pm 0.013$ \\
\hline CB 101 & $0.031 \pm 0.004$ & $0.239 \pm 0.032$ & $0.288 \pm 0.009$ & $0.585 \pm 0.012$ & $0.396 \pm 0.020$ \\
\hline CB 118 & $0.025 \pm 0.000$ & $0.117 \pm 0.010$ & $0.192 \pm 0.007$ & $0.405 \pm 0.007$ & $0.668 \pm 0.021$ \\
\hline CB 123 & $0.025 \pm 0.000$ & $0.037 \pm 0.001$ & $0.212 \pm 0.008$ & $0.446 \pm 0.008$ & $0.076 \pm 0.003$ \\
\hline CB 126 & $0.025 \pm 0.000$ & $0.037 \pm 0.001$ & $0.027 \pm 0.001$ & $0.038 \pm 0.003$ & $0.033 \pm 0.001$ \\
\hline CB 128 & $0.025 \pm 0.000$ & $0.085 \pm 0.003$ & $0.104 \pm 0.004$ & $0.228 \pm 0.005$ & $0.351 \pm 0.013$ \\
\hline CB 138 & $0.080 \pm 0.002$ & $0.791 \pm 0.087$ & $0.331 \pm 0.011$ & $0.690 \pm 0.009$ & $1.048 \pm 0.020$ \\
\hline CB 146 & $0.025 \pm 0.000$ & $0.037 \pm 0.001$ & $0.141 \pm 0.006$ & $0.335 \pm 0.007$ & $0.501 \pm 0.015$ \\
\hline CB 151 & $0.025 \pm 0.000$ & $0.314 \pm 0.010$ & $0.254 \pm 0.009$ & $0.555 \pm 0.009$ & $1.058 \pm 0.039$ \\
\hline CB 153 & $0.025 \pm 0.000$ & $1.862 \pm 0.025$ & $0.766 \pm 0.029$ & $1.772 \pm 0.026$ & $3.126 \pm 0.056$ \\
\hline CB 156 & $0.025 \pm 0.000$ & $0.139 \pm 0.013$ & $0.065 \pm 0.002$ & $0.094 \pm 0.015$ & $0.033 \pm 0.001$ \\
\hline CB 167 & $0.025 \pm 0.000$ & $0.037 \pm 0.001$ & $0.027 \pm 0.001$ & $0.061 \pm 0.003$ & $0.103 \pm 0.004$ \\
\hline CB 170 & $0.025 \pm 0.000$ & $1.847 \pm 0.964$ & $0.154 \pm 0.007$ & $0.346 \pm 0.008$ & $0.798 \pm 0.016$ \\
\hline CB 171 & $0.025 \pm 0.000$ & $0.037 \pm 0.001$ & $0.061 \pm 0.002$ & $0.127 \pm 0.003$ & $0.033 \pm 0.001$ \\
\hline CB 180 & $0.025 \pm 0.000$ & $1.011 \pm 0.266$ & $0.507 \pm 0.019$ & $1.091 \pm 0.018$ & $2.292 \pm 0.040$ \\
\hline CB 183 & $0.025 \pm 0.000$ & $0.276 \pm 0.053$ & $0.170 \pm 0.006$ & $0.355 \pm 0.007$ & $0.573 \pm 0.019$ \\
\hline CB 189 & $0.025 \pm 0.000$ & $0.037 \pm 0.001$ & $0.027 \pm 0.001$ & $0.031 \pm 0.000$ & $0.033 \pm 0.001$ \\
\hline CB 194 & $0.025 \pm 0.000$ & $0.058 \pm 0.022$ & $0.072 \pm 0.008$ & $0.149 \pm 0.020$ & $0.245 \pm 0.009$ \\
\hline CB 195 & $0.025 \pm 0.000$ & $0.039 \pm 0.003$ & $0.027 \pm 0.001$ & $0.033 \pm 0.002$ & $0.033 \pm 0.001$ \\
\hline CB 196 & $0.025 \pm 0.000$ & $1.081 \pm 0.084$ & $0.184 \pm 0.008$ & $0.415 \pm 0.008$ & $1.071 \pm 0.024$ \\
\hline CB 201 & $0.025 \pm 0.000$ & $0.230 \pm 0.034$ & $0.060 \pm 0.002$ & $0.131 \pm 0.003$ & $0.338 \pm 0.010$ \\
\hline $\begin{array}{l}\text { Aroclor } \\
1260\end{array}$ & $0.169 \pm 0.002$ & $11.440 \pm 0.327$ & $4.697 \pm 0.174$ & $10.405 \pm 0.250$ & $20.670 \pm 0.458$ \\
\hline
\end{tabular}

'Diet $A=75 \%$ ocean fish, Diet $B=75 \%$ fish collected above the Oak Ridge Reservation, Diet $C=25 \%$ fish collected on the Oak Ridge Reservation and $50 \%$ ocean fish, Diet $\mathrm{D}=50 \%$ fish collected on the Oak Ridge Reservation and $25 \%$ ocean fish, Diet $\mathrm{E}=\mathbf{7 5 \%}$ fish collected on the Oak Ridge Reservation. 


\section{E-14}

Table E.6. Mean \pm SE lipid adjusted Aroclor 1260 and PCB congener concentrations (ppm, wet wt) in liver tissue from female mink ( $\mathrm{n}=8 / \mathrm{diet})$ fed various diets ${ }^{1}$

\begin{tabular}{|c|c|c|c|c|c|}
\hline & Diet A & Diet B & Diet C & Diet D & Diet E \\
\hline CB 77 & $0.048 \pm 0.016$ & $0.081 \pm 0.010$ & $0.033 \pm 0.004$ & $0.095 \pm 0.040$ & $0.028 \pm 0.005$ \\
\hline CB 81 & $0.048 \pm 0.016$ & $0.054 \pm 0.010$ & $0.033 \pm 0.004$ & $0.095 \pm 0.040$ & $0.197 \pm 0.117$ \\
\hline CB 99 & $0.048 \pm 0.016$ & $0.117 \pm 0.014$ & $0.420 \pm 0.061$ & $0.962 \pm 0.123$ & $0.823 \pm 0.215$ \\
\hline CB 101 & $0.048 \pm 0.016$ & $0.053 \pm 0.011$ & $0.033 \pm 0.004$ & $0.145 \pm 0.019$ & $0.154 \pm 0.015$ \\
\hline CB 118 & $0.141 \pm 0.008$ & $0.590 \pm 0.040$ & $1.066 \pm 0.153$ & $2.157 \pm 0.406$ & $1.656 \pm 0.332$ \\
\hline CB 123 & $0.048 \pm 0.016$ & $0.041 \pm 0.006$ & $0.033 \pm 0.004$ & $0.095 \pm 0.040$ & $1.598 \pm 0.228$ \\
\hline CB 126 & $0.048 \pm 0.016$ & $0.224 \pm 0.023$ & $0.033 \pm 0.004$ & $0.095 \pm 0.040$ & $1.703 \pm 0.251$ \\
\hline CB 128 & $0.048 \pm 0.016$ & $0.174 \pm 0.023$ & $0.151 \pm 0.024$ & $0.353 \pm 0.054$ & $0.691 \pm 0.097$ \\
\hline CB 138 & $0.136 \pm 0.023$ & $2.063 \pm 0.479$ & $2.083 \pm 0.224$ & $4.816 \pm 0.915$ & $5.649 \pm 0.465$ \\
\hline CB 146 & $0.059 \pm 0.015$ & $0.627 \pm 0.051$ & $0.545 \pm 0.055$ & $1.188 \pm 0.113$ & $0.604 \pm 0.111$ \\
\hline CB 153 & $0.206 \pm 0.020$ & $5.075 \pm 0.445$ & $3.858 \pm 0.365$ & $8.063 \pm 1.195$ & $7.242 \pm 1.658$ \\
\hline CB 156 & $0.048 \pm 0.016$ & $0.228 \pm 0.074$ & $0.193 \pm 0.037$ & $0.480 \pm 0.102$ & $0.648 \pm 0.102$ \\
\hline CB 167 & $0.048 \pm 0.016$ & $0.125 \pm 0.013$ & $0.166 \pm 0.020$ & $0.244 \pm 0.077$ & $0.776 \pm 0.100$ \\
\hline CB 170 & $0.057 \pm 0.015$ & $2.249 \pm 0.219$ & $0.774 \pm 0.144$ & $1.971 \pm 0.444$ & $1.878 \pm 0.194$ \\
\hline CB 171 & $0.048 \pm 0.016$ & $0.041 \pm 0.006$ & $0.093 \pm 0.013$ & $0.217 \pm 0.027$ & $0.774 \pm 0.065$ \\
\hline CB 180 & $0.131 \pm 0.015$ & $6.576 \pm 0.772$ & $3.117 \pm 0.390$ & $6.980 \pm 1.296$ & $7.752 \pm 0.815$ \\
\hline CB 183 & $0.048 \pm 0.016$ & $0.412 \pm 0.032$ & $0.229 \pm 0.024$ & $0.479 \pm 0.097$ & $0.527 \pm 0.086$ \\
\hline CB 189 & $0.048 \pm 0.016$ & $0.044 \pm 0.007$ & $0.042 \pm 0.007$ & $0.137 \pm 0.038$ & $0.106 \pm 0.013$ \\
\hline CB 194 & $0.050 \pm 0.016$ & $1.887 \pm 0.208$ & $0.803 \pm 0.086$ & $1.795 \pm 0.202$ & $1.218 \pm 0.174$ \\
\hline CB 195 & $0.048 \pm 0.016$ & $0.041 \pm 0.006$ & $0.192 \pm 0.018$ & $0.457 \pm 0.035$ & $0.115 \pm 0.015$ \\
\hline CB 196 & $0.068 \pm 0.015$ & $2.998 \pm 0.302$ & $0.033 \pm 0.004$ & $0.095 \pm 0.040$ & $1.863 \pm 0.985$ \\
\hline CB 201 & $0.048 \pm 0.016$ & $2.085 \pm 0.261$ & $0.245 \pm 0.084$ & $1.448 \pm 0.459$ & $2.794 \pm 0.356$ \\
\hline $\begin{array}{l}\text { Aroclor } \\
1260\end{array}$ & $0.344 \pm 0.132$ & $0.270 \pm 0.039$ & $0.230 \pm 0.021$ & $0.723 \pm 0.329$ & $79.486 \pm 8.112$ \\
\hline
\end{tabular}

'Diet $A=75 \%$ ocean fish, Diet $B=75 \%$ fish collected above the Oak Ridge Reservation, Diet $C=\mathbf{2 5 \%}$ fish collected on the Oak Ridge Reservation and $50 \%$ ocean fish, Diet $\mathrm{D}=50 \%$ fish collected on the Oak Ridge Reservation and $25 \%$ ocean fish, Diet $\mathrm{E}=\mathbf{7 5 \%}$ fish collected on the Oak Ridge Reservation. 
Table E.7. Mean \pm SE Aroclor 1260 and PCB congener concentrations (ppm, wet wt) in fat tissue from female mink ( $n=8 /$ diet) fed various diets ${ }^{1}$

\begin{tabular}{|c|c|c|c|c|c|}
\hline & Diet A & Diet B & Diet C & Diet D & Diet E \\
\hline CB 77 & $0.011 \pm 0.005$ & $0.035 \pm 0.006$ & $0.046 \pm 0.006$ & $0.083 \pm 0.019$ & $0.138 \pm 0.011$ \\
\hline $\mathrm{CB} 81$ & $0.120 \pm 0.042$ & $0.339 \pm 0.061$ & $0.280 \pm 0.052$ & $0.429 \pm 0.023$ & $0.696 \pm 0.078$ \\
\hline CB 99 & $0.050 \pm 0.018$ & $0.169 \pm 0.029$ & $0.786 \pm 0.168$ & $1.447 \pm 0.265$ & $1.708 \pm 0.272$ \\
\hline CB 101 & $0.016 \pm 0.006$ & $0.098 \pm 0.020$ & $0.107 \pm 0.018$ & $0.263 \pm 0.029$ & $0.311 \pm 0.037$ \\
\hline CB 118 & $0.163 \pm 0.066$ & $0.464 \pm 0.089$ & $1.461 \pm 0.276$ & $2.943 \pm 0.388$ & $3.175 \pm 0.299$ \\
\hline CB 123 & $0.130 \pm 0.036$ & $0.458 \pm 0.088$ & $0.033 \pm 0.006$ & $0.063 \pm 0.006$ & $2.375 \pm 0.330$ \\
\hline CB 126 & $0.064 \pm 0.029$ & $1.171 \pm 0.212$ & $0.196 \pm 0.032$ & $0.481 \pm 0.035$ & $1.511 \pm 0.160$ \\
\hline CB 128 & $0.033 \pm 0.020$ & $0.299 \pm 0.048$ & $0.352 \pm 0.059$ & $0.781 \pm 0.080$ & $1.210 \pm 0.097$ \\
\hline CB 138 & $0.267 \pm 0.135$ & $2.800 \pm 0.609$ & $3.464 \pm 0.638$ & $9.543 \pm 1.036$ & $9.925 \pm 0.833$ \\
\hline CB 146 & $0.041 \pm 0.015$ & $0.500 \pm 0.104$ & $0.600 \pm 0.097$ & $1.421 \pm 0.111$ & $1.771 \pm 0.179$ \\
\hline CB 153 & $0.405 \pm 0.230$ & $5.538 \pm 1.069$ & $5.195 \pm 0.988$ & $15.714 \pm 1.686$ & $15.375 \pm 1.349$ \\
\hline CB 156 & $0.009 \pm 0.003$ & $0.469 \pm 0.084$ & $0.409 \pm 0.073$ & $0.914 \pm 0.086$ & $1.188 \pm 0.077$ \\
\hline CB 167 & $0.040 \pm 0.019$ & $0.350 \pm 0.055$ & $0.621 \pm 0.109$ & $1.347 \pm 0.126$ & $1.500 \pm 0.125$ \\
\hline CB 170 & $0.093 \pm 0.051$ & $2.278 \pm 0.471$ & $0.800 \pm 0.157$ & $2.043 \pm 0.238$ & $3.013 \pm 0.168$ \\
\hline CB 171 & $0.035 \pm 0.017$ & $0.521 \pm 0.093$ & $0.488 \pm 0.086$ & $1.083 \pm 0.100$ & $1.393 \pm 0.084$ \\
\hline CB 180 & $0.290 \pm 0.188$ & $7.175 \pm 1.544$ & $5.264 \pm 1.034$ & $14.571 \pm 1.325$ & $14.750 \pm 1.161$ \\
\hline CB 183 & $0.019 \pm 0.012$ & $0.559 \pm 0.102$ & $0.368 \pm 0.069$ & $0.899 \pm 0.073$ & $1.114 \pm 0.143$ \\
\hline CB 189 & $0.005 \pm 0.001$ & $0.090 \pm 0.019$ & $0.041 \pm 0.006$ & $0.130 \pm 0.015$ & $0.186 \pm 0.018$ \\
\hline CB 194 & $0.060 \pm 0.035$ & $2.103 \pm 0.475$ & $0.918 \pm 0.174$ & $2.386 \pm 0.201$ & $2.688 \pm 0.351$ \\
\hline CB 195 & $0.011 \pm 0.007$ & $0.419 \pm 0.078$ & $0.033 \pm 0.006$ & $0.063 \pm 0.006$ & $0.133 \pm 0.021$ \\
\hline CB 196 & $0.021 \pm 0.014$ & $0.778 \pm 0.163$ & $0.426 \pm 0.091$ & $1.064 \pm 0.105$ & $1.645 \pm 0.295$ \\
\hline CB 201 & $0.031 \pm 0.019$ & $0.889 \pm 0.151$ & $0.477 \pm 0.080$ & $1.226 \pm 0.101$ & $1.813 \pm 0.178$ \\
\hline $\begin{array}{l}\text { Aroclor } \\
1260\end{array}$ & $3.169 \pm 1.849$ & $\begin{array}{l}61.250 \pm 12.56 \\
0\end{array}$ & $0.261 \pm 0.044$ & $105.86 \pm 11.26$ & $128.63 \pm 7.73$ \\
\hline
\end{tabular}

'Diet $A=75 \%$ ocean fish, Diet $B=75 \%$ fish collected above the Oak Ridge Reservation, Diet $C=25 \%$ fish collected on the Oak Ridge Reservation and 50\% ocean fish, Diet $D=50 \%$ fish collected on the Oak Ridge Reservation and $25 \%$ ocean fish, Diet $E=75 \%$ fish collected on the Oak Ridge Reservation. 


\section{E-16}

Table E.8. Mean ${ }^{1} \pm$ SE Aroclor 1260 and PCB congener concentrations (ppm, wet wt) in liver tissue from 6-week-old mink kits from dams fed diets of fish collected from various sources ${ }^{2}$

\begin{tabular}{|c|c|c|c|c|}
\hline & Diet A & Diet B & Diet C & Diet E \\
\hline CB 77 & $0.003 \pm 0.000(9)$ & $0.006 \pm 0.001(9)$ & $0.007 \pm 0.001(8)$ & $0.006 \pm 0.001(9)$ \\
\hline CB 81 & $0.004 \pm 0.000(9)$ & $0.006 \pm 0.001(9)$ & $0.007 \pm 0.001(8)$ & $0.007 \pm 0.001(9)$ \\
\hline CB 99 & $0.003^{2} \pm 0.000(9)$ & $0.006^{4} \pm 0.001(9)$ & $0.016^{2} \pm 0.005(8)$ & $0.049^{b} \pm 0.012(9)$ \\
\hline CB 101 & $0.004 \pm 0.000(9)$ & $0.006 \pm 0.001(9)$ & $0.007 \pm 0.001(8)$ & $0.006 \pm 0.001(9)$ \\
\hline CB 118 & $0.012^{2} \pm 0.001(9)$ & $0.012^{2} \pm 0.002(9)$ & $0.068^{b} \pm 0.014(8)$ & $0.138^{c} \pm 0.025(9)$ \\
\hline CB 123 & $0.008 \pm 0.001(9)$ & $0.007 \pm 0.000(9)$ & $0.007 \pm 0.001(8)$ & $0.006 \pm 0.001(9)$ \\
\hline CB 126 & $0.003^{a} \pm 0.000(9)$ & $0.007^{2} \pm 0.001(9)$ & $0.007^{a} \pm 0.001(8)$ & $0.014^{b} \pm 0.003(9)$ \\
\hline CB 128 & $0.003^{2} \pm 0.000(9)$ & $0.006^{4} \pm 0.001(9)$ & $0.020^{\mathrm{a}} \pm 0.005(8)$ & $0.092^{b} \pm 0.034(9)$ \\
\hline CB 138 & $0.015 \pm 0.002(9)$ & $0.058^{2} \pm 0.011(9)$ & $0.141^{4} \pm 0.033(8)$ & $0.547^{b} \pm 0.200(9)$ \\
\hline CB 146 & $0.004^{4} \pm 0.000(9)$ & $0.011^{2} \pm 0.002(9)$ & $0.033^{2} \pm 0.006(8)$ & $0.143^{b} \pm 0.042(9)$ \\
\hline CB 151 & $0.004 \pm 0.000(9)$ & $0.006 \pm 0.001(9)$ & $0.007 \pm 0.001(8)$ & $0.006 \pm 0.001(9)$ \\
\hline CB 153 & $0.011^{2} \pm 0.002(9)$ & $0.065^{2} \pm 0.010(9)$ & $0.157^{4} \pm 0.039(8)$ & $0.509^{b} \pm 0.137(9)$ \\
\hline CB 156 & $0.003 \pm 0.000(9)$ & $0.008 \pm 0.001(9)$ & $0.009 \pm 0.001(8)$ & $0.006 \pm 0.001(9)$ \\
\hline CB 167 & $0.004^{2} \pm 0.000(9)$ & $0.007^{2} \pm 0.001(9)$ & $0.009^{a} \pm 0.002(8)$ & $0.028^{b} \pm 0.007(9)$ \\
\hline CB 170 & $0.004^{2} \pm 0.000(9)$ & $0.054^{4} \pm 0.009(9)$ & $0.078^{b} \pm 0.014(8)$ & $0.294^{b} \pm 0.118(9)$ \\
\hline CB 171 & $0.003 \pm 0.000(9)$ & $0.008 \pm 0.001(9)$ & $0.007 \pm 0.001(8)$ & $0.006 \pm 0.001(9)$ \\
\hline CB 180 & $0.006^{2} \pm 0.001(9)$ & $0.109^{2} \pm 0.018(9)$ & $0.194^{b} \pm 0.040(8)$ & $0.629^{b} \pm 0.235(9)$ \\
\hline CB 183 & $0.004^{\mathrm{a}} \pm 0.000(9)$ & $0.007^{ \pm} \pm 0.000(9)$ & $0.013^{a} \pm 0.004(8)$ & $0.035^{b} \pm 0.009(9)$ \\
\hline CB 189 & $0.003 \pm 0.000(9)$ & $0.006 \pm 0.001(9)$ & $0.007 \pm 0.001(8)$ & $0.008 \pm 0.002(9)$ \\
\hline CB 194 & $0.004^{\mathrm{a}} \pm 0.000(9)$ & $0.019^{2} \pm 0.003(9)$ & $0.041^{b} \pm 0.008(8)$ & $0.146^{b} \pm 0.055(9)$ \\
\hline CB 195 & $0.003 \pm 0.000(9)$ & $0.006 \pm 0.001(9)$ & $0.007 \pm 0.001(8)$ & $0.006 \pm 0.001(9)$ \\
\hline CB 196 & $0.004^{2} \pm 0.000(9)$ & $0.052^{2} \pm 0.011(9)$ & $0.084^{b} \pm 0.015(8)$ & $0.319^{b} \pm 0.128(9)$ \\
\hline CB 201 & $0.003^{2} \pm 0.000(9)$ & $0.014^{2} \pm 0.002(9)$ & $0.027^{2} \pm 0.005(8)$ & $0.142^{b} \pm 0.032(9)$ \\
\hline $\begin{array}{l}\text { Aroclor } \\
1260\end{array}$ & $0.099 \pm 0.016(9)$ & $0.151 \pm 0.099(9)$ & $0.058 \pm 0.009(8)$ & $0.048 \pm 0.008(9)$ \\
\hline
\end{tabular}

${ }^{2}$ Means with different superscripts are significantly different, $P \leq 0.05$.

${ }^{2}$ Diet $A=75 \%$ ocean fish, Diet $B=75 \%$ fish collected above the Oak Ridge Reservation, Diet $C=25 \%$ fish collected on the Oak Ridge Reservation and 50\% ocean fish, Diet $E=75 \%$ fish collected on the Oak Ridge Reservation. 
Table E.9. Mean ${ }^{1} \pm$ SE Aroclor 1260 and PCB congener concentrations (ppm, wet wt) in carcass ${ }^{2}$ of 6-week-old mink kits from dams fed diets of fish collected from various sources ${ }^{3}$

\begin{tabular}{|c|c|c|c|c|}
\hline & Diet A & Diet B & Diet C & Diet E \\
\hline CB 77 & $0.003 \pm 0.000(9)$ & $0.003 \pm 0.000(9)$ & $0.003 \pm 0.000(8)$ & $0.003 \pm 0.000(9)$ \\
\hline CB 81 & $0.003 \pm 0.000(9)$ & $0.003 \pm 0.000(9)$ & $0.003 \pm 0.000(8)$ & $0.005 \pm 0.001(9)$ \\
\hline CB 99 & $0.003^{2} \pm 0.000(9)$ & $0.009^{2} \pm 0.003(9)$ & $0.017^{4} \pm 0.003(8)$ & $0.096^{b} \pm 0.023(9)$ \\
\hline CB 101 & $0.003^{a} \pm 0.000(9)$ & $0.004^{2} \pm 0.001(9)$ & $0.006^{a} \pm 0.001(8)$ & $0.017^{b} \pm 0.002(9)$ \\
\hline CB 118 & $0.008^{a} \pm 0.001(9)$ & $0.030^{2} \pm 0.009(9)$ & $0.071^{2} \pm 0.018(7)$ & $0.245^{b} \pm 0.036(9)$ \\
\hline CB 123 & $0.003 \pm 0.000(9)$ & $0.011 \pm 0.005(9)$ & $0.003 \pm 0.000(8)$ & $0.008 \pm 0.001(9)$ \\
\hline CB 126 & $0.003 \pm 0.000(9)$ & $0.011 \pm 0.001(9)$ & $0.005 \pm 0.001(8)$ & $0.003 \pm 0.000(9)$ \\
\hline CB 128 & $0.003^{2} \pm 0.000(9)$ & $0.011^{4} \pm 0.004(9)$ & $0.012^{4} \pm 0.002(8)$ & $0.054^{b} \pm 0.007(9)$ \\
\hline CB 138 & $0.008^{2} \pm 0.001(9)$ & $0.112^{2} \pm 0.016(9)$ & $0.106^{2} \pm 0.021(7)$ & $0.634^{b} \pm 0.110(9)$ \\
\hline CB 146 & $0.003^{2} \pm 0.000(9)$ & $0.013^{2} \pm 0.002(9)$ & $0.019^{2} \pm 0.003(8)$ & $0.103^{b} \pm 0.017(9)$ \\
\hline CB 151 & $0.003 \pm 0.000(9)$ & $0.003 \pm 0.000(9)$ & $0.003 \pm 0.000(8)$ & $0.005 \pm 0.001(9)$ \\
\hline CB 153 & $0.009^{2} \pm 0.001(9)$ & $0.141^{2} \pm 0.024(9)$ & $0.119^{2} \pm 0.025(7)$ & $0.619^{b} \pm 0.096(9)$ \\
\hline CB 156 & $0.003^{2} \pm 0.000(9)$ & $0.017^{2 b} \pm 0.003(9)$ & $0.022^{b} \pm 0.003(8)$ & $0.058^{c} \pm 0.008(9)$ \\
\hline CB 167 & $0.003^{2} \pm 0.000(9)$ & $0.014^{b c} \pm 0.002(9)$ & $0.010^{2 b} \pm 0.002(8)$ & $0.022^{c} \pm 0.003(9)$ \\
\hline CB 170 & $0.003^{2} \pm 0.000(9)$ & $0.073^{2} \pm 0.012(9)$ & $0.047^{2} \pm 0.007(8)$ & $0.238^{b} \pm 0.036(9)$ \\
\hline CB 171 & $0.003^{2} \pm 0.000(9)$ & $0.021^{4} \pm 0.003(9)$ & $0.008 \pm 0.004(8)$ & $0.017^{b} \pm 0.002(9)$ \\
\hline CB 180 & $0.004^{2} \pm 0.000(9)$ & $0.203^{2} \pm 0.026(9)$ & $0.121^{2} \pm 0.019(7)$ & $0.611^{b} \pm 0.080(9)$ \\
\hline CB 183 & $0.003^{2} \pm 0.000(9)$ & $0.011^{ \pm} \pm 0.001(9)$ & $0.007 \pm 0.002(8)$ & $0.031^{b} \pm 0.005(9)$ \\
\hline CВ 189 & $0.003 \pm 0.000(9)$ & $0.003 \pm 0.000(9)$ & $0.003 \pm 0.000(8)$ & $0.008 \pm 0.001(9)$ \\
\hline CB 194 & $0.003^{2} \pm 0.000(9)$ & $0.025^{2} \pm 0.003$ (9) & $0.019^{2} \pm 0.004(8)$ & $0.089^{b} \pm 0.010(9)$ \\
\hline CB 195 & $0.003^{2} \pm 0.000(9)$ & $0.003^{2} \pm 0.000(9)$ & $0.004^{4} \pm 0.001(8)$ & $0.023^{b} \pm 0.003(9)$ \\
\hline CB 196 & $0.003 \pm 0.000(9)$ & $0.014 \pm 0.002(9)$ & $0.005 \pm 0.002(8)$ & $0.005 \pm 0.001(9)$ \\
\hline CB 201 & $0.003^{2} \pm 0.000(9)$ & $0.013^{2} \pm 0.002(9)$ & $0.012^{2} \pm 0.002(8)$ & $0.050^{b} \pm 0.009(9)$ \\
\hline $\begin{array}{l}\text { Aroclor } \\
1260\end{array}$ & $0: 082 \pm 0.005(9)$ & $1.791 \pm 0.282(9)$ & $0.353 \pm 0.245(8)$ & $0.049 \pm 0.006(9)$ \\
\hline
\end{tabular}

'Means with different superscripts are significantly different, $P<0.05$. Diet groups were separated based on lipid adjusted concentrations.

${ }^{2}$ Whole body minus liver tissue.

${ }^{3}$ Diet $\mathrm{A}=75 \%$ ocean fish, Diet $\mathrm{B}=75 \%$ fish collected above the Oak Ridge Reservation, Diet $\mathrm{C}=25 \%$ fish collected on the Oak Ridge Reservation and 50\% ocean fish, Diet E= 75\% fish collected on the Oak Ridge Reservation. 
E-18

Table E.10. Reproductive performance of female mink fed diets of $75 \%$ fish from various sources ${ }^{1}$

\begin{tabular}{|c|c|c|c|c|c|}
\hline & Diet A & Diet B & Diet C & Diet D & Diet E \\
\hline Females whelping & 6 & 7 & 4 & 6 & 8 \\
\hline \multicolumn{6}{|l|}{ Female weights } \\
\hline December $^{2}$ & $1269 \pm 64^{3}$ & $1245 \pm 63$ & $1374 \pm 64$ & $1258 \pm 64$ & $1230 \pm 64$ \\
\hline June $e^{4}$ & $1168 \pm 84^{a}$ & $1016 \pm 81$ & $1134 \pm 81$ & $1020 \pm 81$ & $935 \pm 81^{b}$ \\
\hline Gestation (days) & 44.6 & 46.4 & 44.3 & 47.5 & 44.9 \\
\hline Kit wts (6 wks) & $328 \pm 14$ & $311 \pm 10$ & $333 \pm 20$ & $307 \pm 12$ & $295 \pm 11$ \\
\hline Females & $296 \pm 38$ & & & & $268 \pm 37$ \\
\hline Males & $376 \pm 42^{\mathrm{a}}$ & & & & $312 \pm 44^{b}$ \\
\hline Litter size $e^{5}$ & $6.9^{\mathrm{a}}$ & $7.3^{\mathrm{a}}$ & $7.8^{\mathrm{a}}$ & $6.0^{a b}$ & $4.3^{b}$ \\
\hline EROD $^{6}$ & $51 \pm 13^{2}$ & $134 \pm 26^{a b}$ & $124 \pm 32^{\mathrm{ab}}$ & $276 \pm 33^{b}$ & $262.54 \pm 31^{b}$ \\
\hline
\end{tabular}

'Diet $A=75 \%$ ocean fish, Diet $B=75 \%$ fish collected above the Oak Ridge Reservation, Diet $C=25 \%$ fish collected on the Oak Ridge Reservation and $50 \%$ ocean fish, Diet $\mathrm{D}=50 \%$ fish collected on the Oak Ridge Reservation and $25 \%$ ocean fish, Diet $E=75 \%$ fish collected on the Oak Ridge Reservation.

${ }^{2}$ Beginning of study.

${ }^{3}$ Means followed by different superscripts are significantly different, $\mathrm{P}<0.05$.

${ }^{4}$ End of study.

${ }^{5} \mathrm{Kits} / \mathrm{female.}$

${ }^{6}$ Ethoxyresorufin-o-deethylase, pmoles/mg protein/min. 
Appendix F

CONTAMINANT ACCUMULATION AND EFFECTS IN GREAT BLUE HERON 



\title{
CONTAMINANT ACCUMULATION AND EFFECTS IN GREAT BLUE HERON
}

\author{
Richard S. Halbrook \\ Cooperative Wildlife Research Laboratory \\ Southern Illinois University
}

\section{INTRODUCTION}

Plant operations and waste disposal at the Oak Ridge National Laboratory (ORNL), Gaseous Diffusion Plant (ORGDP), and Weapons Plant (Y-12) have introduced an assortment of harmful contaminants into the surrounding environment (Ashwood et al. 1986, Suter 1990). The potential exist for off-reservation transport of contaminants by streams on the Oak Ridge Reservation (ORR) that empty into the Clinch River. Elevated levels of Hg and PCB's have been found in fish collected from East Fork Poplar Creek (EFPC) and from Bear Creek, and elevated levels of PCB's have been found in fish from the White Oak Creek area (Loar 1990). East Fork Poplar Creek and Bear Creek originate within the Y-12 Plant and flow into Poplar Creek north of the K-25 Plant and White Oak Creek flows through ORNL. Both empty into the Clinch River at upper Watts Bar Lake. In the Screening Level Risk Assessment for the Off-Site Ecological Effects in Surface Waters Downstream from the U.S. Department of Energy Oak Ridge Reservation, Suter (1990) identified piscivorous wildlife along the Clinch River as being at risk.

In response to this assessment, monitoring of great blue heron (Ardea herodias) was begun in 1991. The great blue heron was chosen as an indicator species because it (1) is predominantly piscivorous foraging along the major waterways on and downstream of the ORR, (2) is at the top of the aquatic food chain, (3) has been suggested to be a good indicator of aquatic health, (3) is well represented in the scientific literature, including toxicological literature, and, (4) satisfies necessary logistical sampling considerations. Important logistical considerations were the presence of study and reference colonies on or in close proximity to ORR and population densities to meet sampling requirements. In addition, great blue heron are highly visible, facilitating direct observation and site location.

This ongoing study seeks to assess the general health and fecundity of the ORR great blue heron population and document any contaminant-induced effects, particularly with respect to $\mathrm{Hg}$ and $\mathrm{PCB}$ exposure. Reproductive health is of particular concern, and the potential for off-site transportation of contaminants through heron body burdens is addressed.

\section{STUDY SITES}

Four colonies have been utilized for heron chick and egg collection. Two colonies (K25 and Melton Hill colonies) are located within $3 \mathrm{~km}$ of ORR and herons utilizing these colonies are potentially exposed to contaminants occurring on the reservation. The remaining two colonies (Long Island and Looney Island colonies) are located $>10 \mathrm{Km}$ from the ORR and heron utilizing these colonies are assumed not to be exposed to contaminants that occur on the ORR. In general, there has been an increase in heron colonies in eastern Tennessee resulting from recent range expansion of the great blue heron in the upper Tennessee Valley (Pullin, 1990). 
The K-25 colony is located within the boundaries of Oak Ridge Gaseous Diffusion Plant adjacent to Poplar Creek, which flows through this facility. The colony is located on the west bank of Poplar Creek approximately $2 \mathrm{~km}$ from the confluence of Poplar Creek and the Clinch River. Fluctuation of the creek water level is dependent on operations at Watts Bar Dam. Areal surveys by the Tennessee Valley Authority (TVA) established nesting activity at K-25 in 1986 and an estimated 31 nests were active in 1988 (Pullin 1990). The number of nest at this colony have remained at $25-50$ during the 4 years of this study.

The second colony is located among three small islands in Melton Hill Lake approximately 2 $\mathrm{km}$ above Melton Hill Dam. This colony has been active for at least four years (personal communication, Jim Evans, TWRA, Oak Ridge National Laboratory). This colony is composed of approximately 40 active nest.

Colonies on Long Island and Looney Island served as off-site reference locations each greater than $10 \mathrm{~km}$ from ORR. Long Island is approximately $3 \mathrm{~km}$ from the confluence of the Tennessee and Clinch Rivers in the Tennessee River arm of Watts Bar Lake. The colony has been active since at least 1983 and 141 great blue heron nests were active in 1988 (Pullin 1990). Approximately 200 active nests have been observed during each year of the current study.

Looney Island is located in the Tennessee River approximately $30 \mathrm{~km}$ upstream of Long Island in upper Fort Loudon Reservoir. The colony has been active since at least 1992 and an estimated 100 active great blue heron nests were observed on the island during the 1993 and 1994 nesting seasons. Black-crowned night herons also were found nesting on this island during both seasons.

\section{METHODS}

During March - June 1992 - 1994 eggs and chicks were collected from great blue heron colonies. Nest were accessed by climbing trees using ropes and ascenders or using tree climbing spikes.

Egg collection and processing

Collected eggs were individually marked at both ends and transported to the laboratory in styrofoam containers. In the laboratory, egg length, width or circumference, and weights were recorded. Eggs were opened by etching the shell along the greatest circumference of the longitudinal axes using a small tooth file. Contents were transferred to acid washed glass containers and examined for embryonic development. Following examination, egg contents were homogenized using a Waring Blender and 2 approximately $20 \mathrm{~g}$ aliquots were collected in scintillation vials for metal and PCB analyses. Vials were individually labeled and frozen prior to analyses. Egg shells were dried for $>3$ days at room temperature and shell weight $( \pm 0.1 \mathrm{~g})$ was recorded. Shell thickness $( \pm 0.001 \mathrm{~mm})$ was recorded as the average of 6 shell thickness measurements taken at 3 locations on each shell half using a digametic micrometer.

Mercury concentrations in homogenized egg samples collected in 1992 were analyzed by the Analytical Chemistry Division, Oak Ridge National Laboratory, Oak Ridge, TN. Mercury concentration in homogenized egg sámples collected in 1993 and 1994 and PCB concentration in homogenized egg samples collected in 1992, 1993, and 1994 was determined by Southwest Research Institute, San Antonio, TX. 


\section{Chick collection and necropsy}

Collected chicks were lowered to the ground using backpacks. On the ground, a uniquely numbered tag was attached to the leg of each chick. Collected chicks were transported to the laboratory in ventilated turkey boxes prior to weighing, euthanasia, and necropsy. When possible, U.S. Fish and Wildlife bands and ORNL numbered and color coded bands were attached to chicks that were not collected.

In the laboratory, total weight $( \pm 0.1 \mathrm{~kg}$ ) was measured using a $5 \mathrm{~kg}$ spring scale and 3 hematocrit tubes of blood were taken from wing veins followed by euthanasia by asphyxiation with $\mathrm{CO}_{2}$. Total length (from bill tip to end of tail feathers), bill length (from tip to base along dorsal ridge), wing length (from wrist to end of last primary), and tarsometatarsus length ( $\pm 1 \mathrm{~mm}$ ) were recorded. Feathers along the dorsal feather tracts were removed and stored in zip lock plastic bags or aluminum foil prior to metal analysis. An incision was made along the abdomen and the liver, spleen, and heart were removed and weighed $( \pm 0.01 \mathrm{~g})$. Two $1 \mathrm{~g}$ liver samples were taken for enzyme and DNA analysis and the remaining liver was divided into two samples, approximately 20 $\mathrm{g}$ each, for $\mathrm{Hg}$ and PCB analysis. Abdominal fat samples (5 - $10 \mathrm{~g}$ ) were collected for PCB analysis and 2 approximately $20 \mathrm{~g}$ muscle samples were collected from along the tibiotarsus bone for $\mathrm{Hg}$ and PCB analysis. All collected tissues were wrapped in aluminum foil, quick frozen in liquid $\mathrm{N}_{2}$, and stored in permanent liquid $\mathrm{N}_{2}$ storage containers or in $-80^{\circ} \mathrm{C}$ freezers. Hematocrits were determined by averaging the pack cell volume of the 3 hematocrit tubes collected from each chick after centrifugation for $15 \mathrm{~min}$.

To assess heron food preference and availability, fish regurgitated from chicks or found beneath nests were collected and crop contents were examined. Recognizable fish samples were archived prior to $\mathrm{PCB}$ and $\mathrm{Hg}$ analysis. Abnormalities were noted and organ somatic indices were computed.

Results of contaminant analyses, physiological measurements, and reproductive parameters were statistically evaluated for differences between colonies located on and off the ORR. Aroclor 1260 and individual congener differences were evaluated when concentrations in at least one location (on or off ORR) were greater than $30 \mathrm{ppb}$. For congeners that were evaluated, any concentrations below detection limits were assigned a value equal to half the detection limit. Differences between locations were evaluated using a Student's t-test and, when appropriate, differences among colonies were evaluated using an ANOVA or Kruskal-Wallis test.

\section{RESULTS}

Mercury and chromium concentrations were significantly greater in fish collected from colonies located on the ORR compared to colonies located off the ORR (Table F.1). Although Aroclor 1260 concentrations were quantified in collected fish, no significant differences existed between on and off ORR colonies and all congener concentrations were $<20 \mathrm{ppb}$.

\section{Egg and Chick Metal concentrations}

Thirty-three and 34 eggs and 38 and 35 chicks, respectively, were collected from heron colonies on and off the ORR from 1992 - 1994. Extreme Hg concentrations were quantified in one egg from the Melton Hill colony $(\mathrm{KE} 022, \mathrm{Hg}$ concentration $=0.601 \mathrm{ppm}$ ) and one egg from the Long Island colony (LE513, Hg concentration $=0.596 \mathrm{ppm}$ ). The egg from the Melton Hill colony was collected from a nest with 2 chicks approximately 2 weeks of age and this egg did not show signs of development. Egg LE513 was collected from a nest that contained 3 eggs and was in an early stage 
of development. Both concentrations were rejected as outliers by the Dixon and Grubbs test for outlying observations and were eliminated from the data set (Taylor 1987).

No difference existed between mean mercury concentrations in eggs collected from the Long Island and Looney Island colonies (Table F.2), therefore, data from both colonies were used in calculating differences between on and off ORR mercury concentrations in eggs. However, mean mercury concentration in eggs collected from the $\mathrm{K} 25$ colony $(\bar{x} \pm \mathrm{SE}=0.17 \pm 0.02$, ppm) was significantly greater $(P<0.001)$ than the mean concentration in eggs collected from the Melton Hill colony $(\bar{x} \pm \mathrm{SE}=0.07 \pm 0.01, \mathrm{ppm})$. Therefore, only mercury data from eggs collected from the K25 colony was used in statistical test for differences between on and off ORR mercury concentrations in eggs.

Mean mercury concentration in eggs collected on the ORR was significantly greater than the mean concentration in eggs collected off the ORR (Table F.2). Mean concentrations were greatest in eggs collected from the K25 colony followed in decreasing order in eggs collected from the Long Island $(\bar{x}=0.12 \mathrm{ppm})$ and Looney Island $(\bar{x}=0.12 \mathrm{ppm})$ colonies, and the Melton Hill colony $(\bar{x}$ $=0.0 .07 \mathrm{ppm}$ ).

Mean chromium concentration in eggs collected on the ORR was significantly greater $(\mathrm{P}=$ 0.046 ) than the mean concentration in eggs collected off the ORR (Table F.2). Concentrations were greatest in eggs collected from the Melton Hill colony $(\bar{x}=0.22 \mathrm{ppm})$ followed in decreasing order by concentrations in the $K 25(\bar{x}=0.15 \mathrm{ppm})$, Long Island $(\bar{x}=0.11 \mathrm{ppm})$, and Looney Island $(\bar{x}=$ $0.11 \mathrm{ppm}$ ) colonies. Arsenic was quantified in only one egg and the concentration was below the contract required detection limit.

Mean mercury concentrations were significantly greater $(P<0.05)$ in feathers and liver tissue of chicks collected on the ORR compared to those collected off the ORR (Table F.3). Mean feather mercury concentration was significantly greater in chicks collected from the K25 colony $(\bar{x}=2.02$ $\mathrm{ppm}$ ) compared to feathers from chicks collected from the Melton Hill ( $\bar{x}=1.02 \mathrm{ppm})$, Looney Island $(\bar{x}=0.97 \mathrm{ppm})$, and Long Island $(\bar{x}=0.87 \mathrm{ppm})$ colonies. Mean liver mercury concentration was not significantly different between chicks collected from the K25 colony ( $\bar{x}=0.29 \mathrm{ppm})$ and the Looney Island colony $(\bar{x}=0.25 \mathrm{ppm})$. However, mean liver mercury concentration was significantly greater in chicks collected from the K25 colony compared to chicks collected from the Melton Hill $(\bar{x}=0.15 \mathrm{ppm})$ and Long Island $(\bar{x}=0.12 \mathrm{ppm})$ colonies. No significant differences existed between muscle liver concentrations between colonies located on or off the ORR. Mean muscle mercury concentration was significantly greater in chicks collected from the K25 colony $(\bar{x}$ $=0.09 \mathrm{ppm})$ compared to chicks collected from the Melton Hill colony $(\bar{x}=0.05 \mathrm{ppm})$. No significant differences in mean liver, muscle, or feather concentrations of arsenic or chromium were detected between chick collected on and off ORR, or among colonies (Table F.3).

\section{Egg and Chick PCB and Congener concentrations}

Mean concentrations of Aroclor 1260 and $76 \%$ of the quantified congeners were significantly greater $(\mathrm{P}<0.05)$ in eggs collected from the K25 colony compared to those collected from the Melton Hill colony, while, no significant differences were detected in Aroclor 1260 or congener concentrations between Long Island and Looney Island eggs. Therefore, for statistical analysis between on and off ORR colonies, PCB concentrations in K25 eggs were compared to concentrations in Long Island and Looney Island eggs combined. Mean concentrations of Aroclor 1260 and 10 congeners were significantly greater in eggs collected on the ORR compared to concentrations in eggs collected off the ORR (Table F.4). Concentrations of $47 \%$ of the 30 
congeners evaluated in egg homogenates were below $30 \mathrm{ppb}$. Concentrations of congeners 123 and 167 were the only coplanar congeners that differed between eggs from colonies located on and off the ORR.

Aroclor 1260 and a majority of congener concentrations were significantly greater $(P<0.05)$ in fat, liver, and muscle tissue from heron chicks collected from the K25 colony compared to those collected from the Melton Hill colony, while no differences existed between chicks collected from the Long Island and Looney Island colonies. Therefore, comparison of PCB results between on and off ORR was between the K25 colony, and Long Island and Looney Island colonies combined. Aroclor 1260 concentration was significantly greater $(P<0.05)$ in fat, liver, and muscle tissue from chicks collected on the ORR compared to concentrations in chicks collected off the ORR. Although concentrations of all congeners were greater in fat tissue from chicks collected on the ORR, this difference was significant in only $30 \%$ of the congeners quantified (Table F.5). Congener 156 was the only coplanar congener that was significantly different in fat tissue between on and off ORR colonies.

Of the 30 congeners evaluated, 77 and $73 \%$ of the concentrations in chick muscle and liver tissue, respectively, were below $30 \mathrm{ppb}$. In chick liver tissue, concentrations of congeners 110,118 , 151, 153 and 180 differed significantly between on and off ORR colonies (Table F.6). In chick muscle tissue, concentrations of congeners $110,118,138,153$, and 180 differed significantly between on and off ORR colonies (Table F.7). Congener 110 and 118 were the only coplanar congener that differed between on and off ORR colonies in liver and muscle tissue, although concentrations of coplanar congeners ranged from below detection to $18 \mathrm{ppm}$ in chick fat tissue.

\section{Physiological and Reproductive Effects}

No significant differences were observed in the number of eggs or chicks per nest between on and off ORR colonies (Table F.8). The mean weight of eggs collected from colonies on the ORR were significantly heavier than eggs collected off the ORR, however, there was no difference in shell thickness.

Chick weight/length ratios, liver somatic indexes, and hematocrit measurements were not different in chicks collected on and off the ORR. However, liver EROD activity and DNA F values (fraction of double stranded DNA) were significantly greater $(\mathrm{P}<0.05)$ in chicks collected from colonies off the ORR compared to those collected on the ORR (Table F.8).

Although herons occupying the K25 colony have elevated body burdens of mercury and PCBs compared to herons occupying colonies off the ORR, the contaminant levels in tissues do not appear to effect the number of eggs laid or survival of chicks to fledging. Effects on chick survival from fledging to reproductive maturity is yet to be determined. Contaminant data from one adult heron collected on the ORR in August 1992 suggest that body burdens are much greater in adults than in chicks. Mercury concentration in muscle tissue and feathers of this adult were 1.48 and $18.2 \mathrm{ppm}$, respectively, which is greater than the maximum found in chicks collected during this study (maximum chick muscle $\mathrm{Hg}=0.68 \mathrm{ppm}$; maximum chick feather $\mathrm{Hg}=6.35 \mathrm{ppm}$ ). Similarly, Aroclor 1260 concentration in muscle tissue of this adult ( 89 and $38 \mathrm{ppm}$, respectively) was greater than concentrations detected in chicks (maximum chick muscle Aroclor $1260=4.0 \mathrm{ppm}$ ). Congener concentrations in this adult also were greater than concentrations found in chicks. Muscle concentrations of coplanar congeners $77,81,110,118$, and 123 were $1.0,2.0,5.0,5.0$, and 3.8, respectively, which are at least one order of magnitude greater than the maximum concentrations detected in chick muscle tissue $(0.07,0.36,0.29,0.21$, and 0.15 , respectively). This suggests that 


\section{F-8}

some individuals may continue to feed on the ORR after fledging, however, it is not know if the chicks that are born on the ORR return to their birth colony to reproduce. Concentrations of mercury and PCBs in eggs collected on the ORR were greater than concentrations in eggs collected off the ORR, which suggest that at least some adults are exposed prior to egg laying. Monitoring movements of chicks after fledging as well as observations for bands placed on chicks during 1993 and 1994 will provide additional data from addressing this issue. 


\section{F-9}

Table F.1. Mean \pm SE $(N)$ concentrations (ppm, wet $w t$ ) of elements and Aroclor $1260^{1}$ from homogenized fish ${ }^{2}$ collected from great blue heron colonies located on ${ }^{3}$ and off ${ }^{4}$ the ORR

\begin{tabular}{llll}
\hline & ON ORR & OFF ORR & P $^{5}$ \\
\hline Mercury & & & \\
Arsenic & $0.06 \pm 0.02(13)$ & $0.02 \pm 0.00(15)$ & 0.030 \\
Chromium & $0.30 \pm 0.05(13)$ & $0.23 \pm 0.03(15)$ & 0.238 \\
Arocior 1260 & $1.52 \pm 0.54(12)$ & $0.37 \pm 0.08(15)$ & 0.030 \\
& $0.20 \pm 0.04(13)$ & $0.15 \pm 0.03(15)$ & 0.269 \\
\hline
\end{tabular}

'All congeners concentration were $<20 \mathrm{ppb}$.

${ }^{2}$ Various fish species collected from active nest or stomachs of collected great blue heron chicks.

${ }^{3}$ Includes the K25 and Melton Hill colonies.

${ }^{4}$ Includes the Long Island and Looney Island colonies.

${ }^{5}$ T-test $P$ value. 
Table F.2. Metal ${ }^{1}$ concentrations (ppm, wet wt) detected in great blue heron eggs from colonies located ${ }^{2}{ }^{2}$ and off ${ }^{3}$ the ORR during 1992-1994

\begin{tabular}{cccc}
\hline & ON ORR & OFF ORR & $\mathbf{P}^{4}$ \\
\hline Mercury & & & \\
Mean & & & \\
SE & 0.17 & 0.12 & \\
Min & 0.02 & 0.02 & \\
Max & 0.04 & 0.04 & \\
N & 0.31 & 0.29 & \\
& 24 & 34 & 0.046 \\
Chromium & & & \\
Mean & & & \\
SE & 0.18 & 0.11 & \\
Min & 0.03 & 0.01 & \\
Max & 0.05 & 0.06 & \\
N & 0.84 & 0.21 & 26 \\
& 25 & & \\
\hline & & & \\
\hline & & & \\
\hline
\end{tabular}

${ }^{1}$ Arsenic was quantified in one egg at a concentration below the contract required detection limit. 'Includes K25 colony.

${ }^{3}$ Includes Long Island and Looney Island colonies.

${ }^{4} T$-test $P$ value. 


\section{F-11}

Table F.3. Metal concentrations (Mean \pm SE) detected in tissues collected from great blue heron chicks from colonies located on ${ }^{1}(\mathrm{~N}=38)$ and of ${ }^{2}(\mathrm{~N}=35)$ the $\mathrm{ORR}$ during 1992-1994

\begin{tabular}{|c|c|c|c|}
\hline & ON ORR & OFF ORR & $\mathbf{P}^{3}$ \\
\hline \multicolumn{4}{|l|}{ Mercury } \\
\hline Feather & $1.71 \pm 0.21$ & $0.91 \pm 0.08$ & 0.001 \\
\hline Liver & $0.24 \pm 0.03$ & $0.16 \pm 0.02$ & 0.028 \\
\hline Muscle & $0.08 \pm 0.01$ & $0.09 \pm 0.02$ & 0.66 \\
\hline \multicolumn{4}{|l|}{ Chromium } \\
\hline Feather & $0.96 \pm 0.17$ & $1.16 \pm 0.19$ & 0.429 \\
\hline Liver & $1.49 \pm 0.48$ & $1.26 \pm 0.49$ & 0.739 \\
\hline Muscle & $1.86 \pm 0.56$ & $2.84 \pm 0.81$ & 0.322 \\
\hline \multicolumn{4}{|l|}{ Arsenic } \\
\hline Feather & $0.10 \pm 0.01$ & $0.10 \pm 0.01$ & 0.977 \\
\hline Liver & $0.13 \pm 0.03$ & $0.12 \pm 0.02$ & 0.771 \\
\hline Muscle & $0.15 \pm 0.05$ & $0.15 \pm 0.04$ & 0.938 \\
\hline
\end{tabular}

'Includes K25 and Melton Hill colonies.

${ }^{2}$ Includes Long Island and Looney Island colonies.

${ }^{3}$ T-test $P$ value. 


\section{F-12}

Table F.4. Mean $\pm S E(N)$ Aroclor 1260 and congener concentrations ${ }^{1}$ (ppm, wet wt) in great blue heron eggs collected from colonies located on ${ }^{2}$ and off ${ }^{3}$ the ORR

\begin{tabular}{|c|c|c|c|}
\hline & ON ORR & OFF ORR & $\mathbf{P}^{4}$ \\
\hline Aroclor 1260 & $1.68 \pm 0.48(24)$ & $0.27 \pm 0.08$ & 0.008 \\
\hline CB 81 & $0.13 \pm 0.04(16)$ & $0.08 \pm 0.02(26)$ & 0.365 \\
\hline CB 99 & $0.09 \pm 0.03(16)$ & $0.02 \pm 0.01(26)$ & 0.030 \\
\hline CB 101 & $0.04 \pm 0.02(16)$ & $0.00 \pm 0.00(26)$ & 0.018 \\
\hline CB 118 & $0.17 \pm 0.04(16)$ & $0.08 \pm 0.02(26)$ & 0.062 \\
\hline CB 123 & $0.11 \pm 0.04(16)$ & $0.01 \pm 0.00(26)$ & 0.015 \\
\hline CB 138 & $0.29 \pm 0.05(16)$ & $0.14 \pm 0.03(26)$ & 0.025 \\
\hline CB 146 & $0.09 \pm 0.03(16)$ & $0.03 \pm 0.01(26)$ & 0.036 \\
\hline CB 149 & $0.09 \pm 0.05(8)$ & $0.03 \pm 0.01(14)$ & 0.288 \\
\hline CB 153 & $0.37 \pm 0.07(16)$ & $0.16 \pm 0.04(26)$ & 0.019 \\
\hline CB 158 & $0.04 \pm 0.02(16)$ & $0.06 \pm 0.02(26)$ & 0.128 \\
\hline CB 167 & $0.05 \pm 0.01(16)$ & $0.01 \pm 0.00(26)$ & 0.008 \\
\hline CB 170 & $0.09 \pm 0.02(16)$ & $0.04 \pm 0.01(26)$ & 0.012 \\
\hline CB 180 & $0.27 \pm 0.06(16)$ & $0.11 \pm 0.02(26)$ & 0.021 \\
\hline CB 183 & $0.06 \pm 0.01(16)$ & $0.02 \pm 0.00(26)$ & 0.020 \\
\hline CB 194 & $0.04 \pm 0.01(16)$ & $0.02 \pm 0.00(26)$ & 0.076 \\
\hline CB 196 & $0.07 \pm 0.02(16)$ & $0.03 \pm 0.01(26)$ & 0.059 \\
\hline
\end{tabular}

${ }^{1}$ Concentrations of CBs $66,76,77,95,105,110,114,126,128,132,151,156,171$, and 201 were $<30 \mathrm{ppb}$ and are not included.

${ }^{2}$ Includes the $\mathrm{K} 25$ colony.

${ }^{3}$ Includes the Long Island and Looney Island colonies.

${ }^{4}$ T-test $P$ value. 
Table F.5. Mean $\pm \mathrm{SE}(\mathrm{N})$ Aroclor 1260 and congener concentrations (ppm, wet wt) in abdominal fat from great blue heron chicks collected from colonies located on ${ }^{1}$ and off ${ }^{2}$ the ORR

\begin{tabular}{|c|c|c|c|}
\hline & ON ORR & OFF ORR & $\mathbf{P}^{3}$ \\
\hline Aroclor 1260 & $48.63 \pm 11.71(16)$ & $15.70 \pm 2.64(24)$ & 0.014 \\
\hline $\mathrm{CB} 66$ & $1.21 \pm 0.75(16)$ & $0.23 \pm 0.03(24)$ & 0.210 \\
\hline CB 76 & $0.78 \pm 0.55(16)$ & $0.12 \pm 0.02(24)$ & 0.250 \\
\hline CB 77 & $0.27 \pm 0.10(16)$ & $0.20 \pm 0.04(24)$ & 0.556 \\
\hline CB 81 & $1.54 \pm 0.44(16)$ & $1.28 \pm 0.30(24)$ & 0.761 \\
\hline CB 95 & $0.84 \pm 0.54(16)$ & $0.14 \pm 0.04(24)$ & 0.216 \\
\hline CB 99 & $2.70 \pm 1.36(16)$ & $0.56 \pm 0.15(24)$ & 0.138 \\
\hline CB 101 & $2.65 \pm 1.37(16)$ & $0.47 \pm 0.15(24)$ & 0.134 \\
\hline CB 105 & $0.73 \pm 0.36(16)$ & $0.13 \pm 0.02(24)$ & 0.115 \\
\hline CB 110 & $2.40 \pm 1.16(16)$ & $0.49 \pm 0.10(24)$ & 0.122 \\
\hline CB 114 & $0.07 \pm 0.04(16)$ & $0.00 \pm 0.00(24)$ & 0.999 \\
\hline CB 118 & $1.95 \pm 0.82(16)$ & $0.79 \pm 0.11(24)$ & 0.182 \\
\hline CB 123 & $2.53 \pm 1.09(16)$ & $0.63 \pm 0.11(24)$ & 0.102 \\
\hline CB 126 & $0.54 \pm 0.13(16)$ & $0.33 \pm 0.08(24)$ & 0.195 \\
\hline CB 128 & $0.95 \pm 0.37(16)$ & $0.19 \pm 0.02(24)$ & 0.058 \\
\hline CB 132 & $0.76 \pm 0.41(16)$ & $0.14 \pm 0.02(24)$ & 0.146 \\
\hline CB 138 & $5.13 \pm 1.44(16)$ & $1.70 \pm 0.23(24)$ & 0.032 \\
\hline CB 146 & $1.70 \pm 0.37(16)$ & $0.75 \pm 0.11(24)$ & 0.024 \\
\hline CB 149 & $2.76 \pm 0.54(7)$ & $1.04 \pm 0.24(12)$ & 0.018 \\
\hline CB 151 & $0.98 \pm 0.35(16)$ & $0.33 \pm 0.06(24)$ & 0.084 \\
\hline CB 153 & $6.24 \pm 1.35(16)$ & $2.47 \pm 0.45(24)$ & 0.016 \\
\hline CB 156 & $0.31 \pm 0.09(16)$ & $0.12 \pm 0.02(24)$ & 0.043 \\
\hline CB 158 & $0.19 \pm 0.14(16)$ & $0.21 \pm 0.08(24)$ & 0.905 \\
\hline
\end{tabular}




\section{F-14}

Table F.5 (continued)

\begin{tabular}{llll}
\hline & ON ORR & OFF ORR & P $^{3}$ \\
\hline CB 167 & & & \\
CB 170 & $0.86 \pm 0.30(16)$ & $0.29 \pm 0.04(24)$ & 0.078 \\
CB 171 & $1.57 \pm 0.34(16)$ & $0.54 \pm 0.07(24)$ & 0.010 \\
CB 180 & $0.22 \pm 0.09(16)$ & $0.17 \pm 0.05(24)$ & 0.621 \\
CB 183 & $4.27 \pm 0.95(16)$ & $1.37 \pm 0.25(24)$ & 0.009 \\
CB 194 & $0.88 \pm 0.25(16)$ & $0.35 \pm 0.05(24)$ & 0.054 \\
CB 196 & $0.63 \pm 0.12(16)$ & $0.38 \pm 0.05(31)$ & 0.078 \\
CB 201 & $0.93 \pm 0.21(16)$ & $0.37 \pm 0.06(24)$ & 0.018 \\
& $0.53 \pm 0.11(16)$ & $0.22 \pm 0.03(24)$ & 0.012 \\
\hline
\end{tabular}

'Includes the K25 colony.

${ }^{2}$ Includes the Long Island and Looney Island colonies.

${ }^{3}$ T-test $P$ value. 
Table F.6. Mean \pm SE (N) Aroclor 1260 and congener concentrations ${ }^{1}$ (ppm, wet wt) in liver tissue from great blue heron chicks collected from colonies located on ${ }^{2}$ and off $f^{3}$ the ORR

\begin{tabular}{llll}
\hline & ON ORR & OFF ORR & $P^{4}$ \\
\hline Aroclor 1260 & $0.77 \pm 0.23(18)$ & $0.23 \pm 0.03(22)$ & 0.029 \\
CB 110 & $0.06 \pm 0.02(18)$ & $0.02 \pm 0.00(22)$ & 0.050 \\
CB 118 & $0.05 \pm 0.02(18)$ & $0.01 \pm 0.00(22)$ & 0.049 \\
CB 138 & $0.07 \pm 0.03(18)$ & $0.02 \pm 0.00(22)$ & 0.077 \\
CB 149 & $0.06 \pm 0.03(8)$ & $0.02 \pm 0.00(10)$ & 0.209 \\
CB 151 & $0.04 \pm 0.02(18)$ & $0.01 \pm 0.00(22)$ & 0.048 \\
CB 153 & $0.10 \pm 0.03(18)$ & $0.03 \pm 0.00(22)$ & 0.017 \\
CB 180 & $0.07 \pm 0.02(18)$ & $0.02 \pm 0.00(22)$ & 0.021 \\
& & & \\
\hline
\end{tabular}

'Concentrations of CBs 66, 76, 77, 95, 99, 101, 105, 114, 123, 126, 128, 132, 146, 156, 158, 167, 170, 171, $183,194,196$, and 201 were $<30 \mathrm{ppb}$ and are not included.

'Includes the K25 colony.

${ }^{3}$ Includes the Long Island and Looney Island colonies.

${ }^{4}$ T-test $P$ value. 


\section{F-16}

Table F.7. Mean \pm SE (N) Aroclor 1260 and congener concentrations ${ }^{1}$ (ppm, wet wt) in muscle tissue from great blue heron chicks collected from colonies located ${ }^{2}{ }^{2}$ and off ${ }^{\beta}$ the ORR

\begin{tabular}{llll}
\hline & ON ORR & OFF ORR & $\mathrm{P}^{4}$ \\
\hline Aroclor 1260 & $1.05 \pm 0.25(18)$ & $0.35 \pm 0.08(24)$ & 0.015 \\
CB 81 & $0.04 \pm 0.01(18)$ & $0.04 \pm 0.02(24)$ & 0.795 \\
CB 110 & $0.06 \pm 0.02(18)$ & $0.01 \pm 0.00(24)$ & 0.027 \\
CB 118 & $0.06 \pm 0.01(18)$ & $0.02 \pm 0.01(24)$ & 0.015 \\
CB 138 & $0.09 \pm 0.02(18)$ & $0.04 \pm 0.01(24)$ & 0.033 \\
CB 149 & $0.09 \pm 0.03(8)$ & $0.03 \pm 0.01(12)$ & 0.086 \\
CB 153 & $0.16 \pm 0.03(18)$ & $0.05 \pm 0.01(24)$ & 0.009 \\
CB 180 & $0.10 \pm 0.02(18)$ & $0.03 \pm 0.01(24)$ & 0.008 \\
& & & \\
\hline
\end{tabular}

${ }^{1}$ Concentrations of CBs $66,76,77,95,99,101,105,114,123,126,128,132,146,151,156,167,170,171$, $183,194,196$, and 201 were $<30 \mathrm{ppb}$ and are not included.

${ }^{2}$ Includes the K25 colony.

${ }^{3}$ Includes the Long Island and Looney Island colonies.

${ }^{4} \mathrm{~T}$-test $\mathrm{P}$ value, based on lipid adjusted concentrations. 


\section{F-17}

Table F.8. Reproductive, physiological, and biomarker measurements [Mean $\pm \mathrm{SE}(\mathrm{N})]$ in great blue heron from colonies located on ${ }^{1}$ and off ${ }^{2}$ the ORR during 1992-1994

\begin{tabular}{lcc}
\hline & ON ORR & OFF ORR \\
\hline Mean eggs/nest & $3.5 \pm 0.2(26)$ & \\
Egg shell thickness (mm) & $0.427 \pm 0.01(33)$ & $3.2 \pm 0.2(27)$ \\
Egg weight (g) & $69.16 \pm 0.97(33)$ & $0.410 \pm 0.01(34)$ \\
Mean chicks/nest & $2.7 \pm 0.1(55)$ & $66.36 \pm 0.97(34)$ \\
Chick weight/length ratio & $2.06 \pm 0.05(38)$ & $2.7 \pm 0.2(30)$ \\
Liver somatic index & $4.50 \pm 0.16(38)$ & $2.12 \pm 0.06(35)$ \\
Liver EROD activity & $31.9 \pm 2.7(12)$ & $4.64 \pm 0.23(35)$ \\
DNA double-strandedness $(\mathrm{F})^{5}$ & $73 \pm 0.03(26)$ & $41.3 \pm 3.2(12)$ \\
Hematocuit & $32 \pm 0.8(38)$ & $84 \pm 0.02(27)$ \\
& & $31 \pm 0.7(26)$ \\
\hline
\end{tabular}

'Includes K25 and Melton Hill colonies.

${ }^{2}$ Includes Long Island and Looney Island colonies.

${ }^{3}$ Means significantly different ( $\mathrm{T}$-test, $\mathrm{P}=0.048$ ).

${ }^{4} 1994$ data; ethoxyresorufin-0-deethylase activity (pmole/mq protein/min); means significantly different (Ttest, $\mathrm{P}=\mathbf{0 . 0 3 3 )}$.

${ }^{5}$ Means signficantly different ( $\mathrm{T}$-test, $\left.\mathrm{P}=0.006\right), \mathrm{F}=$ fraction of double-stranded DNA. 
Appendix G

TABLES AND FIGURES FOR CHAPTER 5: ASSESSMENT OF RISK TO VERMIVORES AND HERBIVORES ON THE OAK RIDGE RESERVATION 
- 
G-3

Table G.1. Life history parameters for the white-tailed deer (Odocoileus virginianus)

\begin{tabular}{|c|c|c|c|}
\hline Parameter & Value $^{2}$ & Comments & Reference \\
\hline Body weight & $\begin{array}{l}68 \mathrm{~kg}\left(\sigma^{2}\right) \\
45 \mathrm{~kg}(\%) \\
56.5 \mathrm{~kg}\left(\text { mean } \sigma^{2}+q\right)\end{array}$ & & Smith 1991 \\
\hline $\begin{array}{l}\text { Food consumption } \\
\text { rate }\end{array}$ & $1.74 \mathrm{~kg} / \mathrm{d}$ & & Mautz et al. 1976 \\
\hline $\begin{array}{l}\text { Water consumption } \\
\text { rate }\end{array}$ & $3.7 \mathrm{~L} / \mathrm{d}$ & $\begin{array}{l}\text { estimated using } \\
\text { allometric equation } \\
\text { assuming } 56.5 \mathrm{~kg} \\
\text { bw }\end{array}$ & \\
\hline \multirow[t]{2}{*}{ Soil consumption rate } & $<2 \%$ & & Beyer et al. 1994 \\
\hline & $0.0348 \mathrm{~kg} / \mathrm{d}$ & $\begin{array}{l}\text { assuming } 2 \% \text { soil } \\
\text { and } 1.74 \mathrm{~kg} / \mathrm{d} \text { food } \\
\text { consumption rates }\end{array}$ & \\
\hline \multirow[t]{3}{*}{ Diet composition } & $\begin{array}{l}\text { exclusively } \\
\text { herbivorous }\end{array}$ & & \\
\hline & $\begin{array}{l}\text { diet diverse and } \\
\text { variable, depends on } \\
\text { availability. }\end{array}$ & & Zim et al. 1951 \\
\hline & $\begin{array}{l}\text { major foods: } \\
\text { - buds and twigs of } \\
\text { trees and shrubs } \\
\text { - grasses and forbs } \\
\text { (summer) } \\
\text { - mast and fruits (fall) }\end{array}$ & & Smith 1991 \\
\hline Home range & $59-520$ ha & & Marchinton and Hirth 1984 \\
\hline Habitat requirements & $\begin{array}{l}\text { uses a wide variety of } \\
\text { habitats; favors forest- } \\
\text { field-farmland mosaic; } \\
\text { population density } \\
\text { directly related to } \\
\text { number and } \\
\text { distribution of forest } \\
\text { openings }\end{array}$ & & Smith 1991 \\
\hline
\end{tabular}


G-4

Table G.1 (continued)

\begin{tabular}{llll}
\hline \multicolumn{1}{c}{ Parameter } & \multicolumn{1}{c}{ Value } & \multicolumn{1}{c}{ Comments } & \multicolumn{1}{c}{ Reference } \\
\hline Population density & $0.06 /$ ha & $\begin{array}{l}\text { eastern mixed } \\
\text { deciduous forest - } \\
\text { Tennessee }\end{array}$ & Barber 1984 \\
& $0.39-0.78$ ha & $\begin{array}{l}\text { Tok-hickory forest - } \\
\text { oakson and Porath 1984 } \\
\text { midwest }\end{array}$ & $\begin{array}{l}\text { personal communication, } \\
\text { Jim Evans 1995 }\end{array}$ \\
& $\begin{array}{l}\text { 0.1704/ha (calculated } \\
\text { based on 2000 deer on } \\
\text { ORR and available } \\
\text { habitat) }\end{array}$ & $\begin{array}{l}\text { Oak Ridge } \\
\text { Reservation }\end{array}$ & \\
\hline Behavior & $\begin{array}{lll}\text { generally crepuscular } \\
\text { active year-round; does } \\
\text { not hibernate }\end{array}$ & & Smith 1991 \\
\hline
\end{tabular}

a Suggested values for use in exposure assessment are in bold.

${ }^{b}$ Allometric equation for estimation of water consumption for deer is:

where: $\mathrm{WIR}=0.099(\mathrm{BW})^{0.90}$

$\mathrm{WIR}=$ water ingestion rate $(\mathrm{L}$ water/individual/day). 


\section{G-5}

Table G.2. Life history parameters for the wild turkey (Meleagris gallopavo)

\begin{tabular}{|c|c|c|c|}
\hline Parameter & Value & Comments & Reference \\
\hline Body weight & $\begin{array}{l}7.400 \mathrm{~kg}\left(0^{7}\right) \\
4.222 \mathrm{~kg}(\%) \\
5.8 \mathrm{~kg}\left(\text { mean } 0^{7}+9\right) \\
\end{array}$ & & Dunning 1984 \\
\hline $\begin{array}{l}\text { Food consumption } \\
\text { rate }\end{array}$ & $\begin{array}{l}13.6 \mathrm{~g} / \mathrm{lb} \mathrm{bw} / \mathrm{d} \\
0.174 \mathrm{~kg} / \mathrm{d} \\
\end{array}$ & assuming $5.8 \mathrm{~kg} \mathrm{bw}$ & Korschgen 1967 \\
\hline $\begin{array}{l}\text { Water consumption } \\
\text { rate }\end{array}$ & $0.19 \mathrm{~L} / \mathrm{d}$ & $\begin{array}{l}\text { estimated using } \\
\text { allometric equation } \\
\text { assuming } 5.8 \mathrm{~kg} \mathrm{bw} \\
\end{array}$ & \\
\hline $\begin{array}{l}\text { Soil consumption } \\
\text { rate }\end{array}$ & $\begin{array}{l}9.3 \% \\
0.0162 \mathrm{~kg} / \mathrm{d}\end{array}$ & $\begin{array}{l}\text { assuming } 0.174 \mathrm{~kg} / \mathrm{d} \text { food } \\
\text { consumption rates }\end{array}$ & Beyer et al. 1994 \\
\hline Diet composition & $\begin{array}{l}\text { plant material (mast, fruit, } \\
\text { seeds, some foliage) - } \\
90.3 \% \\
\text { animal material (insects, } \\
\text { crayfish, snails, } \\
\text { salamanders) - } 9.7 \%\end{array}$ & & Korschgen 1967 \\
\hline Home range & $150-190$ ha & & Pough $1951^{b}$ \\
\hline Habitat requirements & $\begin{array}{l}\text { mast-producing woodlands } \\
\text { with associated fields and } \\
\text { abundant water }\end{array}$ & & Schorger $1966^{\mathrm{b}}$ \\
\hline Population density & $\begin{array}{l}0.03 / \mathrm{ha} \\
0.06-0.076 / \mathrm{ha}\end{array}$ & $\begin{array}{l}\text { West Virginia } \\
\text { in 'ideal' habitat }\end{array}$ & $\begin{array}{l}\text { Uhling } 1950^{\mathrm{b}} \\
\text { Pough } 1951^{\mathrm{b}}\end{array}$ \\
\hline & $\begin{array}{l}0.0426 \text { /ha (calculated } \\
\text { based on @ } 500 \text { turkey } \\
\text { observed on ORR and } \\
\text { suitable habitat) }\end{array}$ & Oak Ridge Reservation & $\begin{array}{l}\text { Personal Communication, } \\
\text { Jim Evans } 1995\end{array}$ \\
\hline Behavior & $\begin{array}{l}\text { forage primarily on the } \\
\text { ground } \\
\text { roost in trees at night } \\
\text { year-round resident; does } \\
\text { not migrate }\end{array}$ & & $\begin{array}{l}\text { National Geographic } \\
\text { Society } 1987\end{array}$ \\
\hline
\end{tabular}

- Suggested values for use in exposure assessment are in bold.

${ }^{b}$ Cited in DeGraaf et al. 1981.

c Allometric equation for estimation of water consumption for birds is: $\mathrm{WIR}=0.059(\mathrm{BW})^{0.67}$

where:

$\mathrm{WIR}=$ water ingestion rate $(\mathrm{L}$ water/individual/day $)$. 


\section{G-6}

Table G.3. Life history parameters for the short-tailed shrew (Blarina brevicauda)

\begin{tabular}{|c|c|c|c|}
\hline Parameter & Value $^{*}$ & Comments & Reference \\
\hline Body weight & $0.015 \pm 0.00078 \mathrm{~kg}$ & New Hampshire (field) & $\begin{array}{l}\text { Schlessinger and Potter } \\
1974\end{array}$ \\
\hline \multirow{3}{*}{$\begin{array}{l}\text { Food consumption } \\
\text { rate }\end{array}$} & $0.01 \mathrm{~kg} / \mathrm{d}$ & larch sawfly diet (lab) & Buckner 1964 \\
\hline & $\begin{array}{l}0.00795 \pm 0.00017 \\
\mathrm{~kg} / \mathrm{d}\end{array}$ & mealworm diet (lab) & $\begin{array}{l}\text { Barrett and Stueck } \\
1976\end{array}$ \\
\hline & mean $=0.009 \mathrm{~kg} / \mathrm{d}$ & & \\
\hline \multirow{2}{*}{$\begin{array}{l}\text { Water consumption } \\
\text { rate }\end{array}$} & $0.223 \mathrm{ml} / \mathrm{g} \mathrm{bw} / \mathrm{d}$ & & Chew 1951 \\
\hline & $0.033 \mathrm{~L} / \mathrm{d}$ & assuming a $0.015 \mathrm{~kg}$ bw & \\
\hline \multirow[t]{2}{*}{$\begin{array}{l}\text { Soil consumption } \\
\text { rate }\end{array}$} & $13 \%$ of diet & & $\begin{array}{l}\text { Talmage and Walton } \\
1993\end{array}$ \\
\hline & $0.00117 \mathrm{~kg} / \mathrm{d}$ & $\begin{array}{l}\text { assuming diet of } 0.009 \\
\mathrm{~kg} / \mathrm{d}\end{array}$ & \\
\hline Diet composition & $\begin{array}{l}\text { earthworms } 31.4 \% \\
\text { slugs/snails } 27.1 \% \\
\text { soil/litter invert } \\
13.2 \% \\
\text { fungi } 8.4 \% \\
\text { misc. animals } 8.1 \% \\
\text { coleoptera } 5.9 \% \\
\text { vegetation } 5.4 \% \\
\end{array}$ & $\begin{array}{l}\text { percent volume in diet in } \\
\text { summer in New York }\end{array}$ & $\begin{array}{l}\text { Whitaker and Ferraro } \\
1963\end{array}$ \\
\hline Home range & $0.39 \pm 0.036 \mathrm{ha}$ & Manitoba bog & Buckner 1966 \\
\hline \multirow[t]{2}{*}{$\begin{array}{l}\text { Habitat } \\
\text { requirements }\end{array}$} & $\begin{array}{l}\text { broad and variable but } \\
\text { requires }>50 \% \\
\text { herbaceous cover }\end{array}$ & & Miller and Getz 1977 \\
\hline & $\begin{array}{l}\text { forest, wetlands, and } \\
\text { grasslands. most } \\
\text { abundant in hardwood } \\
\text { forests with deep litter } \\
\text { and humus. }\end{array}$ & & van Zyll de Jong 1983 \\
\hline \multirow[t]{2}{*}{ Population density } & $\begin{array}{l}2.3 \text { /ha - winter } \\
5.2 \text { /ha - spring } \\
9.3 \text { /ha -summer } \\
8.1 \text { /ha - fall }\end{array}$ & $\begin{array}{l}\text { Illinois - alfalfa, tallgrass, } \\
\text { and bluegrass; } \\
\text { means derived from graph. }\end{array}$ & Getz 1989 \\
\hline & $\begin{array}{l}2.5-45 / \mathrm{ha} \\
\text { (median= } 23 / \mathrm{ha} \text { ) }\end{array}$ & $\begin{array}{l}\text { range depending on the } \\
\text { habitat }\end{array}$ & \\
\hline
\end{tabular}


G-7

Table G.3 (continued)

\begin{tabular}{|c|c|c|c|}
\hline Parameter & Value $^{2}$ & Comments & Reference \\
\hline \multirow[t]{2}{*}{ Behavior } & $\begin{array}{l}\text { nocturnal, } \\
\text { semifossorial, spends } \\
\text { little time above } \\
\text { surface }\end{array}$ & & George et al. 1986 \\
\hline & $\begin{array}{l}\text { active year-round - } \\
\text { does not hibernate }\end{array}$ & & EPA 1993a \\
\hline Other & $\begin{array}{l}\text { appear to be } \\
\text { unpalatable to most } \\
\text { predators due to } \\
\text { lateral gland }\end{array}$ & & van Zyll de Jong 1983 \\
\hline
\end{tabular}

"Suggested values for use in exposure assessment are in bold. 
Table G.4. Life history parameters for the American woodcock (Scolopax minor)

\begin{tabular}{|c|c|c|c|}
\hline Parameter & Value $^{2}$ & Comments & Reference \\
\hline Body weight & $\begin{array}{l}0.176 \mathrm{~kg}\left(\sigma^{7}\right) \\
0.219 \mathrm{~kg}(\%) \\
\left.0.198 \mathrm{~kg} \text { (mean } \sigma^{\pi}+\%\right)\end{array}$ & & Dunning 1984 \\
\hline $\begin{array}{l}\text { Food consumption } \\
\text { rate }\end{array}$ & $0.15 \mathrm{~kg} / \mathrm{d}$ & & Sheldon 1971 \\
\hline $\begin{array}{l}\text { Water consumption } \\
\text { rate }\end{array}$ & $0.02 \mathrm{~L} / \mathrm{d}$ & $\begin{array}{l}\text { estimated using } \\
\text { allometric equation } \\
\text { assuming } 0.198 \mathrm{~kg} \mathrm{bw} \\
\end{array}$ & \\
\hline $\begin{array}{l}\text { Soil consumption } \\
\text { rate }\end{array}$ & $\begin{array}{l}10.4 \% \\
0.0156 \mathrm{~kg} / \mathrm{d}\end{array}$ & assuming diet of $0.15 \mathrm{~kg} / \mathrm{d}$ & Beyer et al. 1994 \\
\hline Diet composition & $\begin{array}{l}\text { primarily } \\
\text { earthworms (58\% - } \\
\text {-99\%) } \\
\text { plus other ground- } \\
\text { dwelling } \\
\text { invertebrates }\end{array}$ & & $\begin{array}{l}\text { Sperry } 1940 \\
\text { Krohn } 1970 \\
\text { Miller and Causey } \\
1985 \\
\text { Stribling and Doerr } \\
1985\end{array}$ \\
\hline Home range & $\begin{array}{l}\left.\text { 10.5 ha (singing } \sigma^{7}\right) \\
\left.73.6 \text { ha (active } \sigma^{7}\right) \\
3.1 \text { ha (inactive } \sigma^{7} \text { ) }\end{array}$ & $\begin{array}{l}\text { Pennsylvania - mixed forest } \\
\text { fields }\end{array}$ & Hudgins et al. 1985 \\
\hline Habitat requirements & $\begin{array}{l}\text { Breeding: moist early } \\
\text { successional } \\
\text { woodlands, } \\
\text { swamps, river } \\
\text { bottoms, alder } \\
\text { thickets } \\
\text { feeding: moist open } \\
\text { pasture, cultivated } \\
\text { fields, stream banks }\end{array}$ & & DeGraaf et al. 1981 \\
\hline Population density & $\begin{array}{l}3.4 \text { /ha } \\
0.2 \text { /ha } \\
0.034 \text { /ha }\end{array}$ & $\begin{array}{l}\text { North Carolina - winter } \\
\text { untilled soy stubble } \\
\text { untilled corn stubble } \\
\text { rebedded corn }\end{array}$ & $\begin{array}{l}\text { Connors and Doerr } \\
1982\end{array}$ \\
\hline & 0.21 nests $/ \mathrm{ha}$ & $\begin{array}{l}\text { Pennsylvania - mixed pine } \\
\text { hardwoods }\end{array}$ & Coon et al. 1982 \\
\hline & $0.28 / \mathrm{ha}$ & $\begin{array}{l}\text { based on } 5.6 \mathrm{males} / 40 \mathrm{ha} \\
\text { assuming } 1: 1 \mathrm{sex} \text { ration }\end{array}$ & $\begin{array}{l}\text { Stewart and Robbins } \\
1958\end{array}$ \\
\hline
\end{tabular}


G-9

Table G.4 (continued)

\begin{tabular}{llll}
\hline \multicolumn{1}{c}{ Parameter } & \multicolumn{1}{c}{ Value } & Comments & \multicolumn{1}{c}{ Reference } \\
\hline Behavior & $\begin{array}{l}\text { migrate from } \\
\text { northern breeding } \\
\text { range to wintering } \\
\text { range in south } \\
\text { Atlantic and gulf } \\
\text { coast states. }\end{array}$ & Sheldon 1971 \\
& & \\
& early migrants; leave & \\
wintering grounds in & & \\
& February, arrive at \\
& northern breeding \\
grounds lat March. & \\
\hline
\end{tabular}

- Suggested values for use in exposure assessment are in bold.

b Allometric equation for estimation of water consumption for birds is: WIR $=0.059(B W)^{0.67}$

where:

$\mathrm{WIR}=$ water ingestion rate $(\mathrm{L}$ water/individual/day $)$. 
Table G.5. Life history parameters for red fox (Vulpes fulva)

\begin{tabular}{|c|c|c|c|}
\hline Parameter & Value $^{*}$ & Comments & Reference \\
\hline \multirow[t]{3}{*}{ Body Weight } & $\begin{array}{l}5.25 \pm 0.18 \mathrm{~kg}\left(\sigma^{x}\right) \\
4.13 \pm 0.11 \mathrm{~kg}(\%)\end{array}$ & Illinois & Storm et al. 1976 \\
\hline & $\begin{array}{l}4.82 \pm 0.081 \mathrm{~kg}\left(\sigma^{\infty}\right) \\
3.94 \pm 0.079 \mathrm{~kg}\left(\frac{?}{9}\right)\end{array}$ & Iowa & \\
\hline & $4.5 \mathrm{~kg}$ & $\begin{array}{l}\text { mean or+o for both } \\
\text { Illinois and Iowa }\end{array}$ & \\
\hline \multirow[t]{3}{*}{ Food Consumption Rate } & $0.596 \mathrm{~kg} / \mathrm{d}$ & see calculation belowb & $\begin{array}{l}\text { Vogtsberger and Barret } \\
1973\end{array}$ \\
\hline & $0.31 \mathrm{~kg} / \mathrm{d}$ & $\begin{array}{l}0.069 \mathrm{~g} / \mathrm{g} / \mathrm{d} \text { for } \\
\text { nonbreeding adult times } \\
4.5 \mathrm{~kg} \mathrm{bw}\end{array}$ & Sargent 1978 \\
\hline & $0.45 \mathrm{~kg} / \mathrm{d}$ & mean of both estimates & \\
\hline Water Consumption Rate & $0.38 \mathrm{~L} / \mathrm{d}$ & $\begin{array}{l}\text { Estimated using } \\
\text { allometric equationc; } \\
\text { assuming } 4.5 \mathrm{~kg} \mathrm{bw}\end{array}$ & \\
\hline \multirow[t]{2}{*}{ Soil Consumption Rate } & $2.8 \%$ & & Beyer et al. 1994 \\
\hline & $0.0126 \mathrm{~kg} / \mathrm{d}$ & $\begin{array}{l}\text { assuming diet of } 0.45 \\
\mathrm{~kg} / \mathrm{d}\end{array}$ & \\
\hline Diet Composition & $\begin{array}{l}\text { mammals }-68.8 \% \\
\text { birds }-12.0 \% \\
\text { plants }-10.4 \% \\
\text { insects }-0.9 \% \\
\text { misc. }-5.5 \%\end{array}$ & $\begin{array}{l}\text { Maryland, } \\
\text { Appalachian region }\end{array}$ & $\begin{array}{l}\text { Hockman and Chapman } \\
1983\end{array}$ \\
\hline \multirow[t]{2}{*}{ Home Range } & $\begin{array}{l}699 \pm 137 \text { ha } \\
\text { (우 spring) }\end{array}$ & $\begin{array}{l}\text { Minnesota - forest, field, } \\
\text { swamp }\end{array}$ & Sargent 1972 \\
\hline & $\begin{array}{l}717 \text { ha (o' all year) } \\
96 \text { ha ( } \$ \text { all year) }\end{array}$ & $\begin{array}{l}\text { Wisconsin - multiple } \\
\text { habitats }\end{array}$ & Ables 1969 \\
\hline \multirow[t]{2}{*}{ Habitat Requirements } & $\begin{array}{l}\text { wide and diverse - occur } \\
\text { in many habitats }\end{array}$ & & EPA 199̣3b \\
\hline & $\begin{array}{l}\text { prefer mixture of forest } \\
\text { and open habitat }\end{array}$ & & $\begin{array}{l}\text { Burt and Grossenheider } \\
1976\end{array}$ \\
\hline Population Density & $0.046-0.077 / \mathrm{ha}$ & $\begin{array}{l}\text { "good fox range" in North } \\
\text { America }\end{array}$ & EPA 1993b \\
\hline Behavior & $\begin{array}{l}\text { active year round - does } \\
\text { not hibernate }\end{array}$ & & EPA $1993 b$ \\
\hline \multicolumn{4}{|c|}{ 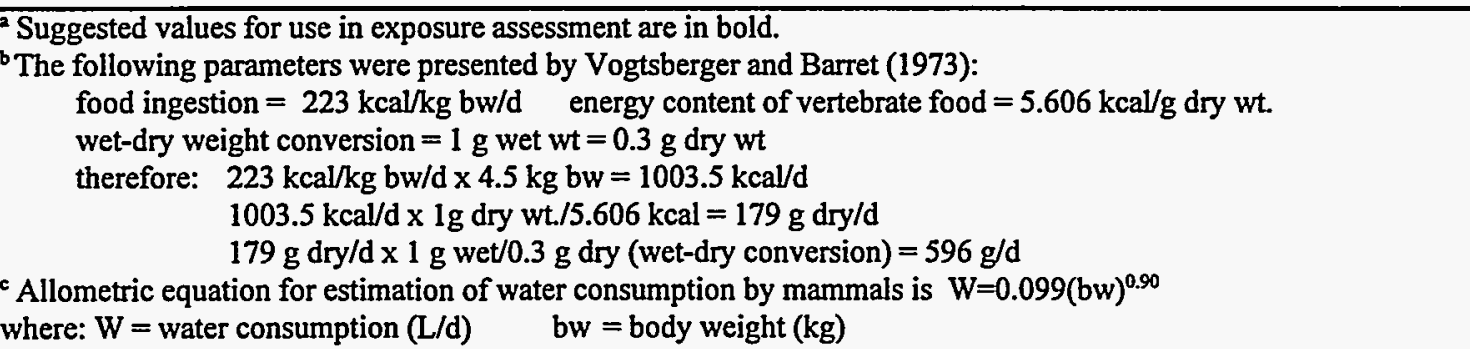 } \\
\hline
\end{tabular}




\section{G-11}

Table G.6. Life history parameters for red-tailed hawks (Buteo jamaicensis)

\begin{tabular}{|c|c|c|c|}
\hline Parameter & Value & Comments & Reference \\
\hline Body Weight & $\begin{array}{l}1.028 \mathrm{~kg}\left(0^{\times}\right) \\
1.224 \mathrm{~kg}\left({ }^{\circ}\right) \\
\left.1.126 \mathrm{~kg} \text { (mean } \sigma^{x}+\%\right)\end{array}$ & & Dunning 1984 \\
\hline Food Consumption Rate & $0.109 \mathrm{~kg} / \mathrm{d}$ & & $\begin{array}{l}\text { Craighead and } \\
\text { Craighead } 1969\end{array}$ \\
\hline Water Consumption Rate & $0.064 \mathrm{~L} / \mathrm{d}$ & $\begin{array}{l}\text { Estimated using } \\
\text { allometric equation } \\
\text { assuming } 1.126 \mathrm{~kg} \text { bw }\end{array}$ & \\
\hline Soil Consumption Rate & $\begin{array}{l}\text { while some soil } \\
\text { attached to prey may } \\
\text { be ingested, amount } \\
\text { is assumed to } \\
\text { negligible }\end{array}$ & & \\
\hline \multirow[t]{2}{*}{ Diet Composition } & $\begin{array}{l}\text { predominantly small } \\
\text { mammals }\end{array}$ & & \\
\hline & $\begin{array}{l}\text { small mammal - } 78.5 \\
\% \\
\text { bird - } 8.5 \% \\
\text { snake - } 13.0 \% \\
\end{array}$ & $\begin{array}{l}\text { Oregon - pasture and } \\
\text { wheat fields }\end{array}$ & Janes 1984 \\
\hline \multirow[t]{2}{*}{ Home Range } & 233 ha & $\begin{array}{l}\text { Oregon - pasture and } \\
\text { wheat fields }\end{array}$ & Janes 1984 \\
\hline & $\begin{array}{l}1936 \text { ha } \\
(957-2465 \text { ha } \\
\text { range })\end{array}$ & $\begin{array}{l}\text { Colorado - } \\
\text { prairie-pinyon/juniper } \\
\text { woodland; } \\
\text { mean of } 4 \text { birds; } 95 \% \\
\text { ellipse and systematic } \\
\text { relocation }\end{array}$ & $\begin{array}{l}\text { Anderson and } \\
\text { Rongstad } 1989\end{array}$ \\
\hline Habitat Requirements & $\begin{array}{l}\text { use wide range of } \\
\text { habitats. prefer } \\
\text { landscapes } \\
\text { containing mixture of } \\
\text { oldfields, wetlands } \\
\text { and pasture for } \\
\text { foraging with trees } \\
\text { interspersed for } \\
\text { perching and nesting }\end{array}$ & & $\begin{array}{l}\text { EPA 1993b } \\
\text { DeGraaf et al. } 1981\end{array}$ \\
\hline Population Density & $\begin{array}{l}0.03->0.005 \\
\text { pairs/ha }\end{array}$ & & EPA $1993 b$ \\
\hline
\end{tabular}


G-12

Table G.6 (continued)

\begin{tabular}{llll}
\hline \multicolumn{1}{c}{ Parameter } & \multicolumn{1}{c}{ Value } & Comments & \multicolumn{1}{c}{ Reference } \\
\hline Behavior & $\begin{array}{l}\text { territorial throughout } \\
\text { year }\end{array}$ & $\begin{array}{l}\text { Brown and Amadon } \\
1968^{\mathrm{b}}\end{array}$ \\
& $\begin{array}{l}\text { northerly populations } \\
\text { migrate; those in the } \\
\text { south do not }\end{array}$ & $\begin{array}{l}\text { National Geographic } \\
\text { Society 1987 }\end{array}$ \\
\hline
\end{tabular}

a Suggested values for use in exposure assessment are in bold.

allometric equation for estimation of water consumption by birds is:

$\mathrm{W}=0.059(\mathrm{bw})^{0.67}$

where: $\mathrm{W}=$ water consumption $(\mathrm{L} / \mathrm{d})$

$\mathrm{bw}=$ body weight $(\mathrm{kg})$ 
Table G.7. Contaminant Concentrations in Soil (mg/kg) on the Oak Ridge Reservation

\begin{tabular}{|c|c|c|c|c|c|c|c|c|c|}
\hline Location & Analyte & Obs & \# Det & \# Nondet & Mean" & $\begin{array}{c}\text { Standard } \\
\text { Error }\end{array}$ & Min & $\operatorname{Max}$ & $95 \%$ UCB \\
\hline $\mathrm{BC}$ OU 2 & 1,1-Dichlorethene & 9 & 9 & 0 & 0.0077 & 0.0002 & 0.0070 & 0.0090 & 0.0081 \\
\hline $\mathrm{BC}$ OU 2 & 1,1,1-trichlorethane & 9 & 9 & 0 & 0.0077 & 0.0002 & 0.0070 & 0.0090 & 0.0081 \\
\hline $\mathrm{BC}$ OU 2 & 1,2-Dichlorethane & 9 & 9 & 0 & 0.0077 & 0.0002 & 0.0070 & 0.0090 & 0.0081 \\
\hline $\mathrm{BC}$ OU 2 & 1,2-Dichlorethene & 9 & 9 & 0 & 0.0077 & 0.0002 & 0.0070 & 0.0090 & 0.0081 \\
\hline $\mathrm{BC}$ OU 2 & 4,4-DDD & 9 & 9 & 0 & 0.0052 & 0.0002 & 0.0044 & 0.0070 & 0.0056 \\
\hline BC OU 2 & 4,4-DDE & 9 & 9 & 0 & 0.0052 & 0.0002 & 0.0044 & 0.0070 & 0.0056 \\
\hline BC OU 2 & 4,4-DDT & 9 & 9 & 0 & 0.0052 & 0.0002 & 0.0044 & 0.0070 & 0.0056 \\
\hline $\mathrm{BC}$ OU 2 & Acetone & 9 & 9 & 0 & 0.0514 & 0.0288 & 0.0130 & 0.2800 & 0.1051 \\
\hline $\mathrm{BC}$ OU 2 & Aldrin & 9 & 9 & 0 & 0.0026 & 0.0001 & 0.0022 & 0.0030 & 0.0028 \\
\hline $\mathrm{BC}$ OU 2 & Alpha-BHC & 9 & 9 & 0 & 0.0026 & 0.0001 & 0.0022 & 0.0030 & 0.0028 \\
\hline $\mathrm{BC}$ OU 2 & Alpha-chlordane & 9 & 9 & 0 & 0.0026 & 0.0001 & 0.0022 & 0.0030 & 0.0028 \\
\hline $\mathrm{BC}$ OU 2 & Aluminum & 13 & 13 & 0 & 26143.8462 & 5485.3630 & 6840.0000 & 63900.0000 & 35920.3400 \\
\hline BC OU 2 & Antimony & 9 & 9 & 0 & 0.3089 & 0.0259 & 0.2300 & 0.4900 & 0.3570 \\
\hline BC OU 2 & Arsenic & 13 & 9 & 4 & 33.3692 & 2.6757 & 15.6000 & 50.3000 & 35.0930 \\
\hline BC OU 2 & Barium & 13 & 13 & 0 & 101.4000 & 29.5003 & 17.9000 & 340.0000 & 153.9779 \\
\hline BC OU 2 & Benzene & 9 & 9 & 0 & 0.0077 & 0.0002 & 0.0070 & 0.0090 & 0.0081 \\
\hline BC OU 2 & Benzo(a)pyrene & 9 & 9 & 0 & 0.4989 & 0.0162 & 0.4300 & 0.6000 & 0.5290 \\
\hline $\mathrm{BC}$ OU 2 & Beryllium & 13 & 13 & 0 & 1.0246 & 0.1631 & 0.2900 & 2.0000 & 1.3154 \\
\hline BC OU 2 & Beta-BHC & 9 & 9 & 0 & 0.0026 & 0.0001 & 0.0022 & 0.0030 & 0.0028 \\
\hline BC OU 2 & Bis(2-ethylhexyl)Phthalate & 9 & 9 & 0 & 0.4989 & 0.0162 & 0.4300 & 0.6000 & 0.5290 \\
\hline BC OU 2 & Boron & 4 & 4 & 0 & 65.5000 & 5.9090 & 50.0000 & 78.0000 & 79.4061 \\
\hline $\mathrm{BC}$ OU 2 & Cadmium & 13 & 9 & 4 & 1.2469 & 0.4118 & 0.1100 & 3.5000 & 0.8571 \\
\hline $\mathrm{BC}$ OU 2 & Carbon tetrachloride & 9 & 9 & 0 & 0.0077 & 0.0002 & 0.0070 & 0.0090 & 0.0081 \\
\hline $\mathrm{BC}$ OU 2 & Chloroform & 9 & 9 & 0 & 0.0077 & 0.0002 & 0.0070 & 0.0090 & 0.0081 \\
\hline BC OU 2 & Chromium & 13 & 13 & 0 & 37.3308 & 3.8723 & 16.5000 & 60.0000 & 44.2323 \\
\hline BC OU 2 & Copper & 13 & 13 & 0 & 39.2231 & 10.1792 & 10.3000 & 131.0000 & 57.3653 \\
\hline $\mathrm{BC}$ OU 2 & Delta-BHC & 9 & 9 & 0 & 0.0026 & 0.0001 & 0.0022 & 0.0030 & 0.0028 \\
\hline $\mathrm{BC}$ OU 2 & Dibenzofuran & 9 & 9 & 0 & 0.4989 & 0.0162 & 0.4300 & 0.6000 & 0.5290 \\
\hline
\end{tabular}


Table G.7 (continued)

\begin{tabular}{|c|c|c|c|c|c|c|c|c|c|}
\hline Location & Analyte & Obs & \# Det & \# Nondet & Mean $^{n}$ & $\begin{array}{l}\text { Standard } \\
\text { Error }\end{array}$ & Min & Max & 95\% UCB \\
\hline $\mathrm{BC}$ OU 2 & Dieldrin & 9 & 9 & 0 & 0.0052 & 0.0002 & 0.0044 & 0.0070 & 0.0056 \\
\hline $\mathrm{BC}$ OU 2 & Diethylphthalate & 9 & 9 & 0 & 0.4989 & 0.0162 & 0.4300 & 0.6000 & 0.5290 \\
\hline BC OU 2 & Di-n-butlyphthalate & 9 & 9 & 0 & 0.4989 & 0.0162 & 0.4300 & 0.6000 & 0.5290 \\
\hline BC OU 2 & Endosulfan I & 9 & 9 & 0 & 0.0026 & 0.0001 & 0.0022 & 0.0030 & 0.0028 \\
\hline BC OU 2 & Endosulfan II & 9 & 9 & 0 & 0.0052 & 0.0002 & 0.0044 & 0.0070 & 0.0056 \\
\hline $\mathrm{BC}$ OU 2 & Endrin & 9 & 9 & 0 & 0.0052 & 0.0002 & 0.0044 & 0.0070 & 0.0056 \\
\hline $\mathrm{BC}$ OU 2 & Gamma-chlordane & 9 & 9 & 0 & 0.0026 & 0.0001 & 0.0022 & 0.0030 & 0.0028 \\
\hline BC OU 2 & Heptachlor & 9 & 9 & 0 & 0.0026 & 0.0001 & 0.0022 & 0.0030 & 0.0028 \\
\hline $\mathrm{BC}$ OU 2 & Lead & 13 & 12 & 1 & 81.0154 & 25.6587 & 18.3000 & 370.0000 & 126.8223 \\
\hline $\mathrm{BC}$ OU 2 & Lindane & 9 & 9 & 0 & 0.0026 & 0.0001 & 0.0022 & 0.0030 & 0.0028 \\
\hline $\mathrm{BC}$ OU 2 & Lithium & 4 & 4 & 0 & 39.2500 & 3.3758 & 33.0000 & 48.0000 & 47.1944 \\
\hline $\mathrm{BC}$ OU 2 & Manganese & 13 & 13 & 0 & 1021.5231 & 425208.0000 & 55.8000 & 6060.0000 & 1779.3673 \\
\hline $\mathrm{BC}$ OU 2 & Mercury & 24 & 24 & 0 & 49.0188 & 15775.0000 & 0.1000 & 300.0000 & 76.0554 \\
\hline $\mathrm{BCOU} 2$ & Methoxychlor & 9 & 9 & 0 & 0.0261 & 0.0012 & 0.0220 & 0.0330 & 0.0284 \\
\hline BC OU 2 & Methylene chloride & 9 & 9 & 0 & 0.0161 & 0.0010 & 0.0130 & 0.0230 & 0.0179 \\
\hline BC OU 2 & Nickel & 13 & 13 & 0 & 32.6000 & 9.9436 & 5.8000 & 147.0000 & 50.3224 \\
\hline $\mathrm{BC}$ OU 2 & Niobium & 4 & 1 & 3 & 9.8500 & 0.4699 & 8.7000 & 11.0000 & $\mathrm{NA}^{\mathrm{b}}$ \\
\hline $\mathrm{BC}$ OU 2 & PCB-1016 & 9 & 9 & 0 & 0.0521 & 0.0023 & 0.0440 & 0.0650 & 0.0565 \\
\hline $\mathrm{BC}$ OU 2 & PCB-1221 & 9 & 9 & 0 & 0.1040 & 0.0045 & 0.0880 & 0.1300 & 0.1124 \\
\hline $\mathrm{BC}$ OU 2 & PCB-1232 & 9 & 9 & 0 & 0.0521 & 0.0023 & 0.0440 & 0.0650 & 0.0565 \\
\hline $\mathrm{BC}$ OU 2 & PCB-1242 & 9 & 9 & 0 & 0.0521 & 0.0023 & 0.0440 & 0.0650 & 0.0565 \\
\hline $\mathrm{BC}$ OU 2 & PCB-1248 & 9 & 9 & $\mathbf{0}$ & 0.0521 & 0.0023 & 0.0440 & 0.0650 & 0.0565 \\
\hline $\mathrm{BC}$ OU 2 & PCB-1254 & 9 & 9 & 0 & 0.0521 & 0.0023 & 0.0440 & 0.0650 & 0.0565 \\
\hline $\mathrm{BC}$ OU 2 & PCB-1260 & 9 & 9 & 0 & 0.0416 & 0.0032 & 0.0210 & 0.0500 & 0.0475 \\
\hline $\mathrm{BC}$ OU 2 & Pentachlorophenol & 9 & 9 & 0 & 1.2111 & 0.0455 & 1.0000 & 1.5000 & 1.2957 \\
\hline $\mathrm{BC}$ OU 2 & Selenium & 9 & 9 & 0 & 1.0944 & 0.3730 & 0.2400 & 3.3000 & 1.7881 \\
\hline BC OU 2 & Strontium & 4 & 4 & 0 & 109.9250 & 10.1746 & 82.7000 & 126.0000 & 133.8695 \\
\hline $\mathrm{BC}$ OU 2 & Tetrachloroethene & 9 & 9 & 0 & 0.0074 & 0.0002 & 0.0070 & 0.0080 & 0.0078 \\
\hline $\mathrm{BC}$ OU 2 & Thallium & 9 & 9 & 0 & 0.3144 & 0.0269 & 0.2100 & 0.4400 & 0.3644 \\
\hline
\end{tabular}


Table G.7 (continued)

\begin{tabular}{|c|c|c|c|c|c|c|c|c|c|}
\hline Location & Analyte & Obs & \# Det & \# Nondet & Mean" & $\begin{array}{c}\text { Standard } \\
\text { Error }\end{array}$ & Min & Max & 95\% UCB \\
\hline BC OU 2 & Toluene & 9 & 9 & 0 & 0.0077 & 0.0002 & 0.0070 & 0.0090 & 0.0081 \\
\hline $\mathrm{BC}$ OU 2 & Toxaphene & 9 & 9 & 0 & 0.2611 & 0.0122 & 0.2200 & 0.3300 & 0.2838 \\
\hline $\mathrm{BC}$ OU 2 & Trichloroethene & 9 & 9 & $\mathbf{0}$ & 0.0077 & 0.0002 & 0.0070 & 0.0090 & 0.0081 \\
\hline BC OU 2 & Uranium & 20 & 20 & 0 & 2.0408 & 0.2752 & 0.5200 & 5.2900 & 2.5166 \\
\hline $\mathrm{BC}$ OU 2 & Vanadium & 13 & 13 & 0 & 54.8385 & 4.3422 & 33.0000 & 82.5000 & 62.5775 \\
\hline BC OU 2 & Vinyl chloride & 9 & 9 & 0 & 0.0153 & 0.0005 & 0.0130 & 0.0180 & 0.0162 \\
\hline BC OU 2 & Zinc & 13 & 13 & 0 & 113.2077 & 20.3168 & 41.0000 & 302.0000 & 149.4180 \\
\hline $\mathrm{BC}$ OU 2 & Zirconium & 4 & 4 & 0 & 59.2500 & 6.4727 & 46.0000 & 77.0000 & 74.4826 \\
\hline $\mathrm{K}-1407$ OU & 1,1,1-trichlorethane & 37 & 1 & 36 & 0.0155 & 0.0005 & 0.0010 & 0.0200 & NA \\
\hline $\mathrm{K}-1407 \mathrm{OU}$ & 1,2-Dichlorethene & 37 & 3 & 34 & 0.0171 & 0.0007 & 0.0120 & 0.0330 & 0.0277 \\
\hline K-1407 OU & Acetone & 37 & 11 & 26 & 0.0285 & 0.0015 & 0.0080 & 0.0420 & 0.0188 \\
\hline K-1407 OU & Aluminum & 81 & 81 & 0 & 26562.9630 & 1298.3185 & 7600.0000 & 69000.0000 & 28723.5270 \\
\hline K-1407 OU & Antimony & 81 & 1 & 80 & 7.1506 & 0.7359 & 4.8000 & 50.0000 & NA \\
\hline $\mathrm{K}-1407$ OU & Arsenic & 81 & 35 & 46 & 12.4333 & 1.1038 & 5.0000 & 50.0000 & 13.0681 \\
\hline $\mathrm{K}-1407$ OU & Barium & 81 & 81 & 0 & 110.4938 & 8.8823 & 25.0000 & 600.0000 & 125.2752 \\
\hline $\mathrm{K}-1407$ OU & Beryllium & 81 & 81 & 0 & 1.0159 & 0.0667 & 0.2500 & 4.9000 & 1.1269 \\
\hline $\mathrm{K}-1407$ OU & Boron & 81 & 38 & 43 & 6.4191 & 1.1358 & 0.4000 & 59.0000 & 8.3996 \\
\hline $\mathrm{K}-1407$ OU & Cadmium & 81 & 70 & 11 & 1.8799 & 0.1743 & 0.3000 & 8.5000 & 2.1492 \\
\hline $\mathrm{K}-1407$ OU & Chloroform & 37 & 4 & 33 & 0.0156 & 0.0004 & 0.0060 & 0.0240 & 0.0119 \\
\hline $\mathrm{K}-1407$ OU & Chromium & 81 & 81 & 0 & 61.0370 & 5.3044 & 18.0000 & 240.0000 & 69.8642 \\
\hline $\mathrm{K}-1407$ OU & Copper & 81 & 79 & 2 & 40.8537 & 4.6847 & 0.5100 & 190.0000 & 48.6398 \\
\hline $\mathrm{K}-1407$ OU & Di-n-butylphthalate & 6 & 6 & 0 & 0.0172 & 0.0007 & 0.0160 & 0.0200 & 0.0185 \\
\hline K-1407 OU & Lead & 81 & 78 & 3 & 30.6753 & 1.5668 & 5.8000 & 72.0000 & 32.9964 \\
\hline $\mathrm{K}-1407$ OU & Manganese & 81 & 81 & 0 & 1184.7778 & 102.4519 & 86.0000 & 3900.0000 & 1355.2705 \\
\hline $\mathrm{K}-1407$ OU & Mercury & 64 & 28 & 36 & 4.7250 & 0.9668 & 1.0000 & 40.0000 & 6.3965 \\
\hline K-1407 OU & Methylene chloride & 37 & 37 & 0 & 0.0175 & 0.0022 & 0.0030 & 0.0360 & 0.0212 \\
\hline K-1407 OU & Molybdenum & 81 & 28 & 53 & 1.8006 & 0.1551 & 0.9600 & 10.0000 & 1.5498 \\
\hline $\mathrm{K}-1407$ OU & Nickel & 81 & 81 & 0 & 192.1790 & 35.4005 & 5.0000 & 1500.0000 & 251.0899 \\
\hline K-1407 OU & Selenium & 81 & 1 & 80 & 7.1519 & 0.7359 & 4.8000 & 50.0000 & NA \\
\hline
\end{tabular}


Table G.7 (continued)

\begin{tabular}{|c|c|c|c|c|c|c|c|c|c|}
\hline Location & Analyte & Obs & \# Det & \# Nondet & Mean $^{2}$ & $\begin{array}{c}\text { Standard } \\
\text { Error }\end{array}$ & Min & $\operatorname{Max}$ & 95\% UCB \\
\hline $\mathrm{K}-1407$ OU & Strontium & 81 & 81 & 0 & 18.1420 & 1.5188 & 1.8000 & 64.0000 & 20.6695 \\
\hline $\mathrm{K}-1407$ OU & Tetrachloroethene & 37 & 8 & 29 & 0.0232 & 0.0046 & 0.0050 & 0.1700 & 0.0243 \\
\hline $\mathrm{K}-1407$ OU & Toluene & 37 & 11 & 26 & 0.0115 & 0.0012 & 0.0009 & 0.0200 & 0.0010 \\
\hline $\mathrm{K}-1407$ OU & Trichloroethene & 37 & 11 & 26 & 0.0246 & 0.0040 & 0.0090 & 0.1300 & 0.0281 \\
\hline $\mathrm{K}-1407$ OU & Uranium & 386 & 353 & 33 & 143.6944 & 68.1672 & 0.1080 & 26190.0000 & 255.8501 \\
\hline $\mathrm{K}-1407$ OU & Vanadium & 81 & 81 & 0 & 38.9753 & 1.4213 & 14.0000 & 75.0000 & 41.3405 \\
\hline $\mathrm{K}-1407$ OU & Zinc & 81 & 81 & 0 & 59.7778 & 2.8203 & 11.0000 & 140.0000 & 64.4711 \\
\hline $\mathrm{K}-1414$ & Acetone & 2 & 1 & 1 & 0.0310 & 0.0190 & 0.0120 & 0.0500 & NA \\
\hline $\mathrm{K}-1414$ & Benzo(a)pyrene & 2 & 1 & 1 & 0.2870 & 0.1930 & 0.0940 & 0.4800 & NA \\
\hline $\mathrm{K}-1414$ & Bis(2-ethylhexyl)phthalate & 2 & 1 & 1 & 0.2235 & 0.1665 & 0.0570 & 0.3900 & $\mathrm{NA}$ \\
\hline $\mathrm{K}-1414$ & Di-n-butlyphthalate & 2 & 2 & 0 & 0.7400 & 0.2600 & 0.4800 & 1.0000 & 2.3816 \\
\hline $\mathrm{K}-1414$ & Methylene chloride & 2 & 2 & 0 & 0.0380 & 0.0190 & 0.0190 & 0.0570 & 0.1580 \\
\hline $\mathrm{K}-1414$ & Tetrachloroethene & 2 & 1 & 1 & 0.0040 & 0.0020 & 0.0020 & 0.0060 & NA \\
\hline $\mathrm{K}-1420 \mathrm{OU}$ & 1,2-Dichlorethane & 5 & 3 & 2 & 0.0054 & 0.0012 & 0.0020 & 0.0090 & 0.0074 \\
\hline $\mathrm{K}-1420$ OU & Acetone & 5 & 3 & 2 & 0.0190 & 0.0028 & 0.0120 & 0.0250 & 0.0249 \\
\hline $\mathrm{K}-1420 \mathrm{OU}$ & Aldrin & 4 & 1 & 3 & 0.0114 & 0.0012 & 0.0096 & 0.0150 & NA \\
\hline $\mathrm{K}-1420 \mathrm{OU}$ & Aluminum & 2 & 2 & 0 & 19950.0000 & 4650.0000 & 15300.0000 & 24600.0000 & 49308945.0000 \\
\hline $\mathrm{K}-1420 \mathrm{OU}$ & Arsenic & 4 & 4 & 0 & 18.4700 & 3.6054 & 8.3800 & 25.5000 & 26.9549 \\
\hline $\mathrm{K}-1420$ OU & Barium & 2 & 2 & 0 & 31.8500 & 8.2500 & 23.6000 & 40.1000 & 83.9384 \\
\hline $\mathrm{K}-1420$ OU & Benzo(a)pyrene & 5 & 2 & 3 & 0.3780 & 0.0659 & 0.1200 & 0.4800 & 0.3862 \\
\hline $\mathrm{K}-1420$ OU & Beryllium & 2 & 2 & 0 & 0.3750 & 0.1450 & 0.2300 & 0.5200 & 1.2905 \\
\hline $\mathrm{K}-1420$ OU & Beta-BHC & 4 & 1 & 3 & $0.0137^{\circ}$ & 0.0035 & 0.0096 & 0.0240 & NA \\
\hline $\mathrm{K}-1420 \mathrm{OU}$ & Bis(2-ethylhexyl)phthalate & 5 & 4 & 1 & 0.2150 & 0.0637 & 0.0750 & 0.4000 & 0.2892 \\
\hline $\mathrm{K}-1420 \mathrm{OU}$ & Boron & 2 & 1 & 1 & 2.7000 & 1.4000 & 1.3000 & 4.1000 & NA \\
\hline $\mathrm{K}-1420 \mathrm{OU}$ & Chromium & 3 & 2 & 1 & 15.2000 & 7.4505 & 0.4000 & 24.1000 & 25.4717 \\
\hline $\mathrm{K}-1420$ OU & Copper & 2 & 2 & 0 & 26.2000 & 3.3000 & 22.9000 & 29.5000 & 47.0354 \\
\hline $\mathrm{K}-1420$ OU & Fluoride & 4 & 2 & 2 & 40.0150 & 23.0854 & 0.0300 & 80.0000 & 0.0300 \\
\hline $\mathrm{K}-1420$ OU & Lead & 4 & 4 & 0 & 66.2500 & 10.3119 & 48.2000 & 93.2000 & 90.5177 \\
\hline $\mathrm{K}-1420$ OU & Lithium & 2 & 2 & 0 & 52.2000 & 27.9000 & 24.3000 & 80.1000 & 228.3537 \\
\hline
\end{tabular}


Table G.7 (continued)

\begin{tabular}{|c|c|c|c|c|c|c|c|c|c|}
\hline Location & Analyte & Obs & \# Det & \# Nondet & Mean $^{2}$ & $\begin{array}{c}\text { Standard } \\
\text { Error }\end{array}$ & Min & $\operatorname{Max}$ & 95\% UCB \\
\hline $\mathrm{K}-1420$ OU & Manganese & 2 & 2 & 0 & 470.0000 & 236.0000 & 234.0000 & 706.0000 & 1960.0454 \\
\hline $\mathrm{K}-1420$ OU & Mercury & 4 & 3 & 1 & 0.2025 & 0.0936 & 0.0300 & 0.4500 & 0.4301 \\
\hline $\mathrm{K}-1420$ OU & Methylene chloride & 5 & 4 & 1 & 0.0070 & 0.0011 & 0.0040 & 0.0100 & 0.0093 \\
\hline $\mathrm{K}-1420 \mathrm{OU}$ & Nickel & 2 & 2 & 0 & 24.0500 & 1.5500 & 22.5000 & 25.6000 & 33.8363 \\
\hline $\mathrm{K}-1420$ OU & Nitrate & 4 & 2 & 2 & 20.0075 & 11.5427 & 0.0100 & 40.0000 & 0.0268 \\
\hline $\mathrm{K}-1420 \mathrm{OU}$ & PCB-1254 & 4 & 3 & 1 & 0.6625 & 0.4128 & 0.2200 & 1.9000 & 1.6934 \\
\hline $\mathrm{K}-1420$ OU & Pentachlorophenol & 5 & 1 & 4 & 2.1060 & 0.6458 & 0.1300 & 4.2000 & NA \\
\hline $\mathrm{K}-1420$ OU & Strontium & 2 & 2 & 0 & 38.2500 & 34.4500 & 3.8000 & 72.7000 & 255.7587 \\
\hline $\mathrm{K}-1420$ OU & Tetrachloroethene & 5 & 1 & 4 & 0.0060 & 0.0003 & 0.0050 & 0.0070 & NA \\
\hline $\mathrm{K}-1420$ OU & Thallium & 2 & 1 & 1 & 0.7200 & 0.2800 & 0.4400 & 1.0000 & NA \\
\hline $\mathrm{K}-1420$ OU & Trichloroethene & 5 & 1 & 4 & 0.0410 & 0.0348 & 0.0060 & 0.1800 & NA \\
\hline $\mathrm{K}-1420$ OU & Uranium & 12 & 12 & 0 & 139.1092 & 79.8794 & 1.9800 & 929.0000 & 282.5634 \\
\hline $\mathrm{K}-1420 \mathrm{OU}$ & Vanadium & 2 & 2 & 0 & 48.9000 & 14.6000 & 34.3000 & 63.5000 & 141.0808 \\
\hline $\mathrm{K}-1420$ OU & Zinc & 2 & 2 & 0 & 84.3500 & 11.0500 & 73.3000 & 95.4000 & 154.1170 \\
\hline LEFPC & 4,4-DDD & 115 & 6 & 109 & 0.0166 & 0.0023 & 0.0001 & 0.2200 & 0.0006 \\
\hline LEFPC & 4,4-DDE & 114 & 36 & 78 & 0.0154 & 0.0023 & 0.0002 & 0.2200 & 228.0000 \\
\hline LEFPC & 4,4-DDT & 115 & 5 & 110 & 0.0168 & 0.0023 & 0.0002 & 0.2200 & 0.0014 \\
\hline LEFPC & Acetone & 12 & 12 & 0 & 0.2536 & 0.1800 & 0.0030 & 2.2000 & 0.5768 \\
\hline LEFPC & Aldrin & 115 & 11 & 104 & 0.0083 & 0.0012 & 0.0001 & 0.1100 & 0.0004 \\
\hline LEFPC & Alpha-chlordane & 115 & 39 & 76 & 0.0730 & 0.0121 & 0.0001 & 1.1000 & 0.0025 \\
\hline LEFPC & Aluminum & 150 & 150 & 0 & 12605.6667 & 377.0456 & 0.0000 & 27900.0000 & 13229.7310 \\
\hline LEFPC & Antimony & 1590 & 1316 & 274 & 1.2837 & 0.0656 & 0.1300 & 53.9000 & 0.7872 \\
\hline LEFPC & Arsenic & 1289 & 1275 & 14 & 7.7788 & 0.1166 & 1.1000 & 77.3000 & 7.9621 \\
\hline LEFPC & Barium & 150 & 150 & 0 & 121.3567 & 5.2507 & 33.7000 & 454.0000 & 130.0473 \\
\hline LEFPC & Benzo(a)Pyrene & 113 & 70 & 43 & 0.4917 & 0.0476 & 0.0500 & 3.5000 & 0.4838 \\
\hline LEFPC & Beryllium & 150 & 146 & 4 & 0.9165 & 0.0383 & 0.2500 & 4.6000 & 0.9781 \\
\hline LEFPC & Bis(2-ethylhexyl)Phthalate & 113 & 62 & 51 & 0.3343 & 0.0229 & 0.0450 & 1.3000 & 0.2007 \\
\hline LEFPC & Cadmium & 150 & 100 & 50 & 4.0894 & 0.3975 & 0.7300 & 41.3000 & 4.6446 \\
\hline LEFPC & Chromium & 1698 & 1698 & 0 & 64.6076 & 0.5609 & 6.9000 & 217.0000 & 65.5307 \\
\hline
\end{tabular}


Table G.7 (continued)

\begin{tabular}{|c|c|c|c|c|c|c|c|c|c|}
\hline Location & Analyte & Obs & \# Det & \# Nondet & Mean" & $\begin{array}{c}\text { Standard } \\
\text { Error }\end{array}$ & Min & Max & $95 \%$ UCB \\
\hline LEFPC & Copper & 150 & 150 & 0 & 78.0333 & 7.0314 & 2.6000 & 397.0000 & 89.6714 \\
\hline LEFPC & Cyanide & 36 & 22 & 14 & 3.0242 & 1.7695 & 0.0000 & 62.6000 & 5.8240 \\
\hline LEFPC & Delta-BHC & 115 & 5 & 110 & 0.0084 & 0.0012 & 0.0001 & 0.1100 & 0.0003 \\
\hline LEFPC & Dibenzofuran & 113 & 9 & 104 & 0.4390 & 0.0158 & 0.0520 & 1.3000 & 0.1178 \\
\hline LEFPC & Dieldrin & 115 & 9 & 106 & 0.0169 & 0.0023 & 0.0002 & 0.2200 & 0.0015 \\
\hline LEFPC & DiethylPhthalate & 113 & 2 & 111 & 0.4612 & 0.0134 & 0.1600 & 1.3000 & 0.1733 \\
\hline LEFPC & Di-n-butlyPhthalate & 113 & 33 & 80 & 0.4212 & 0.0190 & 0.0450 & 1.3000 & 0.1841 \\
\hline LEFPC & Endosulfan I & 115 & 3 & 112 & 0.0084 & 0.0012 & 0.0001 & 0.1100 & 0.0009 \\
\hline LEFPC & Endosulfan II & 115 & 5 & 110 & 0.0167 & 0.0023 & 0.0003 & 0.2200 & 0.0010 \\
\hline LEFPC & Endrin & 115 & 9 & 106 & 0.0166 & 0.0023 & 0.0001 & 0.2200 & 0.0007 \\
\hline LEFPC & Gamma-chlordane & 115 & 33 & 82 & 0.0727 & 0.0121 & 0.0001 & 1.1000 & 0.0014 \\
\hline LEFPC & Heptachlor & 115 & 19 & 96 & 0.0081 & 0.0012 & 0.0001 & 0.1100 & 0.0002 \\
\hline LEFPC & Lead & 148 & 148 & 0 & 53.7993 & 4.6434 & 5.2000 & 625.0000 & 61.4855 \\
\hline LEFPC & Lindane & 115 & 4 & 111 & 0.0085 & 0.0012 & 0.0002 & 0.1100 & 0.0007 \\
\hline LEFPC & Manganese & 150 & 150 & 0 & 1110.0367 & 51.1151 & 25.6000 & 4270.0000 & 1194.6395 \\
\hline LEFPC & Mercury & 1720 & 589 & 1131 & 38.4880 & 3.0932 & 0.1100 & 1870.0000 & 41.6088 \\
\hline LEFPC & Methoxychlor & 115 & 12 & 103 & 0.0835 & 0.0117 & 0.0003 & 1.1000 & 0.0059 \\
\hline LEFPC & Methylene chloride & 12 & 12 & 0 & 0.0373 & 0.0087 & 0.0100 & 0.1100 & 0.0529 \\
\hline LEFPC & Nickel & 150 & 146 & 4 & 34.3673 & 2.1702 & 3.7000 & 174.0000 & 37.9061 \\
\hline LEFPC & PCB-1016 & 146 & 9 . & 137 & 0.0896 & 0.0092 & 0.0330 & 1.1000 & 0.0499 \\
\hline LEFPC & PCB-1221 & 146 & 9 & 137 & 0.1201 & 0.0098 & 0.0670 & 1.1000 & 0.1005 \\
\hline LEFPC & PCB-1232 & 146 & 9 & 137 & 0.0896 & 0.0092 & 0.0330 & 1.1000 & 0.0499 \\
\hline LEFPC & РCB-1242 & 146 & 9 & 137 & 0.0896 & 0.0092 & 0.0330 & 1.1000 & 0.0499 \\
\hline LEFPC & PCB-1248 & 146 & 9 & 137 & 0.0896 & 0.0092 & 0.0330 & 1.1000 & 0.0499 \\
\hline LEFPC & PCB-1254 & 146 & 23 & 123 & 0.2579 & 0.0412 & 0.0330 & 3.0000 & 0.2239 \\
\hline LEFPC & PCB-1260 & 145 & 91 & 54 & 0.4311 & 0.0587 & 0.0030 & 3.8000 & 0.4655 \\
\hline LEFPC & Pentachlorophenol & 113 & 2 & 111 & 1.6920 & 0.0927 & 0.0670 & 6.4000 & 0.3767 \\
\hline LEFPC & Selenium & 1716 & 439 & 1277 & 13.5663 & 0.2453 & 0.6100 & 110.0000 & 8.7045 \\
\hline LEFPC & Thallium & 146 & 1 & 145 & 0.8092 & 0.1281 & 0.4300 & 19.3000 & NA \\
\hline
\end{tabular}


Table G.7 (continued)

\begin{tabular}{|c|c|c|c|c|c|c|c|c|c|}
\hline Location & Analyte & Obs & \# Det & \# Nondet & Mean $^{2}$ & $\begin{array}{c}\text { Standard } \\
\text { Error }\end{array}$ & Min & $\operatorname{Max}$ & 95\% UCB \\
\hline LEFPC & Uranium & 24 & 24 & 0 & 9.7083 & 1.2757 & 1.9800 & 25.5900 & 11.8948 \\
\hline LEFPC & Vanadium & 150 & 150 & 0 & 26.8927 & 0.8537 & 9.6000 & 92.7000 & 28.3057 \\
\hline LEFPC & Zinc & 1701 & 521 & 1180 & 179.9126 & 15.5480 & 14.0000 & 7640.0000 & 166.1992 \\
\hline SCF & 1,1-Dichlorethene & 154 & 9 & 145 & 10.4636 & 5.2994 & 0.0020 & 518.1000 & 19.6786 \\
\hline SCF & 1,1,1-trichlorethane & 84 & 13 & 71 & 0.4363 & 0.3034 & 0.0000 & 19.2100 & 0.9550 \\
\hline SCF & 1,2-Dichlorethane & 84 & 4 & 80 & 60.8926 & 42.2368 & 0.0100 & 2591.0000 & 157.2160 \\
\hline SCF & $4,4-\mathrm{DDD}$ & 23 & 5 & 18 & 0.0045 & 0.0006 & 0.0001 & 0.0110 & 0.0015 \\
\hline SCF & 4,4-DDE & 23 & 13 & 10 & 0.0030 & 0.0006 & 0.0002 & 0.0140 & 0.0018 \\
\hline SCF & 4,4-DDT & 23 & 9 & 14 & 0.0058 & 0.0015 & 0.0002 & 0.0300 & 0.0065 \\
\hline SCF & Acetone & 84 & 16 & 68 & 97.9546 & 67.5711 & 0.0110 & 4145.0000 & 212.9860 \\
\hline SCF & Aldrin & 23 & 3 & 20 & 0.0026 & 0.0004 & 0.0001 & 0.0070 & 0.0004 \\
\hline SCF & Alpha-chlordane & 23 & 5 & 18 & 0.0026 & 0.0004 & 0.0001 & 0.0070 & 0.0013 \\
\hline SCF & Aluminum & 22 & 22 & 0 & 16294.0455 & 2471.5459 & 149.0000 & 47000.0000 & 20546.9410 \\
\hline SCF & Antimony & 103 & 91 & 12 & 3.1252 & 0.7214 & 0.0940 & 38.0000 & 1.2148 \\
\hline SCF & Arsenic & 113 & 111 & 2 & 12.7714 & 1.0468 & 0.8000 & 103.7000 & 14.5344 \\
\hline SCF & Barium & 22 & 20 & 2 & 111.6045 & 15.9635 & 0.4000 & 322.0000 & 139.7386 \\
\hline SCF & Benzene & 84 & 7 & 77 & 0.9165 & 0.6335 & 0.0003 & 38.8600 & 2.0400 \\
\hline SCF & Benzo(a)pyrene & 22 & 7 & 15 & 0.4829 & 0.0640 & 0.0580 & 1.1000 & 0.3224 \\
\hline SCF & Beryllium & 22 & 12 & 10 & 1.4800 & 0.1716 & 0.2500 & 3.9000 & 1.6114 \\
\hline SCF & Bis(2-ethylhexyl)phthalate & 22 & 7 & 15 & 0.4390 & 0.0690 & 0.0500 & 1.1000 & 0.1756 \\
\hline SCF & Cadmium & 113 & 91 & 22 & 6.1319 & 0.9122 & 0.0000 & 85.9900 & 7.4130 \\
\hline SCF & Carbon tetrachloride & 84 & 6 & 78 & 0.0031 & 0.0009 & 0.0000 & 0.0420 & 0.0001 \\
\hline SCF & Chloroform & 84 & 6 & 78 & 0.8859 & 0.6124 & 0.0003 & 37.5600 & 1.9872 \\
\hline SCF & Chromium & 113 & 110 & 3 & 56.8916 & 2.4701 & 2.0000 & 204.7000 & 61.1572 \\
\hline SCF & Copper & 22 & 18 & 4 & 20.5545 & 3.9385 & 3.0000 & 81.2000 & 27.8990 \\
\hline SCF & Delta-BHC & 23 & 4 & 19 & 0.0026 & 0.0004 & 0.0001 & 0.0070 & 0.0004 \\
\hline SCF & Dibenzofuran & 22 & 1 & 21 & 0.5218 & 0.0487 & 0.2900 & 1.1000 & NA \\
\hline SCF & Dieldrin & 23 & 7 & 16 & 0.0041 & 0.0007 & 0.0002 & 0.0110 & 0.0013 \\
\hline $\mathrm{SCF}$ & Di-n-butlyphthalate & 22 & 4 & 18 & 0.4705 & 0.0686 & 0.0610 & 1.4000 & 0.1183 \\
\hline
\end{tabular}


Table G.7 (continued)

\begin{tabular}{|c|c|c|c|c|c|c|c|c|c|}
\hline Location & Analyte & Obs & \# Det & \# Nondet & Mean $^{2}$ & $\begin{array}{c}\text { Standard } \\
\text { Error }\end{array}$ & Min & $\operatorname{Max}$ & 95\% UCB \\
\hline SCF & Endosulfan I & 23 & 1 & 22 & 0.0028 & 0.0003 & 0.0009 & 0.0070 & NA \\
\hline SCF & Endrin & 23 & 4 & 19 & 0.0046 & 0.0006 & 0.0001 & 0.0110 & 0.0011 \\
\hline SCF & Gamma-chlordane & 23 & 3 & 20 & 0.0027 & 0.0003 & 0.0005 & 0.0070 & 0.0010 \\
\hline SCF & Heptachlor & 23 & 1 & 22 & 0.0028 & 0.0003 & 0.0005 & 0.0070 & NA \\
\hline SCF & Lead & 22 & 22 & 0 & 41.5059 & 6.2219 & 0.4300 & 135.0000 & 52.2122 \\
\hline SCF & Manganese & 22 & 21 & 1 & 1392.0923 & 265.3807 & 0.8000 & 4080.0000 & 1849.2636 \\
\hline SCF & Mercury & 113 & 102 & 11 & 0.6817 & 0.1102 & 0.0000 & 6.6000 & 0.8542 \\
\hline SCF & Methoxychlor & 23 & 3 & 20 & 0.0266 & 0.0030 & 0.0024 & 0.0710 & 0.0142 \\
\hline SCF & Methylene chloride & 154 & 8 & 146 & 136.1755 & 68.9493 & 0.0110 & 6736.0000 & 281.1491 \\
\hline SCF & Nickel & 22 & 15 & 7 & 18.4182 & 1.8591 & 5.6000 & 37.2000 & 20.3718 \\
\hline SCF & PCB-1254 & 23 & 3 & 20 & 0.0567 & 0.0064 & 0.0200 & 0.1400 & 0.0375 \\
\hline SCF & P.CB-1260 & 23 & 4 & 19 & 0.0665 & 0.0126 & 0.0330 & 0.3100 & 0.0694 \\
\hline SCF & Pentachlorophenol & 103 & 82 & 21 & 0.2657 & 0.0571 & 0.0000 & 2.7000 & 0.0052 \\
\hline SCF & Selenium & 110 & 91 & 19 & 2.7963 & 0.1575 & 0.0387 & 7.9030 & 2.9646 \\
\hline SCF & Tetrachloroethene & 155 & 10 & 145 & 0.5462 & 0.3456 & 0.0000 & 38.8600 & 1.1422 \\
\hline SCF & Toluene & 84 & 7 & 77 & 0.9167 & 0.6335 & 0.0003 & 38.8600 & 2.0452 \\
\hline SCF & Trichloroethene & 154 & 14 & 140 & 0.7824 & 0.4186 & 0.0001 & 44.0400 & 1.4930 \\
\hline SCF & Uranium & 91 & 91 & 0 & 3.1277 & 0.1117 & 1.1902 & 6.0080 & 3.3133 \\
\hline SCF & Vanadium & 20 & 18 & 2 & 31.4000 & 4.3587 & 2.0000 & 67.3000 & 38.9609 \\
\hline $\mathrm{SCF}$ & Zinc & 113 & 111 & 2 & 114.1718 & 19.2046 & 1.9000 & 1524.0000 & 146.0309 \\
\hline UEFPC OU 2 & Aluminum & 2 & 2 & 0 & 29900.0000 & 5600.0000 & 24300.0000 & 35500.0000 & 65257.0090 \\
\hline UEFPC OU 2 & Arsenic & 2 & 2 & 0 & 1.4600 & 1.1400 & 0.3200 & 2.6000 & 8.6577 \\
\hline UEFPC OU 2 & Barium & 2 & 2 & 0 & 149.8500 & 66.1500 & 83.7000 & 216.0000 & 567.5047 \\
\hline UEFPC OU 2 & Beryllium & 2 & 2 & 0 & 1.2500 & 0.1500 & 1.1000 & 1.4000 & 2.1971 \\
\hline UEFPC OU 2 & Chromium & 2 & 2 & 0 & 39.7000 & 5.9000 & 33.8000 & 45.6000 & 76.9511 \\
\hline UEFPC OU 2 & Copper & 2 & 2 & 0 & 22.1000 & 5.2000 & 16.9000 & 27.3000 & 54.9315 \\
\hline UEFPC OU 2 & Lead & 2 & 2 & 0 & 36.6000 & 33.8000 & 2.8000 & 70.4000 & 250.0048 \\
\hline UEFPC OU 2 & Lithium & 2 & 2 & 0 & 22.7000 & 1.4000 & 21.3000 & 24.1000 & 31.5393 \\
\hline UEFPC OU 2 & Manganese & 2 & 2 & 0 & 484.0000 & 334.0000 & 150.0000 & 818.0000 & 2592.7930 \\
\hline
\end{tabular}


Table G.7 (continued)

\begin{tabular}{|c|c|c|c|c|c|c|c|c|c|}
\hline Location & Analyte & Obs & \# Det & \# Nondet & Mean" $^{2}$ & $\begin{array}{l}\text { Standard } \\
\text { Error }\end{array}$ & Min & Max & 95\% UCB \\
\hline UEFPC OU 2 & Nickel & 2 & 2 & 0 & 36.2000 & 3.3000 & 32.9000 & 39.5000 & 57.0354 \\
\hline UEFPC OU 2 & Nitrate & 2 & 2 & 0 & 0.5850 & 0.0850 & 0.5000 & 0.6700 & 1.1217 \\
\hline UEFPC OU 2 & Strontium & 2 & 2 & 0 & 21.1000 & 15.3000 & 5.8000 & 36.4000 & 117.7004 \\
\hline UEFPC OU 2 & Uranium & 2 & 2 & 0 & 1.5650 & 0.7350 & 0.8300 & 2.3000 & 6.2056 \\
\hline UEFPC OU 2 & Vanadium & 2 & 2 & 0 & 26.0000 & 1.4000 & 24.6000 & 27.4000 & 34.8393 \\
\hline UEFPC OU 2 & Zinc & 2 & 2 & 0 & 86.2000 & 31.8000 & 54.4000 & 118.0000 & 286.9773 \\
\hline WAG 1 & 1,1-Dichlorethene & 168 & 2 & 166 & 0.0076 & 0.0004 & 0.0050 & 0.0340 & 0.0060 \\
\hline WAG 1 & 1,1,1-trichlorethane & 168 & 12 & 156 & 0.0077 & 0.0005 & 0.0020 & 0.0340 & 0.0033 \\
\hline WAG 1 & 1,2-Dichlorethane & 168 & 2 & 166 & 0.0076 & 0.0004 & 0.0050 & 0.0340 & 0.0060 \\
\hline WAG 1 & 1,2-Dichlorethene & 168 & 4 & 164 & 0.0076 & 0.0004 & 0.0020 & 0.0340 & 0.0023 \\
\hline WAG 1 & 4,4-DDD & 63 & 1 & 62 & 0.0214 & 0.0013 & 0.0170 & 0.0900 & NA \\
\hline WAG 1 & 4,4-DDE & 63 & 1 & 62 & 0.0218 & 0.0014 & 0.0170 & 0.0900 & NA \\
\hline WAG 1 & 4,4-DDT & 65 & 3 & 62 & 0.0211 & 0.0012 & 0.0076 & 0.0900 & 0.0101 \\
\hline WAG 1 & Acetone & 168 & 107 & 61 & 0.0278 & 0.0024 & 0.0020 & 0.2300 & 0.0293 \\
\hline WAG 1 & Alpha-BHC & 67 & 1 & 66 & 0.0118 & 0.0013 & 0.0083 & 0.0840 & NA \\
\hline WAG 1 & Alpha-chlordane & 67 & 1 & 66 & 0.1049 & 0.0060 & 0.0830 & 0.4500 & NA \\
\hline WAG 1 & Aluminum & 136 & 135 & 1 & 12152.1588 & 558.6427 & 13.6000 & 35200.0000 & 13085439.0000 \\
\hline WAG 1 & Antimony & 49 & 25 & 24 & 6.1265 & 0.3790 & 2.5000 & 17.4000 & 6.0617 \\
\hline WAG 1 & Arsenic & 136 & 132 & 4 & 9.0118 & 0.5659 & 1.2000 & 29.4000 & 9.7694 \\
\hline WAG 1 & Barium & 136 & 135 & 1 & 107.4636 & 4.7336 & 0.4500 & 410.0000 & 115.3482 \\
\hline WAG 1 & Benzene & 168 & 3 & 165 & 0.0076 & 0.0004 & 0.0030 & 0.0340 & 0.0031 \\
\hline WAG 1 & Benzo(a)Pyrene & 123 & 58 & 65 & 0.6776 & 0.1273 & 0.0390 & 12.0000 & 0.7257 \\
\hline WAG 1 & Beryllium & 137 & 131 & 6 & 0.9493 & 0.0369 & 0.1900 & 2.6000 & 1.0127 \\
\hline WAG 1 & Bis(2-ethylhexyl)Phthalate & 123 & 85 & 38 & 0.4584 & 0.0746 & 0.0220 & 8.5000 & 0.4414 \\
\hline WAG 1 & Boron & 40 & 37 & 3 & 1204.9650 & 329.8646 & 4.8000 & 7000.0000 & 1761.2341 \\
\hline WAG 1 & Cadmium & 137 & 66 & 71 & 1.7696 & 0.1478 & 0.2200 & 10.3000 & 1.9618 \\
\hline WAG 1 & Carbon tetrachloride & 168 & 2 & 166 & 0.0076 & 0.0004 & 0.0050 & 0.0340 & 0.0060 \\
\hline WAG 1 & Chloroform & 168 & 44 & 124 & 0.0098 & 0.0017 & 0.0010 & 0.2400 & 0.0090 \\
\hline WAG 1 & Chromium & 136 & 135 & 1 & 28.9507 & 2.4147 & 2.3000 & 189.0000 & 32.9578 \\
\hline
\end{tabular}


Table G.7 (continued)

\begin{tabular}{|c|c|c|c|c|c|c|c|c|c|}
\hline Location & Analyte & Obs & \# Det & \# Nondet & Mean" & $\begin{array}{c}\text { Standard } \\
\text { Error }\end{array}$ & Min & Max & $95 \%$ UCB \\
\hline WAG 1 & Copper & 136 & 132 & 4 & 19.6249 & 1.5910 & 0.7200 & 125.0000 & 22.2562 \\
\hline WAG 1 & Cyanide & 65 & 1 & 64 & 4.6813 & 0.3108 & 0.0001 & 8.0000 & NA \\
\hline WAG 1 & Dibenzofuran & 123 & 10 & 113 & 0.5403 & 0.0512 & 0.0290 & 5.5000 & 0.1746 \\
\hline WAG 1 & Diethylphthalate & 123 & 10 & 113 & 0.5785 & 0.0578 & 0.0220 & 5.5000 & 0.0481 \\
\hline WAG 1 & Di-n-butlyphthalate & 122 & 73 & 49 & 0.7199 & 0.0595 & 0.0440 & 2.9000 & 0.7003 \\
\hline WAG 1 & Endrin & 66 & 1 & 65 & 0.0210 & 0.0012 & 0.0028 & 0.0900 & NA \\
\hline WAG 1 & Gamma-chlordane & 67 & 1 & 66 & 0.1043 & 0.0060 & 0.0550 & 0.4500 & NA \\
\hline WAG 1 & Heptachlor & 67 & 1 & 66 & 0.0105 & 0.0006 & 0.0083 & 0.0450 & $\mathrm{NA}$ \\
\hline WAG 1 & Lead & 134 & 133 & 1 & 40.8739 & 3.3078 & 2.9000 & 337.0000 & 46.3236 \\
\hline WAG 1 & Manganese & 136 & 135 & 1 & 841.9415 & 40.8851 & 0.4500 & 2970.0000 & 909.9661 \\
\hline WAG 1 & Mercury & 93 & 49 & 44 & 1.3060 & 0.3266 & 0.1000 & 16.4000 & 1.8496 \\
\hline WAG 1 & Methylene chloride & 168 & 152 & 16 & 0.0310 & 0.0035 & 0.0010 & 0.3600 & 0.0366 \\
\hline WAG 1 & Nickel & 136 & 135 & 1 & 19.2610 & 0.7882 & 3.3000 & 47.7000 & 20.5598 \\
\hline WAG 1 & PCB-1254 & 66 & 10 & 56 & 0.3505 & 0.0922 & 0.0800 & 5.8000 & 0.4403 \\
\hline WAG 1 & PCB-1260 & 67 & 10 & 57 & 0.2473 & 0.0289 & 0.0880 & 1.9000 & 0.2270 \\
\hline WAG 1 & Pentachlorophenol & 123 & 5 & 118 & 2.9574 & 0.2817 & 0.0530 & 26.0000 & 0.2800 \\
\hline WAG 1 & Selenium & 102 & 48 & 54 & 14.5650 & 1.6571 & 0.3900 & 52.1000 & 16.8413 \\
\hline WAG 1 & Tetrachloroethene & 168 & 5 & 163 & 0.0076 & 0.0004 & 0.0020 & 0.0340 & 0.0043 \\
\hline WAG 1 & Thallium & 133 & 35 & 98 & 14.1675 & 2.1681 & 0.2200 & 127.0000 & 15.8509 \\
\hline WAG 1 & Tin & 40 & 40 & 0 & 50.7300 & 2.0604 & 31.8000 & 83.9000 & 54.2015 \\
\hline WAG 1 & Toluene & 168 & 41 & 127 & 0.0071 & 0.0004 & 0.0006 & 0.0340 & 0.0035 \\
\hline WAG 1 & Trichloroethene & 168 & 14 & 154 & 0.0074 & 0.0005 & 0.0010 & 0.0340 & 0.0023 \\
\hline WAG 1 & Uranium & 90 & 90 & 0 & 7.9570 & 3.9183 & 0.5200 & 323.0000 & 14.4699 \\
\hline WAG 1 & Vanadium & 137 & 136 & 1 & 21.5983 & 0.7594 & 0.4700 & 54.5000 & 22.8507 \\
\hline WAG 1 & Vinyl chloride & 168 & 2 & 166 & 0.0155 & 0.0009 & 0.0100 & 0.0680 & 0.0120 \\
\hline WAG 1 & Zinc & 136 & 135 & 1 & 91.9930 & 8.2040 & 0.4500 & 514.0000 & 105.6279 \\
\hline WAG 6 & 1,2-Dichlorethene & 37 & 1 & 36 & 0.0068 & 0.0002 & 0.0060 & 0.0150 & NA \\
\hline WAG 6 & 1,4-Dioxane & 4 & 2 & 2 & 6.6750 & 0.3198 & 6.2000 & 7.6000 & 7.5588 \\
\hline WAG 6 & Acetone & 37 & 23 & 14 & 0.0139 & 0.0010 & 0.0060 & 0.0440 & 0.0147 \\
\hline
\end{tabular}


Table G.7 (continued)

\begin{tabular}{|c|c|c|c|c|c|c|c|c|c|}
\hline Location & Analyte & Obs & \# Det & \# Nondet & Mean* & $\begin{array}{c}\text { Standard } \\
\text { Error }\end{array}$ & Min & $\operatorname{Max}$ & 95\% UCB \\
\hline WAG 6 & Aluminum & 32 & 32 & 0 & 15837.8125 & 813.9395 & 7380.0000 & 24600.0000 & 17217862.0000 \\
\hline WAG 6 & Arsenic & 32 & 27 & 5 & 1.7666 & 0.1659 & 0.3700 & 4.2000 & 2.0874 \\
\hline WAG 6 & Barium & 32 & 32 & 0 & 132.8125 & 6.2860 & 70.6000 & 228.0000 & 143.4706 \\
\hline WAG 6 & Beryllium & 32 & 32 & 0 & 1.3834 & 0.0605 & 0.9700 & 2.4000 & 1.4859 \\
\hline WAG 6 & Bis(2-ethylhexyl)phthalate & 32 & 27 & 5 & 0.3983 & 0.0530 & 0.0660 & 1.7000 & 0.4624 \\
\hline WAG 6 & Cadmium & 32 & 28 & 4 & 2.5013 & 0.1860 & 0.5800 & 4.0000 & 2.8456 \\
\hline WAG 6 & Chloroform & 37 & 21 & 16 & 0.0114 & 0.0017 & 0.0020 & 0.0640 & 0.0128 \\
\hline WAG 6 & Chromium & 32 & 32 & 0 & 24.6031 & 1.0401 & 13.1000 & 34.8000 & 26.3667 \\
\hline WAG 6 & Copper & 32 & 32 & 0 & 16.5219 & 0.9470 & 7.1000 & 27.5000 & 18.1276 \\
\hline WAG 6 & Cyanide & 32 & 1 & 31 & 23.8172 & 13.0661 & 0.0100 & 250.0000 & NA \\
\hline WAG 6 & Lead & 31 & 30 & 1 & 15.4981 & 1.7097 & 0.5400 & 46.2000 & 18.4334 \\
\hline WAG 6 & Manganese & 32 & 32 & 0 & 1037.6594 & 116.8054 & 54.1000 & 3530.0000 & 1235.7050 \\
\hline WAG 6 & Mercury & 30 & 4 & 26 & 0.1007 & 0.0080 & 0.0000 & 0.1400 & 0.0374 \\
\hline WAG 6 & Methylene chloride & 37 & 37 & 0 & 0.0283 & 0.0057 & 0.0060 & 0.2000 & 0.0378 \\
\hline WAG 6 & Nickel & 32 & 32 & 0 & 38.2844 & 1.9707 & 18.7000 & 59.7000 & 41.6257 \\
\hline WAG 6 & Tetrachloroethene & 37 & 2 & 35 & 0.0063 & 0.0002 & 0.0020 & 0.0080 & 0.0033 \\
\hline WAG 6 & Tin & 4 & 4 & 0 & 55.0250 & 14.5400 & 25.7000 & 87.1000 & 89.2430 \\
\hline WAG 6 & Toluene & 37 & 17 & 20 & 0.0044 & 0.0004 & 0.0010 & 0.0080 & 0.0025 \\
\hline WAG 6 & Trichloroethene & 37 & 13 & 24 & 0.0055 & 0.0005 & 0.0010 & 0.0170 & 0.0036 \\
\hline WAG 6 & Uranium & 4 & 4 & 0 & 0.8183 & 0.0800 & 0.6870 & 1.0500 & 1.0065 \\
\hline WAG 6 & Vanadium & 32 & 32 & 0 & 17.1344 & 0.8968 & 5.7000 & 32.5000 & 18.6549 \\
\hline WAG 6 & Zinc & 32 & 32 & 0 & 57.4594 & 3.0367 & 23.5000 & 103.0000 & 62.6082 \\
\hline
\end{tabular}

${ }^{\circ}$ Mean: In cases where only a single detected value was observed at that location, the single detected concentration is presented. The $95 \%$ UCB is designated with NA.

${ }^{\mathrm{b}} \mathrm{NA}=$ Not Available. 
Table G.8. Contaminant concentrations in soil (mg/kg) on the ORR compared with background soil levels (ESD 1993)

\begin{tabular}{|c|c|c|c|c|c|c|c|}
\hline \multirow[t]{2}{*}{ LOCATION } & \multirow[t]{2}{*}{ FORMATION" } & \multirow[t]{2}{*}{ ANALYTE } & \multicolumn{2}{|c|}{ BACKGROUND } & \multicolumn{2}{|c|}{ OU SOIL } & \multirow{2}{*}{$\begin{array}{c}\text { Retained }^{\mathrm{b}}- \\
\text { Exceeds } \\
\text { Background? }\end{array}$} \\
\hline & & & $\begin{array}{c}\text { 95\% UCB } \\
\text { HIGH }\end{array}$ & $\begin{array}{c}\text { 95\% UCB } \\
\text { LOW }\end{array}$ & MEAN & $95 \%$ UCB & \\
\hline LEFPC & $\mathrm{CHI}$ & Aluminum & 18600 & NA & 12605.6667 & 13229.7316 & NO \\
\hline LEFPC & & Antimony & NA & NA & 1.2837 & 0.7872 & YES \\
\hline LEFPC & $\mathrm{CHI}$ & Arsenic & 9.73 & NA & 7.7788 & 7.9621 & NO \\
\hline LEFPC & CHI & Barium & 99.6 & NA & 121.3567 & 130.0473 & YES \\
\hline LEFPC & $\mathrm{CHI}$ & Beryllium & 1.120 & NA & 0.9165 & 0.9781 & No \\
\hline LEFPC & & Cadmium & NA & NA & 4.0894 & 4.6446 & YES \\
\hline LEFPC & CHI & Chromium & 38.5 & $\mathrm{NA}$ & 64.6076 & 65.5307 & YES \\
\hline LEFPC & $\mathrm{CHI}$ & Copper & 14.50 & NA & 78.0333 & 89.6714 & YES \\
\hline LEFPC & $\mathrm{CHI}\left(\mathrm{DG}^{\mathrm{c}}\right)$ & Cyanide & .583 & NA & 3.0242 & 5.8240 & YES \\
\hline LEFPC & $\mathrm{CHI}$ & Lead & 43.2 & NA & 53.7993 & 61.4855 & YES \\
\hline LEFPC & $\mathrm{CHI}$ & Manganese & 2290 & NA & 1110.0367 & 1194.6395 & No \\
\hline LEFPC & $\mathrm{CHI}$ & Mercury & 0.5790 & NA & 38.4880 & 41.6088 & YES \\
\hline LEFPC & $\mathrm{CHI}$ & Nickel & 21.30 & NA & 34.3673 & 37.9061 & YES \\
\hline LEFPC & $\mathrm{CHI}$ & Selenium & 0.962 & $\mathrm{NA}$ & 13.5663 & 8.7045 & YES \\
\hline LEFPC & & Thallium & NA & NA & 0.8092 & NA & YES \\
\hline LEFPC & $\mathrm{CHI}$ & Vanadium & 42.0 & NA & 26.8927 & 28.3057 & NO \\
\hline LEFPC & $\mathrm{CHI}$ & Zinc & 56.9 & NA & 179.9126 & 166.1992 & YES \\
\hline $\mathrm{K}-1407$ OU & $\mathrm{CHI}$ & Aluminum & 18600 & NA & 26562.9630 & 28723.5267 & YES \\
\hline
\end{tabular}


Table G.8 (continued)

\begin{tabular}{|c|c|c|c|c|c|c|c|}
\hline \multirow[t]{2}{*}{ LOCATION } & \multirow[t]{2}{*}{ FORMATION } & \multirow[t]{2}{*}{ ANALYTE } & \multicolumn{2}{|c|}{ BACKGROUND } & \multicolumn{2}{|c|}{ OU SOL } & \multirow{2}{*}{$\begin{array}{c}\text { Retained }^{\mathrm{b}}- \\
\text { Exceeds } \\
\text { Background? }\end{array}$} \\
\hline & & & $\begin{array}{c}\text { 95\% UCB } \\
\text { HIGH }\end{array}$ & $\begin{array}{c}\text { 95\% UCB } \\
\text { LOW }\end{array}$ & MEAN & 95\% UCB & \\
\hline $\mathrm{K}-1407$ OU & $\mathrm{CHI}$ & Antimony & NA & NA & 7.1506 & NA & YES \\
\hline $\mathrm{K}-1407 \mathrm{OU}$ & $\mathrm{CHI}$ & Arsenic & 9.73 & NA & 12.4333 & 13.0681 & YES \\
\hline $\mathrm{K}-1407 \mathrm{OU}$ & $\mathrm{CHI}$ & Barium & 99.6 & NA & 110.4938 & 125.2752 & YES \\
\hline $\mathrm{K}-1407$ OU & $\mathrm{CHI}$ & Beryllium & 1.120 & NA & 1.0159 & 1.1269 & YES \\
\hline K-1407 OU & $\mathrm{CHI}$ & Boron & NA & NA & 6.4191 & 8.3996 & YES \\
\hline K-1407 OU & $\mathrm{CHI}$ & Cadmium & NA & NA & 1.8799 & 2.1492 & YES \\
\hline $\mathrm{K}-1407 \mathrm{OU}$ & $\mathrm{CHI}$ & Chromium & 38.5 & NA & 61.0370 & 69.8642 & YES \\
\hline $\mathrm{K}-1407$ OU & $\mathrm{CHI}$ & Copper & 14.50 & $\mathrm{NA}$ & 40.8537 & 48.6398 & YES \\
\hline $\mathrm{K}-1407 \mathrm{OU}$ & $\mathrm{CHI}$ & Lead & 43.2 & NA & 30.6753 & 32.9964 & No \\
\hline $\mathrm{K}-1407$ OU & $\mathrm{CHI}$ & Manganese & 2290 & NA & 1184.7778 & 1355.2705 & No \\
\hline $\mathrm{K}-1407$ OU & $\mathrm{CHI}$ & Mercury & 0.5790 & NA & 4.7250 & 6.3965 & YES \\
\hline $\mathrm{K}-1407 \mathrm{OU}$ & $\mathrm{CHI}$ & Molybdenum & 3.20 & NA & 1.8006 & 1.5498 & No \\
\hline $\mathrm{K}-1407$ OU & $\mathrm{CHI}$ & Nickel & 21.30 & NA & 192.1790 & 251.0899 & YES \\
\hline
\end{tabular}


Table G.8 (continued)

\begin{tabular}{|c|c|c|c|c|c|c|c|}
\hline \multirow[t]{2}{*}{ LOCATION } & \multirow[t]{2}{*}{ FORMATION $^{\wedge}$} & \multirow[t]{2}{*}{ ANALYTE } & \multicolumn{2}{|c|}{ BACKGROUND } & \multicolumn{2}{|c|}{ OU SOL } & \multirow{2}{*}{$\begin{array}{l}\text { Retained }^{\mathrm{b}}- \\
\text { Exceeds } \\
\text { Background? }\end{array}$} \\
\hline & & & $\begin{array}{c}95 \% \text { UCB } \\
\text { HIGH } \\
\end{array}$ & $\begin{array}{c}95 \% \text { UCB } \\
\text { LOW }\end{array}$ & MEAN & $95 \%$ UCB & \\
\hline $\mathrm{K}-1407$ OU & $\mathrm{CHI}$ & Selenium & 0.962 & $\mathrm{NA}$ & 7.1519 & NA & YES \\
\hline $\mathrm{K}-1407$ OU & $\mathrm{CHI}$ & Strontium & 16.000 & $\mathrm{NA}$ & 18.1420 & 20.6695 & YES \\
\hline K-1407 OU & $\mathrm{CHI}$ & Vanadium & 42.0 & NA & 38.9753 & 41.3405 & No \\
\hline $\mathrm{K}-1407$ OU & $\mathrm{CHI}$ & Zinc & 56.9 & NA & 59.7778 & 64.4711 & YES \\
\hline WAG 1 & $\mathrm{DG}, \mathrm{NL}$ & Aluminum & 25000 & 232000 & 12152.1588 & 13085.4391 & No \\
\hline WAG 1 & NL & Antimony & 0.485 & NA & 6.1265 & 6.0617 & YES \\
\hline WAG 1 & $\mathrm{DG}, \mathrm{NL}$ & Arsenic & 8.18 & 7.97 & 9.0118 & 9.7694 & YES \\
\hline WAG 1 & $\mathrm{DG}, \mathrm{NL}$ & Barium & 129.0 & 97.8 & 107.4636 & 115.3482 & NO \\
\hline WAG 1 & $\mathrm{DG}, \mathrm{NL}$ & Beryllium & 0.964 & 0.957 & 0.9493 & 1.0127 & YES \\
\hline WAG 1 & DG & Boron & 22.70 & $\mathrm{NA}$ & 1204.9650 & 1761.2341 & YES \\
\hline WAG 1 & & Cadmium & NA & NA & 1.7696 & 1.9618 & YES \\
\hline WAG 1 & $\mathrm{DG}, \mathrm{NL}$ & Chromium & 34.0 & 29.2 & 28.9507 & 32.9578 & YES \\
\hline WAG 1 & $\mathrm{DG}, \mathrm{NL}$ & Copper & 20.50 & 14.90 & 19.6249 & 22.2562 & YES \\
\hline WAG 1 & DG & Cyanide & 0.398 & NA & 4.6813 & $\mathrm{NA}$ & YES \\
\hline WAG 1 & DG, NL & Lead & 27.7 & 25.1 & 40.8739 & 46.3236 & YES \\
\hline WAG 1 & $\mathrm{DG}, \mathrm{NL}$ & Manganese & 1370 & 895 & 841.9415 & 909.9661 & No \\
\hline WAG 1 & DG, NL & Mercury & 0.3700 & 0.2170 & 1.3060 & 1.8496 & YES \\
\hline
\end{tabular}


Table G.8 (continued)

\begin{tabular}{|c|c|c|c|c|c|c|c|}
\hline \multirow[t]{2}{*}{ LOCATION } & \multirow[t]{2}{*}{ FORMATION $^{2}$} & \multirow[t]{2}{*}{ ANALYTE } & \multicolumn{2}{|c|}{ BACKGROUND } & \multicolumn{2}{|c|}{ OU SOH } & \multirow{2}{*}{$\begin{array}{l}\text { Retained }^{\mathrm{b}}- \\
\text { Exceeds } \\
\text { Background? }\end{array}$} \\
\hline & & & $\begin{array}{c}\text { 95\% UCB } \\
\text { HIGH }\end{array}$ & $\begin{array}{c}\text { 95\% UCB } \\
\text { LOW }\end{array}$ & MEAN & 95\% UCB & \\
\hline WAG 1 & DG, NL & Nickel & 21.40 & 16.70 & 19.2610 & 20.5598 & NO \\
\hline WAG 1 & $\mathrm{DG}, \mathrm{NL}$ & Selenium & 0.931 & 0.718 & 14.5650 & 16.8413 & YES \\
\hline WAG 1 & DG & Thallium & 0.556 & NA & 14.1675 & 15.8509 & YES \\
\hline WAG 1 & DG, NL & Vanadium & 39.1 & 37.1 & 21.5983 & 22.8507 & No \\
\hline WAG 1 & $\mathrm{DG}, \mathrm{NL}$ & Zinc & 62.6 & 46.8 & 91.9930 & 105.6279 & YES \\
\hline WAG 6 & $\mathrm{DG}, \mathrm{NL}$ & Aluminum & 25000 & 23200 & 15837.8125 & 17217.8622 & NO \\
\hline WAG 6 & $\mathrm{DG}, \mathrm{NL}$ & Arsenic & 8.18 & 7.97 & 1.7666 & 2.0874 & NO \\
\hline WAG 6 & $\mathrm{DG}, \mathrm{NL}$ & Barium & 129.0 & 97.8 & 132.8125 & 143.4706 & YES \\
\hline WAG 6 & $\mathrm{DG}, \mathrm{NL}$ & Beryllium & 0.964 & 0.957 & 1.3834 & 1.4859 & YES \\
\hline WAG 6 & & Cadmium & NA & NA & 2.5013 & 2.8456 & YES \\
\hline WAG 6 & DG, NL & Chromium & 34.0 & 29.2 & 24.6031 & 26.3667 & NO \\
\hline WAG 6 & $\mathrm{DG}, \mathrm{NL}$ & Copper & 20.50 & 14.90 & 16.5219 & 18.1276 & NO \\
\hline WAG 6 & $\mathrm{DG}, \mathrm{NL}$ & Cyanide & 0.281 & NA & 23.8172 & $\mathrm{NA}$ & YES \\
\hline WAG 6 & $\mathrm{DG}, \mathrm{NL}$ & Lead & 27.7 & 25.1 & 15.4981 & 18.4334 & NO \\
\hline WAG 6 & $\mathrm{DG}, \mathrm{NL}$ & Manganese & 1370 & 895 & 1037.6594 & 1235.7050 & NO \\
\hline WAG 6 & $\mathrm{DG}, \mathrm{NL}$ & Mercury & 0.3700 & 0.2170 & 0.1007 & 0.0374 & No \\
\hline WAG 6 & $\mathrm{DG}, \mathrm{NL}$ & Nickel & 36.10 & 26.60 & 38.2844 & 41.6257 & YES \\
\hline WAG 6 & $\mathrm{DG}, \mathrm{NL}$ & Vanadium & 39.1 & 37.1 & 17.1344 & 18.6549 & No \\
\hline WAG 6 & $\mathrm{DG}, \mathrm{NL}$ & Zinc & 62.6 & 46.8 & 57.4594 & 62.6082 & No \\
\hline
\end{tabular}


Table G.8 (continued)

\begin{tabular}{|c|c|c|c|c|c|c|c|}
\hline \multirow[t]{2}{*}{ LOCATION } & \multirow[t]{2}{*}{ FORMATION ${ }^{\wedge}$} & \multirow[t]{2}{*}{ ANALYTE } & \multicolumn{2}{|c|}{ BACKGROUND } & \multicolumn{2}{|c|}{ OU SOIL } & \multirow{2}{*}{$\begin{array}{c}\text { Retained }^{\mathrm{b}}- \\
\text { Exceeds } \\
\text { Background? }\end{array}$} \\
\hline & & & $\begin{array}{c}\text { 95\% UCB } \\
\text { HIGH }\end{array}$ & $\begin{array}{c}95 \% \text { UCB } \\
\text { LOW }\end{array}$ & MEAN & 95\% UCB & \\
\hline UEFPC OU 2 & $\mathrm{CHI}$ & Aluminum & 18600 & NA & 29900.0000 & 65257.0085 & YES \\
\hline UEFPC OU 2 & $\mathrm{CHI}$ & Arsenic & 9.73 & NA & 1.4600 & 8.6577 & NO \\
\hline UEFPC OU 2 & $\mathrm{CHI}$ & Barium & 99.6 & NA & 149.8500 & 567.5047 & YES \\
\hline UEFPC OU 2 & $\mathrm{CHI}$ & Beryllium & 1.120 & NA & 1.2500 & 2.1971 & YES \\
\hline UEFPC OU 2 & $\mathrm{CHI}$ & Chromium & 38.5 & NA & 39.7000 & 76.9511 & YES \\
\hline UEFPC OU 2 & $\mathrm{CHI}$ & Copper & 14.50 & NA & 22.1000 & 54.9315 & YES \\
\hline UEFPC OU 2 & $\mathrm{CHI}$ & Lead & 43.2 & NA & 36.6000 & 250.0048 & YES \\
\hline UEFPC OU 2 & $\mathrm{CHI}$ & Lithium & 17.40 & NA & 22.7000 & 31.5393 & YES \\
\hline UEFPC OU 2 & $\mathrm{CHI}$ & Manganese & 2290 & NA & 484.0000 & 2592.7930 & YES \\
\hline UEFPC OU 2 & $\mathrm{CHI}$ & Nickel & 21.30 & NA & 36.2000 & 57.0354 & YES \\
\hline UEFPC OU 2 & $\mathrm{CHI}$ & Strontium & 16.000 & NA & 21.1000 & 117.7004 & YES \\
\hline UEFPC OU 2 & $\mathrm{CHI}$ & Vanadium & 42.0 & NA & 26.0000 & 34.8393 & NO \\
\hline UEFPC OU 2 & $\mathrm{CHI}$ & Zinc & 56.9 & NA & 86.2000 & 286.9773 & YES \\
\hline
\end{tabular}


Table G.8 (continued)

\begin{tabular}{|c|c|c|c|c|c|c|c|}
\hline \multirow[t]{2}{*}{ LOCATION } & \multirow[t]{2}{*}{ FORMATION" } & \multirow[t]{2}{*}{ ANALYTE } & \multicolumn{2}{|c|}{ BACKGROUND } & \multicolumn{2}{|c|}{ OU SOIL } & \multirow{2}{*}{$\begin{array}{c}\text { Retained }^{\mathrm{b}}- \\
\text { Exceeds } \\
\text { Background? }\end{array}$} \\
\hline & & & $\begin{array}{c}\text { 95\% UCB } \\
\text { HIGH }\end{array}$ & $\begin{array}{c}95 \% \text { UCB } \\
\text { LOW }\end{array}$ & MEAN & $95 \%$ UCB & \\
\hline BC OU 2 & $\mathrm{CR}$ & Aluminum & 11800 & NA & 26143.8462 & 35920.3403 & YES \\
\hline $\mathrm{BC}$ OU 2 & & Antimony & $\mathrm{NA}$ & NA & 0.3089 & 0.3570 & YES \\
\hline $\mathrm{BC}$ OU 2 & $\mathrm{CR}$ & Arsenic & 30.70 & NA & 33.3692 & 35.0930 & YES \\
\hline $\mathrm{BC}$ OU 2 & $\mathrm{CR}$ & Barium & 93.2 & NA & 101.4000 & 153.9779 & YES \\
\hline $\mathrm{BC}$ OU 2 & $\mathrm{CR}$ & Beryllium & 0.634 & $\mathrm{NA}$ & 1.0246 & 1.3154 & YES \\
\hline $\mathrm{BC}$ OU 2 & $\mathrm{CR}$ & Boron & $\mathrm{NA}$ & NA & 65.5000 & 79.4061 & YES \\
\hline $\mathrm{BC}$ OU 2 & $\mathrm{CR}$ & Cadmium & NA & $\mathrm{NA}$ & 1.2469 & 0.8571 & YES \\
\hline $\mathrm{BC}$ OU 2 & $\mathrm{CR}$ & Chromium & 18.3 & NA & 37.3308 & 44.2323 & YES \\
\hline $\mathrm{BC}$ OU 2 & $\mathrm{CR}$ & Copper & 8.19 & NA & 39.2231 & 57.3653 & YES \\
\hline $\mathrm{BC}$ OU 2 & $\mathrm{CR}$ & Lead & 23.00 & $\mathrm{NA}$ & 81.0154 & 126.8223 & YES \\
\hline $\mathrm{BC}$ OU 2 & $\mathrm{CR}$ & Lithium & 3.48 & NA & 39.2500 & 47.1944 & YES \\
\hline $\mathrm{BC}$ OU 2 & $\mathrm{CR}$ & Manganese & 1460 & NA & 1021.5231 & 1779.3673 & YES \\
\hline $\mathrm{BC}$ OU 2 & CR & Mercury & 0.184 & NA & 49.0188 & 76.0554 & YES \\
\hline $\mathrm{BC}$ OU 2 & $\mathrm{CR}$ & Nickel & 9.71 & NA & 32.6000 & 50.3224 & YES \\
\hline $\mathrm{BC}$ OU 2 & $\mathrm{CR}$ & Selenium & 0.803 & NA & 1.0944 & 1.7881 & YES \\
\hline $\mathrm{BC}$ OU 2 & $\mathrm{CR}$ & Strontium & 4.810 & $\mathrm{NA}$ & 109.9250 & 133.8695 & YES \\
\hline $\mathrm{BC}$ OU 2 & $\mathrm{CR}$ & Thallium & 1.370 & $\mathrm{NA}$ & 0.3144 & 0.3644 & NO \\
\hline $\mathrm{BC}$ OU 2 & $\mathrm{CR}$ & Vanadium & 30.3 & NA & 54.8385 & 62.5775 & YES \\
\hline $\mathrm{BC}$ OU 2 & $\mathrm{CR}$ & Zinc & 43.2 & NA & 113.2077 & 149.4180 & YES \\
\hline SCF & $\mathrm{CHI}$ & Aluminum & 18600 & NA & 16294.0455 & 20546.9405 & YES \\
\hline
\end{tabular}


Table G.8 (continued)

\begin{tabular}{|c|c|c|c|c|c|c|c|}
\hline \multirow[t]{2}{*}{ LOCATION } & \multirow[t]{2}{*}{ FORMATION" } & \multirow[t]{2}{*}{ ANALYTE } & \multicolumn{2}{|c|}{ BACKGROUND } & \multicolumn{2}{|c|}{ OU SOIL } & \multirow{2}{*}{$\begin{array}{c}\text { Retained }^{\mathrm{b}}- \\
\text { Exceeds } \\
\text { Background? }\end{array}$} \\
\hline & & & $\begin{array}{c}\text { 95\%.UCB } \\
\text { HIGH }\end{array}$ & $\begin{array}{c}95 \% \text { UCB } \\
\text { LOW }\end{array}$ & MEAN & $95 \%$ UCB & \\
\hline SCF & $\mathrm{CHI}$ & Antimony & $\mathrm{NA}$ & NA & 3.1252 & 1.2148 & YES \\
\hline SCF & CHI & Arsenic & 7.99 & NA & 12.7714 & 14.5344 & YES \\
\hline SCF & $\mathrm{CHI}$ & Barium & 103.0 & NA & 111.6045 & 139.7386 & YES \\
\hline SCF & $\mathrm{CHI}$ & Beryllium & 1.250 & NA & 1.4800 & 1.6114 & YES \\
\hline SCF & $\mathrm{CHI}$ & Cadmium & NA & NA & 6.1319 & 7.4130 & YES \\
\hline SCF & $\mathrm{CHI}$ & Chromium & 40.2 & $\mathrm{NA}^{\prime}$ & 56.8916 & 61.1572 & YES \\
\hline SCF & $\mathrm{CHI}$ & Copper & 20.60 & NA & 20.5545 & 27.8990 & YES \\
\hline SCF & $\mathrm{CHI}$ & Lead & 51.1 & NA & 41.5059 & 52.2122 & YES \\
\hline SCF & $\mathrm{CHI}$ & Manganese & 1440 & NA & 1392.0923 & 1849.2636 & YES \\
\hline SCF & $\mathrm{CHI}$ & Mercury & 0.1880 & NA & 0.6817 & 0.8542 & YES \\
\hline SCF & $\mathrm{CHI}$ & Nickel & 16.70 & NA & 18.4182 & 20.3718 & YES \\
\hline SCF & $\mathrm{CHI}$ & Selenium & 0.931 & NA & 2.7963 & 2.9646 & YES \\
\hline SCF & $\mathrm{CHI}$ & Vanadium & 41.9 & $\mathrm{NA}$ & 31.4000 & 38.9609 & NO \\
\hline SCF & $\mathrm{CHI}$ & Zinc & 55.5 & $\mathrm{NA}$ & 114.1718 & 146.0309 & YES \\
\hline $\mathrm{K}-1420$ OU & $\mathrm{CK}^{\mathrm{d}}$ & Aluminum & 15300 & 9510 & 19950.0000 & 49308.9445 & YES \\
\hline $\mathrm{K}-1420$ OU & $\mathrm{CK}$ & Arsenic & 30.70 & 11.80 & 18.4700 & 26.9549 & NO \\
\hline $\mathrm{K}-1420$ OU & CK & Barium & 151.0 & 69.5 & 31.8500 & 83.9384 & YES \\
\hline $\mathrm{K}-1420$ OU & $\mathrm{CK}$ & Beryllium & 0.911 & 0.460 & 0.3750 & 1.2905 & YES \\
\hline
\end{tabular}


Table G.8 (continued)

\begin{tabular}{|c|c|c|c|c|c|c|c|}
\hline \multirow[t]{2}{*}{ LOCATION } & \multirow[t]{2}{*}{ FORMATION" } & \multirow[t]{2}{*}{ ANALYTE } & \multicolumn{2}{|c|}{ BACKGROUND } & \multicolumn{2}{|c|}{ OU SOIL } & \multirow{2}{*}{$\begin{array}{c}\text { Retained }^{\mathrm{b}}- \\
\text { Exceeds } \\
\text { Background? }\end{array}$} \\
\hline & & & $\begin{array}{c}\text { 95\% UCB } \\
\text { HIGH }\end{array}$ & $\begin{array}{c}95 \% \text { UCB } \\
\text { LOW }\end{array}$ & MEAN & 95\% UCB & \\
\hline $\mathrm{K}-1420$ OU & $\mathrm{CK}$ & Boron & 4.87 & NA & 2.7000 & NA & NO \\
\hline $\mathrm{K}-1420$ OU & $\mathrm{CK}$ & Chromium & 23.9 & 15.0 & 15.2000 & 25.4717 & YES \\
\hline $\mathrm{K}-1420 \mathrm{OU}$ & $\mathrm{CK}$ & Copper & 11.6 & 5.26 & 26.2000 & 47.0354 & YES \\
\hline $\mathrm{K}-1420$ OU & $\mathrm{CK}$ & Lead & 52.2 & 24.6 & 66.2500 & 90.5177 & YES \\
\hline $\mathrm{K}-1420$ OU & CK & Lithium & 9.17 & 3.48 & 52.2000 & 228.3537 & YES \\
\hline $\mathrm{K}-1420$ OU & $\mathrm{CK}$ & Manganese & 3060 & 1170 & 470.0000 & 1960.0454 & No \\
\hline $\mathrm{K}-1420$ OU & $\mathrm{CK}$ & Mercury & 0.1840 & 0.1300 & 0.2025 & 0.4301 & YES \\
\hline $\mathrm{K}-1420$ OU & CK & Nickel & 10.70 & 6.06 & 24.0500 & 33.8363 & YES \\
\hline $\mathrm{K}-1420 \mathrm{OU}$ & $\mathrm{CK}$ & Strontium & 7.68 & 3.33 & 38.2500 & 255.7587 & YES \\
\hline $\mathrm{K}-1420 \mathrm{OU}$ & $\mathrm{CK}$ & Thallium & 1.370 & NA & 0.7200 & NA & NO \\
\hline $\mathrm{K}-1420$ OU & $\mathrm{CK}$ & Vanadium & 39.4 & 26.4 & 48.9000 & 141.0808 & YES \\
\hline $\mathrm{K}-1420$ OU & $\mathrm{CK}$ & Zinc & 54.5 & 43.2 & 84.3500 & 154.1170 & YES \\
\hline CR OU2 & $\mathrm{CR}, \mathrm{CK}, \mathrm{CG}, \mathrm{CHE}$ & Aluminum & 18600 & 9510 & NA & 21900 & YES \\
\hline
\end{tabular}


Table G.8 (continued)

\begin{tabular}{|c|c|c|c|c|c|c|c|}
\hline \multirow[t]{2}{*}{ LOCATION } & \multirow[t]{2}{*}{ FORMATION" } & \multirow[t]{2}{*}{ ANALYTE } & \multicolumn{2}{|c|}{ BACKGROUND } & \multicolumn{2}{|c|}{ OU SOL } & \multirow{2}{*}{$\begin{array}{c}\text { Retained }^{\mathrm{b}}- \\
\text { Exceeds } \\
\text { Background? }\end{array}$} \\
\hline & & & $\begin{array}{c}\text { 95\% UCB } \\
\text { HIGH }\end{array}$ & $\begin{array}{l}\text { 95\% UCB } \\
\text { LOW }\end{array}$ & MEAN & $95 \%$ UCB & \\
\hline CR OU2 & $\mathrm{CR}, \mathrm{CK}, \mathrm{CG}, \mathrm{CHE}$ & Arsenic & 30.70 & 9.73 & NA & 131.0 & YES \\
\hline CR OU2 & $\mathrm{CR}, \mathrm{CK}, \mathrm{CG}, \mathrm{CHE}$ & Barium & 151.0 & 69.5 & NA & 450.0 & YES \\
\hline CR OU2 & $\mathrm{CR}, \mathrm{CK}, \mathrm{CG}, \mathrm{CHE}$ & Chromium & 38.5 & 15.0 & NA & 25.1 & No \\
\hline CR OU2 & $\mathrm{CR}, \mathrm{CK}, \mathrm{CG}, \mathrm{CHE}$ & Copper & 20.6 & 5.26 & NA & 69.1 & YES \\
\hline CR OU2 & $\mathrm{CR}, \mathrm{CK}, \mathrm{CG}, \mathrm{CHE}$ & Lead & 52.2 & 24.6 & $\mathrm{NA}$ & 18.8 & NO \\
\hline CR OU2 & $\mathrm{CR}, \mathrm{CK}, \mathrm{CG}, \mathrm{CHE}$ & Manganese & 3060 & 1710 & NA & 152.0 & NO \\
\hline CR OU2 & $\mathrm{CR}, \mathrm{CK}, \mathrm{CG}, \mathrm{CHE}$ & Mercury & 0.184 & 0.130 & NA & 0.705 & YES \\
\hline CR OU2 & $\mathrm{CR}, \mathrm{CK}, \mathrm{CG}, \mathrm{CHE}$ & Nickel & 16.70 & 6.06 & NA & 36.0 & YES \\
\hline CR OU2 & $\mathrm{CR}, \mathrm{CK}, \mathrm{CG}, \mathrm{CHE}$ & Selenium & 1.310 & 0.621 & NA & 14.8 & YES \\
\hline CR OU2 & $\mathrm{CR}, \mathrm{CK}, \mathrm{CG}, \mathrm{CHE}$ & Vanadium & 42.0 & 26.4 & NA & 84.9 & YES \\
\hline CR OU2 & $\mathrm{CR}, \mathrm{CK}, \mathrm{CG}, \mathrm{CHE}$ & Zinc & 55.5 & 43.2 & NA & 53.9 & NO \\
\hline
\end{tabular}

$\mathrm{NA}=$ Not Available.

If data on formation of $\mathrm{OU}$ is not available, then the range of background levels in all formations was used for comparison.

a Formations and Groups: $\mathrm{CHI}=$ Chickamauga Group; $\mathrm{C}(\mathrm{R})=$ Conasauga Group (Remaining) = Dismal Gap Formation and Nolichucky Formation; $\mathrm{CK}=$ Knox Group = Copper Ridge Formation and Chepultepec Formation; $M N=$ Maynardville; Formation; $C K(R)=\mathrm{Knox}$ Group Remaining; NL = Nolichucky Formation; CHE = Chepultepec Formation; DG = Dismal Gap Formation; $\mathrm{CR}=$ Copper Ridge Formation; $\mathrm{R}=\mathrm{Rome}$ Formation

Operable Units and Corresponding Formations or Groups:

BCVOU1 $=\mathrm{C}(\mathrm{R}), \mathrm{DG}, \mathrm{NL}, \mathrm{MN} \quad \mathrm{SCF}=\mathrm{CHI}$

$\mathrm{BCOU} 2=\mathrm{MN}, \mathrm{CR} \quad \mathrm{K} 1420=\mathrm{CK}$

WAG $1=\mathrm{C}(\mathrm{R})$, DG $\mathrm{K} 1407=\mathrm{CR}$, CHI

WAG $6=\mathrm{NL}, \mathrm{DG} \quad$ LEFPC/UEFPC $=\mathrm{CHI}, \mathrm{CK}, \mathrm{CK}(\mathrm{R})$

$\mathrm{CR}$ OU2 $=\mathrm{CR}, \mathrm{CK}, \mathrm{CG}, \mathrm{CHE}$ 
Table G.9. Soil-plant organic contaminant uptake factors using octanol water partition coefficients (Travis and Arms 1988)

\begin{tabular}{lrrc}
\hline \multicolumn{1}{c}{ Chemical } & $\mathbf{K}_{\text {ow }}{ }^{*}$ & \multicolumn{1}{c}{$\log \mathbf{B}_{\mathbf{v}}$} & Soil-plant uptake factor \\
\hline Acetone & -0.24 & 1.72672 & 53.2991 \\
4,4'DDT & 6.53 & -2.18634 & 0.0065 \\
4,4'DDD & 6.53 & -2.18634 & 0.0065 \\
Benzo(a)pyrene & 6.11 & -1.94358 & 0.0114 \\
Bis(2ethylhexyl)phthalate & 7.3 & -2.6314 & 0.0023 \\
Chloroform & 1.92 & 0.47824 & 3.0077 \\
Di-N-Butylphthalate & 4.61 & -1.07658 & 0.0838 \\
Dibenzofuran & 4.12 & -0.79336 & 0.1609 \\
Methylene Chloride & 1.25 & 0.8655 & 7.3367 \\
PCB (1254) & 6.5 & -2.169 & 0.0068 \\
Tetrachloroethylene/ethene & 2.67 & 0.04474 & 1.1085 \\
Toluene & 2.75 & -0.0015 & 0.9966 \\
Aldrin & 6.5 & -2.169 & 0.0068 \\
Endrin & 5.06 & -1.33668 & 0.0461 \\
Heptachlor & 6.26 & -2.03028 & 0.0093 \\
Lindane (gamma BHC) & 3.73 & -0.56794 & 0.2704 \\
1,2 Dichloroethylene & 1.86 & 0.51292 & 3.2578 \\
1,1,1 Trichlorethane & 2.48 & 0.15456 & 1.4274 \\
1,2 Dichloroethane & 1.47 & 0.73834 & 5.4744 \\
Trichloroethene/ethylene & 2.71 & 0.02162 & 1.0510 \\
Dieldrin & 5.37 & -1.51586 & 0.0305 \\
Diethylphthalate & 2.5 & 0.143 & 1.3900 \\
Chlordane & 6.32 & -2.06496 & 0.0086 \\
Benzene & 2.13 & 0.35686 & 2.2744 \\
Vinyl Chloride & 1.5 & 0.721 & 5.2602 \\
\hline & & & \\
\hline
\end{tabular}

Soil-Plant Uptake Factors calculated using the following equation: $\log B_{v}=1.588-0.578 \log K_{\text {ow }}$ Where:

$\mathrm{B}_{\mathrm{v}}=$ Bioaccumulation factor for vegetation = soil-plant uptake factor

$\mathrm{K}_{\mathrm{ow}}=$ Octanol Water Partitioning Coeffient.

- $\mathrm{K}_{\mathrm{ow}}$ Source: Hull and Suter 1994.

${ }^{b} \mathrm{~K}_{\text {ow }}$ for Aldrin Source: Travis and Arms 1988. 


\section{G-34}

Table G.10. Estimated exposure of white-tailed deer to contaminants on the ORR

\begin{tabular}{|c|c|c|c|c|}
\hline Location & Analyte & $\begin{array}{c}\text { Total } \\
\text { Exposure }\end{array}$ & $\begin{array}{c}\text { NOAEL } \\
\text { HQ } \\
\end{array}$ & $\begin{array}{c}\text { LOAEL } \\
\text { HQ }\end{array}$ \\
\hline BC OU 2 & Aluminum & 55.310966 & 188.77 & 18.88 \\
\hline BC OU 2 & Mercury & 0.2693573 & 29.93 & .5 .99 \\
\hline BC OU 2 & Total PCBs & 0.1002301 & 11.14 & 1.18 \\
\hline $\mathrm{BC}$ OU 2 & Vanadium & 0.2004252 & 3.64 & 0.37 \\
\hline $\mathrm{BC}$ OU 2 & Arsenic & 0.0561985 & 2.96 & 0.29 \\
\hline BC OU 2 & Manganese & 20.932918 & 0.84 & 0.26 \\
\hline BC OU 2 & Barium & 1.2186874 & 0.81 & 0.22 \\
\hline BC OU 2 & Niobium & 0.0060669 & 0.25 & 0.03 \\
\hline $\mathrm{BC}$ OU 2 & Thallium & 0.0004826 & 0.24 & 0.02 \\
\hline BC OU 2 & Zirconium & 0.045876 & 0.17 & \\
\hline BC OU 2 & Copper & 0.7084259 & 0.16 & 0.13 \\
\hline $\mathrm{BC}$ OU 2 & Chromium & 0.1185112 & 0.13 & 0.03 \\
\hline $\mathrm{BC}$ OU 2 & Lead & 0.2812088 & 0.13 & 0.01 \\
\hline BC OU 2 & Cadmium & 0.0299591 & 0.11 & 0.01 \\
\hline $\mathrm{BC}$ OU 2 & Selenium & 0.0044054 & 0.08 & 0.05 \\
\hline BC OU 2 & Zinc & 3.3867375 & 0.08 & 0.04 \\
\hline BC OU 2 & Acetone & 0.1725784 & 0.06 & 0.01 \\
\hline BC OU 2 & Vinyl chloride & 0.0026343 & 0.05 & 0.01 \\
\hline $\mathrm{BC}$ OU 2 & Lithium & 0.0784847 & 0.03 & 0.01 \\
\hline $\mathrm{BC}$ OU 2 & Nickel & 0.2727563 & 0.02 & 0.01 \\
\hline BC OU 2 & Beryllium & 0.0024306 & 0.01 & \\
\hline BC OU 2 & Pentachlorophenol & 0.0007981 & 0.01 & 0.00 \\
\hline $\mathrm{BC}$ OU 2 & Antimony & 0.0002199 & 0.01 & 0.00 \\
\hline BC OU 2 & Strontium & 0.8327868 & 0.01 & \\
\hline BC OU 2 & Boron & 0.0489085 & 0.01 & 0.00 \\
\hline BC OU 2 & Uranium & 0.0017051 & 0.00 & 0.00 \\
\hline BC OU 2 & Benzo(a)pyrene & 0.0005113 & 0.00 & 0.00 \\
\hline BC OU 2 & Methylene chloride & 0.0040554 & 0.00 & 0.00 \\
\hline $\mathrm{BC}$ OU 2 & Trichloroethene & 0.0002672 & 0.00 & 0.00 \\
\hline BC OU 2 & Dieldrin & 0.0000087 & 0.00 & 0.00 \\
\hline BC OU 2 & Tetrachloroethene & 0.0002711 & 0.00 & 0.00 \\
\hline $\mathrm{BC}$ OU 2 & Endrin & 0.0000114 & 0.00 & 0.00 \\
\hline $\mathrm{BC}$ OU 2 & Chloroform & 0.0007553 & 0.00 & 0.00 \\
\hline BC OU 2 & 1,2-Dichlorethane & 0.0013706 & 0.00 & \\
\hline $\mathrm{BC}$ OU 2 & Benzene & 0.0005723 & 0.00 & 0.00 \\
\hline BC OU 2 & Bis(2-ethylhexyl)Phthalate & 0.0003639 & 0.00 & 0.00 \\
\hline BC OU 2 & Endosulfan & 0.0000052 & 0.00 & \\
\hline $\mathrm{BC}$ OU 2 & Mixed-BHC & 0.0000501 & 0.00 & 0.00 \\
\hline $\mathrm{BC}$ OU 2 & Toxaphene & 0.0001748 & 0.00 & \\
\hline $\mathrm{BC}$ OU 2 & Heptachlor & 0.0000025 & 0.00 & 0.00 \\
\hline $\mathrm{BC}$ OU 2 & Toluene & 0.0002536 & 0.00 & 0.00 \\
\hline
\end{tabular}


G-35

Table G.10 (Continued)

\begin{tabular}{|c|c|c|c|c|}
\hline Location & Analyte & $\begin{array}{c}\text { Total } \\
\text { Exposure }\end{array}$ & $\begin{array}{c}\text { NOAEL } \\
\text { HQ }\end{array}$ & $\begin{array}{c}\text { LOAEL } \\
\text { HQ }\end{array}$ \\
\hline $\mathrm{BC}$ OU 2 & DDT and metabolites & 0.0000137 & 0.00 & 0.00 \\
\hline $\mathrm{BC}$ OU 2 & Aldrin & 0.0000023 & 0.00 & 0.00 \\
\hline BC OU 2 & Diethylphthalate & 0.02297 & 0.00 & \\
\hline $\mathrm{BC}$ OU 2 & Di-N-Butylphthalate & 0.0016916 & 0.00 & 0.00 \\
\hline $\mathrm{BC}$ OU 2 & Methoxychlor & 0.0000175 & 0.00 & 0.00 \\
\hline $\mathrm{BC}$ OU 2 & Lindane & 0.000025 & 0.00 & \\
\hline $\mathrm{BC}$ OU 2 & Total-chlordane & 0.0000049 & 0.00 & 0.00 \\
\hline $\mathrm{BC}$ OU 2 & Carbon tetrachloride & 0.000005 & 0.00 & \\
\hline $\mathrm{BC}$ OU 2 & 1,2-Dichlorethene & 0.000005 & 0.00 & \\
\hline BC OU 2 & 1,1-Dichlorethene & 0.000005 & 0.00 & \\
\hline BC OU 2 & 1,1,1-Trichlorethane & 0.000005 & 0.00 & \\
\hline K-1407 OU & Aluminum & 44.229148 & 150.95 & 15.10 \\
\hline K-1407 OU & Mercury & 0.0226538 & 2.52 & 0.50 \\
\hline $\mathrm{K}-1407$ OU & Vanadium & 0.1324067 & 2.41 & 0.24 \\
\hline $\mathrm{K}-1407$ OU & Arsenic & 0.0209275 & 1.10 & 0.11 \\
\hline $\mathrm{K}-1407$ OU & Barium & 0.9915144 & 0.66 & 0.18 \\
\hline $\mathrm{K}-1407$ OU & Manganese & 15.943738 & 0.64 & 0.20 \\
\hline K-1407 OU & Uranium & 0.1733441 & 0.38 & 0.19 \\
\hline $\mathrm{K}-1407$ OU & Selenium & 0.0176203 & 0.31 & 0.19 \\
\hline K-1407 OU & Cadmium & 0.0751231 & 0.28 & 0.03 \\
\hline $\mathrm{K}-1407 \mathrm{OU}$ & Antimony & 0.0044043 & 0.23 & 0.02 \\
\hline K-1407 OU & Chromium & 0.1871866 & 0.20 & 0.05 \\
\hline $\mathrm{K}-1407$ OU & Copper & 0.6006714 & 0.14 & 0.11 \\
\hline $\mathrm{K}-1407$ OU & Molybdenum & 0.0050115 & 0.13 & 0.01 \\
\hline K-1407 OU & Nickel & 1.3609517 & 0.12 & 0.06 \\
\hline K-1407 OU & Lead & 0.0731644 & 0.03 & 0.00 \\
\hline K-1407 OU & Zinc & 1.4613145 & 0.03 & 0.02 \\
\hline K-1407 OU & Acetone & 0.0308704 & 0.01 & 0.00 \\
\hline $\mathrm{K}-1407 \mathrm{OU}$ & Beryllium & 0.0020823 & 0.01 & \\
\hline $\mathrm{K}-1407$ OU & Trichloroethene & 0.0009269 & 0.01 & 0.00 \\
\hline $\mathrm{K}-1407 \mathrm{OU}$ & Tetrachloroethene & 0.0008445 & 0.00 & 0.00 \\
\hline $\mathrm{K}-1407$ OU & Methylene chloride & 0.0048031 & 0.00 & 0.00 \\
\hline $\mathrm{K}-1407$ OU & Strontium & 0.1285826 & 0.00 & \\
\hline $\mathrm{K}-1407$ OU & Boron & 0.0051736 & 0.00 & 0.00 \\
\hline K-1407 OU & Chloroform & 0.0011096 & 0.00 & 0.00 \\
\hline K-1407 OU & Toluene & 0.0000313 & 0.00 & 0.00 \\
\hline $\mathrm{K}-1407$ OU & 1,2-Dichlorethene & 0.0000171 & 0.00 & \\
\hline $\mathrm{K}-1407$ OU & Di-N-Butylphthalate & 0.0000592 & 0.00 & 0.00 \\
\hline $\mathrm{K}-1407$ OU & 1,1,1-Trichlorethane & 0.0000095 & 0.00 & \\
\hline $\mathrm{K}-1407$ OU & Methylene chloride & 0.0357965 & 0.02 & 0.00 \\
\hline $\mathrm{K}-1407$ OU & Acetone & 0.0509032 & 0.02 & 0.00 \\
\hline $\mathrm{K}-1407$ OU & Benzo(a)pyrene & 0.0002774 & 0.00 & 0.00 \\
\hline
\end{tabular}


Table G.10 (Continued)

\begin{tabular}{|c|c|c|c|c|}
\hline Location & Analyte & $\begin{array}{c}\text { Total } \\
\text { Exposure }\end{array}$ & $\begin{array}{c}\text { NOAEL } \\
\text { HQ }\end{array}$ & $\begin{array}{c}\text { LOAEL } \\
\text { HQ } \\
\end{array}$ \\
\hline $\mathrm{K}-1407$ OU & Tetrachloroethene & 0.000139 & 0.00 & 0.00 \\
\hline $\mathrm{K}-1407 \mathrm{OU}$ & Di-N-Butylphthalate & 0.0076157 & 0.00 & 0.00 \\
\hline $\mathrm{K}-1407$ OU & Bis(2-ethylhexyl)phthalate & 0.0001537 & 0.00 & 0.00 \\
\hline $\mathrm{K}-1420$ OU & Aluminum & 75927.048 & 259136.68 & 25913.67 \\
\hline $\mathrm{K}-1420$ OU & Total PCBs & 0.3836566 & 42.63 & 4.51 \\
\hline $\mathrm{K}-1420$ OU & Vanadium & 0.4518581 & 8.22 & 0.83 \\
\hline $\mathrm{K}-1420$ OU & Arsenic & 0.043166 & 2.27 & 0.23 \\
\hline $\mathrm{K}-1420$ OU & Manganese & 23.05846 & 0.92 & 0.29 \\
\hline $\mathrm{K}-1420$ OU & Thallium & 0.0009535 & 0.48 & 0.05 \\
\hline $\mathrm{K}-1420 \mathrm{OU}$ & Barium & 0.6643464 & 0.44 & 0.12 \\
\hline $\mathrm{K}-1420$ OU & Uranium & 0.191443 & 0.42 & 0.21 \\
\hline $\mathrm{K}-1420$ OU & Mercury & 0.0015232 & 0.17 & 0.03 \\
\hline $\mathrm{K}-1420$ OU & Lithium & 0.3797542 & 0.15 & 0.07 \\
\hline $\mathrm{K}-1420$ OU & Copper & 0.5808581 & 0.14 & 0.10 \\
\hline $\mathrm{K}-1420$ OU & Lead & 0.200709 & 0.09 & 0.01 \\
\hline $\mathrm{K}-1420$ OU & Zinc & 3.4932459 & 0.08 & 0.04 \\
\hline $\mathrm{K}-1420$ OU & Chromium & 0.0682461 & 0.07 & 0.02 \\
\hline $\mathrm{K}-1420$ OU & Strontium & 1.5910454 & 0.02 & \\
\hline $\mathrm{K}-1420$ OU & Pentachlorophenol & 0.0012971 & 0.02 & 0.00 \\
\hline $\mathrm{K}-1420 \mathrm{OU}$ & Nickel & 0.1833987 & 0.02 & 0.01 \\
\hline $\mathrm{K}-1420$ OU & Acetone & 0.0408868 & 0.01 & 0.00 \\
\hline $\mathrm{K}-1420 \mathrm{OU}$ & Trichloroethene & 0.0013524 & 0.01 & 0.00 \\
\hline $\mathrm{K}-1420$ OU & Beryllium & 0.0023846 & 0.01 & \\
\hline $\mathrm{K}-1420$ OU & Benzo(a)pyrene & 0.0003733 & 0.00 & 0.00 \\
\hline $\mathrm{K}-1420 \mathrm{OU}$ & Methylene chloride & 0.002107 & 0.00 & 0.00 \\
\hline $\mathrm{K}-1420$ OU & Tetrachloroethene & 0.0002085 & 0.00 & 0.00 \\
\hline $\mathrm{K}-1420$ OU & Boron & 0.001663 & 0.00 & 0.00 \\
\hline $\mathrm{K}-1420$ OU & Aldrin & 0.0000094 & 0.00 & 0.00 \\
\hline $\mathrm{K}-1420 \mathrm{OU}$ & 1,2-Dichlorethane & 0.0012521 & 0.00 & \\
\hline $\mathrm{K}-1420$ OU & Bis(2-ethylhexyl)phthalate & 0.0001989 & 0.00 & 0.00 \\
\hline $\mathrm{K}-1420$ OU & Fluoride & 0.0000185 & 0.00 & 0.00 \\
\hline $\mathrm{K}-1420 \mathrm{OU}$ & Nitrate & 0.0000165 & 0.00 & 0.00 \\
\hline LEFPC & Aluminum & 20.371444 & 69.53 & 6.95 \\
\hline LEFPC & Total PCBs & 0.224181 & 24.91 & 2.64 \\
\hline LEFPC & Mercury & 0.1473614 & 16.37 & 3.27 \\
\hline LEFPC & Vanadium & 0.0906584 & 1.65 & 0.17 \\
\hline LEFPC & DDT and metabolites & 0.1861524 & 0.85 & 0.17 \\
\hline LEFPC & Barium & 1.0292841 & 0.69 & 0.18 \\
\hline LEFPC & Arsenic & 0.0127506 & 0.67 & 0.07 \\
\hline LEFPC & Cadmium & 0.1623473 & 0.60 & 0.06 \\
\hline LEFPC & Manganese & 14.054035 & 0.56 & 0.18 \\
\hline LEFPC & Thallium & 0.0010716 & 0.54 & 0.05 \\
\hline
\end{tabular}


Table G.10 (Continued)

\begin{tabular}{|c|c|c|c|c|}
\hline Location & Analyte & $\begin{array}{c}\text { Total } \\
\text { Exposure } \\
\end{array}$ & $\begin{array}{c}\text { NOAEL } \\
\text { HQ }\end{array}$ & $\begin{array}{c}\text { LOAEL } \\
\text { HQ }\end{array}$ \\
\hline LEFPC & Selenium & 0.0214454 & 0.38 & 0.23 \\
\hline LEFPC & Acetone & 0.9471287 & 0.34 & 0.07 \\
\hline LEFPC & Copper & 1.1073862 & 0.26 & 0.20 \\
\hline LEFPC & Chromium & 0.1755759 & 0.19 & 0.05 \\
\hline LEFPC & Zinc & 3.7671034 & 0.08 & 0.04 \\
\hline LEFPC & Lead & 0.1363346 & 0.06 & 0.01 \\
\hline LEFPC & Antimony & 0.0004849 & 0.03 & 0.00 \\
\hline LEFPC & Nickel & 0.2054578 & 0.02 & 0.01 \\
\hline LEFPC & Uranium & 0.008059 & 0.02 & 0.01 \\
\hline LEFPC & Beryllium & 0.0018073 & 0.01 & \\
\hline LEFPC & Methylene chloride & 0.011985 & 0.01 & 0.00 \\
\hline LEFPC & Pentachlorophenol & 0.000232 & 0.00 & 0.00 \\
\hline LEFPC & Benzo(a)Pyrene & 0.0004676 & 0.00 & 0.00 \\
\hline LEFPC & Dieldrin & 0.0000023 & 0.00 & 0.00 \\
\hline LEFPC & Cyanide & 0.0035872 & 0.00 & \\
\hline LEFPC & Endrin & 0.0000014 & 0.00 & 0.00 \\
\hline LEFPC & Bis(2-ethylhexyl)Phthalate & 0.0001381 & 0.00 & 0.00 \\
\hline LEFPC & Endosulfan & 0.0000012 & 0.00 & \\
\hline LEFPC & DiethylPhthalate & 0.007525 & 0.00 & \\
\hline LEFPC & Di-N-Butylphthalate & 0.0005887 & 0.00 & 0.00 \\
\hline LEFPC & Mixed-BHC & 0.0000027 & 0.00 & 0.00 \\
\hline LEFPC & Aldrin & 0.0000003 & 0.00 & 0.00 \\
\hline LEFPC & Heptachlor & 0.0000002 & 0.00 & 0.00 \\
\hline LEFPC & Methoxychlor & 0.0000036 & 0.00 & 0.00 \\
\hline LEFPC & Lindane & 0.0000063 & 0.00 & \\
\hline LEFPC & Total-chlordane & 0.0000012 & 0.00 & 0.00 \\
\hline SCF & Acetone & 349.73153 & 124.90 & 24.98 \\
\hline SCF & Aluminum & 31.638653 & 107.98 & 10.80 \\
\hline SCF & Methylene chloride & 63.697118 & 39.81 & 4.55 \\
\hline SCF & 1,2-Dichlorethane & 26.602428 & 3.37 & \\
\hline SCF & Total PCBs & 0.0242193 & 2.69 & 0.28 \\
\hline SCF & Vanadium & 0.1247852 & 2.27 & 0.23 \\
\hline SCF & Arsenic & 0.0232756 & 1.23 & 0.12 \\
\hline SCF & Cadmium & 0.2591139 & 0.96 & 0.10 \\
\hline SCF & Manganese & 21.755195 & 0.87 & 0.27 \\
\hline SCF & Barium & 1.1059877 & 0.74 & 0.20 \\
\hline SCF & Trichloroethene & 0.0492456 & 0.46 & 0.05 \\
\hline SCF & Mercury & 0.0030252 & 0.34 & 0.07 \\
\hline SCF & Tetrachloroethene & 0.0396962 & 0.19 & 0.04 \\
\hline SCF & Chromium & 0.163858 & 0.18 & 0.04 \\
\hline SCF & Selenium & 0.0073039 & 0.13 & 0.08 \\
\hline SCF & Copper & 0.3445354 & 0.08 & 0.06 \\
\hline
\end{tabular}


G-38

Table G.10 (Continued)

\begin{tabular}{|c|c|c|c|c|}
\hline Location & Analyte & $\begin{array}{c}\text { Total } \\
\text { Exposure } \\
\end{array}$ & $\begin{array}{c}\text { NOAEL } \\
\text { HQ } \\
\end{array}$ & $\begin{array}{c}\text { LOAEL } \\
\text { HQ } \\
\end{array}$ \\
\hline SCF & Zinc & 3.3099648 & 0.07 & 0.04 \\
\hline SCF & Lead & 0.1157725 & 0.05 & 0.01 \\
\hline SCF & Chloroform & 0.1852937 & 0.04 & 0.02 \\
\hline SCF & Antimony & 0.0007482 & 0.04 & 0.00 \\
\hline SCF & Benzene & 0.1441429 & 0.04 & 0.00 \\
\hline SCF & Toluene & 0.0640275 & 0.02 & 0.00 \\
\hline SCF & Beryllium & 0.0029775 & 0.02 & \\
\hline SCF & Nickel & 0.1104188 & 0.01 & 0.00 \\
\hline SCF & Uranium & 0.0022448 & 0.00 & 0.00 \\
\hline SCF & Benzo(a)pyrene & 0.0003116 & 0.00 & 0.00 \\
\hline SCF & 1,1-Dichlọrethene & 0.0121206 & 0.00 & \\
\hline SCF & Dieldrin & 0.000002 & 0.00 & 0.00 \\
\hline SCF & Endrin & 0.0000022 & 0.00 & 0.00 \\
\hline SCF & Heptachlor & 0.0000025 & 0.00 & 0.00 \\
\hline SCF & Pentachlorophenol & 0.0000032 & 0.00 & 0.00 \\
\hline SCF & Bis(2-ethylhexyl)phthalate & 0.0001208 & 0.00 & 0.00 \\
\hline SCF & Endosulfan & 0.0000017 & 0.00 & \\
\hline $\mathrm{SCF}$ & DDT and metabolites & 0.000008 & 0.00 & 0.00 \\
\hline $\mathrm{SCF}$ & Methoxychlor & 0.0000087 & 0.00 & 0.00 \\
\hline SCF & Mixed-BHC & 0.0000036 & 0.00 & 0.00 \\
\hline SCF & Aldrin & 0.0000003 & 0.00 & 0.00 \\
\hline SCF & Di-N-Butylphthalate & 0.0003783 & 0.00 & 0.00 \\
\hline SCF & 1,1,1-Trichlorethane & 0.0005882 & 0.00 & \\
\hline SCF & Total-chlordane & 0.000002 & 0.00 & 0.00 \\
\hline SCF & Carbon tetrachloride & $6.159 e-08$ & 0.00 & \\
\hline UEFPC OU 2 & Aluminum & 100.48424 & 342.95 & 34.29 \\
\hline UEFPC OU 2 & Barium & 4.4916239 & 2.99 & 0.80 \\
\hline UEFPC OU 2 & Vanadium & 0.1115844 & 2.03 & 0.20 \\
\hline UEFPC OU 2 & Manganese & 30.502259 & 1.22 & 0.38 \\
\hline UEFPC OU 2 & Arsenic & 0.0138646 & 0.73 & 0.07 \\
\hline UEFPC OU 2 & Lead & 0.5543469 & 0.25 & 0.02 \\
\hline UEFPC OU 2 & Chromium & 0.2061745 & 0.22 & 0.06 \\
\hline UEFPC OU 2 & Copper & 0.67837 & 0.16 & 0.12 \\
\hline UEFPC OU 2 & Zinc & 6.5046834 & 0.14 & 0.07 \\
\hline UEFPC OU 2 & Nickel & 0.309142 & 0.03 & 0.01 \\
\hline UEFPC OU 2 & Beryllium & 0.0040598 & 0.02 & \\
\hline UEFPC OU 2 & Lithium & 0.0524501 & 0.02 & 0.01 \\
\hline UEFPC OU 2 & Strontium & 0.7322006 & 0.01 & \\
\hline UEFPC OU 2 & Uranium & 0.0042044 & 0.01 & 0.00 \\
\hline UEFPC OU 2 & Nitrate & 0.0006909 & 0.00 & 0.00 \\
\hline WAG 1 & Aluminum & 20149.26 & 68768.81 & 6876.88 \\
\hline WAG 1 & Total PCBs & 0.1511834 & 16.80 & 1.78 \\
\hline
\end{tabular}


Table G.10 (Continued)

\begin{tabular}{|c|c|c|c|c|}
\hline Location & Analyte & $\begin{array}{c}\text { Total } \\
\text { Exposure }\end{array}$ & $\begin{array}{c}\text { NOAEL } \\
\text { HQ } \\
\end{array}$ & $\begin{array}{c}\text { LOAEL } \\
\text { HQ } \\
\end{array}$ \\
\hline WAG 1 & Thallium & 0.0209905 & 10.50 & 1.00 \\
\hline WAG 1 & Vanadium & 0.0731869 & 1.33 & 0.13 \\
\hline WAG 1 & Arsenic & 0.0156449 & 0.82 & 0.08 \\
\hline WAG 1 & Selenium & 0.0414922 & 0.74 & 0.45 \\
\hline WAG 1 & Mercury & 0.0065505 & 0.73 & 0.15 \\
\hline WAG 1 & Barium & 0.9129453 & 0.61 & 0.16 \\
\hline WAG 1 & Manganese & 10.705067 & 0.43 & 0.13 \\
\hline WAG 1 & Cadmium & 0.0685727 & 0.25 & 0.03 \\
\hline WAG 1 & Antimony & 0.0037336 & 0.20 & 0.02 \\
\hline WAG 1 & Boron & 1.0847955 & 0.14 & 0.04 \\
\hline WAG 1 & Chromium & 0.0883036 & 0.10 & 0.02 \\
\hline WAG 1 & Copper & 0.2748503 & 0.06 & 0.05 \\
\hline WAG 1 & Zinc & 2.3941825 & 0.05 & 0.03 \\
\hline WAG 1 & Lead & 0.1027154 & 0.05 & 0.00 \\
\hline WAG 1 & Vinyl chloride & 0.0019513 & 0.04 & 0.00 \\
\hline WAG 1 & Uranium & 0.0098037 & 0.02 & 0.01 \\
\hline WAG 1 & Acetone & 0.0481118 & 0.02 & 0.00 \\
\hline WAG 1 & Nickel & 0.1114378 & 0.01 & 0.00 \\
\hline WAG 1 & Beryllium & 0.0018713 & 0.01 & \\
\hline WAG 1 & Tin & 0.0333843 & 0.01 & 0.01 \\
\hline WAG 1 & Methylene chloride & 0.0082921 & 0.01 & 0.00 \\
\hline WAG 1 & Benzo(a)Pyrene & 0.0007015 & 0.00 & 0.00 \\
\hline WAG 1 & Endrin & 0.0000427 & 0.00 & 0.00 \\
\hline WAG 1 & Pentachlorophenol & 0.0001725 & 0.00 & 0.00 \\
\hline WAG 1 & Trichloroethene & 0.0000759 & 0.00 & 0.00 \\
\hline WAG 1 & Tetrachloroethene & 0.0001494 & 0.00 & 0.00 \\
\hline WAG 1 & Heptachlor & 0.0000095 & 0.00 & 0.00 \\
\hline WAG 1 & Total-chlordane & 0.0001843 & 0.00 & 0.00 \\
\hline WAG 1 & Mixed-BHC & 0.0001055 & 0.00 & 0.00 \\
\hline WAG 1 & Chloroform & 0.0008392 & 0.00 & 0.00 \\
\hline WAG 1 & DDT and metabolites & 0.0000435 & 0.00 & 0.00 \\
\hline WAG 1 & Cyanide & 0.0028833 & 0.00 & \\
\hline WAG 1 & 1,2-Dichlorethane & 0.0010153 & 0.00 & \\
\hline WAG 1 & Bis(2-ethylhexyl)Phthalate & 0.0003036 & 0.00 & 0.00 \\
\hline WAG 1 & Benzene & 0.000219 & 0.00 & 0.00 \\
\hline WAG 1 & Toluene & 0.0001096 & 0.00 & 0.00 \\
\hline WAG 1 & Di-N-Butylphthalate & 0.0022394 & 0.00 & 0.00 \\
\hline WAG 1 & Diethylphthalate & 0.0020886 & 0.00 & \\
\hline WAG 1 & Carbon tetrachloride & 0.0000037 & 0.00 & \\
\hline WAG 1 & 1,1-Dichlorethene & 0.0000037 & 0.00 & \\
\hline WAG 1 & 1,2-Dichlorethene & 0.0000014 & 0.00 & \\
\hline WAG 1 & 1,1,1-Trichlorethane & 0.000002 & 0.00 & \\
\hline
\end{tabular}


Table G.10 (Continued)

\begin{tabular}{|c|c|c|c|c|}
\hline Location & Analyte & $\begin{array}{c}\text { Total } \\
\text { Exposure }\end{array}$ & $\begin{array}{c}\text { NOAEL } \\
\text { HQ }\end{array}$ & $\begin{array}{c}\text { LOAEL } \\
\text { HQ }\end{array}$ \\
\hline WAG 6 & Aluminum & 26512.46 & 90486.21 & 9048.62 \\
\hline WAG 6 & Vanadium & 0.0597485 & 1.09 & 0.11 \\
\hline WAG 6 & Barium & 1.1355254 & 0.76 & 0.20 \\
\hline WAG 6 & Manganese & 14.53714 & 0.58 & 0.18 \\
\hline WAG 6 & Cadmium & 0.0994651 & 0.37 & 0.04 \\
\hline WAG 6 & Arsenic & 0.0033428 & 0.18 & 0.02 \\
\hline WAG 6 & Chromium & 0.0706441 & 0.08 & 0.02 \\
\hline WAG 6 & Copper & 0.2238646 & 0.05 & 0.04 \\
\hline WAG 6 & 1,4-Dioxane & 0.0046557 & 0.03 & 0.02 \\
\hline WAG 6 & Zinc & 1.4190897 & 0.03 & 0.02 \\
\hline WAG 6 & Nickel & 0.2256187 & 0.02 & 0.01 \\
\hline WAG 6 & Lead & 0.0408732 & 0.02 & 0.00 \\
\hline WAG 6 & Tin & 0.0549674 & 0.02 & 0.01 \\
\hline WAG 6 & Mercury & 0.0001325 & 0.01 & 0.00 \\
\hline WAG 6 & Beryllium & 0.0027456 & 0.01 & \\
\hline WAG 6 & Acetone & 0.024138 & 0.01 & 0.00 \\
\hline WAG 6 & Methylene chloride & 0.008564 & 0.01 & 0.00 \\
\hline WAG 6 & Uranium & 0.0006819 & 0.00 & 0.00 \\
\hline WAG 6 & Trichloroethene & 0.0001187 & 0.00 & 0.00 \\
\hline WAG 6 & Cyanide & 0.0146697 & 0.00 & \\
\hline WAG 6 & Tetrachloroethene & 0.0001147 & 0.00 & 0.00 \\
\hline WAG 6 & Chloroform & 0.0011935 & 0.00 & 0.00 \\
\hline WAG 6 & Bis(2-ethylhexyl)phthalate & 0.0003181 & 0.00 & 0.00 \\
\hline WAG 6 & Toluene & 0.0000783 & 0.00 & 0.00 \\
\hline WAG 6 & 1,2-Dichlorethene & 0.0000042 & 0.00 & \\
\hline
\end{tabular}


Table G.11. Estimated exposure of wild turkey to contaminants on the ORR

\begin{tabular}{|c|c|c|c|c|}
\hline Location & Analyte & $\begin{array}{c}\text { Total } \\
\text { Exposure }\end{array}$ & $\begin{array}{c}\text { NOAEL } \\
\text { HQ } \\
\end{array}$ & $\begin{array}{c}\text { LOAEL } \\
\text { HQ }\end{array}$ \\
\hline BC OU 2 & Mercury & 1.39171444969 & 217.46 & 21.75 \\
\hline BC OU 2 & Aluminum & 141.856012184 & 1.29 & \\
\hline $\mathrm{BC}$ OU 2 & Chromium & 1.27616127881 & 1.28 & 0.26 \\
\hline BC OU 2 & Total PCBs & 0.1051021484 & 0.58 & 0.06 \\
\hline BC OU 2 & Lead & 0.59340451546 & 0.53 & 0.05 \\
\hline $\mathrm{BC}$ OU 2 & Zinc & 6.13262773897 & 0.42 & 0.05 \\
\hline $\mathrm{BC}$ OU 2 & Arsenic & 0.21125963008 & 0.09 & 0.03 \\
\hline $\mathrm{BC}$ OU 2 & Barium & 1.4903572444 & 0.07 & 0.04 \\
\hline $\mathrm{BCOU} 2$ & Selenium & 0.0151594286 & 0.04 & 0.02 \\
\hline BC OU 2 & Cadmium & 0.0442705465 & 0.03 & 0.00 \\
\hline BC OU 2 & Vanadium & 0.33320913313 & 0.03 & \\
\hline BC OU 2 & Di-N-Butylphthalate & 0.002678944 & 0.02 & 0.00 \\
\hline $\mathrm{BC}$ OU 2 & Manganese & 23.0252859028 & 0.02 & \\
\hline $\mathrm{BC}$ OU 2 & Copper & 0.89019779148 & 0.02 & 0.01 \\
\hline BC OU 2 & DDT and metabolites & 0.0000499 & 0.02 & 0.00 \\
\hline $\mathrm{BC}$ OU 2 & Nickel & 1.20007216233 & 0.02 & 0.01 \\
\hline $\mathrm{BC}$ OU 2 & Boron & 0.22178945172 & 0.01 & 0.00 \\
\hline BC OU 2 & Endrin & 0.0000226 & 0.00 & 0.00 \\
\hline BC OU 2 & Bis(2-ethylhexyl)Phthalate & 0.001511038 & 0.00 & \\
\hline BC OU 2 & Uranium & 0.007626842 & 0.00 & \\
\hline $\mathrm{BC}$ OU 2 & Dieldrin & 0.0000203 & 0.00 & \\
\hline BC OU 2 & Mixed-BHC & 0.0000567 & 0.00 & 0.00 \\
\hline BC OU 2 & 1,2-Dichlorethane & 0.001223876 & 0.00 & 0.00 \\
\hline BC OU 2 & Lindane & 0.0000283 & 0.00 & 0.00 \\
\hline BC OU 2 & Total-chlordane & 0.0000169 & 0.00 & 0.00 \\
\hline BC OU 2 & Endosulfan & 0.0000235 & 0.00 & \\
\hline $\mathrm{K}-1407$ OU & Mercury & 0.11704759264 & 18.29 & 1.83 \\
\hline $\mathrm{K}-1407$ OU & Chromium & 2.01567602894 & 2.02 & 0.40 \\
\hline $\mathrm{K}-1407$ OU & Aluminum & 113.434477405 & 1.03 & \\
\hline $\mathrm{K}-1407$ OU & Zinc & 2.64611530219 & 0.18 & 0.02 \\
\hline $\mathrm{K}-1407$ OU & Selenium & 0.0606334753 & 0.15 & 0.08 \\
\hline $\mathrm{K}-1407$ OU & Lead & 0.15439092931 & 0.14 & 0.01 \\
\hline $\mathrm{K}-1407$ OU & Nickel & 5.98790994136 & 0.08 & 0.06 \\
\hline $\mathrm{K}-1407$ OU & Cadmium & 0.11100951867 & 0.08 & 0.01 \\
\hline $\mathrm{K}-1407$ OU & Barium & 1.21254285104 & 0.06 & 0.03 \\
\hline $\mathrm{K}-1407$ OU & Uranium & 0.7753827538 & 0.05 & \\
\hline $\mathrm{K}-1407$ OU & Arsenic & 0.0786698764 & 0.03 & 0.01 \\
\hline $\mathrm{K}-1407 \mathrm{OU}$ & Vanadium & 0.22012755652 & 0.02 & \\
\hline $\mathrm{K}-1407$ OU & Manganese & 17.5374082339 & 0.02 & \\
\hline $\mathrm{K}-1407$ OU & Copper & 0.75479501611 & 0.02 & 0.01 \\
\hline $\mathrm{K}-1407 \mathrm{OU}$ & Molybdenum & 0.0173276372 & 0.00 & 0.00 \\
\hline
\end{tabular}


Table G.11. (continued)

\begin{tabular}{|c|c|c|c|c|}
\hline Location & Analyte & $\begin{array}{c}\text { Total } \\
\text { Exposure }\end{array}$ & $\begin{array}{c}\text { NOAEL } \\
\text { HQ }\end{array}$ & $\begin{array}{c}\text { LOAEL } \\
\text { HQ }\end{array}$ \\
\hline $\mathrm{K}-1407 \mathrm{OU}$ & Di-N-Butylphthalate & 0.0000937 & 0.00 & 0.00 \\
\hline $\mathrm{K}-1407$ OU & Boron & 0.0234609517 & 0.00 & 0.00 \\
\hline $\mathrm{K}-1414$ & Di-N-Butylphthalate & 0.0120608166 & 0.11 & 0.01 \\
\hline K-1414 & Bis(2-ethylhexyl)phthalate & 0.00063841 & 0.00 & \\
\hline $\mathrm{K}-1420$ OU & Aluminum & 194730.069446 & 1775.11 & \\
\hline $\mathrm{K}-1420$ OU & Total PCBs & 0.4023055563 & 2.24 & 0.22 \\
\hline $\mathrm{K}-1420$ OU & Mercury & 0.007870268 & 1.23 & 0.12 \\
\hline $\mathrm{K}-1420$ OU & Chromium & 0.73489276491 & 0.73 & 0.15 \\
\hline $\mathrm{K}-1420$ OU & Zinc & 6.32549083275 & 0.44 & 0.05 \\
\hline $\mathrm{K}-1420$ OU & Lead & 0.42353444078 & 0.37 & 0.04 \\
\hline $\mathrm{K}-1420$ OU & Arsenic & 0.1622683214 & 0.07 & 0.02 \\
\hline $\mathrm{K}-1420$ OU & Vanadium & 0.75121906548 & 0.07 & \\
\hline $\mathrm{K}-1420$ OU & Uranium & 0.85634044003 & 0.05 & \\
\hline $\mathrm{K}-1420$ OU & Barium & 0.81244258119 & 0.04 & 0.02 \\
\hline $\mathrm{K}-1420$ OU & Manganese & 25.3632882416 & 0.03 & \\
\hline $\mathrm{K}-1420$ OU & Copper & 0.72989785116 & 0.02 & 0.01 \\
\hline $\mathrm{K}-1420$ OU & Nickel & 0.8069170331 & 0.01 & 0.01 \\
\hline $\mathrm{K}-1420$ OU & Bis(2-ethylhexyl)phthalate & 0.00082607 & 0.00 & \\
\hline $\mathrm{K}-1420$ OU & Boron & 0.007541379 & 0.00 & 0.00 \\
\hline $\mathrm{K}-1420$ OU & 1,2-Dichlorethane & 0.001118109 & 0.00 & 0.00 \\
\hline $\mathrm{K}-1420$ OU & Fluoride & 0.0000838 & 0.00 & 0.00 \\
\hline LEFPC & DDT and metabolites & 0.67704998633 & 241.80 & 24.18 \\
\hline LEFPC & Mercury & 0.76138667595 & 118.97 & 11.90 \\
\hline LEFPC & Chromium & 1.89064873211 & 1.89 & 0.38 \\
\hline LEFPC & Total PCBs & 0.23507815517 & 1.31 & 0.13 \\
\hline LEFPC & Aluminum & 52.2466346903 & 0.48 & \\
\hline LEFPC & Zinc & 6.82138580436 & 0.47 & 0.05 \\
\hline LEFPC & Lead & 0.28769209623 & 0.25 & 0.03 \\
\hline LEFPC & Selenium & 0.0737963458 & 0.18 & 0.09 \\
\hline LEFPC & Cadmium & 0.23990080515 & 0.17 & 0.01 \\
\hline LEFPC & Barium & 1.25873216656 & 0.06 & 0.03 \\
\hline LEFPC & Copper & 1.39152557798 & 0.03 & 0.02 \\
\hline LEFPC & Arsenic & 0.0479317898 & 0.02 & 0.01 \\
\hline LEFPC & Manganese & 15.4588184454 & 0.02 & \\
\hline LEFPC & Vanadium & 0.15072059062 & 0.01 & \\
\hline LEFPC & Nickel & 0.9039722945 & 0.01 & 0.01 \\
\hline LEFPC & Di-N-Butylphthalate & 0.00093231 & 0.01 & 0.00 \\
\hline LEFPC & Uranium & 0.0360485408 & 0.00 & \\
\hline LEFPC & Bis(2-ethylhexyl)Phthalate & 0.00057328 & 0.00 & \\
\hline LEFPC & Endrin & 0.000003 & 0.00 & 0.00 \\
\hline LEFPC & Dieldrin & 0.000005 & 0.00 & \\
\hline LEFPC & Mixed-BHC & 0.000003 & 0.00 & 0.00 \\
\hline
\end{tabular}


G-43

Table G.11. (continued)

\begin{tabular}{|c|c|c|c|c|}
\hline Location & Analyte & $\begin{array}{c}\text { Total } \\
\text { Exposure }\end{array}$ & $\begin{array}{c}\text { NOAEL } \\
\text { HQ } \\
\end{array}$ & $\begin{array}{c}\text { LOAEL } \\
\text { HQ }\end{array}$ \\
\hline LEFPC & Lindane & 0.000007 & 0.00 & 0.00 \\
\hline LEFPC & Total-chlordane & 0.000004 & 0.00 & 0.00 \\
\hline LEFPC & Endosulfan & 0.000005 & 0.00 & \\
\hline SCF & Mercury & 0.0156307439 & 2.44 & 0.24 \\
\hline SCF & Chromium & 1.76446738153 & 1.76 & 0.35 \\
\hline SCF & 1,2-Dichlorethane & 23.7546749984 & 1.38 & 0.69 \\
\hline SCF & Aluminum & 81.1436393099 & 0.74 & \\
\hline SCF & Zinc & 5.99360952554 & 0.41 & 0.05 \\
\hline SCF & Cadmium & 0.38289296571 & 0.26 & 0.02 \\
\hline SCF & Lead & 0.24430210809 & 0.22 & 0.02 \\
\hline SCF & Total PCBs & 0.0253965182 & 0.14 & 0.01 \\
\hline SCF & Barium & 1.35253458342 & 0.07 & 0.03 \\
\hline SCF & Selenium & 0.0251337408 & 0.06 & 0.03 \\
\hline SCF & Arsenic & 0.0874969928 & 0.04 & 0.01 \\
\hline SCF & Manganese & 23.9297547503 & 0.02 & \\
\hline SCF & Vanadium & 0.20745679701 & 0.02 & \\
\hline SCF & DDT and metabolites & 0.0000291 & 0.01 & 0.00 \\
\hline SCF & Copper & 0.43293817315 & 0.01 & 0.01 \\
\hline SCF & Nickel & 0.48582003395 & 0.01 & 0.00 \\
\hline SCF & Di-N-Butylphthalate & 0.00059909 & 0.01 & 0.00 \\
\hline SCF & Uranium & 0.0100413315 & 0.00 & \\
\hline SCF & Bis(2-ethylhexyl)phthalate & 0.00050158 & 0.00 & \\
\hline SCF & Endrin & 0.000004 & 0.00 & 0.00 \\
\hline SCF & Dieldrin & 0.000005 & 0.00 & \\
\hline SCF & Mixed-BHC & 0.000004 & 0.00 & 0.00 \\
\hline SCF & Total-chlordane & 0.000007 & 0.00 & 0.00 \\
\hline SCF & Endosulfan & 0.000008 & 0.00 & \\
\hline UEFPC OU 2 & Aluminum & 257.711899827 & 2.35 & \\
\hline UEFPC OU 2 & Chromium & 2.22014261482 & 2.22 & 0.44 \\
\hline UEFPC OU 2 & Lead & 1.16977832138 & 1.04 & 0.10 \\
\hline UEFPC OU 2 & Zinc & 11.7785337137 & 0.81 & 0.09 \\
\hline UEFPC OU 2 & Barium & 5.49289697335 & 0.26 & 0.13 \\
\hline UEFPC OU 2 & Manganese & 33.5511392796 & 0.03 & \\
\hline UEFPC OU 2 & Arsenic & 0.0521192973 & 0.02 & 0.01 \\
\hline UEFPC OU 2 & Copper & 0.85242995299 & 0.02 & 0.01 \\
\hline UEFPC OU 2 & Nickel & 1.36016159419 & 0.02 & 0.01 \\
\hline UEFPC OU 2 & Vanadium & 0.18551033442 & 0.02 & \\
\hline UEFPC OU 2 & Uranium & 0.0188067748 & 0.00 & \\
\hline WAG 1 & Aluminum & 51676.7991122 & 471.07 & \\
\hline WAG 1 & Mercury & 0.0338452634 & 5.29 & 0.53 \\
\hline WAG 1 & Chromium & 0.9508768071 & 0.95 & 0.19 \\
\hline WAG 1 & Total PCBs & 0.15853224148 & 0.88 & 0.09 \\
\hline
\end{tabular}


Table G.11. (continued)

\begin{tabular}{|c|c|c|c|c|}
\hline Location & Analyte & $\begin{array}{c}\text { Total } \\
\text { Exposure }\end{array}$ & $\begin{array}{c}\text { NOAEL } \\
\text { HQ }\end{array}$ & $\begin{array}{c}\text { LOAEL } \\
\text { HQ }\end{array}$ \\
\hline WAG 1 & Selenium & 0.14277975741 & 0.36 & 0.18 \\
\hline WAG 1 & Zinc & 4.33533168393 & 0.30 & 0.03 \\
\hline WAG 1 & Lead & 0.21674921061 & 0.19 & 0.02 \\
\hline WAG 1 & Boron & 4.91930903793 & 0.17 & 0.05 \\
\hline WAG 1 & Cadmium & 0.10133001755 & 0.07 & 0.01 \\
\hline WAG 1 & DDT and metabolites & 0.00015827 & 0.06 & 0.01 \\
\hline WAG 1 & Barium & 1.116459086 & 0.05 & 0.03 \\
\hline WAG 1 & Di-N-Butylphthalate & 0.003546435 & 0.03 & 0.00 \\
\hline WAG 1 & Arsenic & 0.058811724 & 0.02 & 0.01 \\
\hline WAG 1 & Tin & 0.15139039655 & 0.02 & 0.01 \\
\hline WAG 1 & Manganese & 11.7751009667 & 0.01 & \\
\hline WAG 1 & Vanadium & 0.12167411511 & 0.01 & \\
\hline WAG 1 & Endrin & 0.0000849 & 0.01 & 0.00 \\
\hline WAG 1 & Copper & 0.34537290116 & 0.01 & 0.01 \\
\hline WAG 1 & Nickel & 0.49030339656 & 0.01 & 0.00 \\
\hline WAG 1 & Uranium & 0.0438526735 & 0.00 & \\
\hline WAG 1 & Bis(2-ethylhexyl)Phthalate & 0.001260817 & 0.00 & \\
\hline WAG I & Total-chlordane & 0.00063312 & 0.00 & 0.00 \\
\hline WAG 1 & Mixed-BHC & 0.00011941 & 0.00 & 0.00 \\
\hline WAG 1 & 1,2-Dichlorethane & 0.00090657 & 0.00 & 0.00 \\
\hline WAG 6 & Aluminum & 67996.4956251 & 619.84 & \\
\hline WAG 6 & Chromium & 0.7607147173 & 0.76 & 0.15 \\
\hline WAG 6 & Zinc & 2.56965549002 & 0.18 & 0.02 \\
\hline WAG 6 & Mercury & 0.00068437 & 0.11 & 0.01 \\
\hline WAG 6 & Cadmium & 0.14697966049 & 0.10 & 0.01 \\
\hline WAG 6 & Lead & 0.0862503108 & 0.08 & 0.01 \\
\hline WAG 6 & Barium & 1.38865673624 & 0.07 & 0.03 \\
\hline WAG 6 & Tin & 0.24926493103 & 0.04 & 0.01 \\
\hline WAG 6 & Manganese & 15.9902123168 & 0.02 & \\
\hline WAG 6 & Nickel & 0.99267610066 & 0.01 & 0.01 \\
\hline WAG 6 & Vanadium & 0.0993325566 & 0.01 & \\
\hline WAG 6 & Copper & 0.28130506569 & 0.01 & 0.00 \\
\hline WAG 6 & Arsenic & 0.0125661343 & 0.01 & 0.00 \\
\hline WAG 6 & Bis(2-ethylhexyl)phthalate & 0.001320801 & 0.00 & \\
\hline WAG 6 & Uranium & 0.003050312 & 0.00 & \\
\hline
\end{tabular}


G-45

Table G.12. Estimated exposure of short-tailed shrews to contaminants on the ORR

\begin{tabular}{|c|c|c|c|c|}
\hline Location & Analyte & $\begin{array}{c}\text { Total } \\
\text { Exposure } \\
\end{array}$ & $\begin{array}{c}\text { NOAEL } \\
\text { HQ }\end{array}$ & $\begin{array}{c}\text { LOAEL } \\
\text { HQ } \\
\end{array}$ \\
\hline BC OU 2 & Mercury & 196.7928912 & 2798.11 & 559.62 \\
\hline $\mathrm{BC}$ OU 2 & Aluminum & 5227.271558 & 2277.51 & 227.75 \\
\hline $\mathrm{BC}$ OU 2 & Arsenic & 18.82531699 & 125.64 & 12.56 \\
\hline $\mathrm{BC}$ OU 2 & Total PCBs & 3.228897394 & 48.31 & 4.83 \\
\hline $\mathrm{BC}$ OU 2 & Chromium & 211.3797392 & 29.32 & 7.32 \\
\hline $\mathrm{BC}$ OU 2 & Vanadium & 8.157202404 & 19.04 & 1.90 \\
\hline $\mathrm{BC}$ OU 2 & Niobium & 0.7683 & 4.17 & 0.42 \\
\hline $\mathrm{BC}$ OU 2 & Selenium & 1.549789184 & 3.53 & 2.14 \\
\hline $\mathrm{BC}$ OU 2 & Zirconium & 5.8096428 & 2.81 & \\
\hline $\mathrm{BC}$ OU 2 & Barium & 27.08760739 & 2.29 & 0.62 \\
\hline $\mathrm{BC}$ OU 2 & Nickel & 168.3116404 & 1.91 & 0.96 \\
\hline $\mathrm{BC}$ OU 2 & Thallium & 0.028694751 & 1.75 & 0.17 \\
\hline $\mathrm{BC}$ OU 2 & Zinc & 561.1175437 & 1.60 & 0.80 \\
\hline $\mathrm{BC}$ OU 2 & Cadmium & 3.196439599 & 1.51 & 0.15 \\
\hline $\mathrm{BC}$ OU 2 & Manganese & 277.077382 & 1.43 & 0.44 \\
\hline $\mathrm{BC}$ OU 2 & Lead & 21.83636507 & 1.24 & 0.12 \\
\hline BC OU 2 & Copper & 31.90706173 & 0.95 & 0.73 \\
\hline $\mathrm{BC}$ OU 2 & Beryllium & 0.981214738 & 0.68 & \\
\hline $\mathrm{BC}$ OU 2 & Lithium & 9.509180778 & 0.46 & 0.23 \\
\hline $\mathrm{BC}$ OU 2 & Pentachlorophenol & 0.1010646 & 0.19 & 0.02 \\
\hline $\mathrm{BC}$ OU 2 & Antimony & 0.027846 & 0.19 & 0.02 \\
\hline BC OU 2 & Boron & 6.1936758 & 0.10 & 0.03 \\
\hline $\mathrm{BC}$ OU 2 & Uranium & 0.285877707 & 0.08 & 0.04 \\
\hline $\mathrm{BC}$ OU 2 & Strontium & 32.22088931 & 0.06 & \\
\hline $\mathrm{BC}$ OU 2 & Benzo(a)pyrene & 0.041457173 & 0.03 & 0.00 \\
\hline $\mathrm{BC}$ OU 2 & Vinyl chloride & 0.004024559 & 0.01 & 0.00 \\
\hline $\mathrm{BC}$ OU 2 & Dieldrin & 0.000442332 & 0.01 & 0.00 \\
\hline BC OU 2 & Acetone & 0.189694079 & 0.01 & 0.00 \\
\hline BC OU 2 & Endrin & 0.000445157 & 0.00 & 0.00 \\
\hline $\mathrm{BC}$ OU 2 & Endosulfan & 0.0006552 & 0.00 & \\
\hline $\mathrm{BC}$ OU 2 & Bis(2-ethylhexyl)Phthalate & 0.04130205 & 0.00 & 0.00 \\
\hline $\mathrm{BC}$ OU 2 & Toxaphene & 0.0221364 & 0.00 & \\
\hline $\mathrm{BC}$ OU 2 & Trichloroethene & 0.000907635 & 0.00 & 0.00 \\
\hline BC OU 2 & Heptachlor & 0.000219246 & 0.00 & 0.00 \\
\hline $\mathrm{BC}$ OU 2 & DDT and metabolites & 0.001313944 & 0.00 & 0.00 \\
\hline BC OU 2 & Tetrachloroethene & 0.000888543 & 0.00 & 0.00 \\
\hline $\mathrm{BC}$ OU 2 & Aldrin & 0.000219015 & 0.00 & 0.00 \\
\hline $\mathrm{BC}$ OU 2 & Methylene chloride & 0.005651185 & 0.00 & 0.00 \\
\hline $\mathrm{BC}$ OU 2 & Methoxychlor & 0.0022152 & 0.00 & 0.00 \\
\hline $\mathrm{BCOU} 2$ & Mixed-BHC & 0.000485867 & 0.00 & 0.00 \\
\hline
\end{tabular}


Table G.12. (continued)

\begin{tabular}{|c|c|c|c|c|}
\hline Location & Analyte & $\begin{array}{c}\text { Total } \\
\text { Exposure }\end{array}$ & $\begin{array}{l}\text { NOAEL } \\
\text { HQ } \\
\end{array}$ & $\begin{array}{c}\text { LOAEL } \\
\text { HQ }\end{array}$ \\
\hline $\mathrm{BC}$ OU 2 & Total chlordane & 0.000438362 & 0.00 & 0.00 \\
\hline $\mathrm{BC}$ OU 2 & Di-N-Butylphthalate & 0.042698881 & 0.00 & 0.00 \\
\hline $\mathrm{BC}$ OU 2 & Chloroform & 0.001421151 & 0.00 & 0.00 \\
\hline $\mathrm{BC}$ OU 2 & Benzene & 0.001228684 & 0.00 & 0.00 \\
\hline $\mathrm{BC}$ OU 2 & 1,2-Dichlorethane & 0.002068513 & 0.00 & \\
\hline BC OU 2 & Toluene & 0.000893335 & 0.00 & 0.00 \\
\hline $\mathrm{BC}$ OU 2 & Carbon tetrachloride & 0.0006318 & 0.00 & \\
\hline $\mathrm{BC}$ OU 2 & Lindane & 0.000242934 & 0.00 & \\
\hline $\mathrm{BC}$ OU 2 & Diethylphthalate & 0.065085232 & 0.00 & \\
\hline $\mathrm{BC}$ OU 2 & 1,2-Dichlorethene & 0.0006318 & 0.00 & \\
\hline $\mathrm{BC}$ OU 2 & 1,1-Dichlorethene & 0.0006318 & 0.00 & \\
\hline BC OU 2 & 1,1,1-Trichlorethane & 0.0006318 & 0.00 & \\
\hline K-1407 OU & Aluminum & 4179.962543 & 1821.20 & 182.12 \\
\hline $\mathrm{K}-1407$ OU & Mercury & 16.55090537 & 235.33 & 47.07 \\
\hline K-1407 OU & Arsenic & 7.010262018 & 46.78 & 4.68 \\
\hline $\mathrm{K}-1407$ OU & Chromium & 333.8708675 & 46.31 & 11.56 \\
\hline K-1407 OU & Selenium & 6.198723376 & 14.10 & 8.55 \\
\hline K-1407 OU & Vanadium & 5.388883001 & 12.58 & 1.26 \\
\hline $\mathrm{K}-1407$ OU & Nickel & 839.8119519 & 9.55 & 4.78 \\
\hline $\mathrm{K}-1407$ OU & Uranium & 29.06375264 & 8.10 & 4.06 \\
\hline $\mathrm{K}-1407$ OU & Molybdenum & 1.952868884 & 6.32 & 0.63 \\
\hline $\mathrm{K}-1407$ OU & Cadmium & 8.015153407 & 3.78 & 0.38 \\
\hline K-1407 OU & Antimony & 0.5577468 & 3.75 & 0.38 \\
\hline K-1407 OU & Barium & 22.03826285 & 1.86 & 0.51 \\
\hline K-1407 OU & Manganese & 211.0383854 & 1.09 & 0.34 \\
\hline K-1407 OU & Copper & 27.05386533 & 0.81 & 0.61 \\
\hline $\mathrm{K}-1407$ OU & Zinc & 242.1118291 & 0.69 & 0.34 \\
\hline K-1407 OU & Beryllium & 0.840604294 & 0.58 & \\
\hline $\mathrm{K}-1407$ OU & Lead & 5.681346549 & 0.32 & 0.03 \\
\hline $\mathrm{K}-1407$ OU & Boron & 0.6551688 & 0.01 & 0.00 \\
\hline $\mathrm{K}-1407$ OU & Strontium & 4.974917152 & 0.01 & \\
\hline $\mathrm{K}-1407$ OU & Trichloroethene & 0.003148711 & 0.00 & 0.00 \\
\hline $\mathrm{K}-1407$ OU & Tetrachloroethene & 0.002768153 & 0.00 & 0.00 \\
\hline $\mathrm{K}-1407$ OU & Acetone & 0.033931957 & 0.00 & 0.00 \\
\hline $\mathrm{K}-1407$ OU & Methylene chloride & 0.006693024 & 0.00 & 0.00 \\
\hline $\mathrm{K}-1407$ OU & Chloroform & 0.002087863 & 0.00 & 0.00 \\
\hline $\mathrm{K}-1407 \mathrm{OU}$ & 1,2-Dichlorethene & 0.0021606 & 0.00 & \\
\hline $\mathrm{K}-1407$ OU & Toluene & 0.000110288 & 0.00 & 0.00 \\
\hline $\mathrm{K}-1407$ OU & Di-N-Butylphthalate & 0.00149325 & 0.00 & 0.00 \\
\hline $\mathrm{K}-1407$ OU & 1,1,1-Trichlorethane & 0.001209 & 0.00 & \\
\hline $\mathrm{K}-1414$ & Benzo(a)pyrene & 0.022491888 & 0.02 & 0.00 \\
\hline $\mathrm{K}-1414$ & Methylene chloride & 0.049881969 & 0.00 & 0.00 \\
\hline
\end{tabular}


Table G.12. (continued)

\begin{tabular}{|c|c|c|c|c|}
\hline Location & Analyte & $\begin{array}{c}\text { Total } \\
\text { Exposure }\end{array}$ & $\begin{array}{c}\text { NOAEL } \\
\text { HQ }\end{array}$ & $\begin{array}{c}\text { LOAEL } \\
\text { HQ }\end{array}$ \\
\hline K-1414 & Acetone & 0.055951631 & 0.00 & 0.00 \\
\hline K-1414 & Bis(2-ethylhexyl)phthalate & 0.017449921 & 0.00 & 0.00 \\
\hline $\mathrm{K}-1414$ & Di-N-Butylphthalate & 0.192233751 & 0.00 & 0.00 \\
\hline K-1414 & Tetrachloroethene & 0.000455663 & 0.00 & 0.00 \\
\hline $\mathrm{K}-1420$ OU & Aluminum & 7175634.912 & 3126407.09 & 312640.71 \\
\hline $\mathrm{K}-1420$ OU & Total PCBs & 12.35943682 & 184.92 & 18.49 \\
\hline $\mathrm{K}-1420$ OU & Arsenic & 14.45970812 & 96.50 & 9.65 \\
\hline $\mathrm{K}-1420$ OU & Vanadium & 18.39039017 & 42.92 & 4.29 \\
\hline $\mathrm{K}-1420$ OU & Chromium & 121.7255558 & 16.89 & 4.21 \\
\hline $\mathrm{K}-1420$ OU & Mercury & 1.112881169 & 15.82 & 3.16 \\
\hline $\mathrm{K}-1420$ OU & Uranium & 32.09829804 & 8.94 & 4.48 \\
\hline $\mathrm{K}-1420$ OU & Thallium & 0.056696544 & 3.45 & 0.34 \\
\hline $\mathrm{K}-1420$ OU & Lithium & 46.01089567 & 2.23 & 1.11 \\
\hline $\mathrm{K}-1420$ OU & Zinc & 578.7639541 & 1.65 & 0.82 \\
\hline $\mathrm{K}-1420$ OU & Manganese & 305.2119975 & 1.58 & 0.49 \\
\hline $\mathrm{K}-1420$ OU & Nickel & 113.1711357 & 1.29 & 0.64 \\
\hline $\mathrm{K}-1420$ OU & Barium & 14.7663426 & 1.25 & 0.34 \\
\hline $\mathrm{K}-1420$ OU & Lead & 15.58541 & 0.89 & 0.09 \\
\hline $\mathrm{K}-1420$ OU & Copper & 26.16148458 & 0.78 & 0.59 \\
\hline $\mathrm{K}-1420$ OU & Beryllium & 0.962640732 & 0.66 & \\
\hline $\mathrm{K}-1420$ OU & Pentachlorophenol & 0.164268 & 0.31 & 0.03 \\
\hline $\mathrm{K}-1420$ OU & Strontium & 61.55825459 & 0.11 & \\
\hline $\mathrm{K}-1420$ OU & Benzo(a)pyrene & 0.030266088 & 0.03 & 0.00 \\
\hline $\mathrm{K}-1420$ OU & Trichloroethene & 0.004594204 & 0.01 & 0.00 \\
\hline $\mathrm{K}-1420 \mathrm{OU}$ & Boron & 0.2106 & 0.00 & 0.00 \\
\hline $\mathrm{K}-1420 \mathrm{OU}$ & Acetone & 0.044941794 & 0.00 & 0.00 \\
\hline $\mathrm{K}-1420$ OU & Aldrin & 0.000891703 & 0.00 & 0.00 \\
\hline $\mathrm{K}-1420$ OU & Bis(2-ethylhexyl)phthalate & 0.022579495 & 0.00 & 0.00 \\
\hline $\mathrm{K}-1420$ OU & Tetrachloroethene & 0.000683495 & 0.00 & 0.00 \\
\hline $\mathrm{K}-1420$ OU & Methylene chloride & 0.002936091 & 0.00 & 0.00 \\
\hline $\mathrm{K}-1420 \mathrm{OU}$ & 1,2-Dichlorethane & 0.001889753 & 0.00 & \\
\hline $\mathrm{K}-1420$ OU & Fluoride & 0.00234 & 0.00 & 0.00 \\
\hline $\mathrm{K}-1420$ OU & Nitrate & 0.0020904 & 0.00 & 0.00 \\
\hline LEFPC & Mercury & 107.6625203 & 1530.81 & 306.16 \\
\hline LEFPC & Aluminum & 1925.243374 & 838.82 & 83.88 \\
\hline LEFPC & Total PCBs & 7.221957441 & 108.05 & 10.81 \\
\hline LEFPC & Chromium & 313.1617002 & 43.44 & 10.84 \\
\hline LEFPC & Arsenic & 4.271195294 & 28.51 & 2.85 \\
\hline LEFPC & Selenium & 7.544399058 & 17.16 & 10.40 \\
\hline LEFPC & DDT and metabolites & 17.83225584 & 10.14 & 2.03 \\
\hline
\end{tabular}


Table G.12. (continued)

\begin{tabular}{|c|c|c|c|c|}
\hline Location & Analyte & $\begin{array}{c}\text { Total } \\
\text { Exposure }\end{array}$ & $\begin{array}{c}\text { NOAEL } \\
\text { HQ }\end{array}$ & $\begin{array}{c}\text { LOAEL } \\
\text { HQ }\end{array}$ \\
\hline LEFPC & Vanadium & 3.689749896 & 8.61 & 0.86 \\
\hline LEFPC & Cadmium & 17.32141332 & 8.17 & 0.82 \\
\hline LEFPC & Thallium & 0.063720616 & 3.88 & 0.39 \\
\hline LEFPC & Barium & 22.87776496 & 1.93 & 0.53 \\
\hline LEFPC & Zinc & 624.136897 & 1.77 & 0.89 \\
\hline LEFPC & Copper & 49.87598592 & 1.49 & 1.13 \\
\hline LEFPC & Nickel & 126.783259 & 1.44 & 0.72 \\
\hline LEFPC & Manganese & 186.0254401 & 0.96 & 0.30 \\
\hline LEFPC & Lead & 10.58662258 & 0.60 & 0.06 \\
\hline LEFPC & Beryllium & 0.729607826 & 0.50 & \\
\hline LEFPC & Antimony & 0.0614016 & 0.41 & 0.04 \\
\hline LEFPC & Uranium & 1.351211217 & 0.38 & 0.19 \\
\hline LEFPC & Pentachlorophenol & 0.0293826 & 0.06 & 0.01 \\
\hline LEFPC & Acetone & 1.041061322 & 0.05 & 0.01 \\
\hline LEFPC & Benzo(a)Pyrene & 0.037914897 & 0.03 & 0.00 \\
\hline LEFPC & Cyanide & 0.454272 & 0.00 & \\
\hline LEFPC & Dieldrin & 0.000118482 & 0.00 & 0.00 \\
\hline LEFPC & Methylene chloride & 0.016700988 & 0.00 & 0.00 \\
\hline LEFPC & Bis(2-ethylhexyl)Phthalate & 0.015669795 & 0.00 & 0.00 \\
\hline LEFPC & Endrin & 0.000055645 & 0.00 & 0.00 \\
\hline LEFPC & Endosulfan & 0.0001482 & 0.00 & \\
\hline LEFPC & Aldrin & 0.000031288 & 0.00 & 0.00 \\
\hline LEFPC & Heptachlor & 0.00001566 & 0.00 & 0.00 \\
\hline LEFPC & Methoxychlor & 0.0004602 & 0.00 & 0.00 \\
\hline LEFPC & Di-N-Butylphthalate & 0.014859856 & 0.00 & 0.00 \\
\hline LEFPC & Total chlordane & 0.000109591 & 0.00 & 0.00 \\
\hline LEFPC & Mixed-BHC & 0.000026029 & 0.00 & 0.00 \\
\hline LEFPC & DiethylPhthalate & 0.021321873 & 0.00 & \\
\hline LEFPC & Lindane & 0.000060733 & 0.00 & \\
\hline SCF & Aluminum & 2990.073042 & 1302.77 & 130.28 \\
\hline SCF & Arsenic & 7.796845164 & 52.03 & 5.20 \\
\hline SCF & Chromium & 292.2613788 & 40.54 & 10.12 \\
\hline SCF & Mercury & 2.210237375 & 31.43 & 6.29 \\
\hline SCF & Acetone & 384.4165858 & 17.49 & 3.50 \\
\hline SCF & Cadmium & 27.64579016 & 13.04 & 1.30 \\
\hline SCF & Vanadium & 5.078693574 & 11.85 & 1.19 \\
\hline SCF & Total PCBs & 0.780219556 & 11.67 & 1.17 \\
\hline SCF & Methylene chloride & 88.7612066 & 6.90 & 0.81 \\
\hline SCF & Selenium & 2.56948997 & 5.85 & 3.54 \\
\hline SCF & Barium & 24.58264683 & 2.08 & 0.56 \\
\hline SCF & Zinc & 548.3977829 & 1.56 & 0.78 \\
\hline
\end{tabular}


Table G.12. (continued)

\begin{tabular}{|c|c|c|c|c|}
\hline Location & Analyte & $\begin{array}{c}\text { Total } \\
\text { Exposure }\end{array}$ & $\begin{array}{c}\text { NOAEL } \\
\text { HQ }\end{array}$ & $\begin{array}{c}\text { LOAEL } \\
\text { HQ }\end{array}$ \\
\hline SCF & Manganese & 287.9614101 & 1.49 & 0.46 \\
\hline SCF & Beryllium & 1.202014162 & 0.83 & \\
\hline SCF & Nickel & 68.13687497 & 0.78 & 0.39 \\
\hline SCF & 1,2-Dichlorethane & 40.14856096 & 0.65 & \\
\hline SCF & Antimony & 0.0947544 & 0.64 & 0.06 \\
\hline SCF & Lead & 8.989938366 & 0.51 & 0.05 \\
\hline SCF & Copper & 15.51765815 & 0.46 & 0.35 \\
\hline SCF & Trichloroethene & 0.167296257 & 0.20 & 0.02 \\
\hline SCF & Uranium & 0.376380277 & 0.10 & 0.05 \\
\hline SCF & Tetrachloroethene & 0.130114576 & 0.08 & 0.02 \\
\hline SCF & 1,1-Dichlorethene & 1.5349308 & 0.02 & \\
\hline SCF & Benzo(a)pyrene & 0.025266149 & 0.02 & 0.00 \\
\hline SCF & Chloroform & 0.348655652 & 0.01 & 0.00 \\
\hline $\mathrm{SCF}$ & Benzene & 0.309446372 & 0.01 & 0.00 \\
\hline SCF & Toluene & 0.225561605 & 0.01 & 0.00 \\
\hline SCF & Dieldrin & 0.000102684 & 0.00 & 0.00 \\
\hline SCF & Endrin & 0.000087442 & 0.00 & 0.00 \\
\hline SCF & Pentachlorophenol & 0.0004056 & 0.00 & 0.00 \\
\hline SCF & Heptachlor & 0.000219246 & 0.00 & 0.00 \\
\hline SCF & Endosulfan & 0.0002184 & 0.00 & \\
\hline SCF & Bis(2-ethylhexyl)phthalate & 0.013710094 & 0.00 & 0.00 \\
\hline SCF & DDT and metabolites & 0.000766467 & 0.00 & 0.00 \\
\hline SCF & Methoxychlor & 0.0011076 & 0.00 & 0.00 \\
\hline SCF & Aldrin & 0.000031288 & 0.00 & 0.00 \\
\hline SCF & 1,1,1-Trichlorethane & 0.07449 & 0.00 & \\
\hline SCF & Total chlordane & 0.000180042 & 0.00 & 0.00 \\
\hline SCF & Di-N-Butylphthalate & 0.009548729 & 0.00 & 0.00 \\
\hline SCF & Mixed-BHC & 0.000034705 & 0.00 & 0.00 \\
\hline SCF & Carbon tetrachloride & 0.0000078 & 0.00 & \\
\hline UEFPC OU 2 & Aluminum & 9496.460978 & 4137.59 & 413.76 \\
\hline UEFPC OU 2 & Chromium & 367.7381336 & 51.01 & 12.73 \\
\hline UEFPC OU 2 & Arsenic & 4.644343514 & 31.00 & 3.10 \\
\hline UEFPC OU 2 & Vanadium & 4.541428176 & 10.60 & 1.06 \\
\hline UEFPC OU 2 & Barium & 99.83474582 & 8.44 & 2.29 \\
\hline UEFPC OU 2 & Zinc & 1077.701466 & 3.06 & 1.53 \\
\hline UEFPC OU 2 & Lead & 43.04602647 & 2.45 & 0.24 \\
\hline UEFPC OU 2 & Nickel & 190.764386 & 2.17 & 1.08 \\
\hline UEFPC OU 2 & Manganese & 403.741429 & 2.09 & 0.65 \\
\hline UEFPC OU 2 & Beryllium & 1.638913562 & 1.13 & \\
\hline UEFPC OU 2 & Copper & 30.55336172 & 0.91 & 0.69 \\
\hline UEFPC OU 2 & Lithium & 6.354840941 & 0.31 & 0.15 \\
\hline
\end{tabular}


G-50

Table G.12. (continued)

\begin{tabular}{|c|c|c|c|c|}
\hline Location & Analyte & $\begin{array}{c}\text { Total } \\
\text { Exposure }\end{array}$ & $\begin{array}{c}\text { NOAEL } \\
\text { HQ } \\
\end{array}$ & $\begin{array}{c}\text { LOAEL } \\
\text { HQ } \\
\end{array}$ \\
\hline UEFPC OU 2 & Uranium & 0.704936302 & 0.20 & 0.10 \\
\hline UEFPC OU 2 & Strontium & 28.32916804 & 0.05 & \\
\hline UEFPC OU 2 & Nitrate & 0.0874926 & 0.00 & 0.00 \\
\hline WAG 1 & Aluminum & 1904245.425 & 829675.21 & 82967.52 \\
\hline WAG 1 & Thallium & 1.248182291 & 75.94 & 7.59 \\
\hline WAG 1 & Total PCBs & 4.870350884 & 72.87 & 7.29 \\
\hline WAG 1 & Mercury & 4.785828902 & 68.05 & 13.61 \\
\hline WAG 1 & Arsenic & 5.240704752 & 34.98 & 3.50 \\
\hline WAG 1 & Selenium & 14.5967589 & 33.21 & 20.13 \\
\hline WAG 1 & Chromium & 157.5005407 & 21.85 & 5.45 \\
\hline WAG 1 & Vanadium & 2.978671008 & 6.95 & 0.70 \\
\hline WAG 1 & Cadmium & 7.316270219 & 3.45 & 0.35 \\
\hline WAG 1 & Antimony & 0.4728126 & 3.18 & 0.32 \\
\hline WAG 1 & Boron & 137.3762598 & 2.23 & 0.67 \\
\hline WAG 1 & Barium & 20.29191693 & 1.71 & 0.47 \\
\hline WAG 1 & Zinc & 396.670199 & 1.13 & 0.56 \\
\hline WAG 1 & Nickel & 68.76567225 & 0.78 & 0.39 \\
\hline WAG 1 & Manganese & 141.6970092 & 0.73 & 0.23 \\
\hline WAG 1 & Beryllium & 0.755417489 & 0.52 & \\
\hline WAG 1 & Uranium & 1.643734336 & 0.46 & 0.23 \\
\hline WAG 1 & Lead & 7.976034507 & 0.45 & 0.05 \\
\hline WAG 1 & Copper & 12.37908539 & 0.37 & 0.28 \\
\hline WAG 1 & Tin & 4.227717 & 0.15 & 0.10 \\
\hline WAG 1 & Benzo(a)Pyrene & 0.056872345 & 0.05 & 0.00 \\
\hline WAG 1 & Pentachlorophenol & 0.02184 & 0.04 & 0.00 \\
\hline WAG 1 & Endrin & 0.001669339 & 0.02 & 0.00 \\
\hline WAG 1 & Vinyl chloride & 0.002981155 & 0.01 & 0.00 \\
\hline WAG 1 & Total chlordane & 0.016375964 & 0.00 & 0.00 \\
\hline WAG 1 & Heptachlor & 0.000822173 & 0.00 & 0.00 \\
\hline WAG 1 & Cyanide & 0.3651414 & 0.00 & \\
\hline WAG 1 & Acetone & 0.052883316 & 0.00 & 0.00 \\
\hline WAG 1 & DDT and metabolites & 0.004168644 & 0.00 & 0.00 \\
\hline WAG 1 & Bis(2-ethylhexyl)Phthalate & 0.034462618 & 0.00 & 0.00 \\
\hline WAG 1 & Methylene chloride & 0.011554937 & 0.00 & 0.00 \\
\hline WAG 1 & Trichloroethene & 0.000257724 & 0.00 & 0.00 \\
\hline WAG 1 & Tetrachloroethene & 0.000489838 & 0.00 & 0.00 \\
\hline WAG 1 & Mixed-BHC & 0.001023792 & 0.00 & 0.00 \\
\hline WAG 1 & Di-N-Butylphthalate & 0.056525569 & 0.00 & 0.00 \\
\hline WAG 1 & Chloroform & 0.001579056 & 0.00 & 0.00 \\
\hline WAG 1 & 1,2-Dichlorethane & 0.001532232 & 0.00 & \\
\hline WAG 1 & Benzene & 0.000470237 & 0.00 & 0.00 \\
\hline
\end{tabular}


G-51

Table G.12. (continued)

\begin{tabular}{|c|c|c|c|c|}
\hline Location & Analyte & $\begin{array}{c}\text { Total } \\
\text { Exposure } \\
\end{array}$ & $\begin{array}{l}\text { NOAEL } \\
\text { HQ }\end{array}$ & $\begin{array}{c}\text { LOAEL } \\
\text { HQ } \\
\end{array}$ \\
\hline WAG 1 & Carbon tetrachloride & 0.000468 & 0.00 & \\
\hline WAG 1 & Toluene & 0.000386009 & 0.00 & 0.00 \\
\hline WAG 1 & 1,1-Dichlorethene & 0.000468 & 0.00 & \\
\hline WAG 1 & 1,2-Dichlorethene & 0.0001794 & 0.00 & \\
\hline WAG 1 & Diethylphthalate & 0.005917958 & 0.00 & \\
\hline WAG 1 & 1,1,1-Trichlorethane & 0.0002574 & 0.00 & \\
\hline WAG 6 & Aluminum & 2505612.15 & 1091689.26 & 109168.93 \\
\hline WAG 6 & Chromium & 126.0026309 & 17.48 & 4.36 \\
\hline WAG 6 & Arsenic & 1.119766526 & 7.47 & 0.75 \\
\hline WAG 6 & Vanadium & 2.431733373 & 5.68 & 0.57 \\
\hline WAG 6 & Cadmium & 10.61228389 & 5.01 & 0.50 \\
\hline WAG 6 & Barium & 25.23917579 & 2.13 & 0.58 \\
\hline WAG 6 & Nickel & 139.2240802 & 1.58 & 0.79 \\
\hline WAG 6 & Mercury & 0.096772276 & 1.38 & 0.28 \\
\hline WAG 6 & Manganese & 192.4200283 & 0.99 & 0.31 \\
\hline WAG 6 & Beryllium & 1.10839819 & 0.76 & \\
\hline WAG 6 & Zinc & 235.1159793 & 0.67 & 0.33 \\
\hline WAG 6 & 1,4-Dioxane & 0.5895864 & 0.54 & 0.27 \\
\hline WAG 6 & Copper & 10.08272339 & 0.30 & 0.23 \\
\hline WAG 6 & Tin & 6.960954 & 0.25 & 0.17 \\
\hline WAG 6 & Lead & 3.173877559 & 0.18 & 0.02 \\
\hline WAG 6 & Uranium & 0.114335179 & 0.03 & 0.02 \\
\hline WAG 6 & Cyanide & 1.8577416 & 0.01 & \\
\hline WAG 6 & Bis(2-ethylhexyl)phthalate & 0.036102208 & 0.00 & 0.00 \\
\hline WAG 6 & Acetone & 0.026531903 & 0.00 & 0.00 \\
\hline WAG 6 & Methylene chloride & 0.011933787 & 0.00 & 0.00 \\
\hline WAG 6 & Trichloroethene & 0.000403394 & 0.00 & 0.00 \\
\hline WAG 6 & Tetrachloroethene & 0.000375922 & 0.00 & 0.00 \\
\hline WAG 6 & Chloroform & 0.002245769 & 0.00 & 0.00 \\
\hline WAG 6 & 1,2-Dichlorethene & 0.0005304 & 0.00 & \\
\hline WAG 6 & Toluene & 0.000275721 & 0.00 & 0.00 \\
\hline
\end{tabular}




$$
\text { G-52 }
$$

Table G.13. Estimated exposure of American woodcock to contaminants on the ORR

\begin{tabular}{|c|c|c|c|c|}
\hline Location & Analyte & $\begin{array}{c}\text { Total } \\
\text { Exposure } \\
\end{array}$ & $\begin{array}{c}\text { NOAEL } \\
\text { HQ }\end{array}$ & $\begin{array}{c}\text { LOAEL } \\
\text { HQ } \\
\end{array}$ \\
\hline $\mathrm{BC}$ OU 2 & Mercury & 262.0454236 & 40944.60 & 4094.46 \\
\hline BC OU 2 & Chromium & 282.6510989 & 282.65 & 56.53 \\
\hline BC OU 2 & Aluminum & 6041.148091 & 55.07 & \\
\hline $\mathrm{BC}$ OU 2 & Zinc & 745.1656773 & 51.39 & 5.69 \\
\hline BC OU 2 & Total PCBs & 4.184366667 & 23.25 & 2.32 \\
\hline BC OU 2 & Lead & 25.74877 & 22.79 & 2.28 \\
\hline $\mathrm{BC}$ OU 2 & Arsenic & 24.32582955 & 9.89 & 3.30 \\
\hline BC OU 2 & Selenium & 2.030577197 & 5.08 & 2.54 \\
\hline BC OU 2 & Cadmium & 4.229658636 & 2.92 & 0.21 \\
\hline BC OU 2 & Nickel & 224.4302794 & 2.90 & 2.10 \\
\hline BC OU 2 & Barium & 30.79558 & 1.48 & 0.74 \\
\hline BC OU 2 & Copper & 40.41646136 & 0.86 & 0.66 \\
\hline $\mathrm{BC}$ OU 2 & Vanadium & 9.102181818 & 0.80 & \\
\hline BC OU 2 & DDT and metabolites & 0.001323636 & 0.47 & 0.05 \\
\hline BC OU 2 & Di-N-Butylphthalate & 0.041678788 & 0.38 & 0.04 \\
\hline $\mathrm{BC}$ OU 2 & Manganese & 297.9092222 & 0.30 & \\
\hline BC OU 2 & Boron & 6.256238182 & 0.22 & 0.06 \\
\hline BC OU 2 & Endrin & 0.000441212 & 0.04 & 0.00 \\
\hline BC OU 2 & $\begin{array}{l}\text { Bis(2-ethylhexyl)Phthal } \\
\text { ate }\end{array}$ & 0.041678788 & 0.04 & \\
\hline BC OU 2 & Uranium & 0.31838803 & 0.02 & \\
\hline BC OU 2 & Dieldrin & 0.000441212 & 0.01 & \\
\hline BC OU 2 & Mixed-BHC & 0.000441212 & 0.00 & 0.00 \\
\hline $\mathrm{BC}$ OU 2 & Total chlordane & 0.000441212 & 0.00 & 0.00 \\
\hline $\mathrm{BC}$ OU 2 & Lindane & 0.000220606 & 0.00 & 0.00 \\
\hline BC OU 2 & Endosulfan & 0.000661818 & 0.00 & \\
\hline BC OU 2 & 1,2-Dichlorethane & 0.000638182 & 0.00 & 0.00 \\
\hline $\mathrm{K}-1407$ OU & Mercury & 22.03885 & 3443.57 & 344.36 \\
\hline K-1407 OU & Chromium & 446.4428235 & 446.44 & 89.29 \\
\hline $\mathrm{K}-1407$ OU & Aluminum & 4830.774995 & 44.04 & \\
\hline K-1407 OU & Zinc & 321.5251904 & 22.17 & 2.45 \\
\hline K-1407 OU & Selenium & 8.121740985 & 20.30 & 10.15 \\
\hline $\mathrm{K}-1407$ OU & Nickel & 1119.82291 & 14.47 & 10.47 \\
\hline $\mathrm{K}-1407$ OU & Cadmium & 10.60597636 & 7.31 & 0.53 \\
\hline K-1407 OU & Lead & 6.699269091 & 5.93 & 0.59 \\
\hline $\mathrm{K}-1407$ OU & Arsenic & 9.058569318 & 3.68 & 1.23 \\
\hline K-1407 OU & Uranium & 32.36891417 & 2.02 & \\
\hline K-1407 OU & Barium & 25.05504 & 1.20 & 0.60 \\
\hline K-1407 OU & Molybdenum & 2.577129545 & 0.74 & 0.07 \\
\hline K-1407 OU & Copper & 34.26895 & 0.73 & 0.56 \\
\hline $\mathrm{K}-1407 \mathrm{OU}$ & Vanadium & 6.013163636 & 0.53 & \\
\hline $\mathrm{K}-1407$ OU & Manganese & 226.9051367 & 0.23 & \\
\hline
\end{tabular}


Table G.13. (continued)

\begin{tabular}{|c|c|c|c|c|}
\hline Location & Analyte & $\begin{array}{c}\text { Total } \\
\text { Exposure } \\
\end{array}$ & $\begin{array}{c}\text { NOAEL } \\
\text { HQ } \\
\end{array}$ & $\begin{array}{c}\text { LOAEL } \\
\text { HQ } \\
\end{array}$ \\
\hline $\mathrm{K}-1407$ OU & Boron & 0.661786667 & 0.02 & 0.01 \\
\hline $\mathrm{K}-1407$ OU & Di-N-Butylphthalate & 0.001457576 & 0.01 & 0.00 \\
\hline K-1414 & Di-N-Butylphthalate & 0.187641212 & 1.71 & 0.17 \\
\hline$K-1414$ & $\begin{array}{l}\text { Bis(2-ethylhexyl)phthal } \\
\text { ate }\end{array}$ & 0.017609091 & 0.02 & \\
\hline $\mathrm{K}-1420$ OU & Aluminum & 8292868.023 & 75595.88 & \\
\hline $\mathrm{K}-1420$ OU & Mercury & 1.48189 & 231.55 & 23.15 \\
\hline $\mathrm{K}-1420$ OU & Chromium & 162.7680223 & 162.77 & 32.55 \\
\hline $\mathrm{K}-1420$ OU & Total PCBs & 16.01674167 & 88.98 & 8.90 \\
\hline $\mathrm{K}-1420$ OU & Zinc & 768.6001598 & 53.01 & 5.87 \\
\hline $\mathrm{K}-1420$ OU & Lead & 18.37783606 & 16.26 & 1.63 \\
\hline $\mathrm{K}-1420$ OU & Arsenic & 18.68464659 & 7.60 & 2.53 \\
\hline $\mathrm{K}-1420$ OU & Uranium & 35.74855136 & 2.23 & \\
\hline $\mathrm{K}-1420$ OU & Nickel & 150.9047713 & 1.95 & 1.41 \\
\hline $\mathrm{K}-1420 \mathrm{OU}$ & Vanadium & 20.52084364 & 1.80 & \\
\hline $\mathrm{K}-1420 \mathrm{OU}$ & Barium & 16.78768 & 0.81 & 0.40 \\
\hline $\mathrm{K}-1420$ OU & Copper & 33.13857727 & 0.71 & 0.54 \\
\hline $\mathrm{K}-1420$ OU & Manganese & 328.1591162 & 0.33 & \\
\hline $\mathrm{K}-1420$ OU & $\begin{array}{l}\text { Bis(2-ethylhexyl)phthal } \\
\text { ate }\end{array}$ & 0.022785455 & 0.02 & \\
\hline $\mathrm{K}-1420 \mathrm{OU}$ & Boron & 0.212727273 & 0.01 & 0.00 \\
\hline $\mathrm{K}-1420 \mathrm{OU}$ & Fluoride & 0.002363636 & 0.00 & 0.00 \\
\hline $\mathrm{K}-1420$ OU & 1,2-Dichlorethane & 0.00058303 & 0.00 & 0.00 \\
\hline LEFPC & Mercury & 143.3612291 & 22400.19 & 2240.02 \\
\hline LEFPC & DDT and metabolites & 17.96379394 & 6415.64 & 641.56 \\
\hline LEFPC & Chromium & 418.7511019 & 418.75 & 83.75 \\
\hline LEFPC & Zinc & 828.8555558 & 57.16 & 6.33 \\
\hline LEFPC & Total PCBs & 9.359020833 & 51.99 & 5.20 \\
\hline LEFPC & Selenium & 9.884882955 & 24.71 & 12.36 \\
\hline LEFPC & Aluminum & 2225.000214 & 20.28 & \\
\hline LEFPC & Cadmium & 22.92039727 & 15.81 & 1.15 \\
\hline LEFPC & Lead & 12.4834197 & 11.05 & 1.10 \\
\hline LEFPC & Arsenic & 5.519182955 & 2.24 & 0.75 \\
\hline LEFPC & Nickel & 169.0554627 & 2.18 & 1.58 \\
\hline LEFPC & Copper & 63.17757727 & 1.34 & 1.02 \\
\hline LEFPC & Barium & 26.00946 & 1.25 & 0.62 \\
\hline LEFPC & Vanadium & 4.117192727 & 0.36 & \\
\hline LEFPC & Manganese & 200.0116133 & 0.20 & \\
\hline LEFPC & Di-N-Butylphthalate & 0.014504848 & 0.13 & 0.01 \\
\hline LEFPC & Uranium & 1.504872424 & 0.09 & \\
\hline LEFPC & $\begin{array}{l}\text { Bis(2-ethylhexyl)Phthal } \\
\text { ate. }\end{array}$ & 0.015812727 & 0.01 & \\
\hline
\end{tabular}


Table G.13. (continued)

\begin{tabular}{|c|c|c|c|c|}
\hline Location & Analyte & $\begin{array}{c}\text { Total } \\
\text { Exposure }\end{array}$ & $\begin{array}{c}\text { NOAEL } \\
\text { HQ }\end{array}$ & $\begin{array}{c}\text { LOAEL } \\
\text { HQ }\end{array}$ \\
\hline LEFPC & Endrin & 0.000055152 & 0.01 & 0.00 \\
\hline LEFPC & Dieldrin & 0.000118182 & 0.00 & \\
\hline LEFPC & Total chlordane & 0.000110303 & 0.00 & 0.00 \\
\hline LEFPC & Mixed-BHC & 0.000023636 & 0.00 & 0.00 \\
\hline LEFPC & Lindane & 0.000055152 & 0.00 & 0.00 \\
\hline LEFPC & Endosulfan & 0.000149697 & 0.00 & \\
\hline SCF & Mercury & 2.943107273 & 459.86 & 45.99 \\
\hline SCF & Chromium & 390.8037742 & 390.80 & 78.16 \\
\hline SCF & Zinc & 728.273799 & 50.23 & 5.56 \\
\hline SCF & Aluminum & 3455.621895 & 31.50 & \\
\hline SCF & Cadmium & 36.58203182 & 25.23 & 1.83 \\
\hline SCF & Lead & 10.60065879 & 9.38 & 0.94 \\
\hline SCF & Selenium & 3.366617727 & 8.42 & 4.21 \\
\hline SCF & Total PCBs & 1.011095833 & 5.62 & 0.56 \\
\hline SCF & Arsenic & 10.07498182 & 4.10 & 1.37 \\
\hline SCF & Barium & 27.94772 & 1.34 & 0.67 \\
\hline SCF & Nickel & 90.85514136 & 1.17 & 0.85 \\
\hline SCF & 1,2-Dichlorethane & 12.38671515 & 0.72 & 0.36 \\
\hline SCF & Vanadium & 5.66704 & 0.50 & \\
\hline SCF & Copper & 19.65611364 & 0.42 & 0.32 \\
\hline SCF & Manganese & 309.6115573 & 0.31 & \\
\hline SCF & DDT and metabolites & 0.000772121 & 0.28 & 0.03 \\
\hline SCF & Di-N-Butylphthalate & 0.009320606 & 0.08 & 0.01 \\
\hline SCF & Uranium & 0.419182652 & 0.03 & \\
\hline SCF & $\begin{array}{l}\text { Bis(2-ethylhexyl)phthal } \\
\text { ate }\end{array}$ & 0.013835152 & 0.01 & \\
\hline SCF & Endrin & 0.000086667 & 0.01 & 0.00 \\
\hline SCF & Dieldrin & 0.000102424 & 0.00 & \\
\hline SCF & Total chlordane & 0.000181212 & 0.00 & 0.00 \\
\hline SCF & Mixed-BHC & 0.000031515 & 0.00 & 0.00 \\
\hline SCF & Endosulfan & 0.000220606 & 0.00 & \\
\hline UEFPC OU 2 & Chromium & 491.7291883 & 491.73 & 98.35 \\
\hline UEFPC OU 2 & Aluminum & 10975.04242 & 100.05 & \\
\hline UEFPC OU 2 & Zinc & 1431.19058 & 98.70 & 10.93 \\
\hline UEFPC OU 2 & Lead & 50.7585503 & 44.92 & 4.49 \\
\hline UEFPC OU 2 & Barium & 113.50094 & 5.46 & 2.72 \\
\hline UEFPC OU 2 & Nickel & 254.3692423 & 3.29 & 2.38 \\
\hline UEFPC OU 2 & Arsenic & 6.001360227 & 2.44 & 0.81 \\
\hline UEFPC OU 2 & Copper & 38.70173864 & 0.82 & 0.63 \\
\hline UEFPC OU 2 & Vanadium & 5.067534545 & 0.44 & \\
\hline UEFPC OU 2 & Manganese & 434.0964038 & 0.44 & \\
\hline UEFPC OU 2 & Uranium & 0.785102424 & 0.05 & \\
\hline
\end{tabular}


Table G.13. (continued)

\begin{tabular}{|c|c|c|c|c|}
\hline Location & Analyte & $\begin{array}{c}\text { Total } \\
\text { Exposure } \\
\end{array}$ & $\begin{array}{l}\text { NOAEL } \\
\text { HQ } \\
\end{array}$ & $\begin{array}{c}\text { LOAEL } \\
\text { HQ } \\
\end{array}$ \\
\hline WAG 1 & Aluminum & 2200732.923 & 20061.38 & \\
\hline WAG 1 & Mercury & 6.372712727 & 995.74 & 99.57 \\
\hline WAG 1 & Chromium & 210.6053356 & 210.61 & 42.12 \\
\hline WAG 1 & Selenium & 19.12508235 & 47.81 & 23.91 \\
\hline WAG 1 & Zinc & 526.7791407 & 36.33 & 4.02 \\
\hline WAG 1 & Total PCBs & 6.311545833 & 35.06 & 3.51 \\
\hline WAG 1 & Lead & 9.405094545 & 8.32 & 0.83 \\
\hline WAG 1 & Cadmium & 9.681185758 & 6.68 & 0.48 \\
\hline WAG 1 & Boron & 138.7638988 & 4.82 & 1.39 \\
\hline WAG 1 & Arsenic & 6.771970455 & 2.75 & 0.92 \\
\hline WAG 1 & DDT and metabolites & 0.004199394 & 1.50 & 0.15 \\
\hline WAG 1 & Nickel & 91.69359288 & 1.18 & 0.86 \\
\hline WAG 1 & Barium & 23.06964 & 1.11 & 0.55 \\
\hline WAG 1 & Tin & 4.270421212 & 0.63 & 0.25 \\
\hline WAG 1 & Di-N-Butylphthalate & 0.055175152 & 0.50 & 0.05 \\
\hline WAG 1 & Copper & 15.68050455 & 0.33 & 0.25 \\
\hline WAG 1 & Vanadium & 3.323738182 & 0.29 & \\
\hline WAG 1 & Endrin & 0.001654545 & 0.17 . & 0.02 \\
\hline WAG 1 & Manganese & 152.3503849 & 0.15 & \\
\hline WAG 1 & Uranium & 1.830661591 & 0.11 & \\
\hline WAG 1 & $\begin{array}{l}\text { Bis(2-ethylhexyl)Phthal } \\
\text { ate }\end{array}$ & 0.03477697 & 0.03 & \\
\hline WAG 1 & Total chlordane & 0.016482424 & 0.01 & 0.00 \\
\hline WAG 1 & Mixed-BHC & 0.000929697 & 0.00 & 0.00 \\
\hline WAG 1 & 1,2-Dichlorethane & 0.000472727 & 0.00 & 0.00 \\
\hline WAG 6 & Aluminum & 2895731.336 & 26396.82 & \\
\hline WAG 6 & Chromium & 168.487208 & 168.49 & 33.70 \\
\hline WAG 6 & Zinc & 312.2346823 & 21.53 & 2.38 \\
\hline WAG 6 & Mercury & 0.12886 & 20.13 & 2.01 \\
\hline WAG 6 & Cadmium & 14.04260485 & 9.68 & 0.70 \\
\hline WAG 6 & Lead & 3.742538788 & 3.31 & 0.33 \\
\hline WAG 6 & Nickel & 185.6443151 & 2.40 & 1.73 \\
\hline WAG 6 & Barium & 28.69412 & 1.38 & 0.69 \\
\hline WAG 6 & $\operatorname{Tin}$ & 7.031266667 & 1.03 & 0.42 \\
\hline WAG 6 & Arsenic & 1.446947727 & 0.59 & 0.20 \\
\hline WAG 6 & Copper & 12.77171818 & 0.27 & 0.21 \\
\hline WAG 6 & Vanadium & 2.71344 & 0.24 & \\
\hline WAG 6 & Manganese & 206.8869735 & 0.21 & \\
\hline WAG 6 & $\begin{array}{l}\text { Bis(2-ethylhexyl)phthal } \\
\text { ate }\end{array}$ & 0.036431515 & 0.03 & \\
\hline WAG 6 & Uranium & 0.1273375 & 0.01 & \\
\hline
\end{tabular}


G-56

Table G.14. Estimated exposure of red fox to contaminants on the ORR

\begin{tabular}{|c|c|c|c|c|}
\hline Location & Analyte & $\begin{array}{c}\text { Total } \\
\text { Exposure }\end{array}$ & $\begin{array}{c}\text { NOAEL } \\
\text { HQ } \\
\end{array}$ & $\begin{array}{c}\text { LOAEL } \\
\text { HQ }\end{array}$ \\
\hline BC OU 2 & Mercury & 7.852933005 & 785.29 & 461.94 \\
\hline $\mathrm{BC}$ OU 2 & Aluminum & 189.7168677 & 344.31 & 34.40 \\
\hline BC OU 2 & Arsenic & 0.383075188 & 10.64 & 1.06 \\
\hline BC OU 2 & Total PCBs & 0.269788945 & 2.81 & 0.57 \\
\hline BC OU 2 & Vanadium & 0.27834472 & 2.70 & 0.27 \\
\hline BC OU 2 & Chromium & 4.187312605 & 2.42 & 0.60 \\
\hline BC OU 2 & Barium & 1.786390005 & 0.64 & 0.17 \\
\hline $\mathrm{BC}$ OU 2 & Niobium & 0.02758 & 0.63 & 0.06 \\
\hline BC OU 2 & Selenium & 0.061447699 & 0.58 & 0.35 \\
\hline BC OU 2 & Copper & 4.234890015 & 0.53 & 0.40 \\
\hline BC OU 2 & Thallium & 0.00190246 & 0.48 & 0.05 \\
\hline $\mathrm{BC}$ OU 2 & Zinc & 38.7475539 & 0.46 & 0.23 \\
\hline BC OU 2 & Zirconium & 0.20855128 & 0.42 & \\
\hline $\mathrm{BC}$ OU 2 & Manganese & 14.23209141 & 0.31 & 0.09 \\
\hline BC OU 2 & Lead & 1.067843766 & 0.25 & 0.03 \\
\hline BC OU 2 & Nickel & 3.726796428 & 0.18 & 0.09 \\
\hline BC OU 2 & Cadmium & 0.069827594 & 0.14 & 0.01 \\
\hline BC OU 2 & Lithium & 0.364793834 & 0.07 & 0.04 \\
\hline BC OU 2 & Beryllium & 0.017912591 & 0.05 & \\
\hline $\mathrm{BC}$ OU 2 & Pentachlorophenol & 0.00362796 & 0.03 & 0.00 \\
\hline BC OU 2 & Antimony & 0.0009996 & 0.03 & 0.00 \\
\hline BC OU 2 & Boron & 0.22233708 & 0.02 & 0.00 \\
\hline $\mathrm{BC}$ OU 2 & Acetone & 0.058552345 & 0.01 & 0.00 \\
\hline BC OU 2 & Vinyl chloride & 0.000931594 & 0.01 & 0.00 \\
\hline BC OU 2 & Uranium & 0.008494028 & 0.01 & 0.00 \\
\hline $\mathrm{BC}$ OU 2 & Strontium & 1.23695418 & 0.01 & \\
\hline $\mathrm{BC}$ OU 2 & Benzo(a)pyrene & 0.001543848 & 0.01 & 0.00 \\
\hline $\mathrm{BC}$ OU 2 & Mixed-BHC & 0.00003143 & 0.00 & 0.00 \\
\hline BC OU 2 & Dieldrin & 0.000017456 & 0.00 & 0.00 \\
\hline BC OU 2 & Endrin & 0.000018363 & 0.00 & 0.00 \\
\hline BC OU 2 & Trichloroethene & 0.00011122 & 0.00 & 0.00 \\
\hline BC OU 2 & Methylene chloride & 0.001415918 & 0.00 & 0.00 \\
\hline BC OU 2 & Endosulfan & 0.00002352 & 0.00 & \\
\hline BC OU 2 & Bis(2-ethylhexyl)Phthalate & 0.001494056 & 0.00 & 0.00 \\
\hline $\mathrm{BC}$ OU 2 & Tetrachloroethene & 0.000111762 & 0.00 & 0.00 \\
\hline $\mathrm{BC}$ OU 2 & Toxaphene & 0.00079464 & 0.00 & \\
\hline $\mathrm{BC}$ OU 2 & Heptachlor & 0.000008112 & 0.00 & 0.00 \\
\hline BC OU 2 & DDT and metabolites & 0.000048178 & 0.00 & 0.00 \\
\hline BC OU 2 & Aldrin & 0.000008037 & 0.00 & 0.00 \\
\hline $\mathrm{BC}$ OU 2 & Methoxychlor & 0.00007952 & 0.00 & 0.00 \\
\hline $\mathrm{BC}$ OU 2 & Chloroform & 0.000276052 & 0.00 & 0.00 \\
\hline
\end{tabular}


Table G.14. (continued)

\begin{tabular}{|c|c|c|c|c|}
\hline Location & Analyte & $\begin{array}{c}\text { Total } \\
\text { Exposure } \\
\end{array}$ & $\begin{array}{l}\text { NOAEL } \\
\text { HQ } \\
\end{array}$ & $\begin{array}{c}\text { LOAEL } \\
\text { HQ }\end{array}$ \\
\hline $\mathrm{BC}$ OU 2 & 1,2-Dichlorethane & 0.000483847 & 0.00 & \\
\hline $\mathrm{BC}$ OU 2 & Benzene & 0.000214272 & 0.00 & 0.00 \\
\hline BC OU 2 & Toluene & 0.00010663 & 0.00 & 0.00 \\
\hline $\mathrm{BC}$ OU 2 & Total chlordane & 0.000016181 & 0.00 & 0.00 \\
\hline $\mathrm{BC}$ OU 2 & Di-N-Butylphthalate & 0.001942421 & 0.00 & 0.00 \\
\hline $\mathrm{BC}$ OU 2 & 1,1-Dichlorethene & 0.00002268 & 0.00 & \\
\hline $\mathrm{BC}$ OU 2 & Diethylphthalate & 0.009128163 & 0.00 & \\
\hline BC OU 2 & Lindane & 0.000015715 & 0.00 & \\
\hline BC OU 2 & Carbon tetrachloride & 0.00002268 & 0.00 & \\
\hline $\mathrm{BC}$ OU 2 & 1,2-Dichlorethene & 0.00002268 & 0.00 & \\
\hline $\mathrm{BC}$ OU 2 & 1,1,1-Trichlorethane & 0.00002268 & 0.00 & \\
\hline $\mathrm{K}-1407$ OU & Aluminum & 151.7061802 & 275.33 & 27.51 \\
\hline $\mathrm{K}-1407$ OU & Mercury & 0.660456535 & 66.05 & 38.85 \\
\hline $\mathrm{K}-1407$ OU & Arsenic & 0.14265138 & 3.96 & 0.40 \\
\hline $\mathrm{K}-1407$ OU & Chromium & 6.613792303 & 3.82 & 0.95 \\
\hline $\mathrm{K}-1407$ OU & Selenium & 0.245773613 & 2.32 & 1.41 \\
\hline $\mathrm{K}-1407$ OU & Vanadium & 0.183882544 & 1.79 & 0.18 \\
\hline $\mathrm{K}-1407$ OU & Uranium & 0.863545258 & 1.00 & 0.50 \\
\hline $\mathrm{K}-1407$ OU & Nickel & 18.59531625 & 0.88 & 0.44 \\
\hline K-1407 OU & Antimony & 0.02002168 & 0.56 & 0.06 \\
\hline $\mathrm{K}-1407$ OU & Barium & 1.45339276 & 0.52 & 0.14 \\
\hline K-1407 OU & Molybdenum & 0.035479261 & 0.51 & 0.05 \\
\hline $\mathrm{K}-1407$ OU & Copper & 3.590745683 & 0.45 & 0.34 \\
\hline $\mathrm{K}-1407 \mathrm{OU}$ & Cadmium & 0.175094464 & 0.34 & 0.03 \\
\hline $\mathrm{K}-1407$ OU & Manganese & 10.83999557 & 0.24 & 0.07 \\
\hline $\mathrm{K}-1407$ OU & Zinc & 16.71885196 & 0.20 & 0.10 \\
\hline $\mathrm{K}-1407$ OU & Lead & 0.277829688 & 0.07 & 0.01 \\
\hline $\mathrm{K}-1407$ OU & Beryllium & 0.015345673 & 0.04 & \\
\hline $\mathrm{K}-1407$ OU & Acetone & 0.010473683 & 0.00 & 0.00 \\
\hline $\mathrm{K}-1407$ OU & Trichloroethene & 0.000385836 & 0.00 & 0.00 \\
\hline $\mathrm{K}-1407 \mathrm{OU}$ & Boron & 0.02351888 & 0.00 & 0.00 \\
\hline $\mathrm{K}-1407$ OU & Strontium & 0.19098618 & 0.00 & \\
\hline K-1407 OU & Tetrachloroethene & 0.000348183 & 0.00 & 0.00 \\
\hline $\mathrm{K}-1407$ OU & Methylene chloride & 0.001676953 & 0.00 & 0.00 \\
\hline $\mathrm{K}-1407$ OU & Chloroform & 0.000405558 & 0.00 & 0.00 \\
\hline $\mathrm{K}-1407$ OU & 1,2-Dichlorethene & 0.00007756 & 0.00 & \\
\hline $\mathrm{K}-1407 \mathrm{OU}$ & Toluene & 0.000013164 & 0.00 & 0.00 \\
\hline $\mathrm{K}-1407$ OU & Di-N-Butylphthalate & 0.00006793 & 0.00 & 0.00 \\
\hline $\mathrm{K}-1407$ OU & 1,1,1-Trichlorethane & 0.0000434 & 0.00 & \\
\hline $\mathrm{K}-1414$ & Methylene chloride & 0.012498044 & 0.00 & 0.00 \\
\hline $\mathrm{K}-1414$ & Acetone & 0.017270435 & 0.00 & 0.00 \\
\hline $\mathrm{K}-1414$ & Benzo(a)pyrene & 0.000837589 & 0.00 & 0.00 \\
\hline
\end{tabular}




\section{G-58}

Table G.14. (continued)

\begin{tabular}{|c|c|c|c|c|}
\hline Location & $\begin{array}{r}\text { Analyte } \\
\end{array}$ & $\begin{array}{c}\text { Total } \\
\text { Exposure } \\
\end{array}$ & $\begin{array}{c}\text { NOAEL } \\
\text { HQ }\end{array}$ & $\begin{array}{c}\text { LOAEL } \\
\text { HQ } \\
\end{array}$ \\
\hline $\mathrm{K}-1414$ & Tetrachloroethene & 0.000057314 & 0.00 & 0.00 \\
\hline $\mathrm{K}-1414$ & Bis(2-ethylhexyl)phthalate & 0.000631231 & 0.00 & 0.00 \\
\hline K-1414 & Di-N-Butylphthalate & 0.008744933 & 0.00 & 0.00 \\
\hline $\mathrm{K}-1420$ OU & Aluminum & 260430.1239 & 472649.95 & 47222.14 \\
\hline $\mathrm{K}-1420$ OU & Total PCBs & 1.032686708 & 10.76 & 2.18 \\
\hline $\mathrm{K}-1420 \mathrm{OU}$ & Arsenic & 0.294239688 & 8.17 & 0.82 \\
\hline $\mathrm{K}-1420$ OU & Vanadium & 0.627527398 & 6.09 & 0.61 \\
\hline $\mathrm{K}-1420$ OU & Mercury & 0.044409029 & 4.44 & 2.61 \\
\hline $\mathrm{K}-1420$ OU & Chromium & 2.411314141 & 1.39 & 0.35 \\
\hline $\mathrm{K}-1420$ OU & Uranium & 0.953707988 & 1.11 & 0.55 \\
\hline K-1420 OU & Thallium & 0.003758976 & 0.94 & 0.10 \\
\hline $\mathrm{K}-1420$ OU & Zinc & 39.96611361 & 0.47 & 0.24 \\
\hline $\mathrm{K}-1420$ OU & Copper & 3.472303741 & 0.43 & 0.33 \\
\hline $\mathrm{K}-1420$ OU & Lithium & 1.76508276 & 0.35 & 0.18 \\
\hline $\mathrm{K}-1420$ OU & Barium & 0.973819741 & 0.35 & 0.09 \\
\hline $\mathrm{K}-1420$ OU & Manganese & 15.67722713 & 0.34 & 0.10 \\
\hline $\mathrm{K}-1420$ OU & Lead & 0.762159034 & 0.18 & 0.02 \\
\hline $\mathrm{K}-1420$ OU & Nickel & 2.50586224 & 0.12 & 0.06 \\
\hline $\mathrm{K}-1420$ OU & Beryllium & 0.017573513 & 0.05 & \\
\hline $\mathrm{K}-1420$ OU & Pentachlorophenol & 0.0058968 & 0.05 & 0.00 \\
\hline $\mathrm{K}-1420$ OU & Strontium & 2.363210388 & 0.02 & \\
\hline $\mathrm{K}-1420$ OU & Benzo(a)pyrene & 0.001127097 & 0.00 & 0.00 \\
\hline $\mathrm{K}-1420$ OU & Trichloroethene & 0.000562964 & 0.00 & 0.00 \\
\hline $\mathrm{K}-1420$ OU & Acetone & 0.013872059 & 0.00 & 0.00 \\
\hline $\mathrm{K}-1420$ OU & Boron & 0.00756 & 0.00 & 0.00 \\
\hline $\mathrm{K}-1420$ OU & Aldrin & 0.000032723 & 0.00 & 0.00 \\
\hline $\mathrm{K}-1420 \mathrm{OU}$ & Methylene chloride & 0.000735644 & 0.00 & 0.00 \\
\hline $\mathrm{K}-1420$ OU & Tetrachloroethene & 0.000085971 & 0.00 & 0.00 \\
\hline $\mathrm{K}-1420$ OU & Bis(2-ethylhexyl)phthalate & 0.000816788 & 0.00 & 0.00 \\
\hline $\mathrm{K}-1420$ OU & 1,2-Dichlorethane & 0.000442033 & 0.00 & \\
\hline $\mathrm{K}-1420$ OU & Fluoride & 0.000084 & 0.00 & 0.00 \\
\hline $\mathrm{K}-1420$ OU & Nitrate & 0.00007504 & 0.00 & 0.00 \\
\hline LEFPC & Mercury & 4.296225105 & 429.62 & 252.72 \\
\hline LEFPC & Aluminum & 69.87414725 & 126.81 & 12.67 \\
\hline LEFPC & Total PCBs & 0.603427128 & 6.29 & 1.27 \\
\hline LEFPC & Chromium & 6.203555458 & 3.59 & 0.89 \\
\hline LEFPC & Selenium & 0.299128402 & 2.82 & 1.72 \\
\hline LEFPC & Arsenic & 0.086914284 & 2.41 & 0.24 \\
\hline LEFPC & DDT and metabolites & 0.653845056 & 1.56 & 0.31 \\
\hline LEFPC & Vanadium & 0.125903754 & 1.22 & 0.12 \\
\hline LEFPC & Thallium & 0.004224671 & 1.06 & 0.11 \\
\hline LEFPC & Copper & 6.619829696 & 0.83 & 0.62 \\
\hline
\end{tabular}


Table G.14. (continued)

\begin{tabular}{|c|c|c|c|c|}
\hline Location & Analyte & $\begin{array}{c}\text { Total } \\
\text { Exposure }\end{array}$ & $\begin{array}{c}\text { NOAEL } \\
\text { HQ } \\
\end{array}$ & $\begin{array}{c}\text { LOAEL } \\
\text { HQ } \\
\end{array}$ \\
\hline LEFPC & Cadmium & 0.378393704 & 0.74 & 0.07 \\
\hline LEFPC & Barium & 1.508756756 & 0.54 & 0.14 \\
\hline LEFPC & Zinc & 43.09930838 & 0.51 & 0.26 \\
\hline LEFPC & Manganese & 9.555204577 & 0.21 & 0.06 \\
\hline LEFPC & Nickel & 2.807265116 & 0.13 & 0.07 \\
\hline LEFPC & Lead & 0.51770791 & 0.12 & 0.01 \\
\hline LEFPC & Antimony & 0.00220416 & 0.06 & 0.01 \\
\hline LEFPC & Acetone & 0.321341509 & 0.06 & 0.01 \\
\hline LEFPC & Uranium & 0.040147329 & 0.05 & 0.02 \\
\hline LEFPC & Beryllium & 0.013319375 & 0.04 & \\
\hline LEFPC & Pentachlorophenol & 0.00105476 & 0.01 & 0.00 \\
\hline LEFPC & Benzo(a)Pyrene & 0.001411935 & 0.00 & 0.00 \\
\hline LEFPC & Methylene chloride & 0.004184472 & 0.00 & 0.00 \\
\hline LEFPC & Cyanide & 0.0163072 & 0.00 & \\
\hline LEFPC & Dieldrin & 0.000004676 & 0.00 & 0.00 \\
\hline LEFPC & Mixed-BHC & 0.000001684 & 0.00 & 0.00 \\
\hline LEFPC & Bis(2-ethylhexyl)Phthalate & 0.000566837 & 0.00 & 0.00 \\
\hline LEFPC & Endrin & 0.000002295 & 0.00 & 0.00 \\
\hline LEFPC & Endosulfan & 0.00000532 & 0.00 & \\
\hline LEFPC & Aldrin & 0.000001148 & 0.00 & 0.00 \\
\hline LEFPC & Heptachlor & 0.000000579 & 0.00 & 0.00 \\
\hline LEFPC & Methoxychlor & 0.00001652 & 0.00 & 0.00 \\
\hline LEFPC & Di-N-Butylphthalate & 0.000675992 & 0.00 & 0.00 \\
\hline LEFPC & Total chlordane & 0.000004045 & 0.00 & 0.00 \\
\hline LEFPC & DiethylPhthalate & 0.002990379 & 0.00 & \\
\hline LEFPC & Lindane & 0.000003929 & 0.00 & \\
\hline SCF & Aluminum & 108.5207236 & 196.95 & 19.68 \\
\hline SCF & Acetone & 118.6568006 & 22.39 & 4.49 \\
\hline SCF & Mercury & 0.088198542 & 8.82 & .5 .19 \\
\hline SCF & Methylene chloride & 22.23932855 & 7.17 & 0.84 \\
\hline SCF & Arsenic & 0.15865751 & 4.41 & 0.44 \\
\hline SCF & Chromium & 5.789531958 & 3.35 & 0.83 \\
\hline SCF & Vanadium & 0.173298083 & 1.68 & 0.17 \\
\hline SCF & Cadmium & 0.603934145 & 1.19 & 0.12 \\
\hline SCF & Selenium & 0.101877886 & 0.96 & 0.59 \\
\hline SCF & Total PCBs & 0.065190864 & 0.68 & 0.14 \\
\hline SCF & 1,2-Dichlorethane & 9.391174392 & 0.63 & \\
\hline SCF & Barium & 1.621191342 & 0.58 & 0.15 \\
\hline SCF & Zinc & 37.86920029 & 0.45 & 0.22 \\
\hline SCF & Manganese & 14.79114998 & 0.32 & 0.10 \\
\hline SCF & Copper & 2.059593457 & 0.26 & 0.19 \\
\hline SCF & Lead & 0.439626724 & 0.10 & 0.01 \\
\hline
\end{tabular}




\section{G-60}

Table G.14. (continued)

\begin{tabular}{|c|c|c|c|c|}
\hline Location & Analyte & $\begin{array}{c}\text { Total } \\
\text { Exposure }\end{array}$ & $\begin{array}{c}\text { NOAEL } \\
\text { HQ } \\
\end{array}$ & $\begin{array}{c}\text { LOAEL } \\
\text { HQ } \\
\end{array}$ \\
\hline SCF & Trichloroethene & 0.020500137 & 0.10 & 0.01 \\
\hline SCF & Antimony & 0.00340144 & 0.09 & 0.01 \\
\hline SCF & Nickel & 1.508702913 & 0.07 & 0.04 \\
\hline SCF & Beryllium & 0.021943401 & 0.06 & \\
\hline SCF & Tetrachloroethene & 0.016366029 & 0.04 & 0.01 \\
\hline SCF & 1,1-Dichlorethene & 0.05510008 & 0.02 & \\
\hline SCF & Uranium & 0.01118305 & 0.01 & 0.01 \\
\hline SCF & Chloroform & 0.06772472 & 0.01 & 0.00 \\
\hline SCF & Benzene & 0.05396491 & 0.01 & 0.00 \\
\hline SCF & Toluene & 0.026923302 & 0.00 & 0.00 \\
\hline SCF & Benzo(a)pyrene & 0.000940901 & 0.00 & 0.00 \\
\hline SCF & Dieldrin & 0.000004052 & 0.00 & 0.00 \\
\hline SCF & Mixed-BHC & 0.000002245 & 0.00 & 0.00 \\
\hline SCF & Endrin & 0.000003607 & 0.00 & 0.00 \\
\hline SCF & Heptachlor & 0.000008112 & 0.00 & 0.00 \\
\hline SCF & Pentachlorophenol & 0.00001456 & 0.00 & 0.00 \\
\hline SCF & Endosulfan & 0.00000784 & 0.00 & \\
\hline SCF & Bis(2-ethylhexyl)phthalate & 0.000495947 & 0.00 & 0.00 \\
\hline SCF & DDT and metabolites & 0.000028104 & 0.00 & 0.00 \\
\hline SCF & Methoxychlor & 0.00003976 & 0.00 & 0.00 \\
\hline SCF & Aldrin & 0.000001148 & 0.00 & 0.00 \\
\hline SCF & 1,1,1-Trichlorethane & 0.002674 & 0.00 & \\
\hline SCF & Total chlordane & 0.000006646 & 0.00 & 0.00 \\
\hline SCF & Di-N-Butylphthalate & 0.000434383 & 0.00 & 0.00 \\
\hline $\mathrm{SCF}$ & Carbon tetrachloride & 0.00000028 & 0.00 & \\
\hline UEFPC OU 2 & Aluminum & 344.6614187 & 625.52 & 62.50 \\
\hline UEFPC OU 2 & Chromium & 7.284683613 & 4.21 & 1.05 \\
\hline UEFPC OU 2 & Arsenic & 0.094507453 & 2.63 & 0.26 \\
\hline UEFPC OU 2 & Barium & 6.583962528 & 2.35 & 0.63 \\
\hline UEFPC OU 2 & Vanadium & 0.154965206 & 1.50 & 0.15 \\
\hline UEFPC OU 2 & Zinc & 74.41987176 & 0.88 & 0.44 \\
\hline UEFPC OU 2 & Copper & 4.055219111 & 0.51 & 0.38 \\
\hline UEFPC OU 2 & Lead & 2.105040416 & 0.50 & 0.05 \\
\hline UEFPC OU 2 & Manganese & 20.73819553 & 0.45 & 0.14 \\
\hline UEFPC OU 2 & Nickel & 4.223950467 & 0.20 & 0.10 \\
\hline UEFPC OU 2 & Beryllium & 0.029919229 & 0.09 & \\
\hline UEFPC OU 2 & Lithium & 0.243786173 & 0.05 & 0.02 \\
\hline UEFPC OU 2 & Uranium & 0.020945141 & 0.02 & 0.01 \\
\hline UEFPC OU 2 & Strontium & 1.087551696 & 0.01 & \\
\hline UEFPC OU 2 & Nitrate & 0.00314076 & 0.00 & 0.00 \\
\hline WAG 1 & Aluminum & 69112.05462 & 125430.23 & 12531.65 \\
\hline WAG 1 & Thallium & 0.082754379 & 20.69 & 2.12 \\
\hline
\end{tabular}


G-61

Table G.14. (continued)

\begin{tabular}{|c|c|c|c|c|}
\hline Location & Analyte & $\begin{array}{c}\text { Total } \\
\text { Exposure }\end{array}$ & $\begin{array}{c}\text { NOAEL } \\
\text { HQ } \\
\end{array}$ & $\begin{array}{c}\text { LOAEL } \\
\text { HQ }\end{array}$ \\
\hline WAG 1 & Mercury & 0.190976379 & 19.10 & 11.23 \\
\hline WAG 1 & Selenium & 0.578747906 & 5.46 & 3.33 \\
\hline WAG 1 & Total PCBs & 0.40693979 & 4.24 & 0.86 \\
\hline WAG 1 & Arsenic & 0.10664277 & 2.96 & 0.30 \\
\hline WAG 1 & Chromium & 3.119996278 & 1.80 & 0.45 \\
\hline WAG 1 & Vanadium & 0.101639914 & 0.99 & 0.10 \\
\hline WAG 1 & Barium & 1.338223677 & 0.48 & 0.13 \\
\hline WAG 1 & Antimony & 0.01697276 & 0.47 & 0.05 \\
\hline WAG 1 & Boron & 4.93145548 & 0.33 & 0.10 \\
\hline WAG 1 & Zinc & 27.39176504 & 0.32 & 0.16 \\
\hline WAG 1 & Cadmium & 0.159827061 & 0.31 & 0.03 \\
\hline WAG 1 & Copper & 1.643023904 & 0.21 & 0.16 \\
\hline WAG 1 & Manganese & 7.278272854 & 0.16 & 0.05 \\
\hline WAG 1 & Lead & 0.390044712 & 0.09 & 0.01 \\
\hline WAG 1 & Nickel & 1.522625892 & 0.07 & 0.04 \\
\hline WAG 1 & Uranium & 0.048838806 & 0.06 & 0.03 \\
\hline WAG 1 & Beryllium & 0.013790544 & 0.04 & \\
\hline WAG 1 & Tin & 0.1517642 & 0.02 & 0.02 \\
\hline WAG 1 & Vinyl chloride & 0.00069007 & 0.01 & 0.00 \\
\hline WAG 1 & Benzo(a)Pyrene & 0.002117903 & 0.01 & 0.00 \\
\hline WAG 1 & Mixed-BHC & 0.000066228 & 0.01 & 0.00 \\
\hline WAG 1 & Pentachlorophenol & 0.000784 & 0.01 & 0.00 \\
\hline WAG 1 & Acetone & 0.016323346 & 0.00 & 0.00 \\
\hline WAG 1 & Endrin & 0.000068859 & 0.00 & 0.00 \\
\hline WAG 1 & Methylene chloride & 0.002895117 & 0.00 & 0.00 \\
\hline WAG 1 & Total chlordane & 0.000604494 & 0.00 & 0.00 \\
\hline WAG 1 & Heptachlor & 0.000030418 & 0.00 & 0.00 \\
\hline WAG 1 & Cyanide & 0.01310764 & 0.00 & \\
\hline WAG 1 & DDT and metabolites & 0.000152849 & 0.00 & 0.00 \\
\hline WAG 1 & Bis(2-ethylhexyl)Phthalate & 0.001246647 & 0.00 & 0.00 \\
\hline WAG 1 & Trichloroethene & 0.000031581 & 0.00 & 0.00 \\
\hline WAG 1 & Tetrachloroethene & 0.000061613 & 0.00 & 0.00 \\
\hline WAG 1 & Chloroform & 0.000306724 & 0.00 & 0.00 \\
\hline WAG 1 & 1,2-Dichlorethane & 0.000358405 & 0.00 & \\
\hline WAG 1 & Di-N-Butylphthalate & 0.002571413 & 0.00 & 0.00 \\
\hline WAG 1 & Benzene & 0.000082006 & 0.00 & 0.00 \\
\hline WAG 1 & Toluene & 0.000046074 & 0.00 & 0.00 \\
\hline WAG 1 & 1,1-Dichlorethene & 0.0000168 & 0.00 & \\
\hline WAG 1 & Carbon tetrachloride & 0.0000168 & 0.00 & \\
\hline WAG 1 & Diethylphthalate & 0.00082999 & 0.00 & \\
\hline WAG 1 & 1,2-Dichlorethene & 0.00000644 & 0.00 & \\
\hline WAG 1 & 1,1,1-Trichlorethane & 0.00000924 & 0.00 & \\
\hline
\end{tabular}


Table G.14. (continued)

\begin{tabular}{|c|c|c|c|c|}
\hline Location & Analyte & $\begin{array}{c}\text { Total } \\
\text { Exposure }\end{array}$ & $\begin{array}{c}\text { NOAEL } \\
\text { HQ }\end{array}$ & $\begin{array}{c}\text { LOAEL } \\
\text { HQ }\end{array}$ \\
\hline WAG 6 & Aluminum & 90937.85994 & 165041.49 & 16489.19 \\
\hline WAG 6 & Chromium & 2.496040569 & 1.44 & 0.36 \\
\hline WAG 6 & Vanadium & 0.082976995 & 0.81 & 0.08 \\
\hline WAG 6 & Arsenic & 0.022786058 & 0.63 & 0.06 \\
\hline WAG 6 & Barium & 1.664488513 & 0.59 & 0.16 \\
\hline WAG 6 & Cadmium & 0.231829894 & 0.46 & 0.05 \\
\hline WAG 6 & Mercury & 0.003861655 & 0.39 & 0.23 \\
\hline WAG 6 & Manganese & 9.883662872 & 0.21 & 0.07 \\
\hline WAG 6 & Zinc & 16.23575877 & 0.19 & 0.10 \\
\hline WAG 6 & Copper & 1.33823744 & 0.17 & 0.13 \\
\hline WAG 6 & Nickel & 3.082732741 & 0.15 & 0.07 \\
\hline WAG 6 & 1,4-Dioxane & 0.02116464 & 0.08 & 0.04 \\
\hline WAG 6 & Beryllium & 0.020234392 & 0.06 & \\
\hline WAG 6 & Tin & 0.2498804 & 0.04 & 0.02 \\
\hline WAG 6 & Lead & 0.155209228 & 0.04 & 0.00 \\
\hline WAG 6 & Uranium & 0.003397139 & 0.00 & 0.00 \\
\hline WAG 6 & Cyanide & 0.06668816 & 0.00 & \\
\hline WAG 6 & Acetone & 0.008189529 & 0.00 & 0.00 \\
\hline WAG 6 & Methylene chloride & 0.002990038 & 0.00 & 0.00 \\
\hline WAG 6 & Bis(2-ethylhexyl)phthalate & 0.001305957 & 0.00 & 0.00 \\
\hline WAG 6 & Trichloroethene & 0.000049431 & 0.00 & 0.00 \\
\hline WAG 6 & Tetrachloroethene & 0.000047284 & 0.00 & 0.00 \\
\hline WAG 6 & Chloroform & 0.00043623 & 0.00 & 0.00 \\
\hline WAG 6 & Toluene & 0.00003291 & 0.00 & 0.00 \\
\hline WAG 6 & 1,2-Dichlorethene & 0.00001904 & 0.00 & \\
\hline
\end{tabular}


G-63

Table G.15. Estimated exposure of red-tailed hawk to contaminants on the ORR

\begin{tabular}{|c|c|c|c|c|}
\hline Location & Analyte & $\begin{array}{c}\text { Total } \\
\text { Exposure }\end{array}$ & $\begin{array}{c}\text { NOAEL } \\
\text { HQ } \\
\end{array}$ & $\begin{array}{c}\text { LOAEL } \\
\text { HQ }\end{array}$ \\
\hline BC OU 2 & Mercury & 5.49969701083 & 916.62 & 85.93 \\
\hline $\mathrm{BC}$ OU 2 & Zinc & 34.3811348792 & 2.37 & 0.26 \\
\hline $\mathrm{BC}$ OU 2 & Total PCBs & 0.22354951332 & 1.24 & 0.12 \\
\hline BC OU 2 & Chromium & 0.94628052815 & 0.95 & 0.19 \\
\hline $\mathrm{BC}$ OU 2 & Lead & 0.55245415764 & 0.49 & 0.05 \\
\hline $\mathrm{BC}$ OU 2 & Aluminum & 48.6806739254 & 0.44 & \\
\hline $\mathrm{BC}$ OU 2 & Copper & 4.10931180995 & 0.09 & 0.07 \\
\hline $\mathrm{BC}$ OU 2 & Selenium & 0.03998452034 & 0.08 & 0.04 \\
\hline $\mathrm{BC}$ OU 2 & Barium & 0.90923539707 & 0.04 & 0.02 \\
\hline $\mathrm{BC}$ OU 2 & Nickel & 1.13015350906 & 0.01 & 0.01 \\
\hline $\mathrm{BC}$ OU 2 & Cadmium & 0.01095200249 & 0.01 & 0.00 \\
\hline $\mathrm{BC}$ OU 2 & Arsenic & 0.02717681705 & 0.01 & 0.00 \\
\hline $\mathrm{BC}$ OU 2 & Manganese & 0.86123905728 & 0.00 & \\
\hline $\mathrm{K}-1407$ OU & Mercury & 0.46254193561 & 77.09 & 7.23 \\
\hline K-1407 OU & Chromium & 1.49463473694 & 1.49 & 0.30 \\
\hline K-1407 OU & Zinc & 14.8348230127 & 1.02 & 0.11 \\
\hline $\mathrm{K}-1407$ OU & Aluminum & 38.9272666092 & 0.35 & \\
\hline K-1407 OU & Selenium & 0.15992690062 & 0.32 & 0.16 \\
\hline K-1407 OU & Lead & 0.14373653819 & 0.13 & 0.01 \\
\hline K-1407 OU & Copper & 3.48426844405 & 0.07 & 0.06 \\
\hline $\mathrm{K}-1407$ OU & Nickel & 5.6390420881 & 0.07 & 0.05 \\
\hline K-1407 OU & Barium & 0.73974671829 & 0.04 & 0.02 \\
\hline $\mathrm{K}-1407$ OU & Cadmium & 0.02746242416 & 0.02 & 0.00 \\
\hline K-1407 OU & Arsenic & 0.01012023375 & 0.00 & 0.00 \\
\hline K-1407 OU & Manganese & 0.65597017984 & 0.00 & \\
\hline $\mathrm{K}-1407$ OU & Molybdenum & 0.00150025044 & 0.00 & 0.00 \\
\hline $\mathrm{K}-1420$ OU & Aluminum & 66825.4441119 & 609.17 & \\
\hline $\mathrm{K}-1420$ OU & Mercury & 0.03110127202 & 5.18 & 0.49 \\
\hline $\mathrm{K}-1420$ OU & Total PCBs & 0.85569336767 & 4.75 & 0.48 \\
\hline $\mathrm{K}-1420$ OU & Zinc & 35.4623764485 & 2.45 & 0.27 \\
\hline $\mathrm{K}-1420$ OU & Chromium & 0.54492698162 & 0.54 & 0.11 \\
\hline $\mathrm{K}-1420$ OU & Lead & 0.39430667718 & 0.35 & 0.03 \\
\hline $\mathrm{K}-1420$ OU & Copper & 3.36933868917 & 0.07 & 0.05 \\
\hline $\mathrm{K}-1420$ OU & Barium & 0.49565401563 & 0.02 & 0.01 \\
\hline $\mathrm{K}-1420$ OU & Nickel & 0.7599044 & 0.01 & 0.01 \\
\hline $\mathrm{K}-1420$ OU & Arsenic & 0.02087448739 & 0.00 & 0.00 \\
\hline $\mathrm{K}-1420$ OU & Manganese & 0.94868982504 & 0.00 & \\
\hline LEFPC & Mercury & 3.00880401634 & 501.47 & 47.01 \\
\hline LEFPC & Total PCBs & 0.50000507105 & 2.78 & 0.28 \\
\hline LEFPC & Zinc & 38.2424949606 & 2.64 & 0.29 \\
\hline LEFPC & Chromium & 1.40192631643 & 1.40 & 0.28 \\
\hline
\end{tabular}


Table G.15 (continued)

\begin{tabular}{|c|c|c|c|c|}
\hline Location & Analyte & $\begin{array}{c}\text { Total } \\
\text { Exposure } \\
\end{array}$ & $\begin{array}{l}\text { NOAEL } \\
\text { HQ }\end{array}$ & $\begin{array}{c}\text { LOAEL } \\
\text { HQ } \\
\end{array}$ \\
\hline LEFPC & Selenium & 0.19464529796 & 0.39 & 0.19 \\
\hline LEFPC & Lead, & 0.26783870115 & 0.24 & 0.02 \\
\hline LEFPC & Aluminum & 17.9294578206 & 0.16 & \\
\hline LEFPC & Copper & 6.42353030551 & 0.14 & 0.10 \\
\hline LEFPC & Cadmium & 0.0593485833 & 0.04 & 0.00 \\
\hline LEFPC & Barium & 0.76792584165 & 0.04 & 0.02 \\
\hline LEFPC & Nickel & 0.8513050238 & 0.01 & 0.01 \\
\hline LEFPC & Arsenic & 0.00616603126 & 0.00 & 0.00 \\
\hline LEFPC & Manganese & 0.57822249334 & 0.00 & \\
\hline SCF & Mercury & 0.06176867371 & 10.29 & 0.97 \\
\hline SCF & Zinc & 33.601761966 & 2.32 & 0.26 \\
\hline SCF & Chromium & 1.30836215879 & 1.31 & 0.26 \\
\hline SCF & Total PCBs & 0.05401772824 & 0.30 & 0.03 \\
\hline $\mathrm{SCF}$ & Aluminum & 27.8460319414 & 0.25 & \\
\hline SCF & Lead & 0.22744302043 & 0.20 & 0.02 \\
\hline SCF & Selenium & 0.06629277389 & 0.13 & 0.07 \\
\hline SCF & Cadmium & 0.09472312966 & 0.07 & 0.00 \\
\hline SCF & Copper & 1.99851984014 & 0.04 & 0.03 \\
\hline SCF & Barium & 0.82515270995 & 0.04 & 0.02 \\
\hline SCF & Nickel & 0.45751516732 & 0.01 & 0.00 \\
\hline SCF & Arsenic & 0.0112557698 & 0.00 & 0.00 \\
\hline $\mathrm{SCF}$ & Manganese & 0.89506985968 & 0.00 & \\
\hline UEFPC OU 2 & Zinc & 66.0335786758 & 4.55 & 0.50 \\
\hline UEFPC OU 2 & Chromium & 1.64624782229 & 1.65 & 0.33 \\
\hline UEFPC OU 2 & Lead & 1.08905288099 & 0.96 & 0.10 \\
\hline UEFPC OU 2 & Aluminum & 88.438894968 & 0.81 & \\
\hline UEFPC OU 2 & Barium & 3.35110013348 & 0.16 & 0.08 \\
\hline UEFPC OU 2 & Copper & 3.93496873002 & 0.08 & 0.06 \\
\hline UEFPC OU 2 & Nickel & 1.28091580391 & 0.02 & 0.01 \\
\hline UEFPC OU 2 & Arsenic & 0.00670471972 & 0.00 & 0.00 \\
\hline UEFPC OU 2 & Manganese & 1.25494865453 & 0.00 & \\
\hline WAG 1 & Aluminum & 17733.9075613 & 161.66 & \\
\hline WAG 1 & Mercury & 0.1337477627 & 22.29 & 2.09 \\
\hline WAG 1 & Total PCBs & 0.33719392007 & 1.87 & 0.19 \\
\hline WAG 1 & Zinc & 24.3050173132 & 1.68 & 0.19 \\
\hline WAG 1 & Selenium & 0.37659599707 & 0.75 & 0.38 \\
\hline WAG 1 & Chromium & 0.70508032345 & 0.71 & 0.14 \\
\hline WAG 1 & Lead & 0.20179152575 & 0.18 & 0.02 \\
\hline WAG 1 & Copper & 1.59430292362 & 0.03 & 0.03 \\
\hline WAG 1 & Barium & 0.68112804778 & 0.03 & 0.02 \\
\hline WAG 1 & Cadmium & 0.02506783162 & 0.02 & 0.00 \\
\hline WAG 1 & Nickel & 0.46173732007 & 0.01 & 0.00 \\
\hline
\end{tabular}




\section{G-65}

Table G.15 (continued)

\begin{tabular}{|c|c|c|c|c|}
\hline Location & Analyte & $\begin{array}{c}\text { Total } \\
\text { Exposure }\end{array}$ & $\begin{array}{c}\text { NOAEL } \\
\text { HQ }\end{array}$ & $\begin{array}{c}\text { LOAEL } \\
\text { HQ }\end{array}$ \\
\hline WAG 1 & Arsenic & 0.00756564547 & 0.00 & 0.00 \\
\hline WAG 1 & Manganese & 0.44043652265 & 0.00 & \\
\hline WAG 6 & Aluminum & 23334.331627 & 212.71 & \\
\hline WAG 6 & Zinc & 14.4061690609 & 0.99 & 0.11 \\
\hline WAG 6 & Chromium & 0.56407409973 & 0.56 & 0.11 \\
\hline WAG 6 & Mercury & 0.00270445844 & 0.45 & 0.04 \\
\hline WAG 6 & Lead & 0.08029824778 & 0.07 & 0.01 \\
\hline WAG 6 & Barium & 0.84719007052 & 0.04 & 0.02 \\
\hline WAG 6 & Copper & 1.2985543659 & 0.03 & 0.02 \\
\hline WAG 6 & Cadmium & 0.03636100604 & 0.03 & 0.00 \\
\hline WAG 6 & Nickel & 0.93484076519 & 0.01 & 0.01 \\
\hline WAG 6 & Manganese & 0.59809877886 & 0.00 & \\
\hline WAG 6 & Arsenic & 0.00161653002 & 0.00 & 0.00 \\
\hline
\end{tabular}


Table G.16. Experimental information for derivation of mammalian NOAELs and LOAELs

\begin{tabular}{|c|c|c|c|c|c|c|}
\hline Contaminant & Form & $\begin{array}{c}\text { Test } \\
\text { species }\end{array}$ & $\begin{array}{c}\text { NOAEL } \\
\text { (mg/kg/d) } \\
\text { and duration }\end{array}$ & $\begin{array}{l}\text { LOAEL } \\
\text { (mg/kg/d) } \\
\text { and duration }\end{array}$ & Endpoint & Citation \\
\hline Acetone & NA & rat & $\begin{array}{l}10^{a} \\
90 \mathrm{~d}\end{array}$ & $\begin{array}{l}50^{a} \\
90 \mathrm{~d}\end{array}$ & $\begin{array}{l}\text { liver, kidney } \\
\text { damage }\end{array}$ & EPA 1986c \\
\hline Aldrin & NA & rat & $\begin{array}{l}0.2 \\
3 \text { gen. }\end{array}$ & 1 gen. & reproduction & Treon and Cleveland 1955 \\
\hline Aluminum & $\mathrm{AlCl} 3$ & mouse & $\begin{array}{l}1.93^{b} \\
3 \text { gen. }\end{array}$ & $\begin{array}{l}19.3 \\
3 \text { gen. }\end{array}$ & reproduction & Ondreicka et al. 1966 \\
\hline Antimony & $\begin{array}{l}\text { potassium } \\
\text { tartrate }\end{array}$ & mouse & $\begin{array}{l}0.125 \\
\text { lifetime }\end{array}$ & $\begin{array}{l}1.25 \\
\text { lifetime }\end{array}$ & reproduction & Schroeder et al. 1968 \\
\hline Aroclor-1254 & NA & $\operatorname{mink}$ & $\begin{array}{l}0.14 \\
4.5 \text { months }\end{array}$ & $\begin{array}{l}0.69 \\
4.5 \text { months }\end{array}$ & reproduction & Aulerich and Ringer 1977 \\
\hline Arsenic & Ast3 & mouse & $\begin{array}{l}0.126^{b} \\
3 \text { gen. }\end{array}$ & $\begin{array}{l}1.26 \\
3 \text { gen. }\end{array}$ & reproduction & Schroeder and Mitchner 1971 \\
\hline Barium & chloride & rat & $\begin{array}{l}5.1 \\
16 \text { months }\end{array}$ & & $\begin{array}{l}\text { growth, } \\
\text { hypertension }\end{array}$ & Perry et al. 1983 \\
\hline Barium & chloride & rat & & $\begin{array}{l}19.8^{a} \\
10 \mathrm{~d}\end{array}$ & mortality & Borzelleca et al. 1988 \\
\hline Benzene & NA & mouse & $\begin{array}{l}26.36^{b} \\
6-12 \mathrm{~d}, \text { gest. }\end{array}$ & $\begin{array}{l}263.6 \\
6-12 \text { d, gest. }\end{array}$ & reproduction & Nawrot and Staples 1979 \\
\hline Benzo(a)pyrene & NA & mouse & $\begin{array}{l}1^{b} \\
7-16 \mathrm{~d}, \text { gest. }\end{array}$ & $\begin{array}{l}10 \\
7-16 \text { d, gest. }\end{array}$ & reproduction & Mackenzie and Angevine 1981 \\
\hline Beryllium & sulfate & rat & $\begin{array}{l}0.66 \\
1126 \mathrm{~d}\end{array}$ & & $\begin{array}{l}\text { longevity/ } \\
\text { weight loss }\end{array}$ & Schroeder and Mitchner 1975 \\
\hline
\end{tabular}


Table G.16 (continued)

\begin{tabular}{|c|c|c|c|c|c|c|}
\hline Contaminant & Form & $\begin{array}{c}\text { Test } \\
\text { species }\end{array}$ & $\begin{array}{c}\text { NOAEL } \\
\text { (mg/kg/d) } \\
\text { and duration }\end{array}$ & $\begin{array}{l}\text { LOAEL } \\
\text { (mg/kg/d) } \\
\text { and duration }\end{array}$ & Endpoint & Citation \\
\hline BHC (mixed isomers) & NA & rat & $\begin{array}{l}1.6 \\
4 \text { gen. }\end{array}$ & $\begin{array}{l}3.2 \\
4 \text { gen. }\end{array}$ & reproduction & Grant et al. 1977 \\
\hline $\begin{array}{l}\text { Bis(2-ethylhexyl) } \\
\text { phthalate }\end{array}$ & NA & mouse & $\begin{array}{l}18.3 \\
105 \mathrm{~d}\end{array}$ & $\begin{array}{l}183 \\
105 \mathrm{~d}\end{array}$ & reproduction & Lamb et al. 1987 \\
\hline Boron & $\begin{array}{l}\text { boric acid, } \\
\text { borax }\end{array}$ & rat & $\begin{array}{l}28 \\
3 \text { gen. }\end{array}$ & $\begin{array}{l}93.6 \\
3 \text { gen. }\end{array}$ & reproduction & Weir and Fisher 1972 \\
\hline Cadmium & $\mathrm{CdCl}_{2}$ & rat & $\begin{array}{l}1 \\
6 \mathrm{wks}\end{array}$ & $\begin{array}{l}10 \\
6 \mathrm{wks}\end{array}$ & reproduction & Sutou et al. 1980 \\
\hline Carbon tetrachloride & NA & rat & $\begin{array}{l}16 \\
2 \text { years }\end{array}$ & & reproduction & Alumot et al. 1976a \\
\hline Chlordane & NA & mouse & $\begin{array}{l}4.6 \\
6 \text { gen. }\end{array}$ & $\begin{array}{l}9.2 \\
6 \text { gen. }\end{array}$ & reproduction & $\begin{array}{l}\text { WHO } 1984 \text { (Keplinger et al. } \\
\text { 1968) }\end{array}$ \\
\hline Chromium & $\mathrm{Cr}^{+6}$ & rat & $\begin{array}{l}3.28 \\
1 \text { year }\end{array}$ & & $\begin{array}{l}\text { weight loss, food } \\
\text { consumption }\end{array}$ & Mackenzie et al. 1958 \\
\hline Chromium & $\mathrm{Cr}^{+6}$ & rat & & $\begin{array}{l}13.14^{a} \\
3 \text { months }\end{array}$ & Mortality & Steven et al. 1976 \\
\hline Copper & sulfate & $\operatorname{mink}$ & $\begin{array}{l}11.71 \\
1 \text { year }\end{array}$ & $\begin{array}{l}15.14 \\
1 \text { year }\end{array}$ & reproduction & Aulerich et al. 1982 \\
\hline Cyanide & $\begin{array}{l}\text { potassium } \\
\text { cyanide }\end{array}$ & rat & $\begin{array}{l}68.7 \\
\text { gest. lact. }\end{array}$ & & reproduction & Tewe and Maner 1981 \\
\hline DDT and metabolites & NA & rat & $\begin{array}{l}0.8 \\
2 \text { years }\end{array}$ & $\begin{array}{l}4.0 \\
2 \text { years }\end{array}$ & reproduction & Fitzhugh 1948 \\
\hline
\end{tabular}


Table G.16 (continued)

\begin{tabular}{|c|c|c|c|c|c|c|}
\hline Contaminant & Form & $\begin{array}{c}\text { Test } \\
\text { species }\end{array}$ & $\begin{array}{c}\text { NOAEL } \\
\text { (mg/kg/d) } \\
\text { and duration }\end{array}$ & $\begin{array}{l}\text { LOAEL } \\
\text { (mg/kg/d) } \\
\text { and duration }\end{array}$ & Endpoint & Citation \\
\hline 1,2 Dichloroethane & NA & mouse & $\begin{array}{l}50 \\
2 \text { gen. }\end{array}$ & & reproduction & Lane et al. 1982 \\
\hline 1,1 Dichloroethene & NA & rat & $\begin{array}{l}30 \\
2 \text { years }\end{array}$ & & $\begin{array}{l}\text { mortality, body } \\
\text { weight, blood } \\
\text { chem., liver } \\
\text { histology }\end{array}$ & Quast et al. 1983 \\
\hline 1,1 Dichloroethene & $\mathrm{NA}$ & $\operatorname{dog}$ & $\begin{array}{l}2.5^{a} \\
97 \mathrm{~d}\end{array}$ & & $\begin{array}{l}\text { mortality, body } \\
\text { weight, blood } \\
\text { chem., liver } \\
\text { histology }\end{array}$ & Quast et al. 1983 \\
\hline 1,2 Dichloroethene & $\mathrm{NA}$ & mouse & $\begin{array}{l}45.2^{a} \\
90 \mathrm{~d}\end{array}$ & & $\begin{array}{l}\text { body, organ } \\
\text { weight, blood } \\
\text { chem. hepatic } \\
\text { function }\end{array}$ & Palmer et al. 1979 \\
\hline Dieldrin & NA & rat & $\begin{array}{l}0.02^{b} \\
3 \text { gen. }\end{array}$ & $\begin{array}{l}0.2 \\
3 \text { gen. }\end{array}$ & reproduction & Treon and Cleveland 1955 \\
\hline Diethylphthalate & $\mathrm{NA}$ & mouse & $\begin{array}{l}4583 \\
105 \mathrm{~d}\end{array}$ & & reproduction & Lamb et al. 1987 \\
\hline 1,4-Dioxane & NA & rat & $\begin{array}{l}0.5 \\
\text { gest. }\end{array}$ & $\begin{array}{l}1 \\
\text { gest. }\end{array}$ & reproduction & Giavini et al. 1985 \\
\hline Endosulfan & NA & rat & $\begin{array}{l}0.15^{a} \\
30 \mathrm{~d}\end{array}$ & & $\begin{array}{l}\text { reproduction, } \\
\text { blood chem. }\end{array}$ & Dikshith et al 1984 \\
\hline Endrin & NA & mouse & $\begin{array}{l}0.092^{b} \\
120 \mathrm{~d}\end{array}$ & $\begin{array}{l}0.92 \\
120 \mathrm{~d}\end{array}$ & reproduction & Good and Ware 1969 \\
\hline
\end{tabular}


Table G.16 (continued)

\begin{tabular}{|c|c|c|c|c|c|c|}
\hline Contaminant & Form & $\begin{array}{c}\text { Test } \\
\text { species }\end{array}$ & $\begin{array}{c}\text { NOAEL } \\
\text { (mg/kg/d) } \\
\text { and duration }\end{array}$ & $\begin{array}{l}\text { LOAEL } \\
\text { (mg/kg/d) } \\
\text { and duration }\end{array}$ & Endpoint & Citation \\
\hline Fluoride & $\mathrm{NaF}$ & $\operatorname{mink}$ & $\begin{array}{l}31.37 \\
382 \mathrm{~d}\end{array}$ & $\begin{array}{l}52.75 \\
382 \mathrm{~d}\end{array}$ & reproduction & Aulerich et al. 1987 \\
\hline Heptachlor & NA & $\operatorname{mink}$ & $\begin{array}{l}0.1^{b} \\
181 \mathrm{~d}\end{array}$ & $\begin{array}{l}1 \\
181 \mathrm{~d}\end{array}$ & reproduction & Crum et al. 1993 \\
\hline Lead & acetate & rat & $\begin{array}{l}8 \\
3 \text { gen. }\end{array}$ & $\begin{array}{l}80 \\
3 \text { gen. }\end{array}$ & reproduction & Azar et al. 1973 \\
\hline Lindane & NA & rat & $\begin{array}{l}8 \\
3 \text { gen. }\end{array}$ & & reproduction & Palmer et al. 197 \\
\hline Lithium & carbonate & rat & $\begin{array}{l}9.4 \\
\text { gest. }\end{array}$ & $\begin{array}{l}18.8 \\
\text { gest. }\end{array}$ & reproduction & Marathe and Thomas 1986 \\
\hline Manganese & oxide & rat & $\begin{array}{l}88 \\
224 \text { d, gest. }\end{array}$ & $\begin{array}{l}284 \\
224 \text { d, gest. }\end{array}$ & reproduction & Laskey et al. 1982 \\
\hline Mercury & methyl & $\operatorname{mink}$ & $\begin{array}{l}0.015^{a} \\
93 \mathrm{~d}\end{array}$ & $93 \mathrm{~d}$ & mortality & Wobeser et al. 1976 \\
\hline Mercury & methyl & rat & 3 gen. & $\begin{array}{l}0.16 \\
3 \text { gen. }\end{array}$ & reproduction & Verschuuren et al. 1976 \\
\hline Methylene Chloride & NA & rat & $\begin{array}{l}5.85 \\
2 \mathrm{yr} .\end{array}$ & $\begin{array}{l}50 \\
2 \mathrm{yr} .\end{array}$ & liver histology & NCA 1982 \\
\hline Methoxychlor & NA & rat & $\begin{array}{l}4 \\
11 \text { months }\end{array}$ & $\begin{array}{l}8 \\
11 \text { months }\end{array}$ & reproduction & Gray et al. 1988 \\
\hline Molybdenum & molybdate & mouse & $\begin{array}{l}0.26^{b} \\
3 \text { gen. }\end{array}$ & $\begin{array}{l}2.6 \\
3 \text { gen. }\end{array}$ & reproduction & Schroeder and Mitchner 1971 \\
\hline
\end{tabular}


Table G.16 (continued)

\begin{tabular}{|c|c|c|c|c|c|c|}
\hline Contaminant & Form & $\begin{array}{c}\text { Test } \\
\text { species }\end{array}$ & $\begin{array}{c}\text { NOAEL } \\
\text { (mg/kg/d) } \\
\text { and duration }\end{array}$ & $\begin{array}{l}\text { LOAEL } \\
\text { (mg/kg/d) } \\
\text { and duration }\end{array}$ & Endpoint & Citation \\
\hline Nickel & sulfate & rat & $\begin{array}{l}40 \\
3 \text { gen. }\end{array}$ & $\begin{array}{l}80 \\
3 \text { gen. }\end{array}$ & reproduction & Ambrose et al. 1976 \\
\hline Niobium & $\begin{array}{l}\text { sodium } \\
\text { niobate }\end{array}$ & mouse & $\begin{array}{l}0.155^{b} \\
\text { lifetime }\end{array}$ & $\begin{array}{l}1.55 \\
\text { lifetime }\end{array}$ & $\begin{array}{l}\text { lifespan, } \\
\text { longevity }\end{array}$ & Schroeder et al. 1968 \\
\hline Nitrate & $\begin{array}{l}\text { potassium } \\
\text { nitrate }\end{array}$ & $\begin{array}{l}\text { guinea } \\
\text { pig }\end{array}$ & $\begin{array}{l}507 \\
143-204 \mathrm{~d}\end{array}$ & $\begin{array}{l}1130 \\
143-204 d\end{array}$ & reproduction & Sleight and Atallah 1968 \\
\hline Pentachlorophenol & NA & rat & $\begin{array}{l}0.24 \\
62 \mathrm{~d}+\text { gest. }\end{array}$ & $\begin{array}{l}2.4 \\
62 \mathrm{~d}+\text { gest. }\end{array}$ & reproduction & Schwetz et al. 1978 \\
\hline Selenium & $\begin{array}{l}\text { potassium } \\
\text { selenate }\end{array}$ & rat & $\begin{array}{l}0.2 \\
2 \text { gen. }\end{array}$ & $\begin{array}{l}0.33 \\
2 \text { gen. }\end{array}$ & reproduction & Rosenfeld and Beath 1954 \\
\hline Strontium & chloride & rat & $\begin{array}{l}263 \\
3 \text { years }\end{array}$ & 3 years & $\begin{array}{l}\text { body weight, } \\
\text { bone changes }\end{array}$ & Skoryna 1981 \\
\hline 1,1,2,2-Tetrachloroethene & NA & mouse & $\begin{array}{l}1.4^{a} \\
6 \text { weeks }\end{array}$ & $\begin{array}{l}7^{a} \\
6 \text { weeks }\end{array}$ & Hepatotoxicity & Buben and O'Flaherty 1985 \\
\hline Thallium & sulfate & rat & $\begin{array}{l}0.0074^{a, b} \\
60 \mathrm{~d}\end{array}$ & $\begin{array}{l}0.074^{a b} \\
60 \mathrm{~d}\end{array}$ & reproduction & Formigli et al. 1986 \\
\hline Tin & (ТBTO) & mouse & $\begin{array}{l}23.4 \\
6-15 \text { d, gest. }\end{array}$ & $\begin{array}{l}35 \\
6-15 \mathrm{~d} \text {, gest. }\end{array}$ & reproduction & Davis et al. 1987 \\
\hline Toluene & NA & mouse & $\begin{array}{l}26^{b} \\
6-12 \mathrm{~d}, \text { gest. }\end{array}$ & $\begin{array}{l}260 \\
6-12 \mathrm{~d} \text {, gest. }\end{array}$ & reproduction & Nawrot and Staples 1979 \\
\hline Trichloroethene & NA & mouse & $\begin{array}{l}0.7^{a, b} \\
6 \text { weeks }\end{array}$ & $\begin{array}{l}7^{a} \\
6 \text { weeks }\end{array}$ & hepatotoxicity & Buben and O'Flaherty 1985 \\
\hline
\end{tabular}


Table G.16 (continued)

\begin{tabular}{|c|c|c|c|c|c|c|}
\hline Contaminant & Form & $\begin{array}{c}\text { Test } \\
\text { species }\end{array}$ & $\begin{array}{c}\text { NOAEL } \\
\text { (mg/kg/d) } \\
\text { and duration }\end{array}$ & $\begin{array}{l}\text { LOAEL } \\
\text { (mg/kg/d) } \\
\text { and duration }\end{array}$ & Endpoint & Citation \\
\hline $1,1,1$ Trichloroethane & NA & mouse & $\begin{array}{l}1000 \\
3 \text { gen. }\end{array}$ & 3 gen. & reproduction & Lane et al. 1982 \\
\hline Uranium & acetate & mouse & $\begin{array}{l}3.07 \\
\text { gest. }\end{array}$ & $\begin{array}{l}6.13 \\
\text { gest. }\end{array}$ & reproduction & Paternain et al. 1989 \\
\hline Vanadium & NaVO3 & rat & $\begin{array}{l}0.21^{b} \\
60 \mathrm{~d}+\text { gest. }\end{array}$ & $\begin{array}{l}2.1 \\
60 \mathrm{~d}+\text { gest. }\end{array}$ & reproduction & Domingo et al. 1986 \\
\hline Vinyl chloride & NA & rat & $\begin{array}{l}0.17^{b} \\
\text { lifetime }\end{array}$ & $\begin{array}{l}1.7 \\
\text { lifetime }\end{array}$ & $\begin{array}{l}\text { longevity, } \\
\text { mortality }\end{array}$ & Feron et al. 1981 \\
\hline Zinc & oxide & rat & $\begin{array}{l}160 \\
\text { gest. }\end{array}$ & $\begin{array}{l}320 \\
\text { gest. }\end{array}$ & reproduction & Schlicker and Cox 1968 \\
\hline Zirconium & sulfate & mouse & $\begin{array}{l}1.74 \\
\text { lifetime }\end{array}$ & lifetime & $\begin{array}{l}\text { lifespan, } \\
\text { longevity }\end{array}$ & Schroeder et al. 1968b \\
\hline
\end{tabular}

${ }^{\circ}$ Estimated NOAEL: subchronic to chronic factor of 10 applied.

${ }^{b}$ Estimated NOAEL: LOAEL to NOAEL factor of 10 applied. 
G-72

Table G.17. Estimated NOAELs and LOAELs for mammalian endpoints

\begin{tabular}{|c|c|c|c|c|c|c|}
\hline \multirow[b]{2}{*}{ Contaminant } & \multicolumn{3}{|c|}{ Estimated NOAELs } & \multicolumn{3}{|c|}{ Estimated LOAELs } \\
\hline & Shrew & Fox & Deer & Shrew & Fox & Deer \\
\hline Acetone & 21.978 & 5.281 & 2.806 & 109.892 & 26.405 & 14.028 \\
\hline Aldrin & 0.440 & 0.106 & 0.056 & 2.198 & 0.528 & 0.281 \\
\hline Aluminum & 2.295 & 0.551 & 0.293 & 22.952 & 5.515 & 2.930 \\
\hline Antimony & 0.149 & 0.036 & 0.019 & 1.487 & 0.357 & 0.190 \\
\hline Aroclor 1254 & 0.067 & 0.096 & 0.009 & 0.668 & 0.474 & 0.085 \\
\hline Arsenic & 0.150 & 0.036 & 0.019 & 1.498 & 0.360 & 0.191 \\
\hline Barium & 11.835 & 2.844 & 1.511 & 43.517 & 10.456 & 5.555 \\
\hline Benzene & 31.348 & 7.532 & 4.001 & 313.476 & 75.321 & 40.014 \\
\hline BHC-mixed & 3.517 & 0.010 & 0.449 & 7.033 & 0.096 & 0.898 \\
\hline Benzo(a)pyrene & 1.189 & 0.286 & 0.152 & 11.892 & 2.857 & 1.518 \\
\hline Beryllium & 1.451 & 0.349 & 0.185 & & & \\
\hline Bis(2-ethylhexyl)phthalate & 21.763 & 5.229 & 2.778 & 217.625 & 52.290 & 27.779 \\
\hline Boron & 61.539 & 14.787 & 7.855 & 205.717 & 49.430 & 26.259 \\
\hline Cadmium & 2.12 & 0.509 & 0.271 & 21.2 & 5.1 & 2.7 \\
\hline Carbon Tetrachloride & 35.165 & 8.450 & 4.489 & & & \\
\hline Chlordane & 5.470 & 1.314 & 0.698 & 10.941 & 2.629 & 1.397 \\
\hline Chromium $(\mathrm{Cr}+6)$ & 7.209 & 1.732 & 0.920 & 28.879 & 6.939 & 3.686 \\
\hline Copper & 33.432 & 8.033 & 4.267 & 43.262 & 10.395 & 5.522 \\
\hline Cyanide & 141.890 & 34.095 & 18.113 & & & \\
\hline DDT & 1.758 & 0.422 & 0.224 & 8.791 & 2.112 & 1.122 \\
\hline 1,2-Dichloroethane & 61.797 & 14.849 & 7.888 & & & \\
\hline 1,1-Dichloroethene & 65.935 & 3.052 & 8.417 & & & \\
\hline 1,2-Dichloroethene & 53.752 & 12.915 & 6.861 & & & \\
\hline Dieldrin & 0.044 & 0.011 & 0.006 & 0.440 & 0.106 & 0.056 \\
\hline Diethylphthalate & 5450.149 & 1309.546 & 695.699 & & & \\
\hline 1,4-Dioxane & 1.10 & 0.26 & 0.14 & 2.20 & 0.53 & 0.28 \\
\hline Endosulfan & 0.330 & 0.079 & 0.042 & & & \\
\hline Endrin & 0.109 & 0.026 & 0.014 & 1.094 & 0.263 & 0.140 \\
\hline Fluoride & 89.638 & 21.538 & 11.442 & 150.730 & 36.218 & 19.240 \\
\hline Heptachlor & 0.286 & 0.069 & 0.036 & 2.857 & 0.687 & 0.365 \\
\hline
\end{tabular}


Table G.17 (continued)

\begin{tabular}{|c|c|c|c|c|c|c|}
\hline \multirow[b]{2}{*}{ Contaminant } & \multicolumn{3}{|c|}{ Estimated NOAELs } & \multicolumn{3}{|c|}{ Estimated LOAELs } \\
\hline & Shrew & Fox & Deer & Shrew & Fox & Deer \\
\hline Lead & 17.583 & 4.225 & 2.244 & 175.826 & 42.248 & 22.444 \\
\hline Lindane (Gamma-BHC) & 17.583 & 4.225 & 2.244 & & & \\
\hline Lithium & 20.660 & 4.964 & 2.637 & 41.319 & 9.928 & 5.274 \\
\hline Manganese & 193.409 & 46.473 & 24.688 & 624.140 & 149.980 & 79.676 \\
\hline Methylmercury & 0.070 & 0.010 & 0.009 & 0.352 & 0.085 & 0.045 \\
\hline Methoxychlor & 8.791 & 2.112 & 1.122 & 17.583 & 4.225 & 2.244 \\
\hline Methylene Chloride & 12.9 & 3.1 & 1.6 & 109.9 & 26.4 & 14.0 \\
\hline Molybdenum & 0.309 & 0.074 & 0.039 & 3.092 & 0.743 & 0.395 \\
\hline Nickel & 87.913 & 21.124 & 11.222 & 175.826 & 42.248 & 22.444 \\
\hline Niobium & 0.184 & 0.044 & 0.024 & 1.843 & 0.443 & 0.235 \\
\hline Nitrate & 1395.112 & 335.218 & 178.084 & 3109.421 & 747.133 & 396.913 \\
\hline Pentachlorophenol & 0.527 & 0.127 & 0.067 & 5.275 & 1.267 & 0.673 \\
\hline $\begin{array}{l}\text { Selenium } \\
\text { (Sodium selenite) }\end{array}$ & 0.44 & 0.106 & 0.056 & 0.725 & 0.174 & 0.093 \\
\hline Strontium & 578.029 & 138.890 & 73.785 & & & \\
\hline 1,1,2,2-Tetrachloroethene & 1.665 & 0.400 & 0.213 & 8.324 & 2.000 & 1.063 \\
\hline Thallium & 0.016 & 0.004 & 0.002 & 0.164 & 0.039 & 0.021 \\
\hline Tin & 27.828 & 6.686 & 3.552 & 41.622 & 10.001 & 5.313 \\
\hline Toluene & 30.919 & 7.429 & 3.947 & 309.195 & 74.292 & 39.468 \\
\hline 1,1,1-Trichloroethane & 1235.930 & 296.970 & 157.760 & & & \\
\hline Trichloroethene & 0.832 & 0.200 & 0.106 & 8.324 & 2.000 & 1.063 \\
\hline Uranium & 3.588 & 0.862 & 0.458 & 7.165 & 1.722 & 0.915 \\
\hline Vanadium & 0.428 & 0.103 & 0.055 & 4.285 & 1.030 & 0.547 \\
\hline Vinyl Chloride & 0.374 & 0.090 & 0.048 & 3.736 & 0.898 & 0.477 \\
\hline Xylene(mixed) & 2.497 & 0.600 & 0.319 & 3.092 & 0.743 & 0.395 \\
\hline Zinc & 351.653 & 84.496 & 44.888 & 703.306 & 168.992 & 89.776 \\
\hline Zirconium & 2.069 & 0.497 & 0.264 & & & \\
\hline
\end{tabular}


Table G.18. Estimated NOAELs and LOAELs for avian endpoints

\begin{tabular}{|c|c|c|c|c|c|c|c|c|}
\hline Contaminant & Form & Test species & $\begin{array}{c}\text { NOAEL } \\
\text { (mg/kg/d) } \\
\text { and duration }\end{array}$ & $\begin{array}{c}\text { LOAEL } \\
\text { (mg/kg/d) } \\
\text { and duration }\end{array}$ & Endpoint & Citation & $\begin{array}{c}\text { Estimated } \\
\text { NOAEL } \\
\text { (mg/kg/d) }\end{array}$ & $\begin{array}{c}\text { Estimate } \\
\text { d } \\
\text { LOAEL } \\
(\mathrm{mg} / \mathrm{kg} / \mathrm{d})\end{array}$ \\
\hline Aluminum & $\mathrm{Al}_{2}\left(\mathrm{SO}_{4}\right)_{3}$ & ringed dove & $\begin{array}{l}109.7 \\
4 \text { months }\end{array}$ & & reproduction & Carriere et al. 1986 & 109.7 & \\
\hline Aroclor 1254 & NA & $\begin{array}{l}\text { Ring-necked } \\
\text { pheasant }\end{array}$ & $\begin{array}{l}0.18^{a} \\
17 \text { weeks }\end{array}$ & $\begin{array}{l}1.8 \\
17 \text { weeks }\end{array}$ & reproduction & Dahlgren et al. 1972 & 0.18 & 1.8 \\
\hline Arsenic & arsenite & mallard duck & $\begin{array}{l}5.14 \\
128 \mathrm{~d}\end{array}$ & $\begin{array}{l}12.84 \\
128 \mathrm{~d}\end{array}$ & mortality & USFWS 1964 & 5.14 & 12.84 \\
\hline Barium & hydroxide & $\begin{array}{l}\text { day-old } \\
\text { chicks }\end{array}$ & $\begin{array}{l}20.8^{a} \\
4 \text { weeks }\end{array}$ & $\begin{array}{l}41.7^{a} \\
4 \text { weeks }\end{array}$ & mortality & Johnson et al. 1960 & 20.8 & 41.7 \\
\hline $\begin{array}{l}\text { BHC (mixed } \\
\text { isomers) }\end{array}$ & NA & $\begin{array}{l}\text { Japanese } \\
\text { Quail }\end{array}$ & $\begin{array}{l}0.56 \\
90 \mathrm{~d}\end{array}$ & $\begin{array}{l}2.25 \\
90 \mathrm{~d}\end{array}$ & reproduction & Vos et al. 1971 & 0.56 & 2.25 \\
\hline $\begin{array}{l}\text { bis(2-ethylhexyl) } \\
\text { Phthalate }\end{array}$ & NA & ringed dove & $\begin{array}{l}1.1 \\
4 \text { weeks }\end{array}$ & 4 weeks & reproduction & Peakall 1974 & 1.1 & \\
\hline Boron & boric acid & mallard duck & $\begin{array}{l}28.8 \\
3 \text { weeks } \\
\text { before, } \\
\text { during, } 3 \\
\text { weeks post } \\
\text { reproduction }\end{array}$ & $\begin{array}{l}100 \\
3 \text { weeks } \\
\text { before, } \\
\text { during, } 3 \\
\text { weeks post } \\
\text { reproduction }\end{array}$ & reproduction & Smith and Anders 1989 & 28.8 & 100 \\
\hline Cadmium & $\mathrm{CdCl}_{2}$ & mallard duck & $\begin{array}{l}1.45 \\
90 \mathrm{~d}\end{array}$ & $\begin{array}{l}20 \\
90 \mathrm{~d}\end{array}$ & reproduction & White and Finley 1978 & 1.45 & 20 \\
\hline Chlordane & NA & $\begin{array}{l}\text { red-winged } \\
\text { blackbird }\end{array}$ & $\begin{array}{l}2.14 \\
84 \mathrm{~d}\end{array}$ & $\begin{array}{l}10.7 \\
84 \mathrm{~d}\end{array}$ & mortality & Stickel et al. 1983 & 2.14 & 10.7 \\
\hline
\end{tabular}


Table G.18 (continued)

\begin{tabular}{|c|c|c|c|c|c|c|c|c|}
\hline Contaminant & Form & Test species & $\begin{array}{c}\text { NOAEL } \\
\text { (mg/kg/d) } \\
\text { and duration }\end{array}$ & $\begin{array}{c}\text { LOAEL } \\
\text { (mg/kg/d) } \\
\text { and duration }\end{array}$ & Endpoint & Citation & $\begin{array}{c}\text { Estimated } \\
\text { NOAEL } \\
\text { (mg/kg/d) }\end{array}$ & $\begin{array}{c}\text { Estimate } \\
\text { d } \\
\text { LOAEL } \\
\text { (mg/kg/d) }\end{array}$ \\
\hline Chromium & $\mathrm{Cr}^{+3}$ & black duck & $\begin{array}{l}1 \\
10 \text { months }\end{array}$ & $\begin{array}{l}5 \\
10 \text { months }\end{array}$ & reproduction & $\begin{array}{l}\text { Haseltine et al., } \\
\text { unpubl. data }\end{array}$ & 1 & 5 \\
\hline Copper & oxide & chicken & $\begin{array}{l}33.2 \\
10 \text { weeks }\end{array}$ & $\begin{array}{l}46.97 \\
10 \text { weeks }\end{array}$ & $\begin{array}{l}\text { growth/ } \\
\text { mortality }\end{array}$ & Mehring et al. 1960 & 33.2 & 46.97 \\
\hline 1,2-Dichloroehtane & NA & chicken & $\begin{array}{l}17.2 \\
2 \text { years }\end{array}$ & $\begin{array}{l}34.4 \\
2 \text { years }\end{array}$ & reproduction & Alumot et al. $1976 \mathrm{~b}$ & 17.2 & \\
\hline $\begin{array}{l}\text { DDT and } \\
\text { metabolites }\end{array}$ & NA & $\begin{array}{l}\text { Brown } \\
\text { Pelican }\end{array}$ & $\begin{array}{l}0.0028^{b} \\
>1 \text { year }\end{array}$ & $\begin{array}{l}0.028^{b} \\
>1 \text { year }\end{array}$ & reproduction & Anderson et al. 1975 & 0.0028 & 0.028 \\
\hline Dieldrin & NA & barn owl & $\begin{array}{l}0.077 \\
2 \text { year }\end{array}$ & & reproduction & Mendenhall et al. 1983 & 0.077 & \\
\hline Endosulfan & NA & $\begin{array}{l}\text { gray } \\
\text { partridge }\end{array}$ & $\begin{array}{l}10 \\
4 \text { weeks }\end{array}$ & & reproduction & Abiola 1992 & 10 & \\
\hline Endrin & NA & screech owl & $\begin{array}{l}0.01^{c} \\
83 \mathrm{~d}\end{array}$ & $\begin{array}{l}0.1 \\
83 \mathrm{~d}\end{array}$ & reproduction & Fleming et al. 1982 & 0.01 & 0.1 \\
\hline Fluoride & $\mathrm{NaF}$ & screech owl & $\begin{array}{l}7.8 \\
5-6 \text { months }\end{array}$ & $\begin{array}{l}32 \\
5-6 \text { months }\end{array}$ & reproduction & Pattee et al. 1988 & 7.8 & 32 \\
\hline Lead & acetate & $\begin{array}{l}\text { Japanese } \\
\text { quail }\end{array}$ & $\begin{array}{l}1.13 \\
12 \text { weeks }\end{array}$ & $\begin{array}{l}11.3 \\
12 \text { weeks }\end{array}$ & reproduction & Edens et al. 1976 & 1.13 & 11.3 \\
\hline Lindane & NA & mallard duck & $\begin{array}{l}2^{c} \\
8 \text { weeks }\end{array}$ & $\begin{array}{l}20 \\
8 \text { weeks }\end{array}$ & reproduction & $\begin{array}{l}\text { Chakravarty and Lahiri } \\
1986\end{array}$ & 2 & 20 \\
\hline Manganese & oxide & $\begin{array}{l}\text { Japanese } \\
\text { quail }\end{array}$ & $\begin{array}{l}977 \\
75 \mathrm{~d}\end{array}$ & $75 \mathrm{~d}$ & $\begin{array}{l}\text { growth, } \\
\text { aggresivenes } \\
\text { s }\end{array}$ & Laskey and Edens 1985 & 977 & \\
\hline
\end{tabular}


Table G.18 (continued)

\begin{tabular}{|c|c|c|c|c|c|c|c|c|}
\hline Contaminant & Form & Test species & $\begin{array}{c}\text { NOAEL } \\
\text { (mg/kg/d) } \\
\text { and duration }\end{array}$ & $\begin{array}{c}\text { LOAEL } \\
\text { (mg/kg/d) } \\
\text { and duration }\end{array}$ & Endpoint & Citation & $\begin{array}{c}\text { Estimated } \\
\text { NOAEL } \\
(\mathbf{m g} / \mathbf{k g} / \mathbf{d})\end{array}$ & $\begin{array}{c}\text { Estimate } \\
\text { d } \\
\text { LOAEL } \\
\text { (mg/kg/d) }\end{array}$ \\
\hline Mercury & methyl & mallard duck & $\begin{array}{l}0.0064^{a} \\
3 \text { generations }\end{array}$ & $\begin{array}{l}0.064 \\
3 \text { generations }\end{array}$ & reproduction & Heinz 1979 & 0.0064 & 0.064 \\
\hline Molybdenum & sodium Mo & chicken & $\begin{array}{l}3.5^{\circ} \\
21 \mathrm{~d}\end{array}$ & $\begin{array}{l}35.3 \\
21 \mathrm{~d}\end{array}$ & reproduction & Lepore and Miller & 3.5 & 35.3 \\
\hline Nickel & sulfate & mallard duck & $\begin{array}{l}77.4 \\
90 \mathrm{~d}\end{array}$ & $\begin{array}{l}107 \\
90 \mathrm{~d}\end{array}$ & $\begin{array}{l}\text { mortality, } \\
\text { growth, } \\
\text { behavior }\end{array}$ & Cain and Pafford 1981 & 77.4 & 107 \\
\hline Selenium & selenite & mallard duck & $\begin{array}{l}0.5 \\
10 \text { weeks }\end{array}$ & $\begin{array}{l}1.0 \\
10 \text { weeks }\end{array}$ & reproduction & Heinz et al. 1987 & 0.5 & 1.0 \\
\hline Tin & (TBTO) & $\begin{array}{l}\text { Japanese } \\
\text { quail }\end{array}$ & $\begin{array}{l}6.8 \\
6 \text { weeks }\end{array}$ & $\begin{array}{l}16.9 \\
6 \text { weeks }\end{array}$ & reproduction & Schlatterer et al. 1993 & 6.8 & 16.9 \\
\hline Uranium & $\begin{array}{l}\text { depleted } \\
\text { metal }\end{array}$ & black duck & $\begin{array}{l}16^{a} \\
6 \text { weeks }\end{array}$ & & $\begin{array}{l}\text { mortality, } \\
\text { growth, } \\
\text { behavior }\end{array}$ & Haseltine and Sileo 1983 & 16 & \\
\hline Vanadium & $\begin{array}{l}\text { vanadyl } \\
\text { sulfate }\end{array}$ & mallard duck & $\begin{array}{l}11.4 \\
12 \text { weeks }\end{array}$ & 12 weeks & $\begin{array}{l}\text { mortality, } \\
\text { body weight, } \\
\text { blood chem. }\end{array}$ & White and Dieter 1978 & 11.4 & \\
\hline Zinc & zinc sulfate & chicken & $\begin{array}{l}14.5 \\
44 \text { week(s) }\end{array}$ & $\begin{array}{l}130.9 \\
44 \text { week(s) }\end{array}$ & reproduction & Stahl et al. 1990 & 14.5 & 1309 \\
\hline
\end{tabular}

${ }^{a}$ Estimated NOAEL: subchronic to chronic factor of 10 applied.

${ }^{b}$ From EPA 1993.

'Estimated NOAEL: LOAEL to NOAEL factor of 10 applied. 


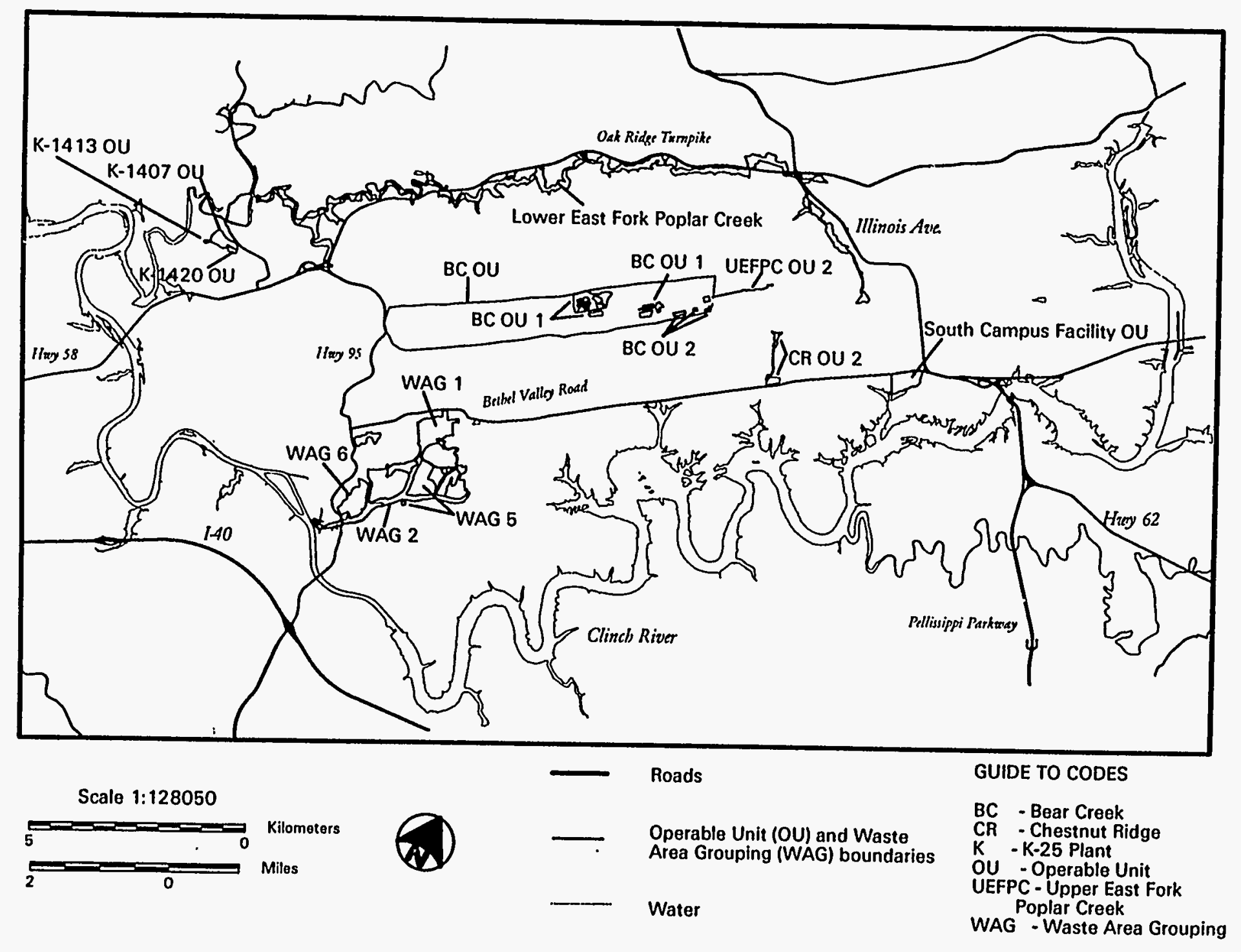

Fig. G.1. Locations of OUs evaluated as part of the ORR-wide assessment of risk to vermivores and herbivores. 



\section{DISTRIBUTION}

1. T. Ashwood

2. L. V. Asplund

3. R. Cook

4. V. Dale

5. R. Efroymson

6. R. Graham

7. S. Hildebrand

8. R. Hinzman

9. C. Hunsaker

10. B. Jackson

11. D. Jones

12. S. B. Kerr

13. J. Loar

14-16. D. M. Matteo

17. C. W. McGinn

18. P. T. Owen

19. P. Parr

20. M. Peterson

21-23. A. S. Quist

24-29. B. Sample

30. F. Sharples

31. G. Southworth

32. G. Suter

33. R. Washington-Allen

34. W. Webb

35. D. C. White

36. ER Doc. Mgmt. Center-RC

37. R. L. Nace, Team Leader, Fernald/Ohio Team, Office of Environmental Restoration, U.S. Department of Energy, Cloverleaf Building, EM-425, 19901 Germantown Road, Germantown, MD 20874

38. J. W. Wagoner II, Team Leader, Portsmouth/Paducah/Weldon Spring Team, Office of Environmental Restoration, U.S. Department of Energy, Cloverleaf Building, EM-424, 19901 Germantown Road, Germantown, MD 20874

39-40. R. C. Sleeman, Director, Environmental Restoration Division, DOE Oak Ridge Operations Office, P.O. Box 2001, Oak Ridge, TN 37831-8541

41. Charles Hadden, Science Applications International Corporation, P.O. Box 2501, 301 Laboratory Road, Oak Ridge, TN 37831 
